\title{
Environmental liability in a federal system : a law and economics analysis
}

Citation for published version (APA):

De Smedt, K. (2007). Environmental liability in a federal system : a law and economics analysis. [Doctoral Thesis, Maastricht University]. Intersentia. https://doi.org/10.26481/dis.20071219kd

Document status and date:

Published: 01/01/2007

DOI:

10.26481/dis.20071219kd

Document Version:

Publisher's PDF, also known as Version of record

\section{Please check the document version of this publication:}

- A submitted manuscript is the version of the article upon submission and before peer-review. There can be important differences between the submitted version and the official published version of record.

People interested in the research are advised to contact the author for the final version of the publication, or visit the DOI to the publisher's website.

- The final author version and the galley proof are versions of the publication after peer review.

- The final published version features the final layout of the paper including the volume, issue and page numbers.

Link to publication

\footnotetext{
General rights rights.

- You may freely distribute the URL identifying the publication in the public portal. please follow below link for the End User Agreement:

www.umlib.nl/taverne-license

Take down policy

If you believe that this document breaches copyright please contact us at:

repository@maastrichtuniversity.nl

providing details and we will investigate your claim.
}

Copyright and moral rights for the publications made accessible in the public portal are retained by the authors and/or other copyright owners and it is a condition of accessing publications that users recognise and abide by the legal requirements associated with these

- Users may download and print one copy of any publication from the public portal for the purpose of private study or research.

- You may not further distribute the material or use it for any profit-making activity or commercial gain

If the publication is distributed under the terms of Article $25 \mathrm{fa}$ of the Dutch Copyright Act, indicated by the "Taverne" license above, 
Environmental Liability in a Federal System A Law and Economics Analysis 


\title{
Environmental Liability in a Federal System A Law and Economics Analysis
}

\author{
PROEFSCHRIFT
}

ter verkrijging van de graad van doctor aan de Universiteit Maastricht, op gezag van de Rector Magnificus, Prof. Mr. G.P.M.F. Mols

volgens het besluit van het College van Decanen,

in het openbaar te verdedigen

op woensdag 19 december 2007 om 16.00 uur

door:

Kristel De Smedt 


\section{Promotor:}

Prof. Dr. M.G. Faure LL.M.

\section{Copromotor:}

Prof. Dr. L.M.C. Vereeck (Universiteit Hasselt)

\section{Beoordelingscommissie:}

Prof. dr. H.E.G.S. Schneider (voorzitter)

Prof. dr. A.M. Draye (Universiteit Hasselt)

Prof. dr. A.I. Ogus (University of Manchester/University of Maastricht)

coverfoto (C) Digital Vision 



\section{ACKNOWLEDGEMENTS}

The common perception of a person writing a thesis is that of a lonely person, sitting behind a desk, which is covered with books. Up to some extend, writing a thesis is indeed a lonely process. On the other hand, I made many new contacts during this time, on conferences and seminars or within the working environment. And only the support and interest of a lot of people made it possible for me to write this thesis. Although I cannot mention everyone who in some role contributed to the writing of this book, there are a few persons I would like to mention explicitly.

First and foremost I am grateful to my promotor Michael Faure. I would like to thank Michael for the many inspiring discussions we had about my thesis. I always left the Metro building with many new ideas, and the courage to continue. I am also grateful to Michael for the opportunities he gave me to participate in conferences and to take part in seminars, so that I could meet and learn from experts in the field of law and economics. I also thank Prof. dr. Lode Vereeck of Hasselt University, who brought me into contact with Michael.

Furthermore, I would like to thank the members of the reading committee, Prof. dr. Hildegard Schneider, Prof. dr. Anthony Ogus and Prof. dr. Anne Marie Draye, for their very valuable comments on an earlier version of the manuscript. Their critical remarks enabled me to improve further the final text of this book.

I also am indebted to the subsequent desk officers, responsible for the Environmental Liability Directive, of DG Environment of the European Commission, Mrs. Carla De Vries-Hess, Mr. Charles Pirotte, and Mr Hans Lopatta, who provided me with valuable information concerning the adoption process of the Directive.

Moreover, I would like to mention my former colleagues and friends of the Universiteit Hasselt where I worked with pleasure as an assistant lecturer during 7 years. I would like to thank these colleagues, and in particular Manuela Mühl, An Kwanten, Linda Philippeth and Bernard Vanheusden for their support and friendship. I also would like to thank the colleagues of Metro for their useful comments or practical help. I am also indebted to Chantal Kuijpers for making the book camera-ready and to Greta Holmer for her review of my English.

Beyond academic life, I would like to thank my family for their everlasting support. In particular my husband, for listening with a friendly ear to my reasoning, my daughter Rhea, for her smile, my father for his useful comments and practical - computer - support and my sister, for cheering me up when the end of this thesis seemed far away. A special attention merits my mother who always supported me, and who certainly would have been proud to see this book.

Kristel De Smedt

Zutendaal, September 2007

The text of this book has been put in its final form in June 2007. Developments that took place after that date could therefore not be taken into account. 



\section{TABLE OF CONTENTS}

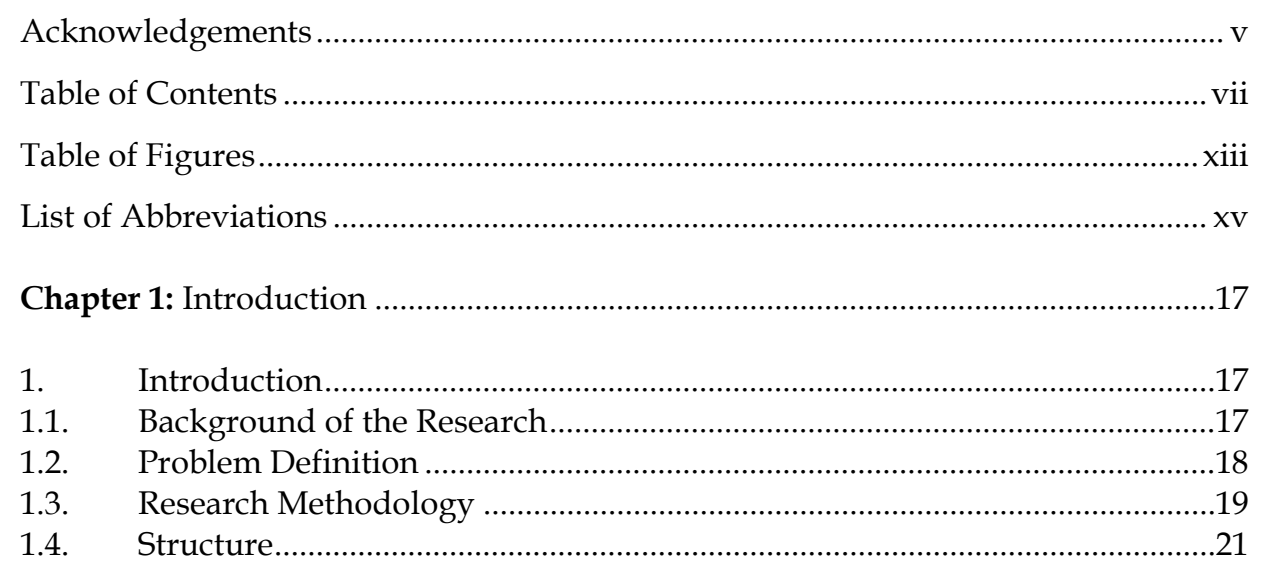

Chapter 2: An Economic Theory of Environmental Liability …………………...........23

1. An Economic Perspective on Environmental Damage .....................................23

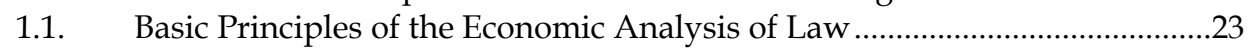

1.2. Environmental Damage as an Externality …………………………….........24

1.3. The Coase Theorem as an Explanation for the Role of Tort Law ...................24

2. Defining an Economic Theory of Environmental Liability …………..............25

2.1. Economic Theory of Tort Law: General Approach …………………………...25

2.1.1. Economic Function of Tort Law …………….................................................26

2.1.1.1. Development of the Economic Analysis of Tort Law .....................................26

2.1.1.2. Deterrence and Compensation Function of Tort Law …….............................26

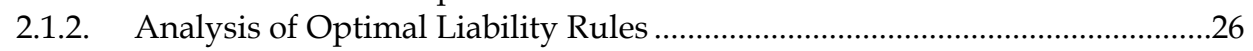

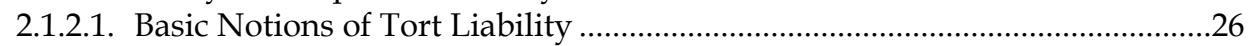

2.1.2.2. Negligence versus Strict Liability in Unilateral Accidents.............................28

2.2. The Economic Theory of Tort Law Applied to Environmental Damage ......29

2.2.1. Negligence versus Strict Liability in Preventing Environmental Damage ...30

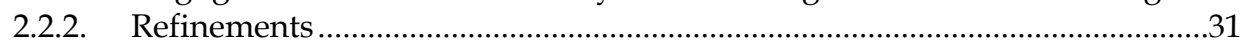

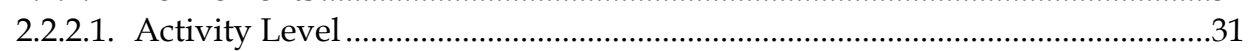

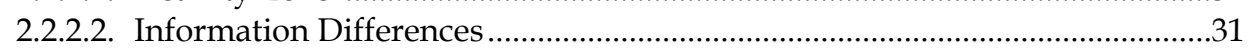

2.2.2.3. Insolvency and Financial Caps: Strict Liability versus Negligence .................32

2.2.3. Remedies to Compensate for Environmental Damage in Case of

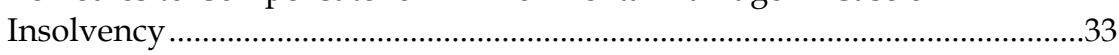

2.3. Liability Rules versus Other Instruments for Controlling Environmental

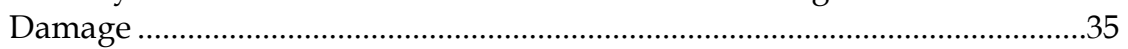

2.3.1. Ex Ante versus Ex Post Instruments for Controlling Environmental

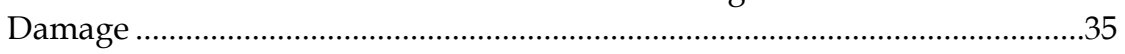

2.3.2. Interaction between Environmental Regulation and Environmental

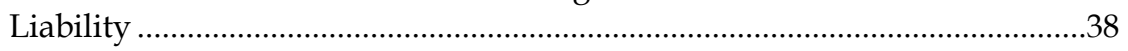

2.3.3. Complementary Relationship between Liability and Environmental Regulation. 
2.4. The Added Value of Liability Rules for Environmental Damage ..................40

2.4.1. Recognition of a Crowding-out Effect ..........................................................40

2.4.2. Fairness and Justice Considerations in the Economic Analysis of Law ........41

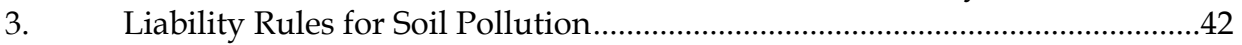

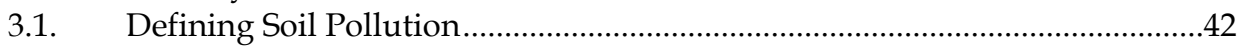

3.1.1. Complexity of Soil Pollution .....................................................................42

3.1.2. Regulation for Preventing and Restoring Soil Pollution ...............................44

3.2. Liability to Prevent and Restore Soil Pollution................................................44

3.2.1. Contribution of Liability Rules in Prevention and Restoration of Soil Pollution ....................................................................................................4 44

3.2.2. Strict Liability versus Negligence for Preventing and Restoring

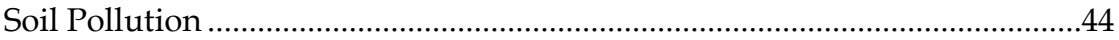

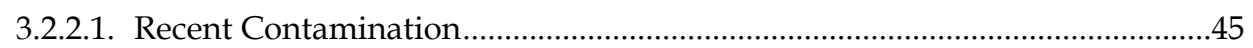

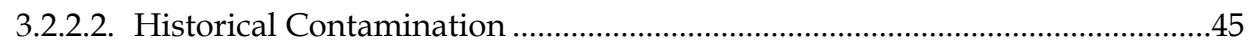

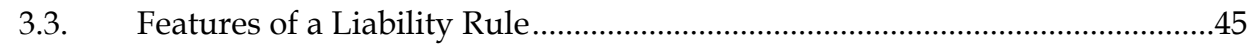

3.3.1. Type and Scope of Liability Rule (Strict Liability versus Negligence) ..........45

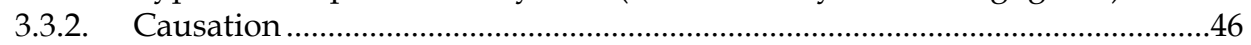

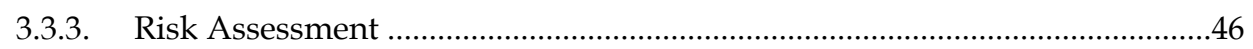

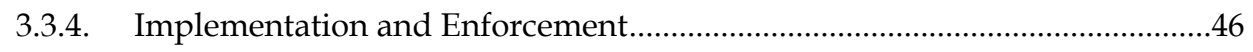

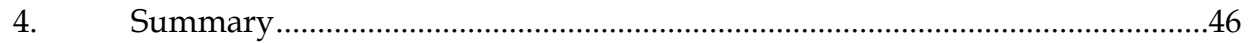

Chapter 3: Optimal decision-making level of environmental liability rules in a federal system.

1. Public Interest Approach on the Optimal Decision-making Level of Liability for Environmental Damage ...........................................................52

1.1. Decentralisation as a Traditional Starting Point .............................................52

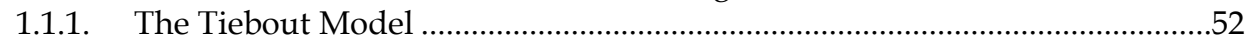

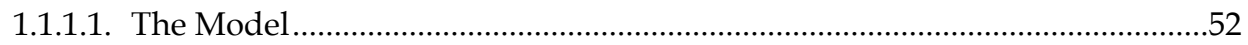

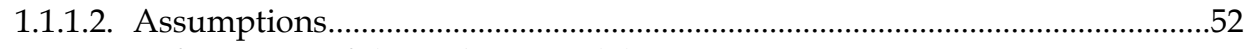

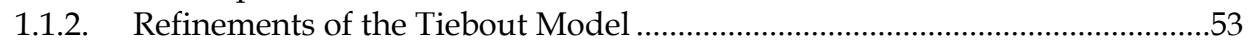

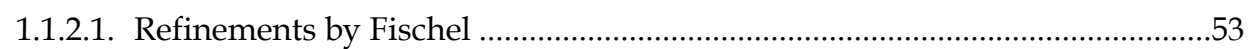

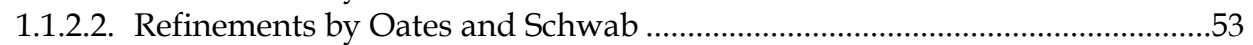

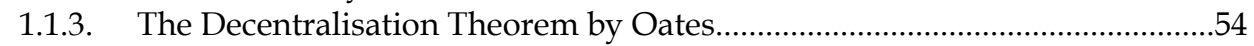

1.1.4. Limitations of the Tiebout Model and the Decentralisation Theorem Applied to Environmental Damage ...............................................................54

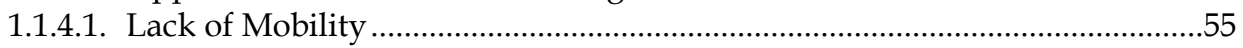

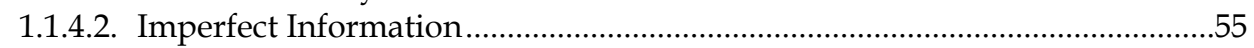

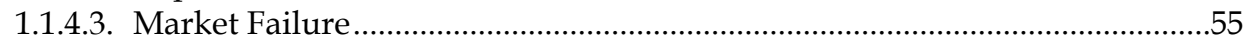

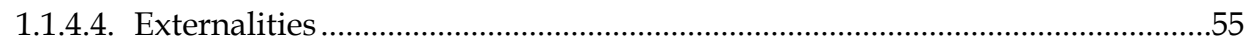

1.2. Arguments for Centralisation of Liability Rules for Environmental

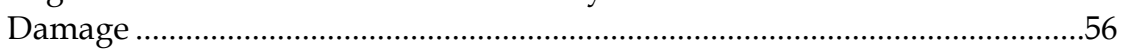

1.2.1. Transboundary Character of an Externality Argument ..................................57

1.2.1.1. Internalisation of Transboundary Environmental Damage Through

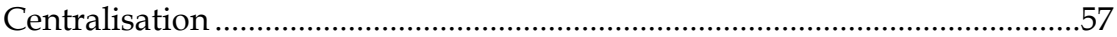

1.2.1.2. Economies of Scale in the Regulation of Environmental Damage ..................60

1.2.1.3. Federal Regulation for Transboundary Environmental Damage Only ..........61

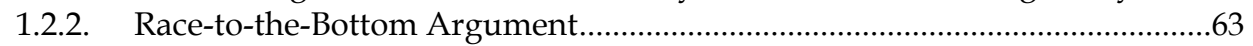

1.2.2.1. Definition of a Race-to-the-bottom ..............................................................63

1.2.2.2. Risk of a Race-to-the-bottom for Environmental Regulation..........................64

1.2.2.3. Risk of a Race-to-the-bottom for Environmental Damage Liability ...............71

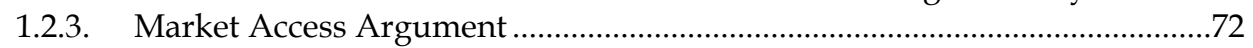

1.2.3.1. A Level Playing Field through Centralisation of Environmental Liability...73

1.2.3.2. Reduction of Transaction Costs Through Centralisation of Environmental Liability ............................................................................. 80

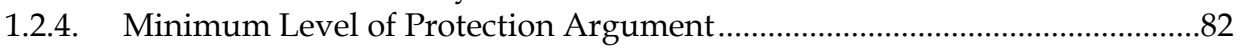

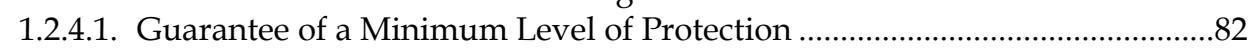

1.2.4.2. Minimum Level of Protection Through Centralisation of Liability for Environmental Damage. 
1.3. Summary of the Public Interest Approach .....................................................85

2. Private Interest Approach on the Optimal Decision-making Level of Liability for Environmental Damage ............................................................8

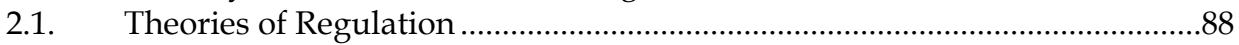

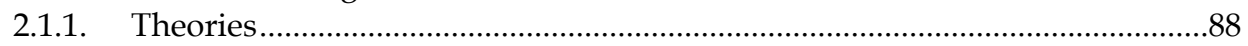

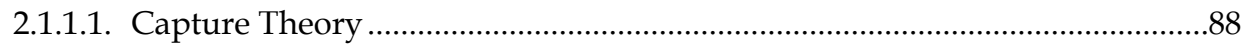

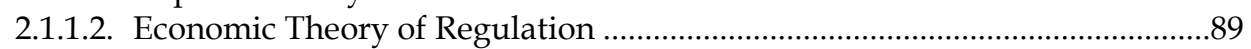

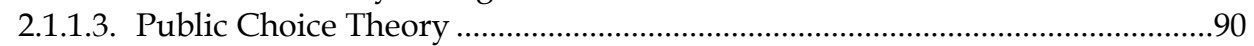

2.1.2. Rent-seeking Behaviour in Environmental Regulation ................................91

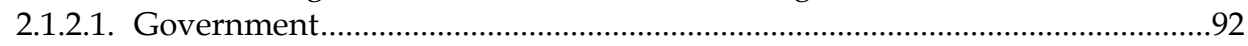

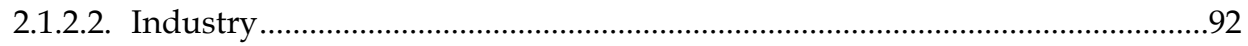

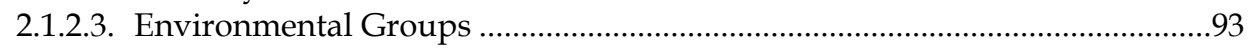

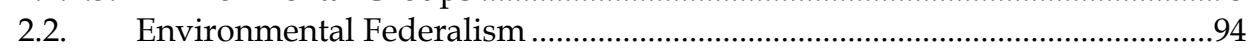

2.2.1. Reasons for Centralisation, Based on Private Interest Distortions..................94

2.2.1.1. Relative Strength of Interest Groups at Different Governmental Levels ......95

2.2.1.2. Race-to-the-bottom Due to Interest Group Lobbying...................................96

2.2.1.3. Harmonisation of Marketing Conditions incited by Interest Groups ...........98

2.2.2. Consequences and Responses to Lobbying Activities .....................................98

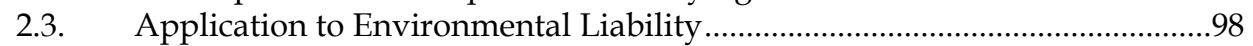

2.4. Summary of the Private Interest Approach ....................................................99

3. Framework for Decision-making on the Optimal Governmental Level for Liability for Environmental Damage in a Federal System, Based on a Public and Private Interest Approach.

3.1. Framework for the Optimal Decision-making Level of Environmental Liability Rules in a Federal System ...........................................................102

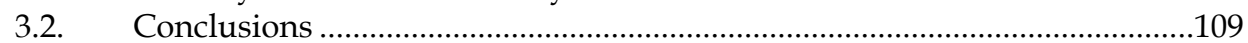

Chapter 4: Liability for environmental damage in the European Union by means of Directive 2004/35/CE on Environmental Liability ..............................................111

1. Competence of the European Union in the Environmental Field .................112

1.1. Division of Competences between the EU and the Member States for Environmental Matters ...............................................................................112

1.1.1. Competence of the EU to Legislate in the Environmental Field ..................112

1.1.2. Principles of Subsidiarity and Proportionality (Article 5 (2) EC)................115

1.1.2.1. The Balance between Sovereignty and Community Action ........................115

1.1.2.2. Application of the Subsidiarity and Proportionality Principles in the Making of European Environmental Law ......................................................118

1.2. Harmonisation of Environmental Standards in the European Union.........120

1.2.1. Harmonisation and Member States' Room for Manoeuvre ..........................120

1.2.2. Implementation and Enforcement of European Environmental Law .........121

2. A European Environmental Liability Regime ...............................................122

2.1. Towards a European Environmental Liability Directive: Legislative

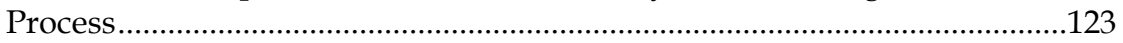

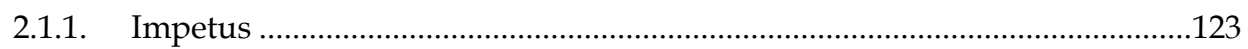

2.1.2. Legislative Process...............................................................................................123

2.2. Directive 2004/35/CE of 21 April 2004 on Environmental Liability with Regard to the Prevention and Remedying of Environmental Damage.......129

2.2.1. Legal Basis of EC Intervention in Environmental Liability...........................129

2.2.2. Justifications for the ELD with Respect to the Subsidiarity and Proportionality Principles ..........................................................................130

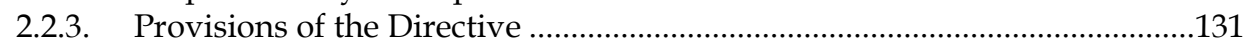

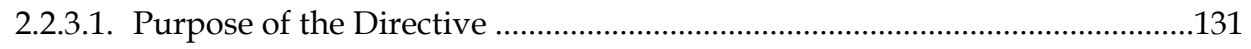

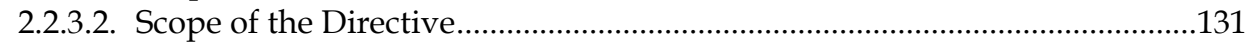

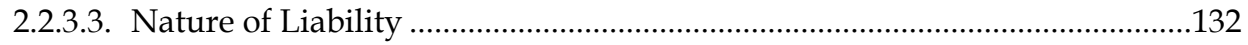

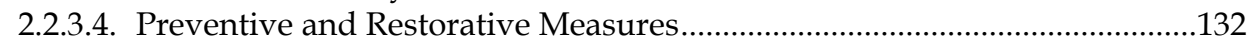

2.2.3.5. Competent Authority and Requests for Action.............................................133

2.2.3.6. Insurance Aspects ............................................................................................134

2.2.3.7. Cooperation between Member States for Transboundary Damage ............134 


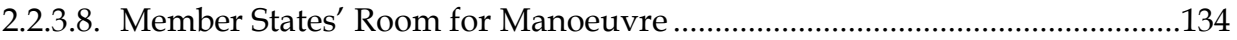

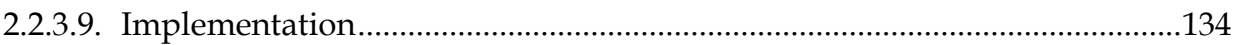

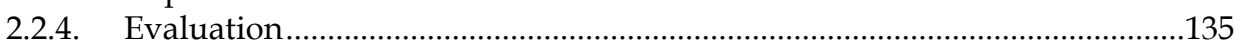

3. Application of the Environmental Liability Directive to Soil Pollution ......135

3.1. Soil Protection Policies in the European Union ..............................................135

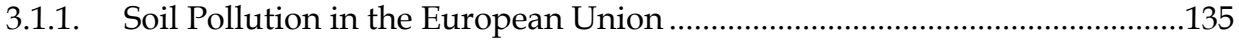

3.1.2. EC Policy for Soil Protection ..........................................................................136

3.2. Application of the Directive to Soil Pollution ................................................139

3.2.1. Scope of the Directive with Respect to Land Damage ...................................139

3.2.2. Remediation of Land Damage under the Scope of the Directive..................141

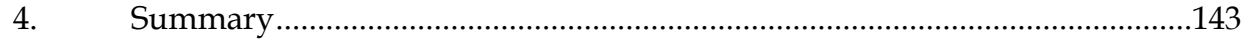

Chapter 5: Economic analysis of Directive 2004/35/EC on Environmental

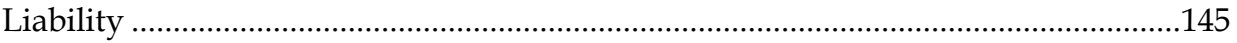

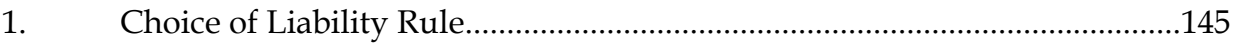

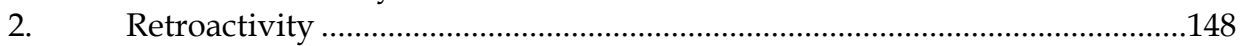

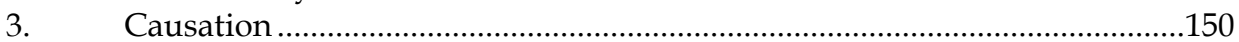

3.1. The Problem of Causation in Environmental Pollution ...............................150

3.2. Economic Approach to Causation ................................................................151

3.3. Case Law in Some of the EU Member States ..............................................152

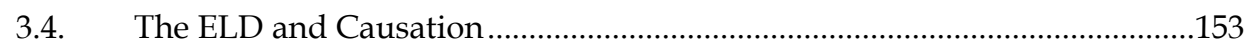

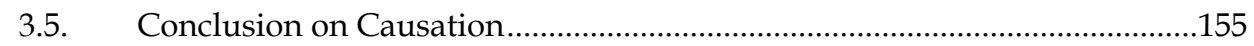

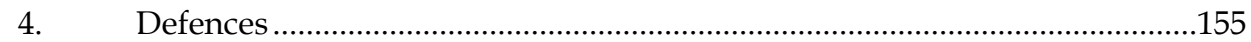

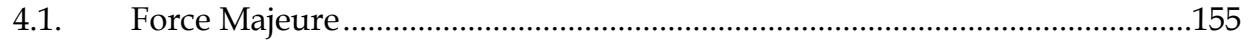

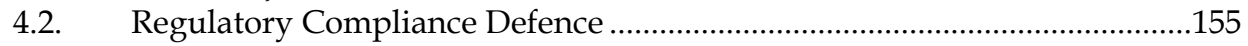

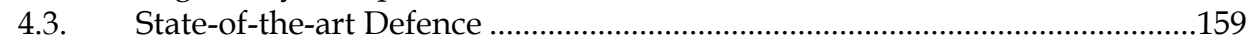

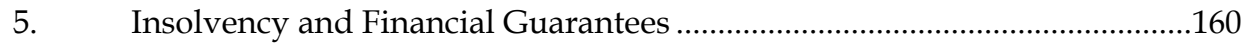

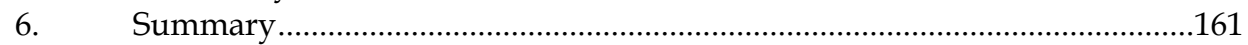

Chapter 6: Optimal decision-making level of liability rules for environmental damage in the European Union.

1. Public Interest Approach on the Optimal Decision-making Level of Liability for Environmental Damage in the European Union ......................163

1.1. Tiebout versus Subsidiarity: Decentralisation as a Starting Point in

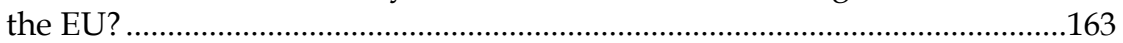

1.2. The Search for Arguments for Centralisation of Liability Rules for Environmental Damage in the EU...............................................................165

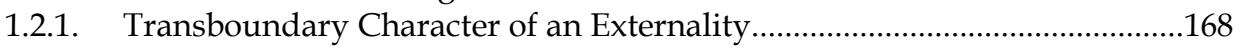

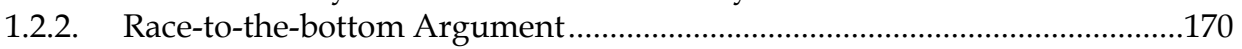

1.2.3. Market Access Argument ..................................................................................171

1.2.4. Realisation of the Polluter Pays, Prevention and Precautionary Principles173

1.2.5. Decontamination and Restoration of the Environment.................................174

1.2.6. Harmonisation to Guarantee a Minimum Level of Protection......................175

1.3. Summary of the Public Interest Approach ...................................................178

2. Private Interest Approach on the Optimal Decision-making Level of Liability for Environmental Damage in the European Union .......................179

2.1. Rent-seeking Behaviour in the Adoption Process of the ELD .....................179

2.1.1. Who is Who in the Lobbying Process Behind the ELD ................................180

2.1.2. Insight into the Adoption Process of the ELD ..............................................185

2.2. Private Interest Analysis of the Adoption Process of the ELD .....................194

2.2.1. Becker versus Buchanan ..................................................................................195

2.2.2. Reasons for Centralisation, Based on Private Interest Distortions...............196

2.2.2.1. Relative Strength of Interest Groups at National and European Level.......196

2.2.2.2. Race-to-the-bottom Due to Interest Group Lobbying.....................................199

2.2.2.3. Harmonisation of Marketing Conditions Incited by Interest Groups .........200

2.3. Summary of the Private Interest Approach .................................................201 
3. Framework for Decision-making on the Optimal Governmental Level for Liability for Environmental Damage in the European Union, Based on a Public and Private Interest Approach .....................................................202

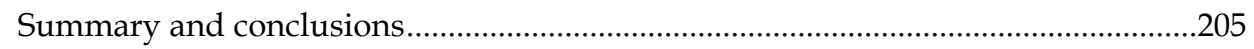

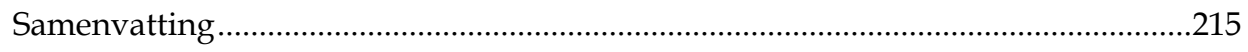

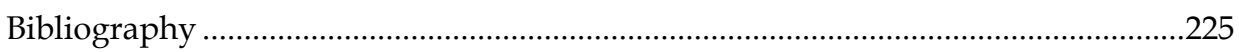

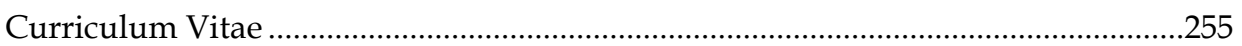





\section{TABLE OF FIGURES}

Figure 1: Liability for environmental damage in a federal system.

Figure 2: Framework for the optimal decision-making level of environmental liability rules in a federal system

Figure 3: Framework for the optimal decision-making level of liability rules for soil pollution in a federal system .104

Figure 4: Reasons for harmonisation advanced by the Commission for Community competence. .166

Figure 5: Who is Who in the legislative process behind the ELD .185

Figure 6: Adoption process of the ELD. 186

Figure 7: Application of the framework for optimal decision-making level of liability rules for soil pollution in the EU. 



\section{LIST OF ABBREVIATIONS}

BIPAR: $\quad$ European Federation of Insurance Intermediaries

CEA:

Comité Européen des Assurances

CEFIC:

European Chemical Industry Council

CBI:

Confederation of British Industry

DG: Directorate-General

EEB: $\quad$ European Environmental Bureau

EC: $\quad$ European Community

EAP: $\quad$ Environmental Action Programme

EEA: $\quad$ European Environment Agency

EEC: $\quad$ European Economic Community

ELD: $\quad$ Environmental Liability Directive

ENGO: $\quad$ Environmental Non-Governmental Organisation

EP: $\quad$ European Parliament

EU: $\quad$ European Union

Eurochambres: Association of European Chambers of Commerce and Industry

EUROPIA: European Petroleum Industry Association

MEP: $\quad$ Member of Parliament

OGP: $\quad$ International Association of Oil \& Gas producers

SEA: $\quad$ European Single Act

TEU: $\quad$ Treaty on European Union

UAPME: $\quad$ European Association of Craft, Small and Medium Sized Enterprises

UNICE: Union of Industrial and Employer's Confederations of Europe

WWF: World Wide Fund for Nature 



\section{Chapter 1}

\section{Introduction}

\subsection{Background of the Research}

A clean and healthy environment is part of a prosperous society. Yet, continued economic growth, both in industrialised and developing countries, has put pressure on the environment. At times, industrial or other activities cause considerable damage to the environment with, for example, contaminated soil or contaminated groundwater as a result. Therefore, protection and restoration of the environment has become a growing global governmental concern. Yet, developing an environmental policy that best prevents pollution and ensures restoration of the environment after damage has occurred, is a highly complex matter.

Firstly, governments face different choices when deciding upon the policy instruments to use to protect their environment. Generally, governments have introduced a framework of public law and regulations in order to reduce pollution and to protect their environment from further damage. This public law framework has frequently been complemented with liability rules for environmentally harmful discharges. Environmental liability rules belong to the private law domain and have become often-used provisions in national law as well as in international conventions. In the 1970's, environmental economists moreover introduced the idea of using incentive instruments like marketable permits or licences and emission charges to reduce pollution. However, these incentive instruments still only play a minor role in the protection of the environment.

Secondly, besides deciding upon the policy instruments to protect the environment, governments also face the choice of how to organise their environmental policy. Federal states must especially make a choice between a uniform, harmonised policy for all regions, a differentiated policy for each state, depending upon the specific problems of the region, or a solution of mixed competences. Federal systems, for example like the European Union ${ }^{1}$ or the United States, both composed of various states, therefore have to decide not only on the choice of instruments but also on the decision-making level for environmental policy.

Scholars became interested in the complex question of what environmental policy to choose and at which level that policy should be designed in a federal system. Harmonisation of environmental regulation became a frequently debated issue in political as well as in academic circles from the late 1960's and 1970's in the United States and from in the 1980's in the European Union. Indeed, with the adoption of the European Single Act in 1986, the European Union obtained the explicit competence to regulate the environment.

Environmental federalism scholars studied at which level environmental policy could best be set, given specific circumstances and developed frameworks for the assessment of the 'optimal policy level' of environmental policy instruments in general. ${ }^{2}$ Besides general analyses, attention was also given to environmental policy instruments in particular, such as environmental liability rules. The contribution of liability rules to the prevention and restoration of environmental damage and the optimal level of these rules has become a frequently discussed issue in academic as well as in political debates. Consequently, some scholars have examined the 'optimal policy level' for environmental liability rules in a federal system. ${ }^{3}$

Yet, in the European Union, the debate did not remain merely theoretical. Indeed, the desire to harmonise environmental liability rules in the European Union already existed at a European level for about 20 years. On 21 April 2004, Directive 2004/35/CE on Environmental Liability with Regard to the

Lawyers may disagree that the European Union is a federal system, and would rather qualify the European Union as a multi-level governance system. Yet, in the Law and Economics literature, on which this research is based, the term 'federal system' is commonly used to indicate a multi-level regulatory structure. Therefore, the use of the term 'federal system' in this research should not have a legal interpretation, but rather be interpreted as a system in which there is regulation at different levels of government.

2 See for example Esty 1996, 570-653 or Revesz 2001a, 3-29.

3 See for example Faure 2003a, 31-82. 
Prevention and Remedying of Environmental Damage was finally adopted. The Member States have until 31 April 2007 to transpose the Directive into national law.

The development process of the Environmental Liability Directive gave rise to much controversy and conflict and resulted in animated academic debates on the role of liability rules for environmental damage and on the question whether a harmonisation of liability rules in the European Union would better protect the environment from damage to occur and ensure restoration in case of an accident.

In this doctoral research I will examine whether the harmonisation of environmental liability rules in the European Union corresponds with the optimal policy level of environmental liability rules as propounded by the economic theory on federalism and, if not, how harmonisation of environmental liability rules can be explained in the European Union. In particular, this research will examine the existence of the Environmental Liability Directive from a public interest approach as well as a private interest approach. As the analysis of the optimal level of liability rules for environmental damage in general is a very broad subject, I will use liability rules for soil pollution as a case-study throughout this research. The choice to use liability rules for soil pollution as an illustration is not arbitrary. The optimal policy level of liability rules for soil pollution has not been examined in much detail up to now. Moreover, soil (pollution) can be seen as a - predominantly local - public good, on which federalism-theories can be perfectly applied.

By this comparison of theory and actual situation in the European Union, this PhD research aims to refine the existing scholarly debate on the optimal decision-making level of environmental regulation.

Refinements to the existing theory will be added in two ways. Firstly, the 'optimal policy level' of liability rules in a federal system will be examined not only from a public interest approach but also from a private interest approach. Accordingly, a theoretical framework on the optimal decision-making level for liability rules for environmental damage in a federal system will be developed. Secondly, the theoretical framework will be applied to the harmonisation of environmental liability through Directive 2004/35/CE in the European Union in order to unravel all factors that played a role in the harmonisation of environmental liability in the European Union. As a case-study, the harmonisation of liability for soil pollution by means of the Directive will be studied. This case-study will again refine the existing scholarly debate. As such, this doctoral research might provide a better understanding of all factors that have to be taken into account when deciding upon the optimal decision-making level of liability rules for environmental damage. This understanding may provide a useful guidance for other kinds of environmental policies. Furthermore, the research would not only provide a contribution to the theory on environmental federalism, but would also have practical relevance, with respect to environmental policy in the European Union.

\subsection{Problem Definition}

The diverse arguments pro and contra harmonisation of environmental regulation and the sometimes fierce debates on harmonisation at an academic as well as at a political level incite the research question of this PhD: was harmonisation of environmental liability rules in the European Union, including liability rules for soil pollution, desirable from an economic point of view and for what reasons did harmonisation take place? Yet, the harmonisation debate is a very complex one, and therefore, in order to answer this research question, subquestions will have to be formulated.

In order to point out the relevance of this research, the first of these questions is: what is the contribution of environmental liability rules in the prevention and restoration of environmental damage and which type of liability rule would be best to prevent and restore environmental damage? Indeed, prior to the question at which level liability rules for environmental damage can be best decided, the question what liability rule would be most efficient from an economic point of view to prevent and restore this damage must be answered. To answer this question, the economic analysis of tort law will be applied to liability for environmental damage. As soil pollution is the case-study throughout this research, the economic analysis will also be applied to liability for soil pollution.

Next, the optimal decision-making level at which liability rules for environmental damage might be decided in a federal system as the European Union can be examined. Therefore, the second question is: what is the optimal decision-making level of liability rules for environmental damage in a federal system from a theoretical perspective? In order to answer this question, the arguments of the so-called public interest approach and the private interest approach on harmonisation will have to be examined. The former approach looks at regulation as a correction for market failure and assumes that governments and other public agencies are able to correct market failures; the latter approach stresses the role of interest groups in the law-making process and emphasises the danger of government failure as a result of lobbying by interest groups. Again, the optimal level of liability rules for soil pollution will be taken as an example. 
The answers to the above two questions would allow the development of a theoretical framework on the optimal decision-making level of liability rules for environmental damage, including liability for soil pollution. This framework can accordingly be tested to the harmonisation of environmental liability rules, including liability rules for soil pollution, through Directive 2004/35/CE in the European Union.

Turning to the European situation, first, an insight in the development process and the provisions of Directive 2004/35/EC would seem to be appropriate. A third sub-question will therefore be: for what reasons did the Community consider harmonisation of environmental liability rules necessary and what are the scope and the provisions of Directive 2004/35/CE on Environmental Liability with Regard to the Prevention and Remedying of Environmental Damage, known as the Environmental Liability Directive, also with respect to soil pollution? In order to answer this question, in a first step, the competence of the European Union to harmonise environmental liability rules will have to be clarified. Next, the development process of Directive 2004/35/CE - or the Environmental Liability Directive - and the reasons provided for by the Community for the harmonisation of environmental liability rules at European level will be discussed. Then, the Directive's provisions and its application to soil pollution can be studied.

Finally, whether the harmonisation of environmental liability rules, including liability rules for soil pollution, through the Environmental Liability Directive, corresponds with the predictions of the theoretical framework presented above can be examined. The fourth and last subquestion would therefore be: does the Environmental Liability Directive correspond with the theoretical framework, with respect to economic efficiency as well as to the decision-making level of liability rules for environmental damage and, if not, why was harmonisation of environmental liability rules, including liability rules for soil pollution, considered necessary in the European Union? As for the theoretical analysis, again, it would be appropriate to examine first whether the liability regime as proposed by the Directive could be considered as efficient. This is independent from the question on the optimal decision-making level of liability rules for environmental damage. Secondly, the optimal decisionmaking level of liability rules for environmental damage, including soil pollution, can be examined for the particular case of the European Union. The arguments that where provided by the Community to justify the Directive will be examined both from a public interest approach and a private interest approach. In this way, the examination of the Environmental Liability Directive complements the theoretical framework and might offer a better understanding of all factors that play a role in a harmonisation debate.

On the basis of these four questions an answer to the main research question can be formulated. By answering this question, this doctoral research might provide a better understanding of all factors that can be taken into account when deciding upon the harmonisation of environmental rules in a federal system.

\subsection{Research Methodology}

Academic research is usually pursued from a specific background. In order to answer the research questions raised above the economic analysis of law, also known as 'Law and Economics' methodology, will be used in this PhD. Law and Economics research can be understood as the application of economic theory, primarily micro-economic efficiency analysis and basic concepts of welfare economics, to examine the formation, structure and economic impact of law, in this case tort law. ${ }^{4}$

Recognition of the impact of legal rules on economic behaviour has existed for almost a century, at least, and can even be traced back to the work of Adam Smith. However, law and economics research only came of age as a separate research discipline in the 1960's and 1970's. The dominant school of thought within Law and Economics research methodology became the Chicago approach to law and economics. The Chicago school primarily emphasises an efficiency analysis of legal rules. The works of scholars like Coase and Posner are considered as the core of the Chicago approach to law and economics. ${ }^{5}$

As soon as the 1970's, the Chicago approach, which focuses on economic efficiency 6 to explain existing law and to prescribe efficient rules, was criticised. The growing awareness of the role of institutions, the importance of social norms and other social science theories in the formation of law, resulted in the emergence of distinct schools or complements to the Chicago law and economics approach. Nowadays, the Institutional law and economics school (Goldberg, Samuels), the Neoinstitutional school (North,

Mercuro \& Medema 2006. For other introductions to law and economics methodology, see also Bouckaert \& De Geest 2000 and Faure \& Van den Bergh 1989.

See Coase 1960, 1-44 and Posner 1998 (first edition 1973), e.a.

The term 'economic efficiency' merits a short explanation. Efficiency in the standard definition of the Chicago approach is mostly based on the Kaldor-Hicks efficiency criterion. This efficiency criterion can be understood as stating that a change in legal rules is efficient if the gainers gain more than the losers lose, so that the gainers of this change in law could compensate the losers and still have profit from it. However, the Kaldor-Hicks criterion does not require that the losers are effectively compensated, this is hypothetical and therefore this criterion has been critiqued. Put differently, the Kaldor-Hicks efficiency criterion states that the wealth of society as a whole must be increased by a change in law. 
Williamson), the Austrian school (Hayek, Rizzo) and the Public Choice approach (Buchanan, Tullock, Olson), focusing on rent seeking behaviour to explain the formation of legal rules, can be placed beside the Chicago approach. The Yale School (Rose-Ackerman, Calabresi, Schwarz) is not usually seen as a distinct school, but as an enrichment of the Chicago approach. The Yale School approach adopts the methodology of the Chicago School but believes in a larger need for government intervention and pleads for recognition of allocative and distributional impacts of legal rules and a concern for justice and fairness. ${ }^{7}$

The first part of this research aims at developing a framework for decision-making that would offer criteria to determine an optimal or efficient level of liability rules for environmental damage in a federal system and can be seen as a positive economic analysis of tort law.

In a first step, the economic analysis of tort law will be used to examine which type of liability rule would most efficiently prevent and restore environmental damage, including soil pollution, from an economic point of view.

Next, the optimal decision-making level of liability rules for environmental damage will be examined. Yet, in a federal system, the debate on the harmonisation of liability rules for environmental damage, including soil pollution, is a very complex matter with a lot of factors that have to be taken into account and that need to be unravelled. Therefore, a deeper understanding of this complex matter in the real world can only be gained by studying the problem from different angels. This research will therefore look at the problem from two different theoretical perspectives within Law and Economics methodology that can both bring useful contributions to the underlying problem. Both perspectives will be brought together in order to provide an overall assessment.

The first perspective, called public interest approach, is based on Chicago School of Law and Economics, complemented with components of Yale School of Law and Economics. Economic efficiency criteria will be used to examine the appropriate federal structure for environmental liability rules, a method that is usually called the theory of federalism. ${ }^{8}$ This involves careful weighing of all arguments in favour or against assigning responsibility to a certain level of government, which can be the central or national government or a more local level of government. Besides the purely economic arguments, non-economic arguments will also be taken into account. However, the level of regulation may appear inefficient according to the theory on federalism, or the content of the regulation may be inexplicable on the basis of the public interest approach. Therefore, a second perspective, that provides insights in the actual division of power between the central level and the local level in a federal system, is needed.

This second perspective, called private interest approach, is based on Public Choice theory. Obviously, environmental rules can have important economic implications. Therefore, rent seeking behaviour and lobbying of different interest groups in the law making process should not be ignored. Public Choice theory looks critically at the belief that government officials would only develop regulations in the public interest. Moreover, Public Choice theory critically examines the role of the people that have to be regulated, and how pressure groups might try to steer the law making process. Politicians may develop regulation that does not (only) serve the public interest, but which is in fact for the benefit of one or another pressure group, this in return for votes at an election and other forms of support. ${ }^{9}$ Hence, the use of Public Choice theory might help to unveil reasons for the harmonisation of environmental liability rules in the European Union that cannot be explained by the economic theory of federalism.

Indeed, although the public interest approach, based on welfare and efficiency criteria, and the private interest approach, based on Public Choice theory, use different conceptual starting points, the approaches complement each other. The reasons for a certain policy can sometimes be best understood if not only the public interest, but also the behaviour of the government officials and pressure groups is taken into account. Hence, the combined use of both approaches might be the best way to develop a framework for decision-making on the optimal level of liability rules for environmental damage, including soil pollution, in a federal system.

The second part of this research consists of a presentation and examination of Directive 2004/35/CE on Environmental Liability with Regard to the Prevention and Remedying of Environmental Damage, by which the Community intends to harmonise environmental liability rules in the European Union. After providing an insight into the development process and contents of the Directive, the theoretical framework can be tested.

In a first step, an efficiency analysis of the Directive, based on the economic analysis of tort law, will be provided. The efficiency of a liability regime in preventing and restoring environmental damage is independent of the level of regulation. At each decision-making level inefficiencies may arise. However, it

See Teijl \& Holzhauer 1990 617-631 and Mackaay 2000, 402-415.

Inman \& Rubinfeld 2000.

See for instance De Geest 1990, 666-673 and Faure \& Van den Bergh 1989, 148-152. 
is interesting to study whether the Environmental Liability Directive will be able to achieve the aims of prevention and restoration of environmental damage, and of soil pollution as an illustration, before studying whether the harmonisation of environmental liability rules in the European Union would be justified from an economic perspective.

Next, the public interest approach and the private interest approach will be applied to the harmonisation of environmental liability rules in the European Union by means of the Directive. Whether the justifications for the harmonisation of environmental liability rules, including liability for soil pollution, in the European Union correspond with the economic theory of federalism, will be examined. As a complement to this public interest approach, a private interest approach, based on public choice theory, will be used to examine whether rent seeking behaviour has played a role in the harmonisation of environmental liability rules in the European Union, and to what extent rent seeking behaviour has influenced the content of the Directive itself. This part of the research can also be seen as a positive analysis of tort law. However, those who wish to do so can of course use the results at the policy level to capture competences for environmental law making in a federal system on the basis of economic efficiency criteria.

\subsection{Structure}

The structure of this doctoral research follows directly from the research questions defined above. The theoretical framework for deciding on the optimal level of liability rules for environmental damage in a federal system, with the example of soil pollution, will be developed in chapters 2 and 3 .

Chapter 2 will provide an introduction into the economic analysis of tort law, and will apply this theory to environmental liability. The contribution of environmental liability rules to prevention and restoration of environmental damage will be shown by means of an assessment of other instruments for the prevention of environmental damage, in general, and soil pollution, in particular, such as regulation, marketable permits and pollution taxes. Moreover, interdependencies between liability rules and regulation will be made clear. Finally, the contribution of liability rules to the prevention and restoration of environmental damage, and of soil pollution as an example thereof, will be clarified. Readers familiar with this analysis might skip chapter 2 and immediately go to chapter 3.

Chapter 3 will examine the optimal decision-making level for environmental damage liability rules in a federal system from two different theoretical perspectives, a public interest approach and a private interest approach. Firstly, the problem will be studied from a public interest perspective. Based on the theory of federalism, economic efficiency criteria will be used to examine the appropriate federal structure for environmental liability rules. This involves careful consideration of all arguments in favour or against assigning responsibility to a certain level of government. Besides economic arguments, non-economic arguments will also be taken into account, like the right to high environmental quality for all citizens. Secondly, a private interest approach, using public choice theory, will be applied to liability rules for environmental damage.

The framework that will accordingly be developed, aims at providing guidance on the optimal policy level of environmental damage liability rules in a federal system. Soil pollution will be used as an example. Next, the framework can be applied to Directive 2004/35/CE on Environmental Liability with Regard to the Prevention and Remedying of Environmental Damage, adopted on 21 April 2004.

Chapter 4 will first outline European environmental policy as far as the division of competences for environmental matters is concerned. Then, the background and provisions of the Environmental Liability Directive and its application to soil pollution will be studied critically.

In Chapters 5 and 6, the theoretical framework developed in chapters 2 and 3, will be applied to the Environmental Liability Directive. Chapter 5 will examine the extent to which the provisions of the Directive correspond with the economic analysis of tort law as provided in Chapter 2 and whether the ELD can efficiently achieve the prevention and restoration of environmental damage and of soil pollution.

Chapter 6 will then examine whether the justifications provided by the European Commission for a harmonised European environmental liability regime, including liability rules for soil pollution, correspond with the predictions of the theoretical framework for harmonisation of environmental liability rules. In a first step, the justifications of the Commission will be compared with the public interest approach. Additional explanations for the harmonisation of environmental liability rules in the European Union will then be sought on the basis of the private interest approach. The findings of this case-study may then be used to refine the framework developed in the theoretical part, in order to refine the existing scholarly debate on the optimal decision-making level for environmental liability rules, and specifically for soil pollution.

Finally, the main results will be summarised, a few conclusions will be formulated and an answer to the main research question will be provided: was harmonisation of environmental liability rules in the 
European Union, including liability rules for soil pollution, desirable from an economic point of view and for what reasons did harmonisation take place? By answering this question, this research tries to contribute to the existing academic debate on the optimal policy level for environmental policy and, in particular, for liability rules for environmental damage. 


\section{Chapter 2}

\section{AN ECONOMIC THEORY OF ENVIRONMENTAL LIABILITY}

This chapter will introduce the reader in the economic analysis of tort law and its application to environmental damage and soil pollution as an example thereof. This research tries to reach readers of various disciplines, economists as well as lawyers or even scholars of other sciences, who are interested in environmental law and policy. This chapter is therefore meant as an introductory chapter. The chapter will explain the contribution of liability rules in the prevention and restoration of environmental damage, and of soil pollution, before examining the optimal division of competences between the central and the local level for environmental liability rules in a federal system. Yet, readers that are familiar with this analysis might continue immediately with chapter 3 .

Tort law is the field of law that defines the applicable liability rules in an accident setting. The chapter will gradually build up an economic theory of environmental liability and will consist of three parts.

Paragraph 1 will explain the starting points of the economic analysis of law, whereby some basic economic notions, such as externalities and the Coase theorem, will be clarified.

Paragraph 2 will then define an economic theory of liability for environmental damage. This will be done in four stages. Firstly, the economic theory of tort law in general will be explained. The functions of tort law from an economic perspective will be clarified and an analysis of optimal liability rules for accident prevention will be presented. Secondly, the economic theory of tort law will be applied to environmental damage. Optimal liability rules for environmental damage will be studied and a few refinements to the general theory will be indicated. Thirdly, liability rules will be compared with other instruments for controlling pollution. By providing a brief assessment of other instruments that can be used to protect the environment, such as regulation, marketable permits and pollution taxes, the contribution of liability rules for the prevention and restoration of environmental damage will be clarified. Moreover, interdependencies between tort law and regulation, and the complementary function of liability rules, will be demonstrated. Fourth, the value added by liability rules for environmental damage will be demonstrated.

Paragraph 3 will apply this economic theory of liability for environmental damage to soil pollution. This paragraph will clarify the contribution of liability rules in the prevention and restoration of soil pollution and the interdependencies between liability rules for soil pollution and regulation of soil quality standards.

Once the contribution of liability rules in the prevention and restoration of environmental damage, including soil pollution, has been clarified, the optimal division of competences between the central and the local level for environmental liability rules in a federal system can be examined in Chapter 3 .

\section{An Economic Perspective on Environmental Damage}

This paragraph will first clarify some basic principles of the economic analysis of law. Next, the role of environmental damage within this economic perspective, and how the role of tort law, or liability rules, can be explained within this framework, will be described.

\subsection{Basic Principles of the Economic Analysis of Law}

The economic analysis of law is primarily based on neo-classical micro-economics, and in particular welfare economics. ${ }^{10}$ This might merit a short explanation. Welfare economics starts from the principle that individuals seek to maximise their own welfare, usually referred to as utility or wealth maximising behaviour. Economics presumes that the market system allows individuals - who are only concerned with maximising their own welfare - to realise efficiency and hence to maximise social welfare, through

$10 \quad$ See Posner 1998, Shavell 1987 and Cooter \& Ulen 2003, 9-44. 
bargaining with one another. However, when the market does not work perfectly, as we will see in the case of environmental damage, individual welfare-maximising behaviour might fail to maximise social welfare. In such circumstances, legal rules can become necessary to steer individual welfare-maximisation behaviour so that an efficient allocation of resources can be achieved. ${ }^{11}$ Fundamentally, the economic analysis of law tries to examine how individuals would respond to changes in law and, hence, under which circumstances a particular rule would maximise social welfare.

\subsection{Environmental Damage as an Externality}

Traditionally, the starting point of the economic analysis of environmental law is that an industrial activity, which may be beneficial for society on its own, may have negative effects on the environment or citizens, called external effects or externalities. ${ }^{12}$ These negative effects of industrial activity are called externalities since the polluting firm is not affected itself by the external effects of its production. Indeed, as the use of the environment has no clear price, the polluter will not take the environmental damage that he caused into account in other costs in his decision-making process. The fact that the polluter does not take these negative effects of production into account might reduce social welfare.

Environmental economics therefore suggests 'pricing' the environment by legal or economic tools in order to force the polluter to take the pollution that he causes into account in his business decisions, like his activity level. This is what economists call the internalisation of negative effects. The traditional economic solution would consist of imposing a tax on the polluting activity. This solution is based on the work of Pigou; the tax is usually referred to as a Pigouvian tax. ${ }^{13}$ In the 1970 's environmental economists introduced the further idea of using incentive instruments like marketable permits and emission charges to reduce pollution. These incentive instruments still play a minor role in the protection of the environment. In practice, governments have generally introduced a framework of command and control regulation, which defines the standards a company has to meet. This public law framework has frequently been complemented by liability rules for environmental harmful discharges. Environmental liability rules belong to the private law domain, and have become often-used provisions, in national law as well as in international conventions. The Coase Theorem is commonly used to explain the role of governmental intervention through regulation or tort law.

\subsection{The Coase Theorem as an Explanation for the Role of Tort Law}

The role of tort law, or liability rules, in internalising externalities is usually explained by the Coase theorem. ${ }^{14}$ However, before the Coase theorem can be explained, a clarification of the notion of property rights is meritted. Economics deals with the use of scarce resources, whereby individuals will seek to maximise their own welfare. Property rights provide the framework for the allocation of scarce resources to individuals. Property rights define what individuals may or may not do with the property they own, and to what extent they may use, transform or even deplete their property. ${ }^{15}$

Coase's theorem can be clarified using the well-known example of the cattle rancher and the farmer. ${ }^{16}$ Suppose that a cattle rancher lives besides a farmer. Although the boundary is clear, there is no fencing between the two properties. Yet, once in a while, the cattle wander onto the farmer's property and damage the corn. The damage to the farmer could be prevented by building a fence. If the law requires the rancher to install the fence, the rancher would have to bear the cost of the fence. In the assumption however, that the law does not require the rancher to build the fence, it would pay for the farmer to start bargaining with the rancher and to offer compensation in order to build the fence, as long as the cost of the fence is lower than the farmer's damage. ${ }^{17}$ Under these circumstances, the fence will be built, irrespective of the provision on the property right in the law.

11 As stated in the introduction, Law and Economics usually uses the Kaldor-Hicks criterion to define efficiency, stating that a change in legal rules is said to be efficient if the winners gain more than the losers lose, so that the winners of this change in law could compensate the losers and still have profit from it. The criterion does not require actual compensation though. See Landes \& Posner 1987, 16.

Endres \& Staiger 1996, 80, and Faure 2001, 127.

Faure 2000, 445.

Coase 1960, 1-44

Coase 1960, 2-6.

Cooter \& Ulen 2003, 74. The latest version of this book has been published in September 2007.

Note that if the cost of the fence is higher than the farmer's damage, the farmer will not bargain. 
Coase's conclusion was that, in the absence of transaction costs, ${ }^{18}$ it does not matter whether an entitlement or right is given to the polluter, or to the person who suffers damage. If the initial allocation would not be efficient, parties will start bargaining - called Coasian bargaining - by which the parties involved can reach maximum individual and social welfare. In this case, there would be no need for intervention; the economic efficient solution would be reached through bargaining.

The Coase theorem raised various criticisms, some of which merit some brief explanation. ${ }^{19}$ First, it should be mentioned that Coase did not consider distributional effects, only efficiency. The Coase theorem therefore does not take social norms of fairness considerations into account. Second, property rights have to be clear and strategic behaviour of both parties in bargaining should be excluded. Furthermore, the Coase theorem does not take the effect of endowment into account. An 'endowment' is an initial assignment of property rights. Experiments revealed that people might demand a higher price to 'sell' a right to, for instance, clean air, then they would pay to buy the same right. The discrepancy between the buying and selling price is called the 'endowment effect', because the price varies depending upon the initial assignment of ownership, which may influence the outcome of the Coasian bargaining. The demand for environmental regulation might, therefore, be importantly affected by the initial allocation. ${ }^{20}$

Still, the most problematic assumption with respect to environmental damage is that the Coase theorem is based on a zero transaction cost assumption. In reality, transaction costs might be prohibitive in allowing Coasian bargaining. With respect to environmental harm, it might be extremely difficult to identify who exactly are the victims of environmental harm. In fact, everybody can suffer from environmental harm. Therefore, ex ante Coasian bargaining between the polluter and the potential victims is mostly not a workable solution for coping with the problem of environmental harm. Governmental intervention through command - and control regulation or liability rules, but also by taxes and pollution permits, may therefore be needed to induce the potential polluter to internalise the negative effect of his activity. ${ }^{21}$

Despite the criticism, the Coase theorem provides a useful starting point in explaining the role of tort law and governmental intervention to prevent environmental damage. The usefulness of the Coase theorem lies in the fact that it might help the legislator to search for that law that would 'mimic' the spontaneous economic efficient result if there had been no transaction costs. Therefore, the Coase theorem might prevent excessive or inefficient regulation.

Taking the Coase theorem as a starting point for the explanation of the role of tort law in preventing environmental damage, the relevant question that has to be answered next is which type of liability rule would then best guarantee the prevention and restoration of environmental damage. Paragraph 2 will turn to this question and will develop an economic theory of liability for environmental damage.

\section{Defining an Economic Theory of Environmental Liability}

\subsection{Economic Theory of Tort Law: General Approach}

In this paragraph, the contribution of liability rules in the prevention and restoration of environmental damage will be clarified and an economic theory of liability for environmental damage will be developed. This theory will be unfolded in four stages. First, a general economic analysis of tort law will be presented. Tort law defines the applicable liability rules when damage has been caused. The economic analysis of tort law evaluates liability rules on their efficiency in accident prevention. Second, this general framework and the analysis of optimal liability rules will be applied to environmental damage and a few refinements to the general theory will be added. Third, liability rules will be compared with other instruments to control pollution. By providing a brief assessment of other instruments that can be used to protect the environment - like regulation, marketable permits and pollution taxes - the contribution of liability rules for the prevention and restoration of environmental damage will be illustrated. Moreover, interdependencies between tort law and regulation and the complementarity of liability rules will be shown. Finally, the value added by liability rules for environmental damage will be demonstrated.

18 Coase did not provide an exact definition of these transaction costs. Hence, a rich literature emerged on the definition of transaction costs. It falls out of the scope of this research to discuss this literature in detail. Therefore, transaction costs will be understood as including, at the most basic level, the costs of negotiating, monitoring and enforcing contractual agreements. See Mercuro \& Medema 2006. For other introductions to law and economics methodology, see also Allen 2000, 893-926.

See Faure \& Van den Bergh 1989, 66 and Cooter \& Ulen 2003, 86-87.

See Sunstein 1993, 217-254, Cooter \& Ulen 2003, 87.

Faure 2000, 446-447. 


\subsubsection{Economic Function of Tort Law}

\subsubsection{Development of the Economic Analysis of Tort Law}

Excellent analyses on the economic function of tort law emerged in the 1960's, with the pioneering works of Calabresi, Coase, Brown, Shavell and Posner. ${ }^{22}$

The lawyer Guido Calabresi was one of the first scholars to examine the effect of tort law on individual behaviour thoroughly from the perspective of law and economics. ${ }^{23}$ In his famous book "The Costs of Accidents' Calabresi showed that tort law has the ability of reducing three different types of costs: primary, secondary and tertiary costs. Primary accident costs are, on the one hand, the costs of accident avoidance, which are the costs of taking precautions, and, on the other hand, the damage that eventually occurs if an accident does happen. Secondary costs refer to the costs of loss spreading. Secondary costs of accidents arise, for example, if those who bear the primary accident costs are risk-averse and take insurance coverage. Tertiary costs are the costs of administrating the legal system in the case of a trial. According to Calabresi, an efficient tort law should give incentives to individuals to achieve a reduction of the total social accident costs, which is the sum of the three types of accident costs.

The Calabresi's ideas were formalised by economists. Posner and Shavell examined the most important liability rules with respect to their effect on a society's wealth. Brown provided a now classical analysis of the economic effects of liability rules.

\subsubsection{Deterrence and Compensation Function of Tort Law}

The economic analysis of tort law starts from the idea that liability rules will give incentives to potential parties of an accident for careful behaviour. As the emphasis is on steering the behaviour of individuals, the law and economics approach examines the prevention or deterrence function of tort law especially. However, liability rules have a second function. Namely, compensation of the victims after damage has occurred, which touches upon fairness notions in society. This compensation function gets most attention from lawyers. ${ }^{24}$ Incorporation of such fairness notions in the economic analysis of liability for environmental damage will be discussed below.

Several authors ${ }^{25}$ refer to this difference in accents between both approaches as an ex ante versus $e x$ post vision. They state that, in general, lawyers tend to be more interested in the accident problem ex post, when a victim needs to be compensated. Economists study the accident problem in an ex ante way by asking how ex post liability for damage will influence ex ante the behaviour of potential parties to an accident, notably by taking precautions in order to prevent the accident.

In any case, the fact that the deterrent function and compensation functions are carefully distinguished as the ex ante and ex post functions of legal instruments has a clear advantage. This distinction notably allows the effect of the various legal mechanisms that one would choose to prevent damage to be evaluated with respect to both the prevention and the compensation function. In this chapter, attention will go to both functions of environmental liability rules to prevent environmental damage. By doing so, the added value of environmental liability rules can be shown.

\subsubsection{Analysis of Optimal Liability Rules}

\subsubsection{Basic Notions of Tort Liability}

The first goal of tort law would be to minimise the costs of accident avoidance and the expected damage in case of an accident, defined by Calabresi as the primary accident costs. Indeed, accidents do not only cause costs from the moment an accident occurs and harm is suffered. Potential parties in an accident make investments in care (precautions) to avoid the occurrence of an accident. This paragraph will discuss the major liability rules and will examine under which circumstances what type of liability rule would minimise the primary accident costs. A distinction will be made between two types of accident risk, nomely, unilateral and bilateral accidents. ${ }^{26}$

In a unilateral accident situation the behaviour of one person (the injurer) can influence the chance that an accident will happen, and the gravity of the accident. In a bilateral accident case, both the injurer as

Calabresi 1970, Coase 1960, Brown 1973, Shavell 1987, Posner 1998. For an overview see Schaefer 2000.

Calabresi 1970.

Faure \& Grimeaud 2003, 19.

Faure \& Grimeaud 2003, 19 and Heyes 1994.

Shavell 1987, 5-32. See also Brown 1973; Landes \& Posner 1987; Faure 2003b, 20. 
the person who is harmed (the victim) can influence the occurrence and gravity of the accident. The accident risk is not, however, influenced solely by the level of precaution taken by the parties in the accident but also by the level of activity, which are the times that the parties engage in the activity. ${ }^{27}$

A liability rule defines whether the injurer is liable for the accident and whether he should pay compensation to the victim. Strict liability and negligence are the major rules of liability used in tort law to deal with situations where one person (the injurer) causes harm to another (the victim). Occasionally these rules are completed with some defence possibility, such as contributory negligence and comparative negligence. ${ }^{28}$

Under a strict liability rule, the injurer has to compensate the victim no matter what care he took in attempting to prevent the accident. He will always have to bear the costs of the accident. Under a negligence rule, on the other hand, the injurer will only be held liable if he did not take appropriate care. The appropriate care level is usually determined by the law and/or the court. This level is called reasonable care or due care. The due care standard specifies a level of care and defines parties who take less care to be at fault. ${ }^{29}$ The question, however, is how this 'due care' level can be determined.

In order to determine what level of precaution will minimise the social costs of an accident, economists use a classic cost-benefit analysis. From an economic point of view, minimisation of costs can be found at the level where the marginal (i.e. one more unit) costs of care taking equals the marginal benefit in accident reduction. The economic logic is that taking precautions also has a price. Therefore, a liability rule should not give incentives to avoid every accident that could occur, but only those accidents that could be avoided by taking precautions of which the marginal costs are lower than or equal to the marginal benefits in accident reduction. ${ }^{30}$ It is possible that more precaution could induce an additional reduction of the accident risk but the marginal costs of these precautions might be much higher than the additional benefit of accident reduction. Investment in precaution when it costs more than the benefits received is clearly economically inefficient and scarce resources would be spoiled. ${ }^{31}$ The level of precautions where the marginal costs of these precautions are equal to the marginal benefits in accident reduction is referred to in the economic literature as optimal or efficient precaution (or care) levels. ${ }^{32} \mathrm{~A}$ liability rule should therefore give an incentive to potential parties in the accident setting to adopt this optimal care level. Once the due care standard has been set, negligence under a negligence rule can be determined.

Interestingly enough, the first person to describe a formula for negligence was not an economist but a judge. Judge Learned Hand developed the Learned-Hand formula in 1947 in the case called United States v. Carroll Towing Co. ${ }^{33}$ : The case concerned the loss of a barge and its cargo after it broke loose from its mooring line in New York Harbour. Judge Learned Hand decided that the accident could have been prevented if the owner had taken precautionary measures. According to him, such preventive measures would have cost less than the expected damage in case of an accident. Consequently, Judge Learned Hand defined three variables that determined negligence: (1) the probability that the accident will occur, (2), the seriousness of the resulting injury, and (3) the costs of adequate precautions. A person is negligent, and hence liable for the accident, if the costs of precautions (B) were less than the probability of harm (P) times the seriousness of the injury $(\mathrm{L})$, which becomes in formula $\mathrm{B}<\mathrm{PL}$. In different words, the Hand rule provides a due care level that defines a party to be negligent if the expected accident losses are greater than the prevention costs that the party has undertaken. ${ }^{34}$ Though mathematical in form the Judge Hand formula does not yield precise results as the variables cannot all be quantified. The Hand rule was further refined by economists by considering the marginal costs instead of total costs..$^{35}$ Nevertheless, the formula is a valuable aid to clear thinking about the factors that are relevant to a judgement of negligence and about the relationship between those factors.

A strict liability rule and a negligence rule have different consequences and effects. As the focus of this chapter is to search for the liability rule that is 'optimal' or efficient, in the sense that it would minimise social costs of accidents, the remainder of this paragraph will concentrate on the general analysis of optimal liability rules, which is mainly based on the analysis of Shavell. ${ }^{36}$ The effects of a negligence rule on taking

Shavell 1987, 6-10.

Shavell 1987, 4. See also Schaefer 2000, 569-577.

Shavell 1987, 4-8. See also Schaefer 2000, 569-577.

Faure \& Grimeaud 2003, 21.

This finding is only valid in a risk neutral setting. In case of risk aversion higher levels of care taking might be efficient since a reduction of accident risk can remove the disutility of risk from the risk averse person, in Faure 2003b, 21.

See for example Landes \& Posner 1987, 58 and Cooter \& Ulen 2003, 301.

United States versus Carroll Towing Co., 159 F 2d 169 (2d Cir. 1947).

Cooter \& Ulen 2003, 313-315, Schaefer 2000, 597-618.

Brown 1973, 332-335. Brown was the first scholar to refine the formula, all authors after him take marginal costs into account.

Shavell 1987, 5-32. 
precautions to avoid an accident can be compared with the precautions that will be taken in case of a strict liability rule. This general analysis will then be used to consider the effects of negligence versus strict liability for environmental damage. This research will only deal with unilateral accidents, as environmental accidents, which are the subject of this study, are mostly unilateral cases.

\subsubsection{Negligence versus Strict Liability in Unilateral Accidents}

In the unilateral case, Shavell distinguishes between two legal rules, which will give the injurer the incentive to take optimal care in order to prevent an accident, namely, the negligence rule and strict liability. ${ }^{37}$

\section{Negligence Rule:}

In case of a negligence rule, the injurer will only be held liable if he did not take appropriate precautions to avoid the accident. This basically means that the injurer took less precautions than the legal standard of due care. Shavell proves that the injurer will take optimal care (which is the level where total social costs are minimised), provided that the due care standard defined in the legal system is equal to the economically optimal care level. ${ }^{38}$ The reasoning behind this result is that the injurer will try to avoid the accident by taking precautions. Taking precautions involves a cost. However, by doing so, he can avoid paying the damage in the case of an accident happening. The injurer could, of course, take more precautions than required by the legal system under a negligence rule, but it would be to no advantage, since he can already avoid liability by following the due care standard. The injurer might also take less care than the legal system requires him to do. He would then have fewer costs of precaution, but he would be exposed to the risk of being liable to pay the damages in the case of an accident occuring. Since the optimal level of precaution was defined as the level of precaution where the marginal costs of care equal the marginal benefits in accident reduction, taking less precaution than the due care standard would be to no advantage either, as it would increase his total expected costs. Therefore, a negligence rule will lead to an optimal result as long as the legal system sets the due care standard equal to the optimal care level. ${ }^{39}$

\section{Strict Liability}

Under a strict liability rule, the courts do not have to define any level of due care because the injurer will have to pay the costs of the accident regardless of the magnitude of his precaution. ${ }^{40}$

In the unilateral case, this means that the injurer has to bear his own costs of precaution as well as the expected damage if an accident occurs. Rationally, the injurer will take that level of precaution that minimises his total expected accident costs. Shavell shows that this minimisation of costs is reached at the optimal care level, as with negligence. The reasoning is that taking more precautions than the optimal level, would increase his costs of precautions inefficiently. Indeed, the costs of precaution would be higher than the benefit from it. On the other hand, spending less on precaution than the optimal level would increase the accident risk, and hence the accident costs. By taking slightly more precaution the potential injurer would reduce accident costs by more than the extra cost of more precaution. Therefore, the injurer will choose the optimal precaution level spontaneously.

\section{Balance}

From the above it can be concluded that in case of unilateral accidents both a negligence rule and a strict liability rule will lead to a minimisation of the primary costs of accidents.

However, it cannot be concluded there are no differences between a negligence rule or a strict liability rule. Indeed, both liability rules have consequences that should not be overlooked. With regard to the three

\footnotetext{
37 The case in which there is no liability (no rule), cannot be efficient, as the injurer would have no incentive for care-taking. He will not 'internalise' the cost of an accident and an inefficient outcome will follow. See Shavell $1987,8$.

38 Obviously it is very difficult for courts or authorities to define the efficient level of care, in order to set the legal standard of due care. Due care is therefore usually defined by comparing the precaution level of the injurer with what a reasonable person would do under similar circumstances: Schaefer \& Schoenenberger 2000, 602.

39 Faure \& Grimeaud 2003, 21-22.

$40 \quad$ Shavell 1987, 8, Schaefer \& and Schoenenberger 2000, 597-618.
} 
types of costs defined by Calabresi, there are differences between the two liability rules in as far as the secondary and tertiary costs are concerned. ${ }^{41}$

Regarding the secondary costs (concerning loss spreading), it is clear that under the negligence rule, the injurer will not be liable for any damage as long as he complies with the due care standard. If this is the case, there will be no compensation for the victim, who will have to bear the costs of any accident himself. On the other hand, under a strict liability rule, victims will always be entitled to compensation. A drawback however, of a strict liability rule is that the injurer might be insolvent, so that the victim cannot be compensated. Therefore, whether the victim will actually receive compensation depends on the funds the injurer has, or whether he took insurance. The insurance issue will be dealt with below, with an application to environmental damage.

Also, the administrative and information costs, which are Calabresi's tertiary costs, will differ for both rules. Under strict liability the number of claims before the court is likely to be higher since the injurer will always be liable, regardless of the care he took. Court costs can therefore be expected to be higher than under a negligence rule. On the other hand, if it comes to a court case under the negligence rule, high information costs might result since the judge will have to determine in a particular case whether the injurer took optimal level of care, i.e. the level where marginal costs and benefits are equal. ${ }^{42}$

Besides differences in secondary and tertiary costs, negligence and strict liability also have a different influence on the activity level of the potential injurer. Shavell has paid special attention to the influence of the activity level as he states that not only the level of precaution influences the accident risk. The activity level proves also to be an important factor that influences the accident risk. The chance of being involved in an accident will not only be influenced by the precaution which is taken when exercising the activity, but also by the number of times the potential parties engage in the activity. ${ }^{43}$

Shavell stresses that the objective of a liability rule should not only be to provide incentives for optimal care taking, but also to provide incentives for adopting an optimal activity level. This influence on the activity level is an important factor in the choice between strict liability and negligence. If accidents are unilateral, and hence only the injurer's activity can influence the accident risk, it can be proven that negligence will not lead to optimal results. Shavell states that negligence only provides incentives to the injurer to take optimal care, but not to adopt an optimal activity level. The reasoning is that when a judge has to define the due care level required by the legal system, he can not take the activity level exercised by the injurer into account. The judge will not be able to identify what an optimal activity level is and will not hold an injurer liable because of negligence since he engaged too often in a certain activity. ${ }^{44}$

Only a strict liability rule will provide incentives for the injurer to adopt an optimal activity level. The reason is that the injurer can minimise his total expected costs by adopting an optimal activity level. Under a strict liability rule the injurer will have to compensate the total accident costs. He therefore knows ex ante that he will have to bear his own costs of precaution and the expected damage. Therefore, he will not only consider his costs of care, but also the number of times he engages in the activity against the resulting expected loss. From the above it follows that when the victim can not influence the accident risk, neither through taking care, nor by adopting an optimal activity level, which is the case in a unilateral accident, only strict liability will lead to an optimal activity level. ${ }^{45}$

Another advantage of the strict liability rule is that it is the injurer who has to search for the optimal level of care. Indeed, in many cases, the injurer is better at deciding which precautions to take and to what extent. He is likely to be familiar with the activity in which he engages that can cause an accident. ${ }^{46}$

In sum, both a negligence rule as a strict liability rule result in an optimal level of precautions in a unilateral accident setting. There are differences though, with respect to the secondary and tertiary costs and the activity level. If the aim of the liability rule is also to reduce the activity level, a strict liability rule might be preferred.

\subsection{The Economic Theory of Tort Law Applied to Environmental Damage}

This paragraph will apply the general economic analysis of optimal liability rules in a unilateral accident setting to environmental damage. Analogue to the economic analysis of tort law in general, liability rules can be seen as a possible solution for internalisation of the negative effect of the polluter's activities on the environment. Environmental liability rules can be considered as a means of providing incentives for the

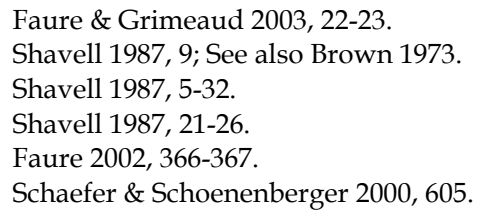


polluter involved to take precautions in prevention of environmental damage ex ante and to act 'efficiently' after environmental damage has been caused, notably in engaging in clean up. Heyes classifies these two objectives of liability rules as ex ante and ex post efficiency. ${ }^{47}$

As for liability rules in general, on the one hand, liability for environmental damage ${ }^{48}$ fulfils a deterrence function ex ante, as it will incite the polluter to take the efficient level of precaution in order to escape liability. On the other hand, liability has a compensation or restoration function ex post, to ensure a 'fair' compensation of damage. ${ }^{49}$

In the following, again only the unilateral case will be discussed. It is assumed that only the potential polluter has the means to influence the damage by taking precautions. Bilateral cases, whereby both injurer and victim can influence the risk by their behaviour are not that common in environmental liability and will therefore not be examined here. ${ }^{50}$

\subsubsection{Negligence versus Strict Liability in Preventing Environmental Damage}

There are several authors that discuss the use of strict liability versus a negligence rule in the case of environmental damage. ${ }^{51}$ Their results and reasoning are essencially the same. As a starting point, Polinky and Shavell consider a firm in which production has a risk of causing environmental damage. If environmentally harmful discharges would occur clean-up efforts by the responsible firm can reduce the level of damage. Social welfare is economically defined as the utility of the firm's production (for consumption), less the total cost of production, which include the costs of prevention and clean-up efforts. ${ }^{52}$ Departing from this situation, it can be examined whether a negligence rule or a strict liability rule will be more efficient in giving incentives to prevent environmental damage, and in clean up if environmentally harmful discharges occurred.

\section{Negligence}

Under the negligence rule, courts will define a due care standard of precaution. In the ideal situation that courts dispose of all relevant information, they will be able to set this due care standard at the economically optimal level, as discussed in the general case. Under the negligence rule, the potential polluter will only be held liable if it can be proven that he did not adopt the due care standard of precaution. Therefore, he only has to internalise clean-up costs in the case where he took less precaution, otherwise he merely has to bear the optimal level of prevention costs. ${ }^{53}$ Assuming rational cost-minimising behaviour, the potential polluter will take the optimal level of precaution, in order to avoid liability. Hence, an optimal level of precaution is achieved under the negligence rule.

\section{Strict Liability}

Under the strict liability rule, the courts do not have to define any level of due care because the injurer will have to pay the costs of the damage regardless the precaution he took. A firm that is strictly liable will therefore, besides his precaution costs, also internalise expected damage costs. If the firm causes environmental damage, it will be responsible for clean up and remain strictly liable for any harm that remains after the clean-up, as Polinsky and Shavell state. Economic rational behaviour is assumed, therefore the firm will try to minimise its total costs, prevention and expected damage costs. It is clear that the more precaution the firm takes, the smaller the expected damage costs will be. The firm will increase precautions up to the level where precaution costs are equal to the expected damage. Beyond that level precaution costs will be higher than the reduction in expected damage. Hence the firm would select the economically optimal level of precaution that will minimise total costs for the society.

Heyes 1994, 294.

For the purpose of this section all kinds of environmental damage are considered. However, it is assumed that liability is limited to environmental damages of which it can be proven that the polluter did indeed cause the accident. It is also assumed that there is no retroactive liability. Retroactive liability is criticised for several reasons. Indeed, if certain behaviour is considered to lead to liability ex post, whereas this was not the case ex ante, a liability rule certainly will not affect the incentives of a polluter for the future. Retroactive liability may even weaken the incentive to take precautions against future pollution costs. See Faure \& Fenn 1999, 487-500.

See for example Bergkamp 2001a, 67-116.

Endres \& Staiger 1996, 79-93.

Bergkamp 2001a; Endres \& Staiger 1996, 79-93; Faure 2003b and Polinksy \& Shavell 1992, 17-24

Polinksy \& Shavell 1992, 17-24.

Endres \& Staiger 1996, 79-93. 
Hence, under a strict liability rule, firms will take the socially optimal precautions to prevent environmentally harmful discharges and realise the optimal amount of clean up if pollution occurs, as they will be liable for any remaing harm. ${ }^{54}$

\section{Balance}

Under the idealistic assumptions of the models presented by the various authors, it can be concluded that, as far as economic efficiency is concerned, both liability regimes induce firms to take the optimal level of precaution. However, this result does not take compensation into account. Both liability regimes differ considerably from this point of view. Under strict liability, the victims will be compensated in any case. With negligence, the victims will have to bear the costs of clean-up themselves, as long as the injurer complied with the legal standard. If the aim of installing a liability regime is to internalise the costs for the environment caused by production, the negligence rule will not reach this aim fully, as part of the damage will not be bourne by the injurer. ${ }^{55}$ Therefore, there might be a preference to opt for a strict liability rule for environmental damage. However, besides a difference in compensation, there are, as in the general case, other important differences between the negligence rule and the strict liability rule that should not be neglected by governments when deciding upon their environmental policy. These differences merit some special attention, and will be dealt with in the next paragraph.

\subsubsection{Refinements}

A closer look at some refinements will facilitate the understanding of the different consequences of a negligence rule versus a strict liability rule.

\subsubsection{Activity Level}

As Shavell pointed out, a liability rule should not only provide incentives for optimal care taking, but should also provide incentives for adopting an optimal activity level. ${ }^{56}$ These are the times when the polluter would engage in the polluting activity, to produce the socially optimal amount of the good. The analysis of environmental liability is similar to the analysis of torts in general.

Under negligence, if the firm complies with the due care standard of precaution, it will not be held liable for harm. This means that the firm will not have to take the costs for clean-up into account in its cost calculation, if it fulfilled the due care standard. As these costs will not be internalised in the firm's costs, the firms will produce too much or, in other words, engage in the polluting activity too often. In addition, these clean up costs will not be reflected in the sales price of the product. Consequently, consumers will purchase too much of the good, the production of which might give rise to environmental harm. This result will reinforce the excessive level of activity and eventually a socially excessive number of discharges causing environmental harm might occur. ${ }^{57}$

Under a strict liability rule, the polluter will always be liable for the damage. The firm will therefore internalise both the cost of prevention and the clean up costs in its cost calculations. This will also be reflected in the sales price of the product. Consumers will thereby purchase the socially optimal amount of the good whose production might give rise to environmental damage.

From the above, one could conclude that a strict liability rule could be favoured in cases of environmental harm. This liability rule would give the injurer optimal incentives for precaution and result in an optimal activity level. This result should, however, be balanced. ${ }^{58}$ It might be possible that goods, the production of which may give rise to environmental damage, are beneficial for society, like medicines. It would not be desirable to reduce the production of those goods. Therefore, the consequences of the introduction of either liability rule should always be assessed carefully.

\subsubsection{Information Differences}

A negligence rule and strict liability rule also differ with respect to the information that a judge will need in case of a trial. ${ }^{59}$ It was mentioned above that a negligence rule requires high information costs for the judge.

This is an assumption of the Shavell-Polinksy model.

Endres \& Staiger 1996, 83.

Shavell 1987, 5-32.

Polinksy \& Shavell 1992, 17-24.

Faure \& Grimeaud 2003, 35.

Faure \& Grimeaud 2003, 34 
The information that is necessary for a judge to determine in a particular case what the due care standard would be and whether the injurer took optimal precautions may not be readily available to the judge. ${ }^{60}$ Under a strict liability rule it will be the injurer, who will bear the costs of defining the optimal care level. Furthermore, it was advanced that the information on the optimal precaution level is better available with firms who perform the activity, than with the judges. Reasonably, it can be assumed that this also holds for firms that engage in production that might cause environmental harm. Hence, information advantages provide another argument in favour of strict liability for environmental harm. ${ }^{61}$

Some remarks should be made, however. In the above it was implicitly assumed that the judge can determine the amount of damage. If courts cannot assess the damages, strict liability might lead to underdeterrence. ${ }^{62}$ One should also note that the various authors start from the economic assumption of risk neutrality. If this assumption is relaxed and risk aversion introduced, then, if the potential polluter is risk averse, he might be reluctant to engage in the activity, which would not be socially beneficial either. It is therefore correctly argued that in such cases strict liability will only induce optimal behaviour if the risk can, to a certain level, be removed from the risk averse polluter, through insurance for example. ${ }^{63}$

\subsubsection{Insolvency and Financial Caps: Strict Liability versus Negligence}

Even if the scale of operations of the firm that engages in potential polluting production is small, it may cause substantial harm to the environment. In such cases, the damage costs can be higher than the assets of the firm, which results in the fact that they cannot pay for the harm. ${ }^{64}$ It might also be possible that a limitation of the compensation that is due to the victim is included in the liability legislation, which is called a 'financial cap'.

In such circumstances, the advantage of the strict liability rule for environmental damage should be reconsidered. ${ }^{65}$ Until now, it was implicitly assumed that the polluter would have the money to compensate the victim or to engage in clean up. However, if the damage costs exceed the firm's assets or if there is a financial cap, this might result in underdeterrence in the case of strict liability.

The explanation is that liability is limited to the amount of the assets of the firm which causes the damage or to the financial cap, if this is a provision in the liability rule. Hence the polluter will only take precautions up to the value of his assets or up to the financial cap. Thus, he will only take the precautions necessary to avoid an accident that results in damage costs equal to his assets. He will not increase his precaution for accidents that may cause higher damage costs than the value of his assets or the cap. In the first case, he will be insolvent, and will not be able to pay for the damage. In the second case, he will not have to pay more than the statutory limit. A problem of underdeterrence will thus arise and a full internalisation of the potential pollution costs will not be achieved.

Under the negligence rule, the insolvency problem is not that pronounced. Under this liability scheme the polluter will still have an incentive to adopt the due care standard required by the legal system as long as the costs of these precautions are less than the value of his assets. Indeed, by complying with the due care standard the potential polluter can avoid liability and hence will not have to pay compensation to the victim, or to engage in clean up activities. Therefore, if a polluter could cause damage to the environment with costs that are higher than his assets (which can often be the case in polluting activities), and when no insurance or other solutions are available (see below), there is an argument in favour of the negligence rule. ${ }^{66}$

Indeed, under negligence, the potential polluter shall still have an incentive to comply with the legal standard of care in order to escape liability. The imposition of strict liability might lead to underdeterrence when the value of the assets is lower than the potential damage. Hence the damage costs will not be fully internalised.

As this last refinement has serious consequences for environmental damage compensation in the case of a strict liability rule the attachment of some remarks on the remedies for insolvency is merited.

Faure \& Grimeaud 2003, 35.

Faure notes that in some cases the regulator may have an information advantage, for instance, because specialised studies have to be conducted. This may, however, be an argument in favour of governmental intervention through regulation. It is not necessarily an argument against strict liability.

Cooter 1984, 1343-1523.

Faure \& Grimeaud 2003, 24, Endres \& Staiger, 1996, Polinksy \& Shavell 1992, 17-24.

Polinksy \& Shavell 1992, 17-24.

Faure \& Grimeaud 2003, 35.

Faure \& Grimeaud 2003, 36 


\subsubsection{Remedies to Compensate for Environmental Damage in Case of Insolvency}

The previous paragraph showed that strict liability gives optimal prevention incentives and guarantees full internalisation of environmental damage costs. Insolvency might, however, distort this compensatory function - or restoration function in the case of environmental damage - of liability.

Several scholars have examined the insolvency problem of strict liability, and provided for diverse remedies. Remedies that are advanced are ex ante safety regulation, extended liability - referred to as 'lender liability' - to the financiers of the firm that caused the environmental damage; ${ }^{67}$ insurance for environmental damages and a public fund for compensation of losses resulting from environmental damage, funded through the tax system. It falls beyond the scope of this research to examine each remedy in detail. Therefore, only a brief explanation of the remedies for insolvency will be provided.

\section{Safety Regulations}

Safety regulations, which are set ex ante by the government, can contribute to solving the problem of underdeterrence. In this case, the potential polluter will have to comply with the regulatory standard, which in the ideal case would be the optimal precautionary level. However, as Faure indicates, there may still be a problem of underdeterrence if the regulation is enforced by monetary sanctions that are higher than the polluter's assets. ${ }^{68}$ This problem might be solved by enforcing the regulation through nonmonetary sanctions. ${ }^{69}$ Nevertheless, regulation and liability can and should be complemented. This complementary relationship will be the main focus of paragraph 2.3 , liability rules versus other instruments in pollution control.

\section{Extended Liability}

Extended liability as a solution for underdeterrence has been a heavily debated issue, in academic as well as political debates. Indeed, Boyer and Laffont point out that extending liability to lenders can have a substantial impact on the decision process and financial structure of the firms that engage in potentially polluting activities.

If only the owners or shareholders of the firm are held strictly liable for accidents, then they are usually held liable by an amount corresponding to the capital provided to the firm and its profits. They will rationally tend to obtain a full external (bank) loan, so that only the firm's profit is exposed to liability claims. The consequence might be that environmental damage may not be fully compensated. The introduction of lender liability may result in incentives for lenders to control the activities of their clients in order to prevent environmental harm. However, extended liability may result in lenders increasing the cost of financing by charging a premium for firms that engage in potentially polluting activities, in order to incorporate the risk of being held liable in case of damage. This may have negative consequences on loan availability and may even discourage the funding of high-risk, but socially beneficial activities. ${ }^{70}$

Besides the disputed possibility of lender liability, insurance for environmental damage might be a relatively new solution for the lacunas in the liability system. It therefore merits some explanation. ${ }^{71}$

\section{Insurance for Environmental Damage}

The traditional insurance system is based on the assumption that risk is quantifiable, in order to define the right premium that the insured will have to pay to the insurer for transferring the risk. The traditional system therefore works on a four phases basis: risk assessment, risk transferring, risk pooling and risk allocation. ${ }^{72}$

\footnotetext{
67 See Bergkamp 2001a; Boyer \& Lafont 1997, 1427-1459, Boyd \& Ingberman 1997, 233-258. The latter article claims that extending liability allows more effective internalisation of damage and a prevention level closer to the social optimum in comparison with the situation when a firm is solely liable. However, literature also includes criticism of liability extension lenders. Heyes 1996, 311-323 states that bank liability causes an increase in the cost of financing in the event of adverse selection impacting on a borrower's risk profile.

Faure \& Grimeaud 2003, 41.

Shavell 1985a, 1232-1262.

Boyer \& Lafont 1997, 1427-1459.

An excellent general discussion on liability and insurance was provided by Shavell 1982, 120-132. Shavell presents a detailed analysis of how competitive insurance markets deal with the second goal of tort law, namely the distribution of accident losses.

$72 \quad$ Monti 2001, 62.
} 
However, insurance for environmental risks represents many difficulties for the insurance market. Insurance is only able to perform its function correctly if a certain amount of information on the probability and possible extent of the damage of a certain risk is available. Precisely this information concerning environmental risk includes several factors of uncertainty, both factual and legal. The so-called gradual pollution poses a special difficulty. This kind of pollution develops slowly over a long period of time and its damaging effects are only apparent in the long run. In the case of gradual pollution it is very difficult to determine when pollution began and how long it continued. Moreover, it is far from easy to identify single polluters.

Furthermore, asymmetrical information, which means that one party has access to information the other party does not have - due to the complexity of modern production technologies - , may give rise to problems of adverse selection for environmental insurance. This means that the insurer cannot accurately differentiate between high risk and low risk clients. Hence, when the insurer bases the insurance premium on the average risk across all firms, the high risk companies will purchase a more than proportionate share of insurance and the insurer will suffer losses, because he could not rightly assess the probability of the risk. ${ }^{73}$

Moral hazard or careless behaviour of the insured, as accidents will be covered by insurance, might pose another serious problem for insurance of environmental accidents, as the insured will take less than optimal precautions. ${ }^{74}$ Ironically, in such a case the insurance coverage and the insurance premium could be understood as a licence to pollute.

There would also be a difference between strict liability and a negligence rule. If the legislator choses a strict liability standard as the applicable rule, this would not constitute a problem in terms of insurability. Insurance of strict liability could, on the other hand, work as a kind of reinsurance, favouring compensation of the injured parties, the environment in this case. In fact, more problems would arise by a negligence standard, in which case liability involves a fault by the insured, by not complying with the legal standard. Hence, it will be even more difficult for the insurer to estimate the risk and the premium for the transfer of liability to the insurer. Moreover, the insurer would also face uncertainty concerning damage estimation by the court. 75

These particular features of environmental risk may explain why, at present, environmental risk is excluded from traditional liability insurance almost everywhere. As long as the damage costs of an accident are extremely difficult to predict ex ante, the insurance market will not be able to evaluate environmental risks properly and, hence, will not be willing to offer reasonably priced coverage.

Consequently, the insurance industry has started to work out new techniques for coping with environmental damage. Insurance companies proposed the introduction of a new phase, referred to as 'risk remodelling', which takes place before the transfer of the risk. Professional risk-assessors would intervene actively on the risk by imposing technical safety standards. Insurance coverage for environmental damage could consequently only be provided on a site-specific basis, as it would require a careful evaluation and classification of the risk to be transferred. ${ }^{76}$ In this way environmental liability insurance could contribute to the insolvency problem of strict liability and would, moreover, enforce an extensive set of precise technical safety standards. ${ }^{77}$ Although this approach would provide a solution for the insolvency problem, in practice, modern environmental insurance is still not widespread at all. Especially gradual pollution coverage is still seen as too risky and most firms do not offer insurance against these environmental risks.

Monti, who has studied the issue of insurance for environmental damage extensively, therefore proposes a system of compulsory pollution insurance. A compulsory insurance might provide a solution for the dilemmas mentioned above, for activities that are particularly polluting for example. However, it has to be acknowledged that environmental insurance must be tailor-made and site specific. A standard framework would force pollution insurance back into the traditional insurance scheme, which does not function properly as environmental risks cannot easily be assessed.

Monti therefore proposes an 'institutional model' that takes all dilemmas and particularities into account. Monti emphasises the need to introduce a system of quasi-compulsory insurance for environmental risks and emphasises that regulation, liability, funds and insurance can be combined in an efficient way. ${ }^{78}$ Within this institutional model, the efficient legal system will use regulation to set minimal safety standards. Those standards will be combined with minimal insurability standards. As an additional condition for operations, the meeting of certain financial requirements shall be imposed on each firm that

Monti 2001, 59.

Shavell 1982, 120-132.

Monti 2001, 58. Note that also joint and several strict liability would have a negative effect.

Monti 2001, 62.

Monti 2001, 62-64.

Monti 2001, 66 
wants to enter or remain on the market. Under such circumstances, environmental insurance will become a viable solution for the economic actors - given that all firms in operation will meet the minimal insurability standards - pollution coverage should be denied to nobody. Insurance for environmental damage would then complement both the liability system and the regulatory scheme.

\section{Compensation Funds}

In order to provide a solution for historical pollution, a fourth remedy, examined by legal and economic scholars, consists of a tax based Compensation Fund. Compensation funds could intervene for certain risks as historical pollution, were the polluter cannot be found anymore. ${ }^{79}$ Nevertheless, it seems appropriate, as Faure indicates, to examine the combined use of liability rules, insurance, and funds, in order to achieve optimal results for restoration of environmental damage. 80

To summarise, when the economic theory of tort law is applied to environmental damage it can be shown that both a negligence rule and a strict liability rule will result in an optimal level of precautions in prevention of environmental damage. However, as in the general analysis, there are substantial differences between these two liability rules. Only a strict liability rule will reduce the activity level. Negative consequences, however, like a reduction in the production of socially desirable goods as pharmaceutics, should be avoided. A strict liability rule, furthermore, does not have as high information costs as a negligence rule and from a compensation point of view, strict liability might ensure full compensation of damage, which would not be the case for negligence. Indeed, the polluter would not have to pay for the damage if he fulfilled the due care standard. Insolvency, however, might distort this compensation. Scholars therefore examined solutions as safety regulations, extended liability, insurance and compensation funds. In the next paragraph, liability rules will be compared with other instruments of pollution control in order to point to the complementary role of liability for environmental damage.

\subsection{Liability Rules versus Other Instruments for Controlling Environmental Damage}

This paragraph will evaluate different instruments for controlling environmental damage in order to sketch the contribution of environmental liability in the prevention and restoration of environmental damage. First, the difference between so called ex ante and ex post instruments to control pollution will be explained. Then, attention will go to the use of regulation in the prevention and restoration of environmental damage. Finally, the complementary relationship of regulation and liability rules will be explained.

\subsubsection{Ex Ante versus Ex Post Instruments for Controlling Environmental Damage}

Governments face different choices when deciding upon the instruments to use to protect their environment. Therefore, governments have to weigh different regulatory (legal and economic) tools. A common dilemma is whether to use regulations or other instruments that impose the quality standards to be achieved in advance - ex ante - or whether to use ex post instruments to control pollution, like liability rules that come into effect after damage has occurred.

Theoretically, the goal of full internalisation of pollution externalities can be achieved through many different legal or economic instruments. On the one hand, there are legal and economic instruments that steer individual behaviour ex ante. Insofar as legal instruments are concerned regulations such as command - and - control rules, standards and sanctions define the environmental quality that is to be reached and set by the government ex ante. Economic ex ante internalising tools that can be mentioned are the attribution of permits to firms and the enforcement of pollution taxes.

On the other hand, internalisation of pollution can also be ensured by ex post imposition of the costs of pollution on the polluter by means of liability, which is enforced by courts. The polluter will be held liable to pay for any damages to the environment in any case where he was strictly liable or in case of negligence, when he did not take due care. If cost minimising behaviour is assumed, the potential polluter will consequently internalise the cost of pollution, as with the ex ante instruments. ${ }^{81}$

It is beyond the scope of this research to provide an extensive overview of the different instruments. However, a short elucidation of each of the internalising tools will provide a better understanding of the role of environmental liability. Both ex ante economic and legal instruments will be compared with ex post liability.

Faure \& Grimeaud 2003, 178 and 234-244. See also Faure \& Hartlief 1996, 321.

Faure \& Grimeaud 2003, 234-244 and Monti 2001, 65-68.

Monti 2001, 51-79. For excellent surveys see Baumol \& Oates 1988, and Cropper \& Oates 1992, 1675-1740. 


\section{Ex ante economic Internalising Instruments}

The environmental economics literature proposes ex ante internalising instruments, which generally try to minimise the total cost of achieving a certain environmental quality. ${ }^{82}$

One instrument that has been shown to create the appropriate incentives, at least in theory, is a marketable permit. Marketable permits are generally thought of as a 'quantity' instrument because they ration a fixed supply of a commodity, in this case pollution. The implementation of marketable permits involves several steps. First, a target level of environmental quality is established. Next, this level of environmental quality is defined in terms of total allowable emissions. The regulator should then grant a firm a number of permits, with each permit allowing the owner to emit a specified amount of pollution. If the firm is able to reduce its emissions, preferably through the use of newer technologies, it can sell its remaining emission permits to another firm that cannot meets its quota. Assuming firms minimise their total production costs, and the market for these permits is competitive, it can be shown that the overall cost of achieving the environmental standard will be minimised.

The opposite of a quantity instrument is a 'pricing' instrument, such as emissions charges or pollution taxes. The pricing technique also starts from a predetermined set of standards for environmental quality and then imposes unit taxes (or subsidies) sufficient to achieve these standards. The idea underlying emissions charges is to charge polluters a fixed price for each unit of pollution. In this way, they are provided with an incentive to economise on the amount of pollution they produce. Economic environmental theory shows that if all firms are charged the same fixed price for each unit of pollution all firms will try to reduce costs. Firms might have a different state of technology though, so that some firms abate more than others. However, in the end, marginal costs (the cost of one more unit) of abatement will be equated across firms. According to economic theory, this result implies that the resulting level of pollution is reached in a cost minimising way. From a practical point of view, it is clear that charges are easier to control than marketable permits, which have not received widespread use. ${ }^{83}$

\section{Ex Ante Economic Instruments versus Ex Post Liability}

A fundamental remark should be made concerning the above mentioned economic internalising tools. Although both instruments achieve efficient results, as far as prevention and precaution behaviour is concerned, they do not give the signal that polluting is 'wrong' and that the polluted area should be restored. In fact, especially a permit, but also a tax when paid, gives a permission to pollute. The compensation function of liability, which can be seen as a restoration function for environmental damage, is therefore not incorporated in the economic instruments, as with a liability rule. Paragraph 2.4 will concentrate on this issue. For the time being, if the compensation function is considered to be important in environmental policy, it should be concluded that ex post liability rules should be preferred to the above mentioned economic ex ante internalising instruments. ${ }^{84}$

\section{Ex Ante Legal Internalising Instruments}

An ex ante legal instrument for ensuring internalisation of environmental pollution is a regulatory system. A government can use a number of ways to control environmental damage and reduce the probability of environmental accidents. The traditional approach is the command and control procedure of setting and enforcing pollution standards. The regulator might oblige firms to limit their emissions, to emit no more than a specified amount of a certain pollutant or to install particular abatement technology, like a filter. The regulator then monitors the firms' compliance. ${ }^{85}$ More recently, voluntary standards have been proposed as an instrument in environmental regulation. ${ }^{86}$

The regulatory system is characterised by a centralised structure. It is based on the assumption that the government has an oversight of the problems and risks of environmental pollution and is therefore well suited to set environmental standards and to enforce the implementation of those standards. However, a drawback might be that regulatory agencies may not be very flexible in adapting to changing conditions or

Hahn 1989, 96. See also Boyer \& Lafont 1999, 137-157.

An extensive analysis falls beyond the scope of this research. For more information see for example Baumol \& Oates 1971, 42-54 or Baumol \& Oates 1975.

See Gunningham \& Grabosky 1998.

Boyer \& Porrini 2001, 5 .

Egelund Olsen 2001. 
knowledge and that a centralised command structure, which relies on expert advice, may be subject to political pressure as well as to lobbying by the regulated firms. ${ }^{87}$

\section{Ex Ante Legal Instruments versus Ex Post Liability}

Governmental regulation of environmental standards can differ from a liability regime in the following aspects: the level of administrative costs, the responsible party to pay for the damage in case of an environmental accident, the information of the parties regarding accident probability and finally, the risk of lobbying. 88

A first element is the difference in administrative expenses incurred by both private persons and the regulator. The cost of a liability system includes the cost of controlling the accident risk, the legal expenses in case of a trial and the public expenses for the operation of legal institutions. The costs of the regulatory system include the public expenses for the functioning of the regulatory agencies and the private cost of compliance with the standards. The liability system has the advantage that a significant part of the administrative costs are only incurred if a trial occurs. The administrative costs of a regulatory system are incurred whether or not an accident happens because the process of regulation is costly by itself. Indeed, the regulator needs to collect information about the parties, their activities and the risks, in order to set pollution standards. ${ }^{89}$

A second element that might differ is the person that bears the cost of environmental damage. In a regulatory system, when due care is exercised by firms according to the standards defined by the regulatory agency, the firm will not bear the costs of restoration. Instead, the costs are usually, directly or indirectly, covered publicly. In a (strict) liability system, restoration costs are imposed on the responsible private parties, given their capacity to pay and their limited liability. With reference to paragraph 2.3, where insurance for environmental damages was discussed, it may be concluded that both systems could profit from some form of compulsory insurance for the losses in excess of the assets of the firm. Potentially, the liability system could also rely on an extended liability regime for the firm's shareholders and financiers. However, this may cause too much deterrence and prohibit socially desirable activities. ${ }^{90}$

A third important difference between regulation and liability is the distribution of knowledge among parties with respect to the benefits of the activity, the cost of precautions and the probability and severity of accidents. Sometimes the nature of the activities is such that the firms have better knowledge of the probability of an accident and the costs of reducing the risk. In such a case a liability system has the advantage of making the private parties responsible for controlling their risks, while a regulation system might, through a lack of information, lead to the overestimation or underestimation of the costs, probability and severity of the risks. But it might also be the case that the regulator has better knowledge of those risks and costs of precaution, in particular when a better knowledge of the risk factors requires a special expertise or centralised information that can be applied to different activities and situations. ${ }^{91}$

Fourthly, the possibility of lobbying should not be neglected. The government might be influenced by external pressure of lobby groups. In general one might argue that courts are less likely to be influenced than the regulating agencies. ${ }^{92}$

\section{Balance}

Both ex ante legal and economic instruments and ex post liability can achieve internalisation of environmental damage by the potential polluter. Ex ante economic instruments are less common, and compensation is not addressed. Therefore these instruments will not explicitly be studied further in this research. Attention will go to the comparison between ex ante regulation and ex post liability. In the law and economic literature, liability for environmental damages and safety regulations are often compared on their efficiency in preventing and restoring environmental damage. ${ }^{93}$ It is often stated that environmental regulation and liability rules can or should be complements of each other. A regulation requires a potential injurer to take specific measures in order to prevent the accident from happening. A liability rule also seeks to deter by making the potential injurer liable for the costs of the accident, should it occur, but alsoprovides

Boyer \& Porrini 2001, 6; Boyer \& Lafont 1999, 137-157.

Boyer \& Porrini 2001, 6 .

Boyer \& Porrini 2001, 7.

Boyer \& Porrini 2001, 7 .

Boyer \& Porrini 2001, 7 .

Boyer \& Porrini2001, 8.

Faure \& Grimeaud 2003, 39-46, See also Dewees 1992, 4446-4467. 
for a ruling on compensation. ${ }^{94}$ The next paragraph will point out the precise role of environmental liability, and its interdependency in relation to environmental regulation.

\subsubsection{Interaction between Environmental Regulation and Environmental Liability}

In the law and economics literature several contributions can be found that weigh liability rules against regulation of environmentally dangerous activities. However, the different scholars reach different conclusions on the exact role both instruments could play and the complementary function regulation and tort law could have in preventing accidents.

Indeed, whether regulation of environmental quality standards is more efficient than liability rules depends on various factors. Shavell distinguishes several factors that should influence the choice between ex ante regulation and ex post liability. ${ }^{95}$ Various authors have discussed these criteria. ${ }^{96}$ As these criteria are fundamental to the assessment of regulation and liability rules, they will be discussed below, first in a general way, then in relation to environmental damage in particular.

\section{Regulation versus Liability: General Situation}

A first important factor that influences the choice between ex ante regulation and ex post liability is the availability of information. Shavell claims that generally private parties might have better information on the accident risk. ${ }^{97}$ They are the ones who undertake the potentially dangerous activities. Therefore, they might be in the best position to estimate the nature of the risks that they create and the costs of taking precautions. This information advantage would then favour a liability rule. On the other hand, if optimal safety standards are publicly known, or if the estimation of risk requires specialised research, an ex ante regulatory system might be better at ensuring optimal safety than tort law. Hence, for every activity, it must be examined whether the government or the private parties would have better information on the accident risk, in order to choose between ex ante regulation or ex post liability.

Second, if injurers might be insolvent and hence unable to pay for the harm they cause, ex post liability will not effectively deter them. Indeed, if the damage exceeds the wealth of the polluter underdeterrence results. Regulation, that determines ex ante the efficient level of precautions, might overcome the insolvency problem. However, if the regulation is enforced by fines based on the expected damage then the insolvency problem still might persist. Shavell therefore proposes that the regulation should be enforced by nonmonetary sanctions. ${ }^{98}$ On the other hand, insurance might solve the underdeterrence of tort law, as was already addressed in paragraph 2.3 .

Other factors that might influence the choice between ex ante regulation and ex post can be grouped under the actual threat of a liability suit. There may be situations in which significant harm to the environment is done, but where no action will be brought against the polluter. In such a situation, ex ante regulation might be preferable. Firstly, governmental regulation may be desirable when harm is diffuse. In such a case, there may be many individuals that suffer a little bit of harm, so that they have little incentive to sue on their own. Due to transaction costs, they are often unable to organise cheaply in order to sue as a group. This situation might lead to systematic undercompensation and consequently to underdeterrence. Underdeterrence might also result from weak causational chains. When the relationship between a certain activity and harm cannot be proven, no liability suit will follow, and the polluter will have no incentive to take optimal precautions. Hence ex ante regulations or taxes might be preferred. ${ }^{99}$

Finally, administrative costs are an important consideration. If the probability of harm is low, ex post systems may be preferable since they only need to come into play when damage occurs.

Assessment of these criteria shows that, depending upon the situation, either regulation or liability or a combination of both will be best to deal with different kinds of harm. Shavell's criteria can now be applied to environmental damage in particular.

Landes \& Posner 1987, 147.

Shavell 1984, 357-374.

See Arcuri 2001, 37-45; Boyer \& Porrini 2001; Faure \& Grimeaud 2003, 40-46; Kolstad, Ulen \& Johnson 1990, 888-901, Schaefer 2000, 576; Rose-Ackerman 1991, 54-58.

Shavell 1984, 359.

98 Shavell, S., Criminal law and the optimal use of non-monetary sanctions as a deterrent, Columbia Law Review, 1985, 1232-1262.

$99 \quad$ Faure \& Grimeaud 2003, 40-46. 
As far as the availability of information is concerned, liability rules might be preferred when private parties have better knowledge concerning the benefits of their activities, the cost of precautions, or the severity of the risks. Whereas, when the information possessed by regulators is superior to the information of private parties, regulation might be favoured' ${ }^{100}$ In the specific case of environmental risks, Arcuri and Faure point out that regulatory bodies may have better knowledge of the risk. Notably, certain risks to the environment, such as oil spills, accidents at chemical or at nuclear-power plants, or the transportation of dangerous goods require expert knowledge in order to assess the accident risk. Regulatory bodies might perform this task better. Small organisations might lack the incentive or resources needed to invest in research to determine the optimal care level for certain dangerous activities. Moreover, they would have little incentive to carry out intensive research if the results would be readily available to competitors in the market, known as the free-rider problem. Finally, economies of scale exist in developing scientific knowledge concerning the risk of these activities to public health or to the environment. Therefore, regulation might be favoured. ${ }^{101}$

The insolvency risk provides another argument for ex ante regulation. Indeed, it should be considered that accidents, causing damage to the environment, might be real disasters. If the amount of damage significantly exceeds the assets of the polluting firms, liability will not provide incentives to take precautions as the firms will probably be incapable of paying for the full magnitude of the damage. Underdeterrence will arise in the case of a liability rule.

Finally, in cases of accidents causing damage to the environment, a long period of time may pass before the full extent of damage becomes apparent. The damage might also be widely spread. Hence, it may be difficult to prove a causal link between the damage and the polluter, which will make it hard for the possibly many - individuals to bring a lawsuit against the polluter. Therefore, the risk of a liability suit might be very small for the polluter. In such circumstances liability rules will not work optimally as polluters will not face the threat of suit for harm done. ${ }^{102}$ Under such circumstances ex ante regulation could be preferred.

In conclusion, based on Shavell's criteria, it appears that there are strong arguments to prevent environmental damage through ex ante regulation, since liability rules may, in certain cases, provide insufficient incentives for firms to take optimal precautions. Furthermore, ex ante regulation might be preferred when harm is large, spread over many victims, when it takes a long time to become apparent, and when it is possible to determine and to control optimal standards or requirements. ${ }^{103}$

The question arises, however, whether this outcome implies that prevention of environmental damage should depend solely upon regulation or whether liability can fulfil a complementary role. The next paragraph will turn to this question.

\subsubsection{Complementary Relationship between Liability and Environmental Regulation}

Various scholars have examined the complementary relationship between regulation and liability for environmental damage. ${ }^{104}$ It appears that liability for environmental damage can complement ex ante safety regulations. The complementary role of liability rules in controlling environmental risks is threefold.

A first reason to combine ex ante regulation with ex post liability is found in the lack-of enforcementargument, so defined by Arcuri. ${ }^{105}$ The effectiveness of ex ante regulation depends upon the ability to enforce the regulation. In the case of weak enforcement, ex post liability might be an effective complement to regulation. If the government does not dispose of sufficient means of control, this might lead to an inefficient high level of risks for society. Liability rules might counterbalance this deficiency of environmental regulation and can act as a supplementary enforcement device. However, as Kolstad and others indicate, this is only possible if the liability rule is equal to or less stringent than the regulatory standard. Obviously, problems will arise if the liability rule, in practise, would impose standards that are higher than the regulatory standards. In such circumstances, firms will be reluctant to produce, as there is always a risk they will be sued, although they complied with the safety standards. Strict liability might, therefore, be inadvisable, a negligence rule could, on the other hand, be an effective complement if due care

Arcuri 2001, 38.

Arcuri 2001, 37-45; Faure \& Grimeaud 2003, 40-46; See also Kolstad, Ulen \& Johnson 1990, 888-901.

On the weaknesses of legal rules to address environmental risk see Menell 1991, 93-113.

See Shavell 1984, 357-374

See for example Arcuri 2001, 37-45; Bergkamp 2001a; Faure \& Grimeaud 2003, 40-46; Kolstad, Ulen \& Johnson 1990, 888901; Shavell 1984, 357-374 and Rose-Ackerman 1995, 312-332.

105 Arcuri 2001, 39-40. See also Bergkamp 2001a. 
is set equal or less stringent than the regulatory standard. ${ }^{106}$ Implementation or enforcement of regulation might also be difficult when diverging interests exist at the political level. The combination of safety regulations and liability rules might, to some extent, overcome the influence of lobby groups on regulation.

Secondly, safety standards and regulation might be outdated relatively fast and might often lack flexibility, which favours a combination with liability rules equally. Due to better information concerning environmental risks, regulation appeared to be a superior tool for dealing with environmental risks, as compared to liability. However, regulation can not be adapted quickly to changes in reality. Indeed, before a new regulation can be issued, the government will have to go through the whole law-making process. On the other hand, technology might evolve rapidly and, as new industrial processes might be developed; new risks might come into existence. Consequently, there will be a gap between the time that the new risk comes into existence and a new regulation being issued to deal with this risk. Therefore, there will be a 'systematic lack of control' 107 over new risks. In such cases liability might be applied until legislation has been passed. Liability rules are indeed adaptable to new situations. They are not designed to deal with a particular situation, but are intended to deal with a wide range of different cases that are not necessarily foreseen. The deficiency of ex ante regulation in relation to the 'systematic-lack-of-control' over new risks, would thus be minimised by the existence of a complementary liability regime. ${ }^{108}$

Finally, liability rules do not only provide incentives to steer individual behaviour towards an internalisation of environmental damage. A liability system might also function as a compensation system, by obliging the polluter to compensate those who suffered damage or to oblige the restoration of the damage. Therefore, if compensation is not addressed in the regulation, either a compensation fund could fill up this gap, if damage is widely spread over many victims, or, if there are few victims, the law could permit private tort actions under liability principles in order to achieve compensation. ${ }^{109}$

Summarising, this paragraph evaluated different instruments for controlling pollution in order to sketch the contribution of environmental liability in the prevention and restoration of environmental damage. It was shown that ex ante legal and economic instruments as well as ex post liability can achieve internalisation of environmental damage by the potential polluter. As ex ante economic instruments are not that common, the focus was on the comparison between ex ante regulation and ex post liability. It can be concluded that for environmental damage, ex ante safety regulation will be needed as in some cases ex post liability might not provide sufficient incentives to take optimal precautionary measures towards accident prevention. However, it was shown that liability rules may play an important complementary role to regulation, not only in the prevention of environmental damage, but also in restoration after pollution. Indeed, the growing attention for environmental liability rules on national and international levels may reflect an increased concern for the compensation and restoration function of environmental liability.

A possible explanation of this concern for compensation of environmental damage will be given in the next paragraph.

\subsection{The Added Value of Liability Rules for Environmental Damage}

Recently, several authors have paid attention to the consequences of different environmental policies on human behaviour and the need to take justice and fairness considerations into account in the analysis of optimal environmental policies. This paragraph is not intended to be exhaustive, as the subject falls outside the scope of the research. However, two important views will be presented.

\subsubsection{Recognition of a Crowding-out Effect}

In his book 'Not just for the Money',110 Bruno Frey emphasises that human behaviour is not solely guided by monetary incentives and proves the importance of intrinsic motivation.

As was mentioned before, governments face different choices when determining their environmental policy. Governments mainly introduced laws and regulations to reduce pollution and to protect the environment. However, environmental economics introduced the idea of the use of incentive instruments like marketable permits or licences and emission charges to reduce pollution. These policy instruments put a price on the use of the environment, and from an economic point of view, they are economically efficient

Kolstad, Ulen \& Johnson 1990, 888-901.

So defined by Arcuri 2001, 39

Arcuri 2001, 39. See also Faure \& Grimeaud 2003, 40-46.

Rose-Ackerman 1991 and Rose-Ackerman 1995, 312-332.

Frey 1997. 
policy instruments. ${ }^{111}$ In that sense, environmental incentive instruments can be seen as successful applications of economic theory, but in the real world they are not often used.

Frey provides an explanation for the rare use of incentive instruments, based on intrinsic motivation. Frey states that human motivation is not restricted to monetary incentives, intrinsic motivation is also crucially important. Worse, external interventions such as permits and licences might under certain circumstances drive out people's intrinsic motivation, a result that Frey calls the 'Crowding-Out Effect'. ${ }^{112}$

Frey indicates that individuals are prepared to behave in an environmental friendly way, if their behaviour costs them little. The more costly it gets the lower the attention for moral concerns. When the cost is very high, only ecological extremists would still behave in an environmental friendly way, while most people would find a lot of reasons why they should not do so. Yet, a firm facing perfect competition will incur high costs if it adopts high environmental standards and other firms do not. On the other hand, environmentally friendly production methods may pay for a firm if it can thereby increase its sales or prevent a boycott from environmental action groups or other stakeholders. Such behaviour might also help to be on good terms with the government for future orders. There are thus various reasons for which individuals and firms might pursue environmentally friendly behaviour. According to Frey, this behaviour shows intrinsic motivation. ${ }^{113}$

When incentive instruments would be introduced to prevent environmental harm, and individuals initially behave in an environmental friendly manner, a crowding-out effect might come into existence. The explanation is that licence permits allow a specific amount of emissions and as long as the firm stays within the emission limits, damage to the environment is not condemned. From this point of view, once a licence has been obtained, the firm has a 'licence to pollute'. Furthermore, in case of a pollution tax, if the tax fails to distinguish between firms that do care for the environment and firms that do not, all firms will get the same average tax. Hence, a firm's environmental conscious behaviour is not recognised, and it is possible that those firms simply adjust their emission level to the sector's average level. Consequently, incentive instruments might fail to acknowledge intrinsically motivated concerns to protect the environment and a Crowding-Out Effect might come into existence. ${ }^{114}$

Frey's theoretical analysis therefore suggests that instruments entailing a moral condemnation of pollution might be preferred. Frey does not exclude incentive instruments, though: they could be modified or used in areas where environmental concern is weak. Regulations, liability and subsidies are, on the other hand, instruments that reward environmentally conscious behaviour. ${ }^{115}$

The fact that liability for environmental damage gives a clear signal that polluting is wrong, and that the polluter should restore the damage is an extra argument for the use of liability as a complement to regulation.

Kaplow and Shavell present another argument for the combination of regulation and liability.

\subsubsection{Fairness and Justice Considerations in the Economic Analysis of Law}

Kaplow and Shavell examined the desirability of incorporating fairness into the economic analysis of law. ${ }^{116}$ They argued that taking notions of fairness into account can, and sometimes will, make society worse off. As the economic analysis of law is based on welfare economics, preference should go to that policy under which everyone is better off than under each of the alternatives. Therefore, any deviation from this optimal state will make everybody worse off. This result does not depend on the particular interpretation of fairness. Any notion of fairness would be subject to their criticism. They argue that if notions of fairness are used as independent evaluative principles in assessing governmental policy and a different legal rule would be chosen than the one which would be optimal according to welfare economics, society as a whole could be made worse off. ${ }^{117}$

Therefore, their analysis suggests that notions of fairness should not be given any weight as independent evaluative principles in assessing governmental policy. Nevertheless, they agree that notions of fairness undoubtedly have appeal both to legal analysts and philosophers, as well as to society more generally. ${ }^{118}$ Therefore, according to Kaplow and Shavell, even though notions of fairness should not be

111 Frey 1997, 56-65. For a discussion of these economic policies, see for instance Cropper \& Oates 1992, 1675-1740.

112 Frey 1997, preface.

Frey 1997, 57-59.

Frey 1997, 61-62.

Frey 1997, 64-65.

Kaplow \& Shavell 2002, 72-73.

Kaplow \& Shavell 2002, 73 and 91.

Kaplow \& Shavell 2002, 123. 
used as independent evaluative principles, the existence of social norms can have relevance when assessing legal rules within the framework of welfare economics. ${ }^{119}$

Indeed, the importance that individuals attach to social norms may translate into a preference for a policy that treats injurers and victims in a manner that is consistent with related notions of fairness. That is, just as individuals will be upset, when an injurer does not compensate a victim when the injurer is wrong in an informal setting, they may be upset if the chosen policy does not require an injurer to compensate a victim when the injurer is wrong.

If citizens have such feelings, this will be relevant under welfare economics, just like any other tastes, whether for material goods or 'moral beliefs', because welfare economics takes all components of an individual's well-being into account. Therefore, if fairness enters into their preferences, it should be included in the welfare analysis of a particular policy. ${ }^{120}$

Thus, the real question is not so much whether social norms or fairness notions have to play a role in policy considerations, but much more what weight these social norms, justice or fairness considerations should get in the welfare economic analysis.

The attention for fairness notions in the choice of an optimal environmental policy, might present another argument for the use of liability as a complement to regulation. Indeed, a liability rule incorporates notions of fairness. The first notion of fairness is concerned with making the injurer pay for the harm he has brought about. The second notion of fairness concerns compensation. A fairness principle might demand both that the injurer pay and that this payment be received by the victim.

Summarising, this paragraph has shown by means of welfare economic analysis that imposing liability for environmental damage - when combined with safety regulation - fulfils economic efficiency and, moreover, gives a clear indication that polluting is wrong. This indication meets the socially accepted idea that the polluter should pay for the damage caused, thereby fulfilling fairness notions in society and preserving intrinsic motivation. It can therefore be concluded that liability rules for environmental damage do indeed provide an added value to environmental policy. The next paragraph will therefore concentrate on the contribution of liability rules in the prevention and restoration of soil pollution, which will be the focus in the remainder of this research.

\section{Liability Rules for Soil Pollution}

\subsection{Defining Soil Pollution}

\subsubsection{Complexity of Soil Pollution}

It falls beyond the scope of this research to go into the details of chemical reactions between hazardous substances and soil, but, as soil pollution will be used as an example throughout this research, a brief idea of what is meant by soil pollution might help to understand the contribution of liability rules in the prevention and restorion of soil pollution.

Soil is the upper layer of the Earth's crust composed of mineral particles, organic matter, water, air and organisms and is the product of climate, geology, vegetation and biological activity. ${ }^{121}$ The exact proportions of these different components determine the physical, chemical and biological properties of a certain soil type. In Europe 320 different soil types have been identified. ${ }^{122}$

Soil has many important functions. By providing nutrients, water and air, soil serves a habitat for numerous organisms and plant life. Agricultural production is soil related and soil is a source of raw materials, used for constructions and buildings. Moreover, soil has a filtering, buffering and transformation function of substances entering the soil. Finally it serves as an archive of natural history. ${ }^{123}$

\footnotetext{
$119 \quad$ Kaplow \& Shavell 2002, 132.

120 Lando 1997, 576-587.

121 International Standard Organisation (ISO), Technical Committee 190 (TC 190). Soil Quality vocabulary (SC1) ISO 11074-1 and ISO/CD 11074-4. The task of the Technical Committee ISO/TC 190 on Soil Quality is to work out standards concerning soil quality. These include classification, definition of terms, sampling, measurement and assessment of soil and reporting of soil characteristics. Excluded is the setting of limits of acceptability for soil pollution. See Egelund Olsen $2001,55$.

122 European Commission, Communication from the Commission to the Council, the European Parliament, the Economic and Social Committee and the Committee of the Regions, Towards a Thematic Strategy for Soil Protection, Com (2002) 179 final, Brussels, 16 April 2002, 8.

123 European Environment Agency, Europe's Environment.Stanners \& Bourdeau 1995, 148.
} 
Soil pollution is a very complex and challenging environmental problem. Soil pollution did not get attention until the late 1970's and was even then not considered to be of major concern. ${ }^{124}$ Nowadays, it is a widespread problem faced by many countries. ${ }^{125}$

At present, there exists no harmonised definition for 'contaminated soil'. At national level, various definitions of soil pollution are used. Some countries have introduced a definition with a quantitative character; other countries use a more qualitative definition in their legislation. At the international level, the ISO Technical Committee TC 190 on Soil Quality has not as yet been able to agree on a definition for 'pollution' and 'contamination'. ${ }^{126}$ The European Environmental Agency has proposed a definition for the term 'contaminated site', whereby a distinction is made between 'potential contaminated sites' and 'contaminated sites'. For both types of sites, a qualitative and a quantitative definition are presented, whereby the quantitative definition is more detailed. There a potentially contaminated site is understood when slightly simplified - as `a location where, as a result of human activity, waste or harmful discharges, suspected to be dangerous to human health or the environment, are present in, on or under the soil and/or in nearby controlled groundwaters and surface water resources'. A contaminated site is 'a location in which the quantities or concentrations of waste or harmful discharges are such that, on the basis of the result of risk assessment, they constitute a danger to human health or the environment'. ${ }^{127}$

Soil pollution is closely related to industrialisation and can have multiple causes. A distinction can be made between local and diffuse soil pollution. Diffuse soil pollution is due to emissions from industry, traffic or agriculture, and isvery difficult to track. The focus of this research, however, will be on local soil contamination. One source of local soil pollution is the inadequate disposal of waste containing hazardous substances in past decades. A second source of local soil pollution is the use of potentially hazardous substances in industrial production processes. These include heavy metals like lead, inorganics (sulphate, asbestos) or organics (oils, dioxins). As the use of chemicals or other potentially hazardous substances is wide-spread in industrial processes, there is hardly any industrial sector where the risk of soil pollution in the course of operation can be excluded. Other sources might be mining activities or former military sites. ${ }^{128}$

As soil serves various functions, soil pollution can have different impacts on the environment and on human health. First, an important hazard that can occur is the contamination of the groundwater. How quickly and severely the groundwater might be contaminated does not only depend on the substance that has been spilled, but also depends on the soil structure itself, as there is a highly variable degree of soil reactivity to a single substance. In the case of permeable soil, substances might more easily contaminate the groundwater, which might have particularly dangerous consequences, whereas clay land might hinder dangerous substances from contaminating the groundwater for a longer period. ${ }^{129}$ Next, direct contact (for example, a children's playground at a former industrial site) with polluted soil might cause irritations and building on former landfill sites showed the risk of explosions of landfill gasses in closed rooms. Furthermore, the risk exists that plants and vegetables absorb the hazardous substances in the soil, thereby entering the food chain. However, depending on the hazardous substance and the soil condition, not all of these possible hazards will arise. It is also important to note that contaminants, present in any form and particularly gases or liquids, can be mobile. How quickly they might migrate beyond the boundaries of the contaminated site depends on the soil structure. It is therefore possible that pollution can spread to surrounding land. In many cases, however, contaminants remain close to the places where they were or are used. ${ }^{130}$

As both the type of hazardous substance as the features of the soil influence the way in which and when a hazard might arise, a simple cause and effect relationship might sometimes be hard to prove. ${ }^{131}$ The difficulty in proving that soil pollution might cause hazards, does not, however, mean that these hazards are negligible, but merely that soil pollution might be difficult to detect and sometimes very slow to appear. ${ }^{132}$

These particular characteristics of soil pollution have to be kept in mind with respect to soil protection policies, the 'optimal' liability rule for preventing and restoring soil pollution and the 'optimal level of

\section{Cairne 1993, 2}

125 Egelund Olsen 2001, 56

126 Egelund Olsen 2001, 57.

127 European Environmental Agency, 'Management of contaminated sites in Western Europe', Topic Report No 13/1999, Copenhague, 2000, 134.

128 European Environmental Agency, 'Management of contaminated sites in Western Europe', Topic Report No 13/1999, EEA 2000, 8; See also Egelund Olsen 2001, 53-64 and Becket 1993, 19.

129 Becket 1993, 1-19. See also Egelund Olsen 2001, 57 and European Environmental Agency, 'Management of contaminated sites in Western Europe', Topic Report No 13/1999, EEA 2000, 8.

Becket 1993,19.

Cairney 1993, 2.

Cairney 1993, 3. 
decision-making' of liability rules for soil pollution, which will be used as a case-study throughout this research.

In short, soil pollution is a complex problem that is widely acknowledged nowadays. Hence, prevention of soil pollution and decontamination seem to have become legislative concerns in most countries.

\subsubsection{Regulation for Preventing and Restoring Soil Pollution}

It falls beyond the scope of this introductory chapter to discuss in detail how various countries have regulated soil pollution. Yet, in general, most countries have established a framework of regulations to prevent and restore soil pollution. These regulations appear to be rather fragmentary and soil pollution is often addressed indirectly in different policy areas. Indeed, as soil pollution can have many sources and many consequences, the scope of national regulations and the approaches used, vary considerably. First, the main focus of legislation might differ depending on the main problems experienced due to soil pollution. For instance, in some countries, soil protection legislation focuses on the protection of groundwater quality, as a source of drinking water. In other countries, the regulations of industrial or agricultural activities are major concerns. In any case, the nature of soil pollution, with wide-spread consequences, might explain why the problem is not solved by legislation that deals uniquely with the prevention of soil pollution, but that it has been incorporated in other fields of regulation like land-use planning. Furthermore, there are different standards and different actual levels of enforcement of environmental legislation. Yet, the legal framework developed for the prevention of soil pollution can show lacunas, has to be enforced, and, in case of an accident, decontamination has to be ensured. In various countries, the regulatory framework is complemented with civil liability, in order to ensure the enforcement of their environmental legislation and to ensure the restoration in case of damage. ${ }^{133}$

It therefore merits studying the contribution of liability rules to prevent and restore soil pollution and the complementary role of environmental regulation and liability rules for soil pollution.

\subsection{Liability to Prevent and Restore Soil Pollution}

\subsubsection{Contribution of Liability Rules in Prevention and Restoration of Soil Pollution}

In paragraph 2, explaining the economic theory on liability for environmental damage, it was already demonstrated that liability rules cannot be the single regulating instrument for protecting the environment, due to problems of insolvency, for instance. However, it was shown that liability rules can play a useful complementary role besides environmental regulation by the government. The same reasoning can be applied to soil pollution.

Liability rules for soil pollution may have two functions. Firstly, as prevention of soil pollution is concerned, civil liability for soil pollution can play a complementary role besides regulations requiring industry to fulfil certain standards or possess certain licences. Indeed, regulation might lag behind or norms might be inefficiently low, due to political pressure or because the causal link between an activity and soil pollution is not always easy to prove. Under these circumstances, liability can induce industry to take all necessary preventive measures that are possible, knowing that they can still be held liable even when they do not go beyond their licence. As Faure indicates, it is in this complementary role that scholars see the surplus value of liability. ${ }^{134}$

Secondly, liability rules can provide compensation for the victims. However, in the case of strict liability, insolvency of the polluter might hinder effective compensation of the victims or restoration of the polluted soil. Therefore, for liability rules to work optimally, a combination with other mechanisms, like an environmental damage insurance, might be necessary.

The question arises, however, what kind of liability rule, strict liability or negligence, would best prevent and restore soil pollution.

\subsubsection{Strict Liability versus Negligence for Preventing and Restoring Soil Pollution}

In order to answer the question: which type of liability rule would be best able to prevent soil pollution or restore existing pollution, a distinction has to be made between historical contamination and recent contamination.

133 Seerden \& Deketelaere 2000, 441-447.

134 Faure \& Grimeaud 2003, 45-46. 


\subsubsection{Recent Contamination}

Regulation to protect the environment can not exclude that accidents still can happen. Furthermore, although nowadays most industries are subject to environmental regulation and control, the enforcement might be not effective enough. ${ }^{135}$ In such cases, a strict liability rule might complement safety standards set by the government. Polinksy and Shavell prove that making industry responsible for restoration and strictly liable for remaining damage would induce industry to take all necessary precautionary measures. Moreover, the optimal activity level will be adopted. ${ }^{136}$ However, other scholars like Bergkamp, for example, state that strict liability offers no additional benefits over fault liability. ${ }^{137}$ Strict liability does indeed have certain drawbacks. First of all, if the damage excedes the polluter's wealth a problem of underdeterrence might arise. Furthermore, if risk aversion might be assumed for certain operators, a strict liability rule might prevent them from engaging in beneficial production. Summarising, in cases of recent contamination, strict liability for dangerous activities might be useful, whereas a negligence rule might be sufficient for non-dangerous activities. This approach is also followed by several European countries.

\subsubsection{Historical Contamination}

Sometimes it might take a long time before becoming clear that some substances has caused soil pollution. Therefore, a wide range of contaminated sites might fall under this category. In some cases, the polluter cannot be found anymore or, in many cases, these sites became contaminated through their use by industry using processes and substances which would not be allowed anymore by current environmental regulation in most western countries, but which were allowed at the time of contamination. Brownfields in older (industrial) cities might be examples of such historical contamination. ${ }^{138}$ These sites obviously also require clean up measures. To develop a liability rule for this damage will be difficult though. The responsible parties might have acted according to legislation at that time.

Hence, for historical contamination, a fault-based liability regime might be preferred, whereby a firm shall be held liable in case fault, damage and causation can be proved. Furthermore, different solutions than liability rules might have to be provided in order to ensure restoration. Often the government itself might engage in clean up. The clean-up cost can either be paid by tax revenues, or by restoration funds through industry payments. 139

In Chapter 3 a framework for making decision regarding the optimal level of liability rules for environmental damage, including soil pollution, in a federal system will be developed, and hence will address the question of whether harmonisation of liability rules would result in better prevention and restoration of environmental damage, including soil pollution, whether a system of liability rules at national level would be preferable or whether a multi-level solution would be best. Before starting this discussion, the features of a liability rule that the harmonisation debate must take into consideration merit some attention.

\subsection{Features of a Liability Rule}

There are four main features of a liability rule that have to be taken into consideration in a harmonisation debate. First, the scope of the liability rule has to be discussed, as well as what type of liability will be chosen. In which cases does strict liability apply, when is a negligence rule appropriate, and is it useful to harmonise the application of either liability rule in a federal system? Second, how will causation be determined for negligence? Third, which scientific basis or standard will be used to decide when there is risk or harm? Or, is there need for a harmonised risk assessment procedure? Finally, who is going to implement and enforce the liability rules? Will this be a central agency or environmental control agencies of the different countries? An overview of the choices to be made is given below.

\subsubsection{Type and Scope of Liability Rule (Strict Liability versus Negligence)}

In the case of harmonisation, countries will have to agree on (industrial) activities that will either be subject to a strict liability rule (for dangerous activities for example), or to a negligence rule (non-dangerous

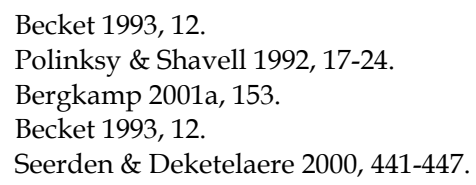


activities). Furthermore, the temporal scope of the liability rule (how long can somebody be held liable), the persons that can be held liable under the liability rule (operators, but also managers, authorisation holders or even parent corporation) or exemptions that will be added to the liability rule, are all features that will have to be addressed.

\subsubsection{Causation}

A feature of liability is that it requires a causal link between the damage and the activity in order to claim that the polluter is liable for the damage. With respect to our case-study, however, it might be very difficult to establish a causal link for soil pollution, as it might take a long time before soil pollution becomes apparent. A thorough local knowledge of the soil, its features and reactivity on the one hand and the industrial activities on the other hand therefore seems crucial in deciding whether there might be a causal link between polluted soil and a certain industry. Whether a standard approach towards causation can be formulated should therefore be examined carefully.

\subsubsection{Risk Assessment}

There are no international or European standards on how identification of potentially contaminated sites would have to be done, nor how risk management, for example clean-up measures or monitoring, should be effectuated. ${ }^{140}$ Nevertheless, when there is harm and when compensation or restoration is required under a liability rule must be defined. Therefore, in the harmonisation debate, eventual harmonisation of risk assessment and risk managementmust also be addressed.

\subsubsection{Implementation and Enforcement}

Finally, in the harmonisation debate, the implementation and enforcement of the liability rule will have to be discussed. Implementation of the liability rules and enforcement could be done by a central agency or environmental control agencies of the different participating countries. The (dis)advantages of both approaches will have to be weighted as well.

\section{Summary}

In this chapter an attempt was made towards explaining the role of environmental liability in the prevention and restoration of environmental damage.

Using a law and economics approach to tort law, it was indicated in paragraph 1 that liability has a twofold function. On the one hand, liability fulfils a preventative function, by giving individuals incentives to internalise the negative effects that their activities impose on others, and hence liability guides individual behaviour in order to maximise social welfare. On the other hand, liability could provide compensation for damage in case an accident should occur. It was shown that both a negligence rule and a strict liability rule would result in an optimal level of precautions in a unilateral accident setting, although there are differences between these liability rules with respect to Calabresi's secondary and tertiary costs and the activity level. If the aim of the liability rule is to reduce the activity level as well, a strict liability rule may be preferred.

In paragraph 2, this general theory was applied to environmental damage. It was shown that a strict liability regime would provide optimal incentives for individuals to take precautions towards preventing environmental damage. However, as in the general analysis, there are substantial differences between these two liability rules. Only a strict liability rule will reduce the activity level. Negative consequences, however, like a reduction in the production of socially desirable goods as medicines, should be avoided. A strict liability rule, furthermore, does not have such high information costs as a negligence rule and, from a compensation point of view, strict liability might ensure full compensation of damage, which would not be the case for negligence. Indeed, under negligence the polluter does not have to pay for the damage if he fulfilled the due care standard. The weaknesses of strict liability in addressing environmental risks were brought to light simultaneously. Insolvency might distort the deterrence and compensation or restorative function of strict liability. Scholars therefore examined remedies to this problem like safety regulations, extended liability, insurance and compensation funds. Moreover, lack of information on the risk, and weak causational chains may result in neither the deterrence function nor the compensation functions of either

140 Egelund Olsen 2001, 60. At international level, though, the ISO has prepared guidelines for the identification of contaminated sites. 
liability rule being accomplished successfully. Hence, other instruments for preventing environmental damage were discussed whereby attention was paid to the difference between ex ante instruments and $e x$ post liability rules. It was shown that economic instruments like marketable permits and taxes could achieve efficient results but are less common. Regulation proved to be an efficient instrument to affect behaviour $e x$ ante without waiting for harm to occur, and could solve the problems that a liability rule would pose on its own. On the other hand, liability could cover lacunas in regulation, such as inflexibility and compensation. It therefore seems that liability and regulation cannot be totally separated. Hence, liability can complement regulation for both the prevention and the restoration of environmental damage, thereby fulfilling fairness notions in society (polluting is wrong) and preserving intrinsic motivation. Consequently, it was claimed that the combination of ex ante regulation and ex post liability rules would achieve the most efficient prevention of environmental damage.

Paragraph 3 tried to answer the question: which type of liability rule would be best to prevent soil pollution or restore existing pollution. Soil pollution is a very complex issue with multiple causes and different impacts on the environment and on human health. In order to determine the optimal liability rule to complement the regulatory framework, a distinction has to be made between recent contamination and historical contamination. For recent contamination, strict liability for dangerous activities might be useful, whereas a negligence rule might be chosen for non-dangerous activities. For historical contamination a negligence liability regime might be adopted, whereby a person shall be liable in case fault, damage and causation can be proved. Furthermore, different solutions than liability rules might have to be provided in order to ensure clean up, like clean-up measures by the state.

Finally, a brief overview was given of the elements of a liability system that have to be taken into account in a harmonisation debate such as, for example, the scope of the liability rule, causation requirements, risk assessment and implementation.

It is not claimed that liability is the perfect solution for all kinds of environmental damage; however, liability can play a valuable complementary role in preventing and restoring environmental damage. Hence, it merits further research into how environmental liability rules could be optimally organised within a federal system. 



\section{Chapter 3}

\section{OPTIMAL DECISION-MAKING LEVEL OF ENVIRONMENTAL LIABILITY RULES IN A FEDERAL SYSTEM}

Chapter 3 will develop a framework for decision-making upon the optimal level of liability rules for environmental damage in a federal system. The harmonisation of liability rules for environmental damage in a federal system is a very complex matter with many factors and criteria that have to be taken into account and that need to be unravelled. Therefore, a deeper understanding of this complex matter can only be gained by studying the problem from different angles. This research will, therefore, look at the problem from two different theoretical perspectives within Law and Economics methodology that can both bring useful contributions to the underlying problem. Both perspectives will be brought together in order to provide an overall assessment.

Chapter 3 will consist of three paragraphs. Paragraph 1 will examine the optimal level of liability rules for environmental damage in a federal system from a public interest approach. The public interest approach is based on Law and Economics methodology. Economic efficiency criteria will be used to examine the appropriate federal structure for environmental liability rules, a method that is usually called the theory of federalism. ${ }^{141}$ The public interest approach will start from the decentralisation principle for regulation, based on the Tiebout Model (1956) and the decentralisation theorem by Oates (1972). Refinements by Fischel and Oates and Schwab will be added. However, when applied to environmental damage, and to soil pollution in particular, some assumptions of the Tiebout model will not be fulfilled, which will give rise to grounds for centralisation. These reasons for centralisation constitute the core of the public interest approach and will be discussed subsequently: the transboundary character an externality (1.2.1), the risk of a race-to-the-bottom (1.2.2), the market access argument for centralisation (1.2.3) and, finally, besides pure economic arguments, non-economic arguments will also be taken into account (1.2.4). Then, these (de)centralisation arguments will be carefully weighted against each other and a balanced conclusion will be formulated, either for or against assigning responsibility to a certain level of government, based on the public interest approach.

Paragraph 2 will examine the optimal decision-making level of liability rules for environmental damage from the second theoretical perspective, called private interest approach. Obviously, environmental rules can have important economic implications. Therefore when deciding upon the 'optimal level' of environmental regulation, rent seeking behaviour and lobbying of different interest groups in the law-making process should not be ignored. The private interest approach applies economic models to political decision-making and tries to take rent seeking into account in the law making process. The contribution of this approach is that it throws light upon the conditions under which laws are made. ${ }^{142}$ The private interest approach will first present an overview of the theories that examine the influence of lobbying on the law-making process (Capture Theory, Public Choice Theory, based on the work of Buchanan and Tullock, and Interest Group Theory, based on Stigler and Becker). Next, these theories will be applied to environmental federalism. The core of the private interest approach will be to examine the relative powers of interest groups at different levels of government, who is lobbying and for what reasons (with respect to the research subject these lobby groups are mainly industry and environmental lobby groups). Links with the public interest approach will be shown. Then, the results can be further refined to environmental liability, and, as an example, to soil pollution. Again, centralisation and decentralisation arguments for environmental damage liability will be weighted against each other, this time based on the private interest approach.

The framework presented in Figure 1 sketches the structure of this research graphically. The structure of both public interest and private interest methodology are shown and interdependencies between the two

$141 \quad$ Inman \& Rubinfeld 2000.

142 De Geest 1990, 625-626. 
theoretical approaches are indicated by means of arrows. The cores of both approaches are represented in a grey box.

Paragraph 3 will bring both perspectives together as they can both bring useful contributions to the harmonisation debate. An overall assessment will be provided and a proposal for a decision-making framework upon the optimal level of liability rules for environmental damage in a federal system will be presented. As an illustration, the optimal level of liability rules for soil polution in a federal system will be developed.

The framework will then be tested in chapters 4,5 and 6 by means of a case-study: the harmonisation of environmental liability rules, including liability for soil pollution, in the European Union. 


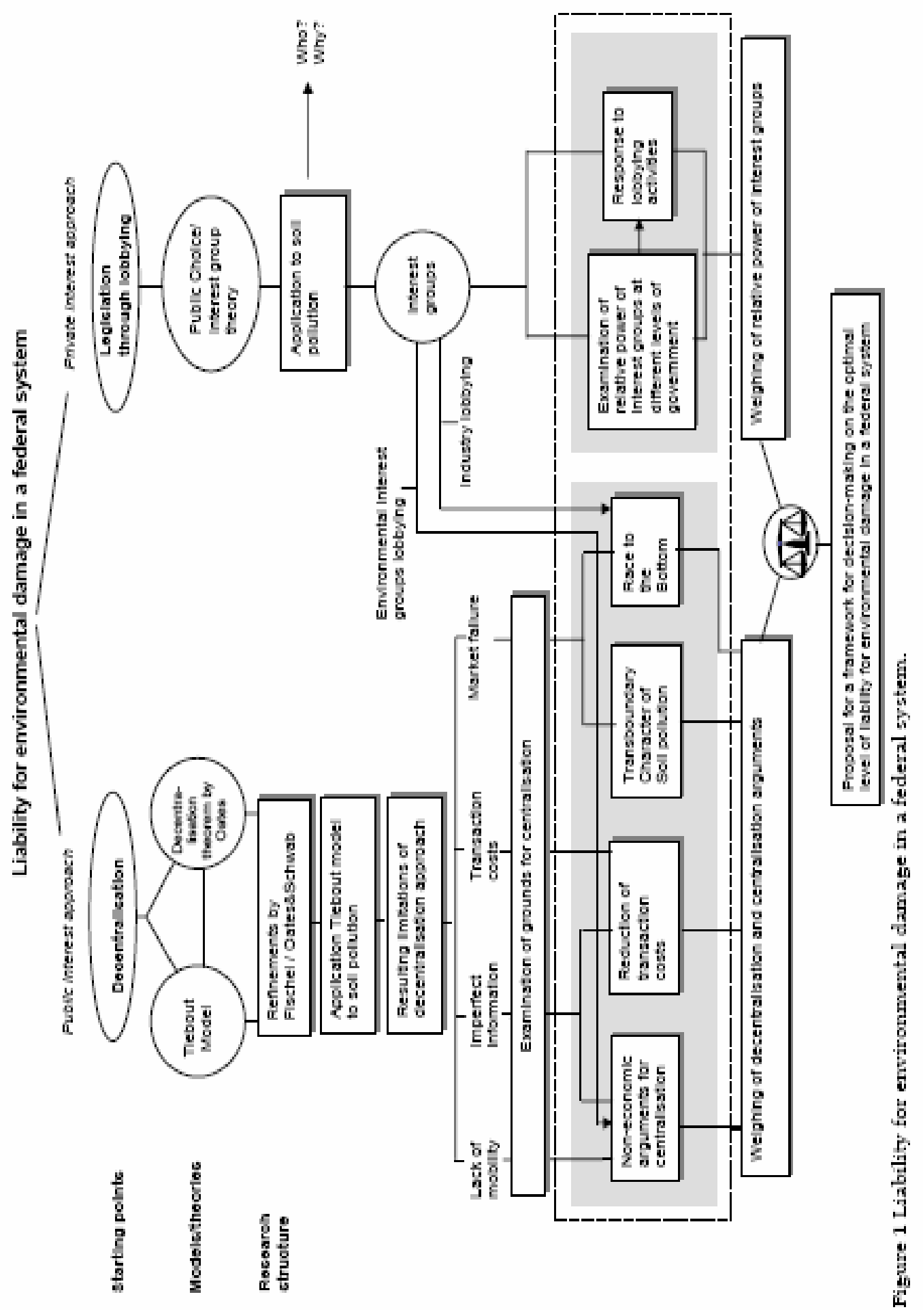




\section{Public Interest Approach on the Optimal Decision-making Level of Liability for Environmental Damage}

\subsection{Decentralisation as a Traditional Starting Point}

Environmental federalism scholars generally start with a bottom-up approach towards centralisation, using the Tiebout Model and the Decentralisation Theorem of Oates as starting points for their analysis. However, certain circumstances might require the intervention of a higher government, through centralisation or even through harmonisation. ${ }^{143}$ In this paragraph, the Tiebout Model and the Decentralisation Theorem by Oates will be explained and applied to environmental damage and to soil pollution in particular. Next, the possible reasons for a federal intervention will be examined.

\subsubsection{The Tiebout Model}

\subsubsection{The Model}

In 1956, Tiebout developed an ideal model of fiscal competition between independent governments. ${ }^{144}$ Tiebout stated that, with decentralised - horizontally arranged - competitive governments, individuals could move along local jurisdictions to select that community with a regulatory combination that best satisfies his preferences for public goods. Governments would try to attract residents on the basis of differing tax and benefit structures. As everybody would go and live where the set of regulations would best suit his or her preferences for public goods, overall social welfare would be maximised and a paretosuperior outcome would be achieved, since no individual can be made better off by moving, he would have done so otherwise. ${ }^{145}$ Tiebout's idea is now commonly known as 'voting with the feet' by citizens. According to Tiebout, the greater the number of communities and the greater the variance among them, the better citizens could realise their preferences. ${ }^{146}$ Tiebout's model of governmental competition is similar to a purely competitive market model between firms with complete information. ${ }^{147}$

Though the Tiebout model was designed for fiscal policies, academic scholars introduced the model in other fields of regulation. The Tiebout model became the starting point for scholars to state that public policies in various fields of regulation should be decentralised, except when there are significant externalities from one jurisdiction to neighbouring jurisdictions. In cases of such externalities, and high transaction costs to overcome these externalities, the oversight of a higher governmental level might be appropriate.

It is, however, important to understand the assumptions on which the Tiebout model relies. If the assumptions are clear, it can be examined whether those assumptions will hold for environmental liability rules and liability rules for soil pollution in particular.

\subsubsection{Assumptions}

Tiebout defines seven assumptions to build his model. ${ }^{148}$ Firstly, Tiebout assumes that households and firms are fully mobile. They can, therefore, move without cost to that jurisdiction which fulfils their preferences.

Secondly, it is assumed that households and businesses are fully informed regarding the fiscal and regulatory policies of each jurisdiction. From these two assumptions together it can be concluded that households and business would move from one jurisdiction to another that better fits their needs, as they are informed about the facilities and they do not face any costs.

A clarification of the meaning of respective centralisation and harmonisation is appropriate here. Often, these two notions are used interchangeably. There is, however, an important distinction. Centralisation means that the decision-making power is transferred to a higher governmental level. Centralisation does not coincide with uniformity though. For example, a certain policy can be set at central level, but the standards may vary across states according to different geographical conditions. Harmonisation, on the other hand, means uniformity of standards. Therefore, when examining all arguments for (de)centralisation, a distinction must be made between arguments pleading for centralisation or for harmonisation. See also Arcuri 2001, 42.

144 Tiebout 1956, 415-424. See also Inman \& Rubinfeld 2000, 661-691.

145 Tiebout 1956, 415-424. See also Esty 1996, 608.

146 Tiebout 1956, 418.

147 Inman \& Rubinfeld 2000, 669.

148 Tiebout 1956, 415-424. For a discussion see also Inman \& Rubinfeld 2000, 661-691. 
The third assumption made by Tiebout is that there is a perfectly elastic supply of governmental services by the competing jurisdictions. This assumption ensures that households or firms have sufficient alternatives between which they can choose.

Next, restrictions due to employment are not considered. Tiebout assumes that all households live on dividend income.

A fifth assumption which certainly should be noted is that Tiebout excludes interjurisdictional externalities or spillovers. This assumption ensures that all public regulatory activities can be provided within these efficient jurisdictions without distortion to other jurisdictions. Furthermore, larger governments or intergovernmental co-operation is unnecessary.

Sixth, it is assumed that an optimal community size exists, for which the service or public good can be provided at minimum average cost. By this assumption, Tiebout also excludes purely public goods. These are goods where additional users of the government's service do not reduce the consumption of other citizens, as with national defence. Goods to which the Tiebout model can be applied are those goods where more users reduce the benefit to the other users, called congested public goods, like education or parks, environment in general and also of soil specifically. ${ }^{149}$ Furthermore, the optimal community size must be sufficiently small so that each household has enough choice and can find a suitable jurisdiction in which to reside.

Finally, communities below the optimum community size will seek to attract new residents to lower average costs, whereas communities above optimum will do the opposite, in order to achieve and keep the optimal size.

If all assumptions hold then, according to Tiebout, a world with fully decentralised competing jurisdictions will achieve economic efficiency. Households and business would be able to consume their preferred levels of the public good at minimum expenditure of production and transaction costs.

The Tiebout Model provides a useful theoretical starting point for federalism as it forces critical thought about the arguments for harmonisation. However, the model uses rather strong assumptions. If they do not hold, the optimality of a complete decentralisation must be reconsidered.

\subsubsection{Refinements of the Tiebout Model}

\subsubsection{Refinements by Fischel}

Later scholars have tried to broaden the reach of Tiebout's analysis by relaxing some of the assumptions or by applying it to a different field of research. Fischel applied the Tiebout model to environmental regulation with a model that addressed pollution and industrial location. ${ }^{150} \mathrm{He}$ concluded that, under restrictive assumptions, environmental externalities could be internalised when polluters would compensate communities for environmental damage. Households would again choose that community that would fulfil their preferences for environmental quality. This would make interjurisdictional competition desirable and social welfare would be optimised. Like Tiebout, Fischel ignored any job-loss problem and based his model on the assumption that citizens are perfectly mobile. ${ }^{151}$

\subsubsection{Refinements by Oates and Schwab}

Oates and Schwab ${ }^{152}$ tried to overcome these weaknesses with a model acknowledging the existence of immobility of labour and wage effects. In their model, jurisdictions could compete for mobile capital choosing either or both of two mechanisms: low taxes or lax environmental standards. Communities would determine tax rates on capital and environmental standards in such a way that they would achieve an optimal mix of industry and pollution. Like Tiebout, Oates and Schwab assumed many jurisdictions, moreover, they assumed that each of them was sufficiently large for all individuals both to live and to work in the same jurisdiction. Furthermore, pollution generated by firms in one jurisdiction does not spill over into other jurisdictions. The output of a jurisdiction's firm depends on the jurisdiction's given stock of capital, labour and allowed polluting emissions. Oates and Schwab conclude that under restrictive conditions, interjurisdictional competition would yield welfare-maximising environmental standards. A rational government would set a tax rate of zero on capital and then achieve a welfare-maximising

\footnotetext{
149 Inman\& Rubinfeld 2000, 661-691.

$150 \quad$ Fischel 1975, 119-174.

151 Fischel 1975, 119-174. See also Esty 1996, 608. See also Oates \& Schwab 1988, 350

152 Oates 1988, 333-354.
} 
environmental policy by reducing pollution until lost wage income would be equal to the gains from reduced pollution damage. ${ }^{153}$

Besides the Tiebout Model, the Decentralisation Theorem by Oates can be referred to as a starting point for decentralisation of regulation.

\subsubsection{The Decentralisation Theorem by Oates}

The Decentralisation Theorem, as formulated by Wallace Oates in 1972, states that, for public goods, it would be economically more efficient if local governments would provide the amount of public goods that would reflect the preferences of their citizens, than if a central government would provide a uniform level of output of the public good across all jurisdictions. ${ }^{154}$ Put differently, with decentralisation, local preferences for public goods are likely to be better fulfilled, and social welfare would be maximised. Furthermore, the advantage of decentralisation would be greater the more the preferences for the public good vary among the different jurisdictions. Indeed, in such situations, the uniform central output would diverge most from the preferred output in the different jurisdictions. Hence, a decentralised provision of public goods would be ideal from the perspective of welfare maximisation. Yet, for the Decentralisation Theorem to hold, it is assumed that the cost of providing the public good in each jurisdiction is the same for the local government as for the central government. Indeed, if the central government could realise economies of scale in providing the public good, then centralisation might be preferred. ${ }^{155}$ However, if no cost savings result from centralisation, Oates' Theorem provides a proposal for decentralisation of the provision of public goods. Hence, applied to the environmental realm, the Theorem would suggest a decentralisation of environmental regulation, such that the regulations would reflect the preferences of the citizens in a jurisdiction.

\subsubsection{Limitations of the Tiebout Model and the Decentralisation Theorem Applied to Environmental Damage}

Both the Tiebout model and the Decentralisation Theorem by Oates are useful starting points for examining the 'optimal level' of liability rules for envionmental damage in a federal system, in order to provide a balanced answer on the harmonisation debate from a public interest approach. Using the Tiebout Model and the Decentralisation Theorem as starting point limitations of the decentralisation of environmental regulations can be shown. Indeed, both the Tiebout model and the Decentralisation Theorem show some shortcomings when applied to environmental regulation, and to liability rules for environmental damage. These shortcomings might be illustrated by means of the example of soil pollution.

In order to understand the shortcomings of the models when applied to the example of soil pollution, it might be helpful at this stage to characterise soil in this debate. Soil might be publicly or privately owned. However, the fact that a particular site is privately owned should not give the owner a right to pollute that site, thereby preventing other citizens to use that soil after closure of the firm. Therefore, soil can be understood as a public good, as all citizens should be able to enjoy its use. Moreover, polluting substances that cause soil pollution, emitted within a certain jurisdiction, will mostly have their effect solely within that same jurisdiction. ${ }^{156}$ Indeed, as was shown in paragraph 3.1.1 of chapter 2, although it is possible that pollution can spread to surrounding land, which are local spillover effects, in many cases contaminants that cause soil pollution remain close to the places where they were or are used. ${ }^{157}$ It is only in rare cases that soil pollution will migrate beyond the boundaries of the jurisdiction, though it might very well be possible for the contamination to spread and damage the property of different owners within the same jurisdiction. Hence, in environmental federalism terminology, soil pollution can be understood as a local public good. This definition of soil pollution as a local public good is important in order to illustrate what the optimal policy level would be of liability rules for soil pollution in a federal system.

The limitations of both theoretical models will be discussed below. They will give rise to reasons for a certain level of centralisation.

\footnotetext{
Oates 1988, 336-343. See also Engel 1997, 307.

Oates 1972, 35. See also Inman \& Rubinfeld 2000, 668.

Oates 1972, 37.

Oates 2001, 4.

Becket 1993, 19.
} 


\subsubsection{Lack of Mobility}

Tiebout's first assumption was that citizens are fully mobile. ${ }^{158}$ However, stating that citizens and business can move between different jurisdictions without costs clearly might be problematic in a real world setting. Work and family might prohibit people from moving to different jurisdictions. Therefore, it seems doubtful that citizens can move without costs to the jurisdiction that best fulfils their preferences for environmental regulation in general or for soil pollution liability specifically.

\subsubsection{Imperfect Information}

In the case of environmental damage, and soil pollution in particular, Tiebout's second assumption, that citizens and business are fully informed about the choices they face, ${ }^{159}$ is highly problematic. Although it must be possible to obtain information on current environmental regulations or policies of the different jurisdictions, in the real world it might be very difficult to obtain accurate information on existing environmental damage and certainly on soil pollution in a certain jurisdiction. It may very well be possible that some jurisdictions have not yet mapped - or might not know - the sites that are polluted. Therefore, it might be very difficult to assess the presence of soil pollution in certain jurisdictions. If there are no clear liability rules in case land is transferred, this might cause uncertainty and might have a negative effect on business.

\subsubsection{Market Failure}

In the Tiebout model, it is stipulated in its third assumption that there is a perfectly elastic supply of political jurisdictions. ${ }^{160}$ Hence, governments are analogous to firms in a perfectly competitive market setting, with free entry and exit from an industry. It will be clear that free entry of new governments, with their own policies on public goods, is a highly problematic assumption in a real world setting. However, if this assumption does not hold, this has several consequences for economic efficiency. Firstly, with a limited number of jurisdictions, it might well be the case that citizens have different views on the government's best policy for a certain public good in the same jurisdiction, as they might not find the jurisdiction that perfectly fulfils their preferences. In this case, if decisions are made by majority, the outcome of the provision of the public good might not necessarily be economically efficient. ${ }^{161}$ Applied to environmental regulation and liability for environmental damage, this would mean that the environmental regulation or the liability rules to prevent and restore environmental damage, including soil pollution, would not fulfil citizens' preferences perfectly, as opposed to what the Tiebout Model or the Decentralisation Theorem suggest.

More critical is that the regulatory policies of a jurisdiction, in a world of limited jurisdictions, now might have effects on the other jurisdictions, which may lead to strategic behaviour. The possible consequences of strategic behaviour have been discussed by several scholars of environmental regulation. If states would relax their environmental regulation in order to attract business, this could lead to a race to the bottom in which environmental regulation would be undersupplied, resulting in reduced overall welfare. ${ }^{162}$ The risk of a race to the bottom, when states would relax their liability rules for environmental damage will be discussed below.

\subsubsection{Externalities}

Besides the fact that jurisdictions cannot be compared with a perfectly competitive market, the fifth assumption of the Tiebout model might be violated often in the case of environmental damage. This assumption states that there are no externalities that might require intervention of a central government. ${ }^{163}$ However, interstate externalities of environmental damage are a major reason for federal oversight over environmental matters. Oil spills or dumping of chemicals in streams for example, might contaminate land far over the border of a certain jurisdiction. The concern is that states will be unable, or presumably unwilling, to take into account the effect that their environmental regulation might have on other states. ${ }^{164}$

\footnotetext{
Tiebout 1956, 419.

Tiebout 1956, 419.

Ibidem.

Inman \& Rubinfeld 2000, 671-672.

Inman \& Rubinfeld 2000???, 669-672.

Tiebout 1956, 419.

Adler 2001, 222.
} 
In that sense, environmental damage does not only pose a threat to social welfare maximisation, but also to the protection of property rights. 165

A spillover of soil pollution to a neighbouring jurisdiction, for example, raises an issue of property rights. As explained in chapter 2, if property rights over environmental resources would have been clearly defined and if transaction costs of negotiating compensation in case of damage or harm would be low, according to Coase, a free market for environmental resources would produce a welfare-maximising result: environmental harm would be internalised, and it would be a fair outcome, in the sense that property rights would be respected, the initial endowment is not debated here. Hence, there would be no need for environmental regulation. Because of the nature of soil pollution such a Coasean bargaining might not work though. It might sometimes take a long time for damage to become apparent and property rights to pollute soil are certainly not defined clearly.

Yet, as stated in chapter 2, soil pollution will stay close to the place where the accident occured in most cases. Therefore, in most cases, for soil pollution, assumption five could hold. This result, however, does not exclude that in some cases, pollution can spread to surrounding land, thereby damaging the property of a neighbour, that it can spread across jurisdictions, or that psychological spillovers might result, because citizens of a foreign jurisdiction will not be able to visit the contaminated area anymore as tourists. Therefore, in case of interjurisdictional spillovers, decentralisation of environmental regulation might not maximise social welfare, a result which would plead for some central oversight.

Summarising, meeting the list of requirements of the Tiebout model is clearly unlikely in the real world. The soil pollution example illustrates this finding clearly. People are just not perfectly mobile, certainly not in Europe, obtaining perfect information might prove impossible, market failures and externalities cannot be excluded, nor can the existence of prohibitive transaction costs for interjurisdictional negotiations. Nevertheless, neither the Tiebout model nor the Decentralisation Theorem should be dismissed too hastily, as they show how different decisions by jurisdictions, with respect to public good provision - like soil quality - might be explained on the basis of their citizens' preferences. Furthermore, both models force us to think critically about the reasons for centralisation or even harmonisation. Indeed, the fact that liability rules for environmental damage do not fully fulfil the Tiebout model, does not mean that full harmonisation in a federal system might be needed. It merely indicates that in some circumstances federal or central guidance might be useful.

\subsection{Arguments for Centralisation of Liability Rules for Environmental Damage}

Decentralisation of the provision of public goods, as proposed by the Tiebout Model and Oates' Decentralisation Theorem, do indeed show some limitations when applied to environmental damage, as was shown by the example of soil pollution. These limitations give rise to arguments for a certain level of centralisation of environmental regulation and of liability rules for environmental damage. These arguments are discussed in academic as well as political debates. For instance, the European Union's proposal for an environmental liability directive ${ }^{166}$ resulted in animated political and academic debates on the role of liability rules for environmental damage and on the question of whether a centralisation or harmonisation of liability rules in the European Union would better protect the environment from future damage than decentralisation. The arguments that are advanced from a public interest perspective, both by politicians and by scholars, will now be analysed carefully, in order to provide an answer to the question on the optimal decision-making level of liability for environmental damage from a public interest perspective. It will also be examined how these arguments can be applied to soil pollution.

Although different scholars might use a slightly different classification, the reasons for centralisation or harmonisation of regulation can be grouped into four main arguments: the transboundary character of an externality argument, the race-to-the-bottom argument, the market access argument and non-economic arguments for centralisation or harmonisation. In order to provide an insight into the optimal decisionmaking level of liability rules for environmental damage from a public interest perspective, each argument for centralisation will be unfolded in two successive steps.

First, the advanced argument will be examined for liability rules in general. A distinction will, hereby, be made as to whether the advanced argument pleads for centralisation or even for more far-reaching harmonisation. The starting point of every argument is why centralisation or even harmonisation would be needed. The approach followed is defined by Van den Bergh as 'bottom-up federalisation' ${ }^{167}$ Furthermore,

\footnotetext{
165 Esty 1996, 575-577.

166 European Commission, Proposal for a Directive on Environmental Liability with regard to the Prevention and Restoration of Environmental Damage, COM (2002) 17 final, 23 January 2002.

167 Van den Bergh 1994, 340.
} 
the question of centralisation of liability rules often cannot be separated from the debate on centralisation of regulation, as liability rules are frequently used as a complement to regulation. Moreover, some countries rely predominantly on regulation instead of liability rules. Therefore, whether the argument would plead for centralisation of liability rules or regulation will be examined as well.

Second, after the argument has been examined for the general case, it will be applied to environmental regulation and to liability rules for environmental damage, with the illustration of soil pollution. Following the same reasoning as for the general case, the starting point of the examination is why centralisation or even harmonisation would be needed. Especially for environmental damage, the question of centralisation of liability rules often cannot be separated from the question of centralisation of regulation for environmental damage, as liability rules are often used as a complement to environmental regulation. Therefore, a distinction will be made as to whether the argument pleads for centralisation/harmonisation of regulation for environmental damage or liability rules for environmental damage, with soil pollution as an example.

After a careful analysis of the four arguments, decentralisation and centralisation arguments will be weighted in order to provide a balanced answer on the harmonisation debate of liability for environmental damage, from a public interest approach. Then, the harmonisation problem can be examined from a second perspective, the private interest approach.

\subsubsection{Transboundary Character of an Externality Argument}

The Tiebout Model, favouring decentralisation of the provision of public goods, only holds if decisions of one jurisdiction have no external (negative) effects on other jurisdictions. When policies of a certain jurisdiction have a transboundary effect on a neighbouring jurisdiction, there is an argument for centralisation. The reasoning is twofold. Firstly, internalisation of transboundary externalities could be ensured by shifting powers to a higher governmental level. Secondly, economies of scale could be reached by - a certain level of - centralisation. ${ }^{168}$

Both strands of the transboundary externality argument will now be studied in detail. Each strand will first be examined in general. Next, the reasoning will be applied to environmental damage and to soil pollution in particular. Finally, the results of both strands will then be merged in order to provide some understanding on the optimal level of liability rules for environmental damage according to the transboundary externality argument.

\subsubsection{Internalisation of Transboundary Environmental Damage Through Centralisation}

\section{General Case}

The problem of interstate externalities or spillovers arises when the effects of a particular activity accrue beyond the boundaries of a jurisdiction to a certain extent. ${ }^{169}$ For example, a jurisdiction might benefit from an (economic) activity, whilst not bearing the full costs of the activity, as part of the costs are endured by neighbouring jurisdictions. The classic example of externality is a physical externality, like pollution caused by an economic activity that spills over to a neighbouring jurisdiction. Externalities may also be of an economic nature. Certain regulations, for example antitrust rules, might have a negative impact on the profits of foreign-based producers and distort competition. ${ }^{170}$ This competition distortion might eventually trigger a so-called race-to-the-bottom, a second argument for centralisation, which will be discussed below. Finally, some authors argue that psychic spillovers might exist. Psychic spillovers would arise when citizens of another jurisdiction are deprived of the enjoyment of certain goods, a natural park, for example, or a coast line within the first jurisdiction, because of pollution. ${ }^{171}$ Psychic spillovers are related to the noneconomic arguments for centralisation, which will be discussed in detail later.

The presence of interstate externalities - physical, economic or psychic - provides a tenable argument for shifting regulatory power to an overarching governmental level. The reasoning is that jurisdictions will not internalise the consequences of their actions that might accrue across their borders. Hence, jurisdictions will have no incentive to impose stringent regulation on their own industry and consequently will underregulate the harmful activity. ${ }^{172}$ This argument in favour of centralisation may hold for both regulation and liability rules. Indeed, the argument could also be advanced in cases of

Faure 2003a, 38-39. See also Ogus 1999, 405-418.

Esty 1996, 587.

Esty 2001, 34.

See for example Esty \& Geradin 2001, 34

Faure 2003a, 38-39. See also Esty \& Geradin 2001, 34 
transboundary torts. Often, accidents as a result of product deficiencies might have transboundary effects which are not internalised in a jurisdiction's regulation or rules. ${ }^{173}$

The logic behind the need to correct externalities by collaboration at an overarching governmental level is not much debated in the academic realm. Even firm advocates of decentralisation do not deny the need to internalise externalities. ${ }^{174}$ However, as Van den Bergh indicates, the need to internalise transboundary externalities should not lead a priori to centralisation or harmonisation of regulation or liability rules. In first instance, Coasean bargaining between jurisdictions could be considered. ${ }^{175}$ Indeed, as explained in Chapter 2, if property rights are clearly defined and if transaction costs of negotiating compensation for damage are low, then, according to economic theory, Coasean bargaining between jurisdictions would lead to a welfare-maximising result.

In cases of transboundary torts, damage costs could be internalised by the responsible jurisdiction through Coasean bargaining, there would then be no under-regulation and compensation could be provided. Hence, there would be no need for centralised liability rules. However, Coasean bargaining may not always be feasible when property rights are not clearly defined. Nonetheless, the basic insight is that the presence of transboundary torts should not automatically justify centralisation of liability rules. Indeed, centralised tort law might be overinclusive, in the sense that it might regulate more than transboundary torts, thus also torts that only have in-state consequences. In such cases, the cure might be worse than the disease. ${ }^{176}$ Therefore, less comprehensive measures than complete harmonisation might be considered for curing interstate externalities. This finding will be important when weighing all arguments for or against centralisation and when alternative solutions can be studied.

In conclusion, transboundary externalities may be an argument for shifting decision-making power to a higher governmental level in cases where decentralised law-making would be unable to remedy the transboundary externalities. However, centralisation should be limited to transboundary externalities preferably. Indeed, in the case of torts, if the effects of a tort are merely local, domestic legal remedies could solve the problem. ${ }^{177}$

\section{Environmental Liability}

Although externalities may arise in many fields of regulation, certain regulatory domains are admitted to frequently cause externalities, like the environmental domain. ${ }^{178}$ As in the general case, three different types of externalities might exist. First of all, environmental damage might cause physical transboundary externalities. Indeed, water pollution might, for example, cross the borders of a jurisdiction. Furthermore, as in the general case, some authors indicate that, besides physical spillovers, psychic spillovers might exist. It is claimed that, if plant life, animal species or a special area are endangered in a jurisdiction because of water or soil pollution, citizens of other jurisdictions might experience harm, as they cannot enjoy the availability of that area anymore. ${ }^{179}$ Other authors are rather critical about the existence of psychic spillovers as a justification for centralisation. Faure, for example, indicates that this would open the scope of centralisation tremendously, which might be against citizens' preferences. ${ }^{180}$ The psychic spillovers reasoning will be examined in detail in the paragraph on non-economic arguments for centralisation. Finally, these transboundary externalities can be economic in nature, if a neighbouring country's crop has been destroyed because of the externality. ${ }^{181}$

Yet, if property rights were clearly defined and if transaction costs of negotiating compensation for damage would be low, then, as for the general case, according to economic theory, Coasean bargaining between jurisdictions could lead to a welfare-maximising result. Transboundary environmental damage would be internalised by the responsible jurisdiction, there would be no under-regulation and compensation might be provided. Hence, in cases of transboundary accidents, there would be no need for centralised liability rules for transboundary pollution. However, because of the nature of environmental damage, Coasean bargaining might not always be feasible. It might take a long time for damage to become apparent sometimes, the causal link might be difficult to prove and the damage actually caused might be

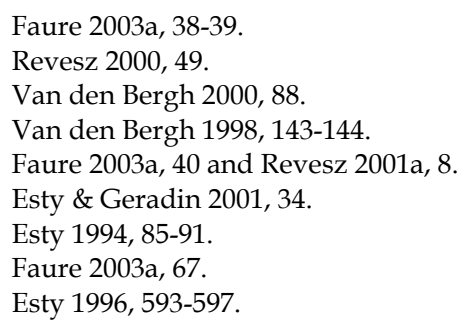


very difficult to assess. Furthermore, property rights over environmental resources certainly might not be defined clearly. Finally, if pollution goes one-way, transaction costs might be high. ${ }^{182}$

Some transaction costs associated with environmental damage result from technical uncertainty, defined by Esty as technical transaction costs. ${ }^{183}$ Even when property rights over environmental resources are clearly defined, the value of the environmental resource is not easily expressed in monetary terms. Individuals cannot easily judge the risks to their health or what ecological damage might have been caused. Furthermore, information on how much harm an environmental problem might cause changes frequently, as scientists might find new links between emissions and public health or ecological injuries and new methods for risk reduction. An additional difficulty is that many pollutants may show threshold effects, such that small amounts of emissions may cause no harm whilst exposure beyond a certain level does cause damage. ${ }^{184}$ Esty identifies further administrative and strategic transaction costs that arise when bargaining. ${ }^{185}$

Therefore, as stated in the general case, legal uncertainty, or poorly defined property rights and high transaction costs, that may make Coasean bargaining unfeasible, provide an argument for a certain interjurisdictional co-operation. ${ }^{186}$ Co-operation might reduce the administrative costs of negotiating property rights or the costs of suing the injurer to claim one's rights. However, as Revesz rightly states, the fact that an intervention by a higher governmental level is justified to solve these transboundary externalities does not imply that all environmental liability rules should be centralised or harmonised. ${ }^{187}$ Indeed, many environmental accidents are confined within the borders of a jurisdiction. As stated in the general case, the transboundary externality argument does not justify harmonisation of liability rules that deal with in-state torts. Moreover, before centralisation is considered, it should be examined whether national legal remedies could solve the externality problem, to prevent a cure worse than the disease. ${ }^{188}$

The case of soil pollution might clarify this position. In order to assess whether the transboundary externalities argument would allow for the centralisation of regulation or liability rules for soil pollution, the nature of soil pollution has to be taken into account. As for environmental resources in general, property rights over soil might not always be clearly defined. And even if property rights over soil were clearly defined, the value of clean soil is not easily expressed in monetary terms. Individuals cannot easily judge the risks that soil pollution poses to their health. Furthermore, information on how much harm soil pollution causes might change, as scientists could find new links between emissions and public health. As for environmental damage in general, soil pollution at low levels may not be harmful, whereas exposure to certain substances beyond a certain level might cause damage. ${ }^{189}$ However, as was explained in chapter 2, in most cases soil pollution will stay close to the place where the accident happened, which implies that local soil pollution will be the major problem to be regulated. Therefore, physical spillovers of soil pollution across jurisdictions might be a minor part of the problem, though transboundary damage cannot be excluded for industrial activities close to the border of a jurisdiction, for example. Moreover, the causes and consequences of soil pollution can vary significantly between jurisdictions in a federal system and even within a single jurisdiction.

Under these circumstances regulation or liability rules tailored to local needs and preferences seem appropriate. The fact that the major part of the problem will be in-state torts, whereby a solution adapted to local circumstances might be appropriate, raises the question of whether a far-reaching harmonisation or a centralisation of regulation or liability rules for soil pollution would be desirable. Possible alternative solutions for transboundary spillovers of soil pollution could be examined as well as whether an appropriate regulatory response could be provided that would be less far-reaching than harmonisation or even a more modest centralisation. ${ }^{190}$

Summarising, as far as the internalising of externalities reasoning is concerned it can be concluded that although the transboundary character of environmental damage would provide an argument for centralisation soil pollution itself will cause mainly in-state torts. Therefore, a far-reaching harmonisation or even centralisation of liability rules for soil pollution might not be justified. When dealing with national torts, states should be able to set liability rules for soil pollution according to the preferences and needs of their citizens. Alternative solutions could be examined to solve transboundary spillovers of soil pollution.

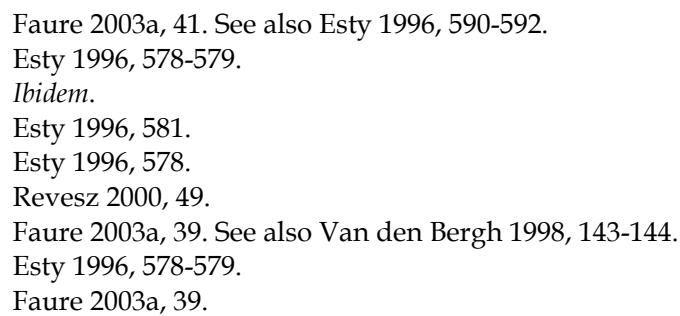


An appropriate regulatory response might consist of co-operation between jurisdictions, instead of centralisation or harmonisation.

However, besides the internalising of externalities, economies of scale might reach a centralisation of certain tasks.

\subsubsection{Economies of Scale in the Regulation of Environmental Damage}

\section{General case}

The second strand of the transboundary externality argument concentrates on the economies of scale that could be reached through centralisation. The reasoning is that the decision-making power should be entrusted to a higher regulatory level, which has a sufficient competence to solve the externality problem adequately. Moreover, if an authority that has competence over a larger territory could deal with the externality, economies of scale could be reached in the provision of public goods. ${ }^{191}$ Indeed, when economies of scale are present, centralisation could be more efficient than regulatory competition. ${ }^{192}$ The economies of scale reasoning is closely related to the transaction costs argument, which will be discussed below in the paragraph on market access, as it could be argued that transaction costs will be lower if regulation is made at a higher level. ${ }^{193}$

Following the second strand of the transboundary externality argument, federal intervention might be justified if the costs of having diversity - the presence of externalities - would outweigh the benefits of having different local rules. ${ }^{194}$ Centralised standards might also be preferred by industry. Indeed, firms selling in different jurisdictions would face a clear legal framework and economies of scale in production could be reached more easily if certain regulations were centralised, like, for example, consumer safety regulations. ${ }^{195}$

However, the economies of scale justification for shifting decision-making to a higher governmental level should not be understood as a plea for total harmonisation of all standards of, for example, food safety or water pollution. This justification merely indicates that whether some regulatory functions would be more efficiently carried out at a higher governmental level, while other tasks would be more appropriately dealt with at the local governmental level, must be examined carefully. ${ }^{196}$

Indeed, in areas that require highly technical information, like environmental problems that have to be regulated, the federal government could provide the public good with research and information. Although states would benefit themselves from doing research, no state might have an incentive to provide the costly technical information that would be needed to develop environmental regulation, for example. The reason is that, once the information is obtained, other states will profit from it, without bearing the costs, which causes a free-rider problem. Besides the free-rider problem, states might lack the technical capacity and the resources necessary to carry out a rigorous analysis. ${ }^{197}$ Furthermore, some elements of regulation are based on technical data that do not vary substantially across states, like consumer safety. Therefore, the shortcomings at local level could be overcome if the federal government would provide scientific research and information, thereby reaching economies of scale. ${ }^{198}$

This presumption in favour of centralisation of technical and scientific research is opposed by the 'state-as laboratories' reasoning. The argumentation is twofold. First, multiple approaches to address a problem might be better at finding the right policy than one centralised analysis. This might improve both the quality of the regulation and governmental efficiency through competition among decentralised jurisdictions. ${ }^{199}$ However, it is debatable whether state officials work more efficiently than federal officials because they are supposed to be in competition with other states. Furthermore, the availability of technical capacity and financial resources at central level should not be ignored. Second, the 'states as laboratories' reasoning addresses problems that are specifically geographically heterogeneous. ${ }^{200}$ It must be admitted that in such circumstances the ground knowledge is crucial and that the diversity of circumstances has to be taken into account. Therefore, in such cases, research at the local level might make sense, so that regulation

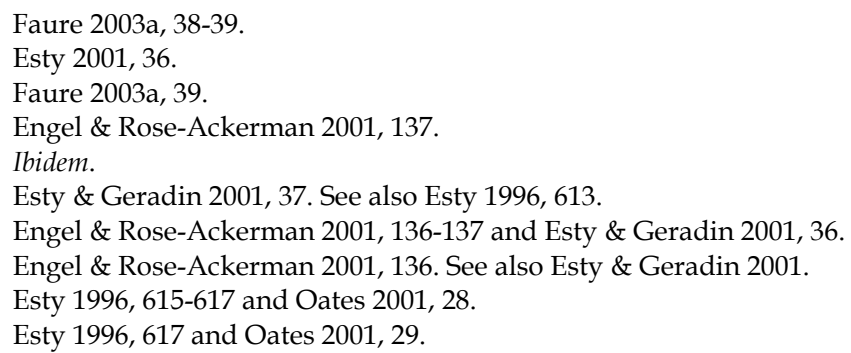


can be tailored to the specific circumstances. However, when there are common problems, centralisation of research might be encouraged in order to profit from economies of scale and expertise. Indeed, as Esty rightly states, diversity of circumstances is an argument against uniformity of standards, but not necessarily against centralisation of certain tasks. ${ }^{201}$ For example, a federal framework regulation on safety standards could be complemented with local rules, adapted to regional circumstances. Hence, a mixed policy structure could be created that would be centralised in part whereby regulatory functions as data gathering that would profit from economies of scale could be more efficiently carried out at a higher governmental level while other tasks that would require on the ground knowledge could be more appropriately dealt with at local governmental level.

Certainly, whereas data collection and data analysis would profit from centralisation and economies of scale, other tasks might be more appropriately carried out at local governmental level. For example, because of the diversity of harms that may exist, governments have to be aware of local circumstances and risks. Therefore, problem identification might preferably be done at local level as the local government is aware of local problems. ${ }^{202}$ For the same reason, implementation, enforcement and policy evaluation might be carried out by the local government to ensure that local circumstances are taken into account and decisions are taken closer to the preferences of the citizens. Moreover, citizens might have easier access to the regulating government. ${ }^{203}$ However, a clear distinction between tasks that are best carried out by the central government and other tasks that are best accomplished at the local governmental level is often not so easy to make and might also depend on specific circumstances. ${ }^{204}$

In conclusion, the economies of scale reasoning of the transboundary externality argument suggests that in order to solve the externality problem adequately, decision-making power should be entrusted to a higher regulatory level, that has a competence that is large enough to deal with the problem. Moreover, by centralisation of certain tasks like technical and scientific research, economies of scale could be reached. These findings can now be applied to regulation for environmental damage, and in particular to soil pollution.

\section{Environmental Liability}

Regulation for environmental damage is certainly a realm that requires highly technical information and where economies of scale could be reached by centralising scientific research and information. Centralisation of scientific research would benefit from economies of scale and hence would reduce the above mentioned technical transaction costs for victims to claim their rights. However, as in the general case, the promise of economies of scale in scientific research does not argue for a centralisation in an excessive sense. One could create a policy structure that would realise scale economies in the technical stage, which could be gathering data on pollution and risk assessment, without centralising other parts of the environmental policy. With respect to the soil pollution case, this could, for example, be reached by the creation of a federal institute that would gather and analyse data on soil pollution and provide scientific support for the different jurisdictions, whereas the jurisdictions would set their own standards and liability provisions. $^{205}$

It is now worthwhile to combine both strands of the transboundary externality argument in order to answer the question whether (a certain level of) centralisation of liability rules for environmental damage would be justified according to the transboundary externality argument.

\subsubsection{Federal Regulation for Transboundary Environmental Damage Only}

The first strand of the transboundary externality argument concentrates on the internalisation of transboundary spillovers through centralisation. It is not much disputed that externalities need to be corrected through some form of interjurisdictional collaboration. ${ }^{206}$ However, as Esty and Geradin indicate, the importance of transboundary spillovers may vary from one field of regulation to another. In some fields spillovers are rare, whereas other fields of regulation are likely to create transboundary externalities. This clearly has significant implications for how to deal with the existing transboundary externalities. Some fields of regulation might require broad interjurisdictional cooperation, whereas spillovers in other domains might be solved by Coasean bargaining and much more emphasis can be placed on regulatory

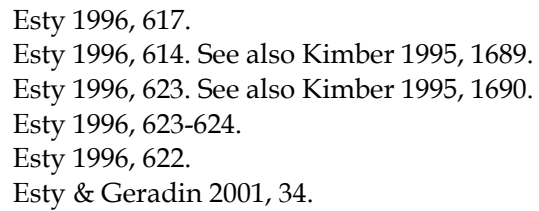


competition and decentralised decision-making. ${ }^{207}$ Yet, in any case, the presence of transboundary spillovers does not automatically justify a far-reaching harmonisation or even centralisation of regulation or liability rules. Indeed, several scholars suggest that centralisation of regulation or liability rules should be limited and targeted to the transboundary externalities and they certainly argue against total harmonisation. ${ }^{208}$ Total harmonisation might not take local circumstances into account and might even be counterproductive. Indeed, in the case of torts, the transboundary externality argument provides no justification for harmonisation of tort law that merely deals with in-state torts.

This result might, however, be complemented by the second strand of the argument. It is suggested that in order to solve an externality problem adequately, it might be necessary to entrust decision-making power to a higher regulatory level that has a competence large enough to deal with the problem. Moreover, centralisation of certain tasks, like technical and scientific research, would generate economies of scale. This reasoning appears to be a bit more lenient towards centralisation of certain tasks, not only in solving transboundary spillovers but also solving problems that are common over different jurisdictions. Indeed, the reasoning suggests that jurisdictions might profit from the centralisation of certain tasks or from some guiding framework developed by the central government. It must be clear, however, that the centralisation of certain tasks or the development of a guiding framework does not equal, and should not justify, harmonisation and fixed uniform standards. The central government might set minimum standards ensuring that all parties meet a basic level of protection in a certain field of regulation. For some jurisdictions, these baseline standards may be the most appropriate endpoint for that particular policy given their level of available resources and other local circumstances. In other jurisdictions, a higher level of economic development and/or a greater public preference for a certain regulation might plead for more stringent standards. ${ }^{209}$ Ultimately, the fact that differing local circumstances and preferences have to be taken into account, does not argue for decentralised regulation without co-operation, but for flexible regulatory policies and strategies. Likewise, the promise of economies of scale in scientific research does not argue for centralisation in an excessive sense. One could create a policy structure that would realise scale economies in the technical stage of the regulatory process without centralising other parts of the regulatory policy. This could, for example, be reached by the creation of a federal institute that would gather and analyse technical data and provide scientific support for the different jurisdictions, but whereby these jurisdictions would set their own standards. ${ }^{210}$

Hence, the transboundary externality argument would allow for a mixed system that would benefit from the merits/expertise of both governmental levels, but would not justify excessive centralisation or harmonisation. Instead, in order to take local circumstances into account, centralised regulation or liability rules for transboundary externalities only could be preferred.

When both strands of the transboundary externality argument are applied to soil pollution in particular, the following conclusion could be made on the optimal level of liability rules for soil pollution in a federal system, according to the transboundary externality argument.

Soil pollution will mostly be a local problem; moreover, the causes and consequences of this pollution can vary significantly within a jurisdiction and between jurisdictions. In these circumstances, regulation tailored to local needs and preferences seems appropriate. Harmonisation of regulation or liability rules for soil pollution in a federal system as a remedy for the case that soil pollution would spill over to neighbouring jurisdictions and is, therefore, not justifiable as differences in circumstances and preferences can not be taken into account. However, the choice does not have to be between fully decentralised or fully centralised liability rules. It is certainly possible to develop a centralised regime dealing with transboundary damage only, or with transboundary damage and damage to areas that are of special interest because of their fauna and flora. Furthermore, economies of scale in technical research might plead for co-operation or centralisation in that part of regulation. Moreover, depending on the willingness of the states, a mixed system might be considered, whereby the federal state would set minimum standards, to ensure that a basic environmental quality would be guaranteed to every citizen, whereby the different jurisdictions could go further, and whereby they would take care of the implementation and enforcement of the liability rules. Such a solution would optimise both the scale of standards and the scale of institutions. ${ }^{211}$ Or one might think of special provisions for area's of special interest, and develop a system of solidarity within the federal system in case of serious pollution of the area of special interest, or foresee in a special federal funding for these accidents.

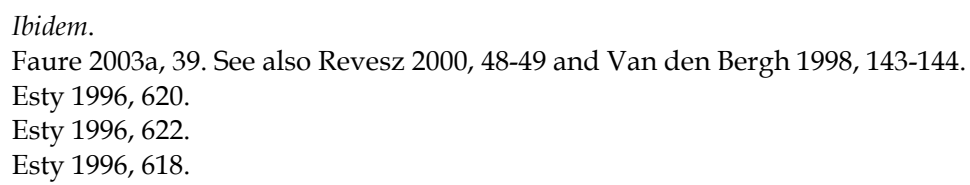


Summarising, with respect to the nature of soil pollution, full centralisation or harmonisation of regulation or liability rules for soil pollution would not be justifiable as it would not take diverse causes, circumstances and preferences into account. Therefore, central regulation of liability rules for soil pollution might preferably go no further than a kind of transboundary - special areas only regime to remedy transboundary soil pollution. This might, however, be completed with centralisation of supporting scientific research and data analysis, as all states and citizens would benefit from it.

This paragraph has tried to provide some understanding on the optimal level of liability rules for environmental damage, with soil pollution as an example, according to the transboundary externality argumentation. The next argument for centralisation that will be discussed is the race-to-the-bottom argument.

\subsubsection{Race-to-the-Bottom Argument}

The race-to-the-bottom rationale might be the most heavily debated economic argument to justify federal environmental liability rules. The argumentation will be explained in three steps. First, a general definition of the race-to-the-bottom will be provided and theoretical foundations will explained. Next, the risk of a race-to-the-bottom in environmental regulation can be discussed. Theoretical grounds as well as empirical evidence of the existence of a race-to-the-bottom in environmental regulation will be analysed. The findings of this analysis might then be further refined for environmental liability and liability for soil pollution in particular. The theoretical grounds that might exist for environmental regulation in general, can indeed be applied to environmental liability as well. Furthermore, it will be examined whether empirical evidence of relaxed liability rules, specifically for soil pollution, in order to attract industry, might be available. The risk of a race-to-the-bottom in environmental liability rules, and in liability rules for soil pollution in particular, can then be assessed, in order to answer the question whether the race-to-the-bottom argument is a valid argument for justifying federal intervention with respect to environmental liability rules.

\subsubsection{Definition of a Race-to-the-bottom}

The term race-to-the-bottom refers to an ongoing relaxation of state regulatory standards, caused by interstate competition to attract industry. This relaxation of regulatory standards would result in a reduction of social welfare below the social welfare level that would exist in absence of this race. ${ }^{212}$ If there is a risk that such destructive competition would arise, centralised standard setting might be advanced as a remedy to prevent states from engaging in this welfare-reducing race-to-the-bottom.

The race-to-the-bottom argument is sometimes confused with the creation of a 'level playing field', especially in the European Union. Indeed, federal regulations enacted under a race-to-the-bottom rationale might, in reality, aim at creating a 'level playing field', or the harmonisation of conditions of competition between states. ${ }^{213}$ In such cases, the aim is much more the reduction of interstate competition and the significance of geographic features that would allow certain states to have lower quality standards, than to actually overcome a race-to-the-bottom as defined above. The prevention of lower quality standards is not the same though as the prevention of a race-to-the-bottom. Lower quality standards - in the sense of lower than average - , could be efficient more particularly when they correspond with citizens' preferences. Moreover, preventing states from using their geographic and other location specific advantages might reduce economic efficiency as it is exactly this geographic diversity that allows gains from trade. ${ }^{214} \mathrm{~A}$ raceto-the-bottom, on the other hand, would result in economic inefficiency, which needs to be remedied. Therefore, the 'level playing field' argumentation to justify centralised regulation is criticised by various scholars. ${ }^{215}$

The 'level playing field' argumentation will be taken up again in the next paragraph on market access. This paragraph will concentrate on the race-to-the-bottom argument.

Scholars have based the race-to-the-bottom theory upon non co-operative game theoretical models, of which the Prisoner's Dilemma may be the best known example. ${ }^{216}$ The Prisoner's Dilemma refers to a situation in which individual welfare maximising behaviour might lead to an outcome that is socially suboptimal, whereas with co-operation all parties would have been better off. A well-known illustration of the Prisoner's Dilemma is the example whereby two prisoners, who committed a crime, each face the same two choices. They can co-operate with each other and both deny any commitment in that crime or they can

Engel 1997, 274.

Faure 2003a, 47-48 and 51-53. See also Van den Bergh 2000, 87.

Engel 1997, 293-295.

See for example Revesz 1992, 1210-1254 and other articles. See also the contributions of Faure, M. and Van den Bergh, R.

Baird, Gertner \& Picker 1998. See also Engel 1997, 274 and Esty 1998, 16. 
confess the crime. If both deny, they will get a light sentence. If both confess, they will get a sentence of medium severity, but if one prisoner confesses and the other did not, the one who confessed will be released, whereas the other prisoner will get a severe sentence. The prisoners will have to make their choice without knowing the other's choice. The result is that, although both would have been better off if they would have denied the crime, following individual self-interest, both will confess and get a medium sentence instead of a light one. ${ }^{217}$

Game theory and the Prisoners' Dilemma were applied to public goods for the first time by Mancur Olson and in the Tragedy of the Commons Garrett Hardin applied the game-theoretical approach specifically to the environment. ${ }^{218}$ The game-theoretical approach suggests that states might behave to attract industry strategically, which might result in a race-to-the-bottom. Indeed, although states would be best off if they would co-operate and agree on optimal regulatory standards, states may, to attract industry, relax regulatory standards to reduce the regulatory burden they impose on industry. Hence, a prisoner's dilemma might arise and this bid for industry could result in a downward pressure on regulatory standards. ${ }^{219}$ Therefore, centralisation is advanced to prevent states from engaging in a welfare-reducing race-to-the-bottom.

Based on the neoclassical model developed by Oates and Schwab, however, opponents of the race-tothe-bottom theory, like Revesz, argue that interstate competition would lead to efficiency and would be welfare-enhancing. ${ }^{220}$ It is not claimed though that states will not lower their standards, only that this behaviour might be welfare-enhancing. 221

This neoclassical approach stands in contrast to the game-theoretical approach, according to which the same behaviour would lead to the opposite result: suboptimal low regulatory standards and reduced social welfare.

The different outcome can be explained by a different assumption that is made. Both approaches assume that individuals are rational and have ordered preferences over their needs. Additionally, both assume that the fulfilment of individual preferences yields 'utility' and that individuals try to maximise their utility. However, the difference that might account for the opposed result is that the neoclassical approach assumes that individuals cannot influence the results of the market and hence that rational pursuit of individuals' self-interest would result in welfare maximisation. Game theory assumes that, under specific circumstances, like a small number of actors, these actors could make a difference in market results, behave strategically, and therefore rational pursuit of their self-interest might not result in welfaremaximisation for society as a whole. ${ }^{222}$

This raises the question which theoretical approach might best reflect actual behaviour of industry and governments where environmental regulation is concerned and hence, whether a risk of a race-to-thebottom could exist in environmental regulation.

The next paragraph will, in a first step, analyse whether the game-theoretical approach or the neoclassical approach would theoretically reflect the real world situation best where environmental regulation is concerned. Second, it will be examined whether empirical evidence can be found of the existence of a race-to-the-bottom in environmental regulation. The findings from this analysis will then be used as a basis for further refinement in an application to environmental liability rules. Accordingly, it can be studied whether differences in liability rules for soil pollution could lead to a race to the bottom, justifying federal intervention.

\subsubsection{Risk of a Race-to-the-bottom for Environmental Regulation}

\section{Theoretical Grounds for a Race-to-the-bottom in Environmental Regulation}

If differences in environmental standards, and thus differences in environmental costs, would induce firms to relocate to states with the lowest environmental standards, a race-to-the-bottom, which in environmental cases is referred to as the 'pollution haven' hypothesis, might occur. ${ }^{223}$ In such circumstances, there might be an economic argument for centralisation. Various scholars have tried to prove the existence or the absence of a race-to-the-bottom in environmental regulations both theoretically and empirically.

217 Baird, Gertner \& Picker 1998. See for example also Engel 1997, 301.

218 See Olson 1971 and Hardin 1968. See also Engel 1997, 298.

219 Adler 2001, 223-224.

220 Revesz 1992, 1210-1254.

221 Revesz 1992, 1219, stating 'that a race-to-the-bottom requires not just the existence of a race, but also that the race be "to the bottom"'".

222 Engel 1997, 300.

223 Faure 2003a, 48 . 
Nevertheless, the results vary and the existence of a race-to-the-bottom in environmental regulations remains debated.

The divergence of opinions concerning the existence of a race-to-the-bottom is owing to the different view of various scholars on the functioning of the environmental regulatory process. The neo-classical approach supposes that the environmental regulatory process resembles a market of perfect competition, whereas adherents of the game-theoretical approach assume that there is imperfect competition between regulators. Therefore, the basic question is whether the environmental regulatory process resembles a market of perfect competition, so that regulatory competition would be welfare-enhancing, which is Revesz' opinion, or whether states might act strategically, so that regulatory competition could result in a race-to-the-bottom and reduce welfare, a view that is shared, for instance, by Engel and Esty. ${ }^{224}$

Relying on the neoclassical model of perfect competition developed by Oates and Schwab, ${ }^{225}$ Revesz suggests that the market for environmental regulation is comparable to a perfectly competitive market. Hence, interjurisdictional competition would lead to maximised social welfare instead of a race-to-thebottom. ${ }^{226}$ In the Oates and Schwab model jurisdictions can compete for mobile capital, choosing either or both of two mechanisms: low taxes or lax environmental standards. It is assumed that the rate of return to capital in equilibrium is constant. Oates and Schwab conclude that, under the restrictions of the model, interjurisdictional competition would yield welfare-maximising environmental standards. ${ }^{227}$ Indeed, a rational government would set a tax rate of zero on capital, which would be the rate that exactly covers the costs of public services provided to the capital, like roads or police protection. The government would then achieve a welfare-maximising environmental policy by reducing pollution until the gains from reduced pollution damage would be equal to lost wage income. ${ }^{228}$ Hence, there would be no race-to-the-bottom in state environmental standard setting. ${ }^{229}$

Based on the game-theoretical approach, however, it is possible to show that, given certain conditions of interstate competition, a race-to-the-bottom might enter into existence. By means of a simple gametheoretical mathematical model Engel illustrated that an island jurisdiction will set standards so that social welfare is maximised. However, in a two-state world, states face the choice of whether to alter (relax) their environmental standards or keep them unchanged. The dilemma arises if a state can attract some industry from the other state by relaxing its environmental standards. If the state relaxes its environmental standards industry will produce more pollution but also more products and economic benefits. Both states will then be subject to a Prisoner's Dilemma and choose to relax standards unless there is a mechanism, like federal intervention, to ensure that optimal environmental standards will be set. Hence, based on the gametheoretical approach and the Prisoner's Dilemma, interjurisdictional competition might result in a race-tothe-bottom, which might be remedied by federal minimum standards. ${ }^{230}$

Nevertheless, Revesz indicates that game-theoretical interactions might also lead to overregulation instead of underregulation. ${ }^{231}$ This might be the case if certain states do not want to have certain industry, known as the 'not in my backyard' (NIMBY) phenomenon. ${ }^{232}$ In that case, federal intervention would require maximum standards instead of minimum standards. Hence, according to Revesz, even if there would be imperfect competition, there would be no clear reason for a race-to-the-bottom, and hence the race-to-the-bottom argument would not be a convincing justification for federal minimum environmental standards.

It appears from the results of both approaches, that the theoretical existence of a race-to-the-bottom for environmental regulation depends crucially on the assumptions that are made concerning states' ability to influence the market (which depends on the number of states that are participating), the taxes and subsidies that are available and what types of market imperfection might exist. Different scholars use different assumptions on the influence of taxes and market imperfections, or place different emphases, which might lead them to reach a different result.

Esty 1996, 630 and Engel 1997, 307.

Oates \& Schwab 1988, 333-354.

Revesz 2000, 41-45.

Oates \& Schwab 1988, 350.

In general, for efficiency, a firm should pay a tax equal to the costs of its operations (environmental costs, public services) for that jurisdiction. If the taxes are higher than those costs, a jurisdiction has an incentive to compensate this by, for example, lowering environmental standards, which might result in a race to the bottom. Indeed, also in the Oates and Schab model, a race-to-the-bottom might occur if capital is taxed at a positive rate, whereas the optimal rate is zero. On the other hand, if capital if taxed inefficiently low, there might be a race-to-the-top. See Wilson 1997, 394-395, 424-425.

229 Revesz 2001a, 4.

230 See Engel 1997, 302-305.

231 Revesz 2001a, 5. See also Markusen, Morey \& Olewiler 1995.

232 Wilson 1997, 394-395, 424-425. 
The game-theoretical approach supposes that there are only a few number of states involved, while in the Oates and Schwab model, the number of states is unspecified, but presumably large. It is indeed the assumption of a large number of states that allows the rate of return to capital in equilibrium to be treated as constant. The importance of this assumption can be demonstrated by the following example. Consider a state, willing to attract foreign capital by lowering its environmental standards. In the Oates and Schwab model, the number of other states from which this capital comes is so large, that only a very small amount comes from every other state. Put differently, the loss of capital is so much spread, that no state can notice it. Hence a state will not be affected by any other state's regulatory decisions and no race-to-the-bottom will follow. The efficient outcome of the Oates and Schwab model therefore crucially depends on this assumption. If the number of states is 'small', an efficient outcome can no longer be predicted by the Oates and Schwab model and it might be necessary to apply game theory. Therefore, to conclude that interstate competition would result in efficient environmental standards at least two sets of conditions must be fulfilled in the real world: the number of participants must be large and their relative market power small. ${ }^{233}$

It still remains unanswered which theoretical approach now best reflects the real world for environmental regulation and thus whether a race-to-the-bottom for environmental regulation might come into existence. As appears from above, a theoretical proof that points clearly in the one or the other direction for a race to the bottom in environmental regulation is hard to give.

Therefore, as it is not possible to proof the validity of the race-to-the-bottom argument in case of environmental regulation on theoretical grounds alone, it merits studying the surveys that were undertaken to find empirical evidence of pollution havens.

\section{Empirical Evidence of Pollution Havens}

Evidence of a race-to-the-bottom in environmental regulation cannot be found that easily. Indeed, evidence might be scattered and hard to discover. Nevertheless, there are different indicators that may point to the existence of or a risk of pollution havens. Indeed, in order to find evidence of the existence of pollution havens, three relevant empirical aspects might be analysed. A first indicator that might point to a risk of a race-to-the-bottom in environmental regulation might be the relative power of industry versus states, as this might indicate that there is no perfect competition and market distortions could arise. Furthermore, a second aspect that is important to analyse, is whether industry would respond to the lowering of environmental standards by industry location decisions. Finally, regardless of industry response, it is worthwhile to examine the willingness of states to engage in strategic interactions in order to attract industry and thus whether states would compete for industry by lowering their environmental standards. ${ }^{234}$

\section{A. Relative Power of Industry versus States}

First, the relative power of industry and states could be an indication that a risk of destructive competition could exist, as it would give information on whether the market for environmental regulation resembles perfect competition or whether it is distorted. Engel suggests that competition between states for industry is higher than the competition between firms for sites for new industrial plants. Hence, industry might have a bargaining advantage. Engel furthermore claims that the demand for new or relocating plants is high relative to supply. Moreover, the number of states competing against each other for (large) firms would be small. Indeed, Engel could show in her survey that government officials, competent for state environmental standard setting, were most familiar with the environmental regulation in neighbouring states, and much less with standards from countries further away. This result could indicate that, if states would compete with other states for industry, they would compete only against a few neighbouring states. Esty is, moreover, also critical of the rationality of governments and doubts that the market for locational rights would be undistorted, and that no prisoner's dilemma could occur. ${ }^{235}$ These findings might suggest that the market for environmental regulations bears more resemblance to the game-theoretic approach, which does not exclude a race-to-the-bottom happening in environmental regulation, than to the neo-classical approach. ${ }^{236}$

Nevertheless, an indication of the relative power of industry versus states is, of course, insufficient to formulate a conclusion concerning the existence of pollution havens. A second indicator that has to be

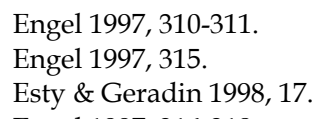


examined is whether environmental standards would influence industry location decisions. Indeed, a commonly used justification for centralised regulation to prevent a race-to-the-bottom in environmental regulation is that the stringency of environmental standards would be an important determinant of industry location. ${ }^{237}$

\section{B. Determinants of Industry Location Decisions}

Several scholars studied the determinants of industry location in order to find evidence that industry would locate in states with the lowest environmental standards. Studies that examine the influence of environmental regulation on firm location decisions use three different methods: (1) surveys of industry executives competent for deciding on plant locations; (2) aggregate studies that compare aggregate measures of economic activity, like economic growth, with aggregate measures of environmental regulatory stringency, which might be indicated by the number of environmental laws adopted. These studies try to link environmental regulatory stringency and a location's overall economic performance; (3) so called 'establishment-level' studies, which correlate new plant sites with economic activity indicators and measures of environmental stringency. 238

Despite much effort, empirical evidence of relocation of industry because of stringent environmental regulation is rather weak.239 Based on an extensive survey of existing location studies, ${ }^{240}$ Jaffe/Peterson/Portney/Stavins conclude that the effect of environmental regulation on industry location decisions is either small or statistically insignificant. ${ }^{241}$ Nevertheless, they add to their conclusion that, although the stringency of environmental regulations will not induce existing firms to relocate, it might influence decisions for new plant locations. ${ }^{242}$ This finding can be explained by the fact that other factors such as tax levels, public services, proximity to markets and raw materials, availability of transportation networks and the unionisation of labour force are much more important determinants of competitiveness. Environmental regulation appears to be only a minor determinant in industry location decisions. ${ }^{243}$ The Jaffe/Peterson/Portney/Stavins survey, however, has been refined somewhat by the study of Xing and Kolstad. ${ }^{244}$ Xing and Kolstad found that lenient environmental regulations may indeed be a significant determinant for foreign direct investment of heavily polluting industries, using chemicals and primary metals. However, conforming to the Jaffe/Peterson/Portney/Stavins study, lenient environmental regulations are insignificant for less polluting industries.

Although the Xing/Kolstad study seems to revise the results of Jaffe/Peterson/Portney/Stavins for heavily polluting industries, it does not contradict their findings that existing firms will not relocate because of stringent environmental regulations. ${ }^{245}$ Several authors indicate, moreover, that multinational corporations, doing business in various jurisdictions, might choose to meet the most stringent standards, because of cost efficiency reasons. Indeed, by doing so, they might use the same production process for each location and have a single company-wide environmental management system. Ogus further indicates that international firms might benefit from these stringent standards as they might induce technical innovation, whereby these firms would gain a comparative advantage over competitors. ${ }^{246}$ Therefore, multinational corporations might be insensitive to local environmental regulations. ${ }^{247}$

Based on these studies some scholars, Revesz in particular, argue that there is no support for a race-tothe-bottom in environmental regulation. ${ }^{248}$ However, to subscribe to the position that there is no support for a race-to-the-bottom seems a little premature, as the behaviour of the states themselves as a third indicator for a risk of a race-to-the-bottom still has to be examined.

\section{Willingness of States to Engage in Strategic Interactions}

A third indicator for the existence of, or a risk of a race-to-the-bottom, might be the willingness of states to engage in strategic interactions or, put differently, whether states would seek to relax their environmental standards to attract or retain industry. In order to study this third indicator empirically, Engel conducted a

Engel 1997, 321.

Engel 1997, 322-323.

Faure 2003a, 48. See also Gray 2002, 307-309.

See for example Bartik 1988, 22-44; McConnell \& Schwab 1990, 67-81; Friedman, Gerlowski \& Silberman 1992, 403-418; Levinson 1992 and Low \& Yeats 1992.

Jaffe, Peterson, Portney \&, Stavins 1995, 157-158

Jaffe, Peterson, Portney \& Stavins 1995, 148.

Jaffe, Peterson, Portney \& Stavins 1995, 157-158.

Xing \& Kolstad 1995, 16-95.

Revesz 2001a, 5. See also Faure 2003a, 48

Ogus 1999, 415. See also Bhagwati \& Srinivasan 1996, 171-172.

Esty \& Geradin 1998, 13 and Levinson 1997, 451.

Revesz 2000, 46. 
survey of five separate groups of respondents who were influential in the decision-making process of a state's environmental standards. ${ }^{249}$ In contrast to the studies referred to above, which concentrated mainly on industry behaviour and the importance of environmental standards in industry location decisions, this survey tried to examine state officials behaviour in environmental standards setting. It was examined whether officials were concerned that industry might relocate to another state and whether this had ever played a role in decision-making on environmental matters. Indeed, states might still believe that, besides lucrative packages and compensations like subsidies and low-interest loans, they can compete for industry through relaxed environmental standards, even if in reality industry would not relocate because of these lenient environmental standards. Hence, a welfare-reducing race-to-the-bottom could arise, as lax environmental standards would not be compensated by increased economic activity. ${ }^{250}$

Engel suggests, on the basis of the survey, that many states are indeed concerned about industry relocation and that this concern could at times influence their policies towards protection of the environment and their policies for environmental quality standards. This does not necessarily mean that states would actually relax their environmental standards. Indeed, as Esty and Geradin claim, probably the most important risk of regulatory competition might be a 'political drag' or a 'regulatory chill'. ${ }^{251}$ This would mean that state officials, fearing industry relocation, would - instead of lowering their standards under political pressure not adopt, raise, implement or effectively enforce environmental standards. It might be very difficult to prove the existence of a political drag though. Indeed, it might be very hard 'to hear a bell that does not ring' ${ }^{252}$ Further research in the field might therefore be appropriate. Furthermore, the private interest section will hopefully shed some light on lobbying practices and the pressure that officials, competent for environmental standards setting, might face.

Using a game-theoretical approach, however, Bommer tried to reveal how a situation of 'regulatory chill' might come to existence. Bommer could show that, under certain circumstances, industries might relocate part of their production to states with lower environmental standards for strategic reasons, rather than due to a real loss in competitiveness caused by stringent environmental standards. Indeed, in a situation in which states have incomplete information about the capability of industry to adapt to stringent environmental standards, under certain assumptions, industries might signal difficulties to adapt to high standards by relocating part of their production. This could incite states to refrain from raising their environmental standards or even from strict enforcement of environmental standards. ${ }^{253}$ In such circumstances, it might therefore be possible that state officials, responsible for environmental standards setting, are under political pressure not to raise or effectively enforce environmental standards. Therefore, if states are concerned with industry relocation, and if this concern might influence their policies towards environmental quality, it might be possible that destructive competition or even a race-to-the-bottom might arise in environmental regulation.

However, to declare that states will lower their environmental standards as a result of interstate competition is premature as well. Indeed, there exists some evidence that states may actually strive for stringent environmental standards, even if this would put extra costs on their industries. ${ }^{254}$ This finding weakens somewhat the claim that states would engage in a race-to-the-bottom as far as environmental standards are concerned. Some countries may in fact be more involved in a race-to-the-top than a race-tothe-bottom. ${ }^{255}$ Indeed, as Vogel explains, international competition and capital mobility might actually encourage states to adopt higher environmental standards than they would have done without this competition. ${ }^{256}$ There are two main reasons that might explain phenomenon.

Firstly, stringent domestic environmental standards might offer market opportunities to firms that export pollution-control equipment and trigger innovation. For example, as a result of their own strict emission limits for coal burning power plants, Germany and Japan succeeded in dominating the world market in scrubbers. Secondly, and although disapproved by the GATT, a state could, through stringent environmental regulations, make it more difficult for foreign producers to sell their products, as they might not fulfil all environmental requirements. This would give a competitive advantage to domestic industry. ${ }^{257}$

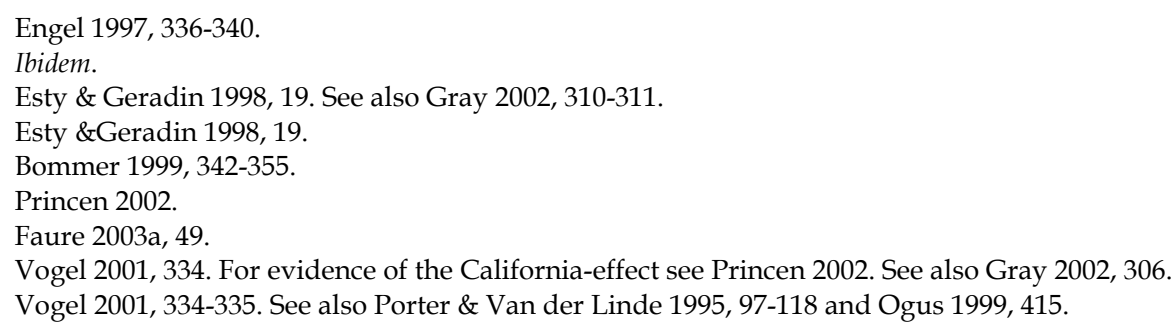


Hence, for a number of environmental regulations, a phenomenon, defined by Vogel as the Californiaeffect, could be noticed. ${ }^{258}$ In general terms, the California-effect is used to describe the upward ratcheting of regulatory standards when economically powerful nations with stringent standards can force producers from other states with lower standards to adopt these strict standards, in order to maintain market access. ${ }^{259}$ For environmental standards, this would mean that stringent environmental (product) standards of a certain state would encourage producers of other states and eventually other states themselves, to adopt these higher standards to be able to sell their products in this important market. The term 'California-effect' refers to the upward ratcheting of US automobile standards caused by California's stricter standards. The 1970 Clean Air Act Amendments gave California the permission to adopt stricter emission standards than the rest of the United States. Other states could choose to adopt the national standards or the stricter California standards. It appeared that several states adopted the stricter California standards. Hence, in the case of automobile emission standards, a downward pressure on emission standards did not occur, in fact precisely the opposite happened. The explanation is that, as California is a very important market, automobile producers had strong incentives to comply with the stringent emission standards, in order to be able to sell their cars. Hence, other states could impose these standards as well. Therefore, economic integration and competition might in some cases stimulate the adoption of more stringent environmental standards instead of resulting in a race-to-the-bottom. ${ }^{260}$

It must be noted, however, that the California effect basically holds for product standards, which regulate the environmental characteristics of a product. Yet, environmental damage is often caused by the way a product is produced. Whereas differences in product standards mainly affect market access, process standards might raise competitiveness concerns as industry in countries with lenient process standards might produce at lower costs. Mainly lenient process standards might cause states to fear industrial relocation and a race-to-the-bottom, which might result in a 'political drag'. ${ }^{261}$ Hence, in order to assess the risk of a race-to-the-bottom in environmental regulation, a distinction should be made between product and process standards.

To recapitulate, as far as the behaviour of states is concerned, the risk of a political drag should not be ignored, but, on the other hand, in some cases economic integration might even stimulate the adoption of more stringent environmental standards.

\section{Synopsis of the Results of the Three Empirical Indicators}

Heaving examined the three empirical indicators that may point to an existence of or a risk of pollution havens, bringing the various results together is now merited, in order to assess the risk of a race-to-thebottom in environmental regulation. Indeed, on the basis of the empirical material that is available, some broad conclusions might be formulated.

Firstly, empirical evidence seems to indicate that regulatory competition might not always yield efficient state environmental standards. As the conditions necessary for perfect competition and the real world, where states compete for industry, can differ to a great extent, it cannot be presumed that interstate competition will always lead to efficient state environmental standards. Indeed, in some circumstances, such as if a small number of states is engaged in interstate competition and if the relative bargaining power is greater for industry than for states, then non co-operative game theory might better reflect the real world as opposed to neo-classical economics. It cannot, therefore, be excluded that states might engage in a race towards more lenient environmental standards at some point in time.

Secondly, although the market for environmental regulations might resemble the game-theoretical approach more than the neo-classical approach, industry location studies mostly conclude that industry does not respond to differences in environmental standards in a significant way, and hence no race-to-thebottom would result. Indeed, environmental regulation appears to be only a minor determinant in industry location decisions, although it must be mentioned that it might influence decisions for new plant locations or for foreign direct investment of heavily polluting industries.

Thirdly, despite the fact that industry will mostly not relocate because of the stringency of environmental standards, state officials still might believe or might be under political pressure to believe that environmental standards are an important determinant in industry location. Moreover, industry might make use of this common belief. Indeed, industry might relocate part of their production to states with lower environmental standards for strategic reasons, rather than due to a real loss in competitiveness caused by stringent environmental standards. By doing so, they might induce states to refrain from raising

\footnotetext{
258 See Vogel 1995. For evidence of the California-effect see Princen 2002.

$259 \quad$ Vogel 2001,337.

260 Vogel 2001, 336.

261 Esty \& Geradin 1997, 268-273.
} 
their environmental standards or even to neglect strict enforcement of environmental standards. A 'political drag' or 'regulatory chill' might then come into existence and environmental standards might be set at a suboptimal level. Hence, environmental damage will not be fully internalised or compensated, which might reduce social welfare. The situation might be different; however, in the case of environmental product standards, whereby a state that is economically powerful enough, can impose its standards on foreign producers, and eventually induce a race-to-the-top.

When these three results are now taken together, it appears that, despite the fact that various studies try to shed some light on the matter, empirical evidence for a race-to-the-bottom in environmental standard setting still does not point into one clear direction. Indeed, there are no strong indications that prove that a race-to-the-bottom in environmental regulation is sure to happen, neither can it be excluded that a race-tothe-bottom might happen in certain cases. Nevertheless, the finding that industry will mostly not respond to lenient environmental standards, combined with the fact that states might still believe that they can attract industry by lenient environmental standards, might indicate that the risk is probably not so much of a race-to-the-bottom but of a 'regulatory chill' or 'political drag'. This is very difficult to prove though, and might therefore need further research. In any case, the risk of a political drag in environmental regulations should not be neglected. Hence, the question that might be asked is whether federal intervention would be appropriate to prevent or overcome such a 'political drag'.

Indeed, a race-to-the-bottom or a 'political drag' - for example the lack of enforcement of environmental standards - might need to be prevented or remedied. However, this would not necessarily plead for full centralisation of all environmental standards. As Revesz indicates, even if states would use lenient environmental standards to attract industry, centralised regulation or harmonisation of environmental standards might not necessarily solve the problem. Indeed, states might compete for industry on many fronts, like labour or safety standards. Therefore, Revesz warns that, as a response to centralised environmental standards, states might reduce standards in other regulatory fields like health care or taxes, to attract industry. 262

Nevertheless, some scholars suggest that, in order to prevent a race-to-the-bottom or a regulatory chill, a limited harmonisation of environmental standards might increase social welfare. ${ }^{263}$ Engel, for example, suggests that federal minimum standards have much to recommend them, as they leave the opportunity for a state to adopt more stringent standards or to co-operate with neighbouring states and to negotiate binding agreements. This co-operation could include uniform standard-setting by a small number of states to address specific regional environmental problems. According to Engel, such an approach would prevent a race-to-the-bottom, which would lower both environmental quality and overall social welfare, and would at the same time avoid the economic inefficiencies of centralised environmental standard setting that are heavily critiqued by some scholars. ${ }^{264}$ This does not mean, however, that other proposals for enhancing the efficiency of environmental regulation should be neglected. Indeed, Esty evaluates different ways of federal intervention for which further theoretical and empirical research might be recommendable. ${ }^{265} \mathrm{In}$ any case, centralisation is not the only way to respond to a risk of a race-to-thebottom or political drag. Various responses, including different degrees of harmonisation, might reduce competitiveness tensions without hampering trade.

In conclusion, contrary to common belief, the risk of a race-to-the-bottom in environmental regulation does not justify full centralisation of environmental regulation. Indeed, although a race-to-the-bottom, or more likely a 'regulatory chill' in environmental regulation cannot be fully excluded, this would not justify full centralisation of environmental standards. States might then compete by other means and centralisation would not leave opportunities open for more stringent standards, or co-operation between states, according to states' preferences. A limited harmonisation or other proposals enhancing the efficiency of environmental regulation might be considered to prevent a regulatory chill. However, which response would be best, depends on the circumstances and the environmental problem under examination. A context-specific analysis might thus be required. Only then an optimal co-operation between the federal and state level can be found in order to prevent a race-to-the-bottom or a 'political drag' in environmental regulation.

The findings of the analysis for environmental regulation in general can now be used as a basis for further refinement, notably the risk of a race-to-the-bottom in the area of environmental liability rules. It will now be examined whether differences in liability rules for soil pollution could lead to a race-to-thebottom, justifying federal intervention in liability rules.

\footnotetext{
262 Revesz 2000, 47-48. See also Faure 2003a, 49.

263 See for example Engel 1997 and Esty \& Geradin 1998, 7.

264 Engel 1997, 280.

265 Esty \& Geradin 1998, 21-46.
} 


\subsubsection{Risk of a Race-to-the-bottom for Environmental Damage Liability}

\section{Theoretical Approach}

The findings for environmental regulation in general suggested that the market for environmental regulations might resemble the game-theoretic approach, which does not exclude the possibility of a raceto-the-bottom happening in environmental regulation, more than the neo-classical approach. However, even in this case, the risk of a race-to-the-bottom in environmental liability rules and, for example, liability for soil pollution depends mainly on the actual behaviour of industry and states. Their behaviour therefore needs to be examined in order to judge whether differences in liability rules would lead to a race-to-thebottom.

Concerning industry behaviour, as in the general case, it might be doubtful that environmental liability rules would play a significant role in attracting or repulsing industry to or from a certain state. Indeed, other factors may play a far more important role in industry location decisions, like labour regulations and taxes. ${ }^{266}$ A stringent environmental liability regime would not create barriers to trade either, as it would not affect product standards. Nevertheless, it might create higher costs for producers, as it might interact with a state's process safety standards, which is the way in which a product is produced. If a firm does not comply with the state's process standards, and damage to the environment occurs, a liability claim might follow. Hence, a stringent liability regime might result in higher production costs for industry for which process standards matter much, for a heavily polluting industry, like the chemical industry, for example. Yet, it must be examined empirically, whether industry would relocate because of a stringent environmental liability regime, eventually interacting with high costs to comply with process standards.

The same reasoning can be applied to liability rules for soil pollution. Indeed, it might be doubtful that liability rules for soil pollution would have a major impact on industry location decisions. However, as for environmental liability rules in general, stringent liability rules for soil pollution might create higher production costs for heavily polluting industry. Nevertheless, whether there is empirical evidence that industry would relocate because of stringent liability rules for soil pollution must be examined.

As far as the behaviour of states is concerned, a state could, theoretically, try to attract industry by reducing the burdens that might be imposed on industry through tort law. For example, a state might impose a higher burden of proof on the victims of environmental damage or a state might require a clear cause-damage relationship. Alternatively, a state might neglect the enforcement of its environmental quality standards. ${ }^{267}$ This behaviour would be difficult to detect and to prove however. A kind of political drag would then exist. The same reasoning could apply to liability rules for soil pollution. A state might indeed impose a higher burden of proof on the victims of soil pollution, or neglect the enforcement of its soil quality standards. Nevertheless, Faure suggests that if environmental liability rules were to have an effect, a race-to-the-top would be more likely than a race-to-the-bottom. Indeed, a lenient environmental liability regulation would limit a state's possibilities of claiming restoration for environmental damage caused by (foreign) industry. In the case of soil pollution, lenient liability rules for soil pollution might mean that industry will not have to pay for the restoration of polluted soil. Therefore, a lax liability regime could be counter to a state's interests. ${ }^{268}$ It might be examined whether a race-to-the-top in liability rules is more likely, provided that enforcement is ensured.

In conclusion, it can be stated that, theoretically, it seems doubtful that a race-to-the-bottom in environmental liability rules would occur. On the one hand, there are more important factors that influence industry location decisions than environmental liability rules, and on the other, states would derive no advantage from a lenient liability regime. Nevertheless, political pressure and risk of a political drag should not be ignored either in the case of environmental liability rules.

Although it seems doubtful, theoretically, that a race-to-the-bottom in environmental liability rules would occur, an examination of whether there is evidence of relaxed environmental liability rules is merited in order to formulate an overall conclusion on the risk of a race-to-the-bottom in environmental liability.

\footnotetext{
Ackerman 1996, 459 and Faure 2003a, 49.

Ackerman 1996, 429-463.

Faure 2003a, 49 .
} 


\section{Empirical evidence}

There are no surveys that explicitly examine the influence of a liability regime on industry location decisions. However, based on the reasoning above, it seems doubtful that evidence would be found that tort law, in casu, liability rules for soil pollution, would play a significant role in attracting or repulsing industry to or from a certain state.

Indeed, other factors may play a far more important role in industry location decisions, such as labour regulations, taxes and the availability of raw materials. Moreover, there exists some evidence that multinational corporations might decide to apply even more stringent standards than local standards, either because of consumer pressure, called by Esty 'green demand' in industrialised nations, or to avoid potential liability. Levinson describes this as the Bhopal-effect, after the Union Carbide accident in Bhopal, India in 1984. ${ }^{269}$ Therefore, from industry's side, even based on empirical evidence, it seems doubtful that industry, and certainly multinationals, would relocate because of lenient liability rules in other countries. The same reasoning might hold for soil pollution liability.

Nor is there any evidence of relaxed regulation on the side of governments. However, it might be possible that state officials believe, or are under political pressure to believe, that a stringent liability regime, like stringent liability rules for soil pollution, might repulse industry from locating in that state. Hence, they might fail to adopt stringent (soil) quality standards and a stringent liability regime or neglect the enforcement of this regime. Further research in this area could provide more information on government behaviour. The private interest section will, hopefully, shed some light on lobbying practices and the pressure that officials, responsible for environmental liability, or liability rules for soil pollution, might face. Nevertheless, it is doubtful that states, European, for example, would engage in a game in which they would strive for a low level of environmental liability or liability for soil pollution and renounce restoration claims in order to attract industry.

In conclusion, it seems doubtful, maybe even more than for environmental regulation in general, that a race-to-the-bottom in environmental liability regulation, including liability for soil pollution, would happen. The risk of a 'regulatory chill' might require further examination though. However, even in that case, this would not justify full centralisation of environmental liability regulation. Some scholars even doubt whether any federal intervention in environmental liability rules, like minimum requirements, would be necessary. Indeed, other solutions for enhancing the efficiency of environmental liability rules should be examined as well.

Nevertheless, federal intervention in environmental liability rules, including liability rules for soil pollution, might be necessary for other purposes than the prevention of a race-to-the-bottom. Hence, even if the existence of a race-to-the-bottom is doubtful, federal intervention might still be justified due to other reasons.

\subsubsection{Market Access Argument}

Market access presents another frequently advanced argument for the harmonisation of environmental rules. For a long time, trade liberalisation and environmental protection policies have moved along separate tracks. Nowadays, trade liberalisation and environmental protection increasingly intersect. Notably, free trade advocates fear that environmental regulations might be used as a justification for protectionism, whereas environmental organisations fear that trade liberalisation might prevent governments from pursuing domestic environmental policy objectives. Yet, free trade and a healthy environment both contribute to social welfare, and therefore neither should be pursued at the expense of the other. ${ }^{270}$ Hence, the increasing interdependence of world economies and the intersection of free trade with environmental policies have become an important aspect of the debate on the optimal level of environmental regulation in a multi-jurisdictional system. ${ }^{271}$

This paragraph will first examine whether harmonisation of environmental regulation would be justified in order to ease the tensions created by the differences in the stringency of environmental regulations of various jurisdictions. Whether harmonisation of environmental liability in particular be justified in order to avoid trade distortions and to improve access to foreign markets will then be examined. The argument will consist of two strands, 'harmonisation of marketing conditions' and 'reduction of transaction costs through harmonisation of legal rules', which will both firstly be examined for

Esty \& Geradin 1998, 13 and Levinson 1997, 451.

Esty \& Geradin 1997, 266-267.

Stewart 2000, 13 
environmental regulation in general, and secondly, for environmental liability rules, including liability rules for soil pollution.

The 'harmonisation of marketing conditions' reasoning concentrates on the trade distortions that could arise from the differences in the stringency of environmental regulations. Therefore, the harmonisation of marketing conditions reasoning is closely linked to the race-to-the-bottom argument. In a first step, concerns of both free trade advocates and environmentalists will be described and the relationship between environmental regulation and international competitiveness will be clarified. Then, the position of the WTO on the use of unilateral trade measures against harmful environmental products or processes will be briefly explained. The general case of how conflicts between free trade and environmental protection might be alleviated will then be studied. Therefore, whether harmonisation of environmental regulation would indeed prevent trade distortions and improve market access will be examined. However, various other policy responses, that might be used to address these concerns, will also be evaluated. ${ }^{272}$ Accordingly, the reasoning can be applied to harmonisation of environmental liability and in particular to liability rules for soil pollution.

The 'reduction of transaction costs through harmonisation of legal rules' reasoning concentrates on the reduction in transaction costs that could be achieved through the harmonisation of legal rules. This would then improve market access. Whether transaction costs savings would indeed be a reason for harmonisation of legal rules will first be examined in general. In a second stage, the reasoning will be applied to environmental liability and in particular to liability rules for soil pollution.

\subsubsection{A Level Playing Field through Centralisation of Environmental Liability}

\section{General Case: Harmonisation of Marketing Conditions}

It is sometimes argued that different levels in the stringency of safety regulations, like environmental regulation, might cause trade distortions and hamper access to foreign markets. ${ }^{273}$ Harmonisation of legal rules would create a 'level playing field' and ease the various competitiveness concerns arising from the intersection of trade liberalisation and safety regulations, such as environmental protection policies. ${ }^{274}$

Firstly, the concerns of both free trade advocates and environmental organisations with respect to market access will be presented. Secondly, the position of the World Trade Organisation (WTO) concerning unilateral trade measures will be explained. Thirdly, the arguments for a harmonisation of marketing conditions will be analysed, and it will be discussed whether this would justify a harmonised environmental regulation. Finally, the argumentation will be applied to environmental liability.

\section{A. Concerns}

This paragraph will spell out the different concerns, firstly of free trade advocates, and secondly of environmental organisations.

The concerns of free trade advocates are related both to environmental product standards, which would hamper market access, and to environmental process standards, which also touches upon competitiveness as well. 275

On the one hand, free trade advocates worry that environmental protection could be used as a justification for trade barriers. In principle, free trade regimes, like the WTO, recognise the right of jurisdictions to protect their citizens against harmful environmental, health or other safety effects of imported products, on the condition that the basic principles of national treatment, non-discrimination and most-favoured nation are respected. This would mean that both domestically produced products and imported products would be subject to the same regulatory measure. However, free trade advocates are concerned that some product-based measures that would nominally apply to both domestically produced products and imported products, in reality would impose a disproportionate burden on importers and protect domestic industry. In other words, these product standards would be disguised trade barriers. Furthermore, there is a fear that inconsistent product regulations, for example of household equipment, like toasters, washing machines, etc., might hamper economies of scale in production and distribution, increase transaction costs and reduce trade. ${ }^{276}$

\footnotetext{
272 Esty \& Geradin 1997, 265-266. See also Esty \& Geradin 1998, 5-46.

273 Esty \& Geradin 1997, 266-269.

274 Esty \& Geradin 1997, 265-266. See also Esty \& Geradin 1998, 5-46. Revesz is more critical about the 'level playing field': Revesz 2001a, 19.

275 Esty \& Geradin 1997, 268.

276 Stewart 2000, 13 and Esty \& Geradin 1997, 270.
} 
In addition to product standards, free trade advocates fear that countries might also introduce process-based trade restrictions. The considerations for introducing process-based restrictions differ from the introduction of product standards. Whereas product standards aim to protect a state's citizens from the (environmental) harmful effects of certain products, process standards try to regulate how a product has to be produced, even if this product would be produced outside the jurisdiction of the importing state. ${ }^{277}$ Competitiveness concerns are generally the ground for introducing such environmental process standards. Indeed, differences in the stringency of process standards may distort competition. Companies operating in jurisdictions with lax environmental regulation might be able to produce at lower costs than companies located in jurisdictions with stringent environmental regulation. If local conditions (strong wind, less dense population) would justify these relatively lax environmental regulations, intervention would be inefficient, as exactly these differences make gains from trade possible. Cost advantages, however, may be unfair in cases where lenient environmental rules are not based on any comparative advantage. ${ }^{278}$ Moreover, free trade advocates fear that differences in the stringency of process standards may induce industrial relocation or even a race-to-the-bottom. As discussed above, there is however, little theoretical or empirical evidence that such shifts toward pollution havens would occur. ${ }^{279}$ Nevertheless, proponents of such process-based trade restrictions argue that such measures are justified to prevent industrial relocation or a race-to-thebottom. ${ }^{280}$

Yet, both product-based and process-based trade restrictions might hamper free trade. Therefore, in order to avoid trade barriers, claims of free trade advocates arise for international harmonisation or policy convergence of environmental policies. ${ }^{281}$

Environmental organisations from their point of view fear that, through competitive pressure, trade liberalisation might weaken both their country's regulatory standards and those of their trading partners, which might also result in the lowest common denominator or in a race-to-the-bottom. Moreover, even in the absence of a race-to-the-bottom, they fear that trade agreementsmight discourage governments from pursuing domestic environmental policy objectives or adopting (more) stringent environmental standards, which was defined as a regulatory chill. ${ }^{282}$ According to environmental organisations, countries might be allowed to use trade measures to offset differences in environmental standards. Therefore, environmental organisations sometimes criticize the WTO as it rejects the use of trade controls and market access by one member, to force other members to raise environmental standards. Environmental organisations would opt for the solution that the right of market access under a trade agreement like the WTO could be linked to commitments to raise environmental standards. Hence, environmental organisations would prefer that either environmental policy would be exempted from WTO obligations, or that environmental policy objectives would be integrated in the global trade order. ${ }^{283}$

Summarising, although for different reasons, free trade advocates as well as environmental organisations plead for international harmonisation or policy convergence of various policy areas, including environmental policy, in order to avoid trade barriers, even if the effects are only 'within the border' of a jurisdiction.

Before it can be examined whether the harmonisation of environmental regulation would indeed be justified in order to ease the tensions arising from the intersection of trade liberalisation and environmental regulation, it merits briefly studying the attitude of the WTO towards the use of unilateral trade measures.

\section{B. WTO Restraints on the Use of Trade Measures}

As far as product standards are concerned, the WTO recognises the right of jurisdictions to protect their citizens against harmful environmental, health or safety effects of products, as long as these countries respect certain key principles. Indeed, the GATT/WTO agreement is built upon a number of key principles that lay down the prohibitions of certain types of trade barriers and discrimination between trading partners. The most important principles are the Most Favoured Nation principle (GATT Article I.1), the National Treatment principle (GATT Art. III) and GATT article XI: 1, which deals with prohibitions on importations. ${ }^{284}$ WTO members should not adopt measures that violate one of these principles. For instance, Member States must guarantee that the measure or policy applies equally to imported and

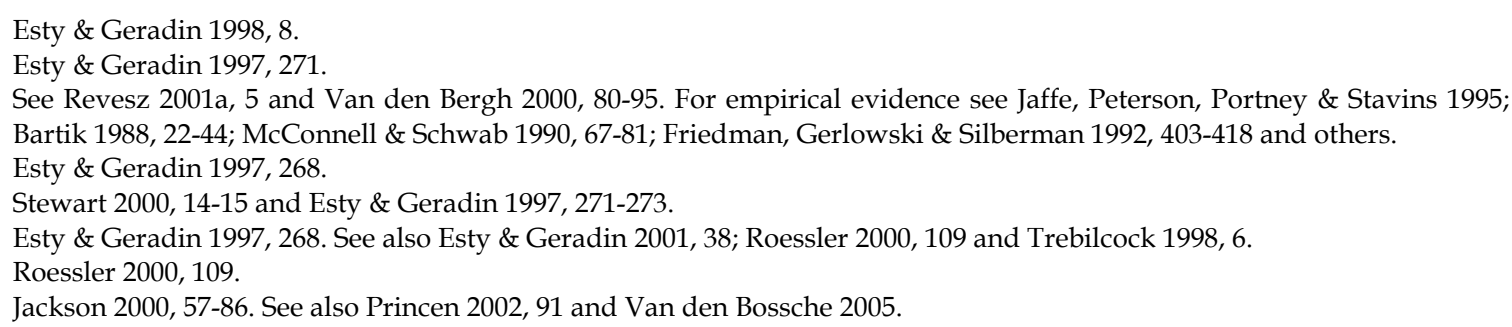


domestic products. The measure therefore should not be a disguised attempt to protect domestic industry. In such circumstances, there is in principle no conflict between WTO law and the pursuit of a domestic environmental policy objective. ${ }^{285}$ Article $\mathrm{XX}$, moreover, elaborates criteria that justify exemptions to these basic principles. A measure, that might potentially hamper free trade, could be adopted, if it is considered to be necessary to protect public morals, to protect human, animal or plant life or health, or necessary for the conservation of exhaustible natural resources. ${ }^{286}$

Process-based trade restrictions present a more difficult case. As the restriction applies to production processes, that took place outside the jurisdiction of the importing country, the traditional GATT position was that all such extra-jurisdictional measures would be inconsistent with free trade and therefore invalid. This position has been reflected in the Tuna/Dolphin cases in 1991 and 1994. ${ }^{287}$ At that time, the United States enacted a legislation that prohibited the use of certain tuna fishing methods, to protect dolphins from being killed in a tuna catch. This legislation required foreign governments to enact a similar legislation; otherwise they would be prohibited to sell their tuna in the United States. In these two cases, the GATT panels held that the ban on tuna imports from countries that allowed less dolphin-friendly fishing techniques, than the U.S. techniques, violated Article XI of the GATT Agreement. The ban could not be justified under Article XX either. The first panel argued that Article XX could only be invoked with respect to environmental threats within the importing country's own jurisdiction; the second panel decided that the exemptions could not be invoked if the measure intended to change the exporting country's domestic policies. ${ }^{288}$ This attitude was slightly modified in the Shrimp/Turtle decisions in 1998. ${ }^{289}$ The background of this dispute is similar to the Tuna-Dolphin cases. The dispute involved a US ban on the importation of shrimps, from countries that did not take precautions to prevent the killing of sea turtles during a shrimp catch. Now, the WTO Reports took a more favourable approach towards the trade restriction. Indeed, the WTO panels in these cases did not reject the possibility that the U.S. regulation could fall under the exemptions of Article XX. Nevertheless, the measure was now rejected on the claim of arbitrary or unjustifiable discrimination.

However, neither the Tuna-Dolphin cases nor the Shrimp-Turtle decisions provide a clear answer whether trade measures based on process standards could be allowed in the future by the WTO. Consequently, the debate on process-based trade restrictions is not finished yet. The main conclusion up to now might be that trade restrictions to protect extraterritorial values, based on article XX (for example for public morals) would not be precluded in principle. However, to date, no measure has been found completely WTO consistent. 290

Nevertheless, the WTO rulings might have discouraged developed countries from using trade restrictions and restricting imports from less developed countries in order to enforce or strengthen process or product standards. ${ }^{291}$ This might also explain the claims, from both free trade advocates and environmentalists, for harmonisation of environmental regulation, or policy convergence. The next paragraph will examine whether harmonisation of environmental regulation would indeed be justified to ease the various concerns, raised by differences in environmental standards.

\section{Harmonisation to Create a Level Playing Field}

The argument that harmonisation of legal rules would be necessary in order to avoid trade distortions and to guarantee market access, seems to imply that a total equality of marketing conditions, sometimes called a level playing field, would be a conditio sine qua non for market access. However, differences in marketing conditions might vary because of different local circumstances, and exactly these differences make gains from trade possible. Therefore, it must be possible to develop a framework of rules that would guarantee market access, without harmonising all rules and standards, which would eliminate gains from trade. This would, for instance, justify the harmonisation of certain product standards, in order to reduce barriers to trade. However, in the environmental realm, the fact that harmonisation of product standards sometimes might be justified in order to guarantee market access, is sometimes used to justify the harmonisation of

\footnotetext{
285 Roessler 2000, 110.

286 Jackson 2000, 57-86. See also Princen 2002, 93.

287 GATT, 1991, 1594-1623 and GATT 1994, 839-903. See also Weiler 2000; See also Princen 2002, 90-101.

288 Trebilcock \& Howse 1998, 35. See also Weiler 2000.

289 WTO, United States: Import Restrictions of Certain Shrimp or Shrimp Products, Report of the Panel, WT/DS58/R, 15 May 1998, available at <www.wto.org/english/tratop_e/dispu_e/distab_e.htm> and WTO, United States: Import Restrictions of Certain Shrimp or Shrimp Products, Report of the Appelate Body, AB-1998-4, WT/DS58/AB/R, 12 October 1998, available at <www.wto.org/english/tratop_e/dispu_e/distab_e.htm>. See also Weiler, J.H.H. (ed.), The EU, the WTO and the NAFTA. Towards a Common Law of International Trade, Oxford University Press, United States, 2000; Vogel 2001, 342 and Princen 2002, 90-101.

$290 \quad$ Princen 2002, 96-101.

291 Vogel 2001, 342. See also Vogel 2003.
} 
process standards as well. However, this aims to harmonise conditions of competition. ${ }^{292}$ It therefore merits making a distinction between environmental product and environmental process standards, when examining whether harmonisation would be justified.

As far as environmental product standards are concerned, it could be argued that differences in product safety standards might indeed create barriers to entry and hamper interstate trade. ${ }^{293}$ Accordingly, trade liberalisation might indeed require some degree of integration in other fields, including environmental regulation. However it is questionable, whether this would justify a total harmonisation of standards. Total harmonisation of standards is certainly not the only available policy option to deal with market access concerns. It should be possible to achieve market integration with less comprehensive instruments than total harmonisation. Indeed, a variety of refined policy tools exit to respond to market access concerns. ${ }^{294}$ Market access can be promoted through various forms of harmonisation. A minimum or essential harmonisation of requirements that lays down the basic safety requirements might well be sufficient. Mutual recognition among trading countries would also offer a mechanism to address market access concerns. Harmonisation of public information might be even far-reaching. Fundamentally, the challenge is to find that policy that offers the advantages of co-ordinated policy and that at the same time reflects diversity in local circumstances. ${ }^{295}$ However, it must be noted that the reasoning above would justify a certain level of centralisation or harmonisation of environmental product standards, not necessarily of tort law.

Process-based trade restrictions on the other hand, try to regulate the way a product is produced, even if outside the jurisdiction of the importing state. Market access is denied because of competitiveness concerns instead of the desire to protect a state's citizens from the (environmentally) harmful effects of certain products. Revesz distinguishes six types of situations in order to examine whether the use of process-based trade restrictions would be justified. ${ }^{296}$ His analysis might help to decide in which cases a harmonisation of process standards would ease these competitiveness concerns. It must be noted that the reasoning below examines whether a certain level of centralisation or harmonisation of environmental process standards would be justified, or put differently, whether a certain level of harmonisation of environmental regulation would be justified. It does not examine whether harmonisation of environmental liability would be justified. This will be examined separately.

Regrouping Revesz' six types of situations, gives three main cases for which whether the use of process-based trade restrictions would be justified and whether harmonisation could overcome these restrictions can be examined. The three cases are the following: firstly, the case where no externalities are present; second, when physical externalities are present, either in the importing country, or in third countries; and third, when psychic externalities might exist.

Firstly, the effect of environmental process standards might be purely domestic in the exporting country. Nevertheless, in order to respond to competitiveness concerns, policy makers of the importing country, industry and environmental interest groups, might call for the use of trade restrictions to imports from jurisdictions that apply lenient environmental standards. ${ }^{297}$ However, as discussed in the argument dealing with externalities, in such case, it would be hard to justify the introduction of trade sanctions by the importing country and equally hard to find a justification for harmonisation of these process standards. Indeed, trade restrictions, instead of equalising marketing conditions, distort trade relationships by eliminating the comparative advantage of countries that can set less stringent environmental standards due to local circumstances. Moreover, as Revesz rightly argues, as the cost of production depends on various factors that differ among countries (labour standards, wages), there is no reason why environmental regulation in particular should be harmonised. 298

However, if the environmental process standards in one jurisdiction would cause physical spillovers in the importing country, economic theory would consider these interstate externalities as a tenable argument for shifting regulatory power to an overarching governmental level. Indeed, as discussed in paragraph 1.2.1, the reasoning was that jurisdictions will not internalise the consequences of their actions that might accrue across their borders. It was argued, though, that the centralisation of regulatory power should be limited to transboundary externalities. In the case of torts, the transboundary externality argument did indeed not provide a justification for harmonisation of tort law that merely dealt with in-state torts.

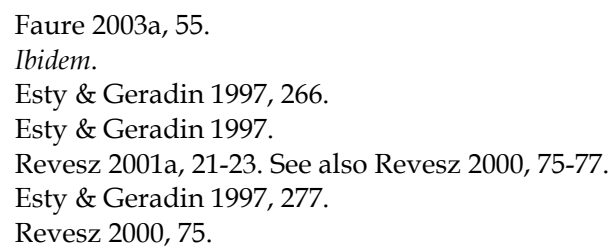


Yet, when dealing with the global trade order, the interaction between environmental regulation and economic integration is different than in federal systems like the European Union. Indeed, the differences in wealth and economic development might be far more pronounced. Moreover, as will be discussed below, environmental conditions in some countries might be so bad that this might give rise to concerns that basic human rights would be violated and therefore need to be protected. Yet, in the international community the capacity for harmonised standard setting might be much weaker, and there might be almost no capacity for harmonised environmental enforcement. ${ }^{299}$ Hence, the importing country might feel that the use of trade restrictions is the only way to protect these citizens. ${ }^{300}$ Indeed, because environmental standards setting and enforcement might be unsatisfactory in developing countries, there might be a stronger tendency in the international community than in federal systems to impose environmentally based trade restrictions. As Revesz indicates, although in the case of interjurisdictional externalities, that a certain level of centralisation might be preferable, it is understandable that states may see state regulation coupled with trade measures as the best available solution if centralised regulation is not viable, or if the enforcement of this regulation is not feasible. ${ }^{301}$

Nevertheless, it merits having a closer look at how a certain level of harmonisation of environmental regulation could solve the spillover problem and the need for trade restrictions. Indeed, by narrowing the gap between the environmental requirements that companies in high-standard jurisdictions have to comply with and the requirements that companies operating in more lenient jurisdictions face, a certain level of harmonisation could minimise the risk of unfair competition, a race to the bottom or a regulatory chill in environmental policy making. Hence, a certain level of harmonisation could eliminate the need for trade restrictions. ${ }^{302}$ It is not claimed that this would require a total harmonisation. There may be less tradedistorting ways to achieve the same result.

Indeed, although it sometimes might be difficult to achieve, countries could adopt a trade agreement, with provisions of enforcement commitments by the jurisdictions of their respective environmental rules. Such an approach, which for example was used in NAFTA, does not ensure market access. However, the commitment to full enforcement of national environmental rules may help to ease competitiveness tensions by preventing that basic environmental standards would be neglected. Hence, the risk of a race to the bottom in environmental policy making could be prevented and consequently there would be no need for trade restrictions. Moreover, enforcement commitments are a relatively non-interventionist strategy, which allows countries to adopt environmental standards that are tailored to their individual circumstances and needs. ${ }^{303}$

In addition to enforcement commitments, a diverse set of harmonisation techniques are available. Indeed, possibilities like minimum standards, multi-tier agreements, convergence of standards, differentiated standards or goal harmonisation should not be overlooked. ${ }^{304}$ Minimum production process standards set a regulatory floor below which no jurisdiction may go. By narrowing the gap between the environmental requirements in high-standard jurisdictions and the requirements in more lenient jurisdictions, minimum standards limit the possibility of distortions of competition. Multi-tier regulatory regimes allow for differentiated standards, for different groups of states, depending on their level of development. By doing so, the benefits of standards adopted to local conditions can be obtained, without losing the advantages of uniform requirements. With a differential standards regime, countries could adopt a free trade agreement in which they could identify environmental targets common to all participating countries, but which would provide for different degrees of stringency, for example in the time limit to achieve the target. Hence, standards would be set centrally but not uniformly. Again, differential standards would be economically more efficient than total harmonisation because they would better match regulatory requirements to local needs. Finally, the presence of common long-term goals could ensure that wide variations in the stringency of environmental protection will not persist over time as countries converge on the jointly defined goal. ${ }^{305}$ It must be clear however, that the reasoning above would argue for a certain level of harmonisation of regulation, not necessarily of environmental liability rules. Environmental liability in particular will be discussed below.

Up until now, it was assumed that the spillovers did arise in the importing country. If these spillovers would arise in third countries, but not in the importing country that introduces the trade restrictions, this would complicate the analysis. Indeed, if the importing country is not affected itself but if it would impose

Revesz 2001a, 20.

Revesz 2001a, 22.

Revesz 2001a, 20.

Esty \& Geradin 1997, 283.

Esty \& Geradin 1997, 275.

Esty \& Geradin 1997, 287.

Esty \& Geradin 1997, 287-292. 
a trade restriction to protect the environment, there might always be a risk of disguised protectionism, instead of purely good intentions. ${ }^{306}$ In this sense it is understandable that the WTO is reluctant to allow such trade measures, although the importing country's trade restriction might increase global social welfare. Nevertheless, it might be important to mention at this point, that for example the U.S. tuna embargo against Mexico has motivated Mexico to strengthen its fishing standards, and incidental dolphin deaths have significantly declined. Hence, although the use of process-based trade sanctions might violate the WTO rules, the interest of some developing countries in obtaining or increasing their market access to rich industrialised markets, has at several occasions provided incentives for these developing countries to strengthen their environmental standards. Therefore, in some cases, a trade restriction might lead to a California effect. The California-effect referred to the upward ratcheting of regulatory standards when economically powerful nations with stringent standards can force producers from other states with lower standards to adopt these strict standards. ${ }^{307}$

Further, in addition to the fact that a country may introduce trade restrictions, because of spillovers in third countries, a country might also introduce trade measures as the citizens of this importing country might suffer psychic losses, caused by the destruction of valuable natural resources or global commons, or because the environmental conditions in some countries might be so bad that this might violate basic human rights and therefore need to be protected. However, even if these psychic losses are real, it might be hard to justify that rich countries may take trade measures or require total harmonisation of certain environmental standards. Indeed, distributional aspects might arise and there might also be a risk of disguised protectionism. Moreover, Revesz points out that, in case of global commons, trade measures might be explicitly allowed by international treaties. International treaties, requiring all countries to meet certain public health or ecological standards, might also ease the concerns of both environmentalists as free trade advocates. ${ }^{308}$ However, as such treaties might take a long time to negotiate; countries may again see unilateral sanctions as the best option to protect the global commons. ${ }^{309}$

In conclusion, the first line of reasoning of the market access argument focused on the need of 'harmonisation of marketing conditions' in order guarantee a level playing field and market access. Indeed, different levels in the stringency of safety regulations, like environmental regulation, might cause trade distortions and hamper access to foreign markets. Therefore, proponents of harmonisation argue that harmonisation would create a 'level playing field' and ease the various concerns, arising from the intersection of trade liberalisation and safety regulations, such as environmental regulation. These concerns carried by free trade advocates and environmental organisations equally relate to both (environmental) product standards and (environmental) process standards.

As far as environmental product standards are concerned, it was argued that differences in product safety standards indeed might create barriers to entry and hamper interstate trade. ${ }^{310}$ Therefore, it was concluded that trade liberalisation might indeed require some degree of integration in other regulatory fields, including environmental regulation. However, this would not justify a total harmonisation of standards. Indeed, it is possible to achieve market integration with less comprehensive instruments than total harmonisation as there are a variety of refined policy tools to respond to market access concerns caused by differing product standards. ${ }^{311}$

In the case of differing process standards, the claim that harmonisation of marketing conditions is needed in order to guarantee free trade is primarily based on competitiveness concerns. Indeed, competitiveness concerns cannot be ignored in the context of trade liberalisation. In order to respond to competitiveness concerns caused by differing environmental process standards, countries may introduce trade restrictions to imports from jurisdictions that apply lenient environmental standards. It consequently was examined whether harmonisation of process standards would be justified in order to ease these competitiveness concerns. It was argued that if the effect of environmental process standards would be purely domestic in the exporting country, it would be hard to justify the introduction of trade sanctions by the importing country and equally hard to find a justification for harmonisation of these process standards. However, where externalities exist, there might be a justification for centralisation of process standards. ${ }^{312}$ Yet, it was shown that other solutions than total harmonisation might be available in order to guarantee market integration. Finally, if these externalities would be psychic, it would be hard to justify that rich countries may take trade measures or require total harmonisation of certain environmental standards.

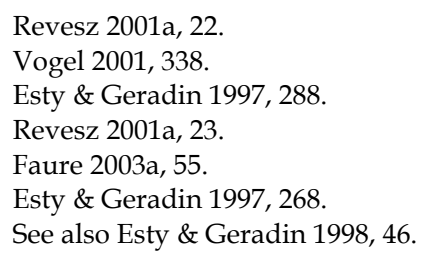


Indeed, distributional aspects might arise and there might also be a risk of disguised protectionism. Centralisation of basic standards through international treaties, requiring all countries to meet certain ecological standards might ease the concerns of both environmentalists as free trade advocates.

This paragraph tried to examine whether - a certain level of - harmonisation could be justified in order to avoid trade distortions and to improve market access. The focus however was on environmental regulation. It merits to now examin whether and how harmonisation of environmental liability could be justified in order to improve marketing conditions and market access.

\section{A Level Playing Field Through the Harmonisation of Environmental Liability Rules}

As discussed above, realising free trade could justify the harmonisation of elementary environmental product or process standards, to avoid incompatibilities which would create barriers to entry and distortions of competition. Yet, it is questionable if the realisation of free trade would justify the harmonisation of civil law such as as environmental liability rules. As was shown above, it is certainly possible to realise free trade without the total harmonisation of all legal rules. The same reasoning holds for environmental liability. Moreover, equal marketing conditions would not necessarily be achieved through the harmonisation of environmental liability rules. Indeed, harmonisation of liability rules would not create a level playing field, as differences in the availability of natural resources, labour standards, etc., are far more important factors that determine the conditions of competition. These factors would still create variations in marketing conditions. ${ }^{313}$ For example in the case of product liability, experience has proven that harmonisation of product liability has not been able to achieve a total harmonisation of marketing conditions. ${ }^{314}$ Furthermore, even if there would be differences in the stringency of environmental liability rules, it seems doubtful that industry would relocate to 'pollution havens', as examined previously. It therefore also seems doubtful that environmental liability would act as a trade barrier or cause competitiveness concerns.

Unlike regulatory measures, liability rules are not subject to restrictions under the WTO framework, provided that they apply only after the harm has occurred and are not used to restrict market access. Indeed, liability rules are not considered to be measures equivalent to quantitative import restrictions under the WTO framework. Hence, this might cause countries to prefer liability rules to target environmentalunfriendly products, instead of using regulatory restrictions, or product regulations might be backed up by liability rules. Introduction of liability rules, however, would not hamper free trade. On the contrary, as Bergkamp indicates it would have a significant advantage. The use of liability rules, eventually complementary to regulation, would prevent disguised protectionism. Indeed, a stringent liability regime will not impede the import of a certain product and in case of harm; a causal link between the environmental harm and the product concerned must still be proven. ${ }^{315}$ Product or process standards, on the other hand, might in name apply as well to domestic products and imports, but in practice it might be more difficult for importers to comply with the standards so that in reality foreign producers might not be able to import their products.

Thus, as diverging liability rules would not hamper free trade, it seems doubtful that a total harmonisation of environmental liability to ensure market access would be necessary. Countries could set their liability rules according to their preferences, and still guarantee market access, whereby disguised protectionism might be prevented. ${ }^{316}$

If liability rules for soil pollution in particular are considered, the reasoning will be essentially the same. Indeed, it seems doubtful that stringent liability rules for soil pollution would act as a trade barrier for certain products. Indeed, a causal link between the soil pollution and the product concerned still must be proven. The advantage moreover would be that disguised protectionism could be prevented. On the other hand, stringent liability rules for soil pollution might influence the production process and require additional precautionary measures like investing in environment-friendly technology, which would make production costs more expensive. Nevertheless, it seems doubtful that industry would relocate to 'pollution havens', as examined previously. This also depends on the regulation in neighbouring countries. Within Europe - even if Eastern Europe is included - and the US, most states have liability rules for soil pollution.

Concluding, it seems very doubtful that harmonisation of environmental liability and liability for soil pollution as an example would be necessary to ensure market access and fair marketing conditions. Nevertheless, federal intervention in environmental liability regulation might be justified for other 
purposes. Hence, it merits to now examin the second strand of the market access argument: reduction of transaction costs through harmonisation of legal rules.

\subsubsection{Reduction of Transaction Costs Through Centralisation of Environmental Liability}

\section{General Case}

In addition to the concern that differences in marketing conditions might hamper market access, there exists the concern that differences in legal rules might cause high transaction costs, and hence that this equally might hamper market access. Therefore, it is sometimes argued that harmonisation would be more efficient because of transaction costs savings that can be realised through harmonised legal rules. This assumption, however, might require further examination. ${ }^{317}$

Some scholars expressed themselves critically about the need to harmonise private law, such as contractual liability, property rights, or family law, in order to ensure market access and free trade. It is claimed that it is not clear that a uniform private law would be a necessary feature to ensure free trade. ${ }^{318}$ Again, a careful weighing of the advantages of harmonisation against the advantages of decentralisation must be made. Indeed, the central question to be posed is whether the eventual transaction cost savings of harmonisation do outweigh the benefits of differentiated legal rules, adapted to the preferences of the citizens. ${ }^{319}$

Advocates of a harmonisation of legal rules argue that uniform legal rules would solve information problems. Citizens and firms of different jurisdictions do not have to spend any more on information costs. They do not have to inform themselves about the differences in the law, or the way the law is enforced. Indeed, these transaction cost savings might be important for companies that are active in interstate commerce, in order to obtain scale economies in production and distribution. ${ }^{320}$ Furthermore, it is claimed that uniform rules tend to bring about legal certainty and a predictable jurisprudence. ${ }^{321}$ However, although these arguments in the field of economic regulation might be valid, it still has to be examined whether harmonisation also would be desirable in the case of private law, such as tort law.

Indeed, the assumption that a harmonised legal system will always be more efficient than decentralisation, because of transaction cost savings and legal certainty, might be somewhat precipitate. Certainly in the field of private law, this reasoning neglects the benefits of decentralisation, as legal rules can be adapted to the preferences and needs of the citizens of the different jurisdictions. Indeed, harmonisation of private law touches upon the sovereignty of states. Moreover, scholars such as Legrand ${ }^{322}$ argue that differences between legal systems and legal cultures might be substantive, hence, the costs of harmonisation might be huge, and the transactions cost savings might be fairly small. ${ }^{323}$ Undeniably, traditions, culture and values might vary substantially across states, which will have an impact on the interpretation of a certain rule. Furthermore, translation problems might lead to different interpretations of the same ruling. Therefore, Legrand is sceptical about 'legal transplants' from one state to another. In such circumstances, Van den Bergh indicates that harmonisation might increase legal uncertainty instead of realising legal certainty. ${ }^{324}$

Hence, it will have to be examined case by case whether differences in certain legal rules are indeed reflecting different preferences of citizens, or whether these differences merely concern 'technicalities', in order to formulate an opinion about the desirability and feasibility of harmonisation of these legal rules.

With application to tort law, there might be cases where a same liability rule, either strict liability or a negligence rule, is applied to a same type of accident in different jurisdictions. It could then be argued that, although formulations might differ, citizens might have the same preference pattern. Hence, the liability rule for that specific accident type could be considered for harmonisation in order to reduce transaction costs. However, it still will have to be examined whether the existing differences can be bridged at low costs. If these differences are rooted in the legal culture of the jurisdictions, the costs of harmonisation still might be huge. Furthermore, it should be guaranteed that a uniform rule does not disregard differences in preferences. ${ }^{325}$

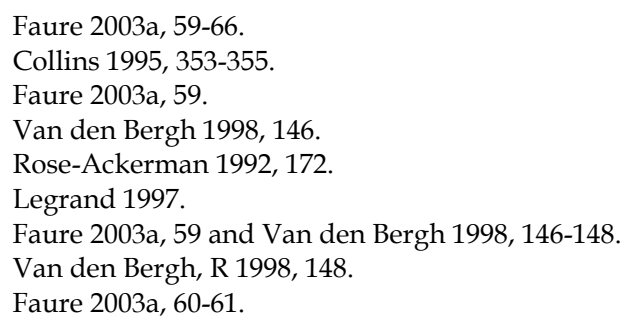


Yet, transaction costs savings do not necessarily require total harmonisation of a certain liability rule, which might neglect differences in citizen's preferences. Indeed, it is very well possible that, for a certain tort, the applicable liability rule would be harmonised, for example a negligence rule, but that the contents of the due care standard is left at state level, according to the preferences and needs of the citizens. Hence, centralisation of a specific liability rule for certain activities might be combined with a differentiation of the specific contents of this rule. In that case, transaction costs could be lowered, and differing preferences could be still respected. Therefore, harmonisation of liability rules in order to reduce transaction costs might allow for a certain level of centralisation, but not for full harmonisation. ${ }^{326}$

Nevertheless, there might be areas in tort law where citizens' preferences are more important than a reduction in transaction costs. It merits therefore examining now whether there would be a scope for a certain level of centralisation of environmental liability, or that citizens' preferences in that field of tort law might differ substantially.

\section{Environmental Liability}

In order to judge whether a certain level of centralisation or even harmonisation might be desirable in the case of environmental liability rules, the central questions that must be answered are whether centralisation or harmonisation would improve legal certainty and reduce transaction costs and whether this harmonisation would then improve market access.

The European experience has proven that increased legal certainty and a reduction in transaction costs, through harmonisation of environmental liability, are not easy to realise. Indeed, most developed countries have certain provisions to deal with environmental damage. Moreover, environmental damage might be very diverse, and one single pollution case might cause different types of damage. The consequences of harmonisation must therefore be very carefully examined. There indeed might be a risk of increased legal complexity, if different rules, on federal and state level, would apply to various types of environmental damage, caused by a single pollution case. Increased legal uncertainty would obviously hamper the reduction in transaction costs. ${ }^{327}$ Besides this problem, environmental protection might have deep roots in a jurisdiction's culture and hence in its legal rules. Therefore, the cost of harmonisation of environmental liability rules might be high and the transaction costs savings might be less than expected.

Hence, a total harmonisation of environmental liability rules does not seem desirable. However, general principles of tort law to protect the environment could be defined centrally, or a specific liability rule for certain activities could be set centrally, combined with a differentiation of the specific contents of this rule. In such circumstances, transaction costs might be lowered, market access might be promoted and still differing preferences could be respected.

These findings may be further refined to liability for soil pollution. Soil pollution and clean up requirements for contaminated soil might be locality specific and dependant on the physical and geographical characteristics of the region. ${ }^{328}$ Combined with the facts that environmental protection might be rooted in a jurisdiction's culture and that it might be doubtful that differences in the stringency of liability rules for soil pollution would significantly hamper market access, total harmonisation of liability rules for soil pollution does not seem desirable either. Indeed, it might be questionable whether the eventual transaction costs savings of harmonisation would outweigh the benefits of differentiated legal rules. Therefore, to achieve some form of harmonisation it might seem wiser to try to harmonise some general principles concerning environmental liability, combined with local determination of for example, the specific content of a due care standard, rather than a total harmonisation of liability for soil pollution. ${ }^{329}$

It merits now to summarise the market access argument as a whole. The argument did consist of two strands of reasoning, 'harmonisation of marketing conditions' and 'reduction of transaction costs through harmonisation of legal rules'.

With respect to the need of harmonisation to equalise marketing conditions, it was concluded that trade liberalisation might indeed require some degree of integration in other fields, including environmental regulation. A distinction was made between process and product standards. Yet, divergences neither in product nor in process standards did justify a total harmonisation of standards. Indeed, it was indicated that it must be possible to achieve market integration with less comprehensive instruments than total harmonisation as there exist a variety of refined policy tools to respond to market access concerns caused by differing product or process standards. When these findings are applied to

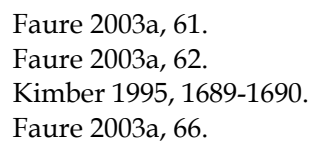

Faure 2003a, 66. 
environmental liability, and to liability for soil pollution, it was concluded that the argument, that harmonisation of environmental liability would be necessary to ensure market access and fair marketing conditions is rather weak. Indeed, diverging liability rules would not hamper free trade. On the contrary, the use of liability rules, eventually complementary to regulation, could prevent disguised protectionism. Indeed, a stringent liability regime will not impede the import of a certain product and in case of harm, a causal link between the environmental harm and the product concerned still must be proven. ${ }^{330}$ Product or process standards, on the other hand, might in name also apply to domestic products and imports, but in practice it might be more difficult for importers to comply with the standards so that in reality foreign producers might not be able to import their products.

With respect to the second line of reasoning, reduction of transaction costs to ensure market access, it was argued that transaction costs savings do not necessarily require total harmonisation of a certain liability rule, which might neglect differences in citizen's preferences. Indeed, it is very well possible to centralise the use of a specific liability rule for certain activities, combined with a differentiation of the specific contents of this rule. In that case, transaction costs could be lowered, and still respecting differing preferences. Therefore, harmonisation of liability rules in order to reduce transaction costs might allow for a certain level of centralisation, but not necessarily for full harmonisation. The same result was achieved for environmental liability and liability for soil pollution.

Hence, the market access argument would not justify a total harmonisation of environmental regulation, nor of environmental liability. Nevertheless, centrally defined principles might ensure market access and free trade and might moreover encourage more stringent environmental protection in regions for which environmental quality might not be the highest priority. A co-operative approach could be adopted, with central minimum requirements of protection, but allowing regions to implement the standards or to adopt more stringent measures in accordance with the objectives of free trade and competition, and conform to the citizen's preferences. ${ }^{331}$

However, again, federal intervention in liability rules for soil pollution might be necessary for other purposes than market access.

\subsubsection{Minimum Level of Protection Argument}

The final argument, harmonisation in order to guarantee a minimum level of protection, falls beyond the pure economic arguments for harmonisation of liability rules. Some authors stay within the economic reasoning and argue that harmonisation would be justified in order to guarantee a minimum level of protection as unacceptably low environmental standards in a certain jurisdiction could present negative psychic externalities to citizens in other jurisdictions. Other authors consider environmental protection as a human right, freed from economic justification. It merits studying this argument first for regulation in general and for environmental regulation. Second, attention will go to tort law in general. Finally, it can be examined whether the minimum level of protection argument would justify a harmonisation of environmental liability rules.

\subsubsection{Guarantee of a Minimum Level of Protection}

In addition to the economic reasons for harmonisation, non-economic arguments could be advanced to plead for harmonisation of legal rules. The main non-economic argument is that harmonisation of legal rules would provide a minimum level of protection to citizens.

In order to justify the harmonisation of legal rules to ensure a minimum level of protection to citizens, some scholars try to incorporate this non-economic argument into the economic arguments for centralisation as the transboundary externalities argument and the market access argument.

First, it is argued that low standards of for example health protection, safety standards or environmental quality, in a certain jurisdiction, could present negative psychic externalities to citizens in other jurisdictions. ${ }^{332}$ Therefore, from a welfare maximising perspective, these psychic externalities should be taking into account in the analysis of the optimal level of regulation. Eventually, psychic spillovers may justify centralisation. ${ }^{333}$

In the environmental realm, it is claimed that psychic spillovers could arise when citizens of another jurisdiction are deprived of the enjoyment of a certain natural resource. It is assumed that people do care

Bergkamp 2001a, 381-382.

Kimber 1995, 1689-1690.

Esty 1996, 638-648. See also Ferejohn 2000, 99-100.

Esty 1996, 638-648. 
about the Brazilian Rainforest, or the water quality in Alaska, even when they do not live there, and probably will never visit it. Hence, the health of (valuable) ecosystems, to which certain citizens might have no physical connection, might still enter into their utility function. Consequently, it is argued that psychic externalities should be taken into account when developing an environmental policy. ${ }^{334}$ Yet, if the existence of psychic externalities would be accepted, this would open the scope of centralisation tremendously. Faure rightly warns that the consequence of a 'harmonisation for a minimum level of protection' might be that citizen's preferences in the different jurisdictions are ignored. Centralisation would then amount to paternalism. ${ }^{335}$

Second, it is argued that maintaining free trade would require a core set of common norms and values to establish guidelines for behaviour. Centralised norms and values for trade, including safety standards, would make liberalised trade possible. Without centralised moral baselines for trade, countries would be under pressure to conduct trade in an unacceptable way. ${ }^{336}$ Moreover, according to Esty, interdependence between states would require, to some degree, integrated environmental protection programmes, or global environmental norms to guide citizen's behaviour. ${ }^{337}$ As was already explained above, market access would not justify a total harmonisation of environmental regulation, nor of environmental liability. Nevertheless, centrally defined principles might encourage more stringent environmental protection in regions for which environmental quality might not be the highest priority. It was stressed however, that a co-operative approach could be adopted, with central minimum requirements of protection, but allowing regions to implement the standards or to adopt more stringent measures in accordance with the objectives of free trade and competition, and conform to the citizen's preferences.

On the other hand, some authors leave the economic debate and argue that minimum standards of environmental protection for all countries would be justified if it is accepted that the environment is a common heritage of all people. ${ }^{338}$ In that sense, environmental protection would be considered as a human right. Harmonisation would guarantee all citizens a similar environmental quality and moreover, the environmental and cultural heritage and human health would be protected. Being a human right, environmental protection would be freed from economic justification. ${ }^{339}$ Indeed, if this argument would be accepted at policy level, and environmental rules would be harmonised, it must be clear that the reason for harmonisation would not be based on economic efficiency, but on the desire to guarantee all citizens a basic level of environmental quality. ${ }^{340}$

Yet, it is not argued that this would not be valid argument, but there is an important consequence of harmonisation of environmental rules, based on the human rights justification or because of the existence of negative psychic externalities. Indeed, in such case, it might be that a basic level of protection would be imposed in a certain jurisdiction, even if this would be contrary to citizens' preferences. As Ogus explains, rights-based arguments might trump arguments based on economic efficiency. For example, the preferences of citizens in certain jurisdictions for lower standards, may sometimes be overruled it the general opinion is that these lower standards would infringe human rights. ${ }^{341}$ And again, it must be clear that, if it is accepted that harmonisation of legal rules is justified, either because of the protection of human rights, or because of the existence of negative psychic externalities, that this would open the scope for harmonisation tremendously.

Moreover, Revesz is critical about this minimum level of protection justification for harmonisation of environmental regulation. As Revesz indicates, environmental risks are part of aggregate health risks. Hence, it is difficult to understand why environmental regulation should be harmonised in order to guarantee a minimum level of protection, if, for example in the European Union, there is no minimum social security, no provision of general health care or no harmonisation of minimum wages. ${ }^{342}$

Yet, even if the existence of psychic externalities would be accepted or the need to protect human rights, the question remains whether the harmonisation of tort law is the appropriate instrument to achieve this minimum level of protection.

The minimum level of protection justification for harmonisation addresses the concern to guarantee all citizens minimum quality standards, which refers to harmonisation of regulation. Therefore, the minimum level of protection argument might in some circumstances justify the harmonisation of regulation, but it is

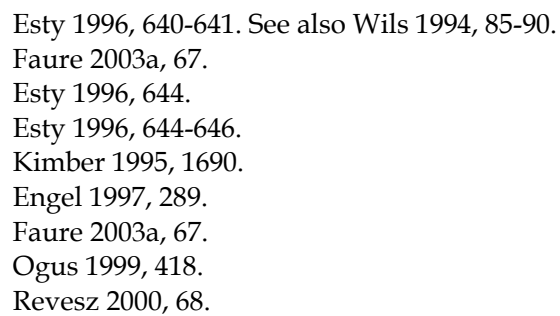


more difficult to justify the harmonisation of tort law. It is indeed questionable that the harmonisation of tort law would be the appropriate instrument to achieve such minimum safety standards. Indeed, it might be more efficient to develop minimum quality standards that must be achieved, before and after an accident, rather than to harmonise the liability rules itself in the different jurisdictions. Moreover, the type of liability rule might reflect differences in preferences of citizens. As Faure argues, in the European Union, for instance, it is doubtful whether the different liability rules in some Member States would not provide a minimum level of protection for accident victims. Hence, there would be no need for harmonisation of tort law. Therefore, regulation or other instruments, as the European Convention on Human Rights, ${ }^{343}$ could be more used more appropriately to guarantee such minimum level of protection, rather than the harmonisation of tort law. ${ }^{344}$ Hence, although the minimum level of protection argument might in some circumstances justify the harmonisation of regulation, the argument seems rather weak to justify the harmonisation of tort law. It will be interesting, however, to apply the minimum quality argument to environmental liability.

\subsubsection{Minimum Level of Protection Through Centralisation of Liability for Environmental Damage}

As for the general case, the minimum level of protection justification for harmonisation addresses the concern to guarantee all citizens minimum environmental quality standards, which actually refers to harmonisation of regulation. Therefore, the minimum level of protection argument might in some circumstances justify the harmonisation of regulation, but again, it might be more difficult to justify the harmonisation of environmental liability rules. The question arises whether the harmonisation of liability rules would guarantee such minimum level of protection for environmental accidents and even if this might be the case, it must be examined whether total harmonisation would be necessary.

Indeed, again, it might be more efficient to develop protection measures for certain rare habitats and minimum standards of environmental quality that must be achieved, before and after an accident, rather than to harmonise the liability rules itself in the different jurisdictions. ${ }^{345}$ Indeed, the type of liability rule might reflect differences in preferences of citizens and even with harmonisation, as was indicated above in the paragraph on reduction of transaction costs, this still might lead to different interpretations and treatment.

Moreover, Bergkamp indicates that there exists a body of international law that deals with the protection of common natural resources, for example the Convention on International Trade in Endangered Species (CITES). ${ }^{346}$ It might well be that this body of international law is insufficient, but additional treaties might be negotiated and enforcement possibilities might be improved, instead of the harmonisation of jurisdictions' liability rules. ${ }^{347}$

In sum, if the minimum level of protection argument would be accepted, it must be emphasised that the reason for harmonisation would not be based on economic efficiency, but on the desire to provide a minimum level of protection against environmental accidents. However, this argument would rather justify harmonisation of minimum standards of environmental quality that must be achieved, before and after an accident, instead of environmental liability rules. It is not claimed though that total harmonisation would be justified. Indeed, there might be other options than total harmonisation of environmental quality standards, like centralisation or coordination of minimum standards, but allowing states to go further, so that differing circumstances and preferences in different jurisdictions would be taken into account. Nevertheless, it is questionable why environmental quality standards should be harmonised, if a minimum level of protection of public health is not harmonised.

For soil pollution in particular, the same reasoning can be followed. Starting from decentralisation, according to the Tiebout model, jurisdictions would be free to set their own clean-up standards and their own liability rules. If the minimum quality standards argument is accepted, then this minimum level of environmental quality could be realised through minimum quality standards that would have to be achieved after the clean-up of contaminated soil. ${ }^{348}$ Hence, this could justify the centralisation of minimum soil quality standards, but it would not be necessary to harmonise liability rules to achieve this basic environmental quality after clean-up. Each jurisdiction could organise this according to its preferences.

Council of Europe, Convention for the Protection of Human Rights and Fundamental Freedoms, Rome, 4 November 1950.

$344 \quad$ Faure 2003a, 68.

345 Bergkamp 2001a, 378.

346 Convention on International Trade in Endangered Species of wildlife and Fauna, Washington, 3 March 1973, 993 UNTS 243, which entered in force on 1 July 1975.

$347 \quad$ Bergkamp 2001a, 378.

348 See Faure 2003a, 69-70. 
Moreover, again, there might be other options than total harmonisation of soil quality standards, like centralisation or coordination of minimum standards, but allowing states to go further, according to their needs and preferences.

In sum, the minimum level of protection argument might justify in some circumstances the centralisation of regulation, by defining certain minimum quality standards, but not necessarily the harmonisation of environmental liability in general or specifically liability for soil pollution.

\subsection{Summary of the Public Interest Approach}

It merits now to recapitulate the results of the public interest approach on the optimal level of decisionmaking for environmental liability rules, with the example of liability rules for soil pollution, and to formulate an intermediate conclusion.

The public interest approach starts from decentralisation of regulatory policies and examines accordingly whether there might be reasons for federal intervention. This bottom-up approach towards centralisation is based upon the Tiebout model and the Decentralisation Theorem of Oates.

The reasons for harmonisation were grouped into four main arguments: the transboundary character of an externality argument, the race-to-the-bottom argument, the market access argument and the minimum level of protection argument.

The first argument for harmonisation was the transboundary character of an externality. The argument consisted of two strands. First, internalisation of transboundary externalities could be ensured by shifting powers to a higher governmental level. Second, economies of scale could be reached by a -certain level of - centralisation.

It was argued that the transboundary externality argument does not justify centralisation and certainly no harmonisation of environmental liability rules to solve transboundary spillovers. Instead, in order to take local circumstances into account, centralised regulation for transboundary externalities only could be preferred. However, according to the economies of scale reasoning, it could be examined whether there are economies of scale and advantages of expertise that can be benefited from without having to give in on diversity. Hence, the transboundary externality argument would allow for a mixed system that would benefit from the merits/expertise of both governmental levels, but would not justify excessive centralisation or harmonisation.

The example of soil pollution clarified this position: with respect to the local nature of soil pollution, full centralisation or harmonisation of liability rules for soil pollution would not be justifiable as it would not take diverse causes, circumstances and preferences into account. Therefore, federal regulation of liability rules for soil pollution preferably might not go further than a kind of transboundary - special areas only regime to remedy transboundary soil pollution. This might however be completed with centralisation of supporting scientific research and data analysis, as all states and citizens would benefit from it.

The second argument for harmonisation was the risk of a race-to-the-bottom. The race-to-the-bottom rationale might be the most heavily debated economic argument to justify federal environmental liability regulation. Theoretical grounds as well as empirical evidence of the existence of a race-to-the-bottom in environmental regulation were analysed.

It was concluded that theoretically, it seems doubtful that a race-to-the-bottom in environmental liability rules would occur. On the one hand, there are more important factors that influence industry location decisions than environmental liability regulation, and on the other hand, states would have no advantage of a lenient liability regime. Nevertheless, political pressure and the risk of a political drag should also not be ignored in the case of environmental liability regulation.

There are no surveys that explicitly examine the influence of a liability regulation on industry location decisions. However, again, it seems doubtful that evidence would be found that environmental liability rules would play a significant role in attracting or repulsing industry to or from a certain state.

Indeed, other factors may play a far more important role in industry location decisions like labour regulations, taxes and the availability of raw materials. Moreover, some evidence that multinational corporations might decide to apply even more stringent standards than local standards, either because of consumer pressure or to avoid potential liability, exists. Therefore, from the side of industry, even based on empirical evidence, it seems doubtful that industry, and certainly multinationals, will relocate because of lenient liability rules in other countries.

The same reasoning might hold for liability for soil pollution. There is no evidence of relaxed regulation on the side of the governments in order to attract industry. However, it might be possible that state officials might believe or are under political pressure to believe that a stringent liability regime, like stringent liability rules for soil pollution, might repulse industry from locating in that state. Hence they 
might fail to adopt stringent (soil) quality standards and a stringent liability regime or neglect the enforcement of this regime. Further research in this area could provide more information on governmental behaviour. The private interest part will hopefully shed a light on lobbying practices and the pressure that officials, competent for environmental liability, or liability rules for soil pollution, might face.

Nevertheless, it is doubtful that, for example in Europe, states would engage in a game in which they would strive for a low level of environmental liability and renounce on restoration claims in order to attract industry, and therefore, the argument would not justify full centralisation of environmental liability rules.

Market access presented the third argument for the harmonisation of environmental liability rules. It is sometimes claimed that harmonisation of environmental regulation would be justified in order to ease the tensions created by the differences in the stringency of environmental regulations of various jurisdictions. The argument consisted of two strands, 'harmonisation of marketing conditions' and 'reduction of transaction costs through harmonisation of legal rules'.

With respect to 'harmonisation of marketing conditions', it was concluded that although realising free trade could justify the harmonisation of elementary environmental product or process standards, to avoid incompatibilities which would create barriers to entry or distortions of competition, it is questionable that the realisation of free trade would justify the harmonisation of private law, such as environmental liability rules. Indeed, it is certainly possible to realise free trade without the total harmonisation of all legal rules. Moreover, equal marketing conditions would not necessarily be achieved through the harmonisation of (environmental) liability rules. Indeed, harmonisation of liability rules would not create a level playing field, as differences in the availability of natural resources or labour standards still would create variations in marketing conditions. Moreover, if countries would prefer liability rules to target environmentalunfriendly products, instead of using regulatory restrictions (which might be under WTO restrictions), this would not hamper free trade, on the contrary, it would have a significant advantage. Indeed, the use of liability rules would prevent disguised protectionism, as a causal link between the environmental harm and the product concerned still must be proven. Hence, it seems doubtful that environmental liability rules would act as a trade barrier or cause competitiveness concerns and that a total harmonisation to ensure market access and fair marketing conditions would be necessary. Countries could set their liability rules according to their preferences, and still guarantee market access, whereby disguised protectionism might be prevented. The same reasoning would hold for soil pollution.

The second strand of the market access argument, the 'reduction of transaction costs through harmonisation of legal rules' reasoning, concentrated on the concern that differences in legal rules might cause high transaction costs and hence that this equally might hamper market access. The reduction in transaction costs through harmonisation would improve market access.

It was concluded that the assumption that a harmonised legal system will always be more efficient than decentralisation, due to transaction costs savings and legal certainty, might be somewhat precipitate. Increased legal certainty and a reduction in transaction costs, through harmonisation of environmental liability, are not easy to realise. Indeed, most developed countries have certain provisions to deal with environmental damage. Moreover, environmental damage might be very diverse, and one single pollution case might cause different types of damage. The consequences of harmonisation must therefore be very carefully examined. There indeed might be a risk of increased legal complexity, if different rules, on federal and state level, would apply to various types of environmental damage, caused by a single pollution case. Increased legal uncertainty would obviously hamper the reduction in transaction cost. In addition to this problem, environmental protection might have deep roots in a jurisdiction's culture and hence in its legal rules. Therefore, the cost of harmonisation of environmental liability rules might be high and the transaction costs savings might be less than expected.

These findings can be further refined to liability for soil pollution. Soil pollution and clean up requirements of contaminated soil might be locality specific and dependant on the physical and geographical characteristics of the region. Combined with the facts that environmental protection might be rooted in a jurisdiction's culture and that it might be doubtful that differences in the stringency of liability rules for soil pollution would significantly hamper market access, total harmonisation of liability rules for soil pollution does not seem desirable either. Indeed, it might be questionable whether the eventual transaction costs savings of harmonisation would outweigh the benefits of differentiated legal rules. Therefore, it might seem wiser to try to harmonise some general principles concerning environmental liability, combined with local determination of for example, the specific content of a due care standard, rather than a total harmonisation of liability for soil pollution.

In sum, the market access argument would not justify a total harmonisation of environmental liability rules. Nevertheless, centrally defined principles might ensure market access and free trade and reduce transactions costs. A co-operative approach could be adopted, with central minimum requirements of 
protection, but allowing regions to implement the standards or to adopt more stringent measures in accordance with the objectives of free trade and competition, and conform to the citizen's preferences.

The final argument, harmonisation in order to guarantee a minimum level of protection, falls beyond the pure economic arguments for harmonisation of liability rules. Some authors stay within the economic reasoning and argue that harmonisation would be justified in order to guarantee a minimum level of protection as unacceptably low environmental standards in a certain jurisdiction could present negative psychic externalities to citizens in other jurisdictions. Other authors consider environmental protection as a human right, freed from economic justification.

It was argued that if the minimum level of protection argument would be accepted, it must be emphasised that the reason for harmonisation would not be economic efficiency, but the desire to provide a minimum level of protection against environmental accidents. Furthermore, if citizens' preferences are not homogeneous, harmonisation might amount to paternalism. Yet, even if the existence of psychic externalities would be accepted or the need to protect human rights, the minimum level of protection justification for harmonisation addresses the concern to guarantee all citizens minimum quality standards, which refers to harmonisation of regulation. Therefore, the minimum level of protection argument would rather justify harmonisation of minimum standards of environmental quality that must be achieved, before and after an accident, instead of environmental liability rules. However, it is not claimed that total harmonisation of standards would be justified. Indeed, there might be other options than total harmonisation of environmental quality standards, like centralisation or coordination of minimum standards, allowing states to go further, so that differing circumstances and preferences in different jurisdictions would be taken into account. Nevertheless, it is questionable why environmental quality standards should be harmonised, if a minimum level of protection of public health is not harmonised.

For soil pollution in particular, the same reasoning can be followed. A minimum level of environmental quality could be ensured through minimum quality standards that would have to be achieved after the clean-up of contaminated soil. Hence, this could justify the centralisation of minimum soil quality standards, but it would not be necessary to harmonise liability rules to achieve this basic environmental quality after clean-up. Each jurisdiction could organise this according to its preferences. Moreover, again, there might be other options than total harmonisation of soil quality standards, like centralisation or coordination of minimum standards, but allowing states to go further, according to their needs and preferences.

In short, the minimum level of protection argument might justify in some circumstances the centralisation of regulation, by defining certain minimum quality standards, but not necessarily the harmonisation of environmental liability in general or specifically liability for soil pollution.

Hence, the intermediate conclusion from the public interest approach is: none of the arguments would justify a total harmonisation of environmental liability rules. Yet, there might be a supportive role for the federal government in the provision of information and scientific research. Besides that, a federal government might develop solutions for transboundary damage or for special conservation area's. Furthermore, general principles of tort law to protect the environment could be defined centrally, or a specific liability rule for certain activities could be set centrally, combined with a differentiation of the specific contents of this rule. In such circumstances, transaction costs might be lowered, market access might be promoted, a minimum level of protection could be guaranteed and still differing preferences could be respected.

The same reasoning holds for liability rules for soil pollution. Perhaps the strongest argument for decentralisation of liability rules for soil pollution is that local conditions, geography, economic strengths and concerns might vary substantially from place to place. Furthermore, local knowledge and expertise with specific soil conditions might prove essential to develop the proper liability rules for soil reclamation. Therefore, certainly in the specific case of soil pollution, a one-size-fits-all approach probably might fit nobody.

Hence, based on a public interest approach, an argument could be made for a multi-level regulatory structure. The main power of decision-making would be with the local authorities, whereby the federal government could provide a supporting framework of data gathering and technical information provision. Moreover, the federal government could provide a solution for transboundary damage and natural conservation area's and could define general principles to protect the environment.

\section{Private Interest Approach on the Optimal Decision-making Level of Liability for Environmental Damage}

The existence or the harmonisation of certain environmental regulations cannot always be explained on the basis of the public interest approach. For a full understanding of environmental policy, the influence of 
lobbying of different interest groups in the law making process must be recognised. 349 Indeed, environmental rules may have significant economic consequences. The costs of environmental regulations are generally more concentrated and borne by industries than the benefits, that are difficult to monetise and that accrue to the general public. ${ }^{350}$ Firms might therefore try to influence the law- making process to their advantage. Moreover, it would be naive to presume that legislators who enact environmental laws are exclusively concerned to protect the public interest. In reality, also environmental politics has a lot to do with the pursuit of power, privilege, and special interests. It should not be surprising that sometimes environmental regulations are designed to serve narrow political and economic interests, instead of the public interest. ${ }^{351}$

Hence, when developing a framework for decision-making upon the optimal level of liability rules for environmental damage in a federal system, rent seeking behaviour and lobbying of different interest groups in the environmental law making process should not be ignored. The public interest approach will therefore have to be complemented with a so-called private interest approach. This approach applies economic models to political decision-making and tries to take rent seeking into account in the law making process. The contribution of this approach is that it throws light upon the conditions under which (environmental) laws are made and that it allows to explain inefficiencies in regulation.

This chapter will first present a brief overview of the theories that examine the influence of lobbying on the law making process: Capture Theory, the Economic Theory of Regulation and Public Choice Theory. Moreover, the various stakes of industry and environmentalists, the main lobby groups in the environmental law making process, will be discussed. In a second step, the results will be applied to environmental federalism. Lobbying might take place at all levels of decision-making. Indeed, lobbying might not only concern the contents of the regulation, but also at what level of government the regulation will be issued. Interest groups, having a stake in a certain area of regulation, might prefer that level of government at which their strength is greatest in comparison to other interest groups with different concerns in the same area. ${ }^{352}$ Therefore, the influence of interest groups on the level of environmental decision-making will be discussed. The relative influence of the interest groups at different levels of government will be studied and links will be shown to the public interest approach. Finally, the potential influence of lobbying for environmental liability rules, and for example for liability for soil pollution, will be examined in order to refine the theory on the optimal decision-making level for environmental liability rules. Again centralisation and decentralisation arguments for liability for enviromental damage, illustrated by soil pollution, will be weighted against each other, this time based on the private interest approach.

\subsection{Theories of Regulation}

\subsubsection{Theories}

A primary motivation for the development of theories that explicitly examine rent seeking behaviour in the law making process has been the observed divergence of actual environmental policy from the efficient policy suggested by economic theory. ${ }^{353}$ Indeed, lobbying by interest groups in the political arena might influence the final design of the regulation. ${ }^{354}$ As environmental measures might impose significant costs on polluting firms, environmental decision-making might be very susceptible to special interest distortions.

This paragraph will briefly introduce the main theories on lobbying in the regulatory process. Successively Capture Theory, the Economic Theory of Regulation and Public Choice Theory will be discussed. In a second stage, attention will go to the various stakes of the main lobby groups in environmental regulation.

\subsubsection{Capture Theory}

The 'Capture Theory', that tries to explain the influence of interest groups in the law-making process, is developed by political scientists. Recognition of the existence of interest groups and the idea of 'capturing' can already be found in the work of Bentley in 1908 or of Truman in 1951. ${ }^{355}$ Yet, attention grew in the

Oates \& Portney 2001, 5.

Esty 1996, 597-598.

Adler 1996, 26-34. See < www.cato.org/pubs/regulation>

Faure \& Skogh 2003, 175. See also Ogus 1994, 103.

Oates \& Portney 2001, 13. For an overview of interest group theories, see also Mitchell \& Munger 1991, 512-546. Reprinted

in Rowley 1993.

354 Svendsen 1998, 31.

355 Bentley 1908 and Truman 1951. 
1960's. The starting point of the 'Capture Theory' is that regulatory agencies can be 'captured', meaning influenced or bribed, by the industry that has to be regulated. This 'capturing' is possible as the regulator is dependent on the industry that has to be regulated, for information on the best available techniques in order to set regulatory standards. The regulator might even have to recruit officials of that industry to work out these regulatory standards. ${ }^{356}$ For environmental regulation for example, the polluting industry will be best informed about technology and the best available techniques. Such a situation of asymmetric information might open possibilities for strategic behaviour by industry. ${ }^{357}$ In such circumstances, the legislator, who should pursue the public interest, might be captured by the industry that has to be regulated and that aims to protect its own interests.

Yet, the Capture Theory lacked theoretical foundations. What was needed was a general theory which could explain how lobbying would influence the law making process.

\subsubsection{Economic Theory of Regulation}

In 1971, Stigler developed a positive Theory of Economic Regulation. 358 This theory also became known as the Chicago theory of regulation. According to Stigler, the existence and the scope of regulation can be predicted as a response by politicians to the demands of - primarily - industry lobby groups. Hence, Stigler's central proposition is that it is the industry itself that asks for regulation. ${ }^{359}$ Stigler's theory holds that every branch of industry, which is powerful enough to do so, will lobby for regulatory measures that restrict entry, like tariffs, or reduce output, like licences. These measures can reduce competition, create cartel-like situations and increase industry profits so that the industry branch would get a comparative advantage. The demand for regulation will be high when the restrictions to competition cannot be obtained by the interest groups themselves, for example by the creation of a cartel. ${ }^{360}$ Falling within the Chicago school of reasoning, Stigler's theory predicts that the outcome of the regulatory process would be economically efficient. ${ }^{361}$ Stigler's theory was formalised and extended by Peltzman. ${ }^{362}$ Peltzman indicates that not only well organised industry groups can be expected to lobby, but that other interest groups and voters will try to influence the decision-making process as well. Politicians will then distribute favours and disfavours among these interest groups in order to maximise their chances of re-election. 363

A further contribution to the Chicago theory of regulation was made by Becker, who concentrated on the competition between interest groups. In 1983, Becker developed a model of competition among interest groups for political influence like taxes, subsidies or protective regulation, and combined public and private interest considerations. ${ }^{364}$ Becker assumes that politicians carry out the political allocations resulting from the competition among various pressure groups. The political equilibrium then depends on the capability of each pressure group in producing pressure on the government. ${ }^{365}$ The model shows that correcting market failures by the government would not necessarily be prevented by the involvement of interest groups. Indeed, according to Becker, it is not the existence of well-organised pressure groups that may be harmful to the economy, but the unequal distribution of political power across these groups. ${ }^{366}$ Hence, Becker unifies the view that governments correct market failure with the finding that governments may also favour certain interest groups. ${ }^{367}$

Yet, the Economic Theory of Regulation has been criticised. The Chicago Theory of Regulation seems primarily suited to explain economic regulation but the theory cannot provide a conclusive explanation for a large array of social regulations. Indeed, some measures, like environmental measures for example, might impose huge costs on the sources of pollution, which is the polluting industry. Therefore, it seems onesided that primarily industry would ask for regulatory measures. ${ }^{368}$ Moreover, the Chicago Theory of Regulation does not pay attention to the motivation and behaviour of the government itself in the

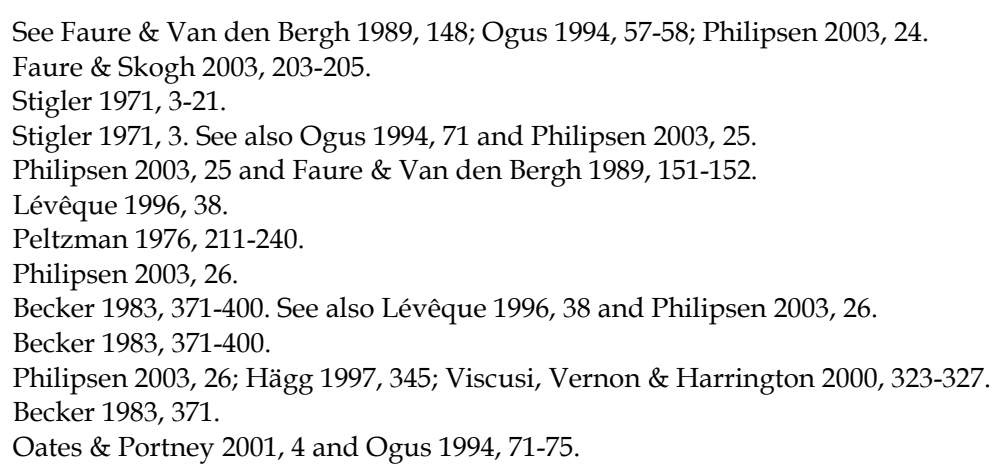


regulatory process. The Chicago Theory of Regulation finally is criticised by Public Choice scholars for its assumption that the outcome of the regulatory process would be economically efficient. ${ }^{369}$

\subsubsection{Public Choice Theory}

Public choice theory attempts to offer an understanding of the complex interactions between the different actors in the law making process. A seminal contribution to the public choice literature came from Buchanan and Tullock in 1962. ${ }^{370}$ Buchanan and Tullock posit that individual behaviour in the political arena basically is the same as in the market: individuals are rational, pursue their private interests and try to maximise utility. ${ }^{371}$ Citizens, on the one hand, will use their voting-power to obtain the maximum benefit for themselves from the collective decision-making process. Politicians, on the other hand, are willing to supply legislative benefits to voters, either individuals or groups, to obtain their votes in order to maximise their changes for re-election or to gain power. Indeed, Buchanan indicates that the government should not be understood as a benevolent despot that tries to maximise public welfare, but as an agent that seeks to increase its spending and power, by, for example, higher taxes. This is also called the Leviathan hypothesis of government. Buchanan argues that decentralisation could prevent that a government would behave as a Leviathan. ${ }^{372}$

Unlike the Chicago Theory of Regulation it is not assumed that the outcome of the regulatory process would be economically efficient. ${ }^{373}$ Indeed, public choice theorists argue that special interest groups might have such powerful influence on the legislative process that general preferences might be overridden. ${ }^{374}$ An explanation for the domination of special interest groups on the legislative outcome is the idea of the ignorant voter. ${ }^{375}$ This notion can be explained as follows: special interest groups can receive large concentrated benefits through lobbying. This lobbying is commonly referred to as rent seeking behaviour. ${ }^{376}$ Rent seeking by industry lobby groups for example could consists of pursuing government intervention that would provide a comparative advantage to these particular industries. The cost for society of such regulation, however, will be spread over many individual taxpayers. Moreover, the number of individual voters is so great that nobody would expect his marginal vote to have an impact on politics. If all individuals would inform themselves critically about legislative proposals, this might result in decisions that would better serve the public interest and prevent redistribution to special interest groups. However, on an individual basis, this effort does not pay. Indeed, a citizen only receives a small share of the gain from more efficient regulations. Consequently, special interest groups may organise and lobby without explicit reaction from the general public that pays and regulatory policies may sometimes be the result of interest group manipulation rather than honest consideration of the public interest. ${ }^{377}$

Two broad types of lobby groups can be distinguished: groups representing a sectional interest, like producer associations, and groups that are zealous for a certain cause, like environmentalists. ${ }^{378}$ In a now famous study, Olson examined what features made a group more or less effective in the political arena. Olson's study draws two important conclusions. First, it is easier to form an effective lobby group from a smaller, rather than a larger group of members. Although larger groups have an advantage in size, they might be more subject to free-riding. Second, the effectiveness of a lobby group depends on the homogeneity of the common interests of the group. Hence, the lobby group will be most effective if the group is small, single-oriented and well-organised. ${ }^{379}$ Olson's theory might explain why certain interest groups, like industry representations, which constitute relatively small and homogeneous groups, are able to organise and represent their interests more effectively than larger and more diffuse groups, like

Den Hertog 2000, 235-244

Buchanan \& Tullock 1962.

Ogus 1994, 63 and 58-59. See also Faure \& Skogh 2003, 172; Faure \& Van den Bergh 1989, 148-149 and Philipsen $2003,24$.

Brennan \& Buchanan 1977, 255-273.

Philipsen 2003, 24.

Ogus 1994, 69-70.

See Faure \& Skogh 2003, 172 and Svendsen 1998, 30

The notion of rent-seeking is a key feature of the so-called Virginia School of Public Choice. See especially Buchanan \& Tullock 1962 and Buchanan, Tollison \& Tullock 1980. See also Adler 1996, 26-34. See <www.cato.org/pubs/regulation> and Philipsen 2003, 24.

377 Adler 1996, 26-34. See <www.cato.org/pubs/regulation>; Faure \& Skogh 2003, 172 and Svendsen 1998, 30.

378 Ogus 1994, 69-70.

379 Olson 1965, Ch. 1-3. See also Philipsen 2003, 27. Oates and Portney moreover indicate that powerful lobby groups are those that perform some other function in addition to lobbying. They might provide direct services to their members or have other means at their disposal to enforce membership on those who benefit from the lobbying. See Oates \& Portney 2001, 11. 
consumers or environmental lobby groups. ${ }^{380}$ Concluding, inefficient regulations might emerge as a result of incomplete representation through interest groups in the political decision-making process. ${ }^{381}$

There is no reason to assume that environmental regulations would be immune from rent seeking. In fact, as they might have significant economic consequences, environmental regulations will be conducive to rent seeking. ${ }^{382}$ Maloney and McCormick were the first to examine rent seeking behaviour in the environmental law making process. They argue that producers and victims of pollution may find it in their self-interest to form coalitions and to lobby for input restrictions or output reductions. ${ }^{383}$ Recent work by Aidt even indicates that lobbying might lead to political equilibria that are economically efficient. As different lobby groups give voice to different aspects of environmental policy, it can be ensured that all aspects are considered in the political debate and reflected in the environmental policy. If all members of society have their interests represented by a lobby group and if interest groups faithfully represent the interests of their members, then the political equilibrium might be socially efficient, leading to a complete political internalisation of the externality. The lobby groups will induce the government both to select the efficient level of externality-generating activities and the efficient regulatory instruments. The internalisation will be incomplete if some citizens do not organise lobby groups. Referring to Olson's theory, some groups cannot overcome the free-rider problem; some groups have much lower organisational costs or are much more effective in providing selective benefits than others. ${ }^{384}$ Hence, the outcome of the interplay of diverse interest groups in the political arena need not be inherently distortionary, yet fully efficient outcomes might be rare. ${ }^{385}$

In short, the private interest approach, based on the three theories described above, focuses on the way in which (environmental) regulation is affected by the lobbying of interest groups. There is no doubt that many environmental statutes and regulations have been enacted to protect the public's well-being. However, it must also be clear that environmental policy is not immune to special interest pressures. Due to the cost and complexity of environmental rules, environmental policy might be very sensitive to rent seeking. Rent seeking in environmental policy is not new, and it is not likely to go away. As long as environmental regulations might reallocate a huge amount of money from one set of interests to another, those interests will ensure to have their say. Yet, the fact that environmental policy measures may be influenced by interest groups does not mean they never achieve environmental goals. Many environmental policy decisions are a mixture of benefits to interest groups and general social welfare maximisation. Indeed, environmental policies, influenced by the push and pull of various interests, may vary from wealth transfers to measures that are sensible responses to environmental concerns. ${ }^{386}$

Which theory - the Chicago theory of regulation arguing that the demand for regulation primarily comes from industry and that the law making process might be efficient, or the public choice theory which points to the behaviour of the government itself in the regulatory process, eventually being a Leviathan best reflects the situation in the European Union with respect to environmental regulation, and in particular to environmental liability, will be studied in Chapter 6, which deals with the Environmental Liability Directive.

Rent seeking might influence the instrument choice to remedy environmental damage (permits, subsidies or regulation), the environmental quality standards that must be achieved, or the level at which regulation is set (centralisation or decentralisation). The next paragraph will present the main actors involved in the environmental law making process - government, industry and environmentalists - and will elaborate their attitude towards rent seeking and their various stakes in the lobbying process with respect to instrument choice and the level of environmental quality. Paragraph 2.2 then turns to environmental federalism and the influence of rent seeking on the level at which regulation is set.

\subsubsection{Rent-seeking Behaviour in Environmental Regulation}

There is an abundance of literature that tries to provide theoretical and empirical support for rent seeking in the case of environmental regulation. ${ }^{387}$ For instance, attention has been paid to the way in which interest groups might try to influence the instrument choice for environmental policy to their advantage. Three instrument options mostly are considered relevant in the literature: traditional command and control

Ogus 1994, 71.

Oates \& Portney 2001, 11.

Adler 1996, 26-34. See < www.cato.org/pubs/regulation>

Maloney \& McCormick 1982, 99-123, 100.

Aidt 1998, 1-16.

Oates \& Portney 2001, 5

Adler 1996, 26-34 and Oates \& Portney 2001, 16.

Faure \& Skogh 2003, 173. 
regulation, emission taxes on all emitted units or a grandfathered permit market, in which polluters can obtain their initial distribution of permits free of charge or by auction. ${ }^{388}$ Research has shown that command-and-control instruments can, in quite realistic circumstances, be more beneficial to certain important interest groups than incentive-based policy measures. ${ }^{389}$ In their seminal article of 1975 , Buchanan and Tullock already indicated that economic rather than environmental considerations could determine the choice of policy instruments and that standards might be preferred over taxes. ${ }^{390}$ Using this basic framework, several authors have examined the effects of lobbying on the choice of environmental policy instruments. ${ }^{391}$

Interest groups might also try to influence the level of environmental quality that must be achieved. Yet, the lobbying behaviour of the main actors involved in environmental regulation might not always be straightforward. As will be discussed below, industry does not always oppose stringent regulation, nor can it be assumed that support for more stringent regulations comes primarily from those who have honest consideration of the public interest. 392

The main actors in environmental regulation are the government, the polluting industry and environmental groups. ${ }^{393}$ This paragraph will try to provide an answer on the following questions: how will the main actors lobby, what are their interests, and in what way can they be expected to influence environmental regulation? Although the behaviour of the different actors is studied separately, in reality the actors may react on each other and co-operate.

\subsubsection{Government}

Lobbying by interest groups affects the final design of the environmental policy and the resulting economic outcome. The politicians, representing the government, cannot just pursue the economic interests of the majority, aiming to be re-elected. In order to achieve political acceptability and avoid conflict, politicians must mediate among the main organised interests and balance public interest and private interest considerations. ${ }^{394}$

As far as the instrument choice, or the kind of environmental regulation to achieve the environmental goal, is concerned, also politicians may have their own interests in choosing a particular instrument. Indeed, the final policy might depend on the particular subject, but one can assume that politicians would choose that policy instrument that would maximise state revenue and hence power. Moreover, for reelection purposes, politicians might choose that policy of which the benefits are more visible than the costs. ${ }^{395}$

With respect to the stringency of regulation (or simply the fact that a regulation is issued), sometimes, the motivation for a certain environmental regulation is the political ambition to provide some action in response to an accident. The demand for regulation might in such case not be initiated by a well-defined interest group. In case of an accident, a so-called shadow interest group might come into existence. Potential victims of an accident that caused environmental harm might be such a shadow interest group. ${ }^{396}$ As such groups might become an effective lobby group, rational politicians, who wish to be re-elected, might under certain circumstances respond to those groups.

\subsubsection{Industry}

Several analyses examined the implications of different policy instruments on the welfare of industry and generated a number of insights into just why a certain policy might be adopted instead of what economic theory and the public interest approach would expect. From these analyses, it appears that industry would prefer direct regulation. Buchanan and Tullock (1975) showed that emission standards (or more precisely quotas on polluting outputs) would generally be preferred to effluent taxes by firms themselves, as these measures effectively may limit entry. ${ }^{397}$ Indeed, environmental regulations may produce a cartel-type

Svendsen 1998,34 .

Oates \& Portney 2001, 14.

Buchanan \& Tullock 1975, 139-147.

See Damania 1999, 415-433, who finds that there is a preference for standards over other instruments; Dewees 1983, 53-71; Hahn 1990, 21-45, in particular 23; Leidy \& Hoekman 1994, 241-258, who examines in an international context the lobbying for a cartel-like solution.

Adler 1996, 26-34.

Svendsen 1998, 1-16.

Svendsen 1998, 31.

Svendsen 1998, 34

Keenan \& Rubin 1988, 21-36.

Buchanan \& Tullock 1975, 139-147. See also Oates \& Portney 2001, 7. 
outcome with increased profits for the industry, if new firms cannot easily comply with the standards. Dewees ${ }^{398}$ confirmed and extended the findings of Buchanan and Tullock. He showed that industrial interest groups would prefer systems of marketable emissions to effluent standards if the permits were distributed free of charge to existing sources. Leidy and Hoekman, ${ }^{399}$ who treat the issue in the context of an open economy, find further reasons for various interest groups to prefer direct regulation to emission taxes. In summary, industry would be expected to oppose a tax because a tax raises production costs for capitalintensive firms and does not create barriers to entry. 400

With respect to industry's lobbying strategy, more technically advanced firms of an industry might argue that the 'best available technique' should be employed, in order to have a competitive advantage over competitors. Environmental measures that prescribe more stringent standards for the new than for existing plants (as is often the case since retrofitting can be expensive) may be welcomed by industry lobby groups as a new barrier to entry into the polluting industry. In the literature, this has been defined as 'predatory regulation'. ${ }^{401}$ It must be noted that in these circumstances, industry might have an ally in environmental lobby groups.

If the motivation for a certain environmental regulation is the political ambition to provide some action in response to an accident as discussed above, then industry, realising that environmental regulation can not be avoided, might try to co-operate and try to change the contents of the regulation to its advantage. ${ }^{402}$ An example might be a grandfather clause, which stipulates that the regulation will not be applicable to firms that are already in existence. In such a way, regulation might introduce a barrier to entry and protect existing industry. Industry will oppose a tax, as it does not create barriers to entry.

With respect to the stringency of regulation, a common presumption is that industry will always try to lobby for lenient regulation. However, lobbying activities of industry might go into various directions. Sometimes industry might lobby for lenient standards; sometimes stringent regulation will be favoured. In general, rent seeking by industry consists of pursuing governmental intervention that would provide a comparative advantage to that particular industry. Various regulatory measures that create a barrier to entry or reduce output like tariffs and licences often reduce competition, create cartels, increase industry profits and would provide such a comparative advantage. ${ }^{403}$

In sum, industry will not necessarily lobby for lenient regulation; it will strive for that policy that provides the industry with a comparative advantage. Dependent on the situation, this might be lenient regulation, but also stringent standards, in case of predatory regulation or a grandfather clause.

\subsubsection{Environmental Groups}

The environmental policy traditionally preferred by environmental groups has been command and control regulation. ${ }^{404}$ Environmental organisations look unfavourably on certain incentive-based instruments. Many environmentalists object to such instruments on philosophical grounds, as policies like pollution taxes or systems of tradable emission permits would provide firms with a licence to pollute and therefore these policies are considered to be immoral and unacceptable. Environmental organisations must also be careful not to alienate their members by supporting such policy measures. Moreover, environmental groups may have serious doubts about such policy instruments in practice. If the government sets too low a tax rate, then the environmental objective will not be realised. Furthermore, it may not be an easy matter to raise tax rates when needed. Furthermore, from an environmentalist's perspective, a policy instrument that explicitly limits levels of polluting activities might more reliably achieve environmental goals than a price instrument, like a tax, the response to which is uncertain. 405 Finally, as Hahn indicates, environmental groups may be more concerned with symbols, such as forced scrubbing, than actual environmental outcomes. Environmentalists may want a high symbolic value for environmental quality for several reasons. First, it may signify a long-term commitment if a government sets standards either at the limits of technological feasibility or beyond the realm of what is currently feasible. Another explanation is that symbols might help to influence the preference structure and values of individuals. Thus, environmentalists may want future generations to grow up with an environmental ethic. ${ }^{406}$

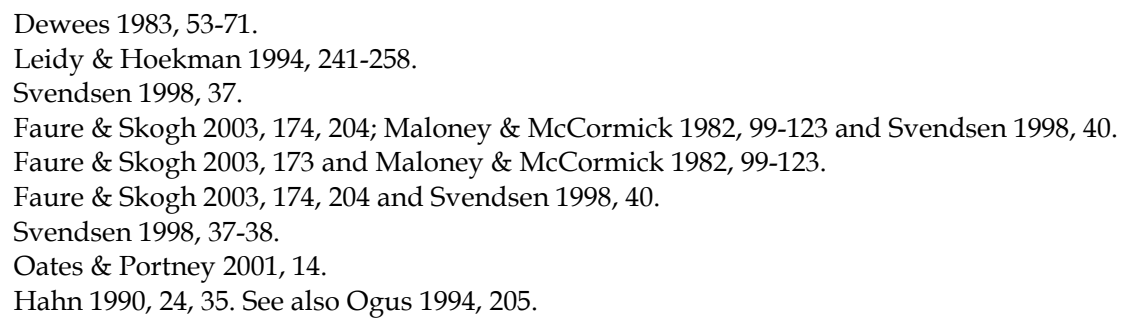


As far as the quality of regulation is concerned, it is clear that environmentalists lobby for environmental quality improvement. Therefore, environmental groups try to maximise membership in order to achieve lobbying power for environmental improvement. Yet, free riding is rational, as no individual can be excluded from the benefit of good environmental quality. ${ }^{407}$ From this perspective, the extent to which environmental groups have mobilised their members so efficiently is surprising. According to Olson's theory, environmental groups represent a large-group case, where it would be difficult to organise. But in seeming contradiction to the prediction of the theory, environmental groups have proved to be a very powerful force in the policy arena. ${ }^{408}$ To explain why this membership exists, reasons other than economic ones must be taken into account like morality, friendship, and social objectives or significant support from foundations. ${ }^{409}$

In sum, to argue that environmental laws would only serve private interests would be equally too one-sided as to argue that environmental regulation only serves the public well-being. Indeed, many environmental statutes are enacted in an attempt to protect public interests. ${ }^{410}$ Nevertheless, it must be admitted that environmental regulations may be very conducive to rent seeking.

Indeed, in the environmental context, both regulated firms and 'public interest' representatives have strong incentives for rent-seeking, as they both might gain from reductions in output and the creation of barriers to entry. Indeed, regulated firms and public interest groups may not always agree on the design of specific regulatory programs, they often share a common interest. ${ }^{411}$ Interests of industry and the environmentalists may coincide, for example, in the case of predatory regulation. ${ }^{412}$ Therefore, one should not be surprised that economic interests lobby, and make alliances with 'public interest' organisations to ensure favourable treatment for their own interests. ${ }^{413}$

It merits now examining how rent seeking might influence the level at which regulation is set.

\subsection{Environmental Federalism}

\subsubsection{Reasons for Centralisation, Based on Private Interest Distortions}

Lobbying might not only concern the contents of the regulation, but also the question at what level of government the regulation will be issued. Interest groups, having a stake in a certain area of regulation, might prefer that level of government to issue a regulation at which their strength is greatest in comparison to other interest groups with different concerns in the same area. ${ }^{414}$ Interest groups might therefore lobby to ensure that a certain regulation is issued at a particular level of government. Hence, sometimes, public choice theory might explain why certain regulations are decided at the central level and why regulations are harmonised, in contrast to what would be efficient according to economic theory. ${ }^{415}$ This paragraph will discuss the influence of interest groups on the level of environmental decision-making.

With respect to environmental regulation, there are three frequently advanced private interest distortions, which might influence the level of decision-making for environmental policy. First, private interest distortions might cause that certain interests are systematically underrepresented at a particular decision-making level. Moreover, two arguments that were dealt with in the public interest approach are also prominent in the private interest debate: states might engage in a race-to-the-bottom due to interest group lobbying and the harmonisation of marketing conditions might be incited by interest groups. This paragraph will examine whether these claims give rise to a preference for environmental regulation at local or central level.

The three claims will be examined successively. First, attention will go to the relative strength of interest groups at different governmental levels. It is frequently advanced that environmental groups are underrepresented at the local level relative to business interests due to public choice distortions. On this ground it is often argued that responsibility for environmental regulation should be assigned to the central level. ${ }^{416}$ It will be examined whether such distortion indeed exists, and whether it would justify centralised

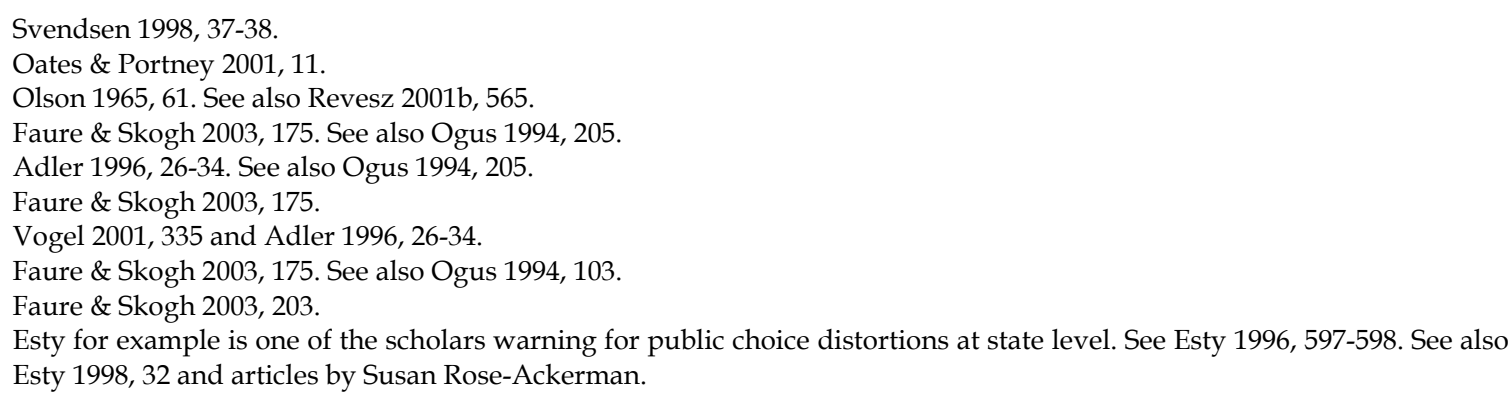


environmental regulation. Second, it will be examined whether the risk of a race-to-the-bottom due to lobbying would justify centralised environmental decision-making and third it will be studied whether the argument that harmonisation of marketing conditions might be incited by interest groups claims gives rise to a preference for regulation at central level.

The examination of these private interest distortions might help to explain why certain regulations are decided at the central level and why regulations are harmonised, in contrast to what would be efficient according to economic theory. In such way, the private interest approach aims to contribute to the theory on the optimal decision-making level for environmental liability rules.

\subsubsection{Relative Strength of Interest Groups at Different Governmental Levels}

Advocates of centralised regulation frequently claim that the decision-making process would be systematically more distorted at local level than at the central level. The justifications for this claim rest upon both the public attention for environmental matters and the interest group structure at respectively local and central level. According to Esty, the public indifference with respect to many state and local environmental decisions, as well as greater media attention to central level activities might lead to more private interest distortion at state and local levels than at the central level. Moreover, Esty expects that at central level lobbying excesses of a certain interest group would be opposed by countervailing interest groups. In contrast, Esty assumes that state and local environmental policy manipulation would be more disguised, due to the difference in the interest group structure at local level. Industry groups, that favour less stringent regulation, tend to be small and cohesive at the local level, and therefore can induce states to adopt lenient environmental standards, whereas the citizens, who support more stringent regulations, are a larger and more diffuse group. As a result of economies of scale in organisation, advocates of centralised regulation argue that environmental groups would be less disadvantaged at the central level than at the local level, where they would be underrepresented relative to business interests. Therefore, the interest group structure of environmentalists and industry pressure groups at respectively state and central level would suggest that centralised decision-making would provide a more balanced playing field for conflicting interests. Hence, this would suggest that responsibility for environmental regulation should be assigned to the central level. 417

Yet, as Revesz indicates, there are several reasons to be sceptical about the soundness of this claim. ${ }^{418}$ Indeed, Olson's theory of collective action showed that large groups generally perform less efficiently than smaller groups. Moreover, the larger the group, the more difficult it might be to overcome the free-riding problem. ${ }^{419}$ Thus, acting at the central level might even magnify the free-rider problems that environmental groups face. It can therefore not be guaranteed that these organisational problems for environmental interest groups would be less serious at the central level. ${ }^{420}$ Indeed, Olson's theory of collective action does not predict greater lobbying power of environmental groups at the central level than at the local level.

Moreover, as Revesz rightly indicates, the question is not only whether environmental groups would be more effective at the local or central level, but also and more importantly, how the effectiveness of environmental groups at both levels relates to the effectiveness of other interest groups with different concerns in the same area, which in most circumstances will be the industry lobby groups. Indeed, for many environmental problems, firms with international operations, like the automobile industry, will comprise an important portion of the industry that will be affected by an environmental regulation. Yet, such firms will not be hampered by any additional free-rider problems or any reduction in the homogeneity of their interests when participating in the policymaking process at the central level. For environmental groups, on the contrary, the national aggregation of environmental interests might result in the loss of homogeneity of interests. Indeed, at local level, some environmental groups might care in particular about air quality, whereas in other states other environmental problems are much more important. This might complicate organisational problems, even if there would be economies of scale at the central level. ${ }^{421}$ The cost of organisation indeed increases as regional and national diversity of interests have to be overcome. Based on these findings, Ogus argues that the further removed the lobbying arena is from local activists, the greater the relative power will be of sectional interests over ideological interests. This would mean that the relative power of industry interest groups would be greater at central level than the power of environmental lobby groups at central level. Based on this reasoning, one might even expect that

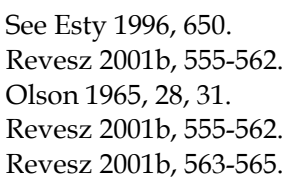


centralised environmental regulation would tend to meet powerful and well-organised industry lobby groups, instead of environmental concerns. ${ }^{422}$

Hence, contrary to the assertions of central environmental regulation advocates, the above reasoning might indicate that environmental groups would not necessarily be more powerful at the central level than at the state level.

Concluding, lobbying of both environmental interest groups and of industry interest groups will take place at the central as well as at the local level. Furthermore, it can not be guaranteed that environmental lobby groups are more powerful at the central level than at local level. In some circumstances it might be the opposite. Hence, the claim that the environmental decision-making process would be systematically more distorted at local level than at the central level and therefore would justify centralised environmental regulation is precipitate. A case by case examination will be necessary to determine the relative strength of all interest groups involved at different governmental levels, the possible lobby attitudes and the eventual outcome at the different levels. Only then, a reasoned decision can be made on the optimal decision-making level for a particular environmental regulation. Moreover, if both levels would yield equivalent environmental policy, a decentralised environmental policy may be preferable if there is significant heterogeneity of the effects of pollution across jurisdictions. A decentralised policy could then be closer to the preferences and needs of the jurisdictions.

\subsubsection{Race-to-the-bottom Due to Interest Group Lobbying}

Besides the claim that the environmental decision-making process would be systematically more distorted at state or local levels than at the central level due to lobbying, it is often argued that the risk of a race-tothe-bottom in environmental standards between states, caused by lobbying at state level, would justify centralised environmental decision-making.

The race-to-the-bottom argument has already been studied when dealing with the public interest approach. This paragraph will look upon the argument from the private interest approach and will examine whether the lobbying activities at the local level would justify centralised environmental regulation. The frequently advanced reasoning is that uniform centralised rules would avoid the economic competition between jurisdictions that might induce these jurisdictions to set excessively lax environmental standards in order to attract industry. It must be admitted that environmental regulations affect competition and therefore attract significant attention from powerful economic interest groups such as oil, chemical and labour lobbies. On the other hand, the consequences of environmental regulation also attract significant interest from non-economic interest groups like environmentalists. ${ }^{423}$ Lobbying activities at local level can therefore not be ignored, but whether such lobbying justifies centralised environmental regulation still has to be examined.

There has emerged a large theoretical and empirical literature that explores interjurisdictional competition, its welfare implications and the existence of a race-to-the-bottom. This literature has been discussed in the public interest approach. Models of interjurisdictional competition, like the Oates and Schwab model, 424 show that economic competition among governments might encourage good environmental decisions. Yet, relaxation of the assumptions of these models showed that there are also circumstances where things can go awry. Game-theoretic models that explore the distortions that competition can generate have been discussed as well. Yet, overall, it was concluded that there is little systematic evidence of any race-to-the-bottom. Although there is no doubt that industry will lobby and that governments actively engage in various forms of economic competition, this does not address the issue. Such competition may encourage good public decisions. The important issue is how large the kinds of distortions due to lobbying and strategic behaviour are. If they represent only small deviations from efficient outcomes, they may not be harmful. Thus, the fact that local governments introduce policy measures and act strategically to influence industrial location does not prove that there will be a race-to-thebottom and neither that this competition would justify centralised environmental regulation. ${ }^{425}$

If there were distorting lobbying, eventually justifying centralised environmental regulation, then one might expect that state governments should exhibit less concern about environmental problems than does the central government and consequently that decentralisation of environmental policies might lead to a deterioration of environmental quality at state level. Moreover, there would be few examples in which

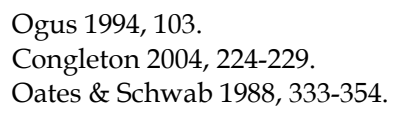


decentralised jurisdictions would introduce environmental measures that are more stringent than the standards that are determined at the central level.

Based on studies conducted in the United States, it appears however that decentralisation did not lead to worse environmental policies. Moreover, various states have introduced regulations, for example automobile emission standards, hazardous waste regulation or municipal solid waste regulation that go beyond federal government requirements. ${ }^{426}$

Many states adopted innovative forms of regulation and imposing costs on in-state firms, also in areas that were not federal compelled. Of course the mere existence of state environmental statutes is not necessarily evidence of state environmental concern because the statutes may be symbolic and not enforced. However, the fact that states are adopting environmental programmes that are not federally compelled, and that impose costs on in-state firms, contradicts the simplistic argument for central intervention that the local level would be more affected by private interest distortions than the central legislative process. ${ }^{427}$

It must also be admitted that not every state is as active in environmental regulation. Some states might take a clear lead in certain environmental regulatory fields, citizens of other states may prefer more lax standards than the central government requires and therefore have no reason to adopt additional environmental programmes. These different responses might be explained in two ways. Either, private interest distortions may preclude at least some states from enacting the types of environmental regulation that reflect the preferences of their citizens. Alternatively, it may be that preferences for environmental protection are not distributed homogeneously among states and that citizens of states with less stringent environmental standards value environmental protection less than competing goals. If indeed differences in preferences for environmental improvements are the reason why certain states adopt more stringent regulations than do others, the pattern of regulation observed across states would not be the result of private interest distortions but instead would reflect differing preferences for environmental protection, and hence would not need to be corrected by centralised regulation. ${ }^{428}$

Furthermore, three recent studies in the United States have examined the impact on environmental policies of the decentralisation of responsibilities for certain aspects of environmental management during the Reagan period. It appears that none of the three studies found any evidence of a race-to-the-bottom. ${ }^{429}$ List and Gerking, who used state-level data, examined at both local and central governmental level environmental quality and abatement expenditures. It was examined whether environmental quality was sacrificed as state and local governments acquired more autonomy in implementing standards and in enforcing regulations. They find no evidence of any deterioration in environmental quality or a decline in abatement efforts. On the contrary, they did find some indications of improvements. Thus, state environmental quality appears to reflect more than just the dictates of federal policy. ${ }^{430}$ In another assessment of the devolution of environmental policy in the Reagan era, Millimet studied airborne emissions of sulphur dioxide and industry spending on pollution abatement. He showed that actual emissions were lower and abatement spending higher than forecasted by his model. This finding suggested a race-to-the-top instead of to-the-bottom. ${ }^{431}$ This result was confirmed by Fredriksson and Millimet whose results provide some evidence for a strategic race to the top among U.S. states. ${ }^{432}$

Hence, the presumption that (industry) lobbying at local level would cause a race-to-the-bottom in environmental quality, justifying centralised environmental regulation, may also be a bit hastened. The findings of the studies above might suggest that, also at local level, industry will not necessarily lobby for lenient regulation. Indeed, various strategies are possible. As Revesz indicates, firms might create rents and barriers to entry by stringent regulation. In such circumstances, the impetus for environmental regulation comes, implicitly or explicitly, from the regulated firms themselves. Stringent regulation gives them an advantage over (foreign) competitors. Moreover, stringent regulation might provide benefits to producers of pollution control equipment. The demand for environmental regulation then comes from manufacturers of pollution control equipment, or environmentally friendly technologies. On the other hand, it can not be excluded that there might be circumstances in which industry indeed may lobby for lenient regulation, for example to obtain an interregional comparative advantage. ${ }^{433}$

In sum, the diverse nature of lobbying activities explains why the outcome of lobbying activities at either local or central level can not be easily predicted. It can only be observed that lobbying activities at the

\section{Ibidem}

Revesz 2001b, 583.

Revesz 2001b, 636, 558.

Oates \& Portney 2001, 23.

List \& Gerking 2000, 453-471.

Millimet 2001, 24.

Fredriksson \& Millimet 2002, 101-122.

Revesz 2001b, 572-575. 
local level do not necessarily need to lead to under-regulation at the local level or to a race-to-the-bottom, and that this argument therefore would not justify centralised regulation. Indeed, public choice theory can better explain ad post interest group rationalisations than provide ex ante predictions for future regulations. ${ }^{434}$ Public choice theory is not able to answer who will win by lobbying and at what level regulation is best to be set. Only a case-by-case study might make it possible to give some indications at which level certain lobby groups will be strongest and what they will lobby for.

\subsubsection{Harmonisation of Marketing Conditions incited by Interest Groups}

The 'harmonisation of competition' reasoning was advanced as an argument for centralisation of environmental regulation, within the public interest approach. Yet, this argument might also be examined from the private-interest approach.

Indeed, centralisation to harmonise conditions of competition might much more serve the interests of industries in heavily regulated areas than the public interest. Industry in states that already have relatively stringent environmental standards may have an incentive to lobby at the central level. The purpose of such lobbying would be to make these stringent environmental standards compulsory throughout the federation in order to force their competitors also to comply and, thus to obtain a competitive advantage and to create barriers to entry. In other words, predatory regulation may explain why many environmental regulations emerge at the central level if economic theory would predict that the problem would be better dealt with at the local level. ${ }^{435}$ Moreover, industries with strong economies of scale tend to prefer uniform federal regulation to a patchwork of different state standards. ${ }^{436}$ Also for new regulatory fields, industry might prefer centralised regulation. Faure and Lefevere argue that this might explain why some industries will lobby in favour of environmental regulation at the European level. For new areas, where no national legislation exists, industry lobby groups may encounter less countervailing power of environmental organisations than at the local level where the environmental problems occur. ${ }^{437}$ Hence, centralised regulation might be more lenient than the regulation that could have been issued at national level.

In sum, centralisation because of the harmonisation of competition might more serve the interests of industries in heavily regulated areas than the public interest. The harmonisation of competition argument therefore does not plead for centralisation, neither from a public interest approach nor from a private interest approach.

\subsubsection{Consequences and Responses to Lobbying Activities}

The results above illustrate that lobbying of both environmental interest groups and of industry interest groups might take place at the central as well as at the local level. Moreover, it appears that lobbying efforts of industry might go in either direction, depending on whether they intend to erect barriers to entry or whether they strive for lenient regulation. This makes it very difficult to predict how lobbying will evolve and at what level a certain regulation is best set. Indeed, public choice theory can better explain ex post interest group behaviour than provide ex ante predictions on future regulations. Only a case-by-case study might make it possible to give some indications at which level certain lobby groups will be strongest and what they will lobby for. Nevertheless, at the local level as well as at the central level, lobbying cannot be avoided but transparency and, for example, consultation of environmental interest groups or other nongovernmental organisations (NGO's) might reduce capturing of the regulator by private interests to the detriment of the public interest.

\subsection{Application to Environmental Liability}

In a first step, the harmonisation of environmental liability rules was examined on the basis of the public interest approach. It was concluded that there are in fact few reasons for a centralised environmental liability regime. Yet, as for environmental regulation in general, it merits to examine the optimal decisionmaking level for environmental liability rules in a federal system from a private interest approach as well. Indeed, the potential influence of lobbying in the decision-making process on environmental liability rules, for example for soil pollution, will have to be examined in order to refine the theory on the optimal decision-making level for environmental liability rules. However, as for environmental regulation in

\footnotetext{
$434 \quad$ Revesz 2001b, 576.

$435 \quad$ Faure \& Skogh 2003, 175, 321

436 Revesz 2001b, 573.

437 Faure \& Skogh 2003, 175, 321. See also Faure \& Lefevere 1995, 320-351.
} 
general, at the theoretical level, it is very difficult to proclaim what industry will lobby for and what the best level of regulation is. Only in a real context it might be possible to indicate where possible lobbying activities might occur and even then it is very difficult to predict the outcome of the law-making process. Nevertheless, paragraph 2 of chapter 6, which examines private interest distortions in the making of the Environmental Liability Directive in the European Union, will go into more detail than what is possible here at the theoretical level.

Indeed, at the theoretical level, advocates of centralised regulation might claim that the decisionmaking process for liability rules would be systematically more distorted at state and local levels than at the central level. At state level, industry interest groups would be stronger relative to environmental lobby groups, so that states, fearing to loose industry, might be hampered to introduce a stringent liability regime for environmental damage. Furthermore, states may only be willing to introduce a stringent liability regime if they are sure that other states have to do the same. ${ }^{438}$ As a result of economies of scale in organisation, advocates of centralised regulation might argue that environmental groups would be less disadvantaged at the central level than at the state level, where they would be underrepresented relative to business interests. Hence, in these circumstances, centralisation of the environmental liability regime would solve public interest distortions at the local level. However, as for the general situation, the question is not only whether environmental groups would be more effective at the state or central level, but more importantly, how the effectiveness of environmental groups at both levels relates to the effectiveness of other interest groups with different concerns in the same area. Hence, the reasoning that the decision-making process for liability rules would be systematically more distorted at state and local levels than at the central level might not always hold in a real context.

Besides the fact that the relative power of different interest groups at different governmental levels might depend on the situation, it is unclear in which direction lobbying efforts will go. It might be that the environmental liability regime at central level might generate, as a compromise, to the 'average' stringency of regulations that had existed at the decentralised level. On the other hand, if some states already have a stringent environmental liability regime, interest groups of these heavily regulated states may have incentives to extend their strict national regulations to the central level, forcing their foreign competitors to comply with this regulation with which they already comply and hence to create barriers to entry. Moreover, environmental lobby groups at the central level will only encourage this demand for a uniform stringent liability regime. In these circumstances the harmonisation or centralisation of a environmental liability regime could be abused to serve the private interests of industry in already heavily regulated states, by erecting barriers to entry instead of serving the public interest. ${ }^{439}$ Still, it is unclear whether environmental liability rules would be used by interest groups to create barriers to entry, although the risk should not be ignored.

In sum, as for regulation in general, it appears difficult to estimate what industry will lobby for and what the best level of regulation is. However, it seems clear that the private interest distortions would not automatically justify a centralised regime, as lobbying affects the local as well as the central level. Unfortunately, public choice theory is not able to predict the magnitude and consequences of the distortions at the local level compared to the central level. However, in any case, transparency in the debate at either level might be welcomed in order to guarantee that a regulation would serve the public interest.

Turning to the example of soil pollution it seems that, as for liability rules in general, at the theoretical level it is very difficult to proclaim at which governmental level lobbying will be strongest. Nevertheless, soil pollution mostly is a local problem, and it could be assumed that therefore, it might be easier for environmental lobby groups to ensure that citizens, confronted with local contamination, support their actions for stringent liability rules. At the central level, at which most citizens are much less involved, industry might have more lobbying power. The argument that centralisation would be necessary because industry interest groups would be stronger relative to environmental lobby groups at local level, might therefore not hold for liability rules for soil pollution.

Yet, paragraph 2 of chapter 6, which examine the private interest distortions in the making of the Environmental Liability Directive in the European Union, will give more insight in how lobbying might influence the law-making process.

\subsection{Summary of the Private Interest Approach}

This chapter first presented a brief overview of the theories that examine the influence of lobbying on the law-making process: Capture Theory, Public Choice Theory and the Economic Theory of Regulation.

$438 \quad$ Bergkamp 2001a, 384.

439 Faure 2003a, 76-77. 
Moreover, the various stakes of the government, the industry and environmentalists, the main lobby groups in the environmental law making process, were discussed. In a second step, these results were applied to environmental federalism. Lobbying might take place at all levels of decision-making. Indeed, lobbying might not only concern the contents of the regulation, but also at what level of government the regulation will be issued. Therefore, the influence of interest groups on the level of environmental decisionmaking was examined. Finally, the potential influence of lobbying on environmental liability rules, in particular for soil pollution was examined in order to refine the theory on the optimal decision-making level for environmental liability rules.

The private interest approach, combining Capture Theory, Public Choice Theory and the Economic Theory of Regulation, focuses on the way in which (environmental) regulation is affected by the influence of a variety of interest groups. It would be too one-sided though, to argue that environmental laws only serve private interests. Many environmental statutes are enacted in an attempt to protect public interests. Nevertheless, it must be admitted that environmental regulations may be very conducive to rent seeking. Yet, from the examination of the various stakes of the actors in the environmental decision-making process, it was concluded that rent seeking behaviour might not always be straightforward. Contrary to common belief, industry does not always oppose regulation, nor can it be assumed that support for more regulations comes primarily from those who have the public's well-being at heart. In the environmental context, both regulated firms and 'public interest' representatives have strong incentives for rent-seeking, as they both stand to gain from reductions in output and the creation of barriers to entry. Indeed, regulated firms and public interest groups may not always agree on the design of specific regulatory programs, they often share a common interest. Interests of industry and the environmentalists may coincide, for example, in the case of predatory regulation. Therefore, one should not be surprised that economic interests lobby, and make alliances with 'public interest' organisations to ensure favourable treatment for their own interests.

These results were applied to environmental federalism. Interest groups, having a stake in a certain area of regulation, might prefer that level of government to issue a regulation at which their strength is greatest in comparison to other interest groups with different concerns in the same area. Interest groups might therefore lobby to ensure that a certain regulation is issued at a particular level of government. Hence, sometimes, public choice theory might explain why certain regulations are decided at the central level and why regulations are harmonised, in contrast to what would be efficient according to economic theory.

Three frequently advanced private interest distortions, that might influence the level of decisionmaking for environmental policy, were examined. First, it is often argued that private interest distortions might cause that environmental interests are systematically underrepresented at the local level. Moreover, two arguments that were dealt with in the public interest approach are also prominent in the public choice debate: states might engage in a race-to-the-bottom due to interest group lobbying and the harmonisation of marketing conditions might be incited by interest groups. It was examined whether these three claims would justify centralisation of environmental regulation.

As far as the first, often repeated argument for federal intervention was concerned, it was concluded that lobbying of both environmental interest groups and of industry interest groups will take place at the central as well as at the state level. Moreover, it can not be ensured that environmental lobby groups are more powerful at the central level than at state level. In some circumstances it might be the opposite. Furthermore, it appears that lobbying efforts of industry might go in either direction, depending whether they intend to erect barriers to entry or whether they strive for lenient regulation. Hence, the claim that the environmental decision-making process would be systematically more distorted at state and local level than at the central level and therefore would justify centralised environmental regulation is precipitate. This negative conclusion should not imply that states would enact optimal environmental regulation, or that states exhibit less serious private interest distortions than the central government. The lobbying process is so complex that any general conclusion is almost certain to be wrong. A case by case examination will be necessary to determine the relative strength of all interest groups involved at different governmental levels, the possible lobby attitudes and the eventual outcome at the different levels. Only then, a reasoned decision can be made on the optimal decision-making level for environmental regulation. Nevertheless, if the stringency of environmental policy is independent from the institutional design, a decentralised environmental policy may be preferable if there is significant heterogeneity of the effects of pollution across jurisdictions so that the regulation can be adapted to the preferences and needs of the citizens.

The presumption that (industry) lobbying at state level would cause a race-to-the-bottom in environmental quality, justifying centralised environmental regulation, appeared also to be somewhat hastened. Industry will not necessarily lobby for lenient regulation. Indeed, various strategies are possible. Firms might create rents and barriers to entry by stringent regulation. In such circumstances, the impetus for environmental regulation comes, implicitly or explicitly, from the regulated firms themselves. Stringent 
regulation gives them an advantage over (foreign) competitors. Moreover, stringent regulation might provide benefits to producers of pollution control equipment. The demand for environmental regulation then comes from manufacturers of pollution control equipment or environmentally friendly technologies. On the other hand, it can not be excluded that there might be circumstances in which industry may indeed lobby for lenient regulation, for example to obtain an interregional comparative advantage.

Finally, it was argued that centralisation because of harmonisation of competition might serve the interests of industries in heavily regulated areas instead of the public interest, for example through predatory regulation. Thus, the harmonisation of competition argument did not plead for centralisation, even when examined from a private interest approach instead of a public interest approach.

In sum, the diverse nature of lobbying activities explains why the outcome of lobbying activities at either state or central level can not be easily predicted. It can only be concluded that lobbying affects the local as well as the central level and that lobbying activities at the state level do not necessarily need to lead to under-regulation at the state level or to a race-to-the-bottom. Hence, private interest distortions would not automatically justify a centralised regime. Only a case-by-case study might make it possible to give some indications at which level certain lobby groups might be strongest, what they would lobby for and what the best level for regulation would be.

The results for environmental federalism were accordingly refined to environmental liability rules in a federal system. As for regulation in general, it appears difficult to estimate what industry will lobby for, what the best level of regulation is and what the result of lobbying will be. However, it seems clear that the private interest distortions would not automatically justify a centralised regime, as lobbying affects the local as well as the central level. Unfortunately, public choice theory is not able to predict the magnitude and consequences of the distortions at the local level compared to the central level. However, in any case, transparency in the debate at either level might be welcomed in order to guarantee that a regulation would serve the public interest. As far as liability rules for soil pollution were concerned, it was argued that soil pollution mostly is a local problem, and it might be assumed that therefore, it might be easier for environmental lobby groups to ensure that citizens support their actions for stringent liability rules at local level then at central level, at which most citizens are much less involved. The argument that centralisation would be necessary because industry interest groups would be stronger relative to environmental lobby groups at local level, might therefore not hold for liability rules for soil pollution.

Therefore, also based on the private interest approach, there remains a strong case for decentralised environmental decision-making where the benefits and costs of such measures are localised.

It merits now merging both public and private interest approaches in order to develop a framework for decision-making on the optimal level of environmental liability rules. As an example, the framework will be applied to liability for soil pollution. Indeed, only a combined public-private interest approach that explicitly recognises the interaction of different interest groups can grasp the complexity of environmental policy.

\section{Framework for Decision-making on the Optimal Governmental Level for Liability for Environmental Damage in a Federal System, Based on a Public and Private Interest Approach}

This doctoral research aims to refine the existing scholarly debate on harmonisation of environmental regulation in a federal system by examining the 'optimal policy level' of liability rules in a federal system from a public interest approach as well as from a private interest approach. The combination of these two theoretical approaches might allow to unravel all factors that might influence the optimal level of regulation. In the above paragraphes, it was examined which distortions could arise, and, starting from decentralisation, for which reasons the decision-making power might be shifted to a higher governmental level. By combining the results of both theoretical approaches, it is now possible, in a first step, to develop a framework that might be used in order to provide guidance on the optimal level of liability rules for environmental damage in a particular federal system.

A framework inherently means simplification. The objective however is not to offer a simple answer on the question at which level to regulate soil pollution or any other environmental problem, but to offer a means to deal with the problem and to evaluate different policy options. In that sense, the framework intends to formalise and generalise the analysis of the public interest and private interest approach above and to show which policy options might be available in a particular situation. As such, the framework may also provide a useful guidance for other kinds of environmental policies.

In a second step, on the basis of the framework, a few intermediate conclusions can be formulated. 


\subsection{Framework for the Optimal Decision-making Level of Environmental Liability Rules in a Federal System}

The starting point of the framework, presented in Figure 2, is decentralisation. Rules can then be optimally adapted to the preferences of the citizens. Consequently, it will be indicated which circumstances would ask for central intervention. Based on the results of the public and the private interest approach, it is possible to derive five evaluation factors upon which a framework for decision-making on the optimal policy level for liability rules might be built. These five evaluation factors are the presence of externalities, the indications for a race-to-the-bottom or political drag, market access distortions through divergence of rules, the need to guarantee a minimum level of protection, all four based on the public interest approach and finally the influence of interest group distortions, based on the private interest approach. These five evaluation factors, that preferably should be evaluated in order to formulate a balanced conclusion about the optimal decision-making level for a particular environmental problem, were of course discussed above in detail. The weight and importance of each of these factors might depend on the actual situation though. Moreover, in certain cases these factors might be connected with each other.

Thus, the framework presents the five evaluation factors and shows the possible policy responses that might be opted for, depending on the distortions that might exist in an actual situation. Hence, starting from this framework, a balanced conclusion could be made about the optimal decision-making level of environmental liability rules in a federal system.

As an example, the framework will be applied to soil pollution (see Figure 3, by means of dotted lines). Indeed, soil (pollution) can be considered as a - predominantly local - public good, on which federalism-theories can perfectly be applied. Again, it will be indicated which circumstances would point to either centralisation or decentralisation and some guiding criteria will be formulated.

An explanation of the evaluation factors and the possible policy responses, for liability for environmental damage and for liability for soil pollution as an example will follow below. 


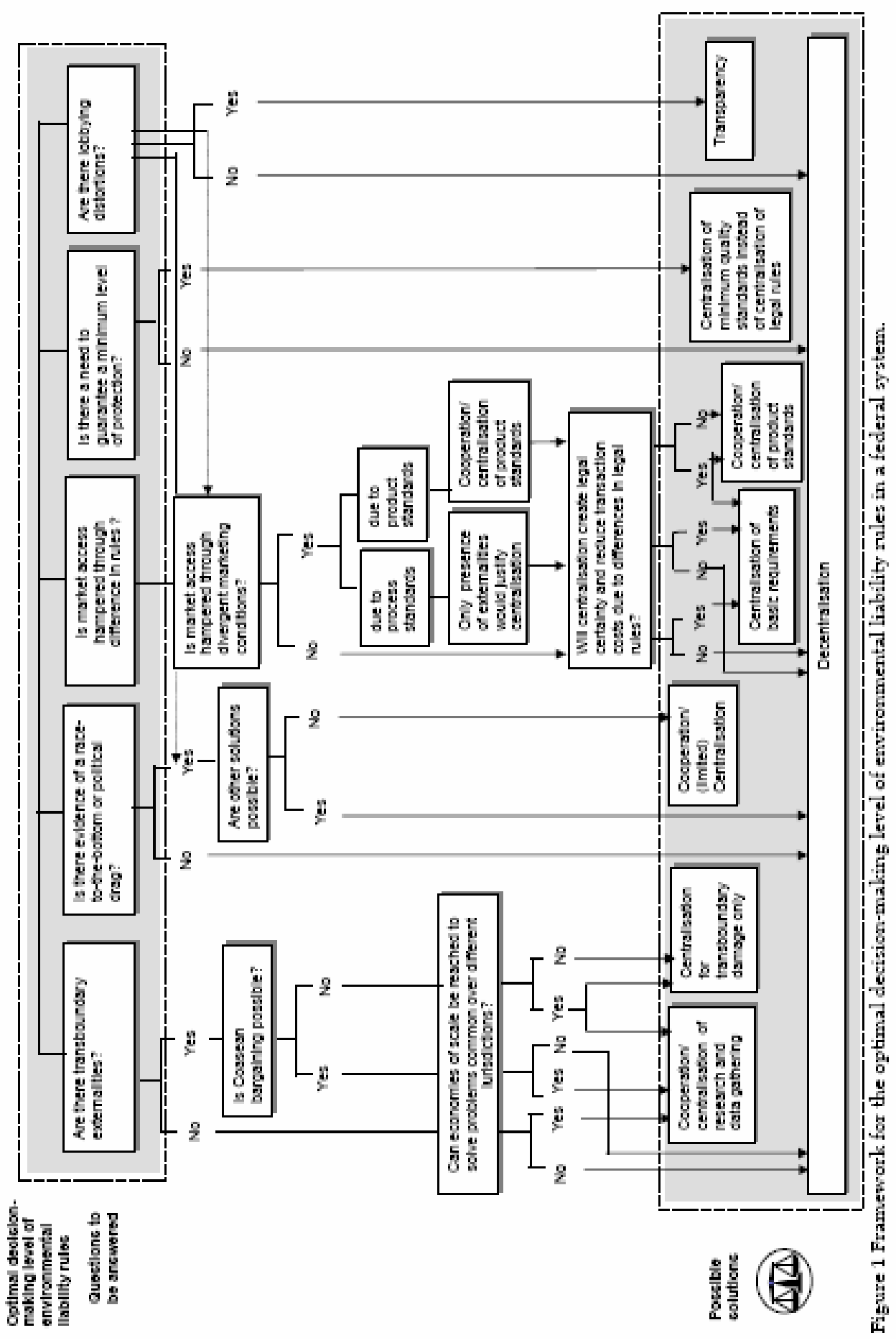




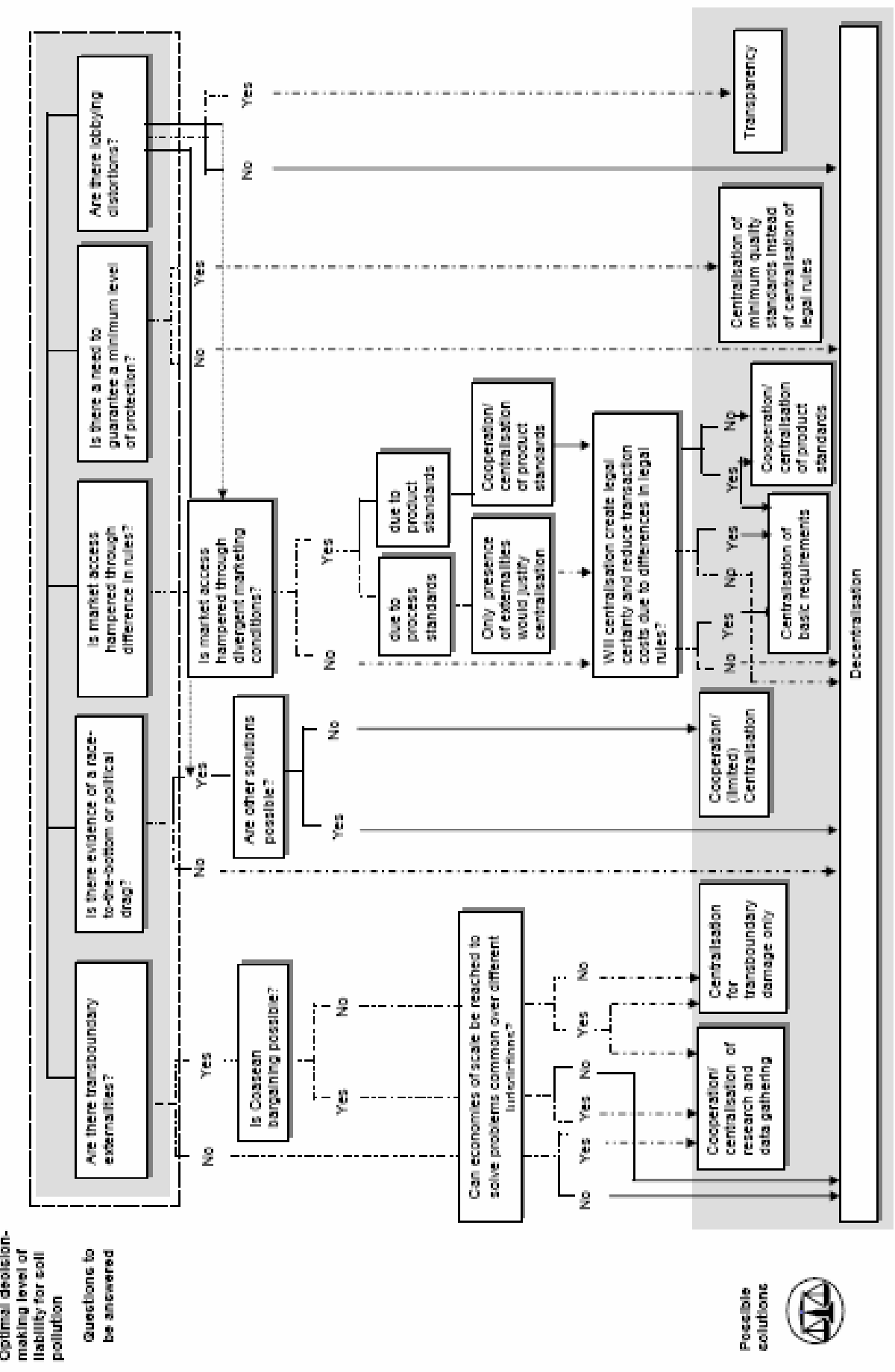




\section{Explanation of the Framework}

Presence of Transboundary Externalities

A first factor for evaluation is the presence of transboundary externalities. The problem of transboundary externalities was discussed in detail in paragraph 1.2.1. It was argued that if there are no transboundary externalities, centralisation of regulation should not be based on this argument. On the other hand, if there are transboundary externalities, it is not much disputed that these externalities need to be corrected through some form of interjurisdictional collaboration. However, the importance of transboundary spillovers may vary from one field of regulation to another. Some fields of regulation might require broad interjurisdictional cooperation, whereas in other domains spillovers might be solved by Coasean bargaining and more emphasis can be placed on regulatory competition and decentralised decision-making. Therefore, if there are externalities, it might first be examined whether other solutions are feasible, as Coasean bargaining. Moreover, even if other solutions are not workable, it was suggested that centralisation of regulation should be limited and targeted to the transboundary externalities. Full harmonisation of regulation might not take local circumstances into account and therefore might even be counterproductive.

Yet, besides the question whether there are transboundary externalities, and irrespective whether the answer is affirmative or negative, it might be examined whether economies of scale might be reached to solve problems that are common over different jurisdictions. Indeed, it was argued that in some circumstances, in order to solve a problem adequately, it might be necessary to entrust decision-making power to a higher regulatory level that has a competence that is large enough to deal with the problem. Moreover, centralisation of certain tasks like technical and scientific research would generate economies of scale. This reasoning is more lenient towards centralisation of certain tasks, not only to solve transboundary spillovers but also to solve problems that are common over different jurisdictions. However, centralisation of certain tasks is not equal to and should not justify harmonisation and fixed uniform standards. On the other hand, the fact that differing local circumstances and preferences have to be taken into account, does not argue for decentralised regulation without co-operation either, but for flexible regulatory policies and strategies.

Hence, the possible policy measures for environmental liability that might result from the analysis of the transboundary externalities factor can be summarised as follows (see Figure 2 above): if there are no externalities and no economies of scale can be reached, decentralised liability rules would be preferable. If there are no externalities but economies of scale in data gathering or scientific research can be reached, interjurisdictional cooperation for research or data gathering might be considered. If there are externalities, but if they might be solved by other solutions than centralisation, it can be examined whether economies of scale might be reached. If no economies of scale would be possible, decentralisation probably would be the best option. If on the other hand economies of scale would be possible and if there are advantages of expertise that can be profited from without having to give in on diversity, an interjurisdictional cooperation of research and data gathering might be considered. Finally, if solutions other than centralisation do not seem feasible, centralisation for transboundary damage only might be the best option in order to take local circumstances into account. Additionally, it might be examined whether cooperation in research and data gathering would contribute to solve common environmental problems. In the affirmative, a combination of centralisation for transboundary damage only and interjurisdictional cooperation of research and data gathering might solve the externality problem and improve environmental quality. Otherwise, only centralisation for transboundary damage might be considered. The weight and importance of transboundary externalities and accordingly the policy measures that might be chosen might depend on the actual situation though.

The transboundary externalities argument can be illustrated for soil pollution (see Figure 3 above). It might be argued that although the transboundary character of environmental damage might provide an argument for centralisation, in most circumstances, soil pollution will cause in-state torts (see 1.2.1.1). Moreover, as was examined in Chapter 2 (see 3.1.1), the causes and consequences of soil pollution can vary significantly within a jurisdiction and over jurisdictions. In these circumstances, regulation tailored to local needs and preferences might be necessary. If occasionally transboundary spillovers of soil pollution might happen, alternative solutions could be examined as for example co-operation between jurisdictions. When co-operation is not feasible, centralisation for transboundary damage only might be considered, however, for soil pollution this seems rarely the case. Hence, full centralisation or harmonisation of liability rules for soil pollution would not be justifiable as it would not take diverse causes, circumstances and preferences into account. It could be examined whether economies of scale might be reached in technical research. If so, this might plead for co-operation or centralisation of certain tasks, like research or data gathering. However, again, the promise of economies of scale in scientific research does not argue for a centralisation in an excessive sense. 
In sum, centralised regulation of liability rules for soil pollution preferably would not go further than a kind of transboundary - or special areas - only regime to remedy transboundary soil pollution. This might however be completed with centralisation of supporting scientific research and data analysis, as all states and citizens might benefit from it. The policy options that might be considered for liability rules for soil pollution with respect to transboundary externalities are given by the dotted lines in Figure 3 above.

\section{Existence of a Race-to-the-bottom}

A second factor for evaluation is the risk of a race-to-the-bottom. The discussion in detail can be found in paragraph 1.2.2. As was indicated there, the existence of a race-to-the-bottom is heavily debated. Theoretical studies as well as empirical evidence for a race-to-the-bottom in environmental standard setting did not point clearly into one direction. Indeed, there are no strong indications that prove that a race-to-thebottom in environmental regulation will surely happen; neither can it be excluded that a race-to-the-bottom might happen in certain cases. Moreover, the risk is probably not so much a race-to-the-bottom but a 'regulatory chill' or 'political drag'. This is very difficult to prove though, and might therefore need further research. The risk of a political drag in environmental regulations should be neither neglected nor exaggerated. Hence, referring to the framework in Figure 2, if after examination it would appear that no evidence of a race-to-the-bottom or 'political drag' can be found, centralisation of environmental regulation cannot be based on this argument and decentralisation probably would be the best policy measure. On the other hand, if there is a feeling that a race-to-the-bottom or a political drag might exist, the question that might be asked, is whether centralisation of liability would be appropriate to prevent or overcome such a race or a 'political drag'.

Indeed, it appeared from the public interest literature that, although a race-to-the-bottom, or more likely a 'political drag' in environmental regulation cannot be fully excluded, this would not justify full centralisation of environmental standards or liability rules. States might then compete by other means. Moreover, centralisation would not leave opportunities open for more stringent standards, or co-operation between states, according to states' preferences. A limited centralisation or other proposals enhancing the efficiency of environmental regulation, to prevent a regulatory chill, might be considered. However, which response would be best, depends on the circumstances and the environmental problem under examination. A context-specific analysis might thus be required. Only then, an optimal co-operation between the central and state level can be found, in order to prevent a race-to-the-bottom or a 'political drag' in environmental regulation. Hence, contrary to common belief, the risk of a race-to-the-bottom or 'political drag', is no convincing argument for centralised environmental liability rules. Therefore, referring to the framework in Figure 2, the possible policy measures that might result from the finding of a race-to-the-bottom are cooperation or limited centralisation.

Turning to soil pollution, it seems doubtful, maybe even more than for environmental regulation in general, that liability rules for soil pollution would play a significant role in attracting or repulsing industry to or from a certain state. Therefore, it seems doubtful that industry, and certainly multinationals, will relocate because of lenient liability rules for soil pollution in other countries. Moreover, states themselves would have no advantage of a lenient liability regime for soil polution in order to attract industry as in such case they would have to renounce on restoration claims. Hence, it seems unlikely that a race-to-the-bottom in liability rules for soil pollution would happen. Therefore, the answer on the question whether a race-tothe-bottom might exist for liability rules for soil pollution will be in most cases negative and decentralisation would be the best policy option. Furthermore, in the case that there is suspicion that a 'regulatory chill' might exist, this would not justify full centralisation of liability rules for soil pollution. Indeed, other solutions to enhance the efficiency of liability rules for soil pollution should also be examined. Only if no other possibilities are feasible, co-operation or limited centralisation might ease race-to-thebottom concerns, as shown in Figure 3. The dotted line however indicates that the risk of a race-to-thebottom in liability for soil pollution is not very likely, and that therefore the best policy option is decentralisation.

\section{Market Access}

Market access presents the third factor that might be evaluated in order to formulate a balanced conclusion about the optimal decision-making level for environmental liability rules. The argument was dealt with in paragraph 1.2.3.

The questions that must be answered to decide on the optimal decision-making level for environmental liability rules are first, whether differences in these liability rules might hamper market 
access (for the whole discussion see 1.2.3.1) and second, whether centralisation or harmonisation of these liability rules would improve legal certainty and reduce transaction costs (see 1.2.3.2).

With respect to the first question, it is questionable that the realisation of free trade would justify the harmonisation of private law, as environmental liability rules. As was shown in paragraph 1.2.3, it is certainly possible to realise free trade without the total harmonisation of all legal rules. Moreover, equal marketing conditions would not necessarily be achieved through the harmonisation of environmental liability rules. Indeed, harmonisation of liability rules would not create a level playing field, as differences in the availability of natural resources, labour standards, etc., are far more important factors that determine the conditions of competition. Moreover, it seems doubtful that stringent liability rules for environmental damage would act as a trade barrier for certain products. Indeed, liability does not hamper market access as product standards might do. If a product is imported, in case of damage, a causal link between the environmental harm and the product concerned still must be proven. Therefore, in comparison to product standards, liability rules might prevent disguised protectionism.

If liability rules for soil pollution in particular are considered, it might be argued that stringent liability rules for soil pollution might influence the production process and require additional precautionary measures like investing in environment-friendly technology, which would make production costs more expensive. Lenient rules, on the other hand, would not oblige such investments. In such circumstances, however, centralisation of liability rules for soil pollution would only be justified if these rules cause transboundary externalities. If the effect of these lenient liability rules has merely in-state effects, it is difficult to justify centralisation.

Hence, it seems doubtful that harmonisation of liability rules for environmental damage, including soil pollution would be necessary to ensure market access and fair marketing conditions. In most circumstances the answer will be negative and it can be examined whether centralisation would create legal certainty and reduced transaction costs, as shown by the policy options in Figure 2. Figure 3 again illustrates the case for soil pollution.

Turning to the second question, it must be realised that increased legal certainty and a reduction in transaction costs, through harmonisation of environmental liability rules, are not easy to realise. Indeed, most developed countries have certain provisions to deal with environmental damage. Moreover, environmental damage might be very diverse, and one single pollution case might cause different types of damage. The consequences of harmonisation must therefore be very carefully examined. There indeed might be a risk of increased legal complexity, if different rules, on central and local level, would apply to various types of environmental damage, caused by a single pollution case.

Referring to the soil pollution example, in particular soil pollution and clean up requirements of contaminated soil might be locality specific and dependant on the physical and geographical characteristics of the region. Additionally, soil protection might be rooted in a jurisdiction's culture. Therefore, it might be questionable whether the eventual transaction costs savings of harmonisation would outweigh the benefits of differentiated legal rules.

If, in a certain case centralisation seems necessary to avoid transboundary externalities, to increase legal certainty and to reduce transaction costs, general principles of tort law could be defined centrally, or a specific liability rule for certain activities could be set centrally, combined with a differentiation of the specific contents of this rule. In such circumstances, transaction costs might be lowered, market access might be promoted and still differing preferences could be respected. A co-operative approach could be adopted, with central minimum requirements of protection, but allowing regions to implement the standards or to adopt more stringent measures in accordance with the objectives of free trade and competition, and conform to the citizen's preferences.

However, total harmonisation of environmental liability rules, including liability for soil pollution, does not seem desirable. Therefore, in most circumstances, the best policy option, based on the examination of the market access factor, might be decentralisation, as shown in Figure 2, for environmental liability and in Figure 3 for soil pollution, indicated with the dotted lines.

\section{Minimum level of Protection}

The final factor for consideration under the public interest approach, the harmonisation in order to guarantee a minimum level of protection, falls beyond the pure economic arguments for harmonisation of regulation. As was argued in paragraph 1.2.4, if the minimum level of protection argument would be accepted, it must be emphasised that the reason for harmonisation would not be based on economic efficiency, but on the desire to provide a minimum level of protection against environmental harm. Furthermore, if citizens' preferences are not homogeneous, harmonisation might amount to paternalism. 
Moreover, even if minimum level of protection argument for harmonisation would be accepted, the argument addresses the concern to guarantee all citizens minimum quality standards, which refers to harmonisation of regulation. It was argued that this argument might in some restrictive circumstances justify the harmonisation of regulation, but it is more difficult to justify the harmonisation of tort law. It is questionable that the harmonisation of tort law would be the appropriate instrument to achieve such a minimum level of protection. Indeed, it might be more efficient to develop minimum quality standards that must be achieved, before and after an accident, rather than to harmonise the liability rules itself in the different jurisdictions.

For soil pollution in particular, the same reasoning can be followed. A minimum level of environmental quality could be ensured through minimum quality standards that would have to be achieved after the clean-up of contaminated soil. Hence, this could justify the centralisation of minimum soil quality standards, but it would not be necessary to harmonise liability rules to achieve this basic environmental quality after clean-up. Each jurisdiction could organise this according to the preferences of its citizens. Moreover, again, there might be other options than total harmonisation of soil quality standards, like centralisation or coordination of minimum standards, but allowing states to go further, according to their needs and preferences.

In sum, the minimum level of protection argument might justify in some circumstances the centralisation of regulation, by defining certain minimum quality standards, but not necessarily the harmonisation of environmental liability in general or specifically liability for soil pollution. These policy options are again visualised in Figure 2, for environmental liability and in Figure 3, for soil pollution.

\section{Lobbying Distortions}

The previous four evaluation factors were based on the public interest approach. Yet, as discussed in paragraph 2, lobbying might also influence the optimal decision-making level for regulation. A general conclusion about the optimal policy making level, however, is hard to give. Indeed, lobbying of both environmental interest groups and of industry interest groups can take place at the central as well as at the local level. It must be examined in every situation whether environmental lobby groups would be more powerful at the central level than at local level. In some circumstances it might be the opposite. Furthermore, it was already indicated that lobbying efforts of industry might go in either direction, depending whether they intend to erect barriers to entry or whether they strive for lenient regulation. Hence, the often made claim that the environmental decision-making process would be systematically more distorted at local level than at central level and therefore would justify centralised environmental regulation is precipitate. On the other hand, it cannot be ensured that the local decision-making level would enact optimal environmental regulation, or that the local level exhibits less serious public choice problems than the central government. The lobbying process is so complex that any general conclusion is almost certain to be wrong.

As shown in the framework in Figure 2, lobbying distortions might influence two other factors for evaluation, the race-to-the-bottom factor and the market access factor.

Yet, the presumption that (industry) lobbying at local level would cause a race-to-the-bottom in environmental quality (see dashed line in the framework to represent the connection), justifying centralised environmental regulation as for instance environmental liability rules, appeared also to be somewhat hastened. Industry will not necessarily lobby for lenient regulation or lenient liability rules. Indeed, various strategies are possible. Firms might create rents and barriers to entry by stringent regulation. In such circumstances, the impetus for environmental regulation comes, implicitly or explicitly, from the regulated firms themselves. Stringent regulation gives them an advantage over (foreign) competitors. Moreover, stringent regulation might provide benefits to producers of pollution control equipment. The demand for environmental regulation then comes from manufacturers of pollution control equipment, or environmentally friendly technologies. On the other hand, it can not be excluded that there might be circumstances in which industry indeed may lobby for lenient regulation, for example to obtain an interregional comparative advantage.

Lobbying distortions can also be connected with market access (see dashed line in the framework to represent the connection). It is argued that centralisation because of harmonisation of competition might serve the interests of industries in heavily regulated areas instead of the public interest, for example through predatory regulation. Hence, a careful examination of the possible consequences of centralisation might be advisable. Thus, the market access factor does not plead for centralisation, even when examined from a private interest instead of a public interest approach.

As for environmental liability rules in general, when dealing with liability rules for soil pollution, it must be realised that it might be difficult to estimate what exactly industry will lobby for and what the 
optimal decision-making level will be. Yet, as far as liability rules for soil pollution are concerned, it was argued that soil pollution mostly is a local problem, and it might be assumed that therefore, it might be easier for environmental lobby groups to ensure that citizens support their actions for stringent liability rules at local level then at central level, in which most citizens are much less involved. The argument that centralisation would be necessary because industry interest groups would be stronger relative to environmental lobby groups at local level, might therefore not hold for liability rules for soil pollution.

Concluding, if there would be no lobbying distortions, obviously decentralisation might be preferred. Moreover, the existence of lobbying distortions would not automatically justify a centralised regime, as lobbying affects the local as well as the central level. Unfortunately, public choice theory is not able to predict the magnitude and consequences of the distortions at the local level compared to the central level. However, in any case, transparency in the debate at either level might be welcomed in order to guarantee that the liability regime would serve the public interest, which is the policy option indicated in Figure 2 and Figure 3 .

\section{A Multi-level Regulatory Structure?}

Based on the above framework, presented in Figure 2, it was tried to present the different policy options that might result from the five factors for evaluation. However, as was stated before, the objective of the framework is not to offer the one and only solution on the question on which level to regulate a certain environmental problem. The one and only solution does not exist. In every case, it will have to be examined for each factor what might be the best option, which weight the factor has in that situation and then an overall conclusion might be formulated. Based on the framework, however, when all factors are taken together, it appears that a presumption could be made for a multi-level regulatory structure. Indeed, from the evaluation of the factors above, it can be concluded that most distortions would allow for a mixed system that would benefit from the merits/expertise of both governmental levels, but would not justify excessive centralisation or harmonisation. The main power of decision-making would be with the local authorities, whereby the central government could provide a supporting framework of data gathering and technical information provision. Moreover, the central government could provide a solution for transboundary damage and nature conservation area's and could define general principles to protect the environment. How much centralisation will be needed will depend on the actual problem though. Case by case, the importance of the different distortions has to be weighted, in order to make a decision on the optimal policy level for a certain environmental problem. Nevertheless, although this framework cannot offer 'the' solution, it tries to offer a means to deal with the problem and to evaluate different policy options and to offer guidance in the decision-making process.

As an example, the framework was applied to liability rules for soil pollution. In order to formulate a balanced opinion on the optimal decision-making level of liability rules for soil pollution, it was useful to examine carefully the above mentioned five evaluation factors. The dotted lines of Figure 3 show the possible policy measures that result from the different distortions. It must be realised, however, that again, no one and only solution might exist. Even if the framework is refined towards soil pollution, in a real situation the importance of the distortions by the five factors will have to be weighted, and even then, multiple solutions might exist. However, this framework tries to offer some guidance and useful evaluation criteria.

\subsection{Conclusions}

The above developed framework might help to grasp the complexity of environmental policy and the interaction of the different evaluation factors that influence the optimal decision-making level of environmental regulation and of liability rules for environmental damage in a federal system. The objective of the framework moreover was not to offer a one-and-only solution, but to offer a means to examine at which level to regulate environmental problems and to evaluate different policy options that might exist.

A few intermediate conclusions can be formulated:

First, for each situation the existence of the various distortions and the weight that must be given to them might be different. Therefore, a one and only solution on the optimal level of governmental decisionmaking might not exist. The framework can only offer some guidance.

Second, even when the framework is refined to the soil pollution example, no one and only solution on the optimal regulatory level can be offered. In every specific case, the different factors will have to be weighted in order to examine how much co-operation or centralisation would be needed.

Third, it appears from the analyses that only in a few circumstances centralisation would be the only (and best) solution to solve a distortion. Yet, centralisation or even harmonisation of environmental 
regulation is often proposed by the European Commission in the European Union. One might ask whether there might be specific circumstances in the European Union, justifying centralisation or even harmonisation, or whether the reasons for centralisation are not necessarily based on public interest considerations.

The remaining of this research will examine the harmonisation of liability for environmental damage in the European Union. The reasons for adopting a Directive on Environmental Liability with Regard to the Prevention and Remedying of Environmental Damage, including soil pollution, in the European Union will be evaluated using the five factors above. The above developed framework will be applied to the Directive in order to refine the existing theory on the optimal decision-making level of environmental regulation. 


\section{Chapter 4}

\section{LIABILITY FOR ENVIRONMENTAL DAMAGE IN THE EUROPEAN UNION BY MEANS OF DIRECTIVE 2004/35/CE ON ENVIRONMENTAL LIABILITY}

The framework on the optimal decision-making level of environmental regulation and specifically of liability rules for environmental damage in a federal system will now be used to analyse the harmonisation of environmental liability rules in the European Union.

The desire to harmonise environmental liability rules in the European Union already existed at European level for about 20 years. After a cumbersome legislative process, Directive 2004/35/CE on Environmental Liability with Regard to the Prevention and Remedying of Environmental Damage ${ }^{440}$ was adopted on 21 April 2004. The EU Member States have now until 30 April 2007 to transpose the Directive into national law.

The question might arise whether it merits to study, on the basis of the above developed framework, the desirability of harmonisation of liability rules for environmental damage and, as an example, for soil pollution in the European Union, if a Directive on Environmental Liability has already been adopted. The answer is definitively affirmative. First, the fact that a directive has been adopted does not mean that a reflection on the necessity of harmonisation of environmental liability rules, and as an example liability rules for soil pollution, is not possible anymore. Indeed, the framework allows for providing a reasoned opinion on the optimal decision-making level of environmental liability rules, including liability rules for soil pollution, in the European Union. The outcome can be compared with the reasons for harmonisation provided by the Commission in the course of the development process of the European Liability Directive, the distortions that are believed to exist, and the weight that is given to them at European level. In this way, this research might help to show the complexity of environmental policy, illustrated by soil pollution, and so refine the existing scholarly debate on the optimal decision-making level of environmental regulation. Second, as the Directive has been adopted, this research will be able to examine as an example the application of the Environmental Liability Directive to soil pollution and might indicate the consequences, opportunities and threats for soil pollution policy in the European Union.

Chapter 4 will provide an insight in the legislative process and the provisions of Directive 2004/35/EC. In a first step, the history of European environmental policy will be sketched, and the competence of the European Union to harmonise environmental liability rules will be clarified. Next, the development process of Directive 2004/35/CE - or the Environmental Liability Directive - and the reasons provided for by the Community for the harmonisation of environmental liability rules at European level will be discussed. Then, the Directive's provisions and its application to soil pollution can be studied. Chapter 4 does not aim to provide a full overview of European environmental policy, rather it will elaborate on those aspects of European environmental policy that are necessary in order to examine in Chapters 5 and 6 whether the harmonisation in the European Union of environmental liability rules, including liability rules for soil pollution, corresponds with the economic theory on federalism.

Chapter 4 will consist of three paragraphs. Paragraph 1 will first sketch the history of European environmental policy, thereby focusing on the division of competences between the European Union and the Member States for environmental policy. The history of European environmental law is inextricable linked with the political debate on the surrender of sovereignty of the Member States to the European level. Therefore, in a second step, paragraph 1 will outline how the balance between sovereignty and harmonisation of environmental rules at European level was sought. Particular attention will go to the principles of subsidiarity and proportionality, which are used to ease the tension between the desire of the Member States to preserve their sovereignty to react to local environmental problems, and the need for a global approach to protect the environment. Indeed, the principles of subsidiarity and proportionality

440 Directive 2004/35/CE of the European Parliament and of the Council of 21 April 2004 on Environmental Liability with Regard to the Prevention and Remedying of Environmental Damage, OJ L 143/56 of 30.04.2004. 
establish the conditions under which the Commission can take up its competence to legislate in the environmental field. Furthermore, it will be examined if and to what extent Member States are entitled to adopt national measures once the Community has taken up its competence. Finally, implementation and enforcement issues will be discussed. Readers familiar with the matter may want to skip this paragraph and continue directly with paragraph 2 which examines Directive 2004/35/CE.

Paragraph 2 will study the European environmental liability regime. The development process of Directive 2004/35/CE - or the Environmental Liability Directive - and the reasons provided by the Community for the harmonisation of environmental liability rules at European level will be discussed. Next, the Directive's scope and provisions will be examined in detail.

Paragraph 3 then turns to soil pollution in the EU. In a first step, the extent of the problem and EU policy towards soil pollution will be sketched. Next, the application of the Environmental Liability Directive to soil pollution will be examined in depth.

\section{Competence of the European Union in the Environmental Field}

The Community's institutions' competences are limited to what has been expressly conferred to the European level by the EC treaty. Indeed, Article 5 of the EC treaty provides that 'The Community shall act within its limits of the powers conferred upon it by this treaty and of the objectives assigned to it therein'. Hence, a Community measure will be invalid if the Community had no competence to deal with the matter. ${ }^{441}$ Environmental matters belong to the 'shared or concurrent competences' of the EU. This means that Member States are entitled to legislate and that the European Union does not take action unless its action would contribute substantial value added to the action undertaken by the Member States.

This paragraph will clarify the competence of the European Union ${ }^{442}$ to legislate in the environmental field and will outline how the balance between sovereignty and harmonisation of environmental rules at European level is sought.

\subsection{Division of Competences between the EU and the Member States for Environmental Matters}

\subsubsection{Competence of the EU to Legislate in the Environmental Field}

At its founding in 1957, the European Economic Community (EEC) had no environmental policy. As stated in Article 2 of the Treaty of Rome, the EEC had as primary objective the promotion of a harmonised development of economic activities. The protection of the environment was not mentioned in the Treaty at that time. ${ }^{43}$ Hence, the objective of the first directives, which may be interpreted retrospectively as environmental measures, was to remove obstacles to the free movement of goods, not to protect the environment. ${ }^{444}$

It was only after the rise of environmental consciousness late 1960's and 1970's, culminated in the 1972 UN Stockholm Environment Conference, that the EEC started to pay attention to the development of an environmental policy. ${ }^{445}$ At the European Council Summit meeting in Paris of that same year, it was declared that economic expansion, which was expressly included as an aim in Article 2 of the EEC Treaty, had to emerge in an improved quality as well as an improved standard of life. ${ }^{446}$ Consequently, although the term 'environmental protection' was not as such to be found in the objectives enumerated in Article 2 of the EEC Treaty, by the extensive interpretation of 'economic expansion', environmental protection could become a subject of Community decision-making. In response to the Council Summit meeting, the first Environment Action Programme (EAP), which set out the environmental objectives, principles and priorities for Community action for the next years, was adopted, covering the period from 1973 to 1976. This was followed by other multi-annual programmes of the same type, which led to the adoption of a

\footnotetext{
441 Jans 2000, 10-11. A new version of this book will appear in November 2007.

442 In this chapter, European Union and European Community are used interchangeable.

443 For an overview of the history of European environmental policy, see Chalmers 1999; Jans 2000; Pfander 1996 and Krämer 2001.

$444 \quad$ For instance Directive 67/548 relating to the classification, packaging and labelling of dangerous preparations, OJ 1967 L196/I, later amended, and Directive 70/157 relating to the permissible sound level and exhaust system of motor vehicles, OJ 1971 L42/16, later amended. See Jans 2000, 3.

445 Jordan 1999,3

446 Jans 2000, 3.
} 
series of directives. ${ }^{447}$ Since 1972, numerous directives and regulations have been adopted on almost every aspect of environment policy.

Yet, due to the absence of a specific Treaty base, environmental initiatives in this period rested upon the provisions of Article 100 (now article 94) and Article 235 (now Article 308), or as was mainly the case, both these provisions. ${ }^{448}$

Article 100 (now article 94 EC Treaty) provided that the Community could issue directives 'for the approximation of laws, regulations or administrative provisions of the Member States that directly affect the establishment or functioning of the common market'. ${ }^{449}$ Hence, Article 100 could be used where differences in national environmental legislation had an adverse effect on the establishment of the common market. 450

Besides Article 100, in the field of environmental protection, article 235 (now article 308) was often used as an additional legal basis. Indeed, as the Community's powers extend only to what has been conferred to the Community by the Treaty, Article 100 could not be used as legal basis for environmental measures other than that where necessary for the functioning of the common market. Therefore, the Council generally invoked Article 235 EEC Treaty (now article 308 EC Treaty). ${ }^{451}$ Article 235 (now Article 308) provided a kind of catch-all authority to the Community and could be used if action by the Community should prove necessary to attain, in the course of the operation of the common market one of the objectives of the Community and this Treaty has not provided the necessary powers' ${ }^{452}$

To a certain extent, European action in the environmental field had logic on its side. Cross-border environmental problems, such as river pollution, could be best dealt with at European level. Yet, despite the absence of a Treaty basis, in these relatively early days of EU environmental policy, the Commission managed to issue a series of directives that had little to do with the establishment of a common market in goods and services or with cross-border environmental problems, as for example the protection of bathing water. ${ }^{453}$ An explanation might be that policy making during the 1970's and early 1980's was extremely closed and technocratic in nature, dominated by national experts, with very little input from the public or local actors. ${ }^{454}$ The Commission purposely concentrated upon 'technical issues' such as environmental standards in order to avoid the political debate about the surrender of sovereignty. ${ }^{455}$ Jordan states that this was part of the Monnet method of cajoling Member States into deeper integration than they otherwise might have accepted. ${ }^{456}$ Hayward calls this period 'integration by stealth'. ${ }^{457}$ In this way, during the 1970's and early 1980's, the discussion on the competence of the EEC to develop a comprehensive environment policy was circumvented.

The Single European Act (SEA), which was signed in 1986 and which entered into force in 1987, represented a milestone for the development of European environmental policy. The Single European Act introduced a specific chapter on environmental policy (Articles 130r to 130t, now Articles 174 to 176 EC Treaty) in the Treaty. Hence, the Community's task in developing a Community environment was formally acknowledged and given legal justification by the SEA. ${ }^{458}$ Nevertheless, the competence of the EEC was delimited by the wording in Article 130r that 'the Community could take action relating to the environment if the objectives of environmental policy could be better attained at Community level than at the level of the individual Member States'. ${ }^{459}$ This provision would become later known and be applied more generally as the subsidiarity principle, which will be discussed in detail in the next paragraph. By the above provision, the SEA tried to reassure both States which favoured a comprehensive environmental policy at EU level, and those seeking to place limits on the competence of the EC in environmental matters. ${ }^{460}$

As regards the legal basis for Community action, the Commission could now base the proposed environmental measure on the specific Treaty Articles on the environment. Nevertheless, Article 100 (now

\footnotetext{
$447 \quad$ Jans $2000,4$.

448 Krämer 2001, 83.

449 Article 94, EC Treaty, Official Journal C 80 of 10 March 2001.

450 Examples of directives based on Article 100 are Directive 85/210 concerning the lead content of petrol, OJ 1985 L96/25, later amended and Directive 73/404 relating to detergents, OJ 1973 L347/51, later amended. See Jans $2000,4$.

451 An example of a directive based solely on Article 235 EEC Treaty is Directive $79 / 409$ on the conservation of wild birds (OJ 1979 L 103/1, later amended).

Article 308, EC Treaty, Official Journal C 80 of 10 March 2001. See Jans 2000, 4, and Pfander 1996, 63.

Council Directive of 8 December 1975 concerning the quality of bathing water (76/160/EEC), OJ L31 of 5.2.1976.

Jordan 1999, 3 and Jordan \& Jeppesen 2000, 64

Jordan \& Jeppesen 2000, 64- 65.

Jordan 1999, 3, op cit.

See for instance Hayward 1996.

Golub 1996a, 688. See also Jans 2000, 7.

Article 130 r, EC Treaty, emphasis added.

Golub 1996a, 688-689.
} 
Article 94 EC Treaty), was still used as legal basis if the measure was considered necessary for the establishment of the common market.

Yet, at that time, the characterisation of a proposal for a directive as a matter relating to the 'internal market' or to the 'environment' led to a different process of decision-making, co-decision procedure in Article 100a (now Article 95) versus consultation procedure in Article 130s (now Article 175), which led to a fierce dispute between the Member States on the legal basis of the action to be taken. In the Titanium Dioxide case of 1991, the European Court of Justice delimitated the reach of both Articles. ${ }^{461}$ The court ruled that preference had to be given to the legal basis that provided the European Parliament the right to cooperate in the decision-making (hence Article 100a (Article 95)), in order to reflect the democratic principle that citizens could take part in the exercise of power through the European Parliament. However, in a judgement of 17 March 1993, the court reached the opposite outcome in the action for annulment procedure of the 1991 Council Directive on Waste. ${ }^{462}$ In that case, the Court accepted Article 130s (now Article 175) as the correct legal basis for the Directive instead of Article 100a (now Article 95), despite its effect on the internal market, because the aim and content of the Directive was related to the objectives and principles of Article 130. Reading the two judgements together, leads to the conclusion that the aim and content of the proposed directive are decisive: when the aim and content of the proposed measure were mainly related to the objectives and principles stated in Article 130, then the measure had to be based on Article 130s (now Article 175), despite its possible impact on the internal market. When the reverse was true, Article 100a (now Article 95) would have been the correct Treaty basis. ${ }^{463}$ Although the co-decision procedure has been extended by the Amsterdam Treaty, the choice of legal basis still has important consequences, as the achievement of the internal market belongs to the Commission's exclusive competences and therefore is not subject to the subsidiarity principle, which will be discussed in 1.1.2. ${ }^{464}$

The entry into force of the EC Treaty in November 1993, which was signed on 7 February 1992 in Maastricht, brought further progress for European environmental policy. For the first time, the term environment was actually referred to in Articles 2 and 3 of the Treaty, which set out the objectives and activities of the Community. Moreover, the EC Treaty added the concept of 'sustainable and noninflationary growth respecting the environment' to the European Community's tasks in Article 2 and wrote the precautionary principle into the title on environment.

The Treaty of Amsterdam, which entered into force in 1999, further clarified the text of Article 2. Furthermore, the clause calling for environmental protection requirements to be integrated into the definition and implementation of other policies, which had been in Article 130r, was placed in Article 6. Hence, by 1999, environmental protection had become a general principle of EU law. The Amsterdam Treaty also renumbered the Treaty Articles so that the relevant Treaty Articles that allow the EU to legislate in the environmental field are now either Article 174-176 EC Treaty (formally Articles 130r to 130t), relating to EU environmental policy or Article 95 EC Treaty (formally Article 100a), relating to the internal market. ${ }^{465}$ No substantive changes have been made by the Treaty of Nice. ${ }^{466}$

Article 175 EC now confers on the EC the competence to adopt all measures which are needed to achieve the objectives referred to in Article 174 EC. ${ }^{467}$ The standard decision-making procedure is the codecision procedure. Under this procedure, the parliament is consulted twice on the measure proposed and it may eventually prevent the adoption of the measure. ${ }^{468}$

461 Commission v Council, Case C-300/89 (Titanium Dioxide case), 1991, ECR I-2867. Old Articles 100 and 130 were relied upon by the Commission and the Council to serve as a legal basis for the 1989 Council Directive on procedures for harmonising the programmes for the reduction or elimination of pollution caused by waste from the titanium dioxide industry.

462 Commission v Council, Case C-155/91, annulment procedure of the 1991 Council Directive on Waste, 1993, ECR I-939.

463 Lenaerts 1994, 868-874.

464 Bjerregaard 2000, 106-107.

465 Jans 2000, 8-9, 44-53. See also Jeppesen 2002, 19-20.

466 European Commission, Environment DG, Information Brochure: An introduction to the Directorate-General for the Environment of the European Commission and to sources of information on EU environmental policy, Office for official publications of the European Communities, Luxemburg, 2002.

467 In Art 174 \$1, the objectives of European environmental policy are formulated: 'Community policy on the environment shall contribute to pursuit of the following objectives: preserving, protecting and improving the quality of the environment; protecting human health; prudent and rational utilization of resources and promoting measures at international level to deal with regional or worldwide environmental problems' and article $174 \$ 2$ sets out the principles on which European environmental policy is based: 'Community policy on the environment shall aim at a high level of protection taking into account the diversity of situations in the various regions of the Community. It shall be based on the precautionary principle and on the principles that preventive action should be taken, that environmental damage should as a priority be rectified at source and that the polluter should pay'.

468 Article 175 EC Treaty states that 'the Council, acting in accordance with the procedure referred to in Article 251 and after consulting the Economic and Social Committee and the Committee of the Regions, shall decide what action is to be taken by the Community in order to achieve the objectives referred to in Article 174'. See also Jans 2000, 44. 
The wording of Article 175 EC indicates that the Community's competence to legislate in the environmental field is delimited by the objectives listed in Article 174 EC. However, as Epiney points out, in reality, this does not pose a real limitation to the competence of the EC in environmental matters. Indeed, the description of the objectives in Article 174 EC is very extensive. The environmental policy of the EU should contribute to preserving, protecting and improving the quality of the environment, to protecting human health, to using national resources in a rational way and to promoting international activities in this field. The formulation of these objectives is so broad that is hard to think of a Community measure that would not satisfy at least one objective. ${ }^{469}$

Second, Article 95 EC would be the appropriate Treaty basis if the measure is considered to be necessary for the establishing or the functioning of the internal market, like for example the harmonisation of environmental product standards or emission limit values. ${ }^{470}$

Hence, the Community evolved from a position of no competence to deal with environmental matters to a position in which it is hardly possible to indicate areas within the environmental field that are of exclusive competence of the Member States. Indeed, Articles 174 and 175 EC or Article 95 EC do not contain any criteria which would it make it possible to define the 'domestic competence' of the Member States in the environmental field, although Art $175 \S 2$ and Art $95 \S 2$ leave some room for derogations, for example for fiscal measures and Article 176 entitles the Member States to maintain or introduce more stringent protective measures once community environmental measures have been adopted. ${ }^{471}$

In sum, nowadays, the Community's competence can extend to all environmental domains, provided that the foreseen measure contributes to the realisation of one of the broad objectives set out in article 174 EC or to the functioning of the internal market. ${ }^{472}$ Nevertheless, as will be explained in the next paragraph, the principles of subsidiarity and proportionality establish the conditions under which the Commission may make use of its competence.

\subsubsection{Principles of Subsidiarity and Proportionality (Article 5 (2) EC)}

\subsubsection{The Balance between Sovereignty and Community Action}

The subsidiarity principle, ${ }^{473}$ introduced in Article 5 of the EC Treaty, states that in areas which do not fall within the Community's exclusive competence, the Community shall take action, in accordance with the principle of subsidiarity, only if and in so far the objectives of the proposed action cannot be sufficiently achieved by the Member States and can therefore, by reason of the scale or effects of the proposed action, be better achieved by the Community. ${ }^{474}$

The subsidiarity principle is connected with the principle of proportionality, which requires that any action by the Community shall not go beyond what is necessary to achieve the objectives of this treaty. ${ }^{475}$

Hence, for all matters that belong to the concurrent competences of the Community, as environmental matters, Community action must be justified with regard to the principles of subsidiarity and proportionality before the Community may use its competence to legislate. The principles of subsidiarity and proportionality are intended to ensure that decisions are taken as closely as possible to the citizen and that action at Community level is justified with respect to the possibilities available at national, regional or local level. ${ }^{476}$

Originally, subsidiarity is a federal term, used to give meaning to the division of power and responsibility between the central government and the Member States of a federal system. Subsidiarity conventionally means that responsibility for a certain policy should be allocated at the lowest level at which the objectives of the policy can be achieved. It therefore provides a strong presumption in favour of decentralisation. 477

Although not explicitly described as subsidiarity, the debate of allocating competences between the Community and the Member States has always been present in European environmental policy. Already in the 1970's, the Member States were sufficiently concerned about the threat posed by EU environmental

\section{Epiney 2003.}

470 Article 95 of the Treaty provides that 'the Council, acting in accordance with the co-decision procedure, shall adopt measures for the approximation of national legislation, which have as their objective the establishment and functioning of the internal market'.

Krämer 2001, 90-91.

Epiney 2003. See also Bekkers, van den Hurk \& Leenknegt 1995, 71

On EU principles see Craig \& De Burca 2003; Schwarze 2006; Tridimas 2006, or Arnull 1990.

Article 5 EC Treaty, italics added. See also Jans 2000, 11-12.

Article 5 \& 3 EC Treaty.

<Europa.eu.int/scadplus/glossary/subsidiarity_en.htm>.

Jordan \& Jeppesen 2000, 66 and Jordan 1999, 8. See also Inman \& Rubinfeld 1998, 545. 
policy making to their sovereignty to include a predecessor of the subsidiarity principle into the First Environmental Action Programme. The First EAP specified that it is necessary to establish the level of action (local, regional, national, Community and international) best suited to the type of pollution and to the geographical zone to be protected. Actions likely to be most effective at Community level should be concentrated at that level; priorities should be determined with care'. ${ }^{478}$

Although Jordan assumes that this provision did not include a presumption in favour of any level of action, Golub believes that the phrasing in the first EAP emphasised action at Community level. The third EAP, adopted in 1983, removed this emphasis and inserted instead a slight presumption against centralisation: 'the Community level should be reserved for those measures which can be most effective there'. 479

According to Golub, the United Kingdom was primarily responsible for the inclusion of the provision that would become the predecessor of the subsidiarity principle in the EAP's. Known for its particularly strong attachment to national sovereignty, the United Kingdom did not welcome a European environmental policy, which after all, was never mentioned in the original Treaty provisions of 1957. Therefore, the United Kingdom saw the provision in the EAP's as a mechanism to limit EC competences. ${ }^{480}$

The division of competences between the European Union and the Member States for environmental matters was further institutionalised by the Single European Act of 1987. The SEA incorporated a provision into the new environmental section of the Treaty that would become known and be applied later more generally as the subsidiarity principle. Article 130r (4) of the SEA held that the Community should take action relating to the environment if the objectives of environmental policy could be better attained at Community level than at the level of the individual Member States' ${ }^{481}$ The inclusion of this provision must be seen in the larger political context of the SEA. Basically, the SEA was the product of an intergovernmental bargain between the governments of the large Member States. The environmental provisions of the SEA constituted a delicate balance between those States which favoured expanding European environmental competences, and those seeking to place limits on the Community's competences in the environmental field. As drafted, the provision reassured each of the camps. It could signal a presumption in favour of national action at the expense of the Community, or, similar to the first EAP, it could suggest that most issues could be solved better at Community level, thereby paving the way for a more comprehensive European environmental policy. ${ }^{482}$

Besides inserting a title on the environment in the Treaty, the SEA did not really change the balance of power between the Member States and the Community. Indeed, Member States' sovereignty was guaranteed by Article 130r (4) and the requirement of council unanimity continued to apply (Article 130s EEC Treaty). Hence, the title on environment simply expressed a clear commitment of the Community to environmental protection. ${ }^{483}$

The EC Treaty removed the subsidiarity principle from the specifically environmental provisions of the Treaty and gave it a general application (Article 3b, now Article 5 EC Treaty). ${ }^{484}$

Again, the introduction of the subsidiarity principle in Article 3b (now Article 5 EC Treaty) must be seen in the wider political context of that time. The Maastricht Treaty drafters wanted to complete the consolidation of the internal market. Yet, the Danish rejection by referendum of the Maastricht Treaty in 1992, and the narrow victory of the 'Yes' vote in the French referendum showed that European integration was met with stronger resistance in the Member States in the early 1990's than before. The Member States were concerned that excessive use of Community powers for non-exclusive competences would trample sovereignty and cultural diversity. In this delicate situation, the Maastricht Treaty drafters turned to 'subsidiarity' as a concept that would build confidence in the new Treaty. Indeed, Member States' confidence was to be maintained through a guarantee of the proximity of government. Hence, subsidiarity was envisaged as the concept that should strike the balance between sovereignty and integration. ${ }^{485}$

Yet, as compared with the SEA, the interpretation of the subsidiarity principle in the Maastricht Treaty is more restrictive towards centralisation. The Maastricht Treaty places the burden of proof upon the Community to show that the proposed action can better be achieved by the Community, rather than the Member States to justify why they should retain competence over the matter. Hence, Article 3b (now Article

First Environmental Action Programme, OJ C112 of 20.12.1973. See Golub 1996a, 688, and Jordan, $1999,3-4$.

Third Environmental Action Programme, OJ 46 of 17.02.1983. Jordan 1999, 5 and Golub 1996a, 688.

Golub 1996a, 688.

Single European Act, Article 130r (4).

Golub 1996a, 688-689.

Lenaerts 1994, 860-861.

Cross 1995, 108.

Jeppesen 2000, 96. 
5 EC Treaty) provides a strong presumption in favour of decentralisation. ${ }^{486}$ Even more, a literal reading of Article 3b (now Article 5 EC Treaty) suggests that community action should be abandoned even in the situation where Community action would produce clear benefits compared to action at the level of the Member States. On the other hand, Community institutions have interpreted subsidiarity as a test of comparative efficiency, which level would achieve the goal more efficiently. ${ }^{487}$ Nevertheless, although the wording of Article 3b (now Article 5 EC Treaty) would allow for such an interpretation, it has not been applied retrospectively to repatriate certain competences back to the Member States. ${ }^{488}$

As far as the division of competences in the environmental domain is concerned, with the entry into force of the EC Treaty, the Community clearly signalled prominence to environmental considerations by enshrining the environment in the preamble and Article 2 of the EC Treaty. Furthermore, the decisionmaking process had been altered through the generalisation of the quality majority voting in the Council. In order to ease the tension between those States which favoured expanding European environmental competences, and those seeking to place limits on the Community's competences, an attempt was made in the environmental chapter of the Treaty (Articles 130r to 130t, now Articles 174 to 176 EC Treaty) to strike the balance between sovereignty and Community action in the environmental field. Article 130r $\$ 2$ (now Article 174 § 2) obliges the Community to take into account the diversity of situations in the various regions of the Community. Moreover, the chapter also foresees a safeguard clause stating that Member States shall not be prevented from maintaining or introducing more stringent protective measures, provided that they are compatible with the Treaty (Article 130t, now Article 176 EC Treaty). Finally, the Member States keep their veto right for politically sensitive matters, as fiscal provisions, management of water or energy resources or matters tending to be of great local significance, as town and country planning, land use (Article 130 s, now Article 175 § 2 EC Treaty).489

Guidelines for interpreting the subsidiarity principle, enshrined in Article 5 EC Treaty, were laid down in a declaration at the Edinburgh European Council of December 1992. The reasons for which the EU might justifiably act can be grouped as follows: trans-national aspects, actions of the Member States that conflict with the requirements of the Treaty, in particular distortions of competition, and action of the Community that would produce clear benefits in terms of scale or effect. The results of the Council were codified in an Interinstitutional Agreement which obliges the Commission to justify all new proposals on the basis of subsidiarity, both in the preamble of the text and in the accompanying explanatory memorandum. ${ }^{490}$ The Treaty of Amsterdam built further on the declaration in a Protocol on the application of the principles of subsidiarity and proportionality annexed to the EC Treaty. This Protocol provides criteria for the analysis of legislative proposals on the principle of subsidiarity. It is advised that the reasons for preferring Community action must be substantiated by qualitative or if possible quantitative indicators. Furthermore, the use of less binding Community measures is recommended, and the Commission must consult widely and explain how its proposal complies with the subsidiarity principle. ${ }^{491}$

In sum, subsidiarity was introduced in the EC Treaty to strike the balance between sovereignty and Community action. The subsidiarity principle would allow for a careful consideration a priori of the optimal decision-making level of an action. Nevertheless, some scholars claim that subsidiarity has been interpreted much more narrowly to mean that the Commission should provide a higher level of justification before it proposes EU legislation as a principle of good law making. ${ }^{492}$ Hence, the debate on the optimal division of competences between the EU and the Member States is not finished yet.

Yet, whereas the subsidiarity principle delimits Community powers towards the Member States, the proportionality principle provides a criterion wereby the intensity of Community measures is assessed. Hence, proportionality complements the principle of subsidiarity. ${ }^{493}$ Proportionality is a long-standing principle in European law. A free translation of the proportionality principle would be: 'don't use a sledgehammmer to crack a nut if a nutcracker will do'. Within the context of European Community law, the principle was used much earlier and with more frequency than the subsidiarity principle. ${ }^{494}$ The first application of the principle was in a dispute under the original Coal and Steel Community Treaty, dating

\section{Jordan 1999, 11.}

Jeppesen 2000, 96 .

Jordan 1999, 11.

Lenaerts 1994, 860-863.

Interinstitutional Agreement on Procedures for Implementing the Principle of Subsidiarity, Official Journal C329 of 6 December 1993, 135. See Jordan 1999, 13.

491 Treaty of Amsterdam amending the Treaty on the European Union, the Treaties establishing the European Communities and related acts, Official Journal C 340, 10 November 1997, Protocol (30) on the application of the principles of subsidiarity and proportionality.

Jordan 1999.

493 Emiliou 1996, 140. See also Ellis 1999 and Van Gerven 1999, 37-63.

494 Shaw, Nadin \& Seaton 2000, 89. 
back to $1955 .{ }^{495}$ Yet, the EC Treaty has closely allied the proportionality principle to the subsidiarity principle by means of an explicit reference to the proportionality principle in Article 3b, now Article 5 EC Treaty.

Once the legitimacy of Community action is determined by applying the subsidiarity principle, the proportionality principle can assist in determining the scope of the legislation, avoiding excessive detail and limiting the intrusiveness of actions. ${ }^{496}$ As such, the proporationality principle aims to protect the sovereignty of the Member States and their subnational authorities, with respect to their residual powers. ${ }^{497}$ Basically, the proportionality principle requires that a Community measure:

i. is suitable to achieve the desired end;

ii. is necessary to achieve the desired end;

iii. does not impose a burden on the individual that was excessive in relation to the objective sought to achieve. ${ }^{498}$

The Edinburgh European Council of December 1992 furthermore agreed upon a set of guidelines regarding the principle of proportionality, which were transposed into the Protocol attached to the Treaty of Amsterdam. The key components of the Protocol with respect to proportionality are that the Community should choose measures which leave the greatest degree of freedom for national decisions and the working of the national legal system should be respected. The use of minimum standards is preferred, whereby Member States are allowed to lay down stricter national standards. Also, the form of Community action should be as simple as possible. Furthermore is the use of a directive is preferred above a regulation and a framework directive above detailed measures. ${ }^{499}$

In sum, the principles of subsidiarity and proportionality place on the institutions of the European Union the obligation to provide both a carefully reasoned explanation of the need for Community action and a justification that the type of action proposed is appropriate to achieve the desired end.500

The next paragraph describes the application of the subsidiarity and proportionality principles in the making of European environmental law and will examine the main reasons that are provided to justify Community action in the environmental field, to comply with the subsidiarity and proportionality principles.

\subsubsection{Application of the Subsidiarity and Proportionality Principles in the Making of European Environmental Law}

As stated above, the subsidiarity principle prescribes that the Community institutions have to justify Community action. If action is justified, the principle of proportionality provides a test on the intensity of action. 501

Hence, the subsidiarity principle involves an assessment of the need of community action. In the legal literature, it is considered that this assessment actually comprises two cumulative tests. ${ }^{502}$ The first is an effective attainment test, which determines if the means available to the Member States are sufficient to attain the objectives of the measure envisaged at Community level, stipulated as the requirement that the Community shall take action only if and in so far as the objectives of the proposed action cannot be sufficiently achieved by the Member States. The second is a test of cross-boundary effects. Indeed, the second part of the subsidiarity principle, stipulated as 'therefore, by reason of the scale or effects of the proposed action, be better achieved by the Community' allows for a consideration of scale economies and externalities. In this interpretation, competences may not be subtracted from the Member States, who are closest to the citizens, and transferred to the European level, if the goals may also be achieved at Member State level. Only if Member States cannot obtain the objectives, the Community may take action. Hence, this interpretation

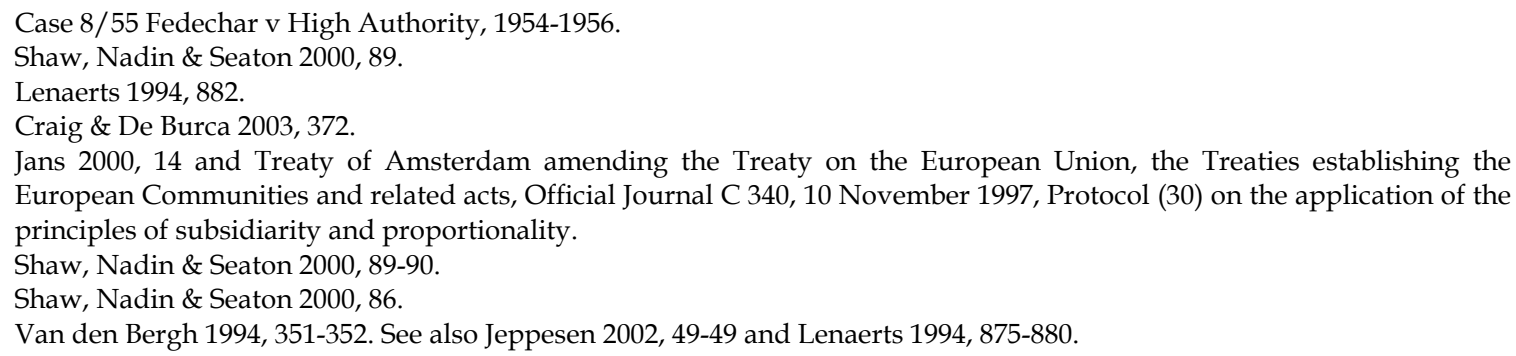


requires absolute necessity of Community action and is clearly very restrictive towards Community action. The Community institutions, however, have interpreted subsidiarity as a test of comparative efficiency, of which level would achieve the goal more efficiently. The latter interpretation is also preferred by Van den Bergh, who pleads for interpreting the subsidiarity principle as one single test of comparative efficiency. ${ }^{503}$ The question then is whether the Community can achieve the envisaged goal more efficiently than the Member States. This interpretation of subsidiarity demands an assessment of arguments in favour of Community action and those in favour of action by the Member States. ${ }^{504}$

From the way in which Community institutions have applied the subsidiarity test and how they have justified Community action in the Explanatory Memoranda and Recitals of new environmental Directives, it is possible to identify four categories of arguments used to justify Community action in the environmental field. ${ }^{505}$

The most frequent and important argument advanced to justify Community action in the environmental field, is the presence of transboundary externalities. In economic theory, it is shown that, if pollution crosses the national borders of a state, that state only internalises the externality present on its own territory. Community action is therefore considered to be necessary in order to fully internalise externalities from transboundary pollution. ${ }^{506}$ This argument corresponds with the stipulation in the subsidiarity principle that the community may take action if the objectives of the proposed action, hence the internalisation of externalities, cannot be sufficiently achieved by the Member States, by reason of scale or effect. 507

Second, the prevention of unequal competition is an important concern and argument of the community institutions for Community action. Centralisation of environmental standards should establish a 'level playing-field' for industry in Europe, which is deemed to be necessary for the functioning of the Common Market. It is believed that disparity between national environmental standards may create unequal conditions for competition among Member States. ${ }^{508}$

The third reason for Community action in the environmental field concerns the harmonisation of product standards to achieve the free movement of goods. Indeed, as stated above, the driving force behind the first directives with an environmental objective was not environmental concern, but the removal of obstacles for market integration. ${ }^{509}$ This reason for Community action in the environmental field might have grown in importance after the accession of the Nordic countries to the EU.

Finally, general concern about the environment and human health is frequently advanced as a justification for Community action for environmental matters. Indeed, as listed in Article 2 and 3 of the EC Treaty, the Community has as its task to promote a high level of protection and improvement of the quality of the environment and the raising of the standard of living and quality of life. Moreover, Article 95 and 174 EC Treaty state that Community policy on the environment shall aim for a high level of protection. On these grounds, the Community institutions advance that Community action in the environmental field is justified to guarantee a basic environmental quality to all European citizens. ${ }^{510}$ This argument is also frequently called the 'European heritage' argument. 511

Yet, it should be noted that environmental directives are often based on a combination of these justifications, and possibly on some additional justifications that are specific for a certain Directive.

Once it has been determined that the Community has legal competence to act and that the proposal satisfies the subsidiarity principle in terms of justifying the need for action, it has to be examined that the proposal satisfies the proportionality principle in terms of arguing that the intensity of the action is appropriate.

In arguing that the intensity of the legislative intervention does not go beyond what is required to meet the objectives of a directive, five arguments are generally put forward. It is mostly claimed that the measure is proportional to the aim to be achieved, necessary and suitable to achieve the objectives of the measure, fair (with respect to the burden imposed on individuals or organisations in ensuring that the

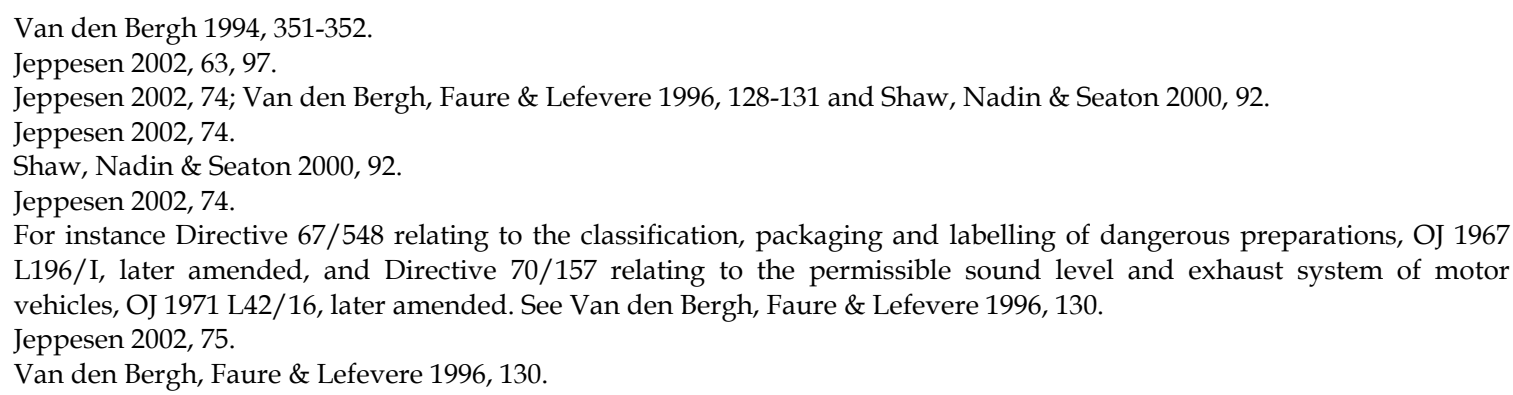

Van den Bergh, Faure \& Lefevere 1996, 130. 
details of the directive are met) and that it allows variation, in the sense that the measure does not prevents higher standards. ${ }^{512}$

Now the competence of the European Union to legislate in the environmental field has been explained and now it is outlined how the balance between sovereignty and Community action for environmental matters is sought by means of the subsidiarity and proportionality principles, it can be examined to what extent Member States are entitled to adopt national measures once the Community has taken up its competence to legislate in the environmental field. In a second stage, implementation and enforcement issues will be discussed.

\subsection{Harmonisation of Environmental Standards in the European Union}

\subsubsection{Harmonisation and Member States' Room for Manoeuvre}

As long as the Community has not taken up its competence to legislate, Member States are free to pursue any environmental policy of their own, provided that it complies with the provisions of the treaty. Yet, once the Community has decided to legislate in a certain area, the extent to which Member States still have room for manoeuvre depends on choice of the legal basis and on the content of the measure concerned. As discussed above, the Community can base the proposed environmental measure on the specific Treaty Articles on the environment (Articles 174-176 EC Treaty) or on Article 95 EC Treaty if the measure is considered to be necessary for the establishing or the functioning of the internal market. Anything out of the scope of the measure remains within the competence of the Member States, within the limits of the EC Treaty. ${ }^{513}$

Proposals for directives relating to the environment, based on Articles 174-176 EC Treaty, mostly prescribe minimum harmonisation. This applies for example to measures to protect the quality of water and air or measures to protect the fauna and flora. Minimum harmonisation by, for example a framework directive, is often used in fields in which differences in national standards have less impact on the functioning of the internal market than do for example environmental product standards. With minimum harmonisation, the Community can ensure a basic level of environmental quality for all European citizens, whilst at the same time Member States are allowed to enact more (but not less) stringent measures, provided that they do not constitute an obstacle to free trade. This provision has been included in Article 176 EC Treaty. 514

Proposals for directives based on Article 95 EC Treaty aim at the approximation of laws or regulations of the Member States, for example of environmental product standards, to guarantee the establishment and the functioning of the internal market. In its proposals, the Commission will take as a base a high level of protection. If a Member State deems it necessary to introduce or to maintain national provisions relating to the protection of the environment or the working environment, it shall notify the Commission of the envisaged provisions as well as the grounds for introducing them. The Commission will then approve or reject the national measures. ${ }^{515}$ Hence, it seems that proposals based on Article 95 EC Treaty leave less room for manoevre to the Member States. ${ }^{516}$

The Protocol on the application of the principles of subsidiarity and proportionality annexed to the Treaty of Amsterdam recommended the use of less binding Community measures, like for example minimum harmonisation. In an empirical study, Jeppesen examined how subsidiarity has affected the development of Community legislation between 1990 and 1998. The results show that although subsidiarity has led to a reduction in the number of new community initiatives, it has not induced the community to adopt less binding instruments. Hence, Jeppesen concludes that subsidiarity has not allowed greater national leeway for the Member States. ${ }^{517}$ However, the challenge within the Community is to balance Community action with local preferences. As Krämer puts it, the Community needs both differentiation and integration of environmental rules, at a high level of protection. ${ }^{518}$

512 Shaw, Nadin \& Seaton 2000, 93-94

513 Jans 2000, 101-102 and Jeppesen 2002, 19-20.

514 Jans 2000, 108-112 and Jeppesen 2002, 19-20.

515 Article 95 EC Treaty.

516 Jeppesen even argues that Article 95 principally requires complete harmonisation, although the Treaty Article does not state this explicitly. See Jeppesen 2002, 19.

517 Jeppesen 2000, 97.

518 Krämer 2001, 100. For a discussion of differentiation and harmonisation in the EU see also Vos 2001. 


\subsubsection{Implementation and Enforcement of European Environmental Law}

Once it has been decided that the Community is the best level to deal with a certain environmental problem, the Community might issue legislation. Yet, in order to deal with the environmental problem, it is necessary that the legislation is correctly implemented and enforced by all Member States.

The instrument most frequently used by the Community to deal with environmental matters is the directive. A directive is binding to the result to be achieved, upon each Member State to which the directive is addressed, but leaves as much room as possible for the Member States as far as the form and method of implementation technique is concerned. ${ }^{519}$ Hence, a directive must be transposed into binding provisions of national law, within the time limits set by the directive. ${ }^{520}$ Yet, in the European Union, there is a significant implementation and enforcement problem, of which the EU Commission itself is aware of. ${ }^{521}$ Its 'Fifth Annual Survey on the implementation and enforcement of EU environmental law' illustrates that not all Community environmental legislation has been implemented correctly or on time, nor is it always properly enforced on the ground by the Member States. ${ }^{522}$ Enforcement is indeed primarily a responsibility of the Member States; there is no Community enforcement policy for environmental matters. Yet, it will be clear that if implementation and enforcement compliance of European environmental regulation differ between the Member States, the objective of the measure may not be reached, which in turn might influence the effectiveness of European environmental policy.

The causes of the implementation and enforcement deficit are multiple. The implementation deficit is not always due to the desire of Member States to protect national industry; it is also very well possible that the Member States could not meet the administrative duties corresponding with the implementation obligation. Yet, for many years, much has been done at European level to ensure the correct implementation of European law. Indeed, the evolution in primary legislation and in particular in case law, dealing with implementation issues, is substantive. ${ }^{523}$

First, primary legislation has increasingly provided the Commission with the necessary powers to ensure that Member States comply with European law. ${ }^{524}$

Indeed, the European Commission's main enforcement tool is Article 226 EC Treaty (ex Article 169). Article 226 EC Treaty foresees an infringement procedure, which enables the Commission to bring Member States before the European Court of Justice for their failure to implement EU law. The Treaty on European Union, or Maastricht Treaty, enforced the infringement procedure by amending Article 228 (ex Article 171) to allow the Court to impose penalty payments on Member States who fail to comply with previous judgments of the Court in infringement cases. ${ }^{525}$ On 4th July 2000, the European Court of Justice delivered its first ruling on such a case.526 The Court ordered Greece to pay the Community's first-ever penalty payment of 20.000,- $€$ for each day of delay in implementing the measures necessary to comply with an earlier judgment of the Court. ${ }^{527}$ Since then, the Court has used penalty payments regularly.

Second, case law has contributed significantly to ensure timely implementation and enforcement of European law. ${ }^{528}$

In a first step, case law has developed the conditions for direct effect of directives. Indeed, if certain conditions are met, unimplemented or incorrectly transposed directives still might have direct effect in proceedings before national courts. In the Van Duyn case, the European Court of Justice (ECJ) ruled that if the content of a directive is clear, sufficiently precise and unconditional, the directive might create enforceable rights and obligations for citizens in proceedings between citizens and Member States. ${ }^{529}$ This is called the 'vertical direct effect' of directives. The direct effect of directives in disputes between citizens (the so-called 'horizontal direct effect') has not been accepted by the ECJ. The ECJ holds that a directive cannot have horizontal direct effect as private individuals cannot be held liable for the consequences of their State's failure to act. ${ }^{530}$ Some recent judgments of the Court, however, may suggest that the ECJ may be willing to

Article 249 EC Treaty.

Jans 2000, 101-102.

Commission of the European Communities, Fifth Annual Survey on the implementation and enforcement of Community environmental law, Commission Staff Working Paper, Brussels, SEC (2004) 1025, 2003.

522 Commission of the European Communities, Fifth Annual Survey on the implementation and enforcement of Community environmental law,. Commission Staff Working Paper, Brussels, SEC (2004) 1025, 2003, foreword.

Faure 2004, 20.

Faure 2004, 20.

Kelemen 2004, 122 and Faure 2004, 20.

Case C-387/97 (Commission v Hellenic Republic), judgment of 4 July 2000, ECR I-5047.

Case C-45/91, (Commission v Hellenic Republic), judgment of 7 April 1992, ECR I-2509. See Kelemen 2004, 122.

Faure 2004, 20.

Case C-41/74 (Van Duyn v. Home Office), 1974, ECR 1337.

Case C-91/91 (Faccini Dori), 1994, ECR I-3325. 
reconsider its opinion, or, as might appear from these judgments, ${ }^{531}$ to confer horizontal direct effect to directives in an indirect way. ${ }^{532}$

Besides the conditional direct effect of directives, national judges and authorities have the obligation to interpret national provisions in conformity with the directives if the time-limit for implementation has expired, whether or not the directive has been implemented. ${ }^{533}$ The obligation applies to all directives, even if they do not have direct effect. Environmental directives, especially framework directives might indeed not meet the conditions to have direct effect. Hence, these directives still might serve as reference for the interpretation of national law and will be invocable before any national court to that effect. ${ }^{534}$

Furthermore, case law has also holds that if Member States fail to adopt all necessary and proportionate measures against private individuals that obstruct the implementation and enforcement of European legislation, this can be considered as a violation of European law. ${ }^{535}$ Moreover, although Member States remain free in their method of implementation of a directive, case law holds that, in case of a violation of implementing legislation, the sanctions should at least be effective, proportional and dissuasive. ${ }^{536}$

Finally, important case law exists on basis of which Member States can be held liable for damage that results from non-implementation or incorrect implementation of European directives. ${ }^{537}$ In the Frankovich case $^{538}$ the Court determined that a Member State must create an action for damages against itself when the Member State did not fulfil its obligation to implement a directive correctly, thereby harming the interests of private parties who would have drawn rights from the directive if it had been correctly implemented. For Member States to be obliged to compensate individuals for breach of European law, the ECJ ruled that the injured party must establish that the objective of the directive includes the conferring of rights to the individual, second, that the content of the rights is identifiable from the directive, and third, there must be a causal link between the breach and the damage caused. In fact, the ruling contains a general principle of Member States liability for harm caused by their infringement of Community law. ${ }^{539}$

Hence, the Community is aware of the need of, and the actions to be taken, to ensure the correct implementation and enforcement of European legislation to guarantee the effectiveness of European environmental policy.

Summarising, paragraph 1 aimed to clarify the competence of the European Union to legislate in the environmental field. The historical evolution of the Union's competence to legislate in the environmental field was sketched and it was explained how the balance between sovereignty and harmonisation of environmental rules at European level is sought by means of the subsidiarity and proportionality principles. Moreover, Member States' room for manoeuvre once the Community has taken up its competence to legislate in the environmental field and implementation and enforcement issues were discussed. Paragraph 1 was meant as a starter for the next paragraph which will study the European environmental liability regime.

\section{A European Environmental Liability Regime}

On 21 April 2004, Directive 2004/35/CE on Environmental Liability with Regard to the Prevention and Remedying of Environmental Damage (hereafter Directive or ELD) was adopted. According to Article 19 of the Directive, Member States have now until 30 April 2007 to transpose the Directive into national law. The adoption of the Directive is the endpoint of a cumbersome development process which began at least 15 years ago. Indeed, the development process of the Directive gave rise to much controversy and conflict of which the final text bears the mark. Much of the conflict addressed the question whether and how far the European Union could go in adopting a European liability regime. Harmonising environmental liability rules indeed touches upon political sensitive subjects as subsidiarity and sovereignty.

\footnotetext{
531 See for instance Case C-215/97 (Barbara Bellone v Yokohama SpA), 1998, ECR I-2191; Case C-77/97 (Unilever v Smithkline Beecham), 1999, ECR I-431 or Case 443/98, (Unilever Italia), 2000, ECR I-7535.

532 Marson 2004,Dougan 2000, 586-612 and Szpunar 2003, 3-4 <www.natolin.edu.pl/pdf/ natolin_publ_2003/Natolin_9-2003.pdf>. 
In order to understand why and how the Directive got to its final form, paragraph 2.1 will sketch very briefly the milestones in the environmental liability saga ${ }^{540}$ before paragraph 2.2 will turn to the provisions of the Directive.

\subsection{Towards a European Environmental Liability Directive: Legislative Process}

\subsubsection{Impetus}

The desire to introduce a European environmental liability regime already existed at European level 20 years ago. The impetus for this desire were a number of highly publicised disasters involving the release of toxic agents in the late 1970's and 1980's, like the accident at the industrial site in Seveso in Italy in 1976. The Community's legislative response to these disasters focused on improving plant safety and emergency procedures, as laid down in Directive 82/501EEC, also known as the Seveso Directive. ${ }^{541}$ Yet, although it was hoped that this approach would reduce the risk of major accidents from happening, it was felt that improving plant safety was not enough. The Seveso Directive indeed did not address liability or compensation of victims in case that an accident happened. Hence, following the Sandoz incident in 1986, the Council of Ministers and the European Parliament called upon the Commission to examine new measures for the prevention and restoration of environmental damage that would ensure clean-up and restoration, coupled with arrangements for liability and compensation by the polluters for damage caused. ${ }^{542}$ This statement opened the door for the possible use of liability rules as a component of the Community's environmental policy. ${ }^{543}$

\subsubsection{Legislative Process}

In response to the Council statement of 1986, the Commission developed a sector specific approach starting with waste. In 1989, a formal proposal on Civil Liability for Damage caused by Waste was laid down. ${ }^{544}$ The proposal envisaged a rather severe strict liability regime and was heavily criticised by industry groups, especially by the waste industry, which felt that is was being unfairly singled out. ${ }^{545}$ The proposal however never got adopted. In 1993, the Commission Green Paper on Remedying Environmental Damage ${ }^{546}$ was published. In response to the request of the Council and the public demand for systems of compensation whenever environmental accidents occurred, the Green Paper considered the use of a broad civil liability regime covering environmental damage, and presented some of the broad concepts on which a European liability regime could rely. ${ }^{547}$ The Commission argued that, first, civil liability could ensure that those responsible for environmental damage would pay compensation for the cost of remedying that damage and second, that civil liability had a secondary function of preventing people from causing damage in the future. ${ }^{548}$

With respect to the need for action at Community level, the Commission advanced two main arguments. First, a Community-wide system of civil liability for environmental damage would draw on a basic principle of civil law, notably the concept that a person should rectify the damage that he causes. This legal principle is strongly related to two principles forming the basis of Community environmental policy, the principle of prevention and the 'polluter pays' principle. Second, the Commission held that if civil liability for environmental damage would operate differently in the Member States, industries in some Member States would be required to pay for the restoration of the damage they cause, while industries in other Member States would be able to avoid those costs, if restoration would not be required or if the cost

540 For an extensive overview of the development process of the ELD see Clarke 2003, 254-268. See also Fogleman 2004, 101115 or Wilde 2002.

541 Council Directive of 24 June 1982 on the major-accident hazards of certain industrial activities (82/501/EEC), OJ No L 230 of 5 August 1982, the so-called Seveso Directive. See Wilde 2002, 171-172.

542 European Commission, Bulletin of the European Communities. No. 11/1986, § 2.1.146.

$543 \quad$ Wilde 2002 171-173 and Fogleman 2004, 101.

544 Commission Communication of 15 September 1989, proposal for a directive on civil Liability for Damage Caused by Waste, COM (89) 282.

545 Clarke 2003, 255.

546 Commission Communication of 14 May 1993, Green Paper on Remedying Environmental Damage, COM (93) 47. A Green Paper is a communication published by the Commission on a specific policy area and is intended to stimulate a debate among the interested parties. In the environmental field, these parties might include industry and environmental organisations. A Green Paper does not provide a specific proposal. Nevertheless, in some cases they might provide impetus for subsequent legislation (www.europa.eu.int/comm).

547 Bergkamp 2000, 105-106.

548 Commission Communication of 14 May 1993, Green Paper on Remedying Environmental Damage, COM (93) 47, 5-6. 
would be passed on to taxpayers. It was argued that the latter industries received, in effect, a competitive advantage. Hence, the Commission held that the use of different systems of civil liability for remedying environmental damage among the Member States could lead to distortions of competition and the single market. 549

Although the Green Paper was only intended to open the debate on possible solutions for remedying environmental damage, it provoked a storm of negative responses from both industry groups and some of the Member States. ${ }^{50}$ Some Member States, as the UK, were against any initiative to harmonise civil liability for environmental damage for reasons of sovereignty and subsidiarity, other Member States preferred their own national regulations and industry was heavily opposed to any regulation which would resemble the American Superfund. ${ }^{551}$ In response to these reactions, the Commission ordered a huge amount on studies, ${ }^{552}$ consulted interested parties and published several working documents in the years after the publication of the Green Paper. Throughout that time, the Commission was influenced by the Council of Europe's Convention on Civil Liability for Damage Resulting from Activities Dangerous to the Environment, which had been opened for signature in Lugano on 21 June 1993. ${ }^{553}$ The Commission even considered accession to the Convention as a solution. ${ }^{554}$ Again, environmental disasters ${ }^{555}$ increased the political pressure to proceed with the development of a liability regime for environmental damage. ${ }^{556}$ In November 1997, the Commission issued a working paper on environmental liability, presenting an outline of its thinking at that time. ${ }^{557}$ After another round of consultations and studies, the European Commission issued a White Paper on environmental Liability, ${ }^{558}$ proposing a civil liability regime for environmental damage. Compared with the Working Paper, the White Paper was less ambitious and vague in some elements. ${ }^{559}$

In the White Paper the Commission described its view on the main features of a future environmental liability directive. ${ }^{560}$

The Commission proposed a framework directive, based on Article 175 EC Treaty, which would not have retroactive effects. As far as the scope of the regime was concerned, the Commission held that the regime should cover both traditional damage (harm to health and property) and environmental damage (site contamination and damage to bio-diversity, which, according to the Commission was not sufficiently covered by the Member States). However, the liability regime would only apply to contaminated sites and traditional damage if caused by an EC-regulated hazardous or potentially hazardous activity. ${ }^{561}$ Damage to bio-diversity would only be covered if the area or species were protected by the Natura 2000 network. These protected areas are or have to be designated by the Member States under the Wild Birds Directive of 1979562 and the Habitats Directive of 1992.563 The Commission proposed that the liability regime would be

Clarke 2003, 256.

Descamps 2005, 5 .

McKenna \& Co. 1996.

Council of Europe, Convention on Civil Liability for Damage Resulting from Activities Dangerous to the Environment, Lugano, 21 June 1993. It should be remarked that the Lugano Convention has not entered into force and it is questionable that this will happen in the near future. See Fogleman 2004, 102.

Clarke 2003, 258.

On 25 April 1998, one of the most important bird breeding and overwintering sites in Spain, the Coto Donana, was severely damaged by the release of 5 million cubic meters of acid waste after a mine dam broke from the Aznalcollar mining complex. On 30 January 2000, a breach in the tailings dam of the Aurul S.A. Baia Mare Company released tailings waste into the river system near Baia Mare in north west of Romania. This spill released approximately 50-100 ton of cyanide, as well as heavy metals into the rivers Somes, Tisza and finally into the Danube before reaching the Black Sea. Descamps 2005, 5 .

Commission of the European Communities, Working Paper on Environmental Liability, Brussels, 1997. For a comment on this draft see e.g. L. Bergkamp 1998, 200-204 and De Vries 1999, 141-147.

Commission Communication of 9 February 2000, White Paper on Environmental Liability, COM (2000) 66. White Papers are documents that contain proposals for Community action in a specific area (www.europa. eu.int/comm.). Bergkamp 2000, 105-106.

For comments on this White Paper see e.g. Bergkamp 2000, 105-114, 141- 188; Betlem 2000, 58-60; Bierbooms \& Brans 2000, 182-188; Rice 2000, 39-45; Rehbinder 2000, 85-96. This research does not aim to discuss the provisions of the White Paper in detail. It will discuss the White Paper briefly and concentrate on the provisions that deal with the division of competences between the EU and the Member States for remedying environmental damage and environmental liability rules, which is the main focus of this research.

EC Regulated dangerous activities include activities involving the discharge or emission of hazardous substances to air or water, dangerous substances, waste, biotechnology and genetically modified organisms, transportation of waste, as well as facilities subject to the Integrated Pollution and Control (IPPC) Directive and the Seveso Directive. Thus, as dangerous substances are used in a wide range of activities, the definition of 'dangerous' was very broad and covered virtually any industrial and commercial activity, from the large Seveso-regulated industrial plant to a dry cleaning or photo shop. See Bergkamp 2000, 111

Council Directive 79/409/EEC of 2 April 1979 on the conservation of wild birds, OJ L 103 of 25.04.1979. 
based on strict liability (this means that no fault by the polluter is required), for damage caused by inherently dangerous activities, and fault-based liability for damage to bio-diversity caused by a nondangerous activity. As far as the liable parties were concerned, the Commission proposed that the liable party should be the operator in control of the activity that caused the damage. Nevertheless, the Commission argued that commonly accepted defences and an alleviation of the plaintiffs' burden of proof and some equitable relief for defendants should be included in the regime. Finally, the Commission argued for an obligation for the polluter to pay compensation for environmental restoration, provisions on the financial security for potentially liable parties and enhanced access to justice in environmental damage cases in line with the Århus Convention on access to information, public participation in decision-making and access to justice in environmental matters. ${ }^{564}$

Besides a framework directive on environmental liability, the Commission considered in the White Paper also other options to remedy environmental damage, as Community accession to the Lugano Convention and a regime for transboundary damage only. According to the Commission, the scope of the Lugano Convention was too wide and gave too little legal certainty and its definitions. Especially in the field of environmental damage its definitions were considered too vague and therefore, accession to the Lugano Convention was rejected. However, it was argued that the Lugano Convention could provide a useful source of inspiration for a future Community directive. ${ }^{565}$ The transboundary regime was rejected on the grounds that a transboundary only regime would leave a gap where liability for biodiversity damage was concerned, since this was not covered by most Member States. Moreover, it was reasoned that a transboundary only system could also lead to national and cross-border cases treated differently, which could possibly violate the principle of equal treatment as developed in the case-law of the European Court of Justice. ${ }^{566}$ Hence, the Commission considered a framework directive on environmental liability as the most appropriate option to remedy environmental damage in the European Union.

However, in accordance with the principles of subsidiarity and proportionality, the Commission had to justify the need for a Community-wide environmental liability regime. ${ }^{567}$ Arguments for harmonisation, brought forward by the Commission to justify Community action with respect to environmental liability, were provided in the introduction, and sections 3, 5 and 6 of the White Paper. 568 The Commission's arguments can be summarised as follows: a Community-wide regime would:

- realise the three grand environmental principles enshrined in Art 174 (2) of the EC Treaty: the polluter pays, precautionary and preventive principles;

- provide an adequate solution for transboundary damage;

- ensure decontamination and restoration of the environment and better integration of environment into other policy areas;

- contribute to a level playing field in the internal market and

- respect the principle of equal treatment.

First, in the Commission's view, the proposed liability regime would realise the three grand environmental principles enshrined in Art 174 (2) of the EC Treaty: the polluter pays, precautionary and preventive principles. According to the Commission, these principles were not implemented in an optimal way throughout the Community. ${ }^{569}$ As illustration, the hiatus - in the view of the Commission - in most Member States' liability regimes concerning bio-diversity damage was mentioned. With this argument, the European Commission clearly referred to the economic theory of cost internalisation. As a firm will always try to minimise its total costs, forcing the polluter to internalise the costs of pollution resulting from production, by obliging him to pay for the damage, would result in more precaution, and hence in

563 Council Directive 92/43/EEC of 21 May 1992 on the conservation of natural habitats and the protection of natural habitats and of wild flora and fauna, OJ L 206 of 22.07.1992.

564 Commission Communication of 9 February 2000, White Paper on Environmental Liability, COM (2000) 66, §4, 16-24.

565 Commission Communication of 9 February 2000, White Paper on Environmental Liability, COM (2000) 66, § 5.1, 25.

566 Commission Communication of 9 February 2000, White Paper on Environmental Liability, COM (2000) 66, § 5.2, 26.

567 Commission Communication of 9 February 2000, White Paper on Environmental Liability, COM (2000) 66, § 6, 28.

568 Bergkamp 2000; 106.

569 Commission Communication of 9 February 2000, White Paper on Environmental Liability, COM (2000) 66, § 6, 28. 
prevention of environmental harm. Furthermore the Commission believed that liability would encourage investment in research and development $(\mathrm{R} \& \mathrm{D}) .570$

Second, already in the introduction to the White Paper, the Commission indicated that harmonisation should be accepted under the subsidiarity principle, as Member States could not adequately deal with transboundary environmental pollution. In section 6 of the White Paper dealing specifically with the subsidiarity issue, the Commission firmly states that national legislation cannot effectively cover transboundary environmental damage as various watercourses and protected habitats cross the borders of the Member States. Therefore it was argued that an EC-wide regime would be necessary in order to avoid inadequate solutions to transboundary damage'. ${ }^{571}$

Third, in its plea for an EC environmental liability regime, the Commission held that a liability regime would ensure decontamination and restoration of the environment and boost the implementation of, and compliance with EC environmental legislation. ${ }^{572}$

Fourth, the Commission stressed that an EC regime would contribute to creating a level playing field in the internal market. ${ }^{573}$ From this argument, it is clear that the Commission had the opinion that differences in the various national regimes would result in cost differences and thus in competitive advantages for companies in Member States with lax environmental liability regimes.

Finally, an argument that is rather hidden in paragraph 5.2 of the White Paper, and that is linked with the transboundary damage argument, deals with the principle of equal treatment. The Commission held that a regime dealing exclusively with cross-border harm, would lead to national and cross-border cases treated differently, which could possibly violate the principle of equal treatment as developed in the caselaw of the European Court of Justice. ${ }^{574}$

The White Paper gave rise to a lot of critique. Some of the large Member States, in particular Germany, France and the UK, still firmly opposed any European initiative to harmonise environmental liability rules for reasons of sovereignty and subsidiarity. ${ }^{575}$ Industry organisations questioned the need for a European environmental liability regime, criticised the vagueness of the regime and for many of them the White Paper went too far with respect to the scope of the regime, the liability provisions and the prove of causal link. Environmental organisations on the other hand, were disappointed as in their view - the proposed regime was too weak, in particular with respect to causality, compensation of ecological damage and the right to sue for environmental organisations. ${ }^{576}$ Obviously, the White Paper was also critically examined by scholars. Some scholars, although adherents of a European liability regime, deplored the vagueness of certain provisions in the White Paper and the fact that in some issues no real decisions had been taken (e.g. causation or defences). ${ }^{577}$ Others were critical with respect to the proposals on action rights of NGO's. ${ }^{578}$ Moreover, certain scholars were critical about the idea to ensure restoration of environmental damage by civil liability. It was proposed that a public law regime would be more effective than a private law regime and that it would be better to deal separately with the compensation of traditional damage, the compensation of ecological damage and the restoration of damage. ${ }^{579}$ Finally, the justifications given by the Commission under the subsidiarity principle were questioned ${ }^{580}$ as well as the need for a harmonised environmental liability directive. ${ }^{581}$

Hence, at the end of July 2001, the Commission changed its strategy and issued a brief Working Paper. ${ }^{582}$ In the Working Paper, the Commission outlined the main features of a proposal for a Directive on prevention and restoration of significant environmental damage. Indeed, in the Working Paper the Commission shifted its focus from civil liability and compensation to prevention and restoration of environmental damage. Moreover, the Commission opted for a public law regime that would be enforced by competent authorities instead of a civil liability regime. ${ }^{583}$ Nevertheless, as some elements as fault and

Commission Communication of 9 February 2000, White Paper on Environmental Liability, COM (2000) 66, §3.1, 14.

Commission Communication of 9 February 2000, White Paper on Environmental Liability, COM (2000) 66, §6, 28.

Commission Communication of 9 February 2000, White Paper on Environmental Liability, COM (2000) 66, §3.2-3.3, 14

Commission Communication of 9 February 2000, White Paper on Environmental Liability, COM (2000) 66, 3.5, 15.

Commission Communication of 9 February 2000, White Paper on Environmental Liability, COM (2000) 66, 5.2, 26.

Bocken 2001, 352.

The numerous comments on the White Paper from Member States and interested parties have been summarised on the Commission's website <www.europa.eu.int/comm/environment/liability>. See also Bocken 2001, 352.

Bierboom \& Brans 2000, 182-188. More critical is Rehbinder 2000, 85-96.

Hunter 2000, 125-126.

Bocken 1998, 8-12 and Bocken 2003, 53-58.

Bergkamp 2000, 105-114, 141- 188

Faure \& De Smedt 2002, 217-237.

European Commission, Environmental Directorate General Working Paper on Prevention and Restoration of Significant Environmental Damage (Environmental liability), 2001.

583 Fogleman 2004, 102 
strict liability were retained from the White Paper, the proposed regime was a hybrid of private and public law. ${ }^{584}$

The main features of the Commission's proposal were the following: the purpose was to establish a Community framework in respect of professional and commercial activities causing Significant Environmental Damage (SED), ${ }^{585}$ addressing both its prevention and restoration. ${ }^{586}$

The liable party would be the operator, who was considered to be the natural or legal person who controlled the activity concerned. Where the activity would be subject to authorisation, the authorisation holder would also be considered as the operator. 587

SED would include biodiversity damage (hence the habitats and species protected under the Habitats Directive and Wild Birds Directive and natural sites protected by national legislation); pollution of water covered by the Community Water Framework Directive, and damage that created serious harm to human health as a result of either of the foregoing categories or land (soil and subsoil) contamination. ${ }^{588}$

The fundamental difference with the White Paper was the juridical (public law) technique to ensure prevention and restoration of environmental damage. ${ }^{589}$ The Working Paper would create legal relations between state and private parties, not between private parties. Indeed, whereas in the White Paper, an important item was the right of interest groups to sue the polluter, the administrative regime of the Working Paper provided that the initiative to request restoration laid with the state and qualified organisations would only be entitled to request that action would be taken. 590

With respect to prevention, the Working Paper created a general duty on operators to prevent an imminent treat of SED. ${ }^{591}$ In case of imminent treat, the Member States would have to request action by the operator, or take the appropriate action themselves, and recover the costs of so doing. ${ }^{592}$

As far as restoration was concerned, the Working Paper defined, similar to the White Paper, that if an activity was listed under EU law as an inherent dangerous activity, strict liability would apply, and if it was not listed, fault liability would apply. Hence, where SED had occurred, there would be a duty on Member States to ensure that operators would comply with their obligations. In the case of strict liability activities they would require the operator to take restorative measures, regardless of fault. In the case of fault based liability activities, they would require the operator to take restorative measures, if he was at fault. If the operator failed to respond to a request, the Member States would take the appropriate action themselves and recover the costs of so doing. ${ }^{593}$ Remarkable is that compared to the White paper the defences for the operator in the Working Paper were more limited. 594

With respect to the subsidiarity principle, the Working Paper sketched the proposed regime's main elements without providing arguments to justify the Community's competence in the matter. Yet, according to Bergkamp, as the EC had already adopted habitats and water legislation, it might be that the Member States felt that the subsidiarity principle was met with respect to regulated habitats and waters and hence that proposal would be politically acceptable. Bergkamp, however, is more doubtful about the EU's competence with respect to harm to human health. ${ }^{595}$

In any case, the reactions of the Member States on the Working Paper were moderately positive. 596 Also at academic level, the shift to a public law regime was welcomed. Nevertheless, Bergkamp argued that the proposed regime, being a hybrid of private and public law, might cause significant implementation

584 Bergkamp 2001b, 208. See also Clarke 2003, 260.

585 The working Paper defined 'significant' with reference to the conservation status (habitats) and quality status (water) of a resource under EC legislation. A deterioration of the resource's status under that legislation would be considered significant damage.

586 European Commission, Environmental Directorate General Working Paper on Prevention and Restoration of Significant Environmental Damage (Environmental liability), 2001, §1.

587 European Commission, Environmental Directorate General Working Paper on Prevention and Restoration of Significant Environmental Damage (Environmental liability), 2001, § 2

588 European Commission, Environmental Directorate General Working Paper on Prevention and Restoration of Significant Environmental Damage (Environmental liability), 2001, §3.

$589 \quad$ Bocken 2001, 353.

590 Bocken 2001, 354; European Commission, Environmental Directorate General Working Paper on Prevention and Restoration of Significant Environmental Damage (Environmental liability), 2001, § 16.

591 European Commission, Environmental Directorate General Working Paper on Prevention and Restoration of Significant Environmental Damage (Environmental liability), 2001, § 6.

592 European Commission, Environmental Directorate General Working Paper on Prevention and Restoration of Significant Environmental Damage (Environmental liability), 2001, § 8.

593 European Commission, Environmental Directorate General Working Paper on Prevention and Restoration of Significant Environmental Damage (Environmental liability), 2001, § 7.

Bocken 2001, 353.

595 Bergkamp 2001b, 210

596 Descamps 2005, 5 and Bocken 2001, 355. 
difficulties. He argued that, given its restoration objective, the proposed EC regime did not have to impose any obligations on operators. Obligations on Member States would have been sufficient. Hence, no liability rules should be required by the EC and Member States should be free to decide how to finance natural resource restoration. Thus, rather than a hybrid regime, Bergkamp advised the EC to adopt a simple public law regime. 597

In order to prevent another deception in the environmental liability project, the Commission continued on the Working Paper and tried to find a compromise between interested parties as industry and environmental organisations. ${ }^{598}$ On 21 February 2002, the Commission submitted a Proposal for a Directive to the European Parliament and the Council, in accordance with the co-decision procedure. ${ }^{599}$ The Proposal built further on the Working Paper.

Indeed, the Proposal presented a framework whereby environmental damage would be prevented and restored. Similar to the Working Paper, environmental damage would include biodiversity damage to Community and nationally protected sites, damage to waters covered by the Water Framework Directive and land contamination which poses a threat to human health. Moreover, the regime would be based on the polluter-pays principle, such that operators, who undertake an inherently dangerous activity, regulated under EC law, could be held liable for any of the three types of harm. Operators of non-dangerous activities would face fault-based liability. However, they could only be held liable for damage to biodiversity. Furthermore, the Proposal imposed liability on the Member States to take the necessary preventive or restoration measures with regard to 'orphan' sites'. ${ }^{600}$ Insurance would not be compulsory, although the Proposal encouraged the operators to use insurance of another form of financial security. Finally, the regime would not apply retrospectively. ${ }^{601}$

Yet, compared to the Working Paper, important concessions were made to industry groups by inserting broad defences against liability in terms of regulatory compliance and state-of the-art knowledge at the time of the damage. These provisions became heavily debated items in the debate during the co-decision phase that followed. ${ }^{602}$ Moreover, compared to the White Paper, the proposed Directive would not provide for a compensation of 'traditional damage' (personal injury, damage to goods and properties) as these were already covered under the liability regimes of the Member States. Also the position of public interest groups had fundamentally changed. In the Proposal, NGO's were now excluded from the right to claim compensation from polluters. Instead, it was held that qualified organisations would only be entitled to request that action would be taken by the competent authority against the polluter. ${ }^{603}$

As far as subsidiarity was concerned, in the Explanatory Memorandum of the Proposal, ${ }^{604}$ the Commission justified European action with respect to environmental liability rules.

First, in the Explanatory Memorandum, the Commission stated that Community action was needed to address site contamination and the loss of biodiversity in the Community. The Commission held that site contamination could pose a threat to human health and referred to some 300,000 sites in the Community that have already been identified as definitely or potentially contaminated. The Commission considered that liability rules were necessary to prevent further contamination by providing an incentive to avoid causing damage in accordance with the preventive principle and to ensure that the potential polluters are liable for the costs of restoring the environmental damage in accordance with the polluter pays principle. Indeed, similar to the justifications in the White Paper, the implementation of three grand environmental principles enshrined in Art 174 (2) of the EC Treaty: the polluter pays, precautionary and preventive principles, is the key justification for the ELD. Indeed, with respect to damage to protected species and habitats, the Wild Birds Directive and the Habitats Directive do not provide liability provisions, and hence the ELD could ensure implementation of the above principles.

Second, the Commission argued that not all Member States ${ }^{605}$ adopted a liability regime for contaminated land. It was argued that without Community action there would be little guaranteeing that the polluter pays principle would be effectively applied across all the Community.

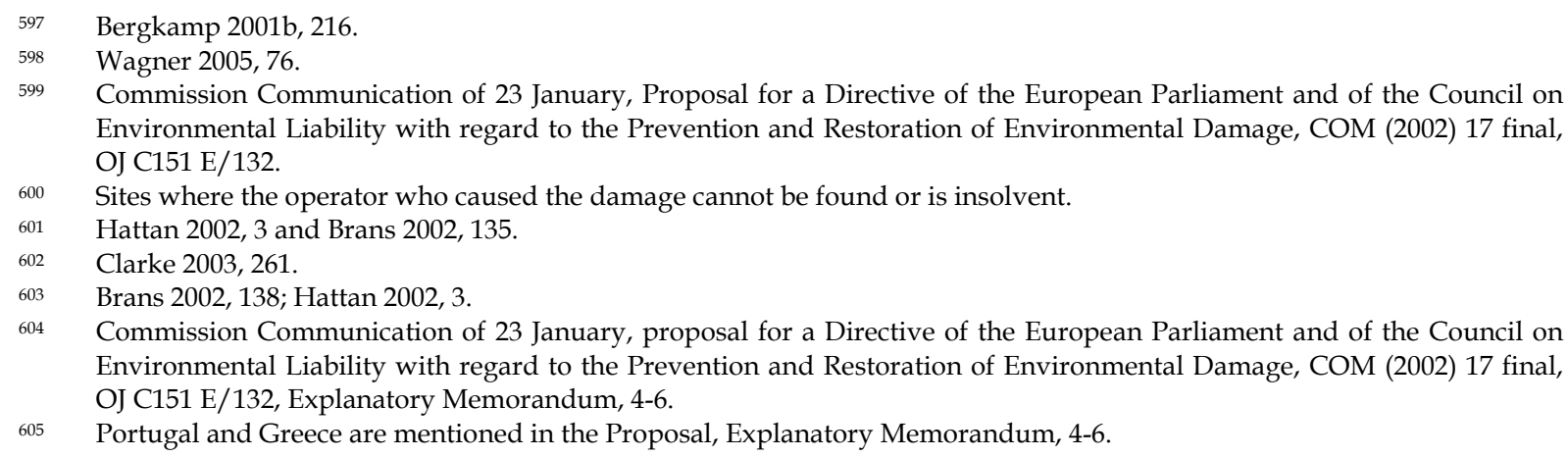

Commission Communication of 23 January, proposal for a Directive of the European Parliament and of the Council on Environmental Liability with regard to the Prevention and Restoration of Environmental Damage, COM (2002) 17 final, OJ C151 E/132, Explanatory Memorandum, 4-6.

605 Portugal and Greece are mentioned in the Proposal, Explanatory Memorandum, 4-6. 
Third, according to the Commission, most Member States' liability regimes for contaminated land did not mandate national authorities to ensure that orphan sites are actually cleaned up. Thus national legislation did not ensure that the objective of restoration was attained.

Fourth, the Commission advanced that few, if any Member States imposed liability for biodiversity damage. However, the Commission referred to the European Commission's proposal for a European Union Sustainable Development Strategy, adopted on 15 May 2001, which recognised that the loss of biodiversity in the Community has accelerated dramatically in recent decades. Hence, it was concluded biodiversity is one of the severe or irreversible threats to the future well-being of European society that warrants priority action.

Finally, the Commission argued, as it did before in the White Paper, that without a harmonised framework at Community level, economic actors could exploit differences in Member States' which would result in unfair competition.

Again, this next step in the environmental liability saga was heavily criticised by interested parties. Industry held that the Proposal was too vague and might become unreasonably onerous for the European industry. Environmental organisations were disappointed by what was called the 'watering down' of the proposal, in particular by including defences and the fact that qualified organisations were now excluded from the right to claim compensation from polluters. ${ }^{606}$ Some environmental organisations claimed that the Proposal did not meet the provisions of the Århus Convention. ${ }^{607}$

After the submission of the Proposal to the European Parliament and the Council, an extensive work programme followed, especially by the environment working party of the Council. The Parliament was slower in considering the proposed directive due to a long-lasting dispute between the Legal Affairs Committee and the Environment Committee as to which of them would be the lead Committee. Heavy lobbying on all sides in this stage of the process should also not be ignored. Chapter 6 will discuss the decision-making process and lobbying activities in detail. Having resolved the dispute in the Parliament by the confirmation of the Legal Affairs Committee as the lead Committee, the European Parliament finished its first reading in May 2003. In September 2003, the Council adopted its Common Position and in December 2003, the Parliament finished its second reading. The conciliation procedure started January 2004 and on 30 and 31 March 2004 respectively, the Council and the European Parliament formally approved the final version of the Environmental Liability Directive. ${ }^{608}$ The European Parliament had wanted to reach agreement on the Directive before 1 May 2004 when enlargement would have required to recommence the political sensitive process with a new Council and a new European Parliament. ${ }^{609}$ In that case it might have taken a long time, if at all, before an environmental liability regime would have been adopted at EU level.

Yet, not only the successive initiatives in the development process of the ELD have been studied and criticised in the academic literature. Also the final version of the ELD recently has been extensively examined and criticised at academic level. The critique addresses subsidiarity and sovereignty issues as well as the provisions of the final version of the ELD itself. Various provisions of the ELD are vague and the Directive leaves important issues up to the Member States. It is therefore now appropriate to examine the justifications given for the ELD under the subsidiarity principle, to examine the most important provisions of the Directive in order to indicate why the ELD has raised so many criticisms and to study in particular its application to soil pollution.

\subsection{Directive 2004/35/CE of 21 April 2004 on Environmental Liability with Regard to the Prevention and Remedying of Environmental Damage}

\subsubsection{Legal Basis of EC Intervention in Environmental Liability}

The Environmental Liability Directive has been based on Article 175 EC, as the aim and content of the proposed measure is mainly related to the objectives and principles stated in Article 174-176 EC Treaty. Indeed 'preventing and remedying environmental damage' contributes to implementing the objectives and principles of the Community's environment policy a set out in the EC Treaty. ${ }^{610}$

\footnotetext{
606 Hattan 2002, 3, 9.

607 Convention on Access to Information, Public Participation in Decision-Making and Access to Justice in Environmental Matters, 25 June 1998, which came into force on 30 October 2001.

608 Krämer 2005, 131; Fogleman, 2004, 102. See also <www.europa.eu.int/comm/codecision> for an overview of the codecision procedure.

609 Fogleman 2004, 103

610 Directive 2004/35/CE of the European Parliament and of the Council of 21 April 2004 on Environmental Liability with Regard to the Prevention and Remedying of Environmental Damage, OJ L 143/56 of 30.04 .2004 (hereafter also in
} 
By using Article 175 EC the Commission offers the Member States as much space as possible to maintain or introduce additional or more stringent national legislation. Indeed, as discussed above, under Article 95 EC of the Treaty, Member States' room for manoeuvre is much more limited.

\subsubsection{Justifications for the ELD with Respect to the Subsidiarity and Proportionality Principles}

The studies that the Commission ordered over the years to document its proposal for an Environmental Liability Directive reveal that most Member States have liability rules for environmental damage, that almost all Member States have adopted soil protection and remediation legislation and that although not all Member States have liability rules for harm to biodiversity, many Member States are working on the subject. ${ }^{611}$ Hence, this triggers the question why there was a need for an environmental liability regime at European level. ${ }^{612}$ A significant part of the disputes during the development process of the ELD indeed considered the question whether and for what reasons a harmonised environmental liability regime was needed in the European Union.

In previous documents as the White Paper and the Explanatory Memorandum of the Proposal of 2002, justifications for Community action were provided. Yet, a clear overview of justifications for a harmonised liability regime cannot be found anymore in the final text of the ELD. Preamble 3 of the ELD states that subsidiarity is met because the ELD's objective, namely to establish a common framework for the prevention and remedying of environmental damage, cannot be sufficiently achieved by the Member States and can therefore be better achieved at Community level by reason of scale or effect. ${ }^{613}$ The Commission does not explain why it is necessary to establish such a framework or why it cannot be achieved by the Member States. Moreover, the Commission's reasoning in Preamble 3 is, as Bergkamp and Faure indicate, merely a description of the subsidiarity principle itself and does not provide any justification. ${ }^{614}$

Bergkamp is also very critical about the justification of the Commission with respect to the proportionality principle. The Commission claims that the Directive does not go beyond what is necessary in order to achieve its objectives. ${ }^{615}$ However, Bergkamp holds that several provisions of the Directive are disproportional. For instance, Bergkamp holds that the restoration objective requires only an obligation to restore; provisions specifying who is to pay for restoration are not needed to achieve this objective. Likewise, Bergkamp states that the broad open-ended operator obligation to take action to prevent environmental damage would be limited only by a vague definition of 'imminent threat' of environmental damage and therefore fails to meet the proportionality principle. ${ }^{616}$

Hence, scholars argue that the Commission, the Parliament and the Council have failed to fulfil the subsidiarity and the proportionality principle. Faure rightly indicates that this critique is not merely a scholarly debate, but that ignoring the subsidiarity and proportionality principle can have substantial negative effects for the European Union. Indeed, such behaviour would encourage eurosceptics and endanger projects where European action would be desirable. ${ }^{617}$

Yet, Chapter 6 of this research will compare the reasons provided by the Commission for a European environmental liability regime, including liability rules for soil pollution, with the above developed framework in order to study whether these arguments indeed justify harmonisation of environmental liability rules at European level. Therefore, the arguments provided by the Commission in previous documents may be taken as a starting point.

Hence, all together, it seems that the Commission considers that there is a need for European action in the field of environmental liability in order to:

- Realise the three grand environmental principles enshrined in Art 174 (2) of the EC Treaty: the polluter pays, precautionary and preventive principles;

- Address soil contamination and loss of biodiversity in the Community by means of liability rules. In order to ensure equal treatment, the Directive must cover both transboundary damage as damage within the Member States;

footnotes ELD), preambule 1. For a critical discussion of the ELD, see for instance Bergkamp 2005; Descamps 2005; Faure 2005; Fogleman 2004; or Wagner 2005.

McKenna \& Co. 1996; Clark 2001.

Bergkamp 2002, 295.

ELD, Preamble 3.

See Bergkamp 2005, 102 and Faure 2005, 8 .

ELD, Preamble 3.

Bergkamp 2002, 297.

Faure 2005, 10. See also Bergkamp 2005, 102. 
- Ensure a level playing field in the European Union.

Yet, although the subsidiarity and proportionality principles apparently are not fulfilled, the Directive ultimately has been adopted and it now merits examining the scope and provisions of the Directive.

\subsubsection{Provisions of the Directive}

\subsubsection{Purpose of the Directive}

The contribution of the ELD would be the prevention and remediation of environmental damage. As such, the ELD would contribute to implementing the objectives and principles of the Community's environment policy as set out in the Treaty. ${ }^{618}$

Indeed, the objective of the Environmental Liability Directive is to establish a framework of environmental liability based on the 'polluter-pays' principle, to prevent and remedy environmental damage. ${ }^{619}$ Yet, the term 'environmental liability' has been criticised as confusing because the ELD does not offer a real civil liability regime, but a mainly public law regime to be enforced by competent authorities, combined with private law aspects as strict liability and fault-based liability. This is comparable with the reasoning in the Working Paper of 2001.620 The ELD imposes obligations on operators to prevent environmental damage and if necessary to remedy it and to report threatening or actual damage to the authorities. The government has the authority to order the operator to take additional measures to prevent or to remedy environmental damage. If the operator does not comply, the competent authority can execute the measures, or have them executed by a third party and recover the cost from the operator. Through this mechanism the Commission hopes to ensure that the polluter-pays principle enshrined in Art 174 (2) of the EC Treaty is realised. ${ }^{621}$

\subsubsection{Scope of the Directive}

In line with the Working Paper of 2001, environmental damage in terms of the Directive includes damage to protected species and habitats, water damage and land damage. ${ }^{622}$ Yet, similar to the Working Paper and the Proposal, in the final version of the ELD, damage to protected species and habitats is limited to species of birds listed in the Wild Birds Directive ${ }^{623}$ and their habitats and those listed in the Habitats Directive ${ }^{624}$ and any other habitat or species so determined by a Member State. ${ }^{625}$ The first two categories are also known as Natura 2000 sites, which covers approximately 10-15\% of the Community's land area. ${ }^{626}$ Consequently, harm to 'unprotected' species and habitats falls outside the scope of the Directive. ${ }^{627}$ Annex I of the Directive provides a list of criteria to determine when there is damage to protected species and habitats.

Water damage only falls within the Directive's scope if the water-course is covered by the Water Framework Directive (Directive 2000/60/EC) ${ }^{628}$ and the Directive is only applicable to land contamination if there is a significant risk that human health is adversely affected. ${ }^{629}$ Hence, land contamination in uninhabited areas will fall out of the scope of the Directive. ${ }^{630}$ As mentioned above, in contrast with the White Paper, traditional damage, such as damage to health and property, has been excluded from the scope of the Directive. Furthermore, the Directive will only have a prospective effect. ${ }^{631}$

\section{ELD, Preamble 1.}

ELD, Article 1.

620 This means that the Directive is concerned with the relationship between the authorities and the citizen, but not with the relationship between citizens.

621 ELD, preamble no 18, Bergkamp 2005, 97.

622 ELD, Article 2.

623 Council Directive 79/409/EEC of 2 April 1979 on the conservation of wild birds, OJ L 103 of 25.04.1979.

${ }_{624}$ Council Directive 92/43/EEC of 21 May 1992 on the conservation of natural habitats and the protection of natural habitats and of wild flora and fauna, OJ L 206 of 22.07.1992.

625 ELD, Article 2, §3c.

626 Descamps 2005, 10 and Layard 2004, 101

$627 \quad$ Layard 2004, 101.

${ }_{228}$ Directive of the European Parliament and of the Council 2000/60/EC of 23 October 2000, establishing a Framework for Community Action in the Field of Water Policy, commonly known as the 'Water Framework Directive', OJ L 327 of 22.12.2000.

629 ELD, Article 2, §1c.

630 Wagner 2005, 80

$631 \quad$ ELD, Article 17. 
Hence, the scope of the ELD is more limited than its supporters originally might have hoped for. Yet, this means that, in case of an accident, besides the Directive, other - national or European - rules will exist, to remedy the damage that does not fall under the scope of the Directive. Depending on the question whether the Directive is applicable, one accident might for example require that two different regimes are applied, the regime of the Directive for the damage that falls within its scope, and a regime for damage outside the scope of the Directive, for example to health and property. As far as consistency and legal certainty is concerned, this might not be a good evolution. ${ }^{632}$ Moreover, sometimes these different regimes might be overlapping or inconsistent.

\subsubsection{Nature of Liability}

In order to implement the polluter-pays principle, the site operator who caused the damage can be held financially liability under the Directive. ${ }^{633}$

The Directive provides for two distinct liability regimes: a strict liability regime and a fault liability regime. First, strict liability applies to operators who professionally conduct risky or potentially risky activities. These activities are listed in Annex III of the Directive. ${ }^{634}$ The strict liability regime covers damage to protected species and natural habitats, water and land damage. Second, fault-based liability applies to all other professional activities. Unlike strict liability, this regime only applies to protected species and natural habitats, not to water or land damage. ${ }^{635}$

Yet, there are a few cases in which operators can be exempted from liability. Exemptions can be found in Article 4 of the Directive and include for example act of war, force majeure and environmental damage that falls under the scope of international conventions listed in Annex IV. Besides these exemptions, the Member States may adopt a partial or a complete state - of - the-art defence or permit compliance defence. ${ }^{636}$ These two defences were heavily disputed in the negotiation process of the ELD. Industry argued that a permit defence was necessary to ensure competitiveness or European industry. Environmental interest groups held that a permit defence would weaken the liability regime. Yet, as with several other controversial issues (for example insurance aspects), the Council left the choice of including these defences up to the Member States. ${ }^{637}$ Bergkamp pleads that Member States would adopt these defences as it would be a basic requirement of administrative law that a government cannot first allow an act and, in case of damage, prohibit that act and recover the costs of the damage from the operator to whom permission was given. Likewise, for the state-of - the-art defence, if it was impossible to know the risk, the operator could not prevent the damage and Bergkamp holds that administrative sanctions or liability are not appropriate. ${ }^{638}$ On the other hand, Faure and Wenneras rightly argue that allowing these defences would seriously undermine the regime of the Directive. 639

\subsubsection{Preventive and Restorative Measures}

The first objective of the ELD is the prevention of environmental damage. A general preventive effect that the ELD might have is the economic threat of liability for the reparation of any damage that does occur. Moreover, in addition to this general preventive effect, the ELD imposes in Article 5 of the ELD the obligation on the operator to prevent environmental damage from occurring. ${ }^{640}$ This means that if there is an imminent treat of environmental damage, the operator shall take the necessary preventive measures. Operators are also obliged to inform the competent authority of all relevant aspects of the situation. The competent authority may require information or give instructions to the operator to be followed concerning

\footnotetext{
632 Faure 2005, 10.
}

633 De Vries 2005, 24.

634 These activities include moreover the operations of installations which are subject to authorisation under the Industrial Plants (IPPC) Directive (96/61/EC) or the Dangerous substances Directive (76/464/EEC), waste management operations which require a permit under the Waste Framework Directive (75/442/EEC) or the Hazardous Waste Directive (91/689/EEC), the treatment of chemical substances falling within the scope of the Classification, Packaging and Labelling of Dangerous Preparations Directive (1999/45/EC), the Pesticides Directive (91/414/EEC) or the Biocidal Products Directive (98/8/EC), the transport of dangerous goods and any contained use of GMO's (90/219/EEC or 2001/18/EC).

635 ELD, Article 3.1 and Annex III. See also Bergkamp 2005, 97.

636 ELD, Article 8, §4.1 (permit defence) and Article 8, §4.2 (state-of-the-art defence).

637 Fogleman 2004, 110.

638 Bergkamp argues that the 'polluter pays twice'. Bergkamp 2005, 121.

639 Faure, 2005, 14. See also Wenneras 2005.

640 Hattan 2002, 7. 
the preventive measures to be taken. If the operator fails to comply with the obligations, the competent authority may take these measures itself. ${ }^{641}$

The second objective of the Directive is the restoration of environmental damage. Article 6 of the Directive lists the obligations of the operator to remedy the damage. When environmental damage has occurred, the operator shall inform the competent authority of all relevant aspects of the situation and take all practical steps to control, contain, remove or otherwise manage the contaminants and/or any other damage factors in order to limit or to prevent further environmental damage and adverse effects on human health or further impairment of services. ${ }^{642}$ Annex II offers a common framework for Member States to select the most appropriate measure to ensure that environmental damage is remedied for protected species and habitats, water and land. Protected species and habitats and water must be restored to baseline condition. This is the condition of the natural resources that would have existed if the environmental damage had not occurred, estimated on the best information available. ${ }^{643}$ Land on the other had, does not need to be remedied to its baseline condition. The ELD provides that land is remedied by removing, controlling, containing or reducing contaminants so as to ensure that the contaminants do not pose a significant risk to human health. ${ }^{644}$

Yet, as with the defences, precise definitions of damage, baseline assessments and restoration criteria are passed on the Member States. ${ }^{645}$

In contrast to the proposal of the Directive, it follows from Article $5 \S 4$ and Article $6 \S 3$ of the ELD that the authorities are not obliged to take preventive or remedial measures themselves in case of orphan sites. ${ }^{646}$ This might somewhat be compensated by the wording of Article $8 \S 2$, which stipulates that the competent authority shall recover, inter alia, via security over property or other appropriate guarantees, from the operator who has caused the damage or the imminent threat of damage, the costs it has incurred. In this sense, Article $8 \S 2$ addresses aims to protect the competent authority against insolvency of the operator. ${ }^{647}$ Moreover, several of the Directives to which the ELD refers to, contain obligations requiring the authorities to take remedial measures. Article $4 \S 4$ of the Wild Birds Directive and Article $6 \S 2$ of the Natural Habitats Directive require Member States to take appropriate measures to avoid pollution. The Water Framework Directive obliges Member States in Article $4 \S 6$ to ensure that all practical measures are taken with the aim of restoring the body of water to its status prior the incident. Moreover, the Member States may be held liable under the Frankovich doctrine if they have committed a serious breach of the Environmental Liability Directive, ${ }^{648}$ for example if they failed to oblige to operator to take preventive or restorative measures. ${ }^{649}$

\subsubsection{Competent Authority and Requests for Action}

Member States have to ensure that effective means of implementation and enforcement are available. The Member States therefore have to designate the competent authority(ies) responsible for assessing the significance of the damage and determining which remedial measures should be taken. 650

A qualified (environmental) NGO or another natural or legal person may submit comments concerning environmental damage or an imminent threat of environmental damage to the relevant competent authority and request the authority to take action under the ELD. ${ }^{651}$ The White Paper attributed to environmental organisations the power to require an operator to conduct preventive and remedial measures. This power has not been retained in the final version of the ELD, nor do citizens acquire any rights from the Directive, as damage to human health and property do not fall within the scope of the Directive. Moreover, the Directive does not foresee a sanction if a Member State does not respond adequately to the NGO's request. As Brans rightly indicates, this omission, which has been one of the main criticisms to the ELD, might undermine the ability of the NGO's to contribute to the effective

641 ELD, Article 5. See also Descamps 2005, 10 and Layard 2004, 27.

$642 \quad$ ELD, Article 6

643 ELD, Article 2 (14), See also Fogleman 2004, 106.

644 ELD, Article 2 (15) and ELD, Annex II, §2.

645 Layard 2004, 104

646 Article $5 \S 4$ on preventive action states that if the operator fails to comply with his obligations, cannot be identified or cannot bear the costs, the competent authority may take these measures itself. Article $6 \$ 3$ states the same for remedial action.

647 Krämer 2005. See also Schueler 2005, 58-72 and Bocken 2006,13-32.

648 The Wells judgement (Case C-201/02) made clear that public authorities can incur state liability for failure to apply EC environmental law.

649 Wenneras 2005, 147-148

650 ELD, Article 11, §1 and Preamble 24.

651 ELD, Article 12. 
implementation and enforcement of the Directive, as foreseen in preamble 25 of the Directive. ${ }^{652}$ Moreover, the ELD seems not to comply with the Århus Convention. ${ }^{653}$ It is clear that this evolution has been deplored and criticised by various scholars and environmental interest groups.

\subsubsection{Insurance Aspects}

Financial security has been another heavily debated issue in the development process of the ELD. The positions ranged from requiring mandatory insurance to omitting any reference to financial security. ${ }^{654}$ The major obstacle was and is the ability of the insurance market to provide financial security instruments for environmental damage. Again, the issue was passed on to the Member States. The ELD only stipulates that Member States shall take measures to encourage the development of financial security instruments with the aim of enabling operators to use financial guarantees to cover their responsibilities under the Directive. The Commission shall, before 30 April 2010, present a report on the 'availability at reasonable costs and on conditions of insurance and other types of financial security for activities covered by Annex III. ${ }^{655}$ Yet, law and economics theory indicates that strict liability without financial security will weaken the preventive effect of liability rules. ${ }^{656}$

\subsubsection{Cooperation between Member States for Transboundary Damage}

The Directive foresees that if environmental damage has occurred that affects - or is likely to affect more than one Member State, these Member States must co-operate in ensuring that preventive actions and where needed remedial actions are taken and that necessary information is exchanged. ${ }^{657}$

Moreover, if a Member State identifies environmental damage within its borders, which has been caused by another Member State, it may seek to recover the costs of preventative or remedial measures the Member state has incurred. ${ }^{658}$ This is not the same though as an obligation for the polluting Member State to pay for the damage.

\subsubsection{Member States' Room for Manoeuvre}

In accordance with Art 176 EC Treaty, Article 16 of the ELD stipulates that Member States may maintain or adopt more stringent provisions in their national law to prevent and restore environmental damage. ${ }^{659}$ Member States may for example give the ELD regime retroactive effect so that historical damage and damage caused before 30 April 2007 fall under the applicable national legislation. They also may add additional activities to the scope of the Directive and impose liability on additional responsible parties. ${ }^{660}$ Consequently, there might be a significant variation between the Member States and the question might rise whether this would not introduce considerable uncertainty into the regime. ${ }^{661}$

\subsubsection{Implementation}

A Directive has to be implemented in national law. The ELD foresees that Member States shall bring into force the laws, regulations and administrative provisions, necessary to comply with the Directive by 30 April 2007. ${ }^{662}$ However, as indicated above, several provisions of the Directive leave important choices up to the Member States, as for example the defences that are allowed. Furthermore, the vagueness of some

652 ELD, Preamble 25 and Brans 2005, 44-46. See also Krämer 2005, 75-91 and Hallo \& De Lange 2004, 119-122.

653 Aahrus Convention on Access to Information, Public Participation in Decision-Making and Access to Justice in Environmental Matters, 25 June 1998, which came into force on 30 October 2001.

$654 \quad$ Bergkamp 2005, 125.

655 ELD, Article 14.

656 See Chapter 2 of this research.

657 ELD, Article 15, §1.

658 ELD, Article 15, §3. See also Fogleman 2004, 114

659 ELD, Article 16.

660 ELD Article 16. See also Bergkamp 2005, 99.

$661 \quad$ Layard 2004, 104.

662 ELD, Article 19, §1 and §2. On 30 April 2007 only three Member States had notified complete transposition (Italy, Latvia and Lithuania). In August 2007 subsequently a further five Member States hade notified full transposition (Hungary, Germany, Romania, Sweden and the Slovak Republic). In addition the Commission has received partial transposition notification by four Member States (Belgium, Czech Republic, Austria and Poland) but, according to Mr. Hans Lapatta (EU Commission DG Environment responsible desk officer) this seems to be at first sight largely very partial. 
provisions allows several interpretations. ${ }^{663}$ Therefore, the implementation of the Directive will be complex and discussions on the Directive are certainly not ended yet. ${ }^{664}$ Moreover, it has to be awaited whether the Directive can be enforced in practice. First, as stated above, Annex I of the Directive provides a list of criteria to determine when there is damage to protected species and habitats. Moreover, the extensive annex II sets out which are the most appropriate measures to ensure the remedying of the damage. Yet, as these criteria are not undoubtedly clear, Bauw expects long-standing appeals before the national courts. Second, also the exclusion of historical damage might hinder the enforcement of the Directive. Bauw argues that the Directive prescribes that remedying environmental damage in relation to water or protected species and or natural habitats is achieved through the restoration of the environment to its baseline condition. Yet, this baseline condition might be difficult to establish in case historical pollution is already present. It might be difficult to distinguish between the historical and the recent damage. Finally, other aspects as causality problems and defences that might be included might influence the practical enforcement of the ELD. ${ }^{665}$

\subsubsection{Evaluation}

With the ELD, the Community aims to establish a framework of environmental liability based on the 'polluter-pays' principle, to prevent and remedy environmental damage. Yet, the ELD has raised various criticisms and questions. The Commission fails to explain why it is necessary to establish such a framework or why it cannot be achieved by the Member States, as is required by the subsidiarity principle. Furthermore, the coverage of the Directive is limited, so that different regimes may apply to different types of damage, in case of an incident. Moreover, the ELD has left crucial aspects, as defences, insurance but also precise definitions of damage or restoration criteria, up to the Member States. Member States may also maintain or adopt more stringent provisions in their national law to prevent and restore environmental damage. Consequently, the ELD provides an uncertain framework and if the Directive comes into force, the EU liability regime will be a less harmonised regime and might create more uncertainty than its adherents originally might have thought. Moreover, it has to be awaited whether the Directive can be of much use in practice.

The next paragraph, which focuses on the application of the Directive to soil pollution, will illustrate that the Directive raises various questions and uncertainty.

\section{Application of the Environmental Liability Directive to Soil Pollution}

This paragraph will first sketch the problem of contaminated land in the European Union and national and European responses to remedy soil contamination. In a second step, the application and consequences of the ELD to soil pollution will be examined.

\subsection{Soil Protection Policies in the European Union}

\subsubsection{Soil Pollution in the European Union}

Assessing the extent of soil pollution in the European Union is extremely difficult. The European Environment Agency (EEA) estimates that as many as 1.5 million industrial and waste disposal sites could be contaminated, of which 300,000 sites are already identified as being contaminated. ${ }^{666}$ This wide range in estimations is due to the lack of a common definition for contaminated sites. Although almost all EU Member States are developing national inventories of contaminated sites, few data is of direct use. The data is not comparable due to different approaches to acceptable risk levels, protection targets and exposure

${ }_{663}$ Regarding the defences and exemptions, it is too early for firm statements (many of the legislation still has to be translated), but the first impression is that no consensus has yet emerged on the implementation of some of the Directive's key optional features. In Italy firms that cause environmental damage will be exempted from liability if they can show the damage was caused by emissions permitted by the authorities. Lithuania, on the other hand, has denied this 'permit defence' to its firms. Member States also differ on whether firms should be obliged to take financial security to cover potential liability to pay pollution clean-up costs. Spain's draft law proposes mandatory cover, while most others do not. See <www.endseuropedaily.com>, 'State of liability law implementation discussed' of 29 May 2006 and 'Spain tables 'groundbreaking' liability law', 27 October 2006.

664 Bergkamp 2005, 98.

665 Bauw 2004, 346-347.

666 European Environmental Agency, 'Management of contaminated sites in Western Europe', Topic Report No 13/1999, EEA, 2000. See also Commission of the European Communities, Communication from the Commission to the Council, the European Parliament, the Economic and Social Committee and the Committee of the regions, Towards a Thematic Strategy for Soil Protection, COM (2002) 179 final, Brussels, 16.4.2002, 12-13. 
parameters and a different attitude in what the Member States regard as potentially or actually contaminated sites. ${ }^{667}$ As the EEA notes, not all states for example, include military sites when creating an inventory of contaminated sites, nor do they all include operational as well as abandoned sites. ${ }^{668}$ Contamination of soils and groundwater around military sides especially is a problem in some of the new EU countries, as the Baltic States, Czech Republic and Hungary. ${ }^{669}$

Consequently, estimates about the amount of contaminated land in the European Union are extremely uncertain and depend entirely on the parameters used. 670

The EU Member States have developed or are developing national strategies to prevent and remedy soil pollution. Yet, national responses vary considerably and depend on policy concerns, the political system and the physical features of each state. ${ }^{671}$ It would be impossible to clarify soil protection measures of all EU Member States. The next paragraphs will therefore only highlight the most important aspect of soil protection legislation in the Member States. ${ }^{672}$

The scope and perspective of Member States' legislations and the approaches used can be very different and depend on the main problems experienced by soil pollution. For instance, in some countries, soil protection legislation focuses on the protection of groundwater quality, as a source of drinking water, like in Denmark. In other countries, soil protection legislation is, besides industrial activities, also applicable to agricultural activities, as in the Netherlands. In other countries such as Spain and France this is not so important. ${ }^{673}$

Due to the nature of soil pollution, with multiple causes and consequences, soil pollution is addressed in different policy domains. Some EU Member States deal with soil pollution in the context of general environmental policy, whilst other deal with it as part of waste regulation (Italy, Greece, Ireland and Portugal) ${ }^{674}$ but it has also become important in land use policy (like in Belgium and Denmark). ${ }^{675}$

Moreover, national strategies are multi-layered, with varying inputs at national, regional and local levels, depending on the political structure of the Member States. ${ }^{676}$ In federal jurisdictions, the regional authorities tend to be important. In Belgium, for example, the regions are entirely responsible for contaminated land. ${ }^{677}$

In order to identify contaminated land, some countries have developed a system of identification and registration of polluted sites (Belgium, Austria, UK, and Spain). Legislation can also put limitations on the transfer of polluted land (Sweden, Belgium). ${ }^{678}$

Finally, restoration of the soil is in most Member States dominated by administrative law, which creates a relationship between the public authorities and the polluter. ${ }^{679}$

Besides these Member States' responses to soil pollution, it merits to have a look at European initiatives to protect soil.

\subsubsection{EC Policy for Soil Protection}

Different EU policies (for instance on water, waste, chemicals, industrial pollution prevention, nature protection, pesticides and agriculture) contribute to soil protection but no coherent policy to soil pollution exists yet at European level.

However, a coherent approach to soil protection is in the making. The 6th Environmental Action Programme (EAP), approved by Council and European Parliament in 2002 and which runs until 2012, introduced soil protection as one of the seven thematic strategies to protect and preserve natural resources and asked the Commission to present a strategy to protect European soil. 680

667 European Environment Agency, Environmental Signals 2001, EEA, Copenhagen, 2001, 94.

668 European Environmental Agency, 'Management of contaminated sites in Western Europe', Topic Report No 13/1999, Copenhague, 2000, 10 and 154.

669 European Environmental Agency, Down to Earth: Soil degradation and sustainable development in Europe. A challenge for the $21^{\text {st }}$ century, EEA, Copenhagen, 2000, 16.

Layard 2004, 103.

Christie \& Teeuw 2000, 24.

The enumeration of Member States is merely done as illustration, and does not mean to be exhaustive.

Seerden \& Deketelaere 2000, 441.

Christie \& Teeuw 2000, 26.

Seerden \& Deketelaere, 2000, 442

Christie \& Teeuw 2000, 24-34. See also Christie \& Teeuw 1998, 175-197.

Christie \& Teeuw 2000, 26.

Seerden \& Deketelaere 2000, 443.

Seerden \& Deketelaere 2000, 446

Decision No 1600/2002/EC of the European Parliament and of the Council of 22 July 2002 laying down the Sixth Community Environment Action Programme, OJ L242, 10.09.2002. The Environmental Action Programmes were launched in 1972 and set the priorities and objectives of Community environmental policy. The other thematic strategies 
A first step in the development of a coherent EU soil policy was the Communication 'Towards a Thematic Strategy for Soil Protection' in 2002, in which the Commission described the multiple functions and features of soil, and the main threats to soil in the EU. ${ }^{681}$ Moreover, the Communication outlined the first steps towards the development of a Thematic Strategy to protect soils in the European Union. Next, the Commission launched a consultation process in February 2003. The Commission asked the opinion of the other European Institutions, the EU Member States and Regional Authorities, and consulted the broad community of European-wide stakeholder organisations as civil society, NGO's, industry, international and professional organisations. The Dutch EU-Presidency organised a high level Conference on 18-19 November 2004 in The Hague. Around 120 representatives of the EU Member States, the Commission itself, experts and stakeholders attended the 'Vital Soil' conference. Moreover, the Commission carried out an extensive internet public consultation. ${ }^{682}$

The consultation showed support for an EU Soil Strategy, although it will be clear that some economic sectors who would be affected do not agree, as for example farmers. ${ }^{683}$ Nevertheless, on 22 September 2006, the Commission adopted a comprehensive EU Soil Protection Strategy. The Thematic Strategy for Soil Protection consists of a Communication from the Commission to the other European Institutions, a proposal for a framework Directive, and an Impact Assessment. The publication of the Strategy was delayed due to objections to some of its provisions by enterprise commissioner Günter Verheugen, in particular with respect to contaminated sites inventories. In the final text, however, most of these provisions seem to be unchanged. ${ }^{684}$

In the Communication ${ }^{685}$ the Commission explains why further Community action is needed to ensure a high level of soil protection, sets the overall objective of the Strategy and explains what kind of measures must be taken. Moreover, it establishes a ten-year work programme for the European Commission.

The Proposal for a Framework Directive ${ }^{686}$ sets out common principles, objectives and actions for the protection of soils across the EU. It requires Member States to adopt a systematic approach to identifying and combating soil degradation, taking precautionary measures and integrating soils protection into other policies. Yet, within this common framework, the Member States would have considerable leeway to decide how best to protect soil and how use it in a sustainable way on their own territory. ${ }^{687}$ The commission decided against setting legally binding soil quality standards or timetables in the proposal. It is argued that this reflects the heterogeneous state of soil degradation in the EU. 688 On the other hand, it is clear that binding targets would make it harder to get the Directive approved. ${ }^{689}$

Member States are required to identify areas where there is a risk of erosion, organic matter decline, compaction, salinisation and landslides. They must set risk reduction targets for those areas and establish programmes of measures that are necessary to achieve these targets. They will also have to prevent further soil contamination. On the basis of a common definition of contaminated sites, Member States will be required to draw up public inventories of contaminated sites, and establish national remediation strategies to address them, starting with sites that pose the greatest risk to health. This is complemented with an obligation for the seller or the prospective buyer to provide, to the administration and the other party in the transaction, a soil status report based on chemical analysis when a site is being sold where a potentially

of the $6^{\text {th }}$ EAP concern the marine environment, pesticides, the urban environment, air pollution, waste, and sustainable use and management of natural resources.

681 Commission of the European Communities, Communication from the Commission to the Council, the European Parliament, the Economic and Social Committee and the Committee of the regions, Towards a Thematic Strategy for Soil Protection, COM (2002) 179 final, Brussels, 16.4.2002.

682 For the results of the internet consultation and the opinions of the European Institutions, see <europa.eu.int/comm/environment/soil/index.htm>. For an overview of the development process, see also European Commission, Soil Protection. The story behind the Strategy, Office for Official Publications of the European Communities, Luxembourg, 2006.

683 Commission of the European Communities, Proposal for a Directive of the European Parliament and of the Council establishing a framework for the protection of soil and amending Directive 2004/35/EC, $\operatorname{COM(2006)} 232$ final, Brussels, 22.09.2006, Explanatory Memorandum, 3. See also ENDS Europe Daily, Consultation shows support for EU Soils Law, 17 October 2005, $<$ www.endseuropedaily.com>.

684 ENDS Europe Daily, EU soil strategy finally reaches ground level, 22 September 2006, <www.endseuropedaily.com>.

685 Commission of the European Communities, Communication from the Commission to the Council, the European Parliament, the European Economic and Social Committee and the Committee of the Regions, Thematic Strategy for Soil Protection, COM (2006) 231 final, Brussels, 22.09.2006.

686 Commission of the European Communities, Proposal for a Directive of the European Parliament and of the Council establishing a framework for the protection of soil and amending Directive 2004/35/EC, COM(2006) 232 final, Brussels, 22.09.2006.

687 ENDS Europe Daily, EU soil strategy finally reaches ground level, 22 September 2006, <www.endseuropedaily.com>.

$688<\mathrm{http} / /$ ec.europa.eu/environment/soil/index.htm>, press release on Thematic Strategy for Soil Protection.

689 ENDS Europe Daily, EU soil strategy finally reaches ground level, 22 September 2006, <www.endseuropedaily.com>. 
contaminating activity ${ }^{690}$ has taken or is taking place. The Proposal also aims to prevent soil contamination by a requirement to limit the introduction of dangerous substances into the soil. Finally, the Member States are required to limit or mitigate the effects of sealing, for example by the rehabilitation of brownfields. ${ }^{691}$

The Impact Assessment ${ }^{692}$ provides an analysis of the economic, social and environmental impacts of the different options that were considered in the preparatory phase of the strategy and of the option (a framework Directive) finally retained by the Commission.

Whether and when the Framework Directive on Soil Protection will be adopted remains to be awaited. If it will be adopted, there will be some consequences for the Environmental Liability Directive's application to soil pollution. This will be further discussed in 4.3.2.

Yet, at present, in absence of a European soil protection policy, the prevention and the restoration of soil pollution is addressed indirectly in different environmental or other policy areas. EC directives that address soil issues are for example found in the area of air, water, waste, and chemical policies. Soil protection is only indirectly addressed. Nevertheless, these directives may implicitly contribute to the protection of the soil. ${ }^{693}$

First, with respect to air, Directive 96/62/EC aims to improve the ambient air quality and sets air quality standards for various pollutants, e.g. sulphur dioxides, nitrogen dioxide or heavy metals. ${ }^{694}$ Through the reduction of air born pollution, these Directives might contribute to the reduction of soil acidification and contamination with heavy metals. ${ }^{695}$

The Water Framework Directive ${ }^{696}$ contributes to the protection of soil through the implementation of the programmes of measures to obtain a good ecological status in all water bodies, and through the implementation of the codes of good agricultural practices in particularly vulnerable zones. ${ }^{697}$ The Nitrate Directive $^{698}$ focuses on the protection of waters against nitrate pollution but is only applicable to pollution caused by agricultural sources.

With respect to waste, soil protection objectives are present in the Waste Framework Directive, ${ }^{699}$ which stipulates that waste is to be disposed of without endangering the soil, but also in other specific waste legislation. Indeed, the Sewage Sludge Directive ${ }^{700}$ regulates the use of sewage sludge in such a way as to prevent harmful effects on soil, but is only applicable to agricultural activities. Another example is the

690 Potentially polluting activities include installations subject to the IPPC and major accident hazards Directives, (air)ports, waste water treatment facilities and landfill sites.

691 Commission of the European Communities, Communication from the Commission to the Council, the European Parliament, the European Economic and Social Committee and the Committee of the Regions, Thematic Strategy for Soil Protection, COM (2006) 231 final, Brussels, 22.09.2006; <http//ec.europa.eu/environment/soil/index.htm>, press release on Thematic Strategy for Soil Protection and ENDS Europe Daily, EU soil strategy finally reaches ground level, 22 September 2006, <www.endseuropedaily.com>.

${ }_{692}$ Commission Staff Working Document, document accompanying the Communication from the Commission to the Council, the European Parliament, the Economic and Social Committee and the Committee of the regions, Towards a Thematic Strategy for Soil Protection, Impact assessment of the Thematic Strategy on Soil Protection SEC(2006)620 and SEC(2006)1165 (Summary of the Impact Assessment), Brussels, 22.09.2006.

${ }_{693}$ Egelund Olsen 2001, 58. The list of directives that indirectly address soil pollution is not meant to be exhaustive. This falls outside the scope of this research. For a complete overview see Ecologic, Institute for International and European Environmental Policy (<www.ecologic.de>), 'EU Soil Protection Policy: Current Status and the Way Forward', Background Paper to the Dutch Ministry of Housing, Spatial Planning and the Environment (VROM), Thematic Assistance to the Conference 'Vital Soil: the next step towards a European Soil Strategy', 18-19 November 2004, The Hague and Commission Staff Working Document, Towards a Thematic Strategy for Soil Protection, Impact assessment of the Thematic Strategy on Soil Protection SEC(2006) 620, 32-34.

${ }_{694}$ Council Directive 96/62/EC of 27 September 1996 on ambient air quality assessment and management, 27 September 1996. The Framework Directive was followed by daughter directives, which set the numerical limit values, as for example Council Directive 1999/30/EC of 22 April 1999 relating to limit values for sulphur dioxide, nitrogen dioxide and oxides of nitrogen, particulate matter and lead in ambient air, OJ L163, 29.6.1999.

695 Ecologic, Institute for International and European Environmental Policy (<www.ecologic.de>), ‘EU Soil Protection Policy: Current Status and the Way Forward', Background Paper to the Dutch Ministry of Housing, Spatial Planning and the Environment (VROM), Thematic Assistance to the Conference 'Vital Soil: the next step towards a European Soil Strategy', 18-19 November 2004, The Hague, 11.

696 Directive 2000/60/EC of the European Parliament and of the Council of 23 October 2000, establishing a framework for Community action in the field of water policy (Water Framework Directive), OJ L 327, 22.12.2000, 1-73.

697 Ecologic, Institute for International and European Environmental Policy (<www.ecologic.de>), ‘EU Soil Protection Policy: Current Status and the Way Forward', Background Paper to the Dutch Ministry of Housing, Spatial Planning and the Environment (VROM), Thematic Assistance to the Conference 'Vital Soil: the next step towards a European Soil Strategy', 18-19 November 2004, The Hague, summary and conclusions.

698 Council Directive 91/676/EEC of 12 December 1991 concerning the protection of waters against pollution caused by nitrates from agricultural sources, OJ L 375, 31.12.1991, p. 1-8.

Council Directive 75/442/EEC of 15 July 1975 on waste. OJ L 194 of 25.07.1975.

700 Council Directive 86/278/EEC of 12 June 1986 on the protection of the environment, and in particular of the soil, when sewage sludge is used in agriculture (Sewage Sludge Directive), OJ L 181, 4.7.1986, 6-12. 
Landfill Directive ${ }^{701}$ which regulates the operation of new and existing landfills and is concentrated on the prevention or reduction of pollution of surface water, groundwater, soil and air. ${ }^{702}$

In chemicals legislation, the initiatives with respect to the use of pesticides, in particular the Directives on Authorisation of Plant Protection Products ${ }^{703}$ and on Biocidal Products, ${ }^{704}$ as well as the $\mathrm{REACH}$ proposal ${ }^{705}$ pay attention to soil protection.

The IPPC Framework Directive 706 introduced an integrated process-oriented approach. The Directive regulates emissions, recommending the use of Best Available Techniques and an integrated approach to emissions to air, water and soil as a condition for granting permits to large industrial installations. ${ }^{707}$

In addition, other European policies, such as the Common Agricultural Policy (CAP), may also have an impact on soil. With the last CAP reform, soil related issues have been addressed in a more coherent way, especially through the introduction of the compulsory cross-compliance scheme. Farmers who receive direct payments are obliged to respect specific statutory management requirements and maintain land in Good Agricultural and Environmental Condition (cross-compliance). These cross compliance standards, defined at national or regional level, should ensure a minimum level of soil protection for agricultural land with respect to erosion, organic matter and compaction. ${ }^{708}$

Summarising, nowadays, soil pollution is a recognised as a widespread environmental problem in the EU. The Member States have started to develop national policies to remedy soil contamination. Yet, soil protection measures vary considerably among the EU Member States and depend on policy concerns, the political system, the physical features of each state and the main problems experienced through soil pollution. Moreover, Member States' responses tend to be multi-layered, with varying inputs at national, regional and local level. Data of contaminated sites and remediation are not comparable due to lack of a common definition for contaminated sites. At present, at EU level, soil pollution is addressed fragmentary and indirectly in other policy areas. However, the EU Commission has taken the first steps to develop a comprehensive European soil protection policy.

The Environmental Liability Directive also applies to soil pollution. The next paragraph will examine the impact of the Directive on soil protection policies in the Member States.

\section{2. $\quad$ Application of the Directive to Soil Pollution}

The ELD, which aim is to establish a framework of environmental liability based on the polluter-pays principle, to prevent and remedy environmental damage, also applies to soil pollution. Article 2 (1c) of the directive, defining 'environmental damage', includes 'land damage, which is any land contamination that creates a significant risk of human health being adversely affected as a result of direct or indirect introduction, in on, or under land, of substances, preparations, organisms or micro-organisms' ${ }^{709}$

This paragraph will examine how much impact the directive might have on Member States' soil protection policies.

\subsubsection{Scope of the Directive with Respect to Land Damage}

As stated above, Article 2 of the Directive includes land damage within environmental damage. However, the application of the Directive, as far as soil contamination is concerned, is limited by various provisions.

701 Council Directive 1999/31/EC of 26 April 1999 on the landfill of waste (landfill Directive), OJ L 182, 16.7.1999, 1-19.

702 Egelund Olsen 2001, 58.

703 Council Directive 91/414/EEC of 15 July 1991 concerning the placing of plant protection products on the market. OJ L230 of 19.9.1991.

704 Directive 98/8/EC of the European Parliament and of the Council of 16 February 1998 concerning the placing of biocidal products on the market, OJ L123/1 of 24.4.98.

705 Commission of the European Communities, Proposal for a Regulation of the European Parliament and of the Council concerning the Registration, Evaluation, Authorisation and Restriction of Chemicals (Reach), establishing a European Chemicals Agency and amending Directive 1999/45/EC, COM (2003) 644 (1), 29 October 2003.

706 Council Directive 96/61/EC of 24 September 1996 concerning integrated pollution prevention and control, OJ L 257, 10.10.1996, 26-40.

707 Egelund Olsen 2001, 58.

708 Council Regulation 2003/1782/EC, OJ L 270, 21.10.2003. Ecologic, Institute for International and European Environmental Policy, 'EU Soil Protection Policy: Current Status and the Way Forward', Background Paper to the Dutch Ministry of Housing, Spatial Planning and the Environment (VROM), Thematic Assistance to the Conference 'Vital Soil: the next step towards a European Soil Strategy', 18-19 November 2004, The Hague, 51 and Commission Staff Working Document, Towards a Thematic Strategy for Soil Protection, Impact assessment of the Thematic Strategy on Soil Protection SEC(2006) 620, 34. 
There are several reasons why most of the contaminated land will fall out of the scope of the Directive once it has been implemented. ${ }^{710}$

First, environmental damage, which includes land damage, is only covered by the Directive if it has been caused by any of the (dangerous) occupational activities listed in Annex III of the Directive, and to any imminent treat of such damage occurring by reason of any of those activities. ${ }^{711}$ If soil contamination has been caused by a professional activity other than those listed in Annex III, the operator cannot be held liable under the Directive and recourse will have to be taken to national provisions. ${ }^{712}$

During the legislative procedure, the European Parliament attempted to widen the scope of the Directive, including an amendment in its Resolution of 14 May 2003 that 'five years from the date of its entry into force, this Directive shall apply to all environmental damage caused or likely to cause by the operation of any occupational activity, not just those listed in Annex III, or any substance used in any such activity or substance'. ${ }^{713}$ This amendment however was not adopted.

Next, land damage only falls under the scope of the Directive if the risk of harm to human health is 'significant'. ${ }^{714}$ This means that soil contamination in uninhabited areas will fall out of the scope of the Directive. ${ }^{715}$ Moreover, it will be impossible for a national authority to oblige, on the basis of the Directive, an operator who causes ecological damage without serious risk for human health, to take restorative measures or the recover the costs from the restoration in case the authority acted itself. Remarkable is also that the Directive does not clearly indicate when there is significant harm to human health. ${ }^{716}$

Furthermore, the Directive 'will only apply to environmental damage or to an imminent treat of such damage caused by pollution of a diffuse character, where it is possible to establish a causal link between the damage and the activities of individual operators'. ${ }^{717}$ The Directive does not give a clear answer whether the authorities or the operator bear the burden of proof of the existence or non-existence of a causal relationship between the damage and the activities of the operator. However, from Article 3 , § 1 and Article $4 \S 5$ which limit the application of the Directive and Article $8 \S 3,{ }^{718}$ which explicitly reverses the burden of proof, can be deducted that the burden of proof lies with the authorities. ${ }^{719}$

Yet, soil might be contaminated by more than one substance, by more than one operator and causal links are rarely clear. The Directive does not require a causal link between one single operator and the harm (Article $4 \S 5$ considers 'individual operators in plural'). For the cost allocation in case of multiple party causation however, the Directive refers to national law. ${ }^{720}$ Nevertheless, this provision still might mean that, for various sites that are contaminated by diffuse pollution, even causing harm to health, individual operators cannot be held liable under the directive if the causal link cannot be undeniably proven. Therefore, this provision might impose a severe restriction on the imposition of liability for contaminated land on the basis of the Directive. This also means that agricultural activities, where diffuse pollution is common, often might be excluded from the scope of the Directive. ${ }^{721}$

Yet, Article $16 \S 1$ allows Member States to maintain or adopt more stringent provisions in relation to the prevention and remedying of environmental damage. Hence, according to Wagner, Member States must be allowed to clarify the causality provisions in national law, or to reverse, under restrictive conditions, the burden of proof on the operator. ${ }^{722}$

A last reason why many contaminated sites will be unaffected by the Directive when it has been implemented is that the Directive only has a prospective effect. Indeed, Article 17 and 19 (1) confirm that the Directive will only have prospective effect. The Directive will not apply to damage caused by an

\section{Layard 2004, 103. \\ ELD, Article $3 \S 1 \mathrm{a}$ \\ Brans 2005, 38 .}

Amending the original article 3, European Parliament legislative resolution on the Council Common Position for adopting a European Parliament and Council Directive on Environmental liability with regard to the prevention and remedying of environmental damage (COM(2002) 17 - C5-0088/2002 - 2002/0021(COD)), available at <http:// www.europa.eu.int/comm/environment/

liability/parlopinion.htm>. See also Layard 2004, 104

ELD, Article 2, \$1c.

Wagner 2005, 80

Brans 2005, 39.

ELD, Article 4 (5).

Article $8 \S 3$ of the ELD states that 'an operator shall not be required to bear the cost of preventive or remedial actions pursuant to this Directive if he can prove that the environmental damage (or threat) was caused by a third party and despite safety measures were in place, or resulted from compliance with a compulsory order from a public authority'.

Wagner 2005, 90

ELD, Article 9.

Layard 2004, 103.

Wagner 2005, 92. 
emission, event or incident that took place before 30 April 2007, when the Directive as to be implemented. ${ }^{723}$ Consequently, the 1.5 million sites currently thought to be contaminated by the EEA will need to be remedied independently of the ELD, regulated - if at all - by domestic provisions in the Member States. ${ }^{724}$

Hence, in the contaminated land context, despite all the concern and high-profile debates, the scope of the ELD is limited. The regime will only apply prospectively and a clear link needs to be established between the operator and the damage. The harm to health must be 'significant' and it must have come about as a result of an operation specified in Annex III of the Directive. ${ }^{725}$ The consequence of the Directive's narrow definition of land damage is that many sites containing pollution will not be included within the scope of the Directive, so that clean-up, if it takes place at all, will be on the account of the individual Member States. ${ }^{726}$ Yet, Member States' different approaches to contaminated land will result in significant variation in the remediation of contaminated sites that fall out of the scope of the Directive.

It might be interesting to note here that Preamble 28 of the Proposal for a Soil Framework Directive stipulates that 'in those contaminated sites where the polluter cannot be found, cannot be held liable for the pollution under national or Community legislation or cannot be made to bear the costs of remediation, also known as orphan sites, responsibility for reducing risk to human health and the environment should fall on the Member States. For those purposes, Member States should put in place specific funding mechanisms to ensure a durable financial source for the remediation of such sites' ${ }^{727}$ This would mean that if the Proposal would be adopted, the ELD should be amended in order to align it with the remediation obligations as stipulated in the Soil Framework Directive. At this moment, the ELD only foresees that, for orphan sites, remedial action may be taken by the competent authority as a last resort.

For contaminated sites within the scope of the Directive, various provisions are left to the Member States, like permit and state-of - the-art defences, so that operators may be exempted from liability. The variation that may exist in the implementation of the ELD by the Member States causes that there still will be significant differences in the soil policies of the Member States and hence the ELD will not create much harmonisation. ${ }^{728}$ On the contrary, the ELD might introduce considerable uncertainty.

Yet, besides the variations that may exist in the implementation of the ELD by the Member States, there might be significant variation between the Member States in the remediation process. Indeed, the Directive gives Member States considerable leeway in Member States' practice of dealing with contaminated land. ${ }^{729}$

\subsubsection{Remediation of Land Damage under the Scope of the Directive}

If a site is considered to be contaminated under the Directive, then Annex II sets out a framework to be followed in order to choose the most appropriate measures to ensure the remedying of the damage. Yet, compared to the provisions for damage to water or protected species and habitats, the paragraph on land damage is very moderate, and the polluter's obligations to remedy the damage are limited. ${ }^{730}$ Indeed, Annex II (2) only requires that 'the necessary measures shall be taken to ensure, as a minimum, that the relevant contaminants are removed, controlled, contained or diminished so that the contaminated land, taking account of its current use or approved future use at the time of the damage, no longer poses any significant risk of adversely affecting human health'. Only when the use of the land is changed, further measures are required.

According to Layard, this is in line with the practice in most of the Member States. ${ }^{731}$ Yet, Wagner indicates that, although the provisions of Annex II are in line with the limited scope of the Directive for soil contamination and presumably with the practice in most of the Member States, it constraints liability to removing the risk from human health and therefore the Directive may stay behind national provisions in certain Member States, as for example in Germany or the Netherlands. ${ }^{732}$

Moreover, Annex II (2) last paragraph indicates that a natural recovery option, which is an option in which no direct human intervention in the recovery process would be taken, shall be considered..$^{733}$

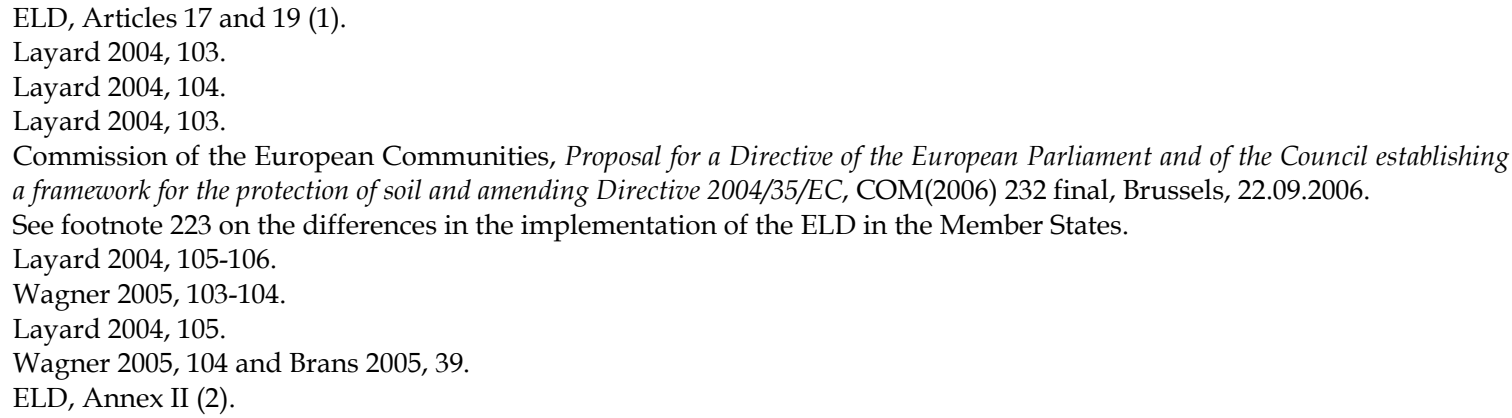


The Directive leaves it to the Member States to determine when damage has occurred and when to intervene, to determine the appropriate method for remediation and to what level remediation should occur. ${ }^{734}$ This is a very flexible but pragmatic approach. Indeed, most Member States have a level at which risk is considered to be unacceptable. Yet, the level at which the 'cut-off' point is set, varies. However, as Christie and Teeuw indicate, it is difficult to establish background levels for a number of contaminants, particularly inorganic ones, as what is normal in one area is not normal in another. Hence, the use of acceptable soil criteria based on background levels for one region may not be suitable for one another. ${ }^{735}$ Consequently, the Community does not have a set of European-wide 'trigger levels' as there exist for water and air. ${ }^{736}$

Moreover, it was already indicated that, due to the limited scope of the Directive, other - national or European - rules will exist, to remedy the damage that does not fall under the scope of the Directive and sometimes the different regimes might be overlapping or inconsistent.

In particular for soil pollution, European waste legislation must be mentioned.737 Indeed, after the ELD was adopted, a ruling of the European Court of Justice raised important questions about the relation of the ELD to European waste legislation. In the Texaco case, the Cour d'appel de Bruxelles of Belgium asked the European Court of Justice whether hydrocarbons which are spilled unintentionally and cause soil and groundwater contamination may be considered to be waste within the meaning of Waste Framework Directive ${ }^{738}$ and secondly whether, in these circumstances, the petroleum undertaking which supplies the service station (in this case Texaco) may be considered to be the producer or holder of such waste within the meaning of Waste Framework Directive. The ECJ ruled that hydrocarbons which are unintentionally spilled and cause soil and groundwater contamination indeed are waste within the meaning of Article 1(a) of Waste Framework Directive. Moreover, the Court held that in circumstances such as those in the main proceedings, the petroleum undertaking which supplied the service station can be considered to be the holder of that waste within the meaning of Article 1(c) of the Waste Framework Directive only if the leak from the service station's storage facilities which gave rise to the waste can be attributed to the conduct of that undertaking. ${ }^{739}$

As a consequence of the Court's judgment in the Texaco case, non-remediation of soil might be considered as 'abandonment of waste'. This is prohibited and subject to sanctions provided by national law. Moreover, the producer of the product that has polluted the soil may, if the incident can be attributed to the conduct of the producer, be liable for the cost of remediation, even if he did not cause the pollution himself. Bergkamp argues that this regime is fully inconsistent with national soil remediation law and with the regime of the ELD. ${ }^{740}$ As the court's Texaco judgment was released after the adoption of the ELD, the ELD does not resolve the conflict. Moreover, Article 3 (2) of the ELD provides that the Directive applies 'without prejudice to more stringent provisions of Community legislation regulating the operation of any activities falling within the scope of this Directive'. ${ }^{741}$ The Directive makes no exception for European waste legislation, which will continue to apply in addition to the Directive. Hence, according to Bergkamp, the 'Texaco-liability' might exist on top of the liability regime of the ELD. ${ }^{742}$ Clearly, overlapping of liability regimes might create disputes and uncertainty.

In sum, the Member States will face the difficult task of implementing the vague ELD. Indeed, the ELD leaves important aspects as defences, precise definitions of damage or restoration criteria up to the Member States, and consequently contaminated land policy will still differ significantly between Member States. Moreover, the Directive will leave many of the contaminated sites in Europe to be cleaned up under national provisions of the Member States.

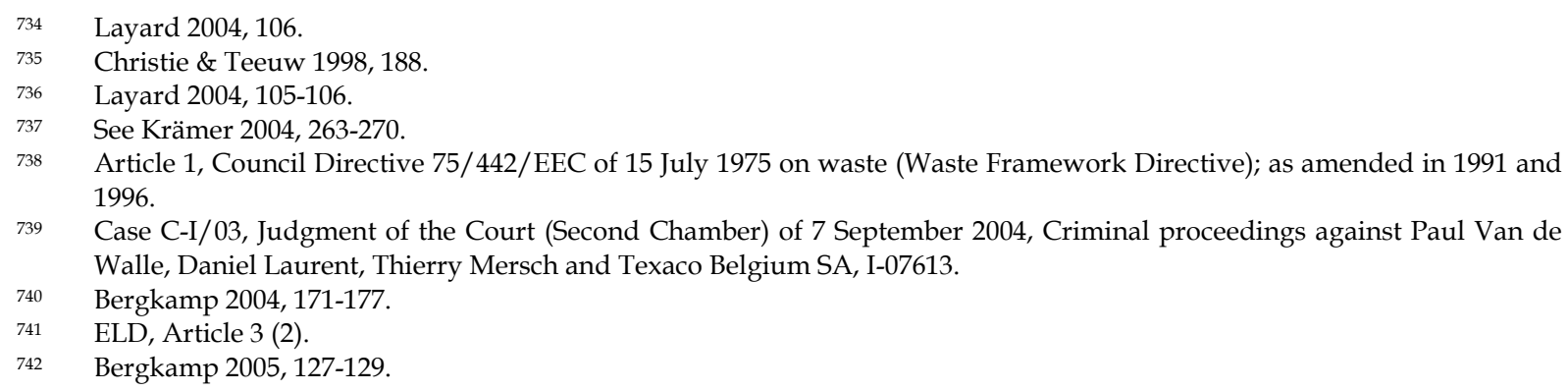




\section{Summary}

Chapter 4 examined the competence of the European Union to harmonise environmental liability rules and studied the provision of Directive 2004/35/CE, the 'Environmental Liability Directive', and as an example its application to soil pollution.

In a first step, the history of European environmental policy was sketched, with the focus on the division of competences between the European level and the Member States for environmental policy. Indeed, the history of European environmental law is inextricable linked with the political debate about the surrender of sovereignty of the Member States to the European level. It was outlined how the balance between sovereignty and harmonisation of environmental rules at European level was sought by means of the principles of subsidiarity and proportionality. Moreover, Member States' room for manoeuvre once the Community has taken up its competence to legislate in the environmental field and implementation and enforcement issues were discussed.

Next, the provisions of the Environmental Liability Directive and the reasons for European action in the field of environmental liability were studied. On 21 April 2004, Directive 2004/35/CE on Environmental Liability with Regard to the Prevention and Remedying of Environmental Damage was adopted. With the ELD, the Community aims to establish a framework of environmental liability based on the 'polluter-pays' principle, to prevent and remedy environmental damage. The development and the adoption of the Directive gave rise to much controversy and conflict. Much of the conflict addressed the question whether and how far the European Union could go in adopting a European liability regime.

In order to understand why and how the Directive got to its final form, the milestones in the environmental liability saga were sketched and the reasons provided by the EU Commission for a harmonised environmental liability regime were examined. It is remarkable that in the final text of the ELD, the Commission fails to explain why it is necessary to establish a harmonised liability regime or why it cannot be achieved by the Member States, as is required by the subsidiarity principle.

Subsequently, the provisions of the Directive were studied. The coverage of the Directive is limited, so that different regimes may apply to different types of damage in case of an accident and the ELD does not clarify its relation to other liability regimes. Moreover, the ELD has left crucial aspects, as defences, insurance but also precise definitions of damage or restoration criteria, up to the Member States. Member States may also maintain or adopt more stringent provisions in their national law to prevent and restore environmental damage. Consequently, the ELD provides an uncertain framework and if the Directive has been implemented, the regime will be a less harmonised regime and might create more uncertainty than its adherents originally might have thought.

Finally, the application of the Directive to soil pollution as an example was examined.

It appeared that with respect to soil pollution, despite all the concern and high-profile debates, the scope of the ELD is limited. The regime will only apply prospectively and a clear link needs to be established between the operator and the damage. The harm to health must be 'significant' and it must have come about as a result of an operation specified in Annex III of the Directive. This means that the Directive will leave many of the contaminated sites in Europe to be cleaned up under national provisions of the Member States.

Yet, as in the general case, for contaminated sites within the scope of the Directive, various provisions are left to the Member States, like permit and state-of-the-art defences, so that operators may be exempted from liability. The variations that may exist in the implementation of the ELD by the Member States, together with the numerous sites that will have to be remedied - if at all - by domestic provisions of the Member States, makes that there still will be significant differences in the soil policies of the Member States and hence the ELD will not create much harmonisation. On the contrary, the ELD might introduce considerable uncertainty as different liability regimes will exist together.

Moreover, besides the variations that may exist in the implementation of the ELD by the Member States, there might be significant variation between the Member States in the remediation process. Indeed, the Directive gives Member States considerable leeway in Member States' practice of dealing with contaminated land. In sum, the ELD creates less integration than its adherents might have hoped for.

Chapters 5 and 6 will now apply the theoretical framework, built up in Chapters 2 and 3, to the Environmental Liability Directive. 



\section{Chapter 5}

\section{ECONOMIC ANALYSIS OF DIRECTIVE 2004/35/EC ON ENVIRONMENTAL LIABILITY}

Although the central focus of this research is the level of government at which liability rules for environmental damage best can be decided, and to study the Environmental Liability Directive from this perspective, a first question might be whether the liability regime as sketched out in the ELD can be considered as an efficient regime to ensure the prevention and restoration of environmental damage as studied in Chapter 2.

Therefore, in a first step, an assessment of the Directive itself will be provided. It will be examined to what extent the provisions of the Directive correspond with the economic analysis of liability rules as provided in Chapter 2. Indeed, Chapter 2 of this research presented an economic analysis of liability rules for environmental damage and clarified the role of liability rules in the prevention and restoration of environmental damage, illustrated by soil pollution. It will be studied on the one hand whether the liability regime of the ELD will indeed stimulate operators to prevent environmental damage from happening, and on the other hand whether the ELD, if prevention failed, can ensure that environmental damage, as soil pollution, will be adequately restored.

The main elements that might influence the preventive effect and the compensation function of the Directive are the choice of the liability rule, the way in which is dealt with retroactivity, causation, the exceptions and defences that are accorded, and whether or not (obligatory) insurance is provided for. These main elements will now be studied successively in order to assess the Directive's efficiency.

\section{Choice of Liability Rule}

The ELD provides for a combination of a strict liability regime for hazardous activities and a negligence regime for non-hazardous activities, in order to ensure the prevention and remedying of environmental damage. Indeed, as studied in Chapter 4, the ELD foresees that strict liability would apply to operators who professionally conduct hazardous or potentially hazardous activities. These activities are listed in Annex III of the Directive. ${ }^{743}$ The strict liability regime covers damage to protected species and natural habitats, water and land damage. Fault-based liability or negligence would apply to all other professional activities. Unlike strict liability, this regime only applies to protected species and natural habitats, not to water or land damage. ${ }^{744}$

Is this regime economically efficient? It seems helpful to summarise briefly the results of the economic analysis of tort law, provided in Chapter 2, in order to compare the regime provided in the ELD with economic theory.

\section{Economic Analysis of Tort Law}

The extensive analysis can of course be found in Chapter 2. This paragraph will only summarise the main results. In brief, in Chapter 2 it was concluded that theoretically, for environmental accidents, both a negligence regime and a strict liability regime could induce injurers to take optimal precautions to prevent environmental damage.

743 These activities include moreover the operations of installations which are subject to authorisation under the Industrial Plants (IPPC) Directive (96/61/EC) or the Dangerous substances Directive (76/464/EEC), waste management operations which require a permit under the Waste Framework Directive (75/442/EEC) or the Hazardous Waste Directive (91/689/EEC), the treatment of chemical substances falling within the scope of the Classification, Packaging and Labelling of Dangerous Preparations Directive (1999/45/EC), the Pesticides Directive (91/414/EEC) or the Biocidal Products Directive (98/8/EC), the transport of dangerous goods and any contained use of GMO's $(90 / 219 /$ EEC or 2001/18/EC).

$744 \quad$ ELD, Article 3.1 and Annex III. 
A negligence rule will lead to an optimal result as long as the legal system sets the due care standard equal to the optimal care level. Under the strict liability rule, the courts do not have to define any level of due care because the injurer will have to pay the costs of the damage regardless the precaution he took. Economic rational behaviour is assumed, therefore the firm will try to minimise its total costs, prevention and expected damage costs. The more precaution the firm takes, the smaller the expected damage costs will be. The firm will increase precautions up to the level where precaution costs are equal to the expected damage. Beyond that level precaution costs will be higher than the reduction in expected damage. Hence, also under a strict liability rule, the firm would select the economically optimal level of precaution that will minimise total costs for the society. ${ }^{745}$

Yet, there are significant differences between a negligence or a strict libility rule, that might determine which rule in which circumstances is preferable.

As Shavell pointed out, a liability rule should not only provide incentives for optimal care taking, but should also provide incentives for adopting an optimal activity level. ${ }^{746}$ These are the times that the polluter would engage in the polluting activity, to produce the social optimal amount of the good. The economic analysis of tort law showed that only a strict liability rule would give the injurer an incentive both to take efficient care and to adopt an optimal activity level. Indeed, under negligence, if the firm complies with the due care standard of precaution, it will not be held liable for harm. This means that the firm will not have to take the costs for clean-up into account in its cost calculation, if it fulfilled the due care standard. As these costs will not be internalised in the firm's costs, the firms will produce too much, or put differently, engage too often in the polluting activity. Under a strict liability rule, however, the polluter will always be liable for the damage. The firm will therefore internalise in its cost calculations both the cost of prevention and the clean up costs and produce the socially optimal amount of the good whose production might give rise to environmental damage. ${ }^{747}$

Hence, authors like Polinsky and Shavell argued that in the case of dangerous industrial activities (which are considered as unilateral accidents) that might cause severe environmental damage, strict liability would be the preferred liability regime as it is most important to control both the injurer's level of care and his activity level. ${ }^{748}$

On the other hand, Faure pointed to the fact that there may be cases where other parties than the polluter, such as public or private actors, can influence the magnitude of environmental damage. For example, public actors may be responsible to manage a natural resource area and to take precautionary measures if damage threatens to happen. Faure rightly argued that in these bilateral accident settings liability should also aim at giving these parties incentives to take preventive measures or to adopt an optimal activity level. ${ }^{749}$

Nevertheless, in case of dangerous industrial activities that might cause severe environmental harm, the influence of the polluter will be still far more important than the influence of the other parties. A strict liability rule would therefore still be preferred to ensure that the polluter will take all preventive measures. Nevertheless, a contributory negligence defence might be added to the strict liability rule to ensure that the other parties also take precautions. ${ }^{750}$

Environmental damage might also be caused by non-dangerous activities. In that case, it might be desirable to give all parties in the accident setting an incentive to take care, and a negligence rule might be adequate.

Both liability regimes also differ with repect to compensation. Under strict liability, the victims will be compensated in any case. Under a negligence rule, the victims will have to bear the costs of clean-up themselves, as long as the injurer complied with the legal standard. It is sometimes argued that if the aim of installing a liability regime is to internalise the costs for the environment caused by production, the negligence rule will not fully reach this aim, as part of the damage will not be born by the injurer. Therefore, again there might be a preference to opt for a strict liability rule for environmental damage. ${ }^{751}$ However, insolvency might distort the deterrence and compensation or restoration function of strict liability. Indeed, strict liability is only efficient if the injurer can pay for the consequences of the accident. If the injurer would be insolvent, or if the judge would underestimate the damage, underdeterrence would follow. ${ }^{752}$ Therefore, Cooter argued that if the judge can determine the optimal level of care, a negligence

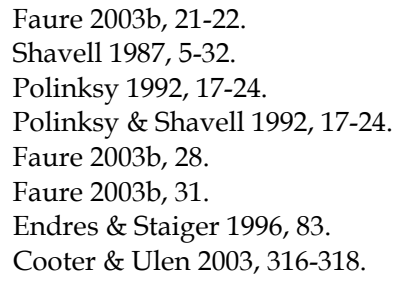


rule would be preferred. On the other hand, if there is uncertainty concerning the optimal care level, a strict liability rule would be preferred. ${ }^{753}$

There is one more refinement that must be made. It was implicitly assumed that the strict liability rule required the polluter to compensate the damage he caused, not less but also not more. Problems may arise if strict liability is combined with other features which might expand the burden of liability on entreprises, as for example joint and several liability, or the removal of the burden of proving of causation. Trebilcock argued that it was especially because of these other features that the strict liability regimes in the United States were found to be 'crushing'. ${ }^{754}$ Hence, the final judgement on the efficiency of a strict liability regime may depend on the way in which the regime deals with issues as for example causation or joint and several liability. ${ }^{755}$

Yet, overall, from an economic efficiency perspective, it is argued that for unilateral dangerous activities that may cause severe environmental damage, a strict liability rule might be referred. As mentioned above, this liability rule would give the polluter optimal incentives for precaution and result in an optimal activity level. Moreover, a strict liability rule might ensure full restoration in the event of damage. However, this assumes that a contributory negligence rule is added to provide incentives to the victims as well, that mechanisms are introduced to cope with the potential insolvency of the polluter (like compulsory insurance), that liability is not retroactive, that the risk of causal uncertainty is not shifted to the polluter and that no joint and several liability rule is imposed. For non-dangerous activities, a negligence rule might be appropriate.

\section{Liability Regime of the Environmental Liability Directive}

A comparison of the results of the economic analysis of tort law with the approach chosen by the ELD shows that the regime of the ELD is to a large extent in line with economic theory. Hazardous activities can often be considered unilateral and in those situations it is important to control both the injurer's level of care and his activity level through a strict liability rule. In case of non-hazardous activities which may cause environmental harm, liability should also aim at giving other parties involved incentives to take preventive measures. Hence, for those cases the ELD indeed proposes a negligence rule. Thus the distinction made by the Community between hazardous activities for which a strict liability rule is required, and non-hazardous activities for which negligence is appropriate, seems therefore to follow the economic logic. ${ }^{756}$

In addition to this general preventive effect that the economic threat of liability for damage is expected to have, Article 5 of the ELD explicitly imposes the obligation on the operator to prevent environmental damage from occurring. ${ }^{757}$ This means that if there is an imminent threat of environmental damage, the operator shall take the necessary preventive measures. Operators are also obliged to inform the competent authority of all relevant aspects of the situation. The competent authority may require information or give instructions to the operator to be followed concerning the preventive measures to be taken. If the operator fails to comply with the obligations, the competent authority may take these measures itself. ${ }^{758}$

Besides the prevention of environmental damage, the ELD also aims to ensure the restoration of environmental damage if prevention failed. Article 6 of the Directive lists the obligations of the operator to remedy the damage. As studied in the previous chapter, when environmental damage has occurred, the operator shall inform the competent authority of all relevant aspects of the situation and take all practical steps to control, contain, remove or otherwise manage the contaminants and/or any other damage factors in order to limit or to prevent further environmental damage and adverse effects on human health or further impairment of services. ${ }^{759}$ Annex II offers a common framework for Member States to select the most appropriate measure to ensure that environmental damage is remedied for protected species and habitats, water and land. Protected species and habitats and water must be restored to baseline condition. Land on the other hand, does not need to be remedied to its baseline condition. The ELD provides that land is remedied by removing, controlling, containing or reducing contaminants so as to ensure that the contaminants do not pose a significant risk to human health. ${ }^{760}$ However, as mentioned before, precise definitions of damage, baseline assessments and restoration criteria are passed on to the Member States, ${ }^{761}$ a

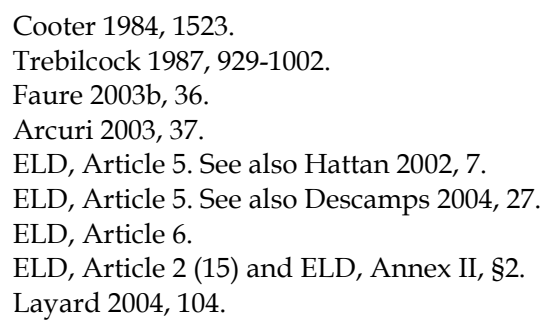


practice which is used for various provisions in the ELD and which will be discussed in more detail when examining the ELD from the public interest approach.

Yet, originally, Article 5 of the Commission's proposal for an environmental liability regime included an obligation for Member States to take, in case of environmental damage, remedial measures and Article 6 proposed that Member States had to ensure that restoration measures were taken also in those cases, where the responsible operator did not cover the necessary costs ('orphan damage'). ${ }^{762}$ These obligations on the Member States would have had an additional preventive effect as all operational activities under Annex III of the Directive require a permit which is to be issued by the Member States' administrations. If the Member States run the risk to have, in certain circumstances, to pay themselves for the restoration of the damage, the Member States might be more attentive to the content of the permit, the conditions attached to it and the financial guarantees that the operator can present to prove his ability to pay for the restoration costs. Moreover, the Member States would have had an incentive to carefully monitor whether the conditions laid down in the permit were actually complied with. However, the final version of the ELD deleted the obligation on the Member States to restore the damage to the environment themselves. Yet, as was already indicated in paragraph 2.2.3.4 of chapter 4, this might somewhat be compensated by Article $8 \S$ 2 of the ELD, which requires that the competent authority shall recover, inter alia, via security over property or other appropriate guarantees, from the operator who has caused the damage or the imminent threat of damage, the costs it has incurred. ${ }^{763}$ Moreover, several of the Directives to which the ELD refers to, contain obligations requiring the authorities to take remedial measures as for instance Article $4 \S 4$ of the Wild Birds Directive, Article $6 \S 2$ of the Natural Habitats Directive and Article $4 \$ 6$ of the Water Framework Directive. Finally, the Member States may be held liable under the Frankovich doctrine if they have committed a serious breach of the Environmental Liability Directive, which would be the case if they failed to oblige the operator to take preventive or restorative measures. ${ }^{764}$

Nevertheless, the absence of an explicit obligation on the Member States to restore, in case of orphan damage, the damage to the environment themselves, denies the positive effect of Member States' responsibility on prevention and restoration, which definitely is a weakness of the regime. ${ }^{765}$

In sum, in broad lines, the combined strict liability/negligence regime that the Community has agreed upon in the ELD and its explicit obligations for the polluter to prevent damage and remedy environmental damage in Article 5 and 6 of the ELD, seems to be in line with the economic analysis of tort law, although it is deplorable that the Member States themselves do not have any direct responsibility towards prevention and restoration.

Yet, the efficiency of the regime does not only depend on the type of liability regime. Indeed, the ELD's practical use will to a large extent depend on the provisions concerning retroactivity and causation, the exceptions and defences that are accorded, and whether or not provisions for (obligatory) insurance are foreseen. The next paragraphs will deal with these issues in order to examine whether the ELD can indeed exert a preventive effect and ensure the restoration of environmental damage.

\section{Retroactivity}

In principle, the ELD stipulates that damage caused before the expiry of the deadline for implementation of the Directive should not be covered by its provisions. ${ }^{766}$

Especially for environmental damage, a long time lapse might exist between an industrial activity causing environmental damage and the moment that the damage is recognised. This time lapse might be due to the fact that it sometimes might take a long time before the risks of the damage are fully understood.

Liability rules aim to provide incentives for the polluter in taking precautions to prevent environmental damage ex ante and at the same time to ensure restoration ex post in case damage could not be prevented. Indeed, the basic idea of tort law is that the fact that the polluter knows that he will be held liable ex post for any damage should give him incentives ex ante for prevention in order to escape liability in the future.

A retroactive application of liability for damage, which was caused in the past, conflicts with this basic idea of tort law and seems to be inefficient. Indeed, if suddenly certain behaviour would lead to liability $e x$ post, whereas this behaviour was not considered wrongful at the time when the accident happened, for

762 Commission of the European Communities, Proposal for a Directive of the European Parliament and of the Council on environmental liability with regard to the prevention and remedying of environmental damage, Brussels, 23.1.2002, $\operatorname{COM}(2002) 17$ final, 20.

763 Schueler 2006, 13-32.

764 Wenneras 2005, 147-148.

765 Krämer 2005a, 132. See also Schueler 2005, 58-72.

766 ELD, preamble 30 and article 17. 
example because the risks were not known, this retrospective application of new standards could never affect the incentives for prevention of the polluter. Indeed, it is hard to argue that retroactive liability can positively affect the incentives for prevention of the polluter if the polluter's behaviour was not considered wrongful at the time of the accident. Hence, retroactive liability does not seem to contribute to the prevention of accidents. ${ }^{767}$ From an economic perspective, the fact that care was not sufficiently taken in the past can be considered as a 'sunk cost', which cannot be changed anymore. Boyd and Kunreuther even argue that retroactive liability may weaken incentives to take precautions against future environmental liability, which is clearly inefficient. ${ }^{768}$ In addition, also from a distributive point of view, retroactive liability can be criticised. As Faure argues, it is hardly fair that an operator of an industrial activity, whose behaviour at the time of the accident was not considered wrongful, should bear the consequences of a collective lack of knowledge of the risks of that industrial activity. ${ }^{769}$

A few refinements might be added though. First, over time new risks might emerge or the standard of care might increase due to changes in technology. It would be too easy to state that the polluter will only have to comply with the 'old' standard of care, and will never be liable for new risks that emerge. Shavell argued that the foresight that there might be liability ex post might give incentives to obtain information about risk to industrial operators. ${ }^{770}$ Indeed, liability for development risks should give an operator appropriate incentives for investment in research to acquire information about risk and about optimal technologies to prevent the risk. It is doubtful, however, whether this argumentation could also justify a retrospective change of a liability rule or changes in the standard of care itself. It is hard to defend that an $e x$ post change in the liability rule will positively affect the incentives for proper behaviour which was not considered wrongful at the time when the act was committed by the operator. In this respect, it is appropriate to recall the aim of a liability rule. A liability rule aims to influence future behaviour and aims to give operators incentives for taking precautions. Acts that happened in the past cannot be changed anymore and are therefore 'sunk costs'. An ex post change of the liability rule for these past actions could never have positively affected future incentives for prevention. A retrospective change of a liability rule might lead to over- or underdeterrence and is therefore inefficient. ${ }^{771}$

Yet, this outcome creates a dilemma. Indeed, the standard setting process can be seen as a process of learning whereby the standard is not static, but dynamically changes in time. ${ }^{772}$ It clearly would be wrong to state that due care standards never change. There may be many reasons, as for example new technological insights, that would justify a more stringent standard of care, adopted by the judge. This new case law could have an important signalling function for other operators in the market who can adopt their future behaviour. The question however arises what should be done with the operator in the particular case in which the new standard is set. Should the operator be sacrificed for the benefit of a more efficient care standard in the future and hence should this operator be made retroactive liable although his behaviour was not considered wrongful at the time the act was committed? A possible solution to this dilemma is the technique of prospective overruling, which means that the court will follow an old duty of care in the particular case, but announces that it will follow a different reasoning in the future..$^{773}$

In sum, the discussion above shows that a distinction has to be made between on the one hand a retrospective application of a new liability regime and on the other hand the liability for development risks. Faure holds that a liability regime for risks which are not known today is not necessarily inefficient, because, if this is known in advance, it will give incentives to obtain information on these new risks and on the optimal techniques to prevent the risk. Thus, a liability for development risks is not inefficient as long as it may positively influence incentives for prevention and as long as the development risk is not a disguised retroactive liability. A retrospective application of new standards or new legislation, which could never have positively affected future incentives for prevention, however, cannot be justified. ${ }^{774}$

Turning to the ELD again, the ELD seems to follow the economic logic on this point. Indeed, the absence of retroactive effect in the European environmental liability regime was already recommended in the studies preceding the White Paper. 775

Yet, Bergkamp argues that, as the Directive foresees in Article 16 that Member States may maintain or adopt more stringent measures in relation to prevention and remedying of environmental damage

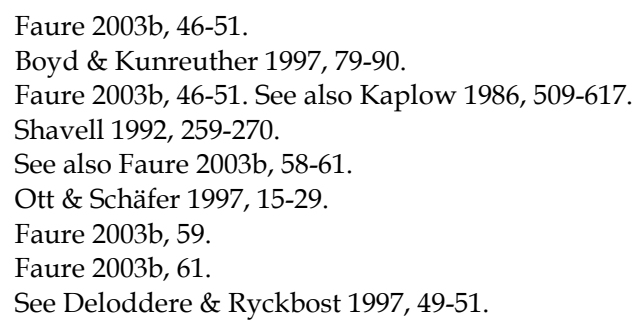


including the prevention and remedying of additional activities, this would mean that Member States would be allowed to apply liability for development risk or even give the ELD retroactive effect so that historical damage and damage caused before 30 April 2007 would fall under the applicable legislation. ${ }^{776}$ Retroactive liability, however, would obviously put a heavy burden on industry in those Member States. Therefore, whether certain Member States will indeed introduce retroactive liability remains to be awaited. As shown above, it would not be an economic efficient option.

Thus, the ELD seems to correspond with the economic analysis of tort law by indicating that the liability regime should be non-retrospective.

\section{Causation}

The economic analysis of tort law starts from the idea that liability rules will deter undesirable activities and will give incentives for prevention. This requires however, that a clear causal relationship between the damage and the activity of the injurer can be established. ${ }^{777}$ Indeed, for example with respect to environmental liability, it is economically inefficient to hold an operator liable for environmental damage which he did not cause, and which he accordingly could not have prevented. However, certainly in the field of environmental damage, it might be difficult to establish that causal link.

In a first step, this paragraph will clarify the problem of causation in environmental pollution. Second, an economic approach to causation will be sketched and possible solutions to the problem will be offered. Next, the case law of some EU Member States will be briefly looked at and fourth, the provisions of the ELD with respect to causation will be examined. Finally, a conclusion will be formulated.

\subsection{The Problem of Causation in Environmental Pollution}

With respect to environmental pollution, it is often very hard to establish a clear causal link between damage to the environment and the wrongful act of a single operator. The problem of scientific uncertainty concerning the causal link between an industrial activity and (health or environmental) damage is receiving increasing attention in the legal literature. ${ }^{778}$

Van den Bergh distinguishes two types of situations which may cause causal uncertainty. ${ }^{779}$ The first type concerns the situation where there are uncertain victims. Suppose for example that in a neighbourhood of a certain factory the number of cancers is higher than the national average. Suppose also that this increased risk might be due to the factory, which emits dangerous substances into the air. Causal uncertainty arises when it cannot be established with certainty which of the many cancers in the neighbourhood are caused by the factory (which is called the exess risk) and which are due to other causes (also called the background risk). Hence, causal uncertainty arises when the damage may have multiple causes and when it is not certain whether the damage has been caused by a particular injurer or by another cause. The second type of situation arises when multiple injurers may be involved but when it is unsure which injurer has caused the particular damage. The well-known Dutch DES-judgement might clarify this situation of causal uncertainty. The drug DES caused birth defects, and some daughters of mothers who took DES during the pregnancy suffered physical harm. The causal link between the drug and the daughters' systoms was undisputed, and the manufacturers that brought DES on the market were also known. Yet, uncertainty existed with respect to which manufacturer had sold the product to a particular mother, and hence who could be held liabe. ${ }^{780}$ Clearly, many other examples could be given of situations, in which it would be difficult to establish, with scientific certainty, a causal relationship between a certain industrial activity and the damage. Yet, all situations of causal uncertainty have one thing in common: the fact that there is damage is certain, but the relationship between the damage and the activity is not. ${ }^{781}$

Faure notes that there is an increasing tendency in tort law, to hold the effects of this uncertainty against the injurer, with the aim to protect the victim. This can take different legal forms. In some cases, full scientific proof of a causal relationship is not demanded from the victim; in other cases the causal uncertainty might result in a reversal of the burden of proof. Another tendency is to hold several tortfeasors jointly and severally liable when it cannot be established who of the different tortfeasors caused the damage. The 'alternative causation' rule under Dutch tort law for instance, allows the victim to claim full

ELD Article 16. See Bergkamp 2005, 99.

Landes \& Posner 1983, 109-134.

See for instance the various contributions in Spier 2000, or Von Bar 2000.

Van den Bergh 2001, 133.

Faure 2003c , 80-83 and Faure \& Bruggeman 2006, 3.

Faure \& Bruggeman 2006, 6. 
compensation from any of the tortfeasors. ${ }^{782}$ The tortfeasor could in theory rebut the presumption of liability by proving that he did not cause the particular damage, but in practice this will often not be feasible. The Dutch Supreme Court for instance applied the 'alternative causation' rule to the DES-case. ${ }^{783}$

Yet, from an economic point of view, this 'victim-friendly' approach might have significant negative consequences. Indeed, shifting the risk of causal uncertainty or a reversal of the burden of proof to the injurer may mean that entreprises will have to pay for the consequences of risks which were not caused by them. This obviously may have devastating consequences for the insurability of risks. ${ }^{784}$

The next paragraph examines four options of how the law could deal with causal uncertainty, for instance with respect to environmental damage.

\subsection{Economic Approach to Causation}

The starting point of the economic approach to causation is that the injurer should only be liable for the damage he actually caused. The question therefore arises how the law could deal with the problem of causal uncertainty between a certain activity and damage. Faure indicates that four options exist. ${ }^{785}$

1. An all or nothing liability rule with victim preference. This means that when in a particular situation is felt that there is a non-negligible probability that a given activity caused harm, all victims receive $100 \%$ compensation.

2. An all or nothing liability rule with injurers preference. This means that when in a particular situation is felt that there is a non-negligible probability that a given activity did not cause harm, all victims are refused compensation.

3. A threshold liability rule. Under this rule, compensation is only rewarded when the probability that the damage was caused by the tort passes a certain threshold, for example $50 \%$. If the probability is lower than the threshold, the victim receives no compensation at all, if the probability is higher than the threshold, the victim receives full compensation. This liability rule is known in the American legal literature as the "more probable than not' rule, because of the fact that the plaintiff must convince the judge that it is 'more probable than not' that its damage was caused by the act of the injurer.

4. A proportional liability rule. This means that the probability that a certain tort caused the damage is reflected in the compensation.If scientific expertise for instance indicates that the likelyhood that the damage is caused by a particular tort feasor is $40 \%$, than the victim can receive compensation for $40 \%$ of its damage.

Yet, which option is most efficient from an economic point of view? It merits to have a closer look at the four options mentionned above. The best way to deal with causal uncertainty has been examined extensively in the economic literature, as for example by Shavell, Rosenberg and Kaye. ${ }^{786}$

The first option, in which the victims can claim full compensation in case of causal uncertainty, is considered to be inefficient and injust. Indeed, Shavell argued that there is a good economic justification for limiting the liability of the injurer to the damage that he has actually caused. If there would be no need to prove a causal link, a consequence might be that, especially in cases of strict liability, a potential injurer (e.g. a factory) could abstain from activitities which are important for the society (such as the production of pharmaceuticals), but which may cause pollution. ${ }^{787}$ Hence, this option might lead to overdeterrence.

The second option, the all or nothing liability rule with injurers preference, is also not eficient from an economic point of view. This rule would require that the victim proves with $100 \%$ certainty that his damage has been caused by a certain operator, in order to get compensation. In practice this might not be feasible. Therefore, the requirement would mean that injurers in many cases might escape liability although their actions might have contributed to the damage. Hence, this option would lead to underdeterrence.

Spier 2000.

See Hoge Raad 9 October 1992, [1994] Nederlandse Jurisprudentie (NJ), 535 (C.J.H.B.). See also Spier, \& Wansink 1993, 176181

Faure 2003c, 80 and Faure \& Bruggeman 2006, 4.

Faure 2003c , 83-84; Faure \& Bruggeman 2006, 7-8.

Kaye 1982, 487-516; Rosenberg 1984, 851-929; Shavell 1985b, 587-609.

Shavell 1987, 108. A similar line of reasoning is followed by Trebilcock who argued that such a liability regime can be considered as 'crushing': Trebilcock 1987, 929-1002. 
The third and fourth option (theshold liability and proportional liability) first require that the probability is calculated in which the injurer has contributed to the damage. Indeed, from an economic perspective, a liability rule should be constructed in such a way that the injurer is only held liable for the excess risk, which was caused by his activity and not for the background risk, which already existed..$^{788}$ Liability for the background risk, which the injurer did not cause, would again lead to overdeterrence as in the first option. Thus, in a first step, it has to be established to what extent the background risk has been increased by the injurer's activity. Scientific evidence might determine the percentage which indicates what the probability is that an injurer's activity caused the damage. This probablity is referred to in the literature as the 'probablity of causation' and can be found by dividing the excess risk by the background risk plus the excess risk. ${ }^{789}$ Yet, which rule, the threshold rule or the proportional liability rule is most efficient to deal with causal uncertainty?

The threshold liability rule leads to a situation in which the victim gets full compensation if the probability of causation passes the threshold, for example of $50 \%$. If the probablity is lower than the threshold, the victim does not receive any compensation. Yet, in a particular case, the probability might be always lower than the threshold. For example, the probability that a certain cancer would have been caused by the activities of a certain factory might be $40 \%$. This means that 40 out of 100 cancers would have been caused by the factory. Yet, for every individual, the probability of causation would be $40 \%$ and hence below the threshold. Hence, in this situation, the factory would not have to compensate any of the victims whereas in a number of cases, the factory might have caused the cancer. This seems inefficient, as it would give the factory insuffient incentives for accident reduction and the rule seems also unfair with respect to victim compensation. ${ }^{790}$

The proportional liability rule might solve this problem. With a proportional liabilty rule, the victim is compensated by the same amount of the probability of causation. For example, if the probability that a factory caused the damage is $40 \%$, the victim will be compensated by $40 \%$ of his damage. In the example above, this would mean that the factory would have to compensate $40 \%$ of the damage to every victims, which would - at the aggregate level - be the same as compensating 40 out of 100 victims, who got cancer because of the factory's activities. ${ }^{791}$ From an economic perspective, this means that the injurer will be precisely liable for the risk which was caused by his activity, and therefore a proportional liability rule would give the injurer optimal incentives for prevention. ${ }^{792}$ Hence, the proportional liability rule is preferred by several scholars and is also defended in the economics analysis of tort law. ${ }^{793}$

\subsection{Case Law in Some of the EU Member States}

It appears that the attitude of the EU Member States with respect to causation varies significantly. ${ }^{794}$

The most victim-friendly attitude may be found in the Netherlands. The Dutch Supreme Court in the DES-case applied the alternative causation rule, meaning that the DES-daughters are allowed to claim full compensation of any of the manufacturers. The particular manufacturer can rebut the presumption of liability by proving that he did not sell the drug to the mother. However, in practice, this will be often impossible. Hence, this result is similar to a joint and several liability rule. ${ }^{795}$ Another example relates to the Dutch Supreme Court case Cijsouw v. De Schelde. In this case, a victim of asbestosis could not prove when he had been in contact with the fatal asbestos fibre that caused his disease. However, the determination of the moment of contact with the final asbestos fibre was crucial for the case. Indeed, Cijsouw worked for the defendant firm De Schelde for several years. Yet, during the first years of his employment, the defendant could not have known - with respect to the state-of-the-art at that time - that he had to take measures to protect his employee against asbestos and thus could not be liable. The Supreme Court again shifted the risk of uncertainty concerning causation to the entreprise by holding that is was presumed that Cijsouw had been in contact with the fatal asbestos fibre during the second period of his employment with the defendant. This presumption could be rebutted if the defendant had been able to proof that it was not

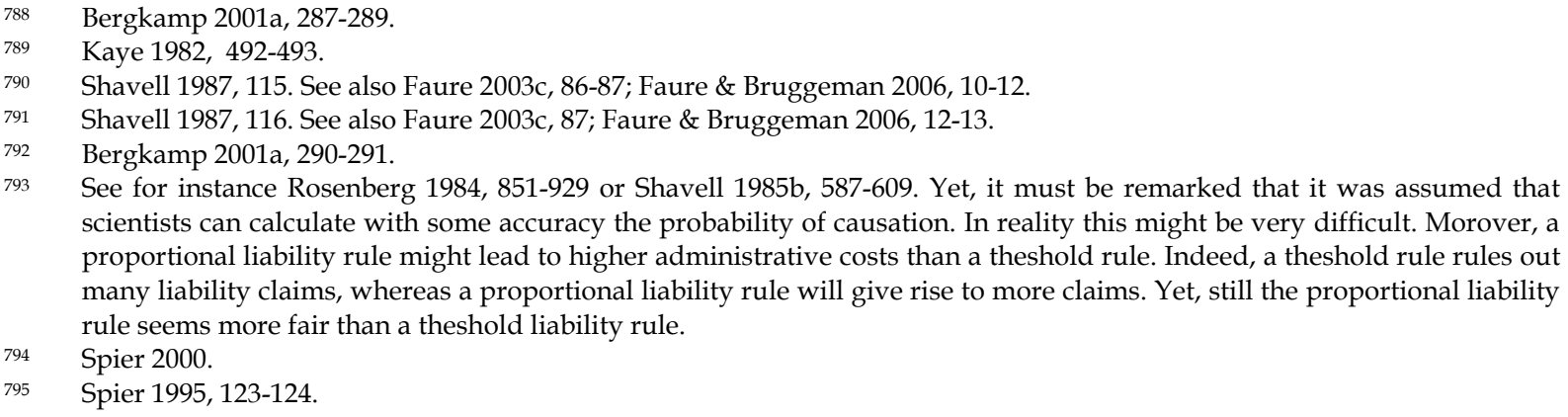
scientists can calculate with some accuracy the probability of causation. In reality this might be very difficult. Morover, a proportional liability rule might lead to higher administrative costs than a theshold rule. Indeed, a theshold rule rules out many liability claims, whereas a proportional liability rule will give rise to more claims. Yet, still the proportional liability rule seems more fair than a theshold liability rule.

795 Spier 1995, 123-124. 
during the second period that Cijsouw was employed by the defendant that he was in contact with the fatal fibre. Again, obviously, this was impossible for the defendant firm. ${ }^{796}$ And recently, the Dutch Supreme Court accepted proportional liability in its judgment of 31 March 2006 on employer's liability for occupational diseases (Karamus v. Nefalit). The Supreme Court argued that, if it is proven that the employer did not take all the safety measures which were required with respect to the dangers of asbestosis, and if therefore the chances to contract lung cancer have been increased substantially, this employer will be liable for the consequences. The employee himself however was a notorious smoker, and there was no stable statistic evidence linking the chance of contracting lung cancer to the asbestosis or to the smoking habits of the employee. Therefore, the court decided that the employer should be sentenced to full compensation, less the extent to which the employee contributed to his disease. ${ }^{797}$

The French concept of perte d'une chance also allows for the application of proportional liability. ${ }^{798}$ The defendant is made liable for the 'amount' of causation which his or her conduct accounts for, in order to avoid the perceived unfairness of either leaving the victim without any compensation, or making the defendant liable for the full amount of the damage, which he however did not cause. ${ }^{799}$ For example, in a French case, the plaintiff skier collided with an unidentified skier. The plaintiff claimed damages from her instructor as he had failed to identify the other skier whilst she lay injured on the ground. The Court of Cassation held that the instructor had breached his duty, whereby he had caused the victim to lose the chance of claiming damages against the other skier. Hence, the instructor was held liable, but only to the amount in which his conduct contributed to the loss of the victim. ${ }^{800}$ Typical examples where 'loss of a chance' is used are failures to provide medical treatment or breaches of the duty to inform the patient of the risks associated with a particular treatment. ${ }^{801}$ For example, when a doctor's negligence resulted in a loss of chance of recovery of 25 per cent, then the victim might claim compensation for these 25 per cent. The patient's compensation is thus not full but is proportional to the lost chance. Belgian and Dutch courts also accept proportional liability, as shown above. ${ }^{802}$

German law has followed a different path then the French law to deal with these situations, by introducing specific rules concerning the burden of proof for the victim (Beweiserleichterung - relief of the burden of proof - or Beweislastumkehr - reversal of the burden of proof -). When compared to the French law, the German approach may put a greater hurdle on the plaintiff, but on the other hand, the plaintiff might also receive full compensation. ${ }^{803}$

In the UK on the other hand, case law shows that English law still demands that the victim demonstrates that is was 'more probable than not' that his damage was caused by a particular injurer. Indeed, a rather similar case to the Dutch Cijsouw case, Fairchild v. Glenhaven Funeral Services, dealt with the exposition to asbestosis of Arthur Fairchild during his employment with several employers. The widow of Fairchild sued two employers but could not prove with whom of the employers her husband had contracted the fatal asbestos fibre. The House of Lords decided that 'on the balance of probability' it could not be proven by which employer Fairchild had been exposed to the fatal asbestos fibre and therefore the two employers could not be held responsible. Hence, the United Kingdom rather prefers the all or nothing approach than the threshold approach and the proportional liability rule. ${ }^{804}$

Hence, as the attitude of the EU Member States clearly varies significantly with respect to causation, the scope of liability might also vary significantly between the Member States. It is therefore particularly important to examine how the ELD dealt with the problem of causation with respect to environmental damage.

\subsection{The ELD and Causation}

The ELD is rather vague with respect to causation. Indeed, the various provisions of the Directive must be carefully studied in order to find indications on the requirement of a causal relationship and the burden of proof.

According to Article 5 (1) and Article 6 (1) of the ELD, the operator is obliged to take the necessary preventive or remedial measures in case damage might occur or has occurred. Articles 5 (1) and 6 (1)

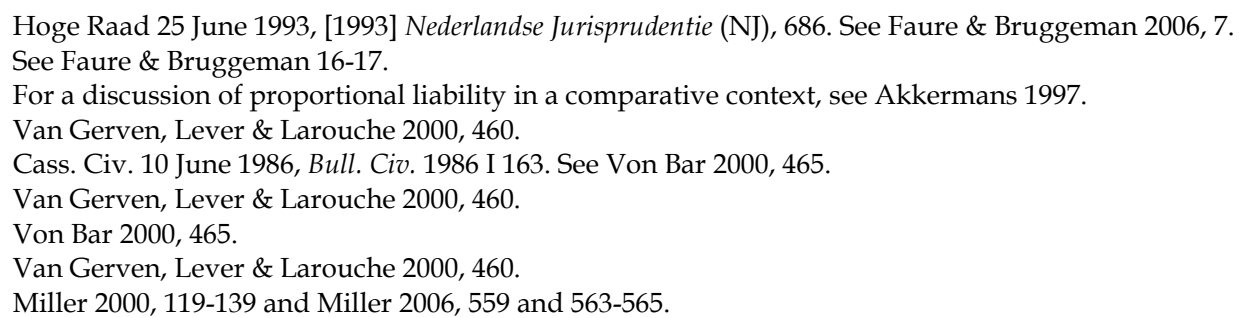


however, do not provide for any causality requirement. It might be thought that the operator is obliged to take the necessary measures, independent whether he has caused this damage and whether he could have prevented it. Yet, the causality requirement could be deducted from the scope of the Directive. Article 3 (1) of the ELD limits the scope of the Directive to occupational activities that have caused environmental damage or to an imminent threat of such damage. Article 4 (5) of the ELD moreover states in case of diffuse pollution that 'the Directive shall only apply to environmental damage or to an imminent threat of such damage caused by pollution of a diffuse character, where it is possible to establish a clear link between the damage and the activities of the individual operator'. Hence, it might be deducted that the preventive and remedial measures obliged in Articles 5 and 6 of the ELD require a causal relationship between the operator and the (potential) damage. It might be questioned of course why the ELD did not stipulate this clearly. ${ }^{805}$

Further, from the Directive it cannot be read immediately whether the burden of proof of the existence of a causal relationship lies with the operator or with the authorities who make allegations of damage. The common practice is that the burden of proof lies with the plaintiff, which in the case of the ELD would be the authorities. This practice seems to be followed by the ELD as the Articles 3 (1) and 4 (5) of the ELD limit the application of the Directive, whereas Article 8 (3) and (4), concerning permit defence and state-of-the-art defence clearly reverse the burden of proof on the operator. ${ }^{806}$ Moreover, the Commission clarified that 'its proposal does not reverse the burden of proof. Anyone who can make allegations of damage (or risk of damage) should give some reasonable supporting evidence that these allegations are founded. The competent authority (or authorities) to be designated by each Member State will be the driving force of the scheme. The proposal foresees that the operator should be obliged to disclose to the competent authority the relevant data and information to help establishing the facts of the case' ${ }^{807}$ Nevertheless, it will be clear that in some cases, it might be difficult to prove that causal link between the operator and the damage. For example, soil pollution is a very complex issue with multiple causes and different impacts on the environment and on human health, so that a causal link might be difficult to prove.

It might be wondered whether the causality requirements, as far as they can be deducted from the wording in Articles 3 (1) and 4 (5) of the ELD could prevent that operators would be held liable for the damage they caused. Indeed, as shown above, the most problematic issue in liability regimes is precisely the causality requirement. As Wagner argues, a strict application of full proof of a causal link between the damage and the operator might paralyse every liability regime. ${ }^{808}$ This might even be more relevant in the case of environmental liability as environmental damage might be caused by multiple sources so that it might be difficult to retrieve the main polluter. Yet, from Article 4 (5) ELD follows that the ELD does not require a causal link between the damage and one single operator, as reference is made to 'operators'. Nevertheless, as far as joint and several liability is concerned, the ELD passes the issue on to the Member States. Article 9 of the ELD states that if more than one operator causes environmental damage, the cost of remedying that damage is allocated among the operators according to the domestic law of Member States, in particular 'the apportionment of liability between the producer and the user of a product'. ${ }^{809}$ Each Member state may thus decide whether to impose joint and several liability for indivisible environmental damage or proportionate liability, depending on its domestic law. However, this might of course influence significantly the burden for the industry within the different Member States. Hence, Faure advises that Member States would introduce proportional liability, so that an operator is only liable for the risk or the damage that he has contributed. Indeed, only with a proportional liability it can be prevented that operators might have to bear the costs for damage that they did not cause, and that they cannot prove that the damage was caused by others. The proportional liability rule therefore is also to be preferred from an insurability point of view. ${ }^{810}$

It has to be awaited whether the causality requirements in the ELD could prevent that operators can be held liable for the damage they caused. Yet, Article 16 (1) of the ELD explicitly allows Member States to maintain or adopt more stringent provisions in relation to the prevention and remedying of environmental damage, so that in principle, the Member States would have the competence to reverse the burden of proof on the operator in cases in which it is judged necessary by the Member States. ${ }^{811}$

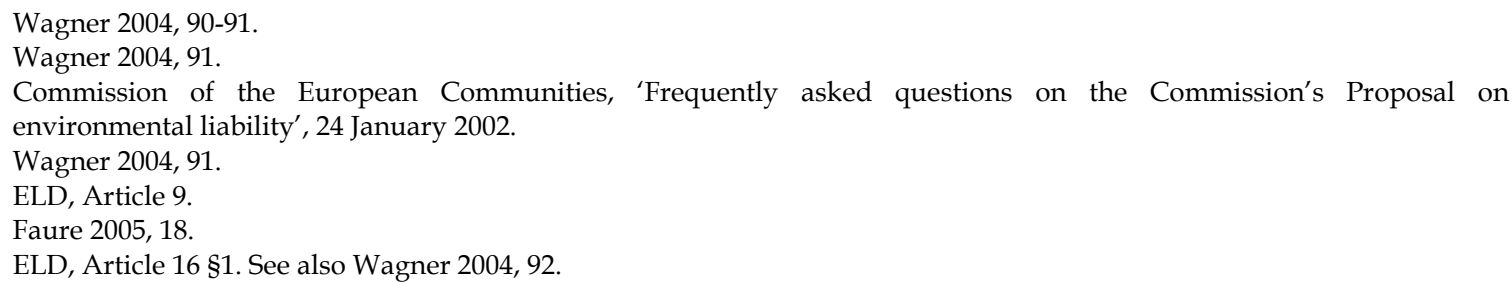




\subsection{Conclusion on Causation}

As was shown above, the main problem with respect to liability for environmental damage is precisely the causality requirement. Yet, the ELD is rather vague with respect to causation, and passes important decisions on to the Member States, as for instance the acceptance of joint and several liability. Moreover, it appears that the attitude of the Member States varies significantly with respect to causation. Hence, after implementation of the Directive, the scope of liability for environmental damage, as stipulated by the directive, might therefore also vary significantly between the Member States.

Yet, one of the arguments for harmonisation was the transaction costs argument, which was also put forward by the European Commission to justify the ELD (Chapter 6 will deal extensively with the justications for the ELD). If the Commission really aimed to lower transaction costs by means of the ELD, it could have harmonised the causality requirements in order to lower transaction costs, for instance by introducing proportional liability, but it did not take the opportunity. Apparantly, the costs for harmonisation were too high. Hence, the transaction costs argument of the Commission for harmonisation of liability for environmental damage becomes very weak.

Hence, all in all, it seems that the basic framework offered by the ELD - a combined system of strict liability and negligence and no retroactivity - corresponds with the economic analysis of tort law, although the fact that the ELD does not address the causation issue, and passes important decisions with respect to causation on to the Member States of cause substantially weakens any 'transaction cost reduction' justification for the ELD.

Yet, liability regimes often accept a number of defences, meaning that the polluter, who otherwise might fulfil the conditions for liability, may not be hold liable. As these defences to a large extent may determine in practice whether the regime will be enforceable, it merits examining now the defences accepted by the ELD from an economic efficiency perspective.

\section{Defences}

\subsection{Force Majeure}

The ELD provides in preamble 20 that an operator should not be required to bear the costs of preventive or remedial actions in situations where the damage in question or imminent threat thereof is the result of certain events beyond the operator's control. ${ }^{812}$

Force majeure is a traditional defence accepted in almost every liability regime. There is a clear economic rationale for the argument that in case of force majeure, there should be no liability. Holding a polluter liable for environmental damage which was caused through certain events beyond his control, does not seem to make sense as the polluter could not influence the accident risk by taking more precautions. Indeed, the economic theory of tort law starts from the idea that liability should affect the incentives for prevention and in the case of force majeure, liability cannot influence the polluter's incentives to take care, as he cannot influence the accident risk. Hence, if the injurer can not be blamed of the accident, he should not be held liable. Thus, even under strict liability, force majeure should remain a defence. ${ }^{813}$ Therefore, the fact that the ELD accepts the defence of force majeure follows the economic logic and can be welcomed.

The other defences that are accepted by the ELD are more controversial though. The ELD provides that the Member States may adopt a partial or complete defence of compliance with a permit issued under any of the EC legislation that is listed in Annex III to the ELD as well as a partial or complete state-of-the-art defence. These two particularly controversial defences will be studied now from an economic efficiency point of view.

\subsection{Regulatory Compliance Defence}

A regulatory compliance defence, also called a permit defence, within a strict liability regime, means that the operator, who otherwise would fulfil the conditions for liability, may be exempted from responsibility because of compliance with the regulatory standards governing his activity. ${ }^{814}$

Article 8 (4) of the ELD states that 'Member States may allow that operators do not have to bear the cost of remedial actions taken pursuant by the Directive if he demonstrates that he was not at fault or

ELD, Preamble 20.

Faure 2003b, 52-54.

Wenneras 2005, 153. 
negligent and that the environmental damage was caused by an emission or event expressly authorised by, and fully in accordance with the conditions of, an authorisation conferred by or given under applicable national laws and regulations which implement the legislative measures adopted by the Community specified in Annex III, as applied at the date of the emission or event' ${ }^{815}$ Hence, the permit defence would only be available to the operators of dangerous occupational activities listed in Annex III of the Directive. Normally, strict liability would apply to these operators.

Scholars are very sceptical about the introduction of a permit defence in a liability regime. Indeed, a permit defence implicitly assumes that regulation represents optimal standards and that regulators are capable of determining such standards. ${ }^{816}$

In reality, however, command and control regulation might contain gaps and imperfections. Indeed, regulators need information in order to determine optimal standards. Collecting this information is costly, time-consuming and difficult to gather. Regulators are also dependent on information from the regulated industry. ${ }^{817}$ Obviously, such information might be difficult to obtain. Moreover, information about risk is often considered as a 'public good' for which industry lacks the incentives to produce data. ${ }^{818}$ Another fundamental problem with regulation is that regulators are under constant pressure and lobbying from different interest groups during the decision-making process. This might bring about the risk of so-called 'agency capture'. ${ }^{819}$ As was studied in the private interest approach, the regulator generally favours pressure groups over dispersed interests. Hence, industry might have a considerable impact on the content of the regulation. There is also the risk of bribery and corruption inside regulatory agencies themselves. Furthermore, regulation is static. It is based on the knowledge at the time of drafting. ${ }^{820}$ Due to new scientific evidence or technical innovations regulation soon might be outdated. ${ }^{821}$ Finally, many or most environmental standards are only minimum requirements. ${ }^{822}$

Clearly, there are enough indications to believe that regulatory standards will not always be optimal. Hence, compliance with regulatory standards may be an insufficient ground to exempt an operator from liability.

As Faure indicates, a first reason to expose an injurer to liability, although he has complied with the regulatory standard, is that this standard is indeed often just a minimum. If compliance with these minimum standards would result into an exemption from liability, the potential injurer would have no incentive to invest more in care than required by these standards, even if additional care could significantly reduce the expected accident costs. Thus, a complete permit defence thwarts any initiative to take precautions in excess of the regulatory standard. ${ }^{823}$ Exposing operators to (strict) liability regardless of compliance will induce operators to take precautionary measures beyond what is needed by the standard. Additionally, liability might stimulate research in cleaner production methods. This might not only serve environmental purposes, the development of new and safer technologies may also create new business opportunities and stimulate increased competition. As strict liability forces operators to internalise the full costs of environmental damage, a clean production method may become a business advantage. Conversely, a permit defence may have an environmentally counter-active effect since investing more in care than the regulatory standard requires, would place the operator in a competitive disadvantage. ${ }^{824}$

A second reason to expose an injurer to liability, although he has complied with the regulatory standard, is that exposure to liability might counterbalance the unavoidable lobbying and public choice effects that come into play when permits are granted. Indeed, if compliance with the permit would exempt from liability, the only thing an operator would have to do is to get a permit with lenient conditions from a friendly public servant. 825

Finally, tort law may be a stop gap for situations that were not foreseen in the regulation. Exposure to liability, notwithstanding the permit, might be in such case an important guarantee that the operator will take efficient care. ${ }^{826}$ This reason for not granting a permit defence seems particularly relevant when the damage concerns soil pollution or damage to biodiversity, which is exactly the field of application of the ELD. One can indeed argue that soil pollution or damage to biodiversity may have a large variety of causes

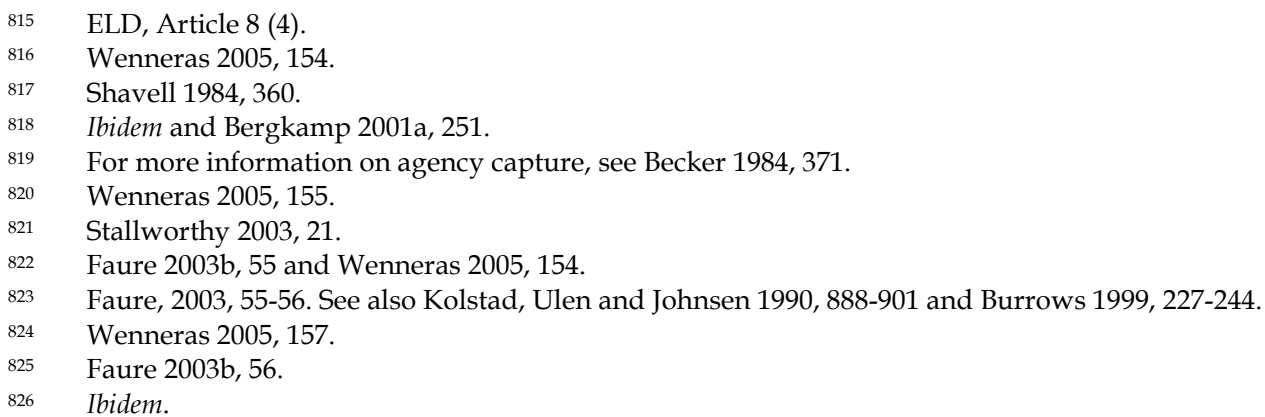


and that there might be unknown risks, so that regulation might only cover a minor part of the potential damage to soil or biodiversity. Complying with the conditions in regulation and licenses is in this case therefore merely the minimum an operator has to do. Indeed, if the operator can take cost efficient measures to further reduce damage to the environment, it would be efficient to hold him liable, even if he complied with the regulatory standards. ${ }^{827}$

Yet, the sceptical attitude of most scholars towards a permit defence is not fully shared by RoseAckerman and Bergkamp. Theoretically, the regulator is supposed to weigh costs and benefits of different standards and to choose that standard that reflects the public interest and the level of risk accepted by the citizens. Thus, if the regulator balanced all interests involved, and accordingly determined the optimal care standard that would deliver the highest social net benefit, Rose-Ackerman argues that the court in a civil liability case should not be 'second guessing' the care standard defined by the regulator. She pleads that in such circumstances a permit defence might be attributed. ${ }^{828}$ In the environmental field, an example might be land use planning and development, where decisions on the allowed degree of damage to biodiversity depend to a large extent upon prior zoning and planning decisions. Suppose that a regulator has balanced all interests involved and has, on the basis of available information, taken an efficient decision concerning the biodiversity damage that would be allowed before granting the permit. In that case it might not be economically efficient if the permit holder would be held liable for damage to biodiversity if the damage consists exactly of the harm which had been foreseen as a result of the permit. ${ }^{829}$ It is precisely in these situations that Rose-Ackerman pleads for no 'second guessing' and the attribution of a permit defence. ${ }^{830}$ Similarly, Bergkamp argues that it is undesirable and inefficient to oblige the polluter to pay twice: once to comply with the permit conditions and once, despite compliance with public law and regulation, for the damage associated with his activity. According to Bergkamp, the regulator cannot change the rule of the game during the game itself and hold the polluter to a different ex post standard by a civil court than the standard agreed upon in the permit. ${ }^{831}$ Bergkamp therefore strongly favoured the insertion of a regulatory compliance defence in the ELD. ${ }^{832}$

Nevertheless, the case that the regulator will be able to define the optimal standard, which would justify a permit defence, seems more to be an exceptional case than the general rule. ${ }^{833}$ Therefore, in general, the economic theory on tort law indicates that compliance with regulatory standards should not exempt from liability.

If compliance with regulatory standards should not exempt from liability, the question obviously raises why the ELD foresees the option of a permit defence in Article 8(4).

The permit defence was among the most contentious issues in the liability debate. Originally, the Commission did not intend to allow for a permit defence, as can be concluded from the text of the White Paper where the permit compliance is not included in the list of common accepted defences. ${ }^{834}$ Yet, the final text of the ELD clearly is the result of fierce lobbying by diverse interest groups, and the permit defence clause definitely is no exception to this practice. Indeed, the permit defence was a key demand of industry lobby groups. ${ }^{835}$ On the other hand, the permit defence was heavily condemned by environmental groups who feared that compliance with a permit would allow operators to avoid liability too easily, without even having to show that they took all necessary measures to avoid environmental damage. ${ }^{836}$ Moreover, a complete permit defence is rarely accepted in the liability regimes of the Member States. If it is recognised as a ground for exemption for liability, the permit defence mostly is restricted to cases in which the authorities have explicitly authorised not only the emission, but also the damage. More often, the operator can only invoke permit compliance as a mitigating factor. ${ }^{837}$

\section{Faure 2003b, 57-58.}

Rose-ackerman 1992, 123

Faure 2003b, 57-58.

Rose-ackerman 1992, 123.

Bergkamp 2001a, 65

Bergkamp 2000, 142-143.

Faure 2003b, 58 and Wenneras 2005, 160-162.

Commission Communication of 9 February 2000, White Paper on Environmental Liability, COM (2000) 66, 18 Nevertheless, it can be read on $\mathrm{p} 19$ of the White Paper that 'Some room might be granted to the court (or any other competent body, e.g. an arbiter) to decide - for instance in cases where the operator who caused the damage can prove that this damage was entirely and exclusively caused by emissions that were explicitly allowed by his permit - that part of the compensation should be borne by the permitting authority, instead of the polluter'.

835 For the opinion of the diverse interest groups and the opinion of the Member States, see $<$ www.europa.eu.int/comm/environment/liability>.

836 Hattan 2002, 8.

837 Clarke <www.europa.eu.int/comm/environment/liability/folluwup.htm>, 21-22; Department for Environment, Food \& Rural Affairs (DEFRA), UK, 'Extended Partial Regulatory Impact Assessment on Proposals for a Directive on Environmental Liability', 15-16, <www.defra.gov.uk> and Wenneras 2005, 169. 
Yet, together with the state-of-the-art defence, which will be discussed below, the permit defence was inserted into the Commission's Proposal for an Environmental Liability Directive at the eleventh hour, largely at the insistence of the enterprise directorate. ${ }^{838}$ Article 9 (1c) of the Commission's Proposal provided that 'This Directive shall not cover environmental damage or an imminent treat of such damage caused by an emission or event allowed in applicable law and regulations, or in the permit or authorisation issued to the operator' ${ }^{\prime}{ }^{839}$ The defence was not available if the operator acted negligently. ${ }^{840}$ By the wording in Article 9 (1c), the Commission excluded from the scope of the Directive all damage caused by activities that were carried out in compliance with a permit. Put differently, permit compliance would exclude any liability suit from being brought altogether. ${ }^{841}$

The permit defence as proposed by the Commission was heavily debated by the Member States in the Council and by the European Parliament during the co-decision procedure that followed.

The UK, France, Portugal and Austria wanted operators who complied with their permit to enjoy full exemption from liability. Most other delegations in the Council wanted such defences to be no more than 'mitigating factors'. ${ }^{842}$ Yet, on the environment ministers meeting in Luxembourg of 13 June 2003, it was agreed that both the permit defence and state-of-the-art defence should not justify exemption from liability, but will be mitigating factors reducing compensation payable by polluting firms. ${ }^{843}$

The European Parliament favoured a compromise so that permit compliance would in certain cases be a mitigating factor, and in others a defence. According to the Dutch MEP Toine Manders, the directive should ensure that the authorities will take permits compliance or the use of state-of-the art technology into account when deciding the level of compensation firms should pay after pollution incidents. ${ }^{844}$

Yet, as with several other controversial issues, the Council left the choice of including the permit defence, when transposing the ELD into their domestic law, up to the individual Member States whilst at the same time the wording of the defence was tightened. Indeed, Article 8(4) of the Directive lays the burden of proof with the operator, who has to demonstrate that he was not at fault or negligent and was fully in accordance with the conditions of the permit. However, in some cases, it might be difficult for an operator to prove he was not at fault or negligent in causing environmental damage. The defence therefore seems to be intended to be narrow. ${ }^{845}$

Yet, as Wenneras rightly indicates, the consequences of the permit defence must be judged within the context of subsidiary state responsibility. As for orphan damage, the ELD does not oblige Member States to engage in clean-up themselves if operators cannot be held liable because of permit defence. Yet, in order to ensure restoration, it is crucial that Member States should be responsible for clean-up in cases where permit defences exempt operators from restoration. Public responsibility might also induce authorities to issue better regulation and stricter permits. Moreover, in cases where damage occurs despite the operator complying fully with the permit, the authorities may have failed to regulate the activity appropriately and therefore can be considered morally responsible. It is therefore of grave concern that, although the European Parliament insisted on state liability in its first reading of the proposal, the Commission and the Council rejected state responsibility in cases where operators cannot be held liable because of permit defence. ${ }^{846}$

It might be argued that state liability is not necessary as authorities may still be held liable under national law or under the Francovich doctrine if there is a breach of EC law. ${ }^{847}$ Yet, in most Member States it is difficult of even impossible to hold states responsible for insufficient regulation. ${ }^{848}$ Moreover, Francovich liability is unlikely to apply to damage to natural resources, as Francovich liability requires the breach of rights of individuals and economic loss. ${ }^{849}$ In addition, the requirements of EC law concerning the issuing of

838 ENDS Europe Daily (Europe's Environmental News Service), <www.endseuropedaily.com>, 10 December 2001; Hattan 2002,8 .

839 Commission of the European Communities, Proposal for a Directive of the European Parliament and of the Council on environmental liability with regard to the prevention and remedying of environmental damage, Brussels, 23.1.2002, $\operatorname{COM}(2002) 17$ final, Article 9 (1c).

840 Hattan 2002, 8

$841 \quad$ Wenneras 2005, 171.

842 ENDS Europe Daily, <www.endseuropedaily.com>, 10 June 2003.

843 ENDS Europe Daily, <www.endseuropedaily.com>, 13 June 2003.

844 Wenneras 2005, 171, ENDS Environment Daily, <www.endseuropedaily.com>, 3 November 2003.

845 Fogleman 2004, 110-111. See also Brans, 2005, 41-42.

846 Wenneras 2005, 175; Krämer 2005a, 132 and Schueler 2005, 58-72.

847 Wenneras 2005, 175

848 Clarke <www.europa.eu.int/comm/environment/liability/folluwup.htm>, 21.

849 Wenneras 2005, 175 
permits are few and general in nature and it may prove very difficult to demonstrate a sufficiently serious breach. ${ }^{850}$

Concluding, the permit defence provision in the ELD is out of step with the economic theory on tort law and the normal practice within the Member States. The permit defence might even undermine the ability of the Directive to ensure prevention and restoration of environmental damage. Furthermore, as Member States have the discretion to acknowledge permit defence or not, the burden for the industry might vary significantly within Member States. ${ }^{851}$ It therefore would have been preferable if the ELD had not foreseen the option of a permit defence in order to achieve its objectives of prevention and remedying of environmental damage. ${ }^{852}$

\subsection{State-of-the-art Defence}

The state-of-the-art defence holds that an operator should not be liable if his activities were not considered to cause harm according to the state of scientific and technical knowledge at the time of the activity. ${ }^{853}$

The ELD stipulates in Article 8 (4) (b) that 'where an emission or activity or any manner of using a product causes damage and the operator demonstrates that scientific and technical knowledge at the time when the emission was released or the activity took place did not consider it likely that such damage would occur, Member States may allow the operator not to bear the restoration costs'. ${ }^{854}$

As stated above, the state-of-the-art-defence was added to the Proposal of the Commission together with the permit defence, mainly to meet industry's requests. In particular, this clause was inserted to exempt damage caused by genetically modified products (GMO's). ${ }^{855}$ The text of the Proposal even provided that 'the Directive shall not cover environmental damage cause by emissions or activities which were not considered harmful according to the state of scientific and technical knowledge at the time when the emission was released or the activity took place'. ${ }^{856}$ As for the permit defence, the final text leaves the discretion to include the defence to the Member States. The defence obviously has angered environmental groups, especially because the GMO Directive (Directive 2001/18/EC), states that liability issues if a GMO causes environmental damage (which in itself may be difficult to prove), are not addressed because they will be incorporated in the general European environmental liability regime. ${ }^{857}$

The Commission justified the state-of-the-art defence by stating that 'failure to include this exemption would have unduly stifled technological development in the EU'. ${ }^{858}$ Yet, the economic theory of tort law holds that liability for development risks might give incentives to the operator to obtain information on new risks and the optimal precautionary measures that might be taken to prevent the risk. It must be clear however, that liability for development risks should not turn into a disguised retro-active liability regime, whereby in reality the contents of the liability rule have changed. ${ }^{859}$ Hence, based on the economic theory of tort law, one could argue that the ELD, aiming at prevention of environmental liability, should include liability for development risks, in order to force operators to obtain information of risks. Indeed, as Krämer states, from the point of view of the environment, there is no reason not to ensure that the precautionary principle is applied also in cases of development risks. ${ }^{860}$

Yet, as with the permit defence, the ELD does not follow the economic logic. Moreover, as with the permit defence, it is regrettable that Member States have the discretion to acknowledge the state-of-the-art defence or not, and therefore the burden for the industry might vary significantly within Member States. Some comfort might be obtained, however, from the restrictive application of a similar provision in Council Directive 85/374/EEC (Product Liability Directive) by the courts. For instance, in the case A and Others v

850 Wenneras 2005, 175. See also Joined Cases C-174,178-9 and 188-90/94 Dillenkofer and Others, 1996, ECR I-4845.

851 As already stated in Chapter 4, although not all Member States have transposed the Directive by August 2007, it seems that no consensus has yet emerged on the implementation of the defences. In Italy for example, firms that cause environmental damage will be exempted from liability if they can show the damage was caused by emissions permitted by the authorities. Lithuania, on the other hand, has denied this 'permit defence' to its firms. See <www.endseuropedaily.com>, 'State of liability law implementation discussed' of 29 May 2006.

852 Faure 2005,14 and Bauw 2004, 346.

853 Wenneras 2005, 153.

$854 \quad$ ELD, Article 8 (4).

$855 \quad$ Krämer 2005a, 133.

856 Commission of the European Communities, Proposal for a Directive of the European Parliament and of the Council on environmental liability with regard to the prevention and remedying of environmental damage, Brussels, 23.1.2002, $\operatorname{COM}(2002) 17$ final, Article 9 (1d).

857 Recital 16 of Directive 2001/18/EC; Hattan 2002, 8.

858 Commission of the European Communities, 'Frequently asked questions on the Commission's Proposal on environmental liability', 24 January 2002

859 Faure 2003b, 58-61 and Wagner 2004, 119-124.

$860 \quad$ Krämer 2005a, 133. 
National Blood Authority, ${ }^{861}$ the UK High Court decided that the state-of-the-art defence cannot be invoked unless the existence of a defect in the product at issue was unknown. Put differently, the defence does not apply to a known defect, even if measures to avoid the risk that was caused by the defect were not available at the time. ${ }^{862}$ It would be advisable if the state-of-the-art defence in the ELD would have a similar restrictive application.

\section{Insolvency and Financial Guarantees}

Another controversial issue in de development process of the ELD concerned the issue of mandatory insurance for economic operators.

As was already indicated above, strict liability will only give incentives for prevention if the insolvency risk can be cured. Indeed, if the potential magnitude of the damage would largely outweigh the financial possibilities of the polluter, and no remedies would be available, strict liability would lead to under-deterrence and negligence would even be preferred. Therefore, from a theoretical perspective it could be argued that a strict liability regime should not be introduced without financial guarantees as a serious insolvency risk might rise. If prevention of environmental damage would be the goal of the liability system, it would than be better to opt for a negligence rule. ${ }^{863}$

During the development process of the ELD, Member States' delegations in the Council were deeply split over the issue of financial security for economic operators. Holding presidency in the first half of 2003, Greece proposed introducing mandatory insurance for hazardous activities five years after the directive entered into force. Other activities would be subject to the same requirement four years later. However, a big block of countries was against the idea of mandatory insurance, including the UK, Italy, France and Ireland, plus the European Commission itself, which originally proposed subsidiarity on the issue. Germany and Belgium argued pro mandatory insurance, though they indicated that clear guidelines were needed before the obligation could come in. Denmark originally opposed mandatory insurance but afterwards accepted it. ${ }^{864}$

On 2 September 2003, the Council issued a Common Position stating that 'Member States should take measures to encourage the use by operators of any appropriate insurance or other forms of financial security and the development of financial security instruments and markets in order to provide effective cover for financial obligations under the Directive'.865 The Common Position clearly signalled that the majority of the Member States rejected mandatory insurance.

This reluctance of the Member States is also reflected in the final text of the ELD. Article 14 of the ELD indeed does not require mandatory insurance, but only provides that the Member States should encourage the development of financial security instruments. Article 14 of the ELD states that 'Member States shall take measures to encourage the development of financial security instruments and markets by the appropriate economic and financial operators, including financial mechanisms in case of insolvency, with the aim of enabling operators to use financial guarantees to cover their responsibilities under the Directive'.866 The Commission will review the situation in 2010, and will examine whether the regime should be modified. If appropriate, the Commission shall submit proposals for a system of harmonised mandatory financial security. ${ }^{867}$

Overall, commentators have generally explained the Common Position and the Directive as excluding any compulsory financial guarantees. The absence of such an obligation could be worrisome because, as indicated above, it follows from Article $5 \S 4$ and Article $6 \S 3$ of the ELD that the Member States are not obliged to take preventive or remedial measures themselves in case of orphan sites. ${ }^{868}$

From an economic point of view, it is regrettable that the ELD does not impose an obligation to have a certain kind of financial security yet. Indeed, the effectiveness of a strict liability rule to provide incentives

A and Others v National Blood Authority [2001], 3 All ER 289 (QBD), see COM v UK Case C-300/95, 1997, All ER, (EC) 481 ECJ.

862 Fogleman 2004, 111; Hattan 2002, 8.

863 Faure 2003b, 39.

864 ENDS Europe Daily, <www.endseuropedaily.com>, 10 June 2003.

865 Council of the European Union, Common position adopted by the Council with a view to the adoption of a Directive of the European Parliament and of the Council on environmental liability with regard to the prevention and remedying of environmental damage, Brussels, 2 September 2003, 2002/0021 (COD).

866 ELD, Article 14, §1.

867 ELD Article 14 §2. See also ENDS Environment Daily, <www.endseuropedaily.com>, issues of 24 February 2004 and 14 May 2004.

868 Article $5 \$ 4$ on preventive action states that if the operator fails to comply with his obligations, cannot be identified or cannot bear the costs, the competent authority may take these measures itself. Article $6 \S 3$ states the same for remedial action. 
for prevention decisively depends on the availability of financial security. As Faure argues, simply trying the new strict liability regime of the ELD and expecting the financial and insurance markets to develop the necessary insurance instruments seems like a dangerous route to take. The question obviously rises whether insurance companies and financial markets can and want to insure environmental risks. Indeed, in the end, it will be the insurance and financial markets which will decide in practice whether they are willing to provide insurance for environmental risks. ${ }^{869}$ Yet, it must be clear that this financial security did not necessarily had to be liability insurance. The ELD could have allowed for a wide variety of mechanisms that could be used to provide this financial security, like first party insurance instead of liability insurance or guarantees in an environmental savings account. ${ }^{870}$ On the other hand, Clark argues that various national liability regimes have been introduced in the last years, without compulsory financial security and they did not collapse. Hence, according to Clark, the fact that the ELD did not provide for compulsory financial security, is no good reason why the ELD should not be adopted. ${ }^{871}$

Moreover, Bocken rejects this 'no mandatory financial security' interpretation of the ELD. ${ }^{872} \mathrm{He}$ points to the fact that Article $8 \$ 2$ of the Directive provides that 'the competent authority shall recover inter alia, via security over property or other appropriate guarantees from the who has caused the damage...the costs it has incurred'. 873 .

Bocken therefore interprets the Directive as follows, Article $8 \$ 2$ aims to protect the authorities against the insolvency of the operator by obligatory requiring Member States to set up a system of security interest that effectively enables the competent authorities to recover from the operator the costs of ex officio measures. This obligation to foresee financial guarantees to prevent the authorities against insolvency of the operators is, according to Bocken, often overlooked. However, one should not forget that Member States have the obligation that the objective of the Directive is reached. Article $14 \S 1$ on the other hand, requires Member States to encourage the development of financial guarantees in order to allow the operators to protect themselves against liability and to satisfy their obligations under Article 8 \$2. In contrast to Article 8 $\$ 2$, the latter provision is not compulsory. However, as stated above, Article 14 §2 opens the possibility for a Commission Proposal with respect to a harmonised system of mandatory financial security if the situation does not prove satisfactorily in eight years. ${ }^{874}$ Hence, the opinion of some of the Members States that they could support the Directive as there was not much in the document that might require them to strengthen their existing laws, as Clarke writes ${ }^{875}$, might, according to Bocken, be a wrong appreciation of the Directive.

In sum, although the combined strict liability regime for dangerous activities/negligence for nondangerous activities, as proposed in the ELD seems to be in line with the economic theory of tort law, it is regrettable that the strict liability regime has not been combined with some kind of obligation to provide financial security as one can assume that an insolvency risk may emerge. In such case, the prevention and restoration of environmental damage cannot be ensured, which is precisely the objective of the ELD. However, the obligation in Article $8 \$ 2$ to foresee financial guarantees to prevent the authorities against insolvency of the operator might compensate to some extent. Moreover, in any case, it remains to be awaited whether the absence of mandatory financial security in order to allow the operators to protect themselves against liability would pose a problem for the effectiveness of the Directive.

\section{Summary}

As far as the choice of liability regime is concerned, the ELD complies with the economic analysis of tort law which predicts that a strict liability is more efficient in case of hazardous activities since in those situations it is more important to control the injurer's activity. For other situations, a fault regime can suffice, which is precisely what the ELD proposes.

However, the crucial elements that in reality will determine the ability of the Directive to achieve the prevention and remediation of environmental damage are the way in which is dealt with retroactivity and causality, the defences that are accorded and whether or not provisions for (obligatory) insurance are foreseen. As argued above, some provisions in the ELD might seriously undermine the ability of the Directive to exert a preventive effect and to ensure restoration of damage. Indeed, in theory, strict liability could be a strong incentive for operators to take all possible risk-minimising measures and it could be a

Faure 2005, 14-15 and Faure 2003b, 247.

Faure 2003b, 39.

Clarke 2003, 268.

Bocken 2006, 13-32.

The Italics show what the Common Position added to Article $7 \S 1$ of the Commission Proposal.

Bocken 2006, 13-32.

Clarke 2003, 268. 
way of implementing the precautionary principle. However, the restricted scope of the Directive, the fact that the burden of proof lays with the authorities, the (possible) availability of the permit and the state-ofthe-art defence and the absence of mandatory insurance in the ELD itself might cause that the ELD might not set a strong incentive for the potential liable operators to invest in risk-minimising measures. All depends in this respect on the implementation of the ELD in the Member States. Moreover, the risk might exist that operators cannot be held liable and that restoration cannot be ensured as Member States do not have direct responsibility for prevention and restoration under the ELD regime. Furthermore, as final decisions concerning these crucial elements are passed on to the Member States, they will certainly influence the burden for industry within the Member States, which will be discussed in more detail in the next chapter.

In sum, the regime of the ELD shows some inefficiencies. It must be clear though that these inefficiencies do not necessary result from the fact that the regime has been issued at European level. Indeed, also at national level these inefficiencies might arise. However, the ELD is clearly the result of a political and economical bargaining process, which definitely has influenced the content of the Directive. Moreover, given the burdensome development process of the ELD, one might get the idea that at some point it was just important to get a Directive adopted and that its provisions could be fine-tuned in later amendments. Indeed, the Directive would certainly benefit from some amendments in a later stage. Meanwhile, the Directive has entered into force and interpreting the Directive in light of its aim and general principles of EC environmental law seems the only option to give the ELD the chance to become an effective instrument to ensure prevention and restoration of environmental damage in the EU.

Yet, this research did not just want to provide an efficiency analysis of the ELD regime. The main question of this research was the level of government at which environmental liability rules, including liability rules for soil pollution, best could be decided. It now merits examining whether the reasons for a harmonised liability regime, provided for by the Commission in the development of the ELD correspond with the economic theory on federalism and if not, how the harmonisation in the European Union of environmental liability rules, including liability rules for soil pollution, can be explained. 


\section{Chapter 6}

\section{OPTIMAL DECISION-MAKING LEVEL OF LIABILITY RULES FOR ENVIRONMENTAL DAMAGE IN THE EUROPEAN UNION}

A significant part of the critique during the development process of the ELD considered the question whether and for what reasons there was a need to shift environmental liability rules from the Member States to the European level.

Therefore, the question that will be dealt with in this chapter is whether the Environmental Liability Directive corresponds with the predictions of the theoretical framework on the optimal decision-making level of liability rules for environmental damage and if not, why was harmonisation of environmental liability rules, including liability rules for soil pollution, considered necessary in the European Union?

As for the theoretical analysis, the arguments provided by the Commission to justify the Directive will be studied from a public interest approach as well as from a private interest approach. In a first step, the arguments of the Commission for a harmonised environmental liability regime in the European Union will be compared with the economic theory of federalism (paragraph 1). In a second step, additional explanations for the harmonisation of environmental liability rules in the European Union will be sought on the basis of the private interest approach (paragraph 2). In this way, the examination of the Environmental Liability Directive complements the theoretical framework and might offer a better understanding of all factors that play in a real harmonisation debate.

\section{Public Interest Approach on the Optimal Decision-making Level of Liability for Environmental Damage in the European Union}

This paragraph will compare the arguments that where provided by the Community to justify the Environmental liability Directive with regard to the principle of subsidiarity, with the arguments for harmonisation provided by the economic theory of federalism in the environmental field. ${ }^{876}$

In a first step, the analogy of the bottom-up approach of the economic theory on federalism with the interpretation of the subsidiarity principle by the Community institutions will be indicated. Next, the arguments for harmonisation that the Commission advanced during the decision-making process of the ELD with regard to the principle of subsidiarity will be examined on the basis of the theoretical framework that was developed in this research. Do the arguments for harmonisation, provided for by the Commission, justify a shift of environmental liability rules, including liability rules for soil pollution, from the Member States to the European level from an economic perspective? This is the question that will be dealt with in this paragraph.

\subsection{Tiebout versus Subsidiarity: Decentralisation as a Starting Point in the EU?}

As was studied in the theoretical part of this research, the economic theory on federalism is based upon the Tiebout Model and the Decentralisation Theorem of Oates and generally takes a bottom-up approach towards centralisation. The starting point is that through decentralisation rules can be adapted to the preferences of the citizens. It was argued, however, that, due to externalities and market failure, transaction costs or imperfect information, some decisions might better be decided at a higher level of decision-making.

876 In paragraph 2.2.2 of chapter 4, it was already indicated that scholars are also very critical about the justification of the Commission with respect to the proportionality principle. The Commission merely claims that the Directive does not go beyond what is necessary in order to achieve its objectives (ELD, Preamble 3), whereas Bergkamp holds that several provisions of the Directive are disproportional. Yet, as the main question that will be dealt with in this research is why harmonisation of environmental liability rules was considered necessary in the European Union in the first place, the reminder of this chapter will concentrate on the reasons provided by the Commission for an environmental liability regime at European level as required by the subsidiarity principle. 
The reasons for harmonisation of regulation were grouped into four main arguments: the transboundary character of an externality, the risk of a race-to-the-bottom, market access concerns and the desire to guarantee a minimum level of protection.

In the European Union, the subsidiarity principle was enshrined in the Maastricht Treaty to strike the balance between sovereignty of the Member States and harmonisation of environmental rules at European level. The principle of subsidiarity is intended to ensure that decisions are taken as closely as possible to the citizen and that action at Community level is justified with respect to the possibilities available at national, regional or local level. ${ }^{877}$ By stating that 'in areas which do not fall within its exclusive competence, the Community shall take action, in accordance with the principle of subsidiarity, only if and in so far as the objectives of the proposed action cannot be sufficiently achieved by the Member States and can therefore, by reason of the scale or effects of the proposed action, be better achieved by the Community', the subsidiarity principle indeed shows resemblance with the bottom-up approach of the economic theory on federalism.

As was already explained in Chapter 4, the Community institutions tend to have interpreted the subsidiarity principle as a test of comparative efficiency, answering the question which level would achieve the envisaged goal more efficiently. This interpretation of subsidiarity requires an assessment of arguments in favour of Community action and those in favour of action by the Member States. ${ }^{878}$ It appears that in this assessment, the Community institutions clearly involve economic efficiency as an instrument to justify harmonisation with regard to subsidiarity. ${ }^{879}$ Indeed, as shown in Chapter 4, from the Explanatory Memoranda and Recitals of new environmental Directives, it is possible to identify four main arguments generally used to justify Community action in the environmental field: the presence of transboundary externalities, the prevention of unequal competition, also called the need for a 'level playing-field', harmonisation to achieve free movement of goods and the European heritage argument. ${ }^{880}$ These arguments for Community action clearly resemble the arguments for centralisation of the economic theory on federalism.

Moreover, the Protocol on the Application of the Principles of Subsidiarity and Proportionality to the Amsterdam Treaty, provides obligatory guidelines, which should be used in examining whether the principle of subsidiarity is met. These guidelines also resemble the arguments for centralisation of the economic theory on federalism: Community action would be justified if the issue under consideration has trans-national aspects which cannot be satisfactorily regulated by action by Member States; if actions by Member States alone or lack of Community action would conflict with the requirements of the Treaty (such as a need to correct distortions of competition or avoid disguised restrictions on trade) or would otherwise significantly damage Member States' interests; or if action at Community level would produce clear benefits by reason of scale or effect compared with action at the level of the Member States. ${ }^{881}$

Yet, the subsidiarity principle remains an elastic concept which leaves significant discretion to the Commission and does not offer a clear rule to decide on the optimal policy level of environmental liability rules in the Community. 882 The Tiebout Model and the Decentralisation Theorem of Oates on the other hand are based on quite restrictive assumptions. Therefore one could question the relevance of these theories in real world problems and in particular in providing guidance on the optimal policy level of environmental liability rules in the European Union. Yet, even though these models cannot fully grasp the complex and political decision-making procedures of the Community, as the interpretation of the subsidiarity principle by the Community institutions shows similarities with the bottom-up approach of the economic theory on federalism and the Community institutions clearly involve economic efficiency as an instrument to justify harmonisation with regard to subsidiarity, a comparison of the arguments provided for by the Community under the subsidiarity principle and the theoretical models would certainly be justified. The comparison would show how in both cases the balance between centralisation and decentralisation would be sought and might clarify whether and for which reasons Community action in the field of environmental liability has been considered appropriate.

Hence, taking decentralisation as a starting point, for what reasons should environmental liability rules be shifted from the Member States to the European level? ${ }^{883}$

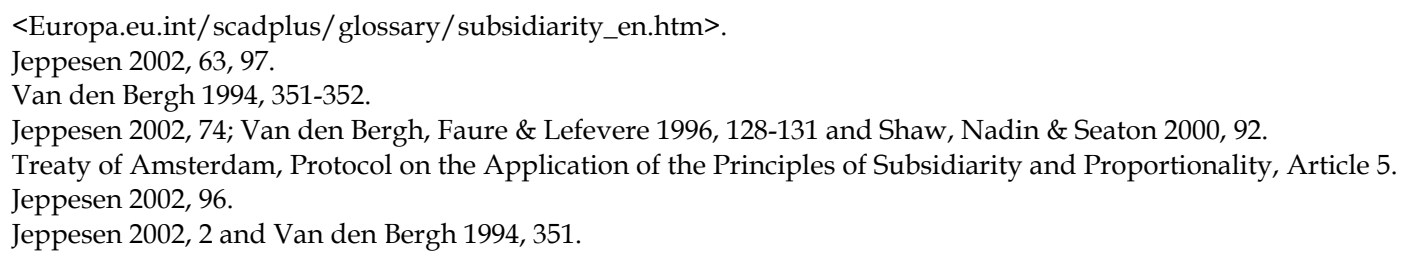




\subsection{The Search for Arguments for Centralisation of Liability Rules for Environmental Damage in the EU}

As was already remarked in Chapter 4, in view of the fierce debates during the adoption process of the ELD precisely on the Community's competence to harmonize environmental liability, it is striking that in the final text of the ELD, the Commission fails to explain why a harmonised liability regime is necessary or why its goals cannot be achieved by the Member States, as required by the subsidiarity principle.

Indeed, although the subsequent documents in the ELD adoption process provide arguments for Community action, a clear overview of arguments for a harmonised liability regime cannot be found anymore in the final text of the ELD. In paragraph 2.2.2 of chapter 4, it was indicated that Preamble 3 of the ELD only states that subsidiarity is met because the ELD's objective, namely to establish a common framework for the prevention and remedying of environmental damage, cannot be sufficiently achieved by the Member States and can therefore be better achieved at Community level by reason of scale or effect. ${ }^{884}$ The Commission does not explain why it is necessary to establish such a framework or why it cannot be achieved by the Member States. Moreover, the Commission's reasoning in Preamble 3 is, as Bergkamp and Faure indicate, merely a description of the subsidiarity principle itself and does not provide any justification. ${ }^{885}$

In order to examine for what reasons it was considered necessary to harmonise environmental liability rules, the subsequent Commission documents in the ELD decision-making process must be consulted. The three documents in the ELD decision-making process that can be referred to in order to examine the reasons for a shift of environmental liability rules from the Member States to the European level are the Commission Green Paper on Remedying Environmental Damage, ${ }^{886}$ the White Paper on Environmental Liability, ${ }^{887}$ and the Explanatory Memorandum to the Proposal for a Directive on Environmental Liability with regard to the Prevention and Restoration of Environmental Damage. 888

Paragraph 2 of chapter 4 already examined in detail the development of these documents and the justifications for European action that were provided by the Commission in each document. Figure 4 recapitulates this examination and provides an overview of the different arguments for European action presented in these subsequent documents, in order to serve as a basis for the public interest analysis.

ELD, Preamble 3.

See Bergkamp 2005, 102 and Faure 2005, 8.

Commission Communication of 14 May 1993, Green Paper on Remedying Environmental Damage, COM (93) 47.

Commission Communication of 9 February 2000, White Paper on Environmental Liability, COM (2000) 66.

Commission Communication of 23 January 2002, Proposal for a Directive of the European Parliament and of the Council on Environmental Liability with regard to the Prevention and Restoration of Environmental Damage, COM (2002) 17 final, OJ C151 E/132. 


\begin{tabular}{|c|c|c|}
\hline \multicolumn{3}{|c|}{$\begin{array}{l}\text { Reasons for harmonisation advanced by the Commission for Community competence: } \\
\text { overview of the subsequent documents }\end{array}$} \\
\hline Year & Document & Reasons advanced by the Commission \\
\hline 1993 & $\begin{array}{l}\text { Commission Green Paper on } \\
\text { Remedying Environmental } \\
\text { Damage }\end{array}$ & $\begin{array}{l}\text { 1. A Community-wide system of civil liability for } \\
\text { environmental damage would be based on the } \\
\text { concept that a person should rectify the damage } \\
\text { that he causes, which strongly related to two } \\
\text { principles forming the basis of Community } \\
\text { environmental policy, the principle of } \\
\text { prevention and the "polluter pays" principle. } \\
\text { 2. Different systems of civil liability for } \\
\text { remedying environmental damage among the } \\
\text { Member States could lead to distortions of } \\
\text { competition and the single market. }\end{array}$ \\
\hline 2000 & $\begin{array}{l}\text { White Paper on } \\
\text { Environmental Liability }\end{array}$ & $\begin{array}{l}\text { A Community-wide system of civil liability for } \\
\text { environmental damage would: } \\
\text { 1. Realise the three grand environmental } \\
\text { principles enshrined in Art } 174 \text { (2) of the EC } \\
\text { Treaty: the polluter pays, precautionary and } \\
\text { preventive principles; } \\
\text { 2. Provide an adequate solution for } \\
\text { transboundary damage; } \\
\text { 3. Ensure decontamination and restoration of } \\
\text { the environment and better integration of } \\
\text { environment into other policy areas; } \\
4 \text {. Contribute to a level playing field in the } \\
\text { internal market } \\
\text { 5. Respect the principle of equal treatment. }\end{array}$ \\
\hline 2001 & $\begin{array}{l}\text { Working Paper on } \\
\text { Prevention and Restoration } \\
\text { of Significant Environmental } \\
\text { Damage }\end{array}$ & $\begin{array}{l}\text { Shift from a civil liability regime to a public law } \\
\text { regime for prevention and restoration of } \\
\text { environmental damage that would be enforced } \\
\text { by competent authorities. No arguments are } \\
\text { provided to justify Community action. }\end{array}$ \\
\hline
\end{tabular}




\begin{tabular}{|c|c|c|}
\hline 2002 & $\begin{array}{l}\text { Proposal for a Directive of } \\
\text { the European Parliament } \\
\text { and of the Council on } \\
\text { Environmental Liability } \\
\text { with regard to the } \\
\text { Prevention and Restoration } \\
\text { of Environmental Damage } \\
\text { (Explanatory Memorandum) }\end{array}$ & $\begin{array}{l}\text { 1. Community action is needed to address site } \\
\text { contamination and the loss of biodiversity in } \\
\text { the Community. Similar to the justifications in } \\
\text { the White Paper, it is argued that a liability } \\
\text { regime would realise the implementation of three } \\
\text { grand environmental principles enshrined in Art } \\
174 \text { (2) of the EC Treaty: the polluter pays, } \\
\text { precautionary and preventive principles. } \\
\text { 2. Not all Member States adopted a liability } \\
\text { regime for contaminated land. Without } \\
\text { Community action there would be no guarantee } \\
\text { that the polluter pays principle would be } \\
\text { effectively applied across all the Community. } \\
\text { 3. Member States' liability regimes for } \\
\text { contaminated land do not mandate national } \\
\text { authorities to ensure that orphan sites are } \\
\text { cleaned up and hence do not ensure that the } \\
\text { objective of restoration is attained. } \\
4 \text {. Few, if any Member States imposed liability } \\
\text { for biodiversity damage; } \\
\text { 5. As was argued in the White Paper, without a } \\
\text { harmonised framework at Community level, } \\
\text { economic actors could exploit differences in } \\
\text { Member States' which would result in unfair } \\
\text { competition. }\end{array}$ \\
\hline
\end{tabular}

Figure 4 Reasons for harmonisation advanced by the Commission for Community competence

As can be seen in Figure 4, a comparison of the subsequent documents reveals that over time, some of the arguments provided by the Commission show consistency, some arguments have been added, and others have disappeared. Moreover, there also seems to be a shift from mainly economic arguments in the White Paper, comparable to the arguments for harmonisation of the economic theory on federalism (for example the harmonisation for transboundary damage or harmonisation to avoid unequal competition), to an emphasis on the prevention and restoration of environmental damage in the Explanatory Memorandum to the Commission Proposal.

Three arguments that are consistently repeated in the subsequent documents. First, it is argued that Community action would be needed to ensure the realisation of the environmental principles which are enshrined in Art 174 \&2 EC Treaty, notably the precautionary, polluter pays and preventive principles. Second, Community action would prevent distortion of competition. Third, Community action would ensure the restoration of environmental damage. The Explanatory Memorandum to the Proposal added that Community action would be needed to address site contamination and the loss of biodiversity in the EU. Moreover, it is argued that not all Member States have liability rules for contaminated land or biodiversity, and the restoration of orphan sites is not always ensured, so that there is no guarantee that the polluter pays principle is fulfilled and restoration is ensured without Community action. Remarkable on the other hand, is that Community action for transboundary damage, which might be an argument for harmonisation in the economic theory of federalism, has only been mentioned in the White Paper, but has not been repeated in the Explanatory Memorandum.

The above mentioned arguments can be grouped into six main reasons for European action in the field of environmental liability: the transboundary character of an externality argument, the race-to-the-bottom argument, the level-playing field argument, the realisation of the polluter pays, prevention and precautionary principles, decontamination and restoration of the environment, and harmonisation to guarantee a minimum level of protection. These arguments provided for by the Commission to justify a European liability regime will now be examined successively. For each argument, it will be studied whether the argument would justify harmonisation from an economic perspective and whether the ELD reflects this outcome. Each argument will be examined for environmental liability rules in general as well as for soil pollution in particular. Moreover, it will studied whether the ELD would indeed solve the problem for which harmonisation was deemed necessary. 


\subsubsection{Transboundary Character of an Externality}

In the White Paper the Commission advanced the argument that a Community-wide liability regime would provide an adequate solution for transboundary damage. The Explanatory Memorandum of the Proposal to the ELD does not mention transboundary damage explicitly as a reason for Community action anymore. However, the Directive clearly addresses transboundary damage. Article 15 of the ELD provides that Member States shall cooperate when environmental damage affects or is likely to affect several Member States. 889

As studied in the theoretical part, in the economic theory of federalism the transboundary aspect of damage is an argument that might justify (a certain level of) harmonisation.

Indeed, the Tiebout Model, favouring decentralisation of the provision of public goods, only holds if decisions of one jurisdiction, have no external (negative) effects on other jurisdictions. When policies of a certain jurisdiction have a transboundary effect on a neighbouring jurisdiction, there is an argument for centralisation. The reasoning is twofold.

First, jurisdictions will not internalise the consequences of their actions that might accrue across their borders. Hence, jurisdictions will have no incentive to impose stringent liability rules on their own industry and consequently will under-regulate the harmful activity. ${ }^{890}$ Therefore, the internalisation of transboundary externalities could be ensured by shifting powers to a higher governmental level.

Article 5 of the Amsterdam protocol on the Application of the Principles of Subsidiarity and Proportionality, also underwrites this idea by stating that 'action can be taken if there are transnational aspects which cannot be satisfactory regulated by action by Member States. ${ }^{891}$

Second, economies of scale could be reached by a - certain level of - centralisation. ${ }^{892}$ The reasoning is that in order to solve the externality problem adequately, decision-making power should be entrusted to a higher regulatory level that has a competence that is large enough to deal with the problem. Moreover, by centralisation of certain tasks like technical and scientific research, economies of scale could be reached.

Nevertheless, in the theoretical part of this research, it was concluded that the transboundary externality argument would not justify full harmonisation of liability rules to solve transboundary externalities. Instead, in order to take local circumstances into account, a so-called 'transboundary only'regime could be preferred. However, it was indicated that, according to the economies of scale reasoning, it could be examined whether there are economies of scale and advantages of expertise that can be profited from without having to give in on diversity. Hence, it was concluded that the transboundary externality argument would allow for a mixed system that would benefit from the merits/expertise of both governmental levels, but would not justify excessive centralisation or harmonisation.

It merits now examining whether the ELD corresponds with the theory on federalism with respect to transboundary externalities.

Based on the first line of reasoning of the transboundary externalities argument, stating that the internalisation of transboundary externalities could be ensured by shifting powers to a higher governmental level, it could be accepted that the Directive rightly addresses transboundary environmental damage. The transboundary externalities argument, however, provides an explanation for only part of the shift of environmental liability rules from the Member States to the European level. Indeed, whilst certain environmental damage will be inter-state, the Directive also addresses intra-state damage which potentially Member States could solve better.

The Directive covers damage to protected species and habitats, commonly referred to as damage to biodiversity, water damage and land damage. There seems little doubt that damage to water might indeed potentially fall under inter-state damage. Examples of water damage are numerous. In the Explanatory Memorandum, the Commission itself mentions the Baia Mare and Baia Borsa accidents in Romania of January and March 2000 where rivers were heavily polluted. ${ }^{893}$

The Commission, however, failed to justify the inclusion of land damage and damage to biodiversity.

For land damage, the Commission states that Community action is needed to address effectively and efficiently site contamination and quotes that about 300.000 sites have been identified as definitively or

ELD, Article 5 .

Faure 2003a, 38-39. See also Esty \& Geradin 2001, 34

Treaty of Amsterdam, Protocol on the Application of the Principles of Subsidiarity and Proportionality, Article 5.

Faure 2003a, 38-39. See also Ogus 1999, 405-418.

Other examples that can be referred to are the heavy pollution of the Rhine river caused by a fire at the Basle Sandoz plant in 1986 and the collapse of a waste retention dam of the Aznalcollar mining complex, on 25 April 1998, in Spain, which has lead to a flow of toxic waters and mud towards the Doñana National Park. See also Proposal for a Directive on Environmental Liability with regard to the Prevention and Restoration of Environmental Damage, Explanatory Memorandum, 2. 
potentially contaminated. ${ }^{894}$ The question however is to what extent contaminated sites are transboundary issues. Bergkamp contends that 'contaminated sites, subject to very few exceptions, do not have crossborder effect, and therefore should be left to the Member States. ${ }^{895}$ The Commission does not elaborate what 'cross-border' land issues might be and does not explain why intra-state contaminated sites would better be restored by an environmental liability regime at European level than by the regimes of the Member States.

With respect to biodiversity, most Member States do have liability regimes for environmental damage, yet biodiversity is mostly not covered. Farnsworth holds that the Directive might be innovative because it introduces liability for damage precisely in this area. ${ }^{896}$ Yet, it is clearly insufficient to state that 'the loss of biodiversity in the Community has accelerated dramatically in recent decades making it one of the severe threats in the future' and that 'Community action to protect and restore biodiversity is warranted to ensure that socially-efficient means are used to finance the remedying of damage to biodiversity in the Community and, by doing so, to encourage efficient prevention', to justify a shift of environmental liability rules from the Member States to the European level. ${ }^{897}$

The main problem is that the Commission does not elaborate further and does not provide concrete examples of why an environmental liability regime at European level would better prevent and restore environmental damage, including land damage, than the regimes at national level. ${ }^{898}$ Hence, a common critique on the ELD is that the Commission failed to justify the scope of the Directive.

Indeed, if transboundary environmental damage might be a problem in the European Union but if Member States could adequately deal with pollution within their borders, then according to economic theory and to the subsidiarity principle, a European liability regime would only be justified for transboundary environmental damage instead of an overall liability regime. This would result in a 'transboundary only'-regime.

At European level, this idea of a 'transboundary only' regime was rejected, since it was argued in the White Paper on Environmental Liability that this could lead to inequalities in treatment of victims in Member States depending on whether they were victim of a transboundary or of a local pollution. 899

Bergkamp indicates that when referring to equality, the Commission no longer argues within the scope of the subsidiarity principle, but simply pleads for uniformity. ${ }^{900}$ As will be argued in the last paragraph, this argument could fit into the public choice theory which holds that industry in heavily regulated (and probably polluted) areas lobbies (supported by green NGO's) to force their very stringent environmental regulations upon other Member States that might not need such stringent measures. In that way, this industry might erect artificial barriers to entry.

Yet, the subsidiarity principle has been included in the EC Treaty to prevent EU action justified mainly on a request for uniformity, possibly by industry in heavily regulated areas. ${ }^{901}$ As mentioned above, the subsidiarity principle allows the community to take action if and only in so far as the objectives of the proposed action cannot be sufficiently achieved by the Member States. As it is not proven that uniformity is necessary for the Member States in order to deal effectively with environmental damage, there is no need for full harmonisation. The equality argument is hence not very convincing, neither from an economic, nor from a legal perspective.

The second strand of the transboundary damage argument, the realisation of economies of scale, appears to be a bit more lenient towards centralisation of certain tasks, not only to solve transboundary spillovers but also to solve problems that are common over different jurisdictions. Indeed, the reasoning suggests that jurisdictions might profit from the centralisation of certain tasks or from some guiding framework developed by the central government.

This line of reasoning was follewed by the environmental NGO's. Birdlife International, European Environmental Bureau, Greenpeace International and WWF European Policy office submitted in their comments on the White Paper that 'the argument that national laws provide sufficient protection in relation to such damage is a fallacy. Indeed, part of the justification for establishing an EU environmental liability scheme was that national rules cannot cope with the various complexities that underlie environmental

\footnotetext{
894 Proposal for a Directive on Environmental Liability with regard to the Prevention and Restoration of Environmental Damage, Explanatory Memorandum, 4 and European Environmental Agency, Management of contaminated sites in Western Europe, Topic Report No 13/1999, Copenhagen, June 2000.

$895 \quad$ Bergkamp 2002, 296.

896 Farnsworth 2004, 179.

897 Proposal for a Directive on Environmental Liability with regard to the Prevention and Restoration of Environmental Damage, Explanatory Memorandum, 6 and ELD, Preamble 1.

898 Farnsworth 2004, 179.

899 White Paper on Environmental Liability, 2000, 25-26.

900 Bergkamp 2000, 107.

901 Ibidem.
} 
liability and that therefore persons, property and biodiversity are not sufficiently protected by national laws in relation to environmental damage' ${ }^{902}$ Moreover, the third guideline on subsidiarity in the Protocol of the Amsterdam Treaty holds that Community action would be justified if action at Community level would produce clear benefits by reason of scale or effect compared with action at the level of the Member States. ${ }^{903}$

The question arises whether an European environmental liability regime, which also covers intra-state damage, is justified because of the complexity of environmental liability and because Community action would better achieve the prevention and remediation of environmental damage than the Member States for reasons of scale or effect. Yet, the Commission does not provide any clear proof for this assumption.

In sum, although transboundary environmental pollution may occur in certain cases in the EU, from an economic point of view, this argument by itself is not sufficient to justify the shift of environmental liability rules from the Member States to the European level. With respect to the particular case of soil pollution, soil pollution itself mostly will cause in-state torts. Moreover the causes and consequences of soil pollution can vary significantly within a jurisdiction and over jurisdictions. In these circumstances, regulation tailored to local needs and preferences seems appropriate. Therefore, a far-reaching harmonisation or even centralisation of liability rules for soil pollution would not be justified. Economies of scale in technical research might plead for co-operation or centralisation of certain tasks, like research or data gathering on soil contamination and restoration. However, again, the promise of economies of scale in scientific research does not argue for a centralisation in an excessive sense. Thus, with respect to the nature of soil pollution, full centralisation or harmonisation of liability rules for soil pollution would not be justifiable as it would not take diverse causes, circumstances and preferences into account. Therefore, the transboundary externality argument seems a weak argument to justify the harmonisation of environmental liability rules and in particular liability rules for soil pollution in the European Union.

The question obviously arises whether the prevention and restoration of transboundary damage, including soil pollution, can be succesfully realised through the ELD. Unfortunately, the answer is negative.

Indeed, it is doubtful that the Directive will ensure the restoration of transboundary damage. Article 15 of the ELD merely provides for 'cooperation' between Member States. This includes the appropriate exchange of information with a view to ensuring that preventive action, and if necessary, remedial action is taken in respect of any environmental damage. In case a Member State identifies damage within its borders, caused by industry of another Member State, it may seek to recover the costs it has incurred in relation to the adoption of preventive or remedial measures. ${ }^{904}$ Yet, article 8(4) of the ELD states that Member States may allow a permit or state-of-the-art defence. If the state, where the accident happens, offers the defence, it obviously will be very difficult for the injured State to be compensated for the damage. Therefore, the lack of an obligation to compensate the injured state may undermine the preventive effect of the liability regime and certainly the restoration of transboundary damage. ${ }^{905}$

Hence, it appears that the transboundary externality argument would only justify a European 'transboundary only'-regime but not full harmonisation. Thus, the regime of the ELD goes further than what would be suggested by economic theory with respect to transboundary externalities. Moreover, it seems that precisely the prevention and remediation of transboundary damage cannot be ensured through the ELD. Yet, there might be other reasons that might justify the ELD.

\subsubsection{Race-to-the-bottom Argument}

In the three subsequent documents in the ELD decision-making process, the Commission argued that without a harmonised framework of liability for environmental damage, economic actors might exploit the differences between Member States which might lead to distortions of competition and the level playing field in the internal market. ${ }^{906}$

As was already indicated in the theoretical part of the research, distortion of competition, eventually leading to a race-to-the-bottom might be the most heavily debated and most frequently advanced economic argument, also in the European Union, to justify harmonised environmental (liability) regulation.

902 Response to the Presidency questions on Environmental Liability: Birdlife International, European Environmental Bureau, Greenpeace International and WWF- European Policy Office <www.eeb.org/activities/env_liability>. See also Farnsworth 2004, 178.

903 Treaty of Amsterdam, Protocol on the Application of the Principles of Subsidiarity and Proportionality, Article 5.

$904 \quad$ ELD, Article $15 \S 1$ and $\S 3$, emphasis added.

905 Farnsworth 2004, 180.

906 See Green Paper on remedying Environmental Damage, White Paper on Environmental Liability and the Proposal for a Directive on Environmental Liability with regard to the Prevention and Restoration of Environmental Damage, Explanatory Memorandum. 
It was also indicated that the race-to-the-bottom argument is sometimes confused with the creation of a 'level playing field', especially in the European Union. Indeed, harmonisation to prevent a race-to-thebottom in environmental standards, in reality might aim to create a 'level playing field', or the harmonisation of conditions of competition between states in order to reduce interstate competition resulting from differences in environmental quality standards. ${ }^{907}$ The 'level playing field' argumentation will be taken up again in the next paragraph on market access. This paragraph will concentrate on the raceto-the-bottom argument in its narrow sense.

In the theoretical part, it was concluded that it seems doubtful that a race-to-the-bottom in environmental liability rules would occur. On the one hand, there are more important factors that influence industry location decisions than environmental liability regulation, and on the other hand, states would have no advantage of a lenient liability regime. 908

Indeed, in theory, in the European Union, a state could try to attract industry by reducing the burdens that might be imposed on industry through liability rules. For example, a state might impose a higher burden of proof on the victims of environmental damage or a state might require a clear cause-damage relationship. Moreover, a state might neglect the enforcement of its environmental quality standards.909 This behavior would be difficult to detect and to prove and a kind of political drag would then exist. The same reasoning could apply to liability rules for soil pollution. A state might indeed impose a higher burden of proof on the victims of soil pollution, or neglect the enforcement of its soil quality standards. In reality, it is however very unlikely that states would show such behaviour. To the contrary, Faure suggests that if environmental liability rules were to have an effect, a race-to-the-top would be more likely to expect than a race-to-the-bottom. Indeed, a lenient environmental liability regulation would limit a state's possibilities to claim restoration for environmental damage caused by (foreign) industry. Therefore, a lax liability regime might be counter to a state's interests. ${ }^{910}$ Still, political pressure and risk of a political drag should not be ignored in the case of environmental liability regulation.

The question, however, arises whether a race-to-the-bottom in environmental liability rules and in particular liability rules for soil pollution, indeed has to be feared in the EU? 911

Although the Commission advances the argument repeatedly, the Commission does not provide any indications that point to the existence of or the risk of a race-to-the-bottom in environmental regulation, or in soil protection legislation. It seems doubtful, maybe even more than for environmental regulation in general, that a race-to-the-bottom in environmental liability rules or in soil protection legislation would happen, especially because Member States would have no advantage of a lenient liability regime as it would limit a state's possibilities to claim restoration for environmental damage caused by industry as for example soil pollution. Yet, although there is no evidence of relaxed liability rules, it might be possible that state officials might believe or are under political pressure to believe that a stringent liability regime might repulse industry from locating in their Member State and that industry might move to other Member States. Hence, they might fail to adopt stringent quality standards and a stringent liability regime or neglect the enforcement of this regime. Further research in this area could provide more information on governmental behavior. Nevertheless, it might be doubtful that in Europe, states would engage in a game in which they would strive for a low level of environmental liability and renounce on restoration claims in order to attract industry. Moreover, even in the case of a 'regulatory chill', theory shows that this would not justify full centralization of environmental liability regulation. Indeed, other solutions to enhance the efficiency of environmental liability rules, including liability rules for soil pollution, may also be examined.

The race-to-the-bottom argument provided for by the Commission, therefore is not convincing to allow for a harmonised environmental liability regime, including liability for soil pollution, in the European Union through the ELD.

Hence, again, the ELD might be justified for other purposes than the prevention of a race-to-thebottom.

\subsubsection{Market Access Argument}

Together with the race-to-the-bottom argument, the Commission has repeatedly argued that a shift of environmental liability rules from the Member States to the European level would be needed to avoid a distortion of competition and to realise a level playing field. ${ }^{912}$

\footnotetext{
Faure 2003a, 51-53. See also Van den Bergh 2000, 87.

Faure 2003a, 49 .

Ackerman 1996, 429.

Faure 2003a, 49.

See also Oates 1998, 1-13.
} 
It is sometimes claimed that harmonisation of environmental regulation would be justified in order to ease the tensions between various jurisdictions, created by the differences in the stringency of their environmental regulations, on the one hand through harmonisation of marketing conditions and on the other hand through the reduction of transaction costs through harmonisation of legal rules.

As far as the harmonisation of marketing conditions is concerned, it was argued in the theoretical part of this research that although the realisation of free trade could justify the harmonisation of elementary environmental product or process standards in order to avoid incompatibilities which would create barriers to entry or distortions of competition, it is questionable that the realization of free trade would justify the harmonisation of private law, as environmental liability rules.

Indeed, it is certainly possible to realise free trade without the total harmonisation of all legal rules, including environmental liability rules. Moreover, equal marketing conditions would not necessarily be achieved through the harmonisation of (environmental) liability rules. As Faure indicates, harmonisation of liability rules in the EU would not create a level playing field, as there are other, far more important factors that determine the conditions of competition. ${ }^{913}$ Indeed, differences in the availability of natural resources or labor standards still would create variations in marketing conditions. Furthermore, if countries would prefer liability rules to target environmental-unfriendly products, instead of using regulatory restrictions (which might be under WTO restrictions), this would not hamper free trade. On the contrary, it would have a significant advantage. Indeed, the use of liability rules would prevent disguised protectionism, as a causal link between the environmental harm and the product concerned still must be proven. ${ }^{914}$ Hence, it seems doubtful that environmental liability rules would act as a trade barrier or cause competitiveness concerns and that a total harmonisation to ensure market access and fair marketing conditions would be necessary. Countries could set their liability rules according to their preferences, and still guarantee market access, whereby disguised protectionism might be prevented.

The second strand of the market access argument, the 'reduction of transaction costs through harmonization of legal rules' reasoning concentrates on the concern that differences in legal rules might cause high transaction costs, and hence that this equally might hamper market access. The reduction in transaction costs through harmonization would improve market access. With respect to transaction costs, it was argued that transaction costs savings do not require a total harmonisation of a certain liability rule, which might neglect differences in citizen's preferences. Indeed, it is very well possible that, for a certain tort, the applicable liability rule would be harmonized, for example a negligence rule, but that the content of the due care standard is left at state level, according to the preferences and needs of the citizens. Hence, centralization of a specific liability rule for certain activities might be combined with a differentiation of the specific contents of this rule. In that case, transaction costs could be lowered, and differing preferences could be still respected. Therefore, harmonisation of liability rules in order to reduce transaction costs might allow for a certain level of centralization, but not for full harmonisation. ${ }^{915}$

With respect to soil pollution in particular, it was argued at theoretical level that it seems doubtful that stringent liability rules for soil pollution would act as a trade barrier for certain products. First, there are far more important factors that determine conditions of competition than liability rules for soil pollution, like for example labour standards. ${ }^{916}$ Second, a causal link between the soil pollution and the product concerned still must be proven, so that disguised protectionism could be prevented. ${ }^{917}$ Hence, it seems doubtful that differences in the stringency of liability rules for soil pollution would significantly hamper market access.

With respect to transaction costs savings, soil pollution and clean up requirements of contaminated soil might be locality specific and dependant on the physical and geographical characteristics of the region. Therefore, it was argued that harmonisation would not outweigh the benefits of differentiated legal rules.

Hence, from a theoretical point of view, the market access argument would not justify a harmonisation of environmental liability rules, including liability rules for soil pollution neither to realise a level playing field nor for the reduction of transaction costs. At the maximum, a co-operative approach could be adopted in order to facilitate market access, with central minimum requirements of protection, but allowing regions to implement the standards or to adopt more stringent measures in accordance with the objectives of free trade and competition, and conform to the citizen's preferences. on Environmental Liability with regard to the Prevention and Restoration of Environmental Damage, Explanatory Memorandum.

Faure 2003a, 55.

Bergkamp 2001a, 381-382.

Faure 2003a, 61.

See for instance Faure 2003a, 55

Bergkamp 2001a, 381-382. 
Yet, if the Commission holds that harmonisation of environmental liability rules, including liability rules for soil pollution, was necessary to realise a level playing field and to reduce transaction costs in the European Union, the question obviously arises whether the ELD can realise these ambitions. A careful examination of the ELD reveals however, that the Directive does not create a level playing field and certainly does not reduce transaction costs.

From the examination of the provisions of the ELD in Chapter 4, it already appeared that the coverage of the Directive is limited, so that different regimes may apply to different types of damage, in case of an accident and the ELD does not clarify its relation to other liability regimes. Moreover, the ELD has left crucial aspects up to the Member States. For instance, and without being exhaustive, Member States may decide whether to allow permit compliance and state-of-the-art defences, they may decide to introduce joint and several liability, Member States may also maintain or adopt more stringent provisions in their national law to prevent and restore environmental damage, and precise definitions of damage or restoration criteria are passed on to the Member States. Hence, there still might be significant differences in the implementation of the Directive by the Member States and consequently, the burden for industry in the different Member States might differ significantly. Hence, the ELD provides an uncertain framework and might create more uncertainty than its adherents originally might have thought, so that the ELD certainly will not create a level playing field, increase legal certainty or realise a reduction in transaction costs.

Some concrete examples with respect to soil pollution will prove this statement.

The Directive takes a prospective approach. Yet, such a prospective approach is not universally adopted in Member States. In Spain, for example, prospective owners are required to check the Property Register to determine whether the land they wish to buy has been registered as polluted. As Vaques notes, they neglect to take the Register into account at their own peril. ${ }^{918}$ As domestic provisions may continue to apply even if the Directive comes into force - Article 16 of the ELD allows Member States to maintain or adopt more stringent measures - , this may introduce considerable uncertainty into the regime. Similarly, Member States can decide to allow for a complete or partial permit compliance or 'state of the art' defence. Again, this will not be the case in all Member States. In Italy, for example, firms that cause environmental damage will be exempted from liability if they can show the damage was caused by emissions permitted by the authorities, whereas in Lithuania or Spain, compliance with a provision will not necessarily exempt the operator from liability. ${ }^{919}$ Furthermore, precise definitions of damage, baseline assessments and restoration criteria are also be left to Member States, and so are differing rules on making the polluter pay, the availability of subsidies and state support. Moreover, as was already indicated in the previous chapter, the scope of the ELD with respect to soil is limited. ${ }^{920}$ The consequence of the Directive's narrow definition of land damage is that many sites containing pollution will not be included within the scope of the Directive, so that clean-up, if it takes place at all, will be on the account of the individual Member States. ${ }^{921}$ Yet, Member States' different approaches to contaminated land will result in significant variation in the remediation of contaminated sites that fall out of the scope of the Directive.

Hence, the ELD will not create legal certainty or reduce transaction costs with respect to environmental liability rules, including liability for soil pollution. The argument of the creation of a level playing field is therefore not sufficient to allow for a harmonised European environmental liability regime.

\subsubsection{Realisation of the Polluter Pays, Prevention and Precautionary Principles}

In all three documents, the Commission holds that Community action is needed to realise the implementation of three grand environmental principles enshrined in Art 174 (2) of the EC Treaty: the polluter pays, precautionary and preventive principles. ${ }^{922}$

In its Explanatory Memorandum to the ELD, the Commission specifically stated that 'the positive incentives provided by liability for efficient levels of prevention should prevail, provided that there is a consistently applied liability policy at Community level. Significant differences among liability standards at Member State level could considerable weaken the positive effects of liability on prevention. ${ }^{\prime 23}$

\footnotetext{
918 Mar Aquilera Vaques 2002, 176-179.

919 See <www.endseuropedaily.com>, 'State of liability law implementation discussed' of 29 May 2006 and 'Spain tables "groundbreaking" liability law', 27 October 2006. See also Mar Aquilera Vaques, 2002, 176-179.

Layard 2004, 104.

Layard 2004, 103.

See Green Paper on remedying Environmental Damage, White Paper on Environmental Liability and the Proposal for a Directive on Environmental Liability with regard to the Prevention and Restoration of Environmental Damage, Explanatory Memorandum.

923 Proposal for a Directive on Environmental Liability with regard to the Prevention and Restoration of Environmental Damage, Explanatory Memorandum, 7. See Krämer 2005, 132.
} 
Yet, although from the point of view of the environment the realisation of the polluter pays, precautionary and preventive principles only can be welcomed, it is doubtful that the realisation of these principles justifies the shift of environmental liability rules from the Member States to the European level. Indeed, it should be clear that the principles as such do not explain why environmental regulation should be issued at the European level. In this respect one could refer to the whole range of regulations that exist already today in the Member States and that in a certain way incorporate these principles.

Moreover, the question obviously arises whether the liability regime of the ELD will indeed create more incentives for prevention than the existing national liability regimes and whether it can be ensured that the polluter pays for the damage caused. However, again, the answer is unfortunately negative.

Certain provisions in the ELD might undermine the ability of the Directive to exert a preventive effect and to ensure that the polluter pays for the damage. Moreover, remarkable and contradictory to the Commissions' own statement in the Explanatory Memorandum, is that the Directive itself establishes the basis for differences between the Member States, precisely for these issues that might weaken the preventive effect of the ELD.

Indeed, in theory, strict liability could be a strong incentive for operators to take all possible riskminimising measures and it could be a way of implementing the precautionary principle. However, the restricted scope of the Directive, the fact that the burden of proof lays with the authorities, and especially the provision that Member States may allow for a permit and/or a state-of-the-art defence and the absence of mandatory insurance might cause that the ELD might not set a strong incentive for the potential liable operators to invest in risk-minimising measures. Moreover, Member States do not have direct responsibility for prevention and restoration under the ELD regime. As already argued in paragraph 1 of chapter 5, this might somewhat be compensated by the wording of Article $8 \S 2$, which stipulates that the competent authority shall recover, inter alia, via security over property or other appropriate guarantees, from the operator who has caused the damage or the imminent threat of damage, the costs it has incurred. Nevertheless, an explicit obligation on the Member States to restore the damage to the environment themselves would have been preferable, as Member States' responsibility could have a positive effect on prevention of the damage, as explained in paragraph 1 of chapter $5 .{ }^{924}$

With respect to soil pollution in particular, it is interesting to note that in the Proposal for a Soil Framework Directive, the Commission tries again to introduce responsibility for the Member States. Indeed, Preamble 28 states that 'in those contaminated sites where the polluter cannot be found, cannot be held liable for the pollution under national or Community legislation or cannot be made to bear the costs of remediation, also known as orphan sites, responsibility for reducing risk to human health and the environment should fall on the Member States' ${ }^{925}$ This shows that the Commission indeed believes that Member States' responsibility could have a positive effect on prevention of environmental damage. It remains to be awaited whether this responsibility will be accepted by the Member States themselves.

In sum, the Commission offers no evidence that the liability regime of the ELD creates more incentives for prevention than the existing national liability schemes or that the regime will ensure that the polluter pays for the damage caused.926 Therefore, the polluter pays, precautionary and preventive principles do not explain or justify, at least from an economic perspective, the need for European action.

\subsubsection{Decontamination and Restoration of the Environment}

Repeatedly, the Commission expressed its expectations that a European liability regime would encourage decontamination and restoration of the environment and improve the implementation of EC environmental legislation. ${ }^{927}$ In particular, the restoration of orphan damage was an argument for Community action mentioned in the Explanatory Memorandum to the Commission Proposal: 'Member States' liability regimes for contaminated land do not mandate national authorities to ensure clean up of orphan sites and hence do not ensure that the objective of restoration is attained' ${ }^{928}$

Bergkamp however holds that the Commission's expectations are probably more idealistic than realistic. Liability is neither a sufficient nor a necessary instrument for realising these two objectives. ${ }^{929}$

924 Krämer 2005, 132. See also Schueler 2005, 58-72.

925 Commission of the European Communities, Proposal for a Directive of the European Parliament and of the Council establishing a framework for the protection of soil and amending Directive 2004/35/EC, COM(2006) 232 final, Brussels, 22.09.2006.

926 Bergkamp 2000, 108.

927 White Paper on Environmental Liability, $§ 3.1$ - 3.2, p. 14, Proposal for a Directive on Environmental Liability with regard to the Prevention and Restoration of Environmental Damage, Explanatory Memorandum, 4-6.

928 Proposal for a Directive of the European Parliament and of the Council on environmental liability with regard to the prevention and remedying of environmental damage, Explanatory Memorandum, 5.

929 Bergkamp 2000, 108. 
Moreover, Bergkamp points out that the argument that a European liability regime is necessary to ensure the restoration of damaged habitats is not sufficient, as Member States are already requested to do so. ${ }^{930} \mathrm{He}$ suggests that, if the objective of an EU environmental liability regime is the remediation of contaminated land, then EC law should solely impose an obligation on Member States to reach this objective. Consequently, the Member States will be free to choose the instruments they will use. This may, but does not have to involve additional liability rules. ${ }^{931}$

Yet, does the directive realise decontamination and restoration of the environment?

Overlapping with the previous argument for centralisation, certain provisions in the ELD might undermine the ability of the Directive to ensure restoration of damage. Again, the restricted scope of the Directive, the fact that the burden of proof lays with the authorities, which sometimes might make it very difficult to prove that a certain polluter caused the damage, and the provision that Member States may allow for a permit and/or a state-of-the-art defence might cause that restoration cannot be ensured as polluter cannot be held liable under the Directive. Originally, Article 5 of the Commission's proposal for an environmental liability regime included an obligation for Member States to take, in case of environmental damage, remedial measures and Article 6 proposed that Member States had to ensure that restoration measures were taken also in those cases, where the responsible operator did not cover the necessary costs ('orphan damage'). ${ }^{932}$

However, the final version of the ELD deleted the obligation on the Member States to restore the damage to the environment, including soil pollution, themselves. Hence, the ELD denies the positive effect on prevention and restoration of Member States' responsibility, which Krämer and Schueler definitely consider as a weakness of the regime. ${ }^{933}$ Yet, again reference can be made to Article $8 \$ 2$, stipulating that the competent authority shall recover, inter alia, via security over property or other appropriate guarantees, from the operator who has caused the damage or the imminent threat of damage, the costs it has incurred and which aims to protect the competent authority against insolvency of the operator, so that restoration can be ensured. ${ }^{934}$

Yet, with respect to soil pollution in particular, it appears that the Directive will not ensure the decontamination of many contaminated sites in the EU. Indeed, the Directive only has a restricted scope. The regime will only apply prospectively and a clear link needs to be established between the operator and the damage. The harm to health must be 'significant' and it must have come about as a result of an operation specified in Annex III of the Directive. 935 As stated above, many contaminated sites will not be included within the scope of the Directive so that clean-up will be on the account of the Member States. ${ }^{936}$ Furthermore, the fact that the burden of proof lays with the authorities, and the option for the Member States to allow for a permit and/or a state-of-the-art defence might cause that polluters cannot be held liable and restoration cannot be ensured. Of course, the competent authority may take remedial measures itself, as a means of last resort, ${ }^{937}$ although an explicit obligation on the Member States probably had been more effective to guarantee the restoration of soil pollution.

In sum, it seems that the Directive will also not be able to live up to the expectations with respect to the decontamination of soil pollution.

\subsubsection{Harmonisation to Guarantee a Minimum Level of Protection}

The first preamble of the ELD states that 'there are currently many contaminated sites in the Community, posing significant health risks, and the loss of biodiversity has dramatically increased over the last decade. Failure to act could result in increased site contamination and greater loss of biodiversity in the Community. Prevention and remedying of environmental damage contributes to implementing the objectives and principles of the Community's environmental policy as set out in the Treaty" ${ }^{938}$

It seems that with this line of argumentation, the Commission tries to justify the ELD by holding that it would guarantee all European citizens a minimum level of protection against environmental damage.

\footnotetext{
930 Council Directive 92/43 on the conservation of natural habitats and wild fauna and flora, OJ L $206,7$.

931 Bergkamp 2000, 108.

932 Proposal for a Directive of the European Parliament and of the Council on environmental liability with regard to the prevention and remedying of environmental damage, Explanatory Memorandum, 20.

933 Krämer 2005, 132. See also Schueler 2005, 58-72.

934 Bocken 2006, 13-32.

935 Layard 2004, 104.

$936 \quad$ Layard 2004, 103.

937 ELD, Article 6

938 ELD, Preamble 1.
} 
In a first step, it might be examined from a legal perspective whether harmonisation of environmental liability rules in order to guarantee a minimum level of protection would be justified on the basis of the Treaty provisions. In a second step, it can be examined whether the minimum level of protection argument would justify harmonisation of environmental liability rules, including liability rules for soil pollution from an economic perspective.

First, in Articles 2 and 3 of the EC Treaty it is stated that the Community is concerned about the environment and that the Community shall promote higher standards of living and better quality of life. Arguably, the protection of the environment is a means of achieving that aim. Article $174 \S 2$ sets out the aims of European environmental policy, namely a high level of protection taking into account the diversity of situations in the various regions of the Community, based on the precautionary principle and on the principles that preventive action should be taken, that environmental damage should as a priority be rectified at source and that the polluter should pay. ${ }^{939}$ Furthermore, the second guideline of the Protocol on the application of the principles of subsidiarity and proportionality holds that Community action is justified if 'actions by Member States alone or lack of Community action would conflict with the requirements of the Treaty or would otherwise significantly damage Member States' interests' ${ }^{940}$

The question is whether by not acting, the Community would be acting outside the requirements of the Treaty. Farnsworth argues that the answer is given by the fact that Article 174(2) states a priority. ${ }^{941}$ Farnsworth argues that given the wording of Article $174 \S 2$ and the application of the precautionary principle in practice can be interpreted that if there is a strong assumption that an activity might cause environmental damage, it is better to act before damage materialises, rather than to wait until scientific evidence is available to prove the causal connection. For example, in hindsight, it could be that the Seveso accident or Baia Mare accident might have been prevented if stricter (European) legislation had been in place to prevent such accidents. Consequently, based on the aims of European environmental policy in Article 174 §2 EC Treaty, European action with respect to environmental liability rules would be justified to guarantee high level of environmental quality in the European Union. ${ }^{942}$

Yet, would the minimum level of protection argument be a valid argument for centralisation from an economic perspective?

From an economic point of view, the reasoning that harmonisation is necessary to ensure a high level of protection or a high level of environmental quality, is hard to justify. Indeed, although the aim to guarantee a minimum level of protection against environmental damage is a noble political aim, it fully ignores the different preferences of the citizens in the different Member States and in a paternalistic way assumes that the Commission knows better than the Member States what the minimum level of protection is for their citizens.

As was explained in the theoretical part of this research, the minimum level of protection argument falls beyond the pure economic arguments for harmonisation of liability rules. Some authors do stay within the economic reasoning and argue that harmonisation would be justified in order to guarantee a minimum level of protection as unacceptably low environmental standards in a certain state could present negative psychic spillovers to citizens in other states. ${ }^{943}$ For example, a certain Member State might dispose of especially scenic or ecologically significant natural resources, which may be admired be citizens of other Member States. Yet, the Belgian interpretation of what is worth preserving might differ to the Greek interpretation, but both, applying it to the spillover argument, should have the right to enjoy the other country's resources. ${ }^{944}$ Consequently, it is argued that psychic externalities should be taken into account when developing an environmental policy. ${ }^{945}$ The prevention of psychic externalities would be one way to accept the existence of the ELD on the basis of the minimum level of protection argument.

Other authors consider environmental protection as a human right, freed from economic justification, so the ELD would not have to be justified on economic grounds. ${ }^{946}$

Some critical remarks might be appropriate though. Faure argues that if the minimum level of protection argument is accepted as a valid justification for a European environmental liability regime, it must be emphasized that the reason for harmonisation would not be based on economic efficiency, but on the desire to provide a minimum level of environmental quality and of protection against environmental

939 Article 174 §2 EC Treaty, emphasis added.

940 Amsterdam Treaty, Protocol on the application of the principles of subsidiarity and proportionality, Article 5 .

941 Farnsworth 2004, 182.

942 Farnsworth 2004, 183.

943 Esty 1996, 638-648. See also Ferejohn 2000, 99-100.

944 See Farnsworth 2004, 181 and Faure \& De Smedt 2001, 229-230.

945 Esty 1996, 640-641. See also Wils 1994, 85-90.

946 Engel 1997, 289. See also Kimber 1995, 1690. 
accidents. ${ }^{947}$ Moreover, the minimum level of protection justification addresses the concern to guarantee all citizens minimum quality standards, which in fact refers to harmonisation of regulation. Therefore, this argument might in some circumstances justify the harmonisation of regulation; however Faure is sceptical whether European environmental protection should incorporate a liability regime. It is indeed questionable that the harmonisation of tort law would be the appropriate instrument to achieve such minimum level of protection. Even more skeptical are Bergkamp and Revesz on the minimum level of protection argument. Indeed, Bergkamp argues that it might be more efficient to develop minimum quality standards that must be achieved, before and after an accident, rather than to harmonize the liability rules itself in the different jurisdictions. ${ }^{948}$ Moreover, as Revesz indicates, it is questionable that environmental quality standards should be harmonised, in order to guarantee a minimum level of protection, if, for example in the European Union, there is no minimum social security, no provision of general health care or no harmonisation of minimum wages. 949

Hence, although the minimum level of protection argument might in some circumstances justify the harmonisation of regulation, it is doubtful whether it is really necessary to harmonise environmental liability rules.

Furthermore, even if it is accepted that the Community should contribute to the protection of environmental quality and human health, if this alone may be sufficient to justify European action, it becomes hard to find any examples of Community environmental measures which cannot be justified. In effect, all Community measures could then be justified by arguing that the aim is to guarantee a minimum level of protection which obviously is not the idea of the subsidiarity principle.

In sum, from a theoretical perspective, if it would be already accepted that the minimum level of protection is a valid justification for a European environmental liability regime, it must be emphasized that the reason for harmonisation would not be based on economic efficiency. Moreover, it would be preferably to develop quality standards that must be achieved, before and after an accident, rather than to harmonize the liability rules. It should then be the responsibility of the Member States to achieve this environmental quality by means that correspond with their citizens' preferences. ${ }^{950}$

Turning back to the ELD and the soil pollution example, supposing that this minimum level of protection argument would be accepted as an argument for centralisation, one might ask what the consequences are with respect to soil pollution in the European Union and would the ELD effectively realise this minimum level of protection for soil pollution?

In a first step, the consequences of harmonisation of liability rules for soil pollution might be examined. The economic theory on federalism generally takes a bottom-up approach towards centralisation, as the main idea is that through decentralisation rules can be adapted to the preferences of the citizens. Indeed, starting from decentralisation, according to the Tiebout model, jurisdictions would be free to set their own clean-up standards and their own liability rules according to their citizens preferences. Hence, if preferences differ between countries, environmental policies should also differ between countries and a uniform environmental policy might not be optimal. By harmonising liability rules for soil pollution through the ELD, it may be concluded that Commission assumes that it knows better than the Member States what the minimum level of protection with respect to soil pollution is for their citizens and that all European citizens have the same preferences with respect to soil quality. Union?

Yet, the question is, are preferences for soil quality really the same for all citizens in the European

The Eurobarometer survey illustrates that Member States' perception is quite divergent with respect to the most efficient solutions for environmental problems as soil pollution, as well as to the most efficient level for regulation. ${ }^{951}$ Moreover, soil clean-up is a difficult operation with very high costs. Expenditure for decontamination of contaminated sites greatly varies between Member States. Such disparities might reflect different preferences and perceptions of the severity of the contamination, different remediation policies and targets, and different ways of estimating expenditure. ${ }^{952}$ Hence, harmonisation of liability rules might neglect the preferences of the citizens in the different citizens and therefore harmonisation may amount to paternalism.

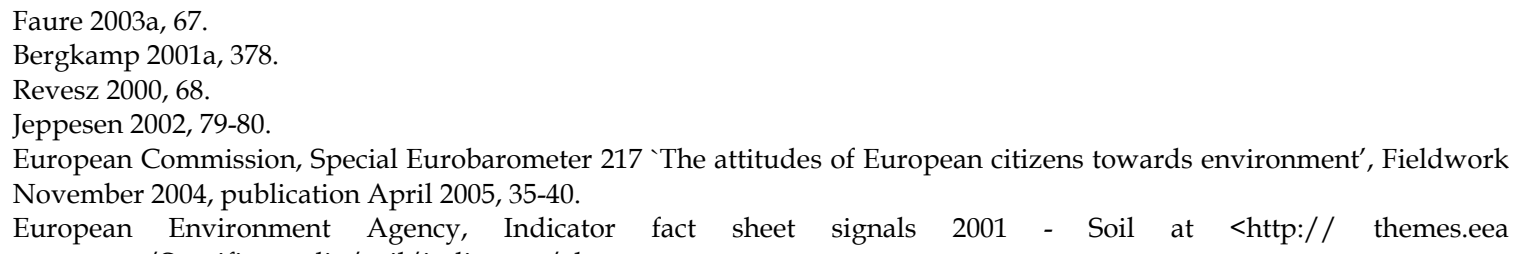


Moreover, this minimum level of environmental quality could also be realised through setting minimum quality standards that would have to be achieved after the clean-up of contaminated soil. 953 Hence, the minimum level of protection argument could justify the centralisation of minimum soil quality standards, but it would not be necessary to harmonise liability rules to achieve this basic environmental quality after clean-up. Each jurisdiction could organise this according to its preferences.

Second, it might be wondered whether the ELD would effectively realise this minimum level of protection for soil pollution. Due to the limited scope of the Directive for soil pollution, many sites will still have to be restored, if at all, under the Member States' legislations, therefore soil quality still might vary significantly between the Member States for those sites that fall outside the ELD regime. Therefore, it is not sure that the aim of a minimum soil quality standard throughout the European Union can be reached.

\subsection{Summary of the Public Interest Approach}

This paragraph examined whether the Environmental Liability Directive corresponds with the predictions of the theoretical framework on the optimal decision-making level of liability rules for environmental damage, with the example of soil pollution, and why there was a need to shift environmental liability rules from the Member States to the European level. Therefore, the arguments that where provided by the Commission to justify the Environmental liability Directive with regard to the subsidiarity principle, were compared with the arguments for harmonisation provided by the economic theory of federalism in the environmental field.

It appears that from an economic point of view, the reasons advanced by the Commission for the ELD seem rather weak, and would not justify a shift from the Member States to the European level of environmental liability rules, including liability rules for soil pollution.

From an economic point of view, the only valid argument for centralisation was the internalisation of transboundary damage, however, only a so-called 'transboundary only'-regime would be justified rather than full harmonisation. Yet, it was shown that the Directive would not necessarily solve this transboundary damage. It was also argued that economies of scale in technical research might allow for cooperation or centralisation of certain tasks, like research or data gathering on for example soil contamination and restoration. However, again, the promise of economies of scale in scientific research would not justify for a centralisation in an excessive sense.

Next it was shown that fears for a race-to-to-bottom or unfair marketing conditions, due to different liability rules in the Member States, seem not very likely to be realised, and therefore these arguments do not justify harmonisation of environmental liability rules in the European Union. Moreover, it was shown that the ELD will not create a level playing field or realise a reduction in transaction costs, neither for environmental liability rules in general nor for liability for soil pollution in particular.

With respect to the next two arguments provided for by the Commission, it was argued that the realisation of the polluter pays, precautionary and preventive principles and restoration and decontamination of environmental damage as such do not explain why environmental regulation should be issued at the European level. Moreover, it was indicated that the ELD will not necessarily realise the polluter pays, precautionary and preventive principles, or the restoration and decontamination of the environment.

Finally, if the minimum level of protection argument would be accepted as a valid argument for shifting environmental liability rules from the Member States to the European level, it must be emphasized that this reason for harmonisation would not be based on economic efficiency, but on the desire to provide a minimum level of environmental quality and of protection against environmental accidents. Moreover, if the preferences of the citizens in the different Member States are ignored, harmonisation of environmental liability rules on the basis of this argument only amounts to paternalism.

The conclusion at the normative level is, however, not necessarily that there should be no European action at all with respect to environmetnal liability. Subsidiarity is not a question of either centralised or decentralised decision-making, but may involve a mixture of powers at different levels. With respect to soil pollution for example, a European register of contaminated land might on the one hand increase transparency which could help in creating a level playing field for multinational corporations and on the other hand it could improve clean-up of contaminated sides. Yet, for soil pollution, even more than for the damage to protected species and natural habitats and for damage to water, local circumstances and preferences need to be taken into account. Indeed, the diversity of soils implies that any soil protection policy needs to have a strong local element build in. The strongest argument for decentralisation of liability rules for soil pollution is that local conditions, geography, economic strengths and concerns might vary 
substantially from place to place. Furthermore, local knowledge and expertise with specific soil conditions might prove essential to develop the proper liability rules for soil reclamation. Therefore, certainly in the specific case of soil pollution, the arguments for a harmonisation of liability rules for soil pollution seem to be weak.

Hence, the Commission fails to explain properly why a harmonised liability regime for environmental damage, including soil pollution is necessary or why its goals cannot be achieved by the Member States, as required by the subsidiarity principle.

Concluding, the regime of the ELD shows some inefficiencies as was illustrated in Chapter 5. Moreover, the comparison of the theoretical framework with the way in which the balance between centralisation and decentralisation is sought in the regime of the ELD, also shows that there is 'more Europe' and that the ELD goes further than what the theoretical framework would predict. Put differently, from an economic point of view, there is an inefficient shift of competences from the Member States to the European level with respect to environmental liability rules and for example of liability rules for soil pollution.

Therefore, it merits searching for additional explanations for the existence of the ELD and for certain provisions in the ELD by means of the private interest approach. Indeed, in order to understand why the decision-making level of environmental liability rules was shifted from the Member States to the European level, how the ELD got to its final form, and why certain provisions are as they are, rent seeking behaviour and lobbying of different interest groups in the decision-making process of the ELD should not be ignored. The private interest approach will be addressed in the next paragraph.

\section{Private Interest Approach on the Optimal Decision-making Level of Liability for Environmental Damage in the European Union}

The existence or the harmonisation of certain environmental regulations can not always be explained on the basis of the public interest approach. For a full understanding of environmental policy, the influence of lobbying of different interest groups in the law making process must be recognised. ${ }^{954}$

Hence, as for the theoretical part, the public interest approach will now be complemented with a private interest approach, which tries to take rent seeking into account in the law making process. The contribution of this paragraph would be to throw light upon the conditions under which ELD was adopted and to provide additional explanations for the existence of the ELD and for certain provisions in the ELD.

This paragraph will consist of two parts. Firstly, the adoption process of the ELD will be studied with respect to interest group lobbying. In a first step, it will be explained which actors were involved in the decision-making process of the ELD and what their stakes were. Secondly, the adoption process of the ELD will be examined chronologically and it will be indicated at which stages and at which institutions lobbying took place. Thirdly, three items that were heavily debated during the adoption process of the ELD will be discussed, in order to explain how certain provisions got to their final form.

Fourthly, it will be examined whether the lobbying activities, observed in the adoption process of the ELD, and the result of this lobbying, correspond with the predictions of the private interest theory, as discussed in the theoretical part (paragraph 2.1 of chapter 3). In particular, it will be examined, on the one hand, whether the inefficient shift of competences to the European level with respect to environmental liability rules resulting in 'too much Europe', as concluded in paragraph 1 of this chapter, has been caused by interest group lobbying and, on the other hand, whether the inefficiencies in the Directive itself can be explained by interest group lobbying.

Finally, it will be examined whether lobbying behaviour by interest groups would cause more distortions at the national level than at the central level so that this would justify Community action in the field of environmental liability, as studied in the theoretical part (paragraph 2.2 of chapter 3).

\subsection{Rent-seeking Behaviour in the Adoption Process of the ELD}

This paragraph will try to unravel the adoption process of the ELD with respect to interest group lobbying. In particular, the following questions will be addressed: who came up with the idea of a European Directive with respect to environmental liability and for what reasons? Who were the main actors in the adoption process of the ELD and what were the different actors' interests in the different stages of the adoption process of the ELD? Was there lobbying pro harmonisation of environmental liability rules at European level, when and by whom? Was this lobbying successful and why? And at which level of government did this lobbying take place? 
Paragraph 2.1.1 will first explain who were the main actors in the adoption process of the ELD and what were there stakes in the different stages of the adoption process.

Paragraph 2.1.2 will then examine the adoption process of the ELD chronologically and will indicate at which stages and at which institutions lobbying took place, and what was lobbied for.

By doing so, this chapter complements chapter 4, which provided an insight in the development process and the provisions of Directive 2004/35/EC.

It must be realised that lobbying behaviour is a very complex matter. The reasons behind certain lobbying behaviour might not always be clear and some reasons might even be hidden. In this paragraph, plausible explanations will be sought for the lobbying behaviour of the different actors in the adoption process of the ELD and certain assumptions will be made with respect to the underlying reasons for certain lobbying behaviour. This sometimes requires a 'reading between the lines' of official statements and it would be rather hard to find somebody who would openly confirm some of the assumptions. Yet, although this paragraph will try to provide a thorough insight in the conditions under which ELD was adopted, it cannot be claimed that this research will be able to unveil all hidden reasons behind the lobbying behaviour of the different actors.

\subsubsection{Who is Who in the Lobbying Process Behind the ELD}

A public choice analysis of the lobbying process in the European Union does not take place along the classical lines whereby rent seeking behaviour by interest groups (such as industry or NGO's) is examined. Rather, when examining lobbying efforts at the level of the EU, attention must also be paid to the role that the various European institutions play. Indeed, in the European legislative process the reasons for shifting powers to the central level have often more to do with competition and power struggle between the various institutions involved (European Commission, European Parliament and Member States) than with struggles by traditional interest groups. The latter of course still play a role, but often in an indirect way. Therefore, an analysis of the legislative process at the European level should also pay attention to the institutional players involved.

Hence, the main players in the decision-making process of the ELD were the European Commission, the European Parliament, the Member States, negotiating with each other in the Council of the European Union, the industry and environmental interest groups, each with their own stakes. The stakes of these different actors in the adoption process of the ELD will now be examined successively.

\section{The European Commission}

In order to sketch the interests of the European Commission in the Environmental Liability Directive, it might merit reminding the background or the ELD. As was already mentioned in Chapter 4, the desire to introduce a European environmental liability regime already existed at European level 15 years ago. The impetus for this desire were a number of environmental disasters involving the release of toxic agents in the late 1970's and 1980's, like the accident at the industrial site in Seveso in Italy in 1976. The Community's legislative response to these disasters focused on improving plant safety and emergency procedures, as laid down in Directive 82/501EEC, also known as the Seveso Directive. ${ }^{955}$ Yet, the Seveso Directive did not address liability or compensation of victims in case that an accident happened. Hence, following the Sandoz incident in 1986 and in response to public indignation, the Council of Ministers and the European Parliament called upon the Commission to examine new measures for the prevention and restoration of environmental damage that would ensure clean-up and restoration, coupled with arrangements for liability and compensation by the polluters for damage caused. 956 This statement opened the door for the possible use of liability rules as a component of the Community's environmental policy. ${ }^{957}$

Hence, in response to the Council statement, the Commission started the development process of a European environmental liability regime, which would take more than 15 years. The Commission favoured an environmental liability regime at European level and considered that a framework of environmental liability rules would broaden its means for environmental protection. Moreover, besides the traditional command-and-control regulation at European level, like IPPC, 958 an environmental liability regime, based on economic incentives, would contribute to ensuring prevention and restoration of environmental 
damage. ${ }^{959}$ Hence, a European environmental liability regime would contribute to the three grand environmental principles enshrined in Article 174 \$2 of the EC Treaty: the polluter pays, the precautionary principle and the preventive principles.

The question now obviously arises whether the Commission only aimed to protect the environment, or whether there were also other reasons at stake?

It cannot be ignored that the ELD enlarges the Community's competences, for example with respect to soil protection policy. Yet, in paragraph 1 of this chapter, it was concluded that there are very few arguments for having a harmonised liability regime for soil pollution. So why did the Commission want to include liability for soil pollution in the Directive?

Soil protection and remediation definitely is an area of interest to the European Commission, but for which it does not have direct competence yet. Nevertheless, it seems that the Commission is determined to develop a comprehensive policy for soil pollution in the European Union, or as Van Calster puts it, the Community intends to get a finger in the pie. Van Calster argues that there might be two main reasons for the attention of the European legislator for harmonising soil protection legislation. A first reason might be the strong interest in biodiversity issues, and nature conservation legislation, which has become an important part of EC environmental law practice, in the European Court of Justice and in national courts. Connected to nature conservation legislation is town and country planning. Yet, with respect to the subsidiarity principle, it would be difficult to justify the need of European action in this area. Soil protection and remediation concerns are inherent in any nature protection and town and country planning and in this way the EU might get a finger in the pie. A second reason might be the possible impact on the internal market of diverging soil protection legislation in the Member States. Indeed, the main reason for European action in the environmental field often is internal market considerations. According to Van Calster, this rationale most certainly plays a role in justifying the Commission's initiatives in the soil protection area, with respect to the subsidiarity principle. ${ }^{960}$

The ELD for the first time directly addresses soil protection remediation, which might open the door for further soil protection measures at Community level. Indeed, as stated before, the Commission has published a Proposal for a Framework Directive for soil protection ${ }^{961}$ which sets out common principles, objectives and actions for the protection of soils across the EU. ${ }^{962}$ The fact that the ELD already addresses soil pollution might maybe help to get the Directive adopted.

Moreover, it is interesting to note, that if the Proposal would be adopted, the ELD should be amended in order to align it with the remediation obligations as stipulated in the Soil Framework Directive. Indeed, Preamble 28 of the Proposal for a Soil Framework Directive stipulates that in those contaminated sites where the polluter cannot be found, cannot be held liable for the pollution under national or Community legislation or cannot be made to bear the costs of remediation, also known as orphan sites, responsibility for reducing risk to human health and the environment should fall on the Member States. For those purposes, Member States should put in place specific funding mechanisms to ensure a durable financial source for the remediation of such sites'. As already noted several times, the ELD does not foresee this obligation on the Member States, although the Commission had included also this provision in the Proposal for the ELD. The Commission might in this way also reach its objectives with respect to Member States' responsibility for the Environmental Liability Directive.

Hence, to the question of who came up with the idea of a European Environmental Liability Directive and for what reasons, one might answer that although the request officially came from the European Parliament and the Council of Ministers, representing the Member States, as a response to public indignation after environmental accidents, the Commission, who has to start off the law making procedure, might have welcomed this request for other reasons than only protecting the environment. Indeed, the Commission might have seen this as a means for enlarging its competences in fields for which it did not have any direct competence yet, as for example soil protection policies.

\section{European Parliament}

In order to encourage the prevention and restoration of environmental damage in the European Union, the European Parliament, as the representative of the European citizens, favoured an environmental liability regime at European level. In April 1994 already, the European Parliament adopted a resolution calling on the Commission to submit 'a proposal for a directive on civil liability in respect of (future) environmental

\footnotetext{
959 Charles Pirotte, European Commission, Directorate-General Environment, desk officer for the ELD, interview

960 Van Calster 2004, 3-17.

961 Commission of the European Communities, Proposal for a Directive of the European Parliament and of the Council establishing a framework for the protection of soil and amending Directive 2004/35/EC, COM(2006) 232 final, Brussels, 22.09.2006.

962 <http://ec.europa.eu/environment/soil/index.htm>.
} 
damage' ${ }^{963}$ In that resolution, the Parliament applied for the first time Article 192(2) (ex-Article 138b(2)) of the EC Treaty, which gives the Parliament the competence to ask the Commission to submit legislative proposals. Since then, the Parliament has called for action in the field of environmental liability on several occasions, such as in the Commission's annual working programmes, in parliamentary questions and in letters to the Commission. ${ }^{964}$

Yet, during the adoption process of the ELD, the Parliament saw itself confronted with a conflict of competence between the Committee on Environment, Public Health and Food Safety, which was more inclined towards environmental concerns and which favoured a strict environmental liability regime, and the Legal Affairs Committee, which was more receptive to industry concerns with respect to a harmonised environmental liability regime. As will be discussed below, the Legal Affairs Committee became the lead Committee in the adoption process of the ELD.

\section{Member States}

In 1986, the Member States, through the Council of Ministers, called upon the Commission to examine new measures for the prevention and restoration of environmental damage. 965 Yet, the first steps towards the ELD, including the Green Paper on Remedying Environmental Damage in 1993 and the White Paper on Environmental Liability in 2000, which proposed a civil liability regime, did not get an unqualified approval by all Member States. Some of the smaller Member States, like Belgium, Greece, Luxembourg, the Netherlands, Austria, Portugal, Finland and Sweden, expressed a favourable opinion with respect to Community action in the field of environmental liability. ${ }^{966}$ An explanation might be that they preferred a harmonised regime in order to avoid that by having a national environmental liability regime, they would put an additional burden on their industry compared to Member States who did not foresee a national environmental liability regime. Yet, some of the large Member States, in particular Germany, France and the UK, firmly opposed any European initiative to harmonise environmental liability rules for reasons of sovereignty and subsidiarity and intended to implement strict liability rules at national level. ${ }^{967}$

Hence, the Commission, on the basis of the regime of the White Paper, was not able to convince the Member States to shift environmental liability rules from the Member States to the European level.

A turning point was reached with the publication of the Working Paper on Prevention and Restoration of Significant Environmental Damage in the summer of 2001. 968 As the comments of interested parties show, the reactions on the Working Paper were mostly moderately positive. The Belgian government for example stated that 'Belgium in general favours the harmonisation, at the level of the European Union, of environmental law and more particularly in the area of enforcement and civil liability. It regretfully accepts that, while agreement on a comprehensive environmental liability regime may not be possible at this moment, alternative approaches towards prevention and restoration of damage have their merits. In this context, it considers the preparation of a draft directive on prevention and restoration of significant environmental damage as a meaningful contribution to the legal instruments for the actual protection of the European environment and for the enforcement of EU environmental law'. A similar attitude was shown by the Dutch authorities.

Especially Member States that already experienced severe environmental damage caused by industrial activities as Spain, ${ }^{969}$ were definitely more positive towards a European environmental liability regime than countries that did not experience environmental disasters. This might be explained because these Member States felt there was a need to have a kind of environmental liability regime, and that it would be easier to harmonise it at European level, so that they did not have to fear that their industry would face a higher burden than the industry in other Member States. It is also remarkable that Portugal and Greece, the only two (pre-accession) Member States who did not already have an environmental liability regime in place, did not oppose the Directive on the basis of subsidiarity. Farnsworth argues that they were waiting for Europe to take the lead in this area, so that they would be in a stronger position to develop their own legislation around the Environmental Liability Directive. ${ }^{970}$

Nevertheless, Member States' opinions on the content of a European environmental liability regime were diverse and large disagreement existed between Member States on key issues as financial security,

963 Resolution of 20 April 1994, OJ C 128, 9.5.1994, p. 165.

964 Commission Communication of 9 February 2000, White Paper on Environmental Liability, COM (2000) 66, 11.

965 European Commission, Bulletin of the European Communities. No. 11/1986, par. 2.1.146.

966 Commission Communication of 9 February 2000, White Paper on Environmental Liability, COM (2000) 66, 12.

967 Bocken 2001, 352 and Clarke 2003, 256

968 Slabbinck, Descamps \& Bocken 2006, 6

969 On 25 April 1998, the collapse of a waste retention dam of the Aznalcollar mining complex in Spain, lead to a flow of toxic waters and mud towards the Doñana National Park.

970 Farnsworth 2004, 178 
subsidiary state liability and permit and state-of-the-art defences. The final text of the ELD allows substantial Member State discretion in various contentious provisions. Maybe this made a European environmental liability regime acceptable also for the more sceptical Member States. Or, as Clark puts it, a reason why the more sceptical Member States might have decided to support the ELD was because there did not appear to be much that would require them to strengthen their existing laws. ${ }^{971}$

\section{Industry}

The first initiatives of the Commission gave rise to a lot of critique from industry. Industry organisations questioned the need for a European environmental liability regime, criticised the vagueness of the regime and for many of them the White Paper went too far with respect to the scope of the regime, the liability provisions and the prove of causal link. Yet, the main difference with the Member States that opposed the Commission's initiatives, was that those Member states were against a European liability regime for reasons of sovereignty, but intended to implement their own liability regime at national level, whereas industry at that time was against a liability regime itself for competitiveness reasons. ${ }^{972}$

Again, the publication of the Working Paper on Prevention and Restoration of Significant Environmental Damage ${ }^{973}$ represented a turning point. After publication of the Working Paper, Unice, a large business interest group, held that 'the working document contains a number of positive elements, which would represent progress in the discussion on environmental liability in Europe".974

Commentary papers of industry lobby groups on the Commission Proposal for a Directive on Environmental Liability indeed show that industry did not oppose the public law regime provided for by the Commission. ${ }^{975}$ The question obviously arises why the industry, who initially heavily opposed a harmonised environmental liability regime at European level, supported the shift of environmental liability rules from the Member States to the European level. A plausible explanation might be that the industry, realising that a kind of environmental liability regime was inevitable at either European or at national level, preferred a consistent (if possible lenient) approach throughout the Community to the patchwork of liability regimes, which existed or which were developed in the Member states. ${ }^{976}$ Industry might then have considered that it would be better to try to turn the content of the Directive into their advantage, instead of opposing it. Moreover, industry might also have considered that a minimum approach at European level might prevent Member States to introduce more stringent liability rules than the Directive requires, in order not to loose industry.

Hence, during the adoption process of the ELD, industry fiercely lobbied for the insertion of defences and the absence of compulsory insurance. Professional associations representing industry, trade and the insurance sector, like the European Federation of Insurance Intermediaries (BIPAR), the Comite Européen des Assurances (CEA), the Association of European Chambers of Commerce and Industry (Eurochambres), UAPME, the small business organisation representing the interests at European level of crafts, trades and SME's, and the Union of Industrial and Employer's Confederations of Europe (UNICE) held that only a Directive on environmental liability with a strictly limited scope, confirming permit and state-of-the-art exemptions and excluding all compulsory insurance would be acceptable for them. ${ }^{977}$ Yet, the final text of the ELD shows that important concessions were made to industry groups by inserting broad defences against liability in terms of regulatory compliance and state-of the-art knowledge at the time of the damage. ${ }^{978}$ With respect to the insurance issue, Member States are only encouraged to develop financial security mechanisms instead. The ELD does not foresee compulsory insurance.

Concluding, the industry initially heavily opposed a harmonised environmental liability regime. However, probably because the industry realised that an environmental liability regime was inevitable, either at European or at national level, it might have preferred a consistent, favourable regime throughout

Clarke 2003, 268

Clarke 2003, 256

Slabbinck, Descamps \& Bocken 2006, 6

$<\mathrm{http}: / /$ ec.europa.eu/environment/liability/wrkdoc_comments.pdf>.

CEFIC, EUROPIA, OGP and UNICE, Commission Proposal for a Directive on Environmental Liability, Common proposals from CEFIC, EUROPIA, OGP and UNICE: 'Recognising the difficulties of dealing with damage to the environment in all Member States, and bearing in mind the studies and consideration in general by academics, NGOs and European and national authorities to progress this matter, we recognise that the Commission proposal of 23 January 2002 makes a significant contribution in this regard...'.

976 See CBI response to the Commission Working Paper on Environmental Liability published on 30th July 2001: 'The EU regime should continue to focus on setting broad principles which can be enacted in each Member State, to ensure a consistent approach' at <http://ec.europa.eu/environment/liability/wrkdoc_comments.pdf $>$.

977 Europe Environment, 'Lobby groups call for Directive on limited environmental liability', March 7, 2003.

978 Clarke 2003, 261. 
the European Union, and therefore started to lobby not on the level of regulation, but on the content of the future Directive.

\section{Environmental Interest Groups}

Environmental NGO's from their side believed in all stages of the decision-making procedure that 'a strong EU-wide regime on Environmental Liability is vital to improve the protection of Europe's most vulnerable wildlife and further the process of sustainable development. The adoption of the Directive is a necessary step in the right direction'. ${ }^{979}$ As far as the final text of the ELD was concerned, environmental NGO's however were 'disappointed that the final Directive was not nearly as ambitious as the previous proposals and that it allows Member States to introduce serious derogations from the 'polluter pays' principle, in particular the 'permit' and 'state-of-the-art' provisions, restricted scope and limited requirements for financial security'. ${ }^{980}$

In sum, Member States, industry and environmental NGO's, all for their own reasons, welcomed or at least did not oppose the idea of the Community to shift environmental liability rules from the Member States to the European level. Therefore, the interests of all actors involved in the ELD decision-making process may not be ignored when examining the reasons for a shift of environmental liability rules from the Member States to the European level, and when explaining the provisions of the ELD itself.

Moreover, in hindsight, it appears that the publication of the Working Paper of 2001 was the moment at which the decision was taken to give the European Community the competence to deal with environmental liability rules. Indeed, at that moment, the Commission felt it that it was supported by most of the Member States, industry and environmental NGO's to continue the preparatory work for a Directive and to develop a proposal for a Directive, which then could, by means of the co-decision procedure, become law. Consequently, from that moment on lobbying addressed, to a much greater extent,the content of the future directive than the level at which an environmental liability regime would be issued.

Figure 5 on the next page illustrates the relations between the different actors in the ELD adoption process graphically.

Next, paragraph 2.1.2 will examine the adoption process of the ELD chronologically and will indicate at which stages lobbying took place, by whom, at which level of decision-making and what was lobbied for. 


\section{Who is Who}

\section{in the decision-making process of the ELD and interests at stake}

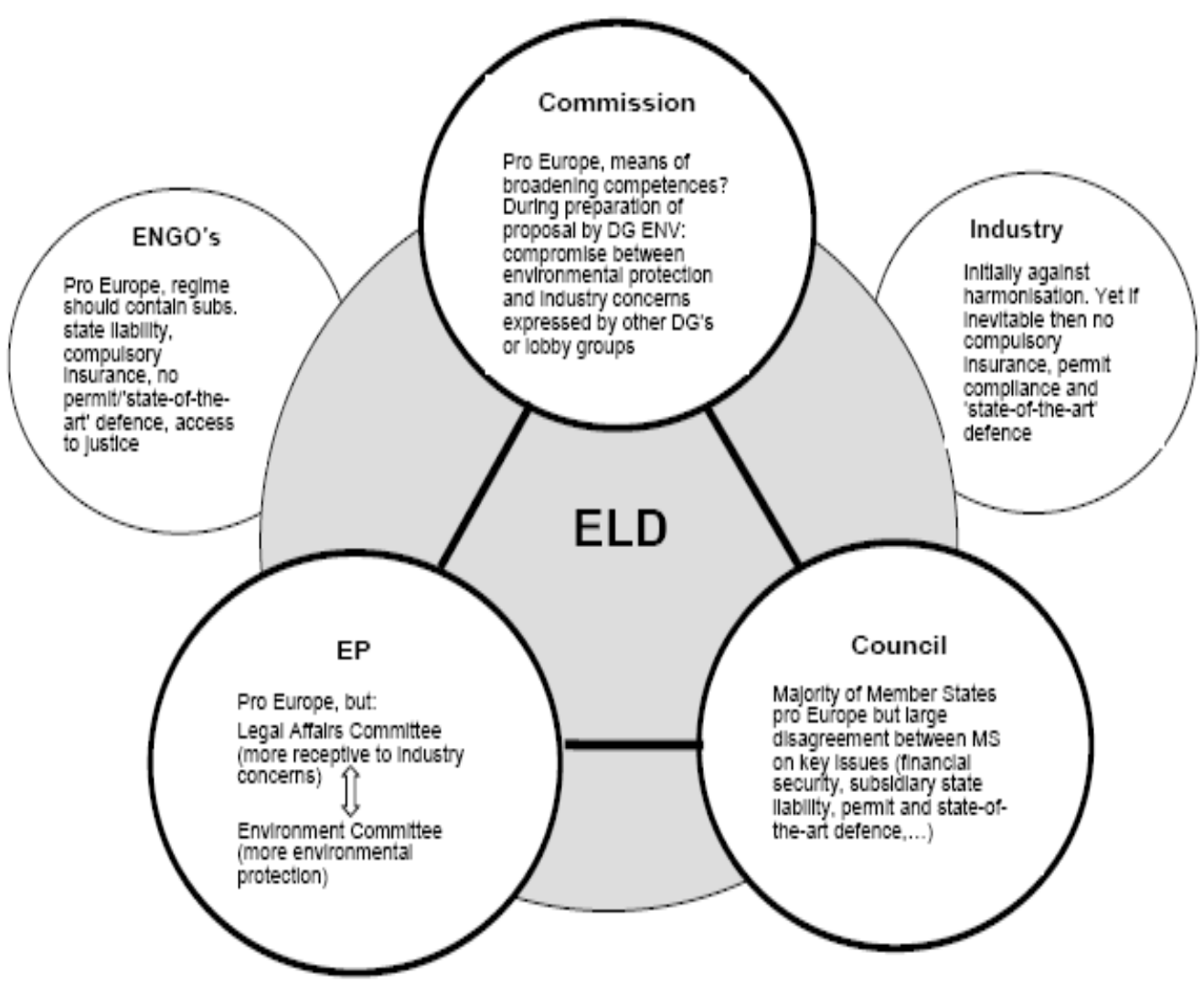

Figure 5 Who is Who in the legislative process behind the ELD

\subsubsection{Insight into the Adoption Process of the ELD}

In order to fully understand how the ELD got to its final form, it is important to know the whole adoption process. Therefore, this paragraph will provide a chronological overview of the adoption process of the ELD. It will be indicated at which stages lobbying took place, by whom, at which governmental level and what was lobbied for. Moreover, the most heavily debated items, by the Member States as well as by industry and environmental NGO's, in the ELD adoption process, were financial security provisions, subsidiary state liability and the possibility to allow for permit defence or state-of-the-art defence. Although there were obviously other points of discussion, this paragraph will indicate how the provisions for these items changed during the adoption process as a consequence of lobbying and negotiation between the Commission, the European Parliament, and the Member States in the Council during the co-decision procedure and will try to explain how the final provisions with respect to these items came into existence.

Figure 6 on the next page shows the adoption process graphically and might provide guidance for the text below. 
Adoption process of the ELD

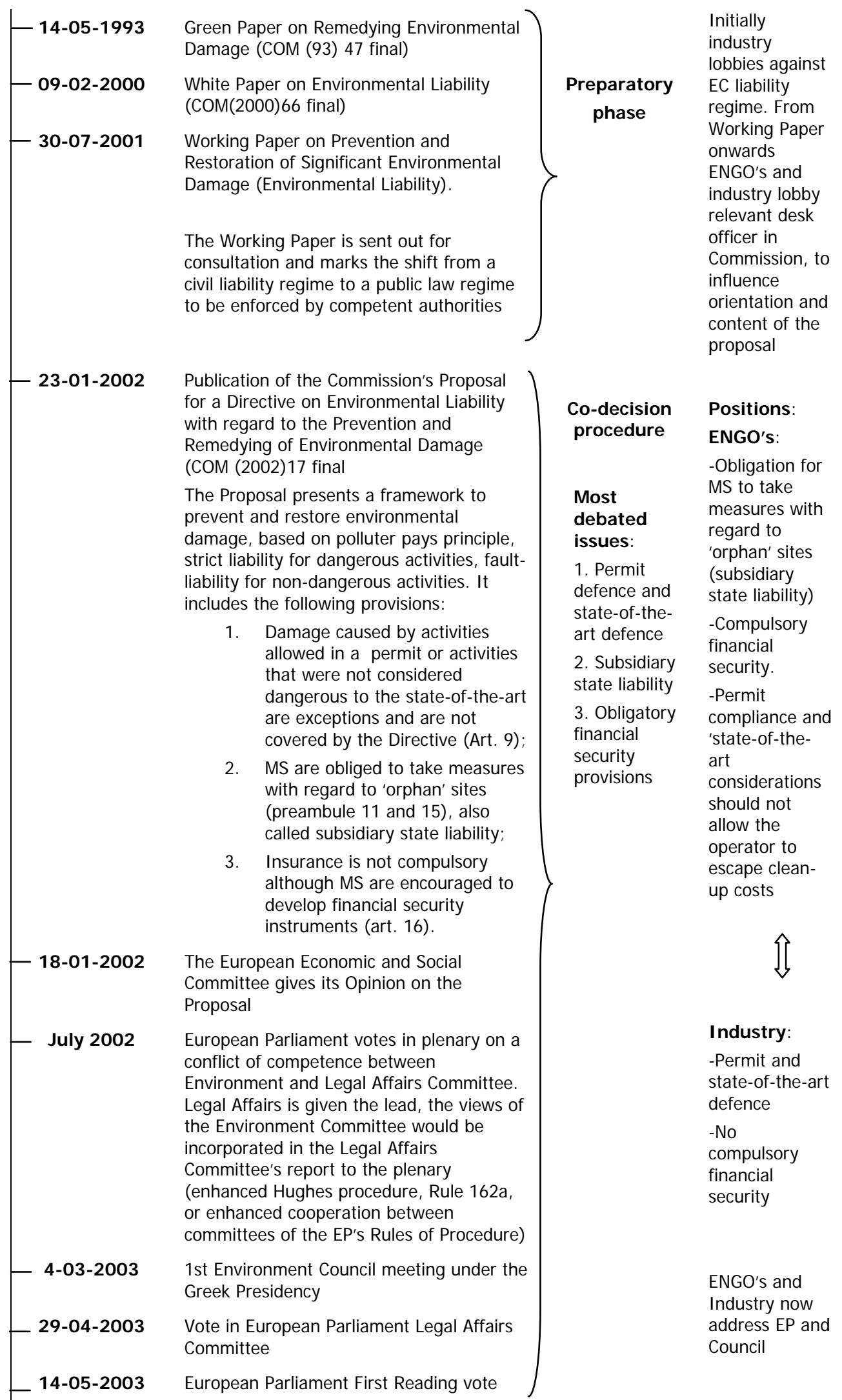


The EP adopts 48 amendments to the proposal, including:

1. Conversion of regulatory compliance and state-of-the-art exemptions into mitigating factors (Art. 11 1st reading)

2. Preservation of obligation for MS to take measures with regard to 'orphan' sites (subsidiary state liability) (preambule 13 and 18 1st reading);

3. Compulsory insurance for IPPC and Annex I activities, phased in over time (art $171^{\text {st }}$ reading).

13-06-2003 Political Agreement Environment Council under Greek Presidency

The Council introduces 26 of 48

amendments of the EP in full or in part and amends the following provisions:

1. The permit compliance and state-of-the-art defence as mitigating factors, exonerating the operator from liability, become an option for MS Compliance conditions are tightened

2. No subsidiary State liability if the operator is insolvent or unidentified $=$ a step too far for the MS;

3. No obligatory insurance. MS are encouraged to develop financial security provisions and the Commission is requested to report on the directive's effectiveness and may on that base make proposals for mandatory financial security.

18-09-2003 Formal adoption of the Council Common Position

19-09-2003 The Commission agrees with the modifications and supports the Common Position

17-12-2003 Second Reading vote in the European Parliament

The Parliament adopts 4 amendments to the Council Common Position. The issues at stake concern:

- Creation of harmonised compulsory financial security for water and soil damage;

- Elimination of the operator's right to limit his liability in accordance with internat. Conventions;

- The Commission report on the application of the provisions in relation to the exclusion of sea and nuclear pollution from the scope of the directive;

- Measures to be taken by the competent authority in the case of remedial action.

- 21-01-2004

The Council states that it is unable to approve all Parliament amendments
EP: the

rapporteur of

the lead

Committee

exerts

important

influence on

the

amendments

put forward by

the EP +

contact of all

MEP's in order

to influence

vote in plenary

Council: More

difficult,

contact with

Council

working groups

is possible but

sometimes

better to

contact

national

officials in the

MS,

responsible for environment 


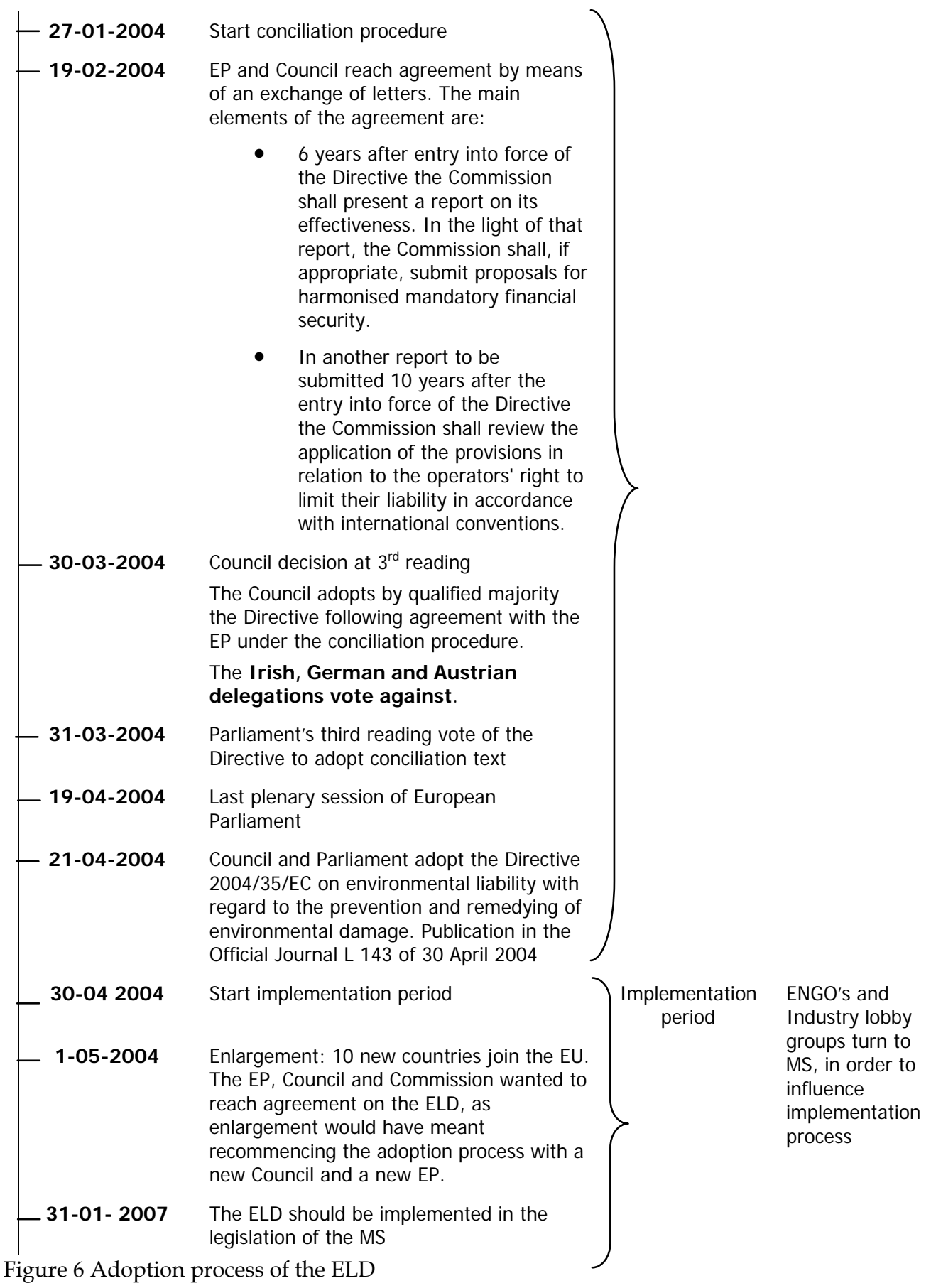

As Figure 6 shows, it is possible to make a distinction between a preparatory phase towards a European environmental liability regime, roughly dating from 1993, with the publication of the Green Paper on Remedying Environmental Damage until the publication of the Working Paper on Prevention and Restoration of Significant Environmental Damage of 2001 and the actual adoption process of the ELD, starting from preparation of the Proposal for a Directive by the Commission, over the co-decision procedure until the adoption by the Council and the European Parliament of the Directive.

The preparatory phase could be seen as a period in which the discussion on the level of issuing environmental liability rules should be taken, still was open. Lobbying therefore addressed the level of regulation. Moreover, it took place at European level. Indeed, at that time, industry still heavily opposed a harmonised environmental liability regime at European level. Hence, industry groups as for example UNICE (Union of Industrial and Employers' Confederations of Europe) tried to oppose and if possible to halt the whole EC liability initiative and attempted to convince the Commission officials that a strict liability regime, as proposed in the White Paper would seriously undermine the competitiveness of 
European business. ${ }^{981}$ Maybe industry felt that by lobbying at European level against an environmental liability regime for competitiveness reasons, they might indirectly prevent Member States from adopting too stringent liability rules in order not to loose industry. Environmental NGO's on the other hand, lobbied at the Commission for harmonisation of environmental liability rules.

Yet, as explained in the previous paragraph, from the moment that the Working Paper was received moderately positive by the Member States and industry, in principle the decision, at which level environmental liability regulation should be issued, had been taken. The Commission felt that the Member States and the industry, who changed its position, each for their own reasons, did not fundamentally object to a European environmental liability regime and that there might be a good chance to get a proposal through the co-decision procedure. Hence, the Commission continued to develop a draft proposal for a European Environmental Liability Directive and unless the Member States would not be able to reach agreement in the end, a directive would be issued at the European level. For the industry and the environmental NGO's it therefore became most important to influence the content and provisions of the future Directive instead of the level of regulation.

Lobbying to influence the content of a future Directive is possible at different stages of the adoption process and at different governmental levels, and hence might address the three different European lawmaking institutions: the Commission, the European Parliament and the Council of Ministers but also the Member States.

The preparation of the proposal by the Commission is the first moment that offers lobby groups the opportunity to influence the content of the directive. Only the Commission can make proposals and start off the law making procedure, which is called the Commission's right of initiatives. ${ }^{982}$ The task of drawing up the proposal and guiding it through the legislative procedure is given to a desk officer within the responsible Directorate-General of the Commission. In order to draft the proposal, the desk officer will carry out extensive consultations with interested parties. Therefore, the desk officer is the most important contact in this stage to influence the orientation and content of the proposal. ${ }^{983}$ Lobbying with the aim to influence the content of future legislation is an activity that is often regarded with suspicion at national level. In contrast, such input into the European Community's law-making procedures is viewed as a necessary element in the legislative process and is generally welcomed by the Community institutions. Indeed, since the Commission has limited resources, it is keen on obtaining additional information from outside its own services. Therefore, anyone with an interest in the subject can provide (correct) information and submits his views on the proposed law. Lobbying in this sense is seen as a means of gathering information. ${ }^{984}$ Hence, in the particular case of the ELD, the Commission, and in this respect DG Environment, ${ }^{985}$ was contacted by diverse industry lobby groups and environmental NGO's to express their views and concern on the matter but also other DG's (as DG Industry) pressed hard for the concessions sought be industry in this stage of the ELD adoption process. 986

Although neither the Parliament nor Council have any formal input at this stage, the Commission desk officer will generally, in this early law-making procedure, have informal contacts with people from these institutions in order to get their opinion. ${ }^{987}$ Lobbying efforts at this stage at the Parliament is focused mainly on those Members of Parliament (MEP's) who are supposed to obtain particular influence in a later stage, as for example the likely rapporteur of the lead Committee or MEP's in the lead Committee who are most interested in the proposal. The function of a rapporteur and the lead committee will be explained below. The Commission desk officer will also have contacts with Council officials and technical advisers. Although the Council is not formally involved at this early stage, there will often be extensive informal consultations long before the proposal is drawn up. The Commission official needs to know the general feeling of each of the Member States, since there is little point in proceeding with a proposal if it has absolutely no chance of being finally adopted by the Council. In this respect, desk officers of the Member States' Permanent Representations may have close contacts with the Commission and may influence proposals. It might therefore also be interesting for lobby groups to contact these people at an early stage.

Turning to the adoption process of the ELD, lobbying with the aim to influence the content of the Directive was fierce at the time of drafting the proposal. The two lobby groups that opposed each other were the industry lobby groups and the environmental NGO's. Industry argued that both permit compliance and state-of-the-art defences should be inserted in the text and that there should be no

Clarke 2003, 257.

EC Treaty, Article 251

Gillies 1998, 179.

Ibidem.

At that stage, the desk officer for the Environmental liability Directive was Mr. Charles Pirotte.

Clarke 2003, 261.

Gillies 1998, 179 
compulsory insurance. ${ }^{988}$ Environmental NGO's on the contrary, pleaded that permit compliance and stateof-the-art considerations should not allow the operator to escape clean-up costs; that there should be a kind of compulsory financial security and that there would be an obligation for the Member States to take measures with regard to orphan sites, also called subsidiary state liability. ${ }^{989}$

The draft proposal of the ELD shows the influence of these lobbying activities. In particular, the Commission proposal provided that 'damage caused by activities allowed in a permit or activities that were not considered dangerous to the state-of-the-art are exceptions and are not covered by the Directive'. 990 These exceptions fundamentally weakened the liability regime and became crucial elements in the codecision phase that followed. Actually, permit and state-of-the-art compliance were deliberately presented not as defences but as exclusions because the Commission proposal contained a duty on the authorities to act where there was no liable party to do so, in general called subsidiary state liability. ${ }^{991}$ By excluding permit and state-of-the-art compliance from the whole regime the Commission intended to meet Member States' concern that the authorities would inherit the liability in cases where operators could show permit compliance or state-of-the-art. ${ }^{92}$ The Commission also provided for a 'safety net' of sorts in preamble 15, stating that Member States should ensure that the necessary preventive or restorative measures are taken when the polluter pays principle could not be implemented. In such cases, Member States should adopt whatever provisions they deem fit in conformity with their legal systems provided that they ensure effectively that the necessary or restorative measures are financed. ${ }^{993}$ By this measure the Commission tried to ensure that restoration would take place. Insurance was not compulsory although Member States were encouraged to develop financial security instruments. ${ }^{994}$

The full draft of the proposal for the ELD was submitted to the Cabinets of the Commissioners and then to the College of Commissioners for approval. Once a text has been approved by the College of Commissioners, the text becomes an official Commission proposal for a directive or regulation and the proposal will be published in all working languages. ${ }^{95}$ The proposal will then be transferred to the European Parliament and the Council of Ministers according to the co-decision procedure. ${ }^{996}$

The first reading stage of the ELD co-decision procedure experienced a difficult start, at least as far as the European Parliament was concerned. Indeed, whereas the Council under the Spanish presidency, favouring European action with respect to environmental liability, started with a large number of working parting meetings during the months January-June 2002, the parliament saw itself confronted with a conflict of competence between two Parliament Committees. Since the Council cannot complete its first reading until it has received the resolution of the Parliament, this dispute slowed down the adoption process of the ELD. ${ }^{997}$

Indeed, when a proposal has been received by the EP, it will be assigned to a 'lead' Committee, which will appoint a rapporteur, a single MEP who will prepare a draft report on the proposal. The report proposing amendments to the proposal will be voted on by the full European Parliament during its plenary session. An environmental proposal would normally be assigned to the Committee on Environment, Public Health and Food Safety. The rapporteur and his staff within his political group may be important contacts for anyone seeking to lobby. Indeed, the rapporteur exerts an important influence on the amendments put forward by the Committee and the EP. In the particular case of the ELD, the Parliament saw itself in a

\footnotetext{
988 For comments of industry lobby groups see: <http://ec.europa.eu/environment/liability/ wrkdoc_comments.pdf>.

989 Birdlife International, EEB, Friends of the Earth, Greenpeace and WWF, Environmental liability Directive, Second Reading Briefing for MEP's.

990 European Commission, Proposal for a Directive of the European Parliament and of the Council on environmental liability with regard to the prevention and remedying of environmental damage, COM (2002) 17 final, 21 February 2002 , Article 9.

991 European Commission, Proposal for a Directive of the European Parliament and of the Council on environmental liability with regard to the prevention and remedying of environmental damage, COM (2002) 17 final, 21 February 2002, Preamble 11.

$992 \quad$ Clarke 2003, 261.

993 European Commission, Proposal for a Directive of the European Parliament and of the Council on environmental liability with regard to the prevention and remedying of environmental damage, COM (2002) 17 final, 21 February 2002, Preamble 15.

994 European Commission, Proposal for a Directive of the European Parliament and of the Council on environmental liability with regard to the prevention and remedying of environmental damage, COM (2002) 17 final, 21 February 2002, Article 16.

995 Gillies 1998, 180.

996 The codecision procedure (Article 251 of the EC Treaty) was introduced by the Treaty of Maastricht. It gives the European Parliament the power to adopt instruments jointly with the Council of the European Union and the procedure comprises one, two or three readings. It increases contacts between the Parliament and the Council, the co-legislators, and the European Commission. See www. europa.eu/scadplus/glossary/codecision_procedure. Clarke 2003, 262
} 
conflict between the competence of the Environment Committee, which would arguably be more inclined towards environmental concerns, and the Legal Affairs Committee, which would be more receptive to industry concerns. The Legal Affairs Committee, which had taken the lead on consideration of the White Paper, stated that it was within the Committee's competences to deal with issues of legal liability. The Environment Committee believed that it should lead on the Directive, as the Directive was an entirely new instrument to prevent and restore environmental damage, based on Article 175 of the Treaty. The question of Committee competence was referred to the Parliament as a whole in July 2002. For the first time in the Parliament's history, Members of the European Parliament voted on an issue of Committee competence, and, by a very slim margin, they referred the dossier to the Legal Affairs Committee. ${ }^{998}$ It was agreed however, that the views of the Environment Committee would be incorporated in the Legal Affairs Committee's report to the plenary. ${ }^{999}$

The Legal Affairs Committee nominated the MEP Mr. Toine Manders (The Netherlands, European Liberal Democrat Reformist Party) as their rapporteur. MEP Mr. Mihail Papayannakis (Greece, European United Left/Nordic Green Left) was spokesman for the Environment Committee. Overall, the legal Affairs Committee proposed a much narrower regime than the Commission proposal, whereas the Environment Committee widened the Commission proposal, by adopting amendments to delete the 'compliance with permit' and 'state of the art' exemptions, and by introducing requirements for financial security and extending the definition of 'biodiversity'. 1000

For the lobby groups it was important at this stage of the adoption process not only to contact the rapporteur or his staff of the lead Committee, but also to provide all MEP's with information on the issue to try to persuade them to vote in a certain way. Indeed, although MEP's will often follow the recommendations of the Committee, this is not always the case. Indeed, the lobbying activity in advance of the plenary vote was intense from industry, environmental NGOs, local authorities, Member States and farmers' associations. The main stakes remained the same however as during the preparation of the Commission proposal: the scope of the Directive, compulsory financial security, subsidiary state liability and permit compliance and state-of-the-art defences. ${ }^{1001}$

The Parliament's first reading vote finally came to an end on 14 May 2003. In a plenary vote, the Parliament passed a resolution holding somehow the middle between the two Committees views. ${ }^{1002}$

The resolution converted the regulatory compliance and state-of-the-art exemptions into mitigating factors that the competent authority and the reviewing court should take into account when deciding the level of responsibility and the amount of financial compensation in respect of liability to be recovered from the operator. ${ }^{1003}$ The obligation for Member States to take measures with regard to 'orphan' sites (subsidiary state liability) was retained as well as the 'safety net' provided for in the Commission Proposal. ${ }^{1004}$ With respect to financial security, the Parliament strengthened the Commission's proposal by providing that compulsory insurance for IPPC and Annex I activities, should be phased in over time. ${ }^{1005}$

In the meantime, after the first ardent work by the Spanish Presidency, the momentum in the Council subsided when Denmark took over the presidency (July-December 2002). Indeed, the progress on the proposed Directive was less significant under the Danish Presidency, as other issues, such as the World Summit on Sustainable Development in Johannesburg, were given priority. Moreover, there was no drive

998 Birdlife International and WWF, The European Directive on Environmental Liability - 'Polluter Pays': from principle to practice? An Environmental NGO commentary on the Environmental Liability Directive: its adoption at EU level and what it means for the future, July 2004, 14.

999 This procedure is known as the enhanced Hughes procedure, or enhanced cooperation between Committees, Rule 162a of the EP's rules of Procedure.

1000 Birdlife International and WWF, The European Directive on Environmental Liability - 'Polluter Pays': from principle to practice? An Environmental NGO commentary on the Environmental Liability Directive: its adoption at EU level and what it means for the future, July 2004, 15 and Clarke 2003, 263.

1001 Birdlife International and WWF, The European Directive on Environmental Liability - 'Polluter Pays': from principle to practice? An Environmental NGO commentary on the Environmental Liability Directive: its adoption at EU level and what it means for the future, July 2004. For comments of ENGO's and industry lobby groups see: <http://ec.europa.eu/ environment/liability/wrkdoc_comments.pdf $>$.

1002 Clarke 2003, 263.

1003 European Parliament legislative resolution on the Proposal for a European Parliament and Council directive on environmental liability with regard to the prevention and remedying of environmental damage (COM (2002) 17 - C50088/2002 - 2002/0021(COD)), Article 11.

1004 European Parliament legislative resolution on the Proposal for a European Parliament and Council directive on environmental liability with regard to the prevention and remedying of environmental damage (COM (2002) 17 - C50088/2002 - 2002/0021(COD)), recital 13 and 18.

1005 European Parliament legislative resolution on the Proposal for a European Parliament and Council directive on environmental liability with regard to the prevention and remedying of environmental damage (COM (2002) 17 - C50088/2002 - 2002/0021(COD)), Article 17. 
to finish a Common Position by the end of the year. Momentum was regained in January 2003 under the leadership of the Greek Presidency. The Greek government hoped that the Council would reach a political agreement by the end of its Presidency in June 2003. This timing was important to allow enough time for a Second Reading in the European Parliament and to complete a possible conciliation process between the Parliament and the Council before the enlargement of the Union with 10 eastern European Countries on 1st May 2004, otherwise the whole adoption process had to be redone with a new Parliament and a new Council. ${ }^{1006}$

As far as lobbying is concerned, lobbying at the Council is much more difficult and can be extremely expensive and time-consuming. Moreover, the positions of the permanent representatives in the COREPER (which precedes the meeting of the Council of Ministers) are normally established by their governments. Therefore, for a lobby group it might be more effective to contact national officials in the Member States, responsible for environment than to contact the Council directly. Hence, in this stage it might therefore have been fruitful for the lobby groups also to lobby at the Member State level. ${ }^{1007}$

Whether or not due to the lobbying of industry and ENGO's, negotiations in the Council were difficult. There still were large disagreements between the Member States on many of the key issues despite frequent working group meetings. The Greek Presidency tried hard to reach compromises with regards to the permit compliance and 'state of the art' exemptions, as well as the financial security system. Similar to the Parliament amendments, the Greek Presidency proposed that permit compliance and the state-of-theart defence should be treated as 'mitigating factors' to be taken into account by national authorities when allocating clean-up costs. However, a number of Member States were unwilling to accept a compromise along these lines, and even made the exemptions `red-line' issues for the negotiations. In particular, France, UK, Austria, and Portugal were unwilling to accept the compromise solution. Instead, they wished to stick to the permit and state-of-the-art exceptions based on the Commission's original proposal. ${ }^{1008}$

With respect to the financial security system, the Greek Presidency proposed a phased-in system, recognising the arguments by the insurance sector and some Member States that the market would not be ready to provide financial security products by the date of entry into force of the Directive. ${ }^{1009}$

With the Parliament resolution passed on to the Council only on the 14th May 2003, the Greek Presidency had 6 weeks left to persuade Member States to agree a Common Position, before Italy would take over the Presidency of the Council in July 2003. Against all odds, the Greek government succeeded in reaching a political agreement on 13th June 2003. ${ }^{1010}$ On 18th September 2003, the Council, under Italian Presidency, formally adopted a Common Position on the Directive. ${ }^{1011}$

The Common Position does not entirely follow the Greek compromise proposal. Moreover, the Common Position reflects how the disagreement between the diverse Member States on various topics was solved: thorny issues were passed on to the Member States. Indeed, using the permit compliance and stateof-the-art defence as mitigating factors, exonerating the operator from liability, became an option for the Member States. Nevertheless, compliance conditions were tightened. ${ }^{1012}$ The Common Position also deleted the Commission Proposal's 'safety net' and the obligation on the Member States to remedy the damage itself in case the operator is insolvent or unidentified. Subsidiary state liability definitively was a step too far for the Member States. It was therefore stipulated that the Member States may decide to take preventive or remedial measures themselves in case the operator is insolvent or unidentified. ${ }^{1013}$ The decision to clean up therefore lies with the Member State.

With respect to financial security, there are some important changes in the Common Proposal, when compared to the Commission's proposal. Conform to the Commission's proposal, the Common Position's

1006 Birdlife International and WWF, The European Directive on Environmental Liability - 'Polluter Pays': from principle to practice? An Environmental NGO commentary on the Environmental Liability Directive: its adoption at EU level and what it means for the future, July 2004, 15 and Clarke 2003, 262.

1007 Gillies 1998, 181-182.

1008 Birdlife International, EEB, Friends of the Earth, Greenpeace and WWF, Joint press release in view of Environment Council meeting, 4 March 2003, letter to the Permanent representation and letter to national governments.

1009 Bocken 2006, 21 and Birdlife International and WWF, The European Directive on Environmental Liability - 'Polluter Pays': from principle to practice? An Environmental NGO commentary on the Environmental Liability Directive: its adoption at EU level and what it means for the future, July 2004, 18.

1010 Clarke 2003, 263.

1011 <http://europa.eu.int/rapid> press release of 18 September 2003, PRES/03/265.

1012 Common Position (EC) No 58/2003, adopted by the Council on 18 September 2003 with a view to the adoption of a Directive 2003/.../EC of the European Parliament and of the Council on environmental liability with regard to the prevention and remedying of environmental damage, article $8, \S 3$ and $\S 4$.

1013 Common Position (EC) No 58/2003, adopted by the Council on 18 September 2003 with a view to the adoption of a Directive 2003/.../EC of the European Parliament and of the Council on environmental liability with regard to the prevention and remedying of environmental damage, Article 5 §3d and Article 6 §2e. 
Article 14 did not provide for compulsory insurance either. This provision in the Common Position was without doubt influenced by the views of industry and insurers and by some of the Member States who did not want to impose new financial burdens on their industry. Yet, there are differences between the Common Position and the Commission's proposal. Article 14 of the Common Position holds that 'Member States shall take measures to encourage the development of financial security instruments. The wording 'use by operators' of the corresponding Article 16 of the Commission's proposal had been dropped. The Common Position seems thus more restrictive. Moreover, Article $14 \S 2$ has been added: the Commission is requested to report, eight years after the entry into force of the Directive, on the Directive's effectiveness and may on that base make proposals for mandatory financial security. Nevertheless, as already explained in paragraph 5 of chapter 5, overall, commentators have generally explained the Common Position and the Directive as excluding any compulsory financial guarantees. Yet, Bocken rejects this interpretation. ${ }^{1014} \mathrm{He}$ points to the fact that Article $8 \S 2$ of the Common Position provides that the competent authority shall recover inter alia, via security over property or other appropriate guarantees from the who has caused the damage ... the costs it has incurred' ${ }^{1015}$

Bocken therefore interprets the Common Position as follows, Article 8 § aims to protect the authorities against the insolvency of the operator by obligatory requiring Member States to set up a system of security interest that effectively enables the competent authorities to recover the costs of ex officio measures from the operator. This obligation to foresee financial guarantees to prevent the authorities against insolvency of the operators is, according to Bocken, often overlooked, although Member States have the obligation to ensure that the objective of the Directive is reached. Article $14 \S 1$ on the other hand, requires Member States to encourage the development of financial guarantees in order to allow the operators to protect themselves against liability and to satisfy their obligations under Article 8 \&2. In contrast to Article 8 §, the latter provision is not compulsory. Article 14 §2 however opens the possibility for a Commission Proposal with respect to a harmonised system of mandatory financial security if the situation does not prove satisfactorily in eight years. ${ }^{1016}$

Besides the three most debated items, other items were also passed on to the Member States. For example, the cost allocation in case of multiple party causation is left entirely within the competence of the Member States. ${ }^{1017}$ Moreover, Member States are allowed to introduce or maintain more stringent national measures. Member States may thus apply the Directive's liability system for example to nuclear damage, oil pollution damage, diffuse pollution and to provide for traditional damage and historical damage (retroactivity) to be covered. ${ }^{1018}$ Finally, the calculation method for the costs is not precisely laid down, and the administrations have a large discretion in the assessments of costs. Hence, the text offered a significant discretion to the Member States, which probably made it possible to agree on a Common Position.

In accordance with the co-decision procedure, the Council Common Position on the ELD, was sent back to the Parliament and the Commission for a second reading. The Commission agreed with the modifications and supported the Common Position. ${ }^{1019}$

With respect to the Parliament, the Common Position will go back to the same lead committee and the same rapporteur and again the rapporteur is responsible for recommending to the committee and the Parliament as a whole whether to accept, reject or amend the Common Position. Therefore, the rapporteur and his staff will remain important contacts for lobby groups in the second stage of the co-decision procedure. ${ }^{1020}$

The European Parliament adopted four amendments to the Common Position. In particular, the Parliament amended Article 14§2. It read that 'five years after entry into force of the Directive the

1014 Bocken 2006, 13-32.

1015 The Italics show what the Common Position added to Article $7 \S 1$ of the Commission Proposal.

1016 Bocken 2006, 13-32.

1017 Common Position (EC) No 58/2003, adopted by the Council on 18 September 2003 with a view to the adoption of a Directive 2003/.../EC of the European Parliament and of the Council on environmental liability with regard to the prevention and remedying of environmental damage, article 9.

1018 Common Position (EC) No 58/2003, adopted by the Council on 18 September 2003 with a view to the adoption of a Directive 2003/.../EC of the European Parliament and of the Council on environmental liability with regard to the prevention and remedying of environmental damage, article 16.

1019 Communication from the Commission to the European Parliament pursuant to the second subparagraph of Article 251 (2) of the EC Treaty concerning the Common Position of the Council on the adoption of a Directive of the European Parliament and the Council on environmental liability with regard to the prevention and remedying of environmental damage. The Commission nevertheless holds that would have preferred stricter conditions regarding subsidiary remedial action by Member States in case of 'orphan damage'. The Commission proposal required Member States to find alternative sources of financing, whereas the Common Position leaves full discretion to the Member States to decide to act or not (p. 16). The obligation in Article $8 \S 2$ indeed will not solve the problem. Yet, the Common Position was accepted to get a Directive finally adopted (Charles Pirotte, EU Commission, DG ENV). 
Commission shall report on the measures adopted by the Member States pursuant Paragraph 1. If no appropriate instrument for financial security have been developed, the Commission shall submit proposals for a harmonised compulsory financial guarantee for water and soil damage, based on a gradual approach' ${ }^{1021}$ In fact, the amendment version seemed a weaker version of the Greek compromise proposal, mentioned above, for a regime of financial security gradually phased in. ${ }^{1022}$

On 21 January 2004, the Council (under Irish Presidency) states that it is unable to approve the Parliament's amendments with respect to financial security and on 27 January, the conciliation procedure, aimed to reach agreement on a text acceptable to both sides, was started. On 19 February 2002, the Parliament and the Council reached agreement by exchange of letters. With respect to the financial security issue, the agreement held that 6 years after entry into force of the Directive the Commission shall present a report on its effectiveness. In the light of that report, the Commission shall, if appropriate, submit proposals for harmonised mandatory financial security. ${ }^{1023}$

It was also agreed in the conciliation procedure that in another report to be submitted ten years after the entry into force of the Directive, the Commission shall review the application of the provisions in relation to the operators' right to limit their liability in accordance with international conventions. Moreover, the Parliament sought to ensure that the competent authority should take the necessary remedial measures by itself, only as a means of last resort. This suggestion has been accepted by the Council. ${ }^{1024}$

On 30 March 2004, the Council adopted by qualified majority the Directive, following the agreement with the European Parliament under the conciliation procedure. The Irish, German and Austrian delegations voted against. On 31 March 2004, the Parliament held its third reading vote to adopt the conciliation text. ${ }^{1025}$

On 21 April 2004, the Council and the European Parliament finally formally adopted Directive 2004/35/EC on environmental liability with regard to the prevention and remediation of environmental damage. The Directive was published in the Official Journal L143 of 30 April 2004. ${ }^{1026}$

Yet, with respect to lobbying, the publication of the Directive in the official Journal, does not mean the end of the work. Indeed, now the ELD has been adopted, the best strategy for industry and environmental lobby groups is to turn their lobbying efforts to the Member States, in order to influence the implementation process in order to make sure that the Directive is implemented in the way they prefer. ${ }^{1027}$

The above paragraph tried to unveil the adoption process of the ELD and tried to clarify why the decision-making level of environmental liability rules was shifted from the Member States to the European level and how certain provisions came into existence. Indeed, the existence and content of the ELD clearly shows the influence of lobbying activities, both by industry and environmental NGO's as the influence of the Member States.

\subsection{Private Interest Analysis of the Adoption Process of the ELD}

It now merits examining whether the lobbying activities, observed in the adoption process of the ELD, and the result of this lobbying, corresponds with the predictions of the private interest theory, as discussed in the theoretical part (paragraph 2.1 of chapter 3). In particular, it can now be examined, on the one hand, whether the inefficient shift of competences to the European level with respect to environmental liability rules resulting in 'too much Europe', as concluded in paragraph 1, has been caused by interest group lobbying and, on the other hand, whether the inefficiencies in the Directive itself can be explained by interest group lobbying. Next, it will be examined whether lobbying behaviour by interest groups would cause more distortions at the national level than at the central level so that this would justify Community action in the field of environmental liability, as studied in the theoretical part (paragraph 2.2 of chapter 3).

1021 European Parliament legislative resolution on the Council Common Position for adopting a European Parliament and Council Directive on environmental liability with regard to the prevention and remedying of environmental damage (10933/5/2003 -C5-0445/2003-2002/0021(COD)), P5_TA-PROV(2003)0575, European Parliament website.

1022 Bocken 2006, 26.

1023 <http://www.europarl.eu.int/code.newsletter/2004_03_en.htm>.

1024 <http://www.europarl.eu.int/code.newsletter/2004_03_en.htm>.

1025 Fogleman 2004, 103.

1026 Directive 2004/35/CE of the European Parliament and of the Council of 21 April 2004 on Environmental Liability with Regard to the Prevention and Remedying of Environmental Damage, OJ L 143/56 of 30.04.2004.

1027 See for example Birdlife International and WWF, The European Directive on Environmental Liability - 'Polluter Pays': from principle to practice? An Environmental NGO commentary on the Environmental Liability Directive: its adoption at EU level and what it means for the future, July 2004, 28 and Cefic, Europia and OGP, The Environmental Liability Directive (Dir 2004/35/CE), Recommendations for implementation, May 2004. 


\subsubsection{Becker versus Buchanan}

In paragraph 2.1 of chapter 3 , the theories that explicitly examine rent seeking behaviour in the law making process, notably the Capture Theory, the Economic Theory of Regulation and Public Choice Theory were examined. Does the existence of the ELD and its content correspond with the predictions of (one of) these theories?

Within the Economic Theory of Regulation, Becker argued that politicians carry out the political allocations resulting from the competition among various pressure groups. The political equilibrium then depends on the capability of each pressure group in producing pressure on the government. ${ }^{1028}$ On the other hand, Buchanan, one of the most prominent public choice scholars, indicated that the government should not be understood as a benevolent despot that tries to maximise public welfare, but as an agent that seeks to increase its own spending and power, which became known as the Leviathan hypothesis of government. Decentralisation would prevent that a government would behave as a Leviathan. ${ }^{1029}$ Also within the public choice theory, Mancur Olson showed that lobby groups would be most effective if the groups are small, single-oriented and well-organised. ${ }^{1030}$ According to his theory, interest groups, like industry, which constitute relatively small and homogeneous groups, are able to organise and represent their interests more effectively than larger and more diffuse groups, like consumers or environmental lobby groups and hence inefficient regulations might emerge as a result of incomplete representation of interest groups in the political decision-making process. ${ }^{1031}$

The question now arises whether the lobbying behaviour, observed in the adoption process of the ELD, and the result of this lobbying resembles a Becker-like situation whereby the different interest groups compete with each other to obtain political influence, and that as a consequence of this competition a kind of equilibrium is reached, or whether the existence and content of the ELD can be better explained by the theory that the Commission, behaving as a Buchanan-like Leviathan, was more receptive for lobbying of single-oriented and well-organised industry lobby groups? ${ }^{1032}$

In order to answer this question, it merits distinguishing between the lobbying for the level at which environmental liability rules would be issued and the lobbying with respect to the content of the Directive.

With respect to lobbying for the level of regulation, it was indicated in the previous paragraph that the Member States, industry and environmental NGO's, all for their own reasons, welcomed or at least did not oppose the idea of the Community to shift environmental liability rules from the Member States to the European level. Indeed, environmental NGO's supported the shift of environmental liability rules from the Member States to the European level, as in their view, a strong EU-wide regime on Environmental Liability would be vital to improve the protection of Europe's environment and the adoption of the Directive would be a first step in the right direction. ${ }^{1033}$ Member States decided to support a European environmental liability regime, although their reasons for this support differed and although large disagreement existed between them on key issues as financial security, subsidiary state liability and permit and state-of-the-art defences. Industry originally opposed any European initiative with respect to environmental liability, but realised that an environmental liability regime was inevitable, either at European or at national level, and therefore preferred a consistent, favourable regime throughout the European Union instead of a patchwork of different (more stringent) national liability regimes. One could argue that the Commission merely took into account the preferences of the Member States, environmental NGO's and industry, and therefore issued an environmental liability regime at European level. From this point of view, the lobbying behaviour with respect to the level of environmental liability rules, would show resemblances with Becker's theory of competition. On the other hand, it certainly cannot be ignored that the Commission might have welcomed a European environmental liability regime for other reasons than only public welfare and protection of the environment. Indeed, the Commission might have seen the ELD as a means for enlarging its own competences in fields for which it did not have any direct competence yet, as for example soil protection policies. This would correspond to Buchanan's theory on government behaviour. Hence, the lobbying behaviour with respect to the content of the regulation shows some elements of both the Becker and the Buchanan theory on lobbying behaviour. Moreover, it seems that all actors involved in the adoption process of the ELD, each for their own reasons, preferred an environmental liability regime at European level, and

\footnotetext{
1028 Becker 1983, 371-400.

1029 Brennan \& Buchanan 1977, 255-273.

1030 Olson 1965, Ch. 1-3.

1031 Ogus 1994, 71 and Oates \& Portney 2001, 11

1032 Olson 1965, Ch. 1-3.

1033 Birdlife International, Greenpeace, WWF, Friends of the Earth, EEB (joint declaration), The Directive on Environmental Liability, The European Parliament's Third Reading Vote, 31 March 2004.
} 
therefore competences were shifted from the Member State level to the European level, contrary to what economic theory would suggest.

In sum, the answer on the question whether the inefficient shift of competences to the European level with respect to environmental liability rules has been caused by interest group lobbying is probably affirmative.

With respect to the content of the Directive itself, it was shown in the analysis of the adoption process of the ELD that the industry, realising that it would be more advantageous to have a consistent, moderate regime at European level instead of various (stringent) national liability regimes, considered that it would be better to try to turn the content of the Directive into their advantage, instead of opposing it. Consequently, the industry, supported by some of the Member States who did not want to put to much pressure on their industries, fiercely lobbied for the insertion of permit compliance and state-of-the-art defences and the absence of mandatory insurance. Contrary to what would be efficient according to economic theory (as discussed in Chapter 5), the industry succeeded in obtaining its claims. Hence, although the other main actors in the ELD adoption process, all for their own reasons, preferred an environmental liability regime at European level, it seems that with respect to the content of the European regime, industry lobbying was most successful. Indeed, as will be discussed in paragraph 2.2.2.1, the final text of the ELD shows the strength of industry lobbying relative to environmental NGO's lobbying. Hence, the lobbying behaviour of the main actors in the ELD adoption process with respect to the content of the Directive might fit better into Olson's theory of successful, single-oriented and well-organised lobby groups, rather than in Becker's theory of competition.

Hence, it seems that also the inefficiencies in the Directive itself can be explained by interest group lobbying, and in particular by industry lobbying.

In sum, it appears that public choice theory indeed provides a useful tool to explain why the ELD has been issued at European level, in contrast to what would be efficient according to economic theory, and why certain provisions are adopted, again contrary to what would be efficient according to economic theory. ${ }^{1034}$

Yet, at all government levels lobbying might exist. The question therefore obviously arises whether the Member States would have had more efficient national environmental liability regimes? It now merits examining whether lobbying behaviour by interest groups would cause more distortions at the national level than at the central level so that this would justify Community action in the field of environmental liability, as studied in the theoretical part (paragraph 2.2 of chapter 3).

\subsubsection{Reasons for Centralisation, Based on Private Interest Distortions}

In the theoretical framework, it was argued that with respect to environmental regulation, there are three frequently advanced public choice distortions that might influence the level of decision-making for environmental policy.

A first public interest distortion is that interest groups, having a stake in a certain area of regulation, might prefer that level of government to issue a regulation at which their strength is greatest in comparison to other interest groups with different concerns in the same area. ${ }^{1035}$ Interest groups might therefore lobby to ensure that a certain regulation is issued at a particular level of government, at which their influence is greatest. If certain interests are systematically underrepresented at a particular governmental level, the outcome of the regulatory process clearly cannot be efficient.

The next two distortions that were dealt with in the public interest approach, are also prominent in the public choice debate: states might engage in a race-to-the-bottom due to interest group lobbying and the harmonisation of marketing conditions might be incited by interest groups. This paragraph will examine whether these claims give rise to a preference for environmental liability rules at European level, although there would be no firm reasons for centralisation based on the public interest approach.

\subsubsection{Relative Strength of Interest Groups at National and European Level}

Advocates of centralised regulation frequently claim that the decision-making process would be systematically more distorted at local level than at the central level. The justifications for this claim rest upon both the public attention for environmental matters and the interest group structure at respectively local and central level. According to Esty, the public indifference to many state and local environmental decisions, as well as greater media attention to central level activities might lead to more private interest

$1034 \quad$ Faure \& Skogh 2003, 203.

1035 Faure \& Skogh 2003, 175. See also Ogus 1994, 103. 
distortion at state and local levels than at the central level. Moreover, Esty expects that at central level lobbying excesses of a certain interest group would be opposed by countervailing interest groups. ${ }^{1036}$

This assumption, however, might not always hold. It merits at this point making a distinction between the American and the European context. As indicated above, American scholars, like Esty or RoseAckerman, argue that the risk of capture is larger at the state level than at the federal level where an open transparent debate exists. European scholars on the other hand, seem to fear more regulatory capture at the European Community level, due to the lack of transparency of the Brussels bureaucracy. ${ }^{1037}$

Ogus argues that, in Europe, if the lobbying power of industrialist groups tends to prevail over that of environmentalists at the state level, the disparity might even be greater at Community level. Ogus advances two explanations for weak(er) lobbying power of environmentalists at the European level.

Firstly, due to the disparity of interests and power of environmental lobby groups at the Member States level, industry lobby groups might co-ordinate their lobbying efforts across national frontiers more easily than environmentalists. Moreover, environmental lobby groups show a lack of resources compared to industry lobby groups. ${ }^{1038}$ Hence, in Europe, industry may be confronted with strong 'green' interest groups at the Member State level, especially in the 'green' Member States such as Denmark and Germany, whereas such countervailing powers may be weaker in Brussels. Hence one can expect European industry to engage in serious lobbying efforts centrally in Brussels. For example, the German environmentally sensitive industries, competing with a powerful green lobby within Germany, may strive for regulation at Community level, where they can find allies from industries in other States, and where the strength of environmentalists is more diluted. ${ }^{1039}$ Industry lobby efforts may go either direction: in case of a new regulatory field, they might lobby in favour of a harmonisation of European limit values, on the other hand they may wish to extend their strict (national) regulations to the European level, forcing foreign competitors to follow the same strict regulation with which they already comply. In that case, industry will lobby for predatory regulation to erect artificial barriers to entry. Environmental interest groups at European level may be in favour of these standards and may, therefore, support the demand to transfer strict national standards to a European standard. Thus industry in heavily regulated and possibly polluted areas may, supported by the environmental lobby, force their stringent emission limit values upon their competitors in other Member States. ${ }^{1040}$

Secondly, even if the authorities in Brussels are receptive to interest group lobbying, they do not have the same motivation to respond to the lobbying as governments at the Member State level. The European Commission and the Council are not voted into power by the European citizens and therefore do not need to purchase electoral support through the promise of legislative favours. This is especially a disadvantage for environmental lobby groups. Indeed, the political influence of environmentalists on the Commission and the Council might be weakened by the fact that they have no direct electoral link with these authorities and therefore cannot force them to issue stringent environmental regulation. On the other hand, the Commission is dependent on the polluting industry. Indeed, if effective laws are to be devised, the Commission needs to obtain information on best available production techniques from the polluting industry, and hence, to a certain degree, will need to appease them. An additional problem for the environmentalist lobby is the absence of effective enforcement at European level of environmental regulations. The European Environment Agency was created in 1990,1041 but its responsibility consists mainly of collecting information from national agencies. It does not have the powers to monitor polluters. It is generally admitted that the Member States have a poor record of implementing European Directives on environmental matters and it cannot be expected that a Member State will pursue a strict enforcement policy if it suspects that other Member States are not doing the same. ${ }^{1042}$

Hence, in the case of the European Union, it appears that it seems a bit precipitate to state that environmental lobby groups are underrepresented at the state level relative to industry interests and that therefore responsibility for environmental regulation should be assigned to the European level. At the European as well as at the Member State level, it might happen that a small number of concentrated industrial interests might overwhelm environmental lobby groups, consisting of a large number of

\footnotetext{
1036 D. Esty for example is one of the scholars warning for public choice distortions at state level. See Esty 1996, 597-598. See also Esty \& Geradin 1998, 32 and articles by Susan Rose-Ackerman.

See for instance Faure \& Skogh 2003, 176 and Ogus 1994, 103, 212.

1038 See also European Parliament, Directorate-General for Research, Working Paper, Lobbying in the European Union: current rules and practices, 2003, 7 .

Ogus 1994, 103, 212.

Faure \& Skogh 2003, 176

1041 Council Regulation (EEC) 1210/90, O.J. L120, 11th May 1990.

1042 Ogus 1994, 103.
} 
environmentally conscious citizens. Moreover, the relative lobbying power of environmentalists and industry lobby groups seems to depend on the particular situation in the Member States.

For liability rules for soil pollution in particular, it is very difficult to proclaim at which governmental level lobbying with respect to soil pollution will be strongest. Nevertheless, soil pollution mostly is a local problem, and it might be assumed that therefore it might be easier for environmental lobby groups to ensure that citizens, confronted with local contamination, support their actions for stringent liability rules. At the central level, at which most citizens are much less involved, industry might have more lobbying power. The argument that centralisation would be necessary because industry interest groups would be stronger relative to environmental lobby groups at Member State level, might therefore not hold for liability rules for soil pollution.

The question arises then at which level environmental regulation could be best decided if both levels can be affected by interest group lobbying. Which governmental level will yield more lenient or more stringent regulation? As already indicated above, the eventual policy outcome due to lobbying might go in either direction. At Member State level, industry might lobby for more lenient standards, but they may be opposed by a strong environmental interest group. At European level the lobbying efforts of industry might go in either direction, depending on whether industry wants to erect barriers to entry, or lenient regulation. Moreover, the power of environmental lobby groups at the European level compared to the Member State level, might depend on the particular situation in the Member States. In 'green' Member States as Germany or Denmark, environmental lobby groups may be stronger than the lobby groups at European level, whereas the situation might be different in Greece or Portugal. Hence, it is difficult to predict which governmental level will yield optimal environmental regulation, when affected by lobbying. Yet, in this context, it is interesting to refer to a study of Fredriksson and Gaston ${ }^{1043}$ who argue that centralised and decentralised environmental decision-making will result in equivalent environmental regulations. In their study, they examine the implications of lobbying on centralised or decentralised environmental decisionmaking. They model workers, environmental and capital owner lobby groups that seek to influence the policy outcome by offering political contributions and they differentiate between two levels of environmental decision-making, the central level and the local level. Fredriksson and Gaston make the plausible assumption that capital is mobile between jurisdictions of a federation, but immobile at centralised level. Organised lobby groups offer the government political contributions in return for more favourable environmental policy outcomes. The government on the other hand tries to maximise both aggregate social welfare and political contributions. At decentralised level, workers lobby, as they are affected by capital flight and their lobbying might influence the local government to reduce the level of regulatory stringency. Under centralised decision-making, industry lobbying may be larger. If the capital stock is assumed immobile, which means that firms cannot move to other federations, capital owners will lobby for political favours, the centralised outcome may degenerate to the decentralised outcome. This occurs because worker lobbying in the decentralised case has a similar effect on environmental regulations to that of capital owner lobbying in the centralised case. Yet, implicitly, their study seems to indicate that if capital flight is still possible at the central level, the central level might issue more stringent environmental regulations. Nevertheless, an important finding of their model is that, under quite realistic circumstances, the stringency of environmental regulation is likely to be independent of institutional design. ${ }^{1044}$ Moreover, they predict that, rather than regulations becoming more stringent at the federal level, 'new' centralised regulations would develop into the 'average' stringency of regulations that had existed at the decentralised level. As an example they refer to the packaging waste regulation in the European Union. The initial proposal immediately was criticised by various industry groups and the new drafts of the regulations were successively less demanding. ${ }^{1045}$

In sum, lobbying of both environmental interest groups and of industry interest groups will take place at the European as well as at the Member State level. Furthermore, it is unlikely that environmental lobby groups are more powerful at the European level than at state level. In some Member States this might be the opposite. Moreover, lobbying efforts of industry might go in either direction, depending whether they intend to erect barriers to entry or whether they strive for lenient regulation. Hence, the claim that the environmental decision-making process would be systematically more distorted at state and local levels than at the federal level and therefore would justify centralised environmental regulation is precipitate, at least in the European case.

With respect to the ELD in particular, compared to the Member States' environmental liability regimes which were already in place, the ELD also includes damage to biodiversity, which might be considered as a

1043 Fredriksson \& Gaston 2000, 501-514.

1044 Frediksson \& Gaston 2000, 502, 512

1045 Frediksson \& Gaston 2000, 508 and Golub 1996b, 313-339. 
novelty. One might therefore argue that in that respect, the ELD might be considered as a new regulatory field. This is also reflected in lobbying behaviour of industry. As was already stated above, comments of the industry on the Working Paper or the Commission Proposal indicate that industry did not oppose a European action in the field of environmental liability as they preferred a consistent (minimum) approach throughout the Community compared to various (more stringent) national liability regimes. ${ }^{1046}$ Environmental NGO's supported the shift of environmental liability rules from the Member States to the European level, as in their view, a strong EU-wide regime on Environmental Liability would be vital to improve the protection of Europe's environment and the adoption of the Directive would be a first step in the right direction. ${ }^{1047}$ Yet, the final text of the ELD shows the strength of industry lobbying relative to environmental NGO's lobbying. Indeed, although environmental NGO's did their very best, industry lobby groups, supported by some of the Member States who did not want to put too much pressure on their industries, realised several of their stakes, as for example the introduction of a permit compliance or stateof-the-art defence and the absence of compulsory insurance. The ELD adoption process might in this respect be comparable with the packaging waste regulation example given by Fredriksson and Gaston. Indeed, due to lobbying, when comparing the Commission proposal with the final text of the ELD, the text of the Directive became during the co-decision procedure successively less demanding. Hence, it is possible that the regime of the ELD developed into the 'average' stringency of liability rules that had existed at the Member State level.

Hence, the claim that centralised regulation would be justified as the decision-making process would be systematically more distorted by lobbying at Member State level than at the European level does not hold for the European Union, and might therefore not justify the ELD.

Yet, the question whether environmental liability rules had been better decided at Member States level and whether the environment had been better protected by national rules, is, precisely with respect to lobbying, difficult to answer. Moreover, the answer probably would have been dependent on the liability regime of the Member State under consideration.

\subsubsection{Race-to-the-bottom Due to Interest Group Lobbying}

In addition to the claim that the environmental decision-making process would be systematically more distorted at state or local levels than at the central level due to lobbying, it is often argued that the risk of a race-to-the-bottom in environmental standards between states, caused by lobbying at state level, would justify centralised environmental decision-making.

The fact that the presumption that (industry) lobbying at state level would cause a race-to-the-bottom in environmental quality, justifying centralised environmental regulation, appeared to be a bit hastened was already discussed in the theoretical part. Industry will not necessarily lobby for lenient regulation. Indeed, various strategies are possible. Firms might create rents and barriers to entry by stringent regulation. In such circumstances, the impetus for environmental regulation comes, implicitly or explicitly, from the regulated firms themselves. Stringent regulation gives them an advantage over (foreign) competitors. Moreover, stringent regulation might provide benefits to producers of pollution control equipment. The demand for environmental regulation then comes from manufacturers of pollution control equipment or environmentally friendly technologies. On the other hand, it can not be excluded that there might be circumstances in which industry may indeed lobby for lenient regulation, for example to obtain an interregional comparative advantage. Furthermore, states may only be willing to introduce a stringent liability regime if they are sure that other states have to do the same. ${ }^{1048}$

Nevertheless, the risk of a race-to-the-bottom in liability rules for soil pollution is not very realistic. Indeed, soil pollution is a mostly local problem. If Member States would issue lenient liability rules for the sake of industry, they would lose their means to recover the costs of clean-up from the polluters. Hence, they do not have any incentive to issue lenient liability rules for soil pollution, eventually leading to a raceto-the-bottom.

Yet, with respect to the ELD, there are no indications that industry strived for a real race-to-thebottom or that Member States would be willing to introduce inefficient lenient liability regimes. More realistically, it seemed that industry preferred a somewhat consistent (minimum) approach in the Community instead of different (more stringent) national environmental liability regimes.

1046 See CBI response to the Commission Working Paper on Environmental Liability published on 30th July 2001: 'The EU regime should continue to focus on setting broad principles which can be enacted in each Member State, to ensure a consistent approach' at <http://ec.europa.eu/environment/liability/wrkdoc_comments.pdf>.

1047 Birdlife International, Greenpeace, WWF, Friends of the Earth, EEB (joint declaration), The Directive on Environmental Liability, The European Parliament's Third Reading Vote, 31 March 2004.

1048 Bergkamp 2001a, 384. 


\subsubsection{Harmonisation of Marketing Conditions Incited by Interest Groups}

The 'harmonisation of competition' reasoning was advanced as an argument for centralisation of environmental regulation, within the public interest approach. Yet, this argument might also be examined from the private-interest approach.

Indeed, as was explained in the theoretical framework, centralisation because of the harmonisation of competition might serve the interests of industries in heavily regulated areas rather than the public interest. On the one hand, industry in states that already have relatively stringent environmental standards may have an incentive to lobby at the central level. The purpose of such lobbying would be to make these stringent environmental standards compulsory throughout the Union in order to force their competitors also to comply and, thus, to obtain a competitive advantage and to create barriers to entry. In other words, predatory regulation may explain why many environmental regulations emerge at the central level if economic theory would predict that the problem would be better dealt with at the local level. ${ }^{1049}$ Moreover, industries with strong economies of scale tend to prefer uniform federal regulation to a patchwork of different state standards. ${ }^{1050}$ Also for new regulatory fields, industry might prefer centralised regulation. Faure and Lefevere argue that this might explain why some industries will lobby in favour of environmental regulation at the European level. For new areas, where no national legislation exists, industry lobby groups may encounter less countervailing power of environmental organisations than at the local level where the environmental problems occur. ${ }^{1051}$ Hence, centralised regulation might be more lenient than the regulation that could have been issued at national level.

The harmonisation for marketing conditions effectively seems to have been an argument for industry to support a shift of environmental liability rules from the Member States to the European level. Indeed, in a joint paper on the implementation of the Directive, CEFIC, EUROPIA and OGP state that 'our industries have accepted their environmental responsibility and have not objected to the principle of a Directive regulating their liability. Our industries however expect that a new environmental liability regime should be fair and contain legally clear definitions and concepts. CEFIC, EUROPIA and OGP urge the Member States to implement the Directive in a fair and harmonised way in order to avoid distortion of competition and legal uncertainty'. ${ }^{1052}$

In particular, these industry lobby groups ask that 'Member States should exempt responsible operators from any liability if they act in compliance with permits and state-of-the-art knowledge'. 1053 Indeed, as the Council could not agree a common line, the decision was passed on to the Member States to accept permit compliance and state-of-the-art knowledge as defences and to relieve the operator - fully, in part or not at all - of restoration costs. Operators who act in compliance with their permits and apply stateof-the-art knowledge might be or might not be liable depending on the implementation of this provision by the Member States. Therefore, CEFIC, EUROPIA and OGP demand that 'all Member States would recognise permit and state-of-the-art defences in order to avoid distortions of competition'. Moreover, they argue that the option for Member States to decide whether to apply joint and several liability or proportional liability could create serious discrepancies between Member States and result in distortion of competition. Only application of proportional liability in all Member States would create an effective, fair and harmonised regime, saving financial and other resources and helping the environment by avoiding lengthy procedures'. ${ }^{1054}$ Hence, it seems clear that a harmonised (lenient) environmental liability regime at European level to equal marketing conditions was favoured by the industry.

It is interesting to note that the fact that the Directive also included liability rules of soil pollution did not create much of a discussion during the adoption process. Maybe this was because industry preferred (minimum) harmonisation with respect to liability for soil pollution rather than differing rules in the various Member States, or maybe because, as Layard suggests, the effective impact of the ELD for soil pollution is rather limited. ${ }^{1055}$

Environmental NGO's from their side hope that the provisions of the Directive might be strengthened in the future and that their lobbying activities might counteract industry's desire for a minimum regime at

\footnotetext{
1049 Faure \& Skogh 2003, 175, 321.

1050 Revesz 2001b, 573.

1051 Faure \& Skogh 2003, 175, 321 See also Faure \& Lefevere 1995, 320-351.

1052 Cefic, Europia and OGP, The Environmental Liability Directive (Dir 2004/35/CE), Recommendations for implementation, May 2004, emphasis added.

1053 Cefic, Europia and OGP, The Environmental Liability Directive (Dir 2004/35/CE), Recommendations for implementation, May 2004, emphasis added.

1054 Cefic, Europia and OGP, The Environmental Liability Directive (Dir 2004/35/CE), Recommendations for implementation, May 2004.

1055 Layard 2004, 103.
} 
European level. In particular, they lobby at their national governments not to choose for allowing companies, operating in compliance with the permit or according to the state of the art, an automatic exemption from all environmental restoration costs. Moreover, they hope that the Commission will use its review obligations as opportunities to improve the Directive in the future. ${ }^{1056}$

Yet, it might be clear that the harmonisation of environmental liability rules, including liability rules for soil pollution for equal marketing conditions, serving the interests of industry, instead of the public interest, is not a good argument to justify the shift of environmental liability from the Member States to the European level by means of the ELD.

In sum, it appears that none of the arguments of the private interest approach would justify a shift of environmental liability rules from the Member States to the European level.

\subsection{Summary of the Private Interest Approach}

The private interest approach tried to provide additional explanations for the existence of the ELD and for certain provisions in the ELD. In particular, it was examined on the one hand, whether the inefficient shift of competences to the European level with respect to environmental liability rules, resulting in 'too much Europe', had been caused by interest group lobbying and, on the other hand, whether the inefficiencies in the Directive itself could be explained by interest group lobbying.

Firstly, the adoption process of the ELD was studied with respect to interest group lobbying. It was explained who were the actors involved in the decision-making process of the ELD and what were their stakes. The adoption process of the ELD was examined in detail and it was indicated at which stages and at which institutions lobbying took place, in particular with respect to permit compliance and state-of-the-art defence, subsidiary state liability and mandatory financial insurance.

It was indicated that the existence and content of the ELD clearly showed the influence of lobbying activities, both by industry and environmental NGO's as the influence of the Member States.Therefore, the lobbying of all actors involved in the ELD decision-making process add to explain the existence and the content of the ELD.

Secondly, it was examined whether the lobbying activities, observed in the adoption process of the ELD, and the result of this lobbying, corresponded with the predictions of private interest theories which were discussed in the theoretical part, as the Economic Theory of Regulation (Becker) and the Public Choice theory (Buchanan, Olson). It appeared that the lobbying behaviour with respect to the level of regulation showed some elements of both the Becker and the Buchanan theory on lobbying behaviour. Moreover, it seemed that environmental NGO's, industry and Member State, all for their own reasons, welcomed or at least did not oppose the idea of a European environmental liability regime. The Commission on its side might have welcomed a European environmental liability regime for other reasons than only public welfare and protection of the environment as for example enlarging its own competences in fields for which it did not have any direct competence yet, as soil protection policies. Hence, competences were shifted from the Member State level to the European level, contrary to what economic theory would suggest. Thus, the answer on the question whether the inefficient shift of competences to the European level with respect to environmental liability rules can be explained by interest group lobbying and private interest distortions is probably affirmative.

With respect to the content of the ELD itself, it was shown that industry was most successful in obtaining its claims, compared to environmental NGO's. Hence, the lobbying behaviour of the main actors in the ELD adoption process with respect to the content of the Directive might fit better into Olson's theory of successful, single-oriented and well-organised lobby groups, rather than in Becker's theory of competition. Yet, it seems that also the inefficiencies in the Directive itself can be explained by interest group lobbying, and in particular by industry lobbying.

Finally, it was examined whether lobbying behaviour by interest groups would cause more distortions at the national level than at the central level so that this would justify Community action in the field of environmental liability.

It was shown that in the case of the European Union, it seems precipitate to state that environmental lobby groups are underrepresented at the state level relative to industry interests and that therefore responsibility for environmental regulation should be assigned to the European level. At the European as well as at the Member State level, industry lobby groups might have more lobbying power relative to environmental interest groups. Indeed, due to lacking resources, and the disparity of interests and power of

1056 See for example Birdlife International and WWF, The European Directive on Environmental Liability - 'Polluter Pays': from principle to practice? An Environmental NGO commentary on the Environmental Liability Directive: its adoption at EU level and what it means for the future, July 2004, 28. 
environmental lobby groups at the Member States level, industry lobby groups might co-ordinate their lobbying efforts across national frontiers more easily than environmentalists. The adoption process of the ELD indeed reflected this inequality and showed that industry lobby groups realised to obtain important concessions in particular with respect to permit compliance and state-of-the-art defence and compulsory insurance. Furthermore, a race-to-the-bottom seems rather unrealistic in the case of environmental liability rules. Indeed, there are no indications that industry strived for a race-to-the-bottom. More realistically, it seemed that industry preferred a somewhat consistent (minimum) approach in the Community. Finally, harmonisation of environmental liability rules might be used by industry to obtain a (minimum) harmonised regime in order to avoid distortions of competition. Yet, harmonisation of marketing conditions to serve the private interest, it certainly is no valid argument for the shift of environmental liability rules from the Member States to the European level.

Hence, the claim that the private interest distortions in the European Union would cause even more distortions at the national level and therefore would justify a European environmental liability regime is precipitate. This negative conclusion should not imply that the Member States would enact optimal environmental regulation, or that private interest distortions are less serious in the Member States than at the European level. The lobbying process is so complex that any general conclusion is almost certain to be wrong.

Concluding, the private interest approach provides useful insights into the lobbying behaviour of the actors involved in the adoption process of the ELD and provides additional explanations for the existence of the ELD and for certain provisions in the ELD. Indeed, the private interest approach provides a useful tool to explain why the ELD has been issued at European level, in contrast to what would be efficient according to economic theory, and why certain provisions are adopted, again contrary to what would be efficient according to economic theory.

\section{Framework for Decision-making on the Optimal Governmental Level for Liability for Environmental Damage in the European Union, Based on a Public and Private Interest Approach}

It now merits merging both public interest and private approaches in order to explain for what reasons environmental liability rules were shifted from the Member States to the European level. Indeed, only a combined public-private interest approach that explicitly recognises the interaction of different interest groups can grasp the complexity of environmental policy.

Figure 7 applies the framework that was developed in Chapter 3 and illustrates the difference between theory and practice. 


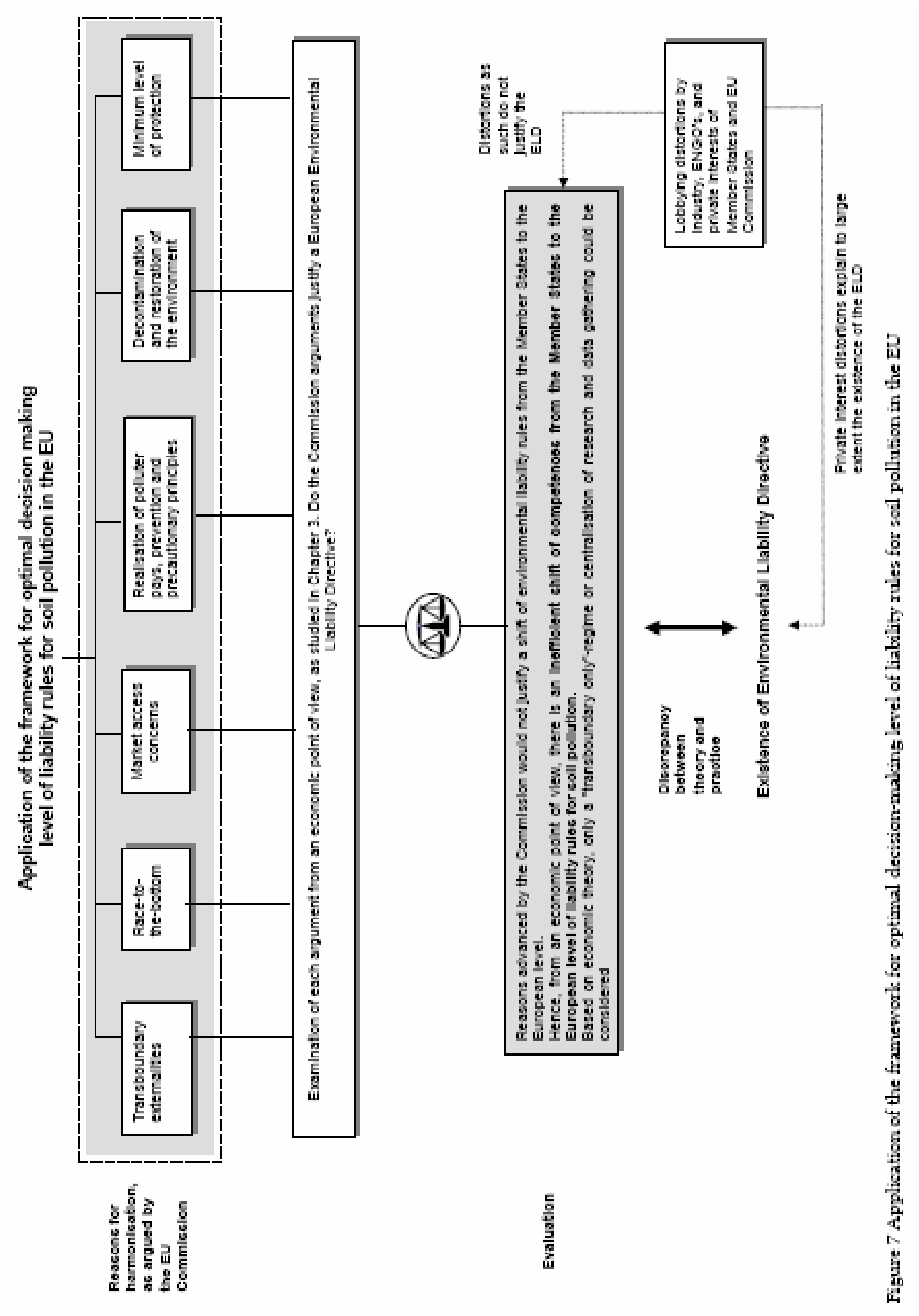


It appears that from an economic point of view, the reasons advanced by the Commission for the ELD seem rather weak, and would not justify a shift from the Member States to the European level of environmental liability rules, including liability rules for soil pollution.

From an economic point of view, the only valid argument for centralisation was the internalisation of transboundary damage, however, only a so-called 'transboundary only'-regime would be justified rather than full harmonisation. Yet, it was shown that the Directive would not necessarily solve this transboundary damage. It was also argued that economies of scale in technical research might allow for cooperation or centralisation of certain tasks, like research or data gathering on soil contamination and restoration. However, again, the promise of economies of scale in scientific research would not justify for a centralisation in an excessive sense. Next, it was shown that fears for a race-to-to-bottom or unfair marketing conditions, due to different liability rules in the Member States seem not very likely to become true, and therefore these arguments do not justify harmonisation of environmental liability rules in the European Union. Moreover, it was shown that the ELD will not create a level playing field or realise a reduction in transaction costs, neither for environmental liability rules in general nor for liability for soil pollution in particular. Also the realisation of the polluter pays, precautionary and preventive principles and restoration and decontamination of environmental damage as such do not explain why environmental regulation should be issued at the European level. Moreover, it was indicated that the ELD will not necessarily realise the polluter pays, precautionary and preventive principles, or the restoration and decontamination of the environment. Finally, it was argued that if the minimum level of protection argument would be accepted as a valid argument for shifting environmental liability rules from the Member States to the European level, it must be emphasized that this reason for harmonisation would not be based on economic efficiency, but on the desire to provide a minimum level of environmental quality and of protection against environmental accidents. Moreover, if the preferences of the citizens in the different Member States are ignored, harmonisation of environmental liability rules on the basis of this argument only amounts to paternalism.

Hence, the reasons advanced by the Commission for the ELD seem rather weak, and would not justify a shift of environmental liability rules from the Member States to the European level and hence, from an economic point of view, there is an inefficient shift of competences from the Member States to the European level with respect to environmental liability rules as shown by the example of liability rules for soil pollution.

The conclusion at the normative level is, however, not necessarily that there should be no European action at all with respect to environmental damage, including soil pollution. It was argued that subsidiarity is not a question of either centralised or decentralised decision-making, but may involve a mixture of powers at different levels.

The main point is that the Commission fails to explain properly why a harmonised liability regime is necessary or why its goals cannot be achieved by the Member States, as required by the subsidiarity principle. However, as was stated above, ignoring the subsidiarity principle can have substantial negative effects for the European Union. Indeed, such behaviour would encourage eurosceptics and endanger projects where European action would be desirable. Therefore, in order to respect the division of competences between Member States and the European level, European action should be properly justified.

Nevertheless, the question remains why environmental liability rules were shifted from the Member States to the European level in contrast to what would be efficient according to economic theory. The private interest approach therefore provided additional explanations for the existence and the content of the ELD. It appeared that environmental NGO's, industry and Member States, and the Commission, all for their own reasons, welcomed the shift of environmental liability rules from the Member States to the European level. Thus, the interests of all parties in the ELD decision-making process may not be ignored when explaining the shift of environmental liability rules from the Member States to the European level, but also when explaining the provisions of the ELD itself. Indeed, the final text of the ELD clearly shows the influence of lobbying activities, both by industry and environmental NGO's as the influence of the Member States themselves. Therefore, private interest theory explains to a large extent why there is an Environmental Liability Directive, and why certain provisions are as they are.

Yet, meanwhile the Directive has entered into force. Interpreting the Directive in light of its aim and general principles of EC environmental law seems the best option to give the ELD the chance to become an effective instrument to ensure prevention and restoration of environmental damage in the European Union. 


\section{Summary and Conclusions}

\section{SUMMARY AND CONCLUSIONS}

This doctoral research aimed to refine the existing scholarly debate on the optimal decision-making level of environmental regulation. The diverse arguments pro and contra harmonisation of environmental regulation and the sometimes fierce debates on harmonisation at academic as well as political level incited this research. In particular, this doctoral research aimed to answer the question whether the harmonisation of environmental liability rules in the European Union, including liability rules for soil pollution, was desirable from an economic point of view and for what reasons harmonisation did take place?

To answer this question, the research was based on the economic analysis of law, also known as 'Law and Economics' methodology. In a first step, on the basis of the economic analysis of tort law, it was examined which type of liability rule would be most efficient from an economic point of view to prevent and restore soil pollution. Next, the optimal decision-making level of these liability rules was examined from two different theoretical perspectives within Law and Economics methodology, a public interest approach and the private interest approach. The public interest approach, based on the economic theory of federalism, considers regulation as a means to correct market failures and assumes that governments are able to correct these market failures and that they take decisions to improve social welfare. The private interest approach on the other hand, is based on capture theory, economic theory of regulation and public choice theory and stresses the role of interest groups in the law-making process and points to the danger of government failure as a result of lobbying by interest groups. The basic idea of this approach is that interest groups try to influence political decisions in order to seek rents for themselves, which is unproductive from a social welfare point of view. On the basis of these two perspectives, a theoretical framework on the optimal decision-making level of liability rules for environmental damage was developed, with soil pollution as an example. This framework was applied to the harmonisation of environmental liability rules, including liability rules for soil pollution, through Directive 2004/35/CE in the European Union. By the comparison of economic theory and recent developments in the European Union, this PhD research aims to contribute to the existing theories on the optimal decision-making level of environmental regulation and to provide more insight in the harmonisation process in a real world situation.

As the harmonisation debate is a very complex matter, four subquestions were formulated to answer the central research question. It merits now providing an answer on all four subquestions and next, to the central research question.

In order to point out the relevance of this research, the first of the subquestions was: what is the contribution of environmental liability rules in the prevention and restoration of enironmental damage and which type of liability rule would be best to prevent and restore environmental damage?

Indeed, prior to the question at which level liability rules for environmental damage can be best decided, the question what liability rule would be most efficient from an economic point of view to prevent and restore environmental damage had to be answered.

In Chapter 2, the economic analysis of tort law was applied to environmental damage. In a first step, the role of liability rules in the prevention and restoration of environmental damage was clarified. It was argued that the function of liability is twofold. On the one hand liability fulfils a prevention function, by giving individuals incentives to internalise the negative effects that their activities pose on others. In this way, liability guides individual behaviour in order to maximise social welfare. On the other hand, liability could provide for compensation for the damage in case an accident would occur. Thus, besides regulation, liability rules can play a valuable complementary role in preventing and restoring environmental damamage, as for instance soil pollution. Indeed, most countries have established a framework of regulations to prevent and restore environmental damage, including soil pollution. Yet, in order to deal with the lacunas in regulation, liability can be introduced. Therefore, liability and regulation apparently are complementary. 
Second, in order to determine the optimal liability rule to complement the existing regulatory framework for environmental damage, a distinction was made between dangerous activities and nondangerous activities. For dangerous activities it was argued that a strict liability would be optimal as it also might reduce the activity level, whereas a negligence rule might be sufficient for non-dangerous activities. It is not claimed that liability is the perfect solution for all kinds of environmental damage, nevertheless, liability can play a valuable complementary role in preventing and restoring environmental damage. Thus, it merits further research on the optimal decision-making level at which these liability rules for environmental damage might be decided in a federal system as the European Union. As an example, liability for soil pollution will be examined.

Accordingly, the second subquestion was: what is the optimal decision-making level of liability rules for environmental damage in a federal system from a theoretical perspective?

In order to answer this second subquestion, in Chapter 3 the arguments of the public interest approach and the private interest approach on harmonisation of environmental regulation were examined.

The public interest approach starts from decentralisation of regulatory policies and examines accordingly whether there might be reasons for federal intervention. This bottom-up approach towards centralisation is based upon the Tiebout model and the Decentralisation Theorem of Oates. The starting point is that through decentralisation rules can be adapted to the preferences of the citizens. However, due to externalities and market failure, transaction costs or imperfect information, some decisions might better be decided at a higher level of decision-making.

The reasons for centralisation, and eventually harmonisation, were grouped into four main arguments: the transboundary character of an externality argument, the race-to-the-bottom argument, the market access argument and minimum level of protection argument. Each argument was first examined for (environmental) regulation. Second, each argument has been applied to environmental liability rules and liability rules for soil pollution as an example.

It would lead us to far afield to give an extensive summary of the analysis of each of the arguments, but a brief summary of the outcome seems appropriate.

It appeared that none of the arguments for harmonisation would justify a total harmonisation of environmental liability rules. Nevertheless, it was argued that there might be a supportive role for the federal government in the provision of information and scientific research. Besides that, a federal government might develop solutions for transboundary damage or for special conservation area's. Furthermore, general principles of tort law to protect the environment could be defined at the central level, or a specific liability rule for certain activities could be set centrally, combined with a differentiation of the specific contents of this rule. In such circumstances, transaction costs might be lowered, market access might be promoted, a minimum level of protection could be guaranteed and still differing preferences could be respected.

The same reasoning held for liability rules for soil pollution. Perhaps the strongest argument for decentralisation of liability rules for soil pollution is that local conditions, geography, economic strengths and concerns might vary substantially from place to place. Furthermore, local knowledge and expertise with specific soil conditions might prove essential to develop the proper liability rules for soil reclamation. Therefore, certainly in the specific case of soil pollution, a one-size-fits-all approach probably might fit nobody.

Yet, it was argued that the existence or the harmonisation of certain environmental regulations in the real world can not always be explained on the basis of the public interest approach alone. Indeed, for a full understanding of environmental policy, the influence of lobbying of different interest groups in the law making process must be recognised. The public interest approach therefore was complemented with a socalled private interest approach. This approach tries to take rent seeking into account in the law making process. The reasons for a certain policy can sometimes be best understood if not only the public interest, but also the behaviour of the government officials and pressure groups is taken into account.

First, a brief overview of the theories that examine the influence of lobbying on the law-making process was prestented: Capture Theory, Public Choice Theory and the Economic Theory of Regulation. Moreover, at a theoretical level, the various stakes of the government, the industry and environmentalists, the main lobby groups in the environmental law making process, were discussed. Second, attention was paid to environmental federalism. It was indicated that lobbying might not only concern the contents of the regulation, but also at what level of government the regulation will be issued. Interest groups, having a stake in a certain area of regulation, might prefer that level of government at which their strength is greatest in comparison to other interest groups with different concerns in the same area. Three frequently advanced private interest distortions, that might influence the level of decision-making for environmental policy, were examined. First, it is often argued that private interest distortions might cause that environmental interests are systematically underrepresented at the local level. Moreover, two arguments that were dealt 
with in the public interest approach are also prominent in the public choice debate: states might engage in a race-to-the-bottom due to interest group lobbying and the harmonisation of marketing conditions might be incited by interest groups. It was examined whether these three claims would justify centralisation of environmental regulation.

It appeared that with respect to environmental liability rules, it is difficult to estimate at a theoretical level what the main actors, and in particular industry, will lobby for, what the best level of regulation is and what the result of lobbying will be. However, it seemed clear that the private interest distortions would not automatically justify a centralised regime, as lobbying affects the local as well as the central level. Unfortunately, public choice theory is not able to predict the magnitude and consequences of the distortions at the local level compared to the central level. However, in any case, transparency in the debate at either level might be welcomed in order to guarantee that a regulation would serve the public interest. As far as liability rules for soil pollution were concerned, it was argued that soil pollution mostly is a local problem, and it might be assumed that therefore, it might be easier for environmental lobby groups to ensure that citizens support their actions for stringent liability rules at local level then at central level, at which most citizens are much less involved. The argument that centralisation would be necessary because industry interest groups would be stronger relative to environmental lobby groups at local level, might therefore not hold for liability rules for soil pollution. Therefore, also based on the private interest approach, there remained a strong case for decentralised environmental decision-making where the benefits and costs of such measures are localised.

The results of both public and private interest approaches were combined in order to develop a framework for decision-making on the optimal level of environmental liability rules. Indeed, only a combined public-private interest approach that explicitly recognises the interaction of different interest groups can grasp the complexity of environmental policy and the interaction of the different factors that influence the optimal decision-making level of environmental liability rules in a federal system. The framework was applied to liability for soil pollution as an example.

The framework aimed to provide guidance to the answer of the second subquestion, what is the optimal decision-making level of liability rules for environmental damage in a federal system from a theoretical perspective?

The objective of the framework was not to offer a simple answer on this question - as it appears that a one and only solution does not exist - but to offer a means to deal with the problem and to evaluate different policy options. The starting point of the framework is decentralisation. Rules can then be optimally adapted to the preferences of the citizens. Consequently, it is indicated which circumstances would ask for central intervention. Based on the results of the public and the private interest approach, five evaluation factors upon were indicated which might support the decision-making on the optimal policy level for liability rules. These five evaluation factors are the presence of externalities, the indications for a race-to-the-bottom or political drag, market access distortions through divergence of rules, the need to guarantee a minimum level of protection, all four based on the public interest approach and finally the influence of interest group distortions, based on the private interest approach. The weight and importance of each of these factors might depend on the actual situation. Moreover, in certain cases these factors might be connected with each other.

On the basis of the framework, a few intermediate conclusions were formulated with respect to the optimal decision-making level of environmental liability rules in a federal system:

First, for each situation the existence of the various distortions and the weight that must be given to them might be different. Therefore, a one and only solution on the optimal level of governmental decisionmaking might not exist. The framework can only offer some guidance.

Second, even when the framework is refined to soil pollution, no one and only solution on the optimal regulatory level can be offered. In every specific case, the different factors will have to be weighted in order to examine how much co-operation or centralisation would be needed. None of the factors would justify a total harmonisation of liability rules for soil pollution though. Perhaps the strongest argument for decentralisation of liability rules for soil pollution is that local conditions, geography, economic strengths and concerns might vary substantially from place to place. Furthermore, local knowledge and expertise with specific soil conditions might prove essential to develop the proper liability rules for soil pollution. Therefore, certainly in the specific case of soil pollution, a one-size-fits-all approach probably might fit nobody. Nevertheless, this does not mean that in some circumstances, a multi-level regulatory structure might not be beneficial. The main power of decision-making could be with the local authorities, whereby the central government could provide a supporting framework of data gathering and technical information provision. Moreover, the central government could provide a solution for transboundary damage and nature conservation areas.

Third, it appears that only in a few circumstances centralisation would be the only (and best) solution to solve a distortion. 
Yet, the desire to harmonise environmental liability rules in the European Union already existed at European level for about 20 years. On 21 April 2004, Directive 2004/35/CE on Environmental Liability with Regard to the Prevention and Remedying of Environmental Damage (ELD) was finally adopted. One might ask whether there might be specific circumstances in the European Union, justifying centralisation or even harmonisation of environmental liability rules, including liability for soil pollution, or whether the reasons for centralisation are not necessarily based on public interest considerations.

A third sub-question therefore was: for what reasons did the Community consider harmonisation of environmental liability rules necessary and what are the scope and the provisions of Directive 2004/35/CE on Environmental Liability with Regard to the Prevention and Remedying of Environmental Damage, also called the Environmental Liability Directive, also with respect to soil pollution?

In Chapter 4, first, the competence of the European Union to harmonise environmental liability rules was clarified. Next, the development process of Directive 2004/35/CE - or the Environmental Liability Directive - and the reasons provided for by the Community for the harmonisation of environmental liability rules at European level were discussed. Finally, the Directive's provisions and its application to soil pollution were studied.

With Directive 2004/35/CE on Environmental Liability with Regard to the Prevention and Remedying of Environmental Damage, the Community aims to establish a framework of environmental liability based on the 'polluter-pays' principle, to prevent and remedy environmental damage. The development and the adoption of the Directive gave rise to much controversy and conflict. Much of the conflict addressed the question whether and how far the European Union could go in adopting a European liability regime. Yet, it is remarkable that in the final text of the ELD, the Commission fails to explain why it is necessary to establish a harmonised liability regime or why it cannot be achieved by the Member States, as is required by the subsidiarity principle. Therefore, in order to examine for what reasons it was considered necessary to harmonise environmental liability rules, the subsequent Commission documents in the ELD decision-making process were consulted. The three documents in the ELD decision-making process that can be referred to in order to examine the reasons for a shift of environmental liability rules from the Member States to the European level are the Commission Green Paper on Remedying Environmental Damage, the White Paper on Environmental Liability, and the Explanatory Memorandum to the Proposal for a Directive on Environmental Liability with regard to the Prevention and Restoration of Environmental Damage. It appears that the Commission advances six main reasons for European action in the field of environmental liability: the transboundary character of an externality argument, the race-to-thebottom argument, the level-playing field argument, the realisation of the polluter pays, prevention and precautionary principles, decontamination and restoration of the environment, and harmonisation to guarantee a minimum level of protection.

Subsequently, the provisions of the Directive were studied. It appeared that the coverage of the Directive is limited, so that different regimes may apply to different types of damage in case of an accident and the ELD does not clarify its relation to other liability regimes. Moreover, the ELD has left crucial aspects, as defences, insurance but also precise definitions of damage or restoration criteria, up to the Member States. Member States may also maintain or adopt more stringent provisions in their national law to prevent and restore environmental damage.

With respect to the application of the Directive to soil pollution, it appeared that, despite all the concern and high-profile debates, the scope of the ELD is limited. The regime will only apply prospectively and a clear link needs to be established between the operator and the damage. The harm to health must be 'significant' and it must have come about as a result of an operation specified in Annex III of the Directive. This means that the Directive will leave many of the contaminated sites in Europe to be cleaned up under national provisions of the Member States.

Moreover, also for contaminated sites within the scope of the Directive, various provisions are left to the Member states, like permit and state-of-the-art defences, so that operators may be exempted from liability. The variations that may exist in the implementation of the ELD by the Member States, together with the numerous sites that will have to be remedied - if at all - by domestic provisions of the Member States, makes that there still will be significant differences in the soil policies of the Member States and hence the ELD will not create much harmonisation. On the contrary, the ELD might introduce considerable uncertainty as different liability regimes will exist together.

Finally, besides the variations that may exist in the implementation of the ELD by the Member States, there might be significant variation between the Member states in the remediation process. Indeed, the Directive gives Member States considerable leeway in Member States' practice of dealing with contaminated land. Consequently, the ELD provides an uncertain framework and the regime will be a less harmonised regime and might create more uncertainty than its adherents originally might have thought. 
The analysis in Chapter 4 and the answer on the third subquestion inevitably lead to the last subquestion: does the Environmental Liability Directive correspond with the theoretical framework, with respect to economic efficiency as well as to the decision-making level of liability rules for environmental damage and if not, why was harmonisation of environmental liability rules, including liability rules for soil pollution, considered necessary in the European Union?

As for the theoretical analysis, it was appropriate to examine first whether the liability regime as proposed by the Directive could be considered as efficient. This is independent from the question on the optimal decision-making level of liability rules for environmental damage. Second, the optimal decisionmaking level of liability rules for environmental damage could be examined for the particular case of the European Union, by means of the theoretical framework that was developed in Chapter 3. The arguments that where provided by the Community to justify the Directive were examined both from a public interest approach and a private interest approach. In this way, the examination of the Environmental Liability Directive complements the theoretical framework and might offer a better understanding of all factors that play in a real harmonisation debate.

Chapter 5 examined the economic efficiency of the Directive. It was concluded that as far as the choice of liability regime is concerned, the ELD complies with the economic analysis of tort law which predicts that a strict liability is more efficient in case of hazardous activities since in those situations it is more important to control the injurer's activity. For other situations, a fault regime can suffice, which is precisely what the ELD proposes.

However, the crucial elements that in reality will determine the ability of the Directive to achieve the prevention and remediation of environmental damage are the way in which is dealt with retroactivity and causality, the defences that are accorded and whether or not provisions for (obligatory) insurance are foreseen. As studied above, some provisions in the ELD might seriously undermine the ability of the Directive to exert a preventive effect and to ensure restoration of damage. Indeed, in theory, strict liability could be a strong incentive for operators to take all possible risk-minimising measures and it could be a way of implementing the precautionary principle. However, the restricted scope of the Directive, the fact that the burden of proof lays with the authorities, the availability of the permit and the state-of-the-art defence and the absence of mandatory insurance might cause that the ELD might not set a strong incentive for the potential liable operators to invest in risk-minimising measures. Moreover, the risk might exist that operators cannot be held liable and that restoration cannot be ensured as Member States do not have direct responsibility for prevention and restoration under the ELD regime. Furthermore, as final decisions concerning these crucial elements are passed on to the Member States, they will influence certainly the burden for industry within the Member States, which will be discussed in more detail in the next chapter.

In sum, the regime of the ELD shows some inefficiencies. It must be clear though that these inefficiencies do not necessary result from the fact that the regime has been issued at European level. Indeed, also at national level these inefficiencies might arise. However, the ELD is clearly the result of a political and economical bargaining process, which definitely has influenced the content of the Directive. Moreover, given the burdensome development process of the ELD, one might get the idea that at some point it was just important to get a Directive adopted and that its provisions could be fine-tuned in later amendments.

Yet, why was there a need to shift environmental liability rules from the Member States to the European level?

Chapter 6 examined whether the Environmental Liability Directive corresponds with the predictions of the theoretical framework on the optimal decision-making level of liability rules for environmental damage and if not, how the harmonisation in the European Union of environmental liability rules, including liability rules for soil pollution, can be explained. Therefore, the arguments that where provided by the Commission to justify the Environmental Liability Directive with regard to the subsidiarity principle, were compared with the arguments for harmonisation provided by the economic theory of federalism in the environmental field.

It appeared that from an economic point of view, the reasons advanced by the Commission for the ELD seem rather weak, and would not justify a shift from the Member States to the European level of environmental liability rules, including liability rules for soil pollution.

Indeed, from an economic point of view, the only valid argument for centralisation was the internalisation of transboundary damage, however, only a so-called 'transboundary only'-regime would be justified rather than full harmonisation. Yet, it was shown that the Directive would not necessarily solve this transboundary damage. It was also argued that economies of scale in technical research might allow for co-operation or centralisation of certain tasks, like research or data gathering on soil contamination and restoration. However, again, the promise of economies of scale in scientific research would not justify for a centralisation in an excessive sense. 
Next, it was shown that fears for a race-to-to-bottom or unfair marketing conditions, due to different liability rules in the Member States seem not very likely to become true, and therefore these arguments do not justify harmonisation of environmental liability rules in the European Union. Moreover, it was shown that the ELD will not create a level playing field or realise a reduction in transaction costs, neither for environmental liability rules in general nor for liability for soil pollution in particular.

With respect to the next two arguments provided for by the Commission, it was argued that the realisation of the polluter pays, precautionary and preventive principles and restoration and decontamination of environmental damage as such do not explain why environmental regulation should be issued at the European level. Moreover, it was indicated that the ELD will not necessarily realise the polluter pays, precautionary and preventive principles, or the restoration and decontamination of the environment.

Finally, if the minimum level of protection argument would be accepted as a valid argument for shifting environmental liability rules from the Member States to the European level, it must be emphasized that this reason for harmonisation would not be based on economic efficiency, but on the desire to provide a minimum level of environmental quality and of protection against environmental accidents. Moreover, if the preferences of the citizens in the different Member States are ignored, harmonisation of environmental liability rules on the basis of this argument only amounts to paternalism.

The conclusion at the normative level was, however, not necessarily that there should be no European action at all with respect to environmental liability. Subsidiarity is not a question of either centralised or decentralised decision-making, but may involve a mixture of powers at different levels. With respect to soil pollution in particular, a European register of contaminated land might on the one hand increase transparency which could help in creating a level playing field for multinational corporations and on the other hand it could improve clean-up of contaminated sides. Nevertheless, the diversity of soils implies that any soil protection policy needs to have a strong local element build in. Therefore, certainly in the specific case of soil pollution, the arguments for harmonisation of liability rules for soil pollution seems to be weak.

Concluding, the regime of the ELD shows some inefficiencies and the comparison of the theoretical framework with the way in which the balance between centralisation and decentralisation is sought in the regime of the ELD shows that there is 'more Europe' and that the ELD goes further than what the theoretical framework would predict. Put differently, from an economic point of view, there is an inefficient shift of competences from the Member States to the European level with respect to environmental liability rules as shown by the example of liability rules for soil pollution.

Therefore, additional explanations were sought for the existence of the ELD and for certain provisions in the ELD by means of the private interest approach. Indeed, in order to understand why the decisionmaking level of environmental liability rules was shifted from the Member States to the European level, how the ELD got to its final form, and why certain provisions are as they are, rent seeking behaviour and lobbying of different interest groups in the decision-making process of the ELD should not be ignored. The use of private interest theories might help to unveil reasons for the harmonisation of environmental liability rules in the European Union that cannot be explained by the economic theory of federalism.

In particular, it was examined on the one hand, whether the inefficient shift of competences to the European level with respect to environmental liability rules, resulting in 'too much Europe', had been caused by interest group lobbying and, on the other hand, whether the inefficiencies in the Directive itself could be explained by interest group lobbying.

First, the adoption process of the ELD was studied with respect to interest group lobbying. It was explained who were the actors involved in the decision-making process of the ELD and what their stakes were. The adoption process of the ELD was examined in detail and it was indicated at which stages and at which institutions lobbying took place, in particular with respect to permit compliance and state-of-the-art defence, subsidiary state liability and mandatory financial insurance.

It appeared that the existence and content of the ELD clearly showed the influence of lobbying activities, both by industry and environmental NGO's as the influence of the Member States.Therefore, the lobbying of all actors involved in the ELD decision-making process add to explain the existence and the content of the ELD.

Next, it was examined whether the lobbying activities, observed in the adoption process of the ELD, and the result of this lobbying, corresponded with the predictions of private interest theories which were discussed in the theoretical part. It seemed that the lobbying behaviour with respect to the level of the regulation showed some elements of both the Becker and the Buchanan theory on lobbying behaviour. Moreover, it seemed that environmental NGO's, industry and Member States, all for their own reasons, welcomed or at least did not oppose the idea of a European environmental liability regime. The Commission on its side might have welcomed a European environmental liability regime for other reasons than only public welfare and protection of the environment as for example enlarging its own competences 
in fields for which it did not have any direct competence yet, as soil protection policies. Hence, competences were shifted from the Member State level to the European level, contrary to what economic theory would suggest. Thus, the answer on the question whether the inefficient shift of competences to the European level with respect to environmental liability rules can be explained by interest group lobbying and private interest distortions is probably affirmative.

With respect to the content of the ELD itself, it was shown that industry was most successful in obtaining its claims, compared to environmental NGO's. Hence, the lobbying behaviour of the main actors in the ELD adoption process with respect to the content of the Directive might fit better into Olson's theory of successful, single-oriented and well-organised lobby groups, rather than in Becker's theory of competition. Yet, it seems that also the inefficiencies in the Directive itself can be explained by interest group lobbying, and in particular by industry lobbying.

Hence, also the answer on the question whether the inefficiencies in the Directive itself could be explained by interest group lobbying is probably affirmative.

Finally, it was examined whether lobbying behaviour by interest groups would cause more distortions at the national level than at the central level so that this would justify Community action in the field of environmental liability, as examined in the theoretical part.

It was shown that in the case of the European Union, it seems precipitate to state that environmental lobby groups are underrepresented at the state level relative to industry interests and that therefore responsibility for environmental regulation should be assigned to the European level. At the European as well as at the Member State level, industry lobby groups might have more lobbying power relative to environmental interest groups. Indeed, due to lacking resources, and the disparity of interests and power of environmental lobby groups at the Member States level, industry lobby groups might co-ordinate their lobbying efforts across national frontiers more easily than environmentalists. The adoption process of the ELD indeed reflected this inequality and showed that industry lobby groups realised to obtain important concessions in particular with respect to permit compliance and state-of-the-art defence and compulsory insurance. Furthermore, a race-to-the-bottom seems rather unrealistic in the case of environmental liability rules. Indeed, there are no indications that industry strived for a race-to-the-bottom. More realistically, it seemed that industry preferred a somewhat consistent (minimum) approach in the Community. Finally, harmonisation of environmental liability rules might be used by industry to obtain a (minimum) harmonised regime in order to avoid distortions of competition. Yet, harmonisation of marketing conditions to serve the private interest, it certainly is no valid argument for the shift of environmental liability rules from the Member States to the European level.

Hence, the claim that the lobbying would cause more distortions at the national level than at the central level and therefore this would justify a European environmental liability regime is precipitate. This negative conclusion should not imply that the Member States would enact optimal environmental regulation, or that private interest distortions are less serious in the Member States than at the European level. The lobbying process is so complex that any general conclusion is almost certain to be wrong.

In sum, the private interest approach provides useful insights into the lobbying behaviour of the actors involved in the adoption process of the ELD and provides additional explanations for the existence of the ELD and for certain provisions in the ELD. Indeed, the private interest approach clarifies why the ELD has been issued at European level, in contrast to what would be efficient according to economic theory, and why certain provisions are adopted, again contrary to what would be efficient according to economic theory.

Hence, the question whether the harmonisation of environmental liability rules in the European Union, including liability rules for soil pollution, was desirable from an economic point of view and for what reasons harmonisation did take place can be answered as follows: from an economic point of view there are few reasons for harmonisation of environmental liability rules, including liability rules for soil pollution, and hence, harmonisation was not desirable. Yet, harmonisation did take place mainly in response to private interests.

In order to visualise the analysis, the framework on the optimal decision-making level of liability rules for soil pollution, which was developed in Chapter 3, and which combined both public interest and private approaches was applied to the particular case of the Environmental liability Directive. The framework shows that, from an economic point of view, the reasons advanced by the Commission for the ELD seem rather weak, and would not justify a shift of environmental liability rules from the Member States to the European level and hence, from an economic point of view, there is an inefficient shift of competences from the Member States to the European level with respect to environmental liability rules and for example of liability rules for soil pollution. However, private interest theory explains to a large extent why there is an Environmental Liability Directive, and why certain provisions are as they are. 
Concluding, this research learns us that: the shift as such of environmental liability rules to the European level was inefficient and does not correspond with the economic criteria or centralisation. At the same time, the analysis in this research also made clear that an ELD was unavoidable for private interest reasons. Remarkably, there seemed to be a strange coalition between different interests who all (for various reasons) were in favour of shifting legislative powers for environmental liability to Brussels. The most important institutional player -the European Commission- clearly was in favour of the ELD because it would strengthen its institutional position and because it would allow the Commission to undertake action in an area where it in fact had no formal competences (eg. soil pollution). Moreover, both industries and ENGO's were in favour for different reasons: ENGO's hoped that shifting powers to Europe would lead to a more stringent environmental liability regime, so that European powers would lead to an overall increase of environmental quality in Europe. Industry was, for different reasons, also in favour of harmonization. Their main concern was harmonization of marketing conditions for industry.

However, if one looks at the final contents of the ELD, Chapter 5 showed that many inefficiencies appeared. They were precisely the result of the fact that all the parties involved were in favour of shifting powers to Europe, but of course disagreed on the contents of the environmental liability regime. ENGO's were against a state of the art and a permit compliance defence, whereas this was strongly favoured by industry. As a result of that, Europe now indeed has an environmental liability directive, but the impact is (precisely because it is the result of a compromise) rather limited. Therefore, it is also difficult to establish who can be qualified as a winner in the lobbying process. The reason is that many crucial issues have either been deferred to the Member States or have been shifted to a longer term (like the decision on whether or not to introduce financial securities). Industry therefore did get an environmental liability directive (which was also wanted by ENGO's and the European Commission) but the final scope of liability will crucially depend upon issues which will have to be fixed by the Member States (such as causation and the influence of the permit on liability). The ELD therefore surely does not harmonize marketing conditions and it is equally doubtful whether it will lead to an overall improvement of environmental quality. The real winner is probably the European Commission who could once more prove to be able to make legislation in an important area of environmental law. The fact that the result may be an inefficient compromise following the legislative process apparently did not bother neither the civil servants at the Commission, nor the politicians in the Council who adopted the ELD.

Furthermore, the process of the coming into being of the ELD nicely illustrates that the decisionmaking on centralization/decentralization in Europe not surprisingly does not take place along the lines of economic reasoning. Economic criteria for centralization are advanced by the Commission, but mostly these criteria do not justify centralisation. Apparently, other values than economics play a more important role in the decision concerning shifting of powers to the European level. In some cases, these reasons may be justice related. For example, the European Commission clearly refused a 'transboundary only' regime for environmental liability (whereby the European regime would only apply to cases of transboundary pollution) since this was considered to violate the equality principle. However, in addition to these justice related arguments, it is more likely that the desire for power and expansion of competences by the European institutions was the most important driving force behind the ELD and probably in other areas as well.

Although one could therefore pessimistically argue that economic analysis is apparently not taken into account when decisions are made at the European level concerning (de)centralization we believe that using economic arguments in the way we have presented in this research still is useful. At the positive level, the advantage of economics is that it allows a better understanding of why certain shifts to a central level have taken place. Even if public interest criteria cannot always provide an explanation, private interest theory can in some cases provide a better understanding of inefficient centralization attempts. In addition to the positive use of economics, one can also use economic arguments at the policy level. Indeed, for those (lawyers, politicians or other social engineers) interested in promoting public welfare, the economic criteria are useful since they illustrate in what circumstances centralisation may effectively contribute to increasing social welfare. Moreover, economic theory can also be used to show at to some extent an inefficient shift to the European level takes place merely because of an increased struggle for power between the European Commission and the Member States. Finally, public choice analysis sometimes clearly shows that especially in the area of environmental law, centralisation is merely desired by industry in order to erect barriers to entry.

Hence, even those who are traditionally critical of the use of economic arguments in the policy debate may find it useful to employ these arguments either at the positive or at the normative level. This type of economic analysis indeed also allows showing several undesirable (averse) effects of a centralisation which does not take place on the basis of economic criteria. Hence, economic analysis may provide also a 
contribution in fighting the lobbying by interest groups and the European Commission for an inefficient shift of powers to Europe.

Yet, meanwhile the Directive has entered into force. Interpreting the Directive in light of its aim and general principles of EC environmental law seems the best option to give the ELD the chance to become an effective instrument to ensure prevention and restoration of environmental damage in the European Union. 



\section{Samenvatting}

\section{SAMENVATTING}

Dit onderzoek tracht een bijdrage te leveren aan het debat over het optimale beslissingsniveau van milieuregulering in een federaal systeem. De diverse argumenten voor en tegen harmonisatie van milieuwetgeving en de - bij tijden - hevige debatten over harmonisatie, zowel in academisch kringen als op politiek niveau, inspireerden dit onderzoek. Centraal staat de vraag of harmonisatie van milieuaansprakelijkheidsregels in Europa, waaronder aansprakelijkheid voor bodemverontreiniging, wenselijk was vanuit economisch perspectief, en om welke redenen harmonisatie plaatsvond.

Om deze vraag te beantwoorden, maakt het onderzoek gebruik van een rechtseconomische methodologie. In een eerste stap wordt de economische analyse van aansprakelijkheidsrecht gebruikt om te onderzoeken welk type aansprakelijkheidsregel, vanuit economisch perspectief, het meest efficiënt is om milieuverontreiniging te vermijden en te herstellen. Vervolgens wordt het optimale beslissingsniveau van deze aansprakelijkheidregels onderzocht vanuit twee verschillende theoretische invalshoeken binnen de rechtseconomie: een 'public interest benadering' en een 'private interest benadering'. De 'public interest' benadering, gebaseerd op de economische theorie rond federalisme, ziet regulering als een mogelijkheid om marktfalen te corrigeren. De public interest theorie veronderstelt dat de overheid in staat is om dit marktfalen te corrigeren en beslissingen neemt in het publiek belang. De 'private interest' benadering daarentegen is gebaseerd op drie economische theorieën die de rol van belangengroepen in het wetgevingsproces benadrukken. Deze theorieën zijn de 'capture theory', de 'economic theory of regulation' en 'public choice theory'. De basisidee van deze theorieën is dat belangengroepen proberen om politieke besluiten (en dus wetgeving) te beïnvloeden, om zo zelf winsten of voordeel te behalen. Dit is onproductief vanuit een welvaartseconomisch perspectief. Op basis van deze twee invalshoeken wordt een theoretisch kader ontworpen met betrekking tot het optimale beslissingsniveau voor aansprakelijkheidsregels voor milieuverontreiniging. Als voorbeeld wordt bodemverontreiniging bestudeerdntreniginggde ecoonmische theorie rond federalisme. Dit theoretisch kader wordt vervolgens getoetst aan de harmonisatie van milieuaansprakelijkheidsregels, waaronder aansprakelijkheid voor bodemverontreini ging, in de Europese Unie, door middel van Richtlijn 2004/35/EC. Door de vergelijking van economische theorie met de actuele ontwikkelingen in de Europese Unie, hoopt dit doctoraatsonderzoek bij te dragen aan de bestaande theorieën in verband met het optimale beslissingsniveau voor milieureglementering in een federaal systeem. Een tweede doelstelling is meer inzicht te verstrekken in de redenen voor harmonisatie in een concrete situatie.

Aangezien harmonisatie een zeer complexe materie is, worden vier subvragen geformuleerd om de bovenstaande centrale onderzoeksvraag te beantwoorden.

Om de relevantie van dit onderzoek te duiden, luidt de eerste subvraag: wat is de bijdrage van milieuaansprakelijkheidsregels in het voorkomen en herstellen van milieuverontreiniging en welk type van aansprakelijkheidsregel is het meest efficiënt in het voorkomen en herstellen van milieuverontreiniging? Inderdaad, voorafgaand aan de vraag op welk beslissingsniveau aansprakelijkheid voor milieuverontreiniging best geregeld kan worden, moet de vraag beantwoord worden welke aansprakelijkheidsregel het meest efficiënt is vanuit economisch perspectief om milieuverontreiniging te vermijden en indien nodig te herstel te verzekeren.

Om deze vraag te beantwoorden, wordt in Hoofdstuk 2 de economische analyse van het aansprakelijkheidsrecht toegepast op milieuverontreiniging. Er wordt aangetoond dat de functie van aansprakelijkheid tweevoudig is. Enerzijds heeft aansprakelijkheid een preventieve functie, doordat aansprakelijkheid individuen een reden geeft om rekening te houden met de negatieve effecten van hun activiteiten op anderen. Daardoor kan aansprakelijkheid het gedrag van individuen sturen zodat welvaart in de samenleving gemaximaliseerd kan worden. Anderzijds kan aansprakelijkheid compensatie voor schade in geval van een ongeval verzekeren. Er wordt daarom geconcludeerd dat, naast regulering, aansprakelijkheidsregels een waardevolle complementaire rol kunnen spelen in de preventie en het herstel 
van bodemverontreiniging. Inderdaad, de meeste Europese lidstaten hebben wetgeving ter preventie en herstel van bodemverontreiniging. Om leemtes in de wetgeving op te vangen, wordt deze vaak met aansprakelijkheidsregels gecombineerd. Kortom, regulering en aansprakelijkheid zijn complementair.

Om de optimale aansprakelijkheidsregel te bepalen om de bestaande regulering voor bodemverontreiniging aan te vullen, wordt een onderscheid gemaakt tussen inherent gevaarlijke activiteiten en niet-gevaarlijke activiteiten. Voor gevaarlijke activiteiten blijkt risicoaansprakelijkheid optimaal, aangezien dan ook het activiteitenniveau beperkt kan worden. Voor niet-gevaarlijke activiteiten volstaat schuldaansprakelijkheid. Er wordt niet beweerd dat aanprakelijkheid de perfecte oplossing is voor alle gevallen van milieuschade. Niettemin kan aansprakelijkheid een waardevolle complementaire rol spelen in de preventie en herstel van bodemverontreiniging. Conclusie: verder onderzoek naar het optimale beslissingsniveau voor aansprakelijkheidsregels voor bodemverontreiniging in een federaal systeem zoals de Europese Unie, is zonder twijfel waardevol.

Aldus luidt de tweede subvraag: wat is het optimale beslissingsniveau voor aansprakelijkheidsregels voor milieuverontreiniging in een federaal systeem vanuit theoretisch perspectief?

Om deze tweede subvraag te beantwoorden, worden in Hoofdstuk 3 de argumenten van de 'public interest' benadering en van de 'private interest' benadering voor harmonisering van milieureglementering onderzocht.

Het uitgangspunt van de 'public interest' benadering is decentralisatie van besluitvorming. Vervolgens wordtisatie, onderscheiddn dat onderzocht of er redenen zijn om deze besluitvorming op te tillen naar een hoger beslissingsniveau. Deze zogenaamde 'bottom-up benadering' met betrekking tot centralisatie is gebaseerd op het Tiebout Model en het Decentralisatie Theorema van Oates. Het idee is dat door decentralisatie wetgeving aangepast kan worden aan de preferenties van de burgers. Echter, door externaliteiten (of externe effecten) en marktfalen, transactiekosten of onvolledige informatie, kan het zijn dat sommige beslissingen beter genomen worden op een hoger overheidsniveau.

Op basis van de 'public interest' benadering worden vier redenen voor centralisatie, en eventueel zelfs voor harmonisatie, onderscheiden: het grensoverschrijdend karakter van milieuschade, het race-to-thebottom argument, harmonisering van marktvoorwaarden en het minimum beschermingsniveau of Europees-erfgoed argument. Elk argument wordt eerst onderzocht voor milieuregulering. Vervolgens wordt het argument toegepast op milieuaansprakelijkheidsregels, en als voorbeeld op aansprakelijkheid voor bodemvervuiling.

Het valt buiten het bestek van deze samenvatting om een uitgebreide analyse van deze argumenten (hiervoor zie Hoofdstuk 3) te geven, maar een kort overzicht lijkt aangewezen.

Het blijkt dat geen van bovenstaande argumenten een volledige harmonisatie van milieuaansprakelijkheidsregels zou rechtvaardigen. Wel zou de federale overheid een ondersteunende taak kunnen hebben wat betreft informatieverstrekking en wetenschappelijk onderzoek. Daarnaast zou de federale overheid oplossingen voor grensoverschrijdende schade of voor speciale beschermingsgebieden kunnen uitwerken. Algemene principes van aansprakelijkheid ter bescherming van het milieu, of een specifiek aansprakelijkheidsregime voor bepaalde activiteiten zouden eveneens op centraal niveau gedefinieerd kunnen worden, gecombineerd met differentiatie wat betreft de inhoud van dit regime. In zulke omstandigheden zouden transactiekosten verlaagd kunnen worden, markttoegang verbeterd, een minimum beschermingsniveau gegarandeerd worden en toch zouden verschillen in preferenties van de burgers gerespecteerd kunnen worden.

Dezelfde redenering gaat ook op voor aansprakelijkheid voor bodemverontreiniging. Het meest doorslaggevende argument voor decentralisatie van aansprakelijkheid voor bodemverontreiniging is dat geografie, plaatselijke condities, economische mogelijkheden en problemen substantieel kunnen verschillen van plaats tot plaats. Bovendien zijn kennis van en ervaring met de specifieke bodemtoestand op een bepaalde plaats cruciaal om een gepast aansprakelijkheidsregime te ontwerpen voor bodemverontreiniging. Daarom, zeker in het geval van bodemverontreiniging lijkt de 'one-size-fits-all' benadering geen goede keuze.

Het blijkt echter dat in het echte leven het bestaan of de harmonisering van milieureglementering niet altijd verklaard kan worden op basis van de 'public interest' benadering alleen. Voor een volledig inzicht in het milieu-wetgevingsproces, moet de invloed van belangengroepen op de besluitvorming erkend worden. De 'public interest' benadering wordt daarom aangevuld met de zogenaamde 'private interest' benadering. Deze benadering onderzoekt de invloed van lobbying of 'rent seeking' op het wetgevingsproces. De (achterliggende) redenen voor een bepaalde politiek kunnen soms het best begrepen worden als niet alleen het publiek belang, maar ook het gedrag van de overheid en van belangengroepen in overweging genomen wordt.

Eerst wordt een overzicht gegeven van de economische theorieën die de rol van belangengroepen in het wetgevingsproces onderzoeken: de 'capture theory', de economic theory of regulation en public choice 
theory. Daarna worden, op theoretisch niveau, de belangen geanalyseerd van de voornaamste belangengroepen op het gebied van milieuwetgeving: de overheid, de industrie en milieugroeperingen. Vervolgens gaat de aandacht uit naar 'milieu-federalisme'. Lobby-activititeiten kunnen immers niet alleen de inhoud van een bepaalde regelgeving beïnvloeden, maar ook het beslissingsniveau waarop deze regelgeving tot stand zal komen. Belangengroepen, die baat hebben bij een bepaalde regulering, zullen dat beslissingsniveau prefereren waar hun macht het grootst is ten opzichte van andere groeperingen, die andere bezorgdheden hebben. Meer bepaald worden drie 'private interest' storingen onderzocht, die het beslissingsniveau voor milieureglementering kunnen beïnvloeden. Ten eerste wordt vaak beweerd dat milieubelangen systematisch ondervertegenwoordigd zijn op het decentraal niveau. Verder hebben twee argumenten voor harmonisatie uit de 'public interest' benadering raakpunten met de 'private interest' benadering: landen zouden over kunnen gaan tot een race-to-the-bottom, als gevolg van lobby-activiteiten van de industrie, en de harmonisatie van marktvoorwaarden kan in het voordeel zijn van bepaalde belangengroepen. Er wordt onderzocht of deze drie 'private interest' storingen centralisatie of harmonisatie van milieureglementering, en in het bijzonder milieuaansprakelijkheid, zouden rechtvaardigen.

Het blijkt dat, wat betreft milieuaansprakelijkheid, het moeilijk is om op theoretisch niveau in te schatten wat de posities van de belangrijkste belangengroepen in het milieu-wetgevingsproces zullen zijn, wat het optimale niveau van regulering zal zijn, en wat het resultaat van de lobbying zal zijn. Niettemin kan gesteld worden dat lobby-activiteiten niet automatisch centralisatie rechtvaardigen, omdat lobbying zowel op decentraal als centraal niveau plaatsvindt. Helaas is de public choice theorie niet in staat om de invloed en de gevolgen van lobbying op het decentraal niveau ten opzichte van het centraal niveau te voorspellen. Alleen openheid op ieder niveau kan garanderen dat beslissingen genomen worden in het publiek belang in plaats van in het voordeel van bepaalde belangengroepen. Wat betreft aansprakelijkheid voor bodemverontreiniging, kan gesteld worden dat bodemverontreiniging meestal een lokaal probleem is, en men kan daarom veronderstellen dat het gemakkelijker zou kunnen zijn voor milieugroeperingen om de steun van de burgers te krijgen voor hun acties voor strenge aansprakelijkheidsregels op decentraal niveau, dan op centraal niveau, waar de burgers veel minder betrokken zijn.

De redenering dat centralisatie nodig zou zijn omdat industrie sterker zou zijn dan milieugroeperingen op decentraal niveau, lijkt daarom niet te op te gaan voor aansprakelijkheid voor bodemverontreiniging. Kortom, ook op basis van de 'private interest' benadering, blijft er een sterke voorkeur voor een decentraal milieubeleid, waar de kosten en baten van dit beleid tastbaar zijn.

De resultaten van de public en private interest benaderingen worden gecombineerd tot een 'framework' of leiddraad ter ondersteuning van het onderzoek naar het optimale beslissingsniveau voor milieuaansprakelijkheidsregels in een federaal systeem. Immers, alleen een gecombineerde public-private interest benadering kan de complexiteit van milieubeleid weergeven en de verschillende factoren aangeven die het optimale beslissingsniveau voor milieuaansprakelijkheidsregels beïnvloeden. Als voorbeeld wordt bodemverontreiniging bestudeerd.

Het doel van dit framework is niet om een eenduidig antwoord te geven op de vraag wat nu het optimale beslissingsniveau is voor aansprakelijkheidsregels voor milieuverontreiniging in een federaal systeem vanuit theoretisch perspectief. De vraag of milieuaansprakelijkheid in een federaal systeem gedecentraliseerd of gecentraliseerd moet worden kan immers niet in zwart-wit bewoordingen beantwoord worden. De enige juiste oplossing bestaat niet. Het framework dient eerder gezien te worden als een middel om het probleem te bestuderen en om verschillende beleidsopties te evalueren. Het uitgangspunt van het framework is decentralisatie. Vervolgens kan onderzocht worden in welke omstandigheden centralisatie gerechtvaardigd zou zijn. Gebaseerd op de resultaten van de public en de private interest benadering, worden vijf evaluatiefactoren opgesteld, die de beslissing in verband met het optimale beslissingsniveau voor milieuaansprakelijkheidsregels kunnen ondersteunen: aanwezigheid van externe effecten, risico op een race-to-the-bottom, verschillen in markvoorwaarden, de noodzaak van een minimum beschermingsniveau, en de invloed van lobby-activiteiten. Het bestaan, gewicht en het belang van elk van deze factoren is afhankelijk van de concrete situatie. schermingsniveau, ce-to-the-bottomor milieuaansprakelijkhidsregels, kunnen ondersteunen. u lijkBovendien kunnen deze factoren elkaar beïnvloeden.

Steunend op dit framework, kan nu een antwoord gegeven worden op de tweede subvraag. Het blijkt dat, vanuit theoretisch perspectief, geen eenduidig antwoord gegeven kan worden op de vraag op welk niveau aansprakelijkheid voor milieuverontreiniging best gereguleerd kan worden. In een concrete situatie zullen de verschillende factoren en gevolgen tegen elkaar afgewogen moeten worden om te onderzoeken of samenwerking of centralisatie nodig zou zijn. Echter, geen van de factoren zou een volledige harmonisatie van aansprakelijkheid voor milieuverontreiniging rechtvaardigen. Ook zijn er, vanuit economisch perspectief, maar weinig omstandigheden waarin economisch perspectief, decentralisatie de enige en beste oplossing zou zijn. Specifiek voor bodemverontreiniging, is het belangrijkste argument voor decentralisatie 
van aansprakelijkheid voor bodemverontreiniging dat plaatselijke omstandigheden, geografie, gevolgen van vervuiling en economische belangen substantieel kunnen variëren tussen landen. Bovendien zijn kennis van en ervaring met de specifieke bodemtoestand op een bepaalde plaats cruciaal om een gepast aansprakelijkheidsregime te ontwerpen voor bodemverontreiniging. Dit betekent echter niet dat, in bepaalde omstandigheden, een samenwerking tussen verschillende overheidsniveaus niet voordelig zou kunnen zijn. De beslissingsbevoegdheid zou in principe bij de decentrale overheid kunnen liggen, terwijl de centrale overheid een ondersteunende taak zou kunnen hebben wat betreft informatieverstrekking en wetenschappelijk onderzoek of het uitwerken van oplossingen voor grensoverschrijdende schade of voor speciale beschermingsgebieden.

Schijnbaar in tegenstelling met bovenstaande economische analyse, bestond, op Europees niveau, de wens om milieuaansprakelijkheid in Europa te harmoniseren al zo'n 20 jaar. Op 21 april 2004, werd Richtlijn 2004/35/CE betreffende milieuaansprakelijkheid met betrekking tot het voorkomen en herstellen van milieuschade (eindelijk) aangenomen. Zijn er specifieke omstandigheden in de Europese Unie die pleiten voor centralisatie of zelfs harmonisatie van milieuaansprakelijkheidsregels, waaronder aansprakelijkheid voor bodemverontreiniging, of zijn de redenen voor centralisatie niet noodzakelijk gebaseerd op public interest beschouwingen?

Een derde subvraag daarom is: om welke redenen werd, op Europees niveau, de harmonisatie van milieuaansprakelijkheid noodzakelijk geacht, wat is het toepassingsgebied van de richtlijn en wat voorziet de richtlijn, bijvoorbeeld voor bodemverontreiniging?

In hoofdstuk 4 wordt eerst de bevoegdheid van de Europese Unie om milieuaansprakelijkheidsregels te harmoniseren verduidelijkt. Vervolgens worden de verschillende fases in de ontwikkeling van de richtlijn besproken en worden de redenen die de Europese Commissie opgaf in deze verschillende fases voor de harmonisering van milieuaansprakelijkheid aangegeven. Tot slot worden het toepassingsgebied en de voorzieningen in de richtlijn voor bodemverontreiniging bestudeerd.

Met Richtlijn 2004/35/CE betreffende milieuaansprakelijkheid met betrekking tot het voorkomen en herstellen van milieuschade, wil de Europese Unie een gemeenschappelijk kader van aansprakelijkheidsregels tot stand brengen voor het voorkomen en herstellen van milieuschade, gebaseerd op het 'vervuiler betaalt' principe. De ontwikkeling van de richtlijn en de richtlijn zelf, deden heel wat stof opwaaien, zowel in academische kringen als op politiek niveau. Het voornaamste punt van discussie betrof de vraag of en hoe ver de Europese Unie kan gaan in het opstellen van een Europees aansprakelijkheidsregime. Daarom is het opmerkelijk dat, in de uiteindelijke tekst van de richtlijn, de Commissie geen afdoende verklaring geeft waarom een Europees milieuaansprakelijkheidsregime nodig is en waarom de Lidstaten dit niet zelf kunnen doen, zoals de Commissie behoort te doen op basis van het subsidiariteitbeginsel. De redenen waarom harmonisatie noodzakelijkheid werd geacht, situeren zich veeleer in de documenten, die de richtlijn voorafgingen. De drie documenten waarnaar verwezen kan worden om de redenen na te gaan voor de overdracht van bevoegdheid voor milieuaansprakelijkheidsregels van de Lidstaten naar het Europees niveau zijn: het Groenboek betreffende het Herstellen van Milieuschade, het Witboek betreffende Milieuaansprakelijkheid en het Commissie voorstel voor een richtlijn betreffende milieuaansprakelijkheid met betrekking tot het voorkomen en herstellen van milieuschade (in het bijzonder het Explanatory Memorandum). Uit deze drie documenten blijkt dat de Commissie zes hoofdredenen aanhaalt voor Europese actie op het gebied van milieuaansprakelijkheid: het grensoverschrijdende karakter van milieuschade, het race-to-the-bottom argument, het gelijke marktvoorwaarden argument (ook het 'level-playing field' argument genoemd), de realisatie van het 'vervuiler-betaalt'-principe, het nakomen van het preventie- en het voorzorgsbeginsel, sanering en herstel van het milieu, en de garantie op een minimum beschermingsniveau.

Vervolgens wordt het toepassingsgebied van de richtlijn bestudeerd. Het blijkt dat het toepassingsgebied van de richtlijn beperkt is, zodat verschillende aansprakelijkheidsregimes van toepassing kunnen zijn op verschillende vormen van schade bij eenzelfde ongeval. Bovendien verduidelijkt de richtlijn de verhouding met andere aansprakelijkheidsregimes niet. Ook zijn verschillende cruciale aspecten van een aansprakelijkheidsregime, zoals het al dan niet toekennen van verweren, verzekeringsaspecten maar ook precieze definities van schade en herstelcriteria overgelaten aan de Lidstaten. Lidstaten mogen eveneens strengere regels behouden of opnemen in hun nationaal recht om milieuschade te voorkomen en te herstellen. Bijgevolg voorziet de richtlijn een onzeker kader en creëert de richtlijn minder harmonisatie dan de voorstanders van de richtlijn misschien hadden gehoopt.

Met betrekking tot bodemverontreiniging blijkt dat de toepassing van de richtlijn eveneens beperkt zal zijn. De richtlijn is alleen van toepassing bij schade die na de inwerkingtreding van de richtlijn (30 april 2007) is veroorzaakt, en er moet een duidelijk verband zijn tussen de vervuiler en de schade. Bovendien moet de schade aan de gezondheid 'significant' zijn, en moet deze veroorzaakt zijn door een activiteit, zoals 
gespecificeerd in Annex III van de richtlijn. Dit betekent dat veel vervuilde sites in Europa gesaneerd zullen moeten worden onder de desbetreffende wetgeving van de Lidstaten zelf.

Bovendien, ook voor de vervuilde sites die binnen het toepassingsgebied van de richtlijn vallen, zijn verschillende aspecten aan de Lidstaten overgelaten, zoals het toekennen van een vergunningsverweer of een state-of-the-art verweer, zodat de vervuiler vrijgesteld kan worden van aansprakelijkheid. De implementatie van de richtlijn kan dus behoorlijk verschillen in de verschillende Lidstaten. Ook geeft de richtlijn een grote vrijheid wat betreft de sanering van de vervuilde sites. Samen met de talrijke sites die onder nationale wetgeving dienen te worden gesaneerd, maakt dit dat de richtlijn weinig harmonisatie zal creëren. Integendeel, de richtlijn zou zelfs onzekerheid kunnen veroorzaken omdat verschillende aansprakelijkheidsregimes van toepassing kunnen zijn.

De analyse in Hoofdstuk 4 en het antwoord op de derde subvraag geven vanzelf aanleiding tot de laatste subvraag: komt de richtlijn overeen met het theoretisch kader, zowel wat betreft economische efficiëntie als wat betreft het beslissingsniveau voor aansprakelijkheid voor milieuverontreiniging, en indien niet, waarom werd harmonisatie van milieuaansprakelijkheid, waaronder aansprakelijkheid voor bodemverontreiniging, noodzakelijk geacht in de Europese Unie?

Analoog aan de theoretische analyse, is het aangewezen om eerst te onderzoeken of het aansprakelijkheidsregime zoals voorzien in de richtlijn efficiënt is, en overeenkomt met de economische theorie. Dit is onafhankelijk van het optimale beslissingsniveau voor aansprakelijkheidsregels voor milieuverontreiniging. Vervolgens kan het optimale beslissingsniveau voor aansprakelijkheidsregels voor mlieuverontreiniging onderzocht worden voor Europa, op basis van het theoretische kader dat in Hoofdstuk 3 werd opgesteld. Ook hier worden de argumenten van de Europese Commissie ter rechtvaardiging van de richtlijn onderzocht vanuit een 'public interest'-benadering en een 'private interest' benadering. Op deze manier kan de studie van de richtlijn het theoretisch kader aanvullen en een beter inzicht geven in alle factoren die meespelen in een concreet harmonisatiedebat.

Hoofdstuk 5 onderzoekt de economische efficiëntie van de richtlijn. Er wordt geconcludeerd dat, wat betreft de keuze van het type aansprakelijkheid, de richtlijn overeenkomt met de economische analyse van aansprakelijkheidsrecht. Deze analyse voorspelt immers dat risicoaansprakelijkheid efficiënter is voor gevaarlijke activiteiten, omdat men zo ook het activiteitenniveau van de vervuiler kan beïnvloeden. Voor niet-gevaarlijk activiteiten volstaat schuldaansprakelijkheid, hetgeen precies is wat de richtlijn voorziet.

Echter, sommige voorzieningen in de richtlijn kunnen het preventieve effect van de richtlijn ondermijnen als ook de mogelijkheid om herstel te verzekeren. Immers, in theorie kan risicoaansprakelijkheid een goede stimulans zijn voor bedrijven om alle mogelijke risico-minimaliserende maatregelen te nemen, en om het voorzorgsbeginsel te implementeren. Echter, het beperkte toepassingsgebied van de richtlijn, het feit dat de bewijslast rust op de autoriteiten, de mogelijkheid om een vergunningsverweer of een state-of-the-art verweer toe te kennen en de afwezigheid van verplichte verzekering zou er toe kunnen leiden dat de richtlijn geen overtuigende stimulans is voor bedrijven om in risico-minimaliserende maatregelen te investeren. Bovendien bestaat het risico dat bedrijven niet aansprakelijk gehouden kunnen worden en dat herstel van de schade niet verzekerd kan worden omdat de Lidstaten zelf geen directe verplichting hebben om de schade te herstellen. Bovendien, omdat de uiteindelijke beslissing voor een aantal van deze cruciale factoren doorgeschoven is naar de Lidstaten, kan de invloed van de richtlijn en de kost voor de industrie verschillen tussen de verschillende Lidstaten.

Er kan dus geconcludeerd worden dat het regime van de richtlijn enkele inefficiënties vertoond. Het moet echter duidelijk zijn dat deze inefficiënties niet noodzakelijk te wijten zijn aan het feit dat de richtlijn op Europees niveau tot stand is gekomen. Inderdaad, ook op het niveau van de Lidstaten kunnen dergelijke inefficiënties voorkomen. Toch is de richtlijn duidelijk het resultaat van een politiek onderhandelingsproces, hetgeen de inhoud van de richtlijn heeft beïnvloed. Met de moeizame onderhandelingen tijdens het ontwikkelingsproces van de richtlijn in het achterhoofd, krijgt men zelfs het idee dat op een gegeven moment het aannemen van de richtlijn belangrijker geacht werd, dan de inhoud van de richtlijn. Die inhoud kon op een later moment nog wel bijgeschaafd worden.

Maar waarom werd het nodig geacht om de bevoegdheid voor milieuaansprakelijkheid te verschuiven van de Lidstaten naar het Europees niveau?

Hoofdstuk 6 onderzoekt of de richtlijn overeenkomt met de voorspellingen van het theoretische kader voor het optimale beslissingsniveau van aansprakelijkheid voor milieuverontreiniging, en indien niet, hoe de harmonisatie van milieuaansprakelijkheid, waaronder aansprakelijkheid voor bodemverontreiniging, in Europa verklaard kan worden. Hiervoor worden de argumenten van de Europese Commissie om de richtlijn te rechtvaardigen, zoals vereist op basis van het subsidiariteitsbeginsel en het proportionaliteitsbeginsel, vergeleken met de argumenten voor harmonisatie uit de economische theorie.

Het blijkt dat, vanuit economisch standpunt, de redenen van de Commissie voor de richtlijn eerder zwak zijn, en dat deze geen verschuiving van de bevoegdheid voor milieuaansprakelijkheid, waaronder 
ook aansprakelijkheid voor bodemverontreiniging, van de Lidstaten naar het Europees niveau zou rechtvaardigen.

Inderdaad, vanuit economisch perspectief is de enige valabele reden voor centralisatie de internalisering van grensoverschrijdende schade. Echter, ook in dit geval zou een 'transboundary-only' regime volstaan, en zou geen volledige harmonisatie nodig zijn. Analyse van de richtlijn toont bovendien aan dat de richtlijn niet noodzakelijk het probleem van grensoverschrijdende schade zou oplossen. Anderzijds was al eerder aangehaald dat, omwille van schaalvoordelen in wetenschappelijk onderzoek of informatieverzameling, samenwerking tussen verschillende overheidsniveaus voordelig zou kunnen zijn. Echter, ook de mogelijkheid tot schaalvoordelen is geen reden voor vergaande centralisatie of harmonisatie.

Vervolgens wordt aangetoond dat het risico op een race-to-the-bottom of op oneerlijke concurrentie, te wijten aan verschillen in aansprakelijkheidsregels in de Lidstaten, niet erg waarschijnlijk is, en dat deze argumenten daarom de harmonisatie van milieuaansprakelijkheid in Europa niet kunnen rechtvaardigen. Bovendien toont het doctoraatsonderzoek aan, dat de richtlijn geen 'level playing field' kan garanderen, of een vermindering in de transactiekosten kan realiseren, noch voor milieuaansprakelijkheid in het algemeen, noch specifiek voor aansprakelijkheid voor bodemverontreiniging.

Met betrekking tot de twee volgende argumenten van de Commissie, wordt geargumenteerd dat de realisatie van het 'vervuiler betaalt' beginsel, het preventie- en het voorzorgsbeginsel, en de sanering en het herstel van het milieu op zich niet verklaren waarom milieuaansprakelijkheid op Europees niveau geregeld moest worden en waarom de Lidstaten dit niet zelf kunnen realiseren. Bovendien is het twijfelachtig dat de richtlijn het 'vervuiler betaalt' beginsel, het preventie- en het voorzorgsbeginsel, en de sanering en het herstel van het milieu zal kunnen realiseren.

Tot slot, als het minimum beschermingsniveau argument geaccepteerd wordt als een valabele reden voor harmonisatie van milieuaansprakelijkheid op Europees niveau, dan moet er op gewezen worden dat deze reden voor harmonisatie niet gebaseerd is op economische efficiëntie, maar op de wens om de Europese burger een minimum milieukwaliteit te garanderen en te beschermen tegen milieuschade. Indien men hierbij echter de preferenties van de burgers in de verschillende Lidstaten ignoreert, is harmonisatie van milieuaansprakelijkheid op basis van dit argument, vanuit economisch perspectief, paternalistisch.

Het besluit van deze analyse is niet dat er helemaal geen Europese actie zou mogen zijn op het gebied van bodemverontreiniging. Meer nog dan op theoretisch niveau moet en kan de vraag of milieuaansprakelijkheid in Europa gedecentraliseerd of gecentraliseerd moet worden niet in zwart-wit bewoordingen beantwoord worden. Bovendien is subsidiariteit geen kwestie van decentralisatie of centralisatie, maar laat het principe samenwerking tussen verschillende overheidsniveaus toe. Voor bodemverontreiniging bijvoorbeeld zou een Europees register van vervuilde sites een overzicht kunnen geven, duidelijkheid voor industrie kunnen scheppen en mogelijk de sanering van deze sites kunnen stimuleren. Niettemin vereist de diversiteit van de bodem in Europa en de verschillende problemen in de Lidstaten een lokaal bodembeleid. Daarom, zeker in het geval van bodemverontreiniging lijken de argumenten voor harmonisatie van aansprakelijkheid voor bodemverontreiniging, vanuit economisch perspectief, zwak.

Samenvattend kan gesteld worden dat het regime van de richtlijn enkele inefficiënties vertoont. Bovendien blijkt uit de vergelijking van het theoretisch kader met 'de praktijk' in Europa dat er 'meer Europa' is en dat de richtlijn verder gaat dan wat het theoretische model zou suggereren. Anders gezegd, vanuit economisch perspectief is er een inefficiënte verschuiving van bevoegdheden van de Lidstaten naar het Europees niveau wat betreft milieuaansprakelijkheidsregels, waaronder aansprakelijkheid voor bodemverontreiniging.

Daarom worden aanvullende redenen gezocht voor het bestaan van de richtlijn milieuaansprakelijkheid en voor bepaalde voorzieningen in de richtlijn zelf, op basis van de 'private interest' benadering. Inderdaad, om te begrijpen waarom de verschuiving van bevoegdheden voor milieuaansprakelijkheid van de Lidstaten naar het Europees niveau plaatsvond, en waarom de inhoud van de richtlijn is zoals ze is, mogen lobby-activiteiten van de verschillende belangengroepen in het wetgevingsproces van de richtlijn niet vergeten worden. Private interest theorieën kunnen hierbij helpen om de redenen te achterhalen voor de harmonisatie van milieuaansprakelijkheid in Europa, die niet gevonden konden worden op basis van de public interest benadering.

In het bijzonder wordt onderzocht of, enerzijds, de inefficiënte verschuiving van bevoegdheden voor milieuaansprakelijkheid van de Lidstaten naar Europa veroorzaakt is door lobby-activiteiten van belangengroepen, en anderzijds, of de inefficiënties in de richtlijn zelf verklaard kunnen worden door deze lobby-activiteiten.

Eerst wordt het wetgevingsproces van de richtlijn geanalyseerd op lobby-activiteiten. In een eerste stap wordt uitgelegd welke actoren betrokken waren bij het wetgevingsproces van de richtlijn, en wat hun belangen waren. Het wetgevingsproces van de richtlijn wordt in detail bestudeerd en er wordt aangegeven 
in welke stadia en waar lobbying plaatsvond. In het bijzonder wordt gekeken naar lobby-activiteiten die betrekking hadden op vergunningsverweer en state-of-the-art verweer, additionele aansprakelijkheid van de Lidstaten en verplichte financiële verzekering.

Het blijkt dat het bestaan en de inhoud van de richtlijn duidelijk beïnvloed zijn door lobbyactiviteiten, zowel van industrie als van milieuorganisaties, en door de invloed van de Lidstaten en de Commissie zelf. Dus, lobby-activiteiten van alle actoren die betrokken waren in het beslissingsproces van de richtlijn dragen bij tot de verklaring van het bestaan en de inhoud van de richtlijn.

Vervolgens wordt onderzocht of de lobby-activiteiten, die waargenomen werden in het beslissingsproces van de richtlijn, en het resultaat van deze lobbying overeenkomen met de voorspellingen van de private interest theorieën die in het theoretisch deel besproken werden. Het lijkt dat het lobbygedrag wat betreft het overheidsniveau, waarop aansprakelijkheidsregels bepaald zouden kunnen worden, overeenkomsten vertoont met zowel de Becker als de Buchanon theorie over lobbying. Bovendien lijkt het dat milieugroeperingen, industrie, en de Lidstaten zelf, elk met hun eigen redenen, niet tegen het idee van een Europees aansprakelijkheidsregime waren of dit zelfs verwelkomden. De Commissie van haar kant zou (eveneens) het Europees aansprakelijkheidsregime verwelkomd kunnen hebben uit andere motieven dan het belang van de Europese burger en de bescherming van het milieu, zoals bijvoorbeeld de mogelijkheid om haar bevoegdheden uit te breiden op domeinen waar de Commissie tot op heden geen bevoegdheid had, zoals bijvoorbeeld bodembeleid. Kortom, de aanwezigheid van private belangen kunnen verklaren waarom de verschuiving van bevoegdheden voor milieuaansprakelijkheid plaatvond van de Lidstaten naar het Europees niveau, in tegenstelling tot wat de economische theorie suggereert. Bijgevolg, het antwoord op de vraag of de inefficiënte verschuiving van bevoegdheden voor milieuaansprakelijkheid van de Lidstaten naar Europa kan verklaard worden door lobby-activiteiten van belangengroepen kan positief beantwoord worden.

Wat betreft de inhoud van de richtlijn zelf, wordt aangetoond dat de industrie, in vergelijking met milieugroeperingen, het meest succesvol was om zijn belangen te verdedigen en om bepaalde eisen ingewilligd te krijgen. Bijgevolg past het lobby-gedrag van de belangrijkste actoren in het beslissingsproces van de richtlijn wat betreft de inhoud van de richtlijn beter in Olson's theorie van succesvolle, goed georganiseerde lobby-groepen, dan in Becker's competitietheorie. Het lijkt dat ook de inefficiënties in de richtlijn zelf verklaard kunnen worden door lobby-activiteiten, en in het bijzonder door industrie-lobbying. Het antwoord op de vraag of de inefficiënties in de richtlijn zelf ook kunnen verklaard worden door lobbying, is daarom ook positief.

Tot slot wordt onderzocht of lobbying meer inefficiënties veroorzaakt op het niveau van de lidstaten dan op Europees niveau en of daarom Europese actie gerechtvaardigd zou zijn, zoals ook onderzocht werd in het theoretisch deel.

Er wordt aangetoond dat, in het geval van de Europese Unie, het voorbarig zou zijn te stellen dat milieugroeperingen altijd ondervertegenwoordigd zijn op Lidstaatniveau, in vergelijking met de industrie en dat daarom de bevoegdheid voor milieuregulering toegewezen moet worden aan het Europese niveau. In Europa kan het zijn dat industrie zowel op Europees niveau als Lidstaatniveau meer invloed heeft in vergelijking met milieugroeperingen. Redenen hiervoor zijn meer middelen en eenzelfde doel zodat industrie zich makkelijker over de landsgrenzen kan groeperen dan milieugroeperingen, die in sommige lidstaten meer invloed kunnen hebben dan in andere lidstaten. Het beslissingsproces van de richtlijn reflecteert inderdaad deze ongelijkheid en toont dat de industrie-lobby belangrijke toegevingen verkreeg, met name wat betreft het vergunningsverweer en het state-of-the-art verweer en verplichte verzekering. Niettemin lijkt het onrealistisch dat de industrie streefde naar een race-to-the-bottom in milieuaansprakelijkheid, en zijn hier geen indicaties voor. Het is realistischer dat de industrie een enigszins coherente (minimum) aanpak verkoos boven verschillende nationale aansprakelijkheidsregimes. In die zin kan de harmonisatie van milieuaansprakelijkheid in Europa gebruikt worden door de industrie om concurrentieverstoringen te vermijden. Echter, harmonisatie van marktvoorwaarden, om private belangen te dienen, is zeker geen valabel argument voor de verschuiving van bevoegdheden voor milieuaansprakelijkheid van de Lidstaten naar het Europese niveau.

Dus, de redenering dat lobby-activiteiten meer verstoringen zouden veroorzaken op nationaal niveau dan op Europees niveau en dat daarom een Europees milieuaansprakelijkheidsregime gerechtvaardigd zou zijn, is voorbarig. Deze negatieve conclusie betekent niet dat de Lidstaten een efficiënt milieuaansprakelijkheidsregime zouden ontwerpen of dat lobbying minder ernstig is in de Lidstaten dan op Europees niveau. Het lobby-gedrag is zo complex dat iedere algemene conclusie vrijwel zeker fout zou zijn.

Samenvattend, vanuit economisch perspectief, zijn de redenen die de Commissie aanhaalt ter verantwoording van de richtlijn eerder zwak, en rechtvaardigen ze geen verschuiving van bevoegdheden voor milieuaansprakelijkheid van de Lidstaten naar Europa. De private interest benadering levert echter 
een waardevol inzicht in het lobby-gedrag tijdens het beslissingsproces van de richtlijn en draagt in belangrijke mate bij tot de verklaring waarom de richtlijn aangenomen werd op Europees niveau, in tegenstelling tot wat de economische theorie suggereert, en waarom bepaalde voorzieningen opgenomen zijn in de richtlijn, opnieuw in tegenstelling tot wat efficiënt zou zijn volgens de economische theorie.

Concluderend leert dit onderzoek ons het volgende: De verschuiving van bevoegdheid voor milieuaansprakelijkheid van de Lidstaten naar het Europees niveau was inefficiënt en komt niet overeen met de economische criteria voor centralisatie. Tegelijkertijd maakt dit onderzoek duidelijk dat een milieuaansprakelijkheidsregime op Europees niveau onvermijdbaar was gezien de private belangen die speelden. Inderdaad, het is opmerkelijk dat alle belanghebbenden in het beslissingproces van de richtlijn eensgezind een aansprakelijkheidsregime op Europees niveau verwelkomden, zij het ieder om hun eigen redenen. De belangrijkste institutionele speler - de Europese Commissie - was voorstander van de richtlijn omdat deze de mogelijkheid bood om haar bevoegdheden uit te breiden op domeinen waar de Commissie tot dan toe geen bevoegdheid had, zoals bodembeleid. Ook de industrie en de milieugroeperingen waren voorstander van een aansprakelijkheidsregime op Europees niveau. Milieugroeperingen hoopten dat de verschuiving van bevoegdheid naar Europa zou leiden tot een strenger milieuaansprakelijkheidsregime en dat dit dan zou leiden tot een betere milieukwaliteit in Europa. De industrie prefereerde een Europees milieuaansprakelijkheidsregime dan weer voornamelijk voor het creëren van een 'level playing field' en gelijke marktvoorwaarden voor de industrie in alle Lidstaten.

Indien men echter naar de inhoud van de richtlijn kijkt, dan blijkt, zoals in Hoofdstuk 5 wordt aangetoond, dat het regime van de richtlijn enkele inefficiënties vertoont. Deze zijn het resultaat van het feit dat alle belanghebbenden weliswaar een aansprakelijkheidsregime op Europees niveau wilden, maar uiteraard van mening verschilden over de inhoud van een dergelijk Europees milieuaansprakelijkheidsregime. Milieugroeperingen waren bijvoorbeeld hevig gekant tegen het vergunningsverweer en het state-of-the-art verweer, terwijl deze verweren voor de industrie een absolute must waren. Het gevolg is dat Europa nu inderdaad een Richtlijn Milieuaansprakelijkheid heeft, maar dat de invloed - precies omdat het een compromis tussen de verschillende belangengroepen betreft - eerder beperkt is. Het is bovendien ook moeilijk om een eenduidige winnaar van het lobbying proces aan te duiden. De reden hiervoor is dat cruciale voorzieningen ofwel doorgeschoven zijn naar de Lidstaten (bijvoorbeeld het al dan niet toekennen van het vergunningsverweer of het state-of-the-art verweer), ofwel op de lange baan geschoven zijn (zoals de beslissing om al dan niet verplichte financiële zekerheden te voorzien). De industrie, de milieugroeperingen en de Europese Commissie hebben dus nu wel een Europees milieuaansprakelijkheidsregime, maar de uiteindelijke invloed van de richtlijn zal afhangen van de implementatie van de richtlijn in de verschillende Lidstaten. De richtlijn zal bijgevolg geen gelijke marktvoorwaarden garanderen en het is al even twijfelachtig of de richtlijn zal zorgen voor een algehele verbetering van de milieukwaliteit in Europa. De echte winnaar is misschien nog eerder de Europese Commissie, die terrein heeft gewonnen op een belangrijk gebied van het milieurecht, namelijk bodemverontreiniging. Dat de richtlijn een inefficiënt compromis geworden is, deerde de Commissie blijkbaar niet, evenmin als de politici in de Raad, die de richtlijn aangenomen hebben.

Verder toont het beslissingsproces van de richtlijn mooi aan dat de centralisatie/decentralisatie beslissing in Europa niet alleen gebaseerd is op economische overwegingen. De Commissie geeft weliswaar economische redenen voor centralisatie, maar in praktijk rechtvaardigen deze criteria geen centralisatie. Andere redenen spelen duidelijk een belangrijkere rol in de beslissing om de bevoegdheid van de Lidstaten naar het Europees niveau te verschuiven. Een andere reden die de Commissie aanhaalt heeft met rechtvaardigheid te maken. Het 'transboundary only'-regime (waarbij een Europees regime alleen zou gelden voor grensoverschrijdende milieuschade) werd bijvoorbeeld door de Commissie verworpen omdat dit het gelijkheidsbeginsel in Europa zou schenden. Echter, het is waarschijnlijker dat macht en de uitbreiding van bevoegdheden voor de Europese instellingen de belangrijkste drijfveren waren achter de richtlijn.

Alhoewel men op basis van bovenstaande analyse pessimistisch zou kunnen stellen dat in Europa geen rekening gehouden wordt met economische analyse en economische argumenten bij (de)centralisatiebeslissingen, geloven we dat het gebruik van economische argumenten op de manier zoals in dit onderzoek gebeurd is, toch nuttig is.

Ten eerste kan door een positieve economische analyse een beter inzicht verkregen worden waarom bepaalde verschuivingen van bevoegdheid van het nationaal niveau naar het Europees niveau hebben plaatsgevonden. Als de public interest benadering geen afdoende verklaring kan geven voor bepaalde inefficiënte centralisatiepogingen, kan de private interest benadering een aanvullende verklaring bieden voor deze centralisatiepogingen.

Ten tweede kunnen economische argumenten ook gebruikt worden op beleidsniveau. Inderdaad, voor beleidsmakers die geïnteresseerd zijn in het publiek belang, zijn economische criteria nuttig omdat ze 
weergeven onder welke omstandigheden centralisatie kan bijdragen tot sociale welvaart en in welke omstandigheden niet. Ook kan economische theorie ook gebruikt worden om aan te tonen dat een inefficiënte verschuiving van bevoegdheden naar het Europees niveau soms plaatsvindt louter omwille van een machtsstrijd tussen de Europese Commissie en de Lidstaten.economische argumenten in het bied van milieurecht, centralisatie gewenst is door de industie om of kan public choice analyse aantonen dat, speciaal op het gebied van milieurecht, centralisatie soms gewenst is door de industrie, puur en alleen om handelsbarrières te creëren.

Bijgevolg, de economische analyse, zoals toegepast in dit onderzoek, laat toe om de gevolgen aan te tonen van een centralisatie die niet gebaseerd is op economische criteria, en kan zowel op positief als normatief niveau gebruikt worden. Bovendien kan de economische analyse een bijdrage leveren in de strijd tegen de lobbying van belangengroepen en de Europese Commissie voor een inefficiëntie verschuiving van bevoegdheden naar Europa.

$\mathrm{Nu}$, hoe het ook zij, de richtlijn is in werking getreden. Een interpretatie van de richtlijn conform zijn doel en de algemene beginselen van het Europese milieubeleid lijkt de beste optie om de richtlijn de kans te geven om uit te groeien tot een bruikbaar instrument om milieuverontreiniging in de Europese Unie te voorkomen en te herstellen. 



\section{BIBLIOGRAPHY}

\section{Ackerman 1996}

Ackerman, R. M., 'Tort Law and Federalism: Whatever happened to Devolution?', Yale Law and Policy Review, Symposium Issue: 429, 1996, p. 429-463.

\section{Adler 1996}

Adler, J.H., 'Rent Seeking Behind the Green Curtain', Regulation, Vol. 19, no 4, 1996. See $<$ www.cato.org/pubs/regulation>.

\section{Adler 2001}

Adler, J.H., ‘The Ducks Stop Here? The Environmental Challenge to Federalism?' 9 Supreme court Economic Review 205, 2001, p. 205-241.

\section{Aidt 1998}

Aidt, T.S., 'Political Internalization of Economic Externalities and Environmental Policy', Journal of Public Economics, 69, 1998, p. 1-16.

\section{Akkermans 1997}

Akkermans, A., Proportionele aansprakelijkheid bij onzeker causaal verband, dissertation, University of Tilburg, 1997.

\section{Allen 2000}

Allen, D.W., 'Transaction costs', in: Bouckaert, B., and De Geest, G. (eds.), Encyclopaedia for law and economics, Cheltenham: Edward Elgar Publishing, 2000, p. 893-926.

\section{Aquilera Vaques 2002}

Aquilera Vaques, M., 'Soil pollution and decontamination in Spain', European Environmental Law Review, 2002, p. 174-186.

\section{Arcuri 2001}

Arcuri, A., 'Controlling Environmental Risk in Europe: the complementary role of an EC environmental liability regime', Tijdschrift voor Milieuaansprakelijkheid, 2001, p. 37-45. 


\section{Arnull 1990}

Arnull, A., The general principles of EEC law and the individual, United Kingdom: Leicester University Press, 1990.

\section{Bhagwati \& Srinivasan 1996}

Bhagwati, J. and Srinivasan, T.N., 'Trade and Environment: Does Environmental Diversity Detract from the Case for Free Trade?', in: Bhagwati, J. and Hudec, R.E., (eds.), Fair Trade and Harmonisation, Vol. 1. Economic Analysis, Cambridge and London: MIT Press, 1996, p. 159-224.

\section{Baird, Gertner \& Picker 1998}

Baird, D.G, Gertner, R.H., Picker, R.C., Game Theory and the Law, United States: Harvard University Press, 1998.

\section{Bartik 1988}

Bartik, T., 'The Effects of Environmental Regulation on Business Location in the United States', Growth Change, 1988, 19 (3), p. 22-44.

\section{Baumol \& Oates 1971}

Baumol, W.J. and Oates, W.E., The use of Standards and Prices for Protection of the Environment', Swed. Journal of Economics, 1971, p. $42-54$.

\section{Baumol \& Oates 1975}

Baumol, W.J. and Oates, W.E., The Theory of Environmental Policy. Externalities, Public outlays, and the Quality of Life, United States: Prentice-Hall, 1975.

\section{Baumol \& Oates 1988}

Baumol, W.J., and Oates, W.E., The Theory of Environmental Policy, 2nd edition, Cambridge: Cambridge University Press, 1988.

\section{Bauw 2004}

Bauw, E., 'Richtlijn 2004/35/EG vernieuwend, maar ook uitvoerbaar?', Nederlands Tijdschrift voor Europees Recht, No 12, 2004, p. 344-347.

\section{Becker 1983}

Becker, G.S., 'A Theory of Competition Among Pressure Groups for Political Influence', Quarterly Journal of Economics, 98, 1983, p. 371-400.

\section{Becket 1993}

Becket, M.J., 'Land Contamination', in: Cairney, T. (ed.), Contaminated Land. Problems and Solutions, London: Blackie Academic and Professional, 1993.

\section{Bekkers, van den Hurk \& Leenknegt 1995}

Bekkers V., van den Hurk, H., Leenknegt, G., (eds.), Subsidiariteit en Europese integratie, Een oude wijsheid in een nieuwe context, Zwolle: W.E.J. Tjeenk Willink, 1995. 


\section{Bentley 1908}

Bentley, A.F., The Process of Government, Chicago: University of Chicago Press, 1908.

\section{Bergkamp 1998}

Bergkamp, L., 'A future environmental liability regime', European Environmental Law Review, 1998, 200-204.

\section{Bergkamp 2000}

Bergkamp, L., 'The Commission's White Paper on Environmental Liability: A Weak Case for an EC Strict Liability Regime', European Environmental Law Review, Vol. 9, No 5, 2000, p. 105-114.

\section{Bergkamp 2001a}

Bergkamp, L., Liability and Environment. Private and Public Law Aspects of Civil Liability for Environmental Harm in an International Context, The Hague: Kluwer Law International, 2001.

\section{Bergkamp 2001b}

Bergkamp, L., 'The Commission July 2001 Working Paper on Environmental Liability: Civil or Administrative Law to prevent and Restore Environmental Harm?', Environmental Liability, vol. 9, no 5, 2001, p. 207-216

\section{Bergkamp 2002}

Bergkamp, L. 'The Proposed Environmental Liability Directive', European Environmental Law Review, 2002, p. 294-341.

\section{Bergkamp 2004}

Bergkamp, L. 'A new court-made environmental liability regime for europe', Environmental Liability, 2004, p. 171-177.

\section{Bergkamp 2005}

Bergkamp, L., 'The European Environmental Liability Directive and its effects on Industry and Economy', in: Mellenbergh, R. and Uylenburg R. (eds.), Aansprakelijkheid voor schade aan de natuur, Groningen: Europa Law Publishing, 2005, p. 95-132.

\section{Betlem 2000}

Betlem, G., 'Commission adopts White Paper on Environmental Liability', Tijdschrift voor Milieuaansprakelijkheid (TMA), 2000, p. 58-60.

\section{Bierbooms \& Brans 2000}

Bierbooms P.F.A and Brans E.H.P., 'Het EU Witboek milieu-aansprakelijkheid: de vage contouren van een toekomstig aansprakelijkheidsregime', Milieu en Recht, 2000, p. 182-188.

\section{Birdlife International}

Birdlife International, European Environmental Bureau, Greenpeace International and WWF- European Policy Office, Response to the Presidency questions on Environmental Liability $<$ www.eeb.org/activities/env_liability>. 


\section{Birdlife International}

Birdlife International, EEB, Friends of the Earth, Greenpeace and WWF, Environmental liability Directive, Second Reading Briefing for MEP's.

\section{Birdlife International 2003}

Birdlife International, EEB, Friends of the Earth, Greenpeace and WWF, Joint press release in view of Environment Council meeting, 4 March 2003, letter to the Permanent representation and letter to national governments.

\section{Birdlife International 2004}

Birdlife International, Greenpeace, WWF, Friends of the Earth, EEB (joint declaration), The Directive on Environmental Liability, The European Parliament's Third Reading Vote, 31 March 2004.

\section{Birdlife International 2004}

Birdlife International and WWF, The European Directive on Environmental Liability - 'Polluter Pays': from principle to practice? An Environmental NGO commentary on the Environmental Liability Directive: its adoption at EU level and what it means for the future, July 2004.

\section{Bjerregaard 2000}

Bjerregaard, R., 'Policy Review: Subsidiarity and Environment', European Environment, 10, 2000, p. 106-107.

\section{Bocken 2001}

Bocken, H., 'Het Working Paper on Prevention and Restoration of Significant Environmental Damage. Het Witboek betreffende Milieuaansprakelijkheid terzijde gelegd.', Tijdschrift voor Milieurecht, no 5, 2001, p. 350355.

\section{Bocken 1998}

Bocken, H., 'A new EU initiative with respect to environmental liability', AIDA Bulletin, Pollution, Products and New Technologies, no 11, 1998, p. 8-12.

\section{Bocken 2003}

Bocken, $\mathrm{H}$., 'Who is liable and for what. The scope of the environmental liability regime in the EU Commission's White Paper on Environmental liability', in: Jens Hamer, (ed.), Umwelthaftung in der EU. Environmental liability in the EU, Bonn: ERA, 2003, p. 53-58.

\section{Bocken 2006}

Bocken, H., 'Financial Guarantees in the Environmental Liability Directive: Next Time Better', European Environmental Law Review (EELR), 2006, p. 13-32.

\section{Bommer 1999}

Bommer, R.,'Environmental Policy and Industrial Competitiveness: The Pollution Haven Hypothesis Reconsidered.', Review of International Economics, 7(2), 1999, p. 342-355.

\section{Bouckaert \& De Geest 2000}

Bouckaert, B., and De Geest, G., Encylcopedia for law and economics, Cheltenham: Edward Elgar Publishing, 2000. 


\section{Boyd \& Ingberman 1997}

Boyd, J. and Ingberman D., 'The search of Deep Pocket: is 'Extended Liability' expensive Liability?', Journal of Law, Economics and Organisation, 13, no.1, 1997, p. 233-258.

\section{Boyd \& Kunreuther 1997}

Boyd, J., Kunreuther, H., 'Retroactive Liability or the Public Purse?', Journal of Regulatory Economics (JRE), 1997, p. 79-90.

\section{Boyer \& Lafont 1997}

Boyer, M., and Lafont, J.J., 'Environmental Risk and Bank Liability', European Economic Review, 41, 1997, p. 1427-1459.

\section{Boyer \& Lafont 1999}

Boyer M., and Lafont, J.J., 'Toward a Political Theory of the Emergence of Environmental Incentive Regulation', Rand Journal of Economics, vol 30, no. 1, 1999, p. 137-157.

\section{Boyer \& Porrini 2001}

Boyer M., and Porrini, D., 'Law versus Regulation: A political Economy Model of Instruments Choice in Environmental Policy', in: Heyes, A., ed., Law and Economics of the Environment, Cheltenham: Edward Elgar publishing, 2001.

\section{Brans 2002}

Brans, E., 'EC Proposal for an Environmental Liability Directive: Standing and Assessment of Damages', Environmental liability, Vol 10, Issue 4, 2002, p. 135-147.

\section{Brans 2005}

Brans, E.H.P., 'De EU Richtlijn Milieuaansprakelijkheid', in: Mellenbergh, R. and Uylenburg R. (eds.), Aansprakelijkheid voor schade aan de natuur, Groningen: Europa Law Publishing, 2005, p. 33-56.

\section{Brennan \& Buchanan 1977}

Brennan, G. and Buchanan, J.M., 'Towards a Tax Constitution for Leviathan', Journal of Public Economics, vol. 8, 1977, p. 255-273.

\section{Buchanan \& Tullock 1962}

Buchanan, J.M. and Tullock, G., The Calculus of Consent: Logical foundations of constitutional democracy, Ann Arbor: University of Michigan Press, 1962.

\section{Buchanan \& Tullock 1975}

Buchanan, J.M. and Tullock, G., 'Polluters' profits and political response: Direct Controls versus taxes', American Economic Review, 65, 1975, p. 139-147.

\section{Buchanan, Tollison \& Tullock 1980}

Buchanan, J.M., Tollison, R.D. and Tullock, G. (eds.), Toward a Theory of the Rent-seeking society, College Station, Texas: A\&M University Press, 1980. 


\section{Burrows 1999}

Burrows, P., 'Combining regulation and liability for the control of external costs, International Review of Law and Economics, vol. 19, 1999, p. 227-244.

\section{Cairney 1993}

Cairney T., (ed.), Contaminated Land. Problems and Solutions, London: Blackie Academic and Professional, 1993.

\section{Calabresi 1970}

Calabresi, G., The Costs of Accidents. A Legal and Economic Analysis, New Haven: Yale University Press, 1970.

\section{Cefic}

Cefic, Europai, OGP and UNICE, Commission Proposal for a Directive on Environmental Liability, Common proposals from CEFIC, EUROPIA, OGP and UNICE.

\section{Cefic}

Cefic, Europia and OGP, The Environmental Liability Directive (Dir 2004/35/CE), Recommendations for implementation, May 2004.

\section{Chalmers 1999}

Chalmers, D., 'Inhabitants in the Field of EC Environmental Law', in: Craig, P. and De Burca, G. (eds.), The Evolution of EU Law, United Kingdom: Oxford University Press, 1999, p. 672-684.

\section{Christie \& Teeuw 1998}

Christie, S. and Teeuw, R.M.,'Varied Policy of European Union States on Contaminated Land', Environmental Impact Assessment Review, 1998, Vol. 18, no 2, p. 175-197.

\section{Christie \& Teeuw 2000}

Christie, S. and Teeuw, R.M, 'Policy and administration of contaminated land within the European Union', European Environment, 10, 2000, p. 24-34.

\section{Clarke 2001}

Clark, C., 'Update Comparative Legal Study', Study Contract No. 201919/MAR/B3, London, 2001.

\section{Clarke 2003}

Clarke, C., 'The Proposed EC Liability Directive: Half-Way through Co-Decision', Review of European Community and International Environmental Law (RECIEL), 12 (3), 2003, p. 254-268.

\section{Coase 1960}

Coase, R.H., 'The Problem of social Cost', Journal of Law and Economics, 1960, p. 1-44.

\section{Collins 1995}

Collins, H., 'European Private Law and the Cultural Identity of States', European Review of Private Law, 3, 1995, p. 353-355. 


\section{Congleton 2004}

Congleton, R.D., Environmental politics and Economic Development, in: Rowley, Ch K, and Schneider, F., (eds.), The Encyclopedia of Public Choice, United Kingdom: Kluwer Academic Publishers, 2004, p. 224-229.

\section{Cooter 1984}

Cooter, R., 'Prices and Sanctions', Columbia Law Review, vol. 84, 1984, p. 1343-1523.

\section{Cooter \& Ulen 2003}

Cooter, R. and Ulen, Th., Law and Economics, 4rd edition, Illinois: Glenview, 2003.

\section{Craig \& De Burca 2003}

Craig, P. and De Burca, G., 'EU Law. Text, Cases and Materials', third edition, United Kingdom: Oxford University Press, 2003.

\section{Cropper \& Oates 1992}

Cropper, M.L., and Oates, W., 'Environmental Economics: A survey', Journal of Economic Literature, June, 1992, p. 1675-1740.

\section{Cross 1995}

Cross, G., 'Subsidiarity and the Environment', in: Barav A. and Wyatt D. (eds.), Yearbook of European Law, Oxford: Clarendon, 1995, p. 107-134.

\section{Damania 1999}

Damania, R., 'Political Competition, Rent Seeking and the Choice of Environmental Policy Instruments', Environmental and Resource Economics, vol. 13, 1999, p. 415-433.

\section{De Geest 1990}

De Geest G., 'Public Choice en rechtseconomie', Ars Aequi, 39 (10), 1990, p. 666-673.

\section{Den Hertog 2000}

Den Hertog, J., 'General Theories of Regulation', in Bouckaert, B and De Geest, G. (eds.), Encyclopedia of Law and Economics, Cheltenham: Edward Elgar, 2000, p. 223-270.

\section{Deloddere \& Ryckbost 1997}

Deloddere, S., Ryckbost, D., 'Liability for contaminated sites', Background Paper for the EU White Paper on Environmental Liability, 26 september 1997.

\section{Descamps 2005}

Descamps, H., 'De Europese richtlijn milieuschade en haar implementatie: wie doet wat?', in: Deketelaere K. and Deketelaere M. (eds), Jaarboek Milieurecht, Leuven: Die Keure, 2005, p. 5-54.

\section{De Smedt 2004}

De Smedt, K., 'Is Harmonization of Environmental Liability Rules needed in an Enlarged European Union?', Review of European Community \& International Environmental Law (RECIEL), Vol. 13, issue 2, 2004, p. 164-174. 


\section{De Smedt 2007}

De Smedt, K. 'Shifts in Compensation of Environmental Damage: From Member States to Europe', in: Faure, M. and Verheij, A. (eds.), Shifts in Compensation for Environmental Damage, Tort and Insurance Law, Wien: Springer Verlag, 2007, p. 103-131.

\section{De Vries 1999}

De Vries, C., Community action on environmental liability, in: L. Wiggers-Rust and K. Deketelaere (eds.) Aansprakelijkheid voor milieuschade en financiële zekerheid, 1999, p. 141-147.

\section{De Vries 2005}

De Vries, J.S., 'De totstandkoming van de Richtlijn Milieuaansprakelijkheid', in: Mellenbergh, R. and Uylenburg R. (eds.), Aansprakelijkheid voor schade aan de natuur, Groningen: Europa Law Publishing, 2005, p. 23-30.

\section{Dewees 1992}

Dewees, D., 'The Comparative Efficacy of of Tort Law and Regulation for environmental protection', The Geneva Papers on Risk and Insurance, 1992, p. 446-467.

\section{Dewees 1983}

Dewees, D., 'Instrument Choice in Environmental Policy', Economic Inquiry, 21, 1983, p. 53-71.

\section{Dougan 2000}

Dougan, M., 'The ‘Disguised' Vertical Direct Effect of Directives?' Cambridge Law Journal, 59, 3, 2000, p. 586612.

\section{Ecologic}

Ecologic, Institute for International and European Environmental Policy <www.ecologic.de>, 'EU Soil Protection Policy: Current Status and the Way Forward', Background Paper to the Dutch Ministry of Housing, Spatial Planning and the Environment (VROM), Thematic Assistance to the Conference 'Vital Soil: the next step towards a European Soil Strategy', 18-19 November 2004, The Hague.

\section{Egelund Olsen 2001}

Egelund Olsen, B., 'Voluntary standards as an Instrument in Environmental Regulations: The Problem of Contaminated Soil', Environmental Liability, 2, 2001, p. 53-64.

\section{Ellis 1999}

Ellis, E. (ed.), The Principle of Proportionality in the Laws of Europe, United Kingdom: Hart Publishing, 1999.

\section{Emiliou 1996}

Emiliou, N., The Principle of Proportionality in European Law. A Comparative Study., European Monographs, United Kingdom: Kluwer Law International,1996.

\section{Endres \& Staiger 1996}

Endres, A. and Staiger, B., 'Oekonomische Aspekte des Umwelthaftungsrecht', in: Ahrens, M. and Simon, J. (eds.), Umwelthaftung, Risikosteuerung und Versicherung, 1996, p. 79-93. 


\section{ENDS}

ENDS Europe daily (Europe's Environmental News Service), <www.europedaily.com>.

\section{Engel 1997}

Engel, K.H., 'State Environmental Standard Setting: Is There a 'Race' and Is it 'to the Bottom'? Hasting Law Journal, 48, 1997, p. 271-398.

\section{Engel \& Rose-Ackerman 2001}

Engel, K. and Rose-Ackerman S., 'Environmental Federalism in the United States: the Risks of Devolution', in: Esty, D.C., Geradin D. (eds.), Regulatory Competition and Economic Integration. Comperative Perspectives, New York: Oxford University Press, 2001, p. 135-153.

\section{Epiney 2000}

Epiney, A., 'Division of Competence between Member States and the EC', in: The European Convention and the Future of European Law, Prof. Jans J.H. (ed.), The Avosetta series I, Groningen: Europa Law Publishing, 2000, p. 45-53.

\section{Esty 1996}

Esty, D.C., 'Revitalising Environmental Federalism', Vol. 95:570, Ann Arbor: Michigan Law Review, 1996, p. 570-653.

\section{Esty \& Geradin 1997}

Esty, D., Geradin, D., 'Market Access, Competitiveness, and Harmonization: Environmental Protection in Regional Trade Agreements.', Harvard Environmental Law Review, Vol. 21, 1997, p. 265-336.

\section{Esty \& Geradin 1998}

Esty, D.C., Geradin D., 'Environmental Protection and International Competitiveness, A Conceptual Framework', Jourrnal of World Trade, Vol. 32, 1998, p. 5-46.

\section{Esty \& Geradin 2001}

Esty, D.C., Geradin D., 'Regulatory Co-Opetition', in: Esty, D.C., Geradin D. (eds), Regulatory Competition and Economic Integration. Comperative Perspectives, New York: Oxford University Press, 2001, p. 30-46.

\section{European Commission 2002}

European Commission, Communication from the Commission to the Council, the European Parliament, the Economic and Social Committee and the Committee of the Regions, Towards a Thematic Strategy for Soil Protection, Com (2002) 179 final, Brussels, 16 April 2002.

\section{European Commission 2003}

European Commission, press release of 18 September 2003, PRES/03/265, <http:// europa.eu.int/rapid>.

\section{European Commission 2005}

European Commission, Special Eurobarometer 217 'The attitudes of European citizens towards environment', Fieldwork November 2004, publication April 2005. 


\section{European Commission 2006}

European Commission, Soil Protection. The story behind the Strategy, Office for Official Publications of the European Communities, Luxembourg, 2006.

\section{European Environment Agency 1995}

European Environment Agency, Europe's Environment. The Dobris Assessment, Stanners, D. and Bourdeau, P. (eds), EEA, Copenhague, 1995.

\section{European Environment Agency 2000}

European Environment Agency, 'Management of contaminated sites in Western Europe', Topic Report No 13/1999, EEA, Copenhague, 2000.

\section{European Environment Agency 2000}

European Environment Agency, Down to Earth: Soil degradation and sustainable development in Europe. A challenge for the 21st century, EEA, Copenhagen, 2000.

\section{European Environment Agency 2001}

European Environment Agency, Environmental Signals 2001, EEA, Copenhagen, 2001.

\section{European Environment Agency 2001}

European Environment Agency, Indicator fact sheet signals 2001 - Soil at $<\mathrm{http}: / /$ themes.eea.europa.eu/Specific_media/soil/indicators/clean_up>.

\section{European Parliament 2003}

European Parliament, Directorate-General for Research, Working Paper, Lobbying in the European Union: current rules and practices, 2003.

\section{Europe Environment 2003}

Europe Environment, 'Lobby groups call for Directive on limited environmental liability', March 7, 2003.

\section{European Parliament 2004}

European Parliament, newsletter, http://www.europarl.eu.int/code.newsletter/2004_03_en.htm.

\section{Farnsworth 2004}

Farnsworth, N., 'Subsidiarity - A Conventional Industry Defence. Is the Directive on Environmental Liability with regard to Prevention and Remedying of Environmental Damage justified under the subsidiarity principle?', European Environmental Law Review (EELR), 2004, p. 176-185.

\section{Faure 2000}

Faure, M.G., 'Environmental Regulation', in: Bouckaert, B., and De Geest, G., Encylcopedia for law and economics, Cheltenham: Edward Elgar Publishing, 2000, p. 443-520.

\section{Faure 2001}

Faure, M.,G., 'Economic Analysis of Environmental Law: An Introduction', Economie Publique: Etudes et Recherches, no. 7, Institut d'Economie Publique (IDEP), De Boeck Université, 2001/1, p. 127-147. 


\section{Faure 2002}

Faure, M.G., 'Economic Analysis', in: Koch, B.A. and Koziol, H. (eds.), Unification of Tort Law: Strict Liability, United Kingdom: Kluwer Law International, 2002, p. 361-394.

\section{Faure 2003a}

Faure, M.G., 'How Law and Economics May Contribute to the Harmonization of Tort Law in Europe', in: Zimmermann, R. (ed.), Grundstrukturen des Europäischen Deliktsrechts, Baden-Baden: Nomos Verlagsgesellschaft, 2003, p. 31-82.

\section{Faure 2003b}

Faure, M.G., (ed.), 'Deterrence, Insurability, and Compensation in Environmental Liability, Tort and Insurance Law Vol. 5, European Centre of Tort and Insurance Law (ECTIL), Wien/New York: Springer, 2003.

\section{Faure 2003c}

Faure, M.G., 'Causal Uncertainty, Joint and Several Liability and Insurance', in: Koziol, H., and Spier, J. (eds.), Liber Amicorum Pierre Widmer, Tort and Insurance Law Vol. 10, European Centre of Tort and Insurance Law, Wien/New York: Springer, 2003 , p. 79-98.

\section{Faure 2004}

Faure, M.G., 'European Environmental Criminal Law: Do we really need it?', European Environmental Law Review, January 2004, p. 18-29.

\section{Faure 2005}

Faure, M.G., 'De Europese Richtlijn Milieuaansprakelijkheid: kritische inleidende bedenkingen', in: Mellenbergh, R. and Uylenburg R. (eds.), Aansprakelijkheid voor schade aan de natuur, Groningen: Europa Law Publishing, 2005, p. 3-20.

\section{Faure \& Bruggeman 2006}

Faure, M., and Bruggeman, V., 'Causal Uncertainty and Proportional Liability', Paper presented at the conference Causation in Law, Prague, 27-28 October 2006, p. 1-22.

\section{Faure \& De Smedt 2001}

Faure, M. en De Smedt, K., 'Harmonisatie van milieuaansprakelijkheid in de Europese Unie: een rechtseconomische analyse', Tijdschrift voor Milieurecht, November 2001/5, p. 356-365.

\section{Faure \& De Smedt 2001}

Faure, M. en De Smedt, K., 'Should Europe Harmonise Environmental Liability Legislation?', Environmental Liability, Vol 9 Issue 5, October 2001, p. 217-237.

\section{Faure \& De Smedt 2002}

Faure, M. and De Smedt, K, 'Should Europe Harmonise Environmental Liability Legislation?', Environmental Liability, Vol 9, Issue 5, 2002, p. 217-237. 


\section{Faure \& De Smedt 2003}

Faure, M., and De Smedt, K., 'Harmonization of environmental liability legislation in the European Union' in: Marciano, A., Josselin, J.M. (eds.), From Economic to Legal Competition, New Perspectives on Law and Institutions in Europe, New Perspectives on Law and Institutions in Europe, New Horizons in Law and Economics, United Kingdom: Edward Elgar, 2003, 212p.

\section{Faure \& Fenn 1999}

Faure, M.G. and Fenn, P., 'Retroactive Liability and the Insurability of Long-Tail Risks', International Review of Law and Economics (IRLE), 19, 1999, p. 487-500.

\section{Faure \& Grimeaud 2003}

Faure, M.G., and Grimeaud, D., 'Financial Assurance issues of Environmental Liability', in: Faure, M. (ed.), 'Deterrence, Insurability, and Compensation in Environmental Liability. Future Developments in the European Union, Tort and Insurance Law Vol. 5, European Centre of Tort and Insurance Law (CTIL), Wien/New York: Springer, 2003, p. 7-255.

\section{Faure \& Hartlief 1996}

Faure, M.G., and Hartlief, T., 'Compensation Funds versus Liability and Insurance for Remedying Environmental Damage', Review of European Community and International Environmental Law, 5, 1996, p. 321326.

\section{Faure \& Lefevere 1995}

Faure, M.G., Lefevere, J.G.J., 'Some public interest and private interest aspects of environmental standard setting in the European Community', in: Mayes, D.G. (ed.), The evolution of rules for a single European market, Proceedings from the COST A7 workshop in Exeter, UK, 8-11 September 1994, Brussels, ECSC-EC-EAEC, 1995, p. 320-351.

\section{Faure \& Skogh 2003}

Faure, M.,G. and Skogh, G., The Economic Analysis of Environmental Policy and Law. An Introduction, United Kingdom: Edward Elgar, 2003.

\section{Faure \& Van den Bergh 1989}

Faure, M.G. and Van den Bergh, R., Objectieve Aansprakelijkheid, Verplichte Verzekering en Veiligheidsregulering, Antwerpen-Apeldoorn: Maklu uitgevers, 1989.

\section{Ferejoghn 2000}

Ferejohn, J., 'Political Economy of Pollution Control in a Federal System', in: Revesz, R., Sands, P, Stewart, R. (eds.), Environmental law, the economy and sustainable development: the United States, the European Union and the international community, Cambridge: Cambridge University Press, 2000, p. 96-105.

\section{Fischel 1975}

Fischel, W.A., 'Fiscal and Environmental Considerations in the Location of Firms in Suburban Communities', in: Mills, E. and Oates, W.E., (eds.), Fiscal zoning and Land Use Controls, 1975, p. 119-174.

\section{Fogleman 2004}

Fogleman, V., 'The Environmental Liability Directive', Environmental Liability, 3, 2004, p. 101-115. 


\section{Fredriksson \& Gaston 2000}

Fredriksson, P.G., and Gaston, N., 'Environmental Governance in Federal Systems: the Effects of Capital Competition and Lobby Groups', Economic Inquiry, Vol 38, No 3, 2000, p. 501-514.

\section{Fredriksson \& Millimet 2002}

Fredriksson, P.G. and D.L. Millimet, 'Strategic Interaction and the Determination of Environmental Policy Across US States', Journal of Urban Economics, 51(1), 2002, p. 101-122.

\section{Freys 1997}

Frey B.S., Not just for the Money, an Economic Theory of Personal Motivation, Cheltenham, UK - Brookfield US: Edward Elgar publishing, 1997.

\section{Friedman, Gerlowski \& Silberman 1992}

Friedman, J., Gerlowski, D.A., Silberman, J., 'What attracts foreign multinational corporations? Evidence from branch plant locations in the United States', Journal of Regional Science, 32(4), 1992, p. 403-418.

\section{GATT 1991}

GATT, 'United States - Restrictions on Imports of Tuna', Report of the Panel, Not Adopted, Submitted to the parties on 16 August 1991, International Legal Materials, Vol. 30, 1991, p. 1594-1623.

\section{GATT 1994}

GATT, 'United States - Restrictions on Imports of Tuna', Report of the Panel, Not Adopted, Released in June 1994, International Legal Materials, Vol. 33, 1994, p. 839-903.

\section{Gillies 1998}

Gillies, D., 'Lobbying and European Environmental Law', European Environment, 8, 1998, p. 175-183.

\section{Golub 1996a}

Golub, J., 'Sovereignty and Subsidiarity in EU Environmental Policy', Political Studies, XLIV, 1996, p. 686703.

\section{Golub 1996b}

Golub, J.S., State Power and Institutional Influence in European Integration: Lessons from the Packaging Waste Directive, Journal of Common Market Studies, 34, 3, 1996, p. 313-339.

\section{Gray 2002}

Gray, K.R., 'Foreign Direct Investment and Environmental Impacts - is the Debate Over?', Review of European Community and International Environmental Law (RECIEL), 11:3, 2002, p. 307-309.

\section{Gunningham \& Grabosky 1998}

Gunningham, N., Grabosky, P., Smart Regulation. Designing Environmental Policy, Oxford Socio-Legal Studies, Oxford: Clarendon Press, 1998.

\section{Hägg 1997}

Hägg, P.G.T., 'Theories on the Economics of Regulation: A survey of the literature from a European Perspective', European Journal of Law and Economics, 4, 1997, p. 337-370. 


\section{Hahn 1989}

Hahn, R.W., Economic Prescripts for Environmental Problems: How the Patient Followed the Doctor's Orders, Journal of Economic Perspectives, Vol 3, 1989, p. 95-114.

\section{Hahn 1990}

Hahn, R.W., 'The Political economy of environmental regulation: Towards a unifying framework', Public Choice, 65, 1990, p. 21-47.

\section{Hallo \& De Lange 2004}

Hallo, R and De Lange, F., 'De EU Richtlijn milieuaansprakelijkheid en de rol van milieuorganisaties', Tijdschrift voor Milieuaansprakelijkheid, 2004, p. 119-122.

\section{Hardin 1968}

Hardin, G., The Tragedy of the Commons, Science, vol. 162, 1968.

\section{Hattan 2002}

Hattan, E., 'The Environmental Liability Directive', Environmental Liability, Vol. 10, Issue 1, 2002, p. 3-10.

\section{Hayward 1996}

Hayward, J., 'Has Unification By Stealth A Future?', in: Hayward, J., (ed.), Elitism, Populism and European Politics, Oxford: Clarendon Press, 1996.

\section{Heyes 1994}

Heyes, A.G., 'The Economics of Strict and Fault-Based Liability', European Environmental Law Review, 1994.

\section{Heyes 1996}

Heyes, A.G., 'Lender Penalty for Environmental Damage and the Equilibrium Cost of Capital', Economica, 63, 1996, p. 311-323.

\section{Hunter 2000}

Hunter, R., 'European Commission White Paper proposals on NGO rights of action: wrongful rights of action', Tijdschrift voor Milieuaansprakelijkheid, 2000, p. 125-126.

\section{Inman \& Rubinfeld 1998}

Inman, R.P. and Rubinfeld, D.L., 'Subsidiarity and the European Union', in: Newman, P. (ed.), The New Palgrave Dictionary of Economics and the Law (excerpt, Vol 2.), Palgrave: Macmillan Reference Limited, 1998, p. 545-551.

\section{Inman \& Rubinfeld 2000}

Inman, R.P. and Rubinfeld, D.L., 'Federalism' in: Bouckaert, B., and De Geest, G. (eds.), Encyclopedia for law and economics, Cheltenham: Edward Elgar Publishing, 2000, p. 661-691.

\section{Jackson 2000}

Jackson, J.H., The Jurisprudence of GATT and the WTO. Insights on treaty law and economic relations, United Kingdom: Cambridge University Press, 2000. 


\section{Jaffe, Peterson, Portney \& Stavins 1995}

Jaffe A., Peterson S., Portney P., Stavins R., 'Environmental Regulation and the Competitiveness of US Manufacturing: What does the Evidence Tell Us?', Journal of Economic Literature, Vol. XXXIII, 1995, p. 132163.

\section{Jans 2000}

Jans, J.H., European Environmental law, Groningen: Europa Law Publishing, 2000.

\section{Jeppesen 2000}

Jeppesen, T., 'EU Environmental Policy in the 1990's: Allowing Greater National Leeway?', European Environment, 2000, p. 96-105.

\section{Jeppesen 2002}

Jeppesen, T., Environmental Regulation in a Federal System. Framing Environmental Policy in the European Union, Cheltenham, UK:Edward Elgar, New Horizons in Economics, 2002.

\section{Jordan 1999}

Jordan, A., Subsidiarity and Environmental Policy: Which Level of Government should do what in the European Union, CSERGE (Centre for Social and Economic Research on the Global Environment, University of East Anglia and University College London), Working Paper GEC 99-133, 1999, p. 1-27.

\section{Jordan \& Jeppesen 2000}

Jordan, A and Jeppesen, T., 'EU Environmental Policy: Adapting to the Principle of Subsidiarity', European Environment, 10, 2000, p. 64-74.

\section{Kaplow 1986}

Kaplow, L., 'An Economic Analysis of Legal Transition', Harvard Law Review, 99, 1986, p. 509-617.

\section{Kaplow \& Shavell 2002}

Kaplow, L. and Shavell, S., Principles of Fairness versus Human Welfare, Harvard University Press, 2002.

\section{Kaye 1982}

Kaye, D., 'The limits of the preponderance of the evidence standard: justifiably naked statistical evidence and mutliple causation', American Bar Foundation Research Journal, 1982, p. 487-516.

\section{Keenan \& Rubin 1988}

Keenan, D., and Rubin, P., 'Shadow Interest Groups and Safety Regulation', International Review of Law and Economics, 8, 1988, p. 21-36.

\section{Kelemen 2004}

Kelemen, R., 'Environmental Federalism in the United States and the European Union', in: Vig, N. and Faure, M. (eds.), Green Giants? Environmental Policies of the United States and the European Union, Massachusetts: MIT Press, 2004, p. 113-134. 


\section{Kimber 1995}

Kimber, C., 'A Comparison of Environmental Federalism in the United States and the European Union', Maryland Law Review, Vol. 54, 1995, p. 1658-1690.

\section{Kolstad, Ulen \& Johnson 1990}

Kolstad, Ch., Ulen, T., and Johnson, g. 'Ex post Liability versus ex ante Safety Regulation: Substitutes or Compliments?, American Economic Review, 80 (4), 1990, p. 888-901.

\section{Krämer 2001}

Krämer, L., 'Differentiation in EU Environmental Policy', in: De Witte, B., Hanf, D., Vos, E. (eds.), The many faces of differentiation in EU law, Intersentia, 2001, p. 83-100.

\section{Krämer 2004}

Krämer, L., 'Decontamination of soil and EU waste legislation', Environmental Liability, 2004, p. $263-270$.

\section{Krämer 2005a}

Krämer, L. 'Directive 2004/35 on environmental liability and environmental principles, Tijdschrift voor Milieuschade en Aansprakelijkheidsrecht, no. 4, 2005, p. 131-134.

\section{Krämer 2005b}

Krämer, L., 'De positie van de milieuorganisaties als gevolg van de Richtlijn Milieuaansprakelijkheid', in Mellenbergh, R. and Uylenburg R. (eds.), Aansprakelijkheid voor schade aan de natuur, Groningen: Europa Law Publishing 2005, p. 75-91.

\section{Landes \& Posner 1983}

Landes, W. and Posner, R., 'Causation in tort law: an economic approach', Joural of Legal Studies (JLS), 1983, p. 109-134.

\section{Landes \& Posner 1987}

Landes, W. and Posner, R., The Economic Structure of Tort Law, Cambridge: Harvard University Press, 1987.

\section{Lando 1997}

Lando H., 'An attempt to incorporate fairness into an economic model of tort law', International Review of Law and Economics, 17, 1997, p. 575-587.

\section{Layard 2004}

Layard, A. ,'The Europeanisation of Contaminated Land', Environmental Law Review, 6, 2004, p. 97-110.

\section{Legrand 1997}

Legrand, P., 'The Impossiblity of Legal Transplants', Maastricht Journal of European and Comparative Law, 1997, p. 111-124.

\section{Leidy \& Hoekman 1994}

Leidy, M.P., and Hoekman, B.M., “Cleaning up' while cleaning up? Pollution abatement, interest groups and contingent trade policies', Public Choice, 78, 1994, p. 241-258. 


\section{Lenaerts 1994}

Lenaerts, K., 'The principle of Subsidiarity and the Environment in the European Union: Keeping the Balance of Federalism', Fordham International Law Journal, 1994, p. 868-874.

\section{Lévêque 1996}

Lévêque, F., 'The regulatory game', in: Lévêque, F. (ed.), Environmental Policy in Europe. Industry, Competition and the Policy Process, United Kingdom: Edward Elgar Publishing, 1996, p. 31-51.

\section{Levinson 1996}

Levinson, A., 'Environmental regulations and manufacturers' location choices: Evidence from the Census of Manufactures', Journal of Public Economics, Elsevier, vol. 62(1-2), 1996, p. 5-29.

\section{Levinson 1997}

Levinson, A., 'Environmental Regulations and Industry Location: International and Domestic Evidence', in: Bhagwati J., Hudec, R. (eds.), Fair Trade and Harmonisation. Prerequisites for Free Trade?, Vol 1, Massachusetts: MIT Press, 2nd printing, 1997, p. 429-458.

\section{List \& Gerking 2000}

List, J.A. and Gerking, S., 'Regulatory Federalism and Environmental Protection in the United States', Journal of Regional Science, Vol. 40, No. 3, 2000, p. 453-471.

\section{Low \& Yeats 1992}

Low, P. and Yeats A., 'Do "dirty" Industries migrate?', in: Low, P., (ed.), International Trade and the Environment, Washington DC: World Bank, 1992, p. 89-103.

\section{Maciej Szpunar 2003}

Maciej Szpunar, Direct Effect of Community Directives in National Courts: some remarks concerning recent developments, Centrum Europejskie Natolin, Warszawa, 2003, p. 3-4 www.natolin.edu.pl/pdf/natolin_publ_2003/Natolin_9-2003.pdf.

\section{Mackaay 2000}

Mackaay E., 'Schools: General' in Bouckaert B., De Geest G. (eds.), Encyclopedia of Law and Economics, Cheltenham: Edward Elgar, 2000, p. 402-415.

\section{Maloney \& McCormick 1982}

Maloney, M.T., and McCormick, R.E., 'A Positive Theory of Environmental Quality Regulation', Journal of Law and Economics, 25,1982, p. 99-123.

\section{Markusen, Morey \& Olewiler 1995}

Markusen, J.R., Morey, E.R., Olewiler, N., 'Competition in regional environmental policies when plant locations are endogenous', Journal of Public Economics, 56, 1995.

\section{Marson 2004}

Marson, J., 'Access to justice: a deconstructionist approach to horizontal direct effect', Web Journal of Current Legal Issues, 2004, no. 4. 


\section{McConnell \& Schwab 1990}

McConnell, V.D. and Schwab, R.M., 'The impact of environmental regulation on industry location decisions: The motor vehicle industry.', Land Economics, 66, no.1, 1990, p. 67-81.

\section{McKenna \& Co. 1996}

McKenna \& Co., 'Study of Civil Liability Regimes for Remedying Environmental Damage, 1996, copies available from European Commission DG XI.

\section{Millimet 2001}

Millimet D., Assessing the Empirical Impact of Environmental Federalism, Unpublished paper. See Oates, W.E., and Portney, P.R., 'The Political Economy of Environmental Policy', Resources for the Future, Discussion Paper 01-55, 2001.

\section{Menell 1991}

Menell, P.S., The Limitations of Legal Institutions for addressing Environmental Risks, Journal of Economic Perspectives, vol 5, no 3, 1991, p. 93-113.

\section{Mercuro \& Medema 2006}

Mercuro, N. and Medema, S.G., Economics and the Law. From Posner to Post-Modernism, United Kingdom: Princeton University Press, second edition, 2006.

\section{Miller 2000}

Miller, C., 'Judicial approaches to contested causation: Fairchild v. Glenhaven Funeral Services in context', Law, Probability and risk, 1 (2), 2000, p. 119-139.

\section{Miller 2006}

Miller, C., 'Causation in personal injury: legal or epidemiological common sense?', Legal Studies, 26, No 4, December 2006, 559 and p. 563-565.

\section{Mitchell \& Munger 1991}

Mitchell M.C., and Munger, W.C., 'Economic Models of Interest Groups, an Introductory Survey', American Journal of Political Science, Vol. 35, No. 2, 1991, p. 512-546. Reprinted in Rowley, CH., K., (ed.), Public Choice Theory Volume I, The International Library of Critical Writings in Economics, United Kingdom: Edward Elgar, 1993.

\section{Monti 2001}

Monti, A., 'Environmental Risk: a comparative law and economics approach to liability and insurance', European Review of Private Law, 1, 2001, p. 19-58.

\section{Oates 1972}

Oates W.E. Fiscal Federalism, Harcourt Brace Jovanovich Inc., United States, 1972.

\section{Oates 1998}

Oates, W. E., 'Environmental policy in the European Community: Harmonisation or National Standards', Empirica, 25, 1998, p. 1-13. 


\section{Oates 2001}

Oates, W.E., 'A Reconsideration of Environmental Federalism', Resources for the Future, Discussion Paper 01-54, November 2001.

\section{Oates \& Portney 2001}

Oates, W.E., and Portney, P.R., 'The Political Economy of Environmental Policy', Resources for the Future, Discussion Paper 01-55, 2001.

\section{Oates \& Schwab 1988}

Oates, W.E. and Schwab, R. M., 'Economic Competition among Jurisdictions, Efficiency enhancing or distortion inducing?, Journal of Public Economics, 35, 1988, p. 333-354.

\section{Ogus 1994}

Ogus, A., Regulation. Legal Form and Economic Theory, Oxford: Clarendon Press, 1994.

\section{Ogus 1999}

Ogus, A.., 'Competition between national legal systems: a contribution of economic analysis to comparative law', The International and Comparative Law quarterly, vol. 48, 1999, p. 405-418.

\section{Olson 1971}

Olson, M., The logic of collective action: public goods and the theory of groups, United States: Harvard University Press, 1971.

\section{Ott \& Schäfer 1997}

Ott, C., and Schäfer, H.B., 'Negligence as Untaken Precaution, Limited Information and Efficient Standard Formation in the Civil Liability System, International Review of Law and Economics (IRLE), 1997, p. 15-29.

\section{Peltzman 1976}

Peltzman, S., 'Toward a More General Theory of Regulation', Journal of Law and Economics, 19, 1976, p. 211240.

\section{Pfander 1996}

Pfander, J.E., 'Environmental Federalism in Europe and the United States: A Comparative Assessment of Regulation Through the Agency of Member States', in: Braden, JB, Folmer, H and Ulen, T.S. (eds.), Environmental Policy with Political and Economic Integration. The European Union and the United States, United Kingdom: Edward Elgar, 1996, p. 59-131.

\section{Philipsen 2003}

Philipsen, N.J., Regulation of and by Pharmacists in the Netherlands and Belgium: an Economic Approach, Proefschrift Universiteit Maastricht, Antwerpen: Intersentia, 2003.

\section{Posner 1998}

Posner, R., Economic Analysis of Law, 5th Edition, Aspen Law and Business, 1998 (first edition 1973). 


\section{Porter \& Van der Linde 1995}

Porter, M.E.. and Van der Linde, C., 'Toward a New Conception of the Environment-Competitiveness Relationship', Journal of Economic Perspectives, Vol. 9., No. 4, 1995, p. 97-118.

\section{Polinksy \& Shavell 1992}

Polinksy, A.M., Shavell S., 'Optimal Cleanup and Liability after Environmentally Harmful Discharges', 16, Research in Law and Economics, 16, 1992, p. 17-24.

\section{Princen 2002}

Princen, S., The California Effect in the Transatlantic Relationship, Proefschrift Universiteit Utrecht, 2002.

\section{Rehbinder 2000}

Rehbinder, E., 'Towards a Community Environmental Liability Regime: The Commission's White Paper on Environmental Liability', Environmental Liability, 2000, p. 85-96.

\section{Revesz 1992}

Revesz, R., 'Rehabilitating Interstate Competition: Rethinking the "Race-To-The-Bottom" rationale for Federal Environmental Regulation', New York University Law Review, Vol. 67, 1992, p. 1210-1254.

\section{Revesz 2000}

Revesz, R., 'Federalism and Environmental Regulation: an Overview', in: Revesz, R., Sands, P., Stewart, R.B. (eds.), Environmental Law, the Economy and Sustainable Development. The United States, the European Union and the International Community, United Kingdom: Cambridge University Press, 2000, p. 37-79

\section{Revesz 2001a}

Revesz, R., 'Federalism and Regulation: Some Generalisations', in: D.C. Esty and D. Geradin (eds.), Regulatory Competition and Economic Integration. Comparative Perspectives, New York: Oxford University Press, 2001, p. 3-29.

\section{Revesz 2001b}

Revesz, R. 'Federalism and Environmental regulation: a Public Choice Analysis', Harvard Law Review, Vol 115,2001 , p. 555-641.

\section{Rice 2000}

Rice, P., 'From Lugano to Brussels via Arhus: Environmental Liability White Paper Published', Environmental Liability, 2000, p. 39-45.

\section{Roessler 2000}

Roessler, F., 'Environmental protection and the global trade order', in: Revesz, R., Sands, P, Stewart, R. (eds.), Environmental law, the economy and sustainable development: the United States, the European Union and the international community, United Kingdom: Cambridge University Press, 2000, p. 107-126.

\section{Rosenberg 1984}

Rosenberg, D., 'The causal connection in mass exposure cases: 'public law' vision of the tort system', Harvard Law Review, 1984, p. 851-929. 


\section{Rose-Ackerman 1991}

Rose-Ackerman, S., Tort Law as a Regulatory System. Regulation and the Law of Torts, American Economic Review, Papers and Proceedings, Vol 81, no 2,1991, p. 54-58.

\section{Rose-Ackerman 1992}

Rose-Ackerman, S., Rethinking the Progressive agenda. The Reform of the American Regulatory State, New York: Free Press, 1992.

\section{Rose-Ackerman 1995}

Rose-Ackerman, S., 'Public Law versus Private Law in Environmental Regulation. European Union Proposals in the Light of United States Experience', Review of European Community and International Environmental Law (RECIEL), 1995, p. 312-332.

\section{Schaefer 2000}

Schaefer, H.-B., 'Tort Law: General', in: Bouckaert, B., and De Geest, G. (eds.), Encylcopedia for law and economics, Cheltenham: Edward Elgar Publishing, 2000, p. 569-596.

\section{Schaefer \& Schoenenberger 2000}

Schaefer, H.-B., and Schoenenberger, A., "Strict Liability Versus Negligence" in Bouckaert, B., and De Geest, G., Encylcopedia for law and economics, Cheltenham: Edward Elgar Publishing, 2000, p. 597-624.

\section{Schueler 2005}

Schueler, B.J., De aansprakelijkheid van de overheid als gevolg van de Richtlijn Milieuaansprakelijkheid, in: R. Mellenbergh/ R. Uylenburg (eds.), Aansprakelijkheid voor schade aan de natuur, Groningen: Europa Law Publishing, 2005, p. 59-72.

\section{Schwarze 2006}

Schwarze, J., European Administrative law, United Kingdom: Sweet \& Maxwell, 2006.

\section{Seerden \& Deketelaere 2000}

Seerden R., Deketelaere, K.. (eds.), Legal Aspects of Soil Pollution and Decontamination in the EU Member States and the United States, Antwerpen: Intersentia Uitgevers, 2000.

\section{Shavell 1982}

Shavell, S., 'On Liability and Insurance', Bell Journal of Economics, 1982, p. 120-132.

\section{Shavell 1984}

Shavell, S., 'Liability for harm versus regulation of safety, Journal of Legal Studies, 1984, p. 357-374.

\section{Shavell 1985a}

Shavell, S., Criminal law and the optimal use of non-monetary sanctions as a deterrent, Columbia Law Review, 1985, p. 1232-1262.

\section{Shavell 1985b}

Shavell, S, 'Uncertainty over causation and the determination of civil liability', Journal of Law and Economics, 1985, p. 587-609. 


\section{Shavell 1987}

Shavell, S., Economic Analysis of Accident Law, Cambridge: Harvard University Press, 1987.

\section{Shavell 1992}

Shavell, S., 'Liability and the Incentive to obtain Information about Risk', Journal of Legal Studies, 1992, p. 259-270.

\section{Shaw, Nadin \& Seaton 2000}

Shaw, D., Nadin, V., and Seaton, K., 'The Application of Subsidiarity in the Making of European Environmental law', European Environment, 2000, p. 85-95.

\section{Slabbinck, Descamps \& Bocken 2006}

Slabbinck, R., Descamps, H., Bocken, H., 'Implementation of the Environmental Damage Directive in Belgium (Flanders)', Environmental Liability, 1, 2006, p. 3-12.

\section{Spier 1995}

Spier, J. (ed.), The limits of Liability, Keeping the Floodgates Shut, The Hague: Kluwer Law International, 1995.

\section{Spier 2000}

Spier, J. (ed.), Unification of Tort Law: Causation, The Hague: Kluwer Law International, 2000.

\section{Spier \& Wansink 1993}

Spier, J. and Wansink, J.H., 'Joint and Several Liability of DES Manufacturers: A Dutch Tort Crisis', International Insurance Law Review (IILR), 1993, p. 176-181.

\section{Stallworthy 2003}

Stallworthy, M., 'Environmental Liability and the Impact of Statutory Authority', Journal of Environmental Law, 15, 2003.

\section{Stewart 2000}

Stewart, R., 'Introduction: environmental regulation in multi-jurisdictional regimes', in: Revesz, R., Sands, P, Stewart, R. (eds.), Environmental law, the economy and sustainable development: the United States, the European Union and the international community, United Kingdom: Cambridge University Press, 2000, p. 1-36.

\section{Stigler 1971}

Stigler, G.J., 'The Theory of Economic Regulation', Bell Journal of Economics and Management Science, 2, 1971, p. 3-21.

\section{Sunstein 1993}

Sunstein, C. R., 'Endogenous preferences, environmental law', Journal of Legal Studies, 22, 1993, p. $217-254$.

\section{Svendsen 1998}

Svendsen, G.T., Public Choice and Environmental Regulation. Tradable Permit systems in the United States and CO2 Taxation in Europe. New Horizons in Environmental Economics, United Kingdom: Edward Elgar, 1998. 


\section{Teijl \& Holzhauer 1990}

Teijl R., and Holzhauer, R.W., 'Pluriformiteit in de rechtseconomie: een verkenning van scholen', Ars Aequi , $39.10,1990$, p. 617-631.

\section{Tiebout 1956}

Tiebout, C., 'A pure theory of local government expenditures', Journal of Political Economy, 64:5, 1956, p. 415424.

\section{Trebilcock 1987}

Trebilcock, M., 'The Social Insurance-Deterrence Dilemma of Modern North America Tort Law: A Canadian Perspective on the Liability Insurance Crisis, San Diego Law Review (SDLR), 24, 1987, p. 929-1002.

\section{Trebilcock \& Howse 1998}

Trebilcock, M., Howse, R., Trade Liberalisation and Regulatory Diversity: Reconciling Competitive Markets with Competitive Politics, European Journal of Law and Economics, 1998, p. 5-37.

\section{Tridimas 2006}

Tridimas, T., The general principles of EU law, United Kingdom: Oxford University Press, 2006.

\section{Truman 1951}

Truman, D.B., The Government Process: Political Interests and public opinion, New York: Knopf, 1951.

\section{Van Calster 2004}

Van Calster, G., 'Will the EC get a finger in each pie? EC law and policy developments in soil protection and brownfields redevelopment', Journal of environmental law, 16(1), 2004, p. 3-17.

\section{Van den Bergh 1994}

Van den Bergh, R., 'The Subsidiarity Principle in European Community Law: Some Insights from Law and Economics,' Maastricht Journal of European and Comparative Law, 1994, p. 337-366.

\section{Van den Bergh 1998}

Van den Bergh, R., 'Subsidiarity as an Economic Demarcation Principle and the Emergence of European Private Law', Maastricht Journal of European and Comparative Law, 5, 1998, p. 129-152.

\section{Van den Bergh 2000}

Van den Bergh, R., 'Economic criteria for applying the subsidiarity principle', in: Revesz, R., Sands, P., Stewart, R. (eds.), Environmental Law, the Economy and Sustainable Development. The United States, the European Union and the International Community, United Kingdom: Cambridge University Press, 2000, p. 80-95.

\section{Van den Bergh 2001}

Van den Bergh, R., 'Gronden en grenzen van aansprakelijkheid: Rechtseconomische kanttekeningen', in: Bergh, R.J. van den, Duk, R.A.A. , Dunné, J.M. van, Kortmann, S.C.J.J. , Nieuwenhuis, J.H. , Schilfgaarde, P. van, Snijders, W. , Spier, J. , Zijderveld, A.C. (Eds.), Aansprakelijkheid: gronden en grenzen, Grotius Akademie, Deventer: Kluwer, 2001, p. 111-142. 


\section{Van den Bergh, Faure \& Lefevere 1996}

Van den Bergh, R., Faure, M., and Lefevere, J., 'The Subsidiarity Principle in European Environmental Law: An Economic Analysis', in: Eide, E. and Van den Bergh, R. (eds.), Law and Economics of the Environment, Oslo: Juridisk Forlag, 1996, p. 121-166.

\section{Van den Bossche 2005}

Van den Bossche, P., The Law and Policy of the World Trade Organisation. Text, Cases and Materials, United Kingdom: Cambridge University Press, 2005.

\section{Van Gerven 1999}

Van Gerven, W., 'The Effect of Proportionality on the Actions of Member States of the European Community: National Viewpoints from Continental Europe', in: Ellis, E. (ed.), The Principle of Proportionality in the Laws of Europe, United Kingdom: Hart Publishing, 1999, p. 37-63.

\section{Van Gerven, Lever \& Larouche 2000}

Van Gerven, W, Lever, J., Larouche, P., Cases, Materials and Text on National, Supranational and International Tort Law, The Common Law of Europe Casebooks Series, United Kingdom: Hart Publishing, 2000.

\section{Von Bar 2000}

Von Bar, C., The Common European Law of Torts, Volume Two: Damage and Damages, Liability for and without Personal Conduct, Causality and Defences, Oxford: Clarendon Press, 2000.

\section{Viscusi, Vernon \& Harrington 2000}

Viscusi, J.K., Vernon, J.M. and Harrington, J.E., Economics of Regulation and Antitrust, Third Edition, Cambridge: MIT Press, 2000.

\section{Vogel 1995}

Vogel, D., Trading Up: Consumer and Environmental Regulation in the Global Economy, Cambridge: Harvard University Press, 1995.

\section{Vogel 2001}

Vogel, D., 'Environmental Regulation and Economic Integration', in: Esty, D.C. and Geradin, D. (eds.), Regulatory Competition and Economic Integration. Comparative Perspectives., New York: Oxford University Press, 2001, p. 330-347.

\section{Vogel 2003}

Vogel, D., 'The Politics of Risk Regulation in Europe and the United States', in: Somsen, H. (ed.), The Yearbook of European Environmental Law, Vol. 3, United States: Oxford University Press, 2003, available at http:/ / faculty.haas.berkeley.edu/vogel/uk\%20 oct.pdf.

\section{Vos 2001}

Vos, E., 'Differentiation, Harmonisation and Governance' in: De Witte, B., Hanf, D., Vos, E. (eds.), The many faces of differentiation in EU law, Antwerp: Intersentia, 2001, p. 145-179. 


\section{Wagner 2005}

Wagner, G.,'Die gemeinschaftsrechtliche Umwelthaftung aus der Sicht des Zivilrechts, in: Hendler, R. et al., Umwelt- und Technikrecht, sonderndruck aus Umwelthaftung nach neuem EG-Recht. 20. Trierer Kolloquium zum Umwelt- und Technikrecht, 5-7 September 2004, Berlin: Erich Schmidt Verlag, 2005, p. 177-189.

\section{Weiler 2000}

Weiler, J.H.H. (ed.), The EU, the WTO and the NAFTA. Towards a Common Law of International Trade, United States: Oxford University Press, 2000.

\section{Wenneras 2005a}

Wenneras, P, 'Permit Defences in Environmental Liability Regimes - Subsidizing Environmental Damage in the EC?', in: Etty, T and Somsen, H. (eds.), The Yearbook of European Law, Vol. 4, United Kingdom: Oxford University Press, 2005.

\section{Wenneras 2005b}

Wenneras, P., 'A Progressive Interpretation of the Environmental Liability Directive in Conformity with EC Law', in: Mellenbergh, R. and Uylenburg R. (eds.), Aansprakelijkheid voor schade aan de natuur, Groningen: Europa Law Publishing, 2005, p. 135-150.

\section{Wilde 2002}

Wilde, M., Civil liability for Environmental Damage. A Comparative Analysis of Law and Policy in Europe and the United States, The Netherlands: Kluwer Law International, 2002.

\section{Wils 1994}

Wils, W., 'Subsidiarity and the E.C. Environmental Policy: Taking People's Concerns Seriously', Journal of Environmental Law, 1994, p. 85-91.

\section{Wilson 1997}

Wilson, J.D., 'Capital Mobility and Environmental Standards: Is there a Theoretical Basis for a Race to the Bottom?', in: Bhagwati J., Hudec, R. (eds.), Fair Trade and Harmonisation. Prerequisites for Free Trade?, Vol 1, Massachusetts: MIT Press, 2nd printing 1997, p. 394-427.

\section{WTO 1998}

WTO, United States: Import Restrictions of Certain Shrimp or Shrimp Products, Report of the Panel, WT/DS58/R, 15 May 1998, available at < www.wto.org/english/tratop_e/ dispu_e/distab_e.htm>.

\section{WTO 1998}

WTO, United States: Import Restrictions of Certain Shrimp or Shrimp Products, Report of the Appelate Body, AB-1998-4, WT/DS58/AB/R, 12 October 1998, available at $<$ www.wto.org/english/tratop_e/dispu_e/distab_e.htm>.

\section{Xing 1995}

Xing, Y., Kolstad, C.,'Do Lax Environmental Regulations Attract Foreign Investment?', Working Papers in Economics, University of California, 1995, p. 16-95. 


\section{References to Legal Documents}

Council of Europe, Convention for the Protection of Human Rights and Fundamental Freedoms, Rome, 4 November 1950.

Convention on International Trade in Endangered Species of wildlife and Fauna, Washington, 3 March 1973, 993 UNTS 243, which entered in force on 1 July 1975.

European Commission, Bulletin of the European Communities. No. 11/1986, para 2.1.146.

Commission Communication of 15 September 1989, proposal for a directive on civil Liability for Damage Caused by Waste, COM (89) 282

Council Regulation (EEC) 1210/90, O.J. L120, 11th May 1990, establishing the European Environment Agency.

Hoge Raad 9 October 1992, [1994] Nederlandse Jurisprudentie (NJ), 535 (C.J.H.B.) (DES judgement).

Hoge Raad 25 June 1993, [1993] Nederlandse Jurisprudentie (NJ), 686 (Cijsouw v. De Schelde judgement).

Interinstitutional Agreement on Procedures for Implementing the Principle of Subsidiarity, Official Journal C329 of 6 December 1993.

Commission Communication of 14 May 1993, Green Paper on Remedying Environmental Damage, COM (93) 47.

Council of Europe, Convention on Civil Liability for Damage Resulting from Activities Dangerous to the Environment, Lugano, 21 June 1993.

Parliament Resolution of 20 April 1994, OJ C 128, 9.5.1994, p. 165.

Treaty of Amsterdam amending the Treaty on the European Union, the Treaties establishing the European Communities and related acts, Official Journal C 340, 10 November 1997 and Protocol (30) on the application of the principles of subsidiarity and proportionality.

Commission of the European Communities, Working Paper on Environmental Liability, Brussels, 1997.

Commission Communication of 9 February 2000, White Paper on Environmental Liability, COM (2000) 66.

Treaty of Nice, Official Journal C 80 of 10 March 2001.

European Commission, Environmental Directorate General Working Paper on Prevention and Restoration of Significant Environmental Damage (Environmental liability), 2001.

Convention on Access to Information, Public Participation in Decision-Making and Access to Justice in Environmental Matters (Århus Convention), 25 June 1998, which came into force on 30 October 2001.

Commission Communication of 23 January, Proposal for a Directive of the European Parliament and of the Council on Environmental Liability with regard to the Prevention and Restoration of Environmental Damage, COM (2002) 17 final, OJ C151 E/132.

Commission of the European Communities, 'Frequently asked questions on the Commission's Proposal on environmental liability', 24 January 2002.

European Parliament legislative resolution on the Proposal for a European Parliament and Council directive on environmental liability with regard to the prevention and remedying of environmental damage (COM (2002) 17 - C5-0088/2002 - 2002/0021(COD)). 
Commission of the European Communities, Communication from the Commission to the Council, the European Parliament, the Economic and Social Committee and the Committee of the regions, Towards a Thematic Strategy for Soil Protection, COM (2002) 179 final, Brussels, 16.4.2002.

Decision No 1600/2002/EC of the European Parliament and of the Council of 22 July 2002 laying down the Sixth Community Environment Action Programme, OJ L242, 10.09.2002.

Council of the European Union, Common position adopted by the Council with a view to the adoption of a Directive of the European Parliament and of the Council on environmental liability with regard to the prevention and remedying of environmental damage, Brussels, 2 September 2003, 2002/0021 (COD).

Department for Environment, Food \& Rural Affairs (DEFRA), UK, 'Extended Partial Regulatory Impact Assessment on Proposals for a Directive on Environmental Liability', <www.defra.gov.uk>.

Commission of the European Communities, Fifth Annual Survey on the implementation and enforcement of Community environmental law, Commission Staff Working Paper, Brussels, SEC (2004) 1025, 2003.

Communication from the Commission to the European Parliament pursuant to the second subparagraph of Article 251 (2) of the EC Treaty concerning the Common Position of the Council on the adoption of a Directive of the European Parliament and the Council on environmental liability with regard to the prevention and remedying of environmental damage.

Common Position (EC) No 58/2003, adopted by the Council on 18 September 2003 with a view to the adoption of a Directive 2003/.../EC of the European Parliament and of the Council on environmental liability with regard to the prevention and remedying of environmental damage.

Commission of the European Communities, Proposal for a Regulation of the European Parliament and of the Council concerning the Registration, Evaluation, Authorisation and Restriction of Chemicals (Reach), establishing a European Chemicals Agency and amending Directive 1999/45/EC, COM (2003) 644 (1), 29 October 2003.

Commission of the European Communities, Proposal for a Directive of the European Parliament and of the Council establishing a framework for the protection of soil and amending Directive 2004/35/EC, $\operatorname{COM}(2006) 232$ final, Brussels, 22.09.2006.

Commission Staff Working Document, document accompanying the Communication from the Commission to the Council, the European Parliament, the Economic and Social Committee and the Committee of the regions, Towards a Thematic Strategy for Soil Protection, Impact assessment of the Thematic Strategy on Soil Protection SEC(2006)620 and SEC(2006)1165 (Summary of the Impact Assessment), Brussels, 22.09.2006.

\section{European Legislation}

Council Directive 67/548 relating to the classification, packaging and labelling of dangerous preparations, OJ 1967 L196/I, later amended.

Council Directive 70/157 relating to the permissible sound level and exhaust system of motor vehicles, OJ 1971 L42/16, later amended.

Council Directive 73/404 relating to detergents, OJ 1973 L347/51, later amended.

Council Directive 75/442/EEC of 15 July 1975 on waste (Waste Framework Directive); OJ L 194 of 25.07.1975 as amended in 1991 and 1996.

Council Directive 76/160/EEC of 8 December 1975 concerning the quality of bathing water, OJ L 31, 5.2.1976.

Council Directive (76/464/EEC) on dangerous substances. 
Directive 79/409/EEC of 2 April 1979 on the conservation of wild birds OJ 1979 L 103/1 of 25.04.1979, later amended.

Council Directive of 24 June 1982 on the major-accident hazards of certain industrial activities (82/501/EEC), OJ No L 230 of 5 August 1982 (Seveso Directive).

Directive 85/210 concerning the lead content of petrol, OJ 1985 L96/25, later amended.

Council Directive 86/278/EEC of 12 June 1986 on the protection of the environment, and in particular of the soil, when sewage sludge is used in agriculture (Sewage Sludge Directive), OJ L 181, 4.7.1986.

Council Directive 90/219/EEC of 23 April 1990 on the contained use of genetically modified microorganisms, OJ L 117, 8.5.1990.

Council Directive 91/676/EEC of 12 December 1991 concerning the protection of waters against pollution caused by nitrates from agricultural sources, OJ L 375, 31.12.1991.

Council Directive 91/414/EEC of 15 July 1991 concerning the placing of plant protection products on the market (pesticides), OJ L230 of 19.9.1991.

Council Directive 91/689/EEC of 12 December 1991 on hazardous waste OJ L 377, 31.12.1991.

Council Directive 92/43/EEC of 21 May 1992 on the conservation of natural habitats and the protection of natural habitats and of wild flora and fauna, OJ L 206 of 22.07.1992.

Council Directive 94/55/EC of 21 November 1994 on the approximation of the laws of the Member States with regard to the transport of dangerous goods by road.

Council Directive 96/62/EC of 27 September 1996 on ambient air quality assessment and management, 27 September 1996.

Council Directive 96/61/EC of 24 September 1996 concerning integrated pollution prevention and control, OJ L 257, 10.10.1996 (IPPC Directive).

Directive 98/8/EC of the European Parliament and of the Council of 16 February 1998 concerning the placing of biocidal products on the market, OJ L123/1 of 24.4.98.

Council Directive 1999/31/EC of 26 April 1999 on the landfill of waste (landfill Directive), OJ L 182, 16.7.1999.

Directive of the European Parliament and of the Council 2000/60/EC of 23 October 2000, establishing a Framework for Community Action in the Field of Water Policy, (Water Framework Directive), OJ L 327 of 22.12.2000.

Council Regulation 2003/1782/EC, OJ L 270, 21.10.2003 on Good Agricultural and Environmental Condition (cross-compliance).

Directive 2004/35/CE of the European Parliament and of the Council of 21 April 2004 on Environmental Liability with Regard to the Prevention and Remedying of Environmental Damage, OJ L 143/56 of 30.04.2004. 


\section{References to European Jurisprudence}

Case C-41/74 (Van Duyn v. Home Office), 1974, ECR 1337.

Case C-68/88 (Greek corn), 1989, ECR 2979.

Case 106/89 (Marleasing), 1990, ECR I-4135.

Joined cases C-6/90 and C-9/90 (Frankovich v Italy), 1991, ECR I-5357.

Case C-45/91, (Commission v Hellenic Republic), judgment of 7 April 1992, ECR I-2509.

Case C-91/91 (Faccini Dori), 1994, ECR I-3325.

Joined Cases C-174,178-9 and 188-90/94 Dillenkofer and Others, 1996, ECR.

Case C-265/95 (Spanish Strawberries), 1997, ECR I-6959.

A and Others v National Blood Authority [2001], 3 All ER 289 (QBD), see COM v UK Case C-300/95, 1997, All ER, (EC) 481 ECJ.

Case C-215/97 (Barbara Bellone v Yokohama SpA), 1998, ECR I-2191.

Case C-77/97 (Unilever v Smithkline Beecham), 1999, ECR I-431.

Case 443/98, (Unilever Italia), 2000, ECR I-7535.

Case C-387/97 (Commission v Hellenic Republic), judgment of 4 July 2000, ECR I-5047.

Case C-201/02 (Wells judgement).

Case C-I/03, Judgment of the Court (Second Chamber) of 7 September 2004, Criminal proceedings against Paul Van de Walle, Daniel Laurent, Thierry Mersch and Texaco Belgium SA, I-07613. 



\section{CURRICULUM VITAE}

Kristel De Smedt was born on 6 October 1974 in Bilzen, Belgium. From September 1992 to June 1996 she studied 'Applied Economic Sciences' at Hasselt University (formally Limburg University Centre), Belgium. Additionally, she obtained an M.A. Degree in Economics of International Trade and European Integration in June 1997 and a Diplôme d'Etudes Approfondies (D.E.A.) de Droit Communautaire and a Diplôme d'Etudes Supérieures Européennes Droit et Sciences Politiques (D.E.S.E) at the European University Centre (CEU) in Nancy (France) in June 1998. After her studies she completed a traineeship at the Belgian Ministry for Foreign Affairs (September 1998 - February 1999) and a stage at the European Commission (March 1999 - July 1999) in Brussels. In September 1999, she returned to Hasselt University as an assistant lecturer and started a PhD research under the supervision of Prof. Dr. Michael Faure in December 2000. This PhD research on the harmonisation of environmental liability in a federal system gave her the opportunity to combine at the same time her knowledge of economics and European law and her deep interest in European law-making. She published several articles on the harmonisation of environmental liability in the European Union. Since September 2006, Kristel De Smedt is working as a teacher at the Faculty of Economics and Business Administration of Maastricht University. Her research and teaching interests include law and economics, public economics and European policies. 

A peer-reviewed book series in which the common foundations of the legal systems of the Member States of the European Community are the central focus.

The Ius Commune Europaeum series includes horizontal comparative legal studies as well as studies on the effect of treaties within the national legal systems. All the classic fields of law are covered. The books are published in various European languages under the auspices of METRO, the Institute for Transnational Legal Research at the Maastricht University.

Editorial Board: Prof.Dr. J. SMITS (chair), Prof.Dr. M. FAuRE and Prof.Dr. E. Vos.

Recently published:

Volume 55: Gehuwd of niet: maakt het iets uit?, C. FORDER en A. VERBEKE (eds.)

Volume 56: European Integration and Law, D. CURTIN, A. KLIP, J. SMITS and J. MCCAHERY (eds.)

Volume 57: The Right Judge for Each Case: A Study of Case Assignment and Impartiality in Six European Judiciaries, P. LANGBROEK and M. FABRI

Volume 58: Grensoverschrijdend Recht, M. FAURE en M. PEETERS (eds.)

Volume 59: Towards a Unified System of Land Burdens?, S. VAN ERP and B. AKKERMANS (eds.)

Volume 60: Contract Interpretation and Gap Filling: Comparative and Theoretical Perspectives, N. KORNET

Volume 61: Selected Issues in Equal Treatment law: A Multi-layered Comparison of European, English and Dutch Law, M. GIJZEN

Volume 62: Food Safety Regulation in Europe. A Comparative Institutional Analysis, E. Vos and F. WENDLER (eds.)

Volume 63: Quality of Judicial Organisation and Checks and Balances, G.Y. NG

Volume 64: Suspects in Europe. Procedural Rights at the Investigative Stage of the Criminal Process in the European Union, E. CAPE, J. HODGSON, T. PRAKKEN and T. SPRONKEN (eds.)

Volume 65: Constitutions Compared. An Introduction to Comparative Constitutional Law, A.W. HERINGA AND PH. KIIVER

Volume 66: Nordic Law - Between Tradition and Dynamism, J. HuSA, K. NuOTIO AND H. PIHLAJAMÄKI (eds.)

Volume 67: Ondergrondse constructies in het Belgische en Nederlandse recht, C. ADRIAANSENS en V. SAGAERT (eds.)

Volume 68: Administrative Law of the European Union, Its Member States and the United States, 2nd edition, R.J.G.H. SEERDEN (ed.)

Volume 69: Vennootschappelijke beleidsbepaling in geval van financiële moeilijkheden; de positie van bestuurders en aandeelhouders, M. OLAERTS

Volume 70:

Volume 71:

Volume 72: Environmental Liability in a Federal System. A Law and Economics Perspective, K. DE SMEDT 